\title{
Panel Survey of Young People in Egypt (SYPE) 2014: Generating evidence for policy, programs, and research
}

Rania Roushdy

Population Council

Maia Sieverding

Follow this and additional works at: https://knowledgecommons.popcouncil.org/departments_sbsr-pgy

Part of the Demography, Population, and Ecology Commons, Family, Life Course, and Society Commons, and the International Public Health Commons How does access to this work benefit you? Let us know!

\section{Recommended Citation}

Roushdy, Rania and Maia Sieverding. 2015. "Panel Survey of Young People in Egypt (SYPE) 2014:

Generating evidence for policy, programs, and research." Cairo: Population Council. 


\section{POPUlation} COUNCIL

Ideas. Evidence. Impact.

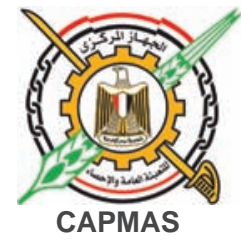

PANEL SURVEY OF

YOUNG PEOPLE IN EGYPT (SYPE) 2014

Generating Evidence for Policy, Programs, and Research

Edited by Rania Roushdy and Maia Sieverding
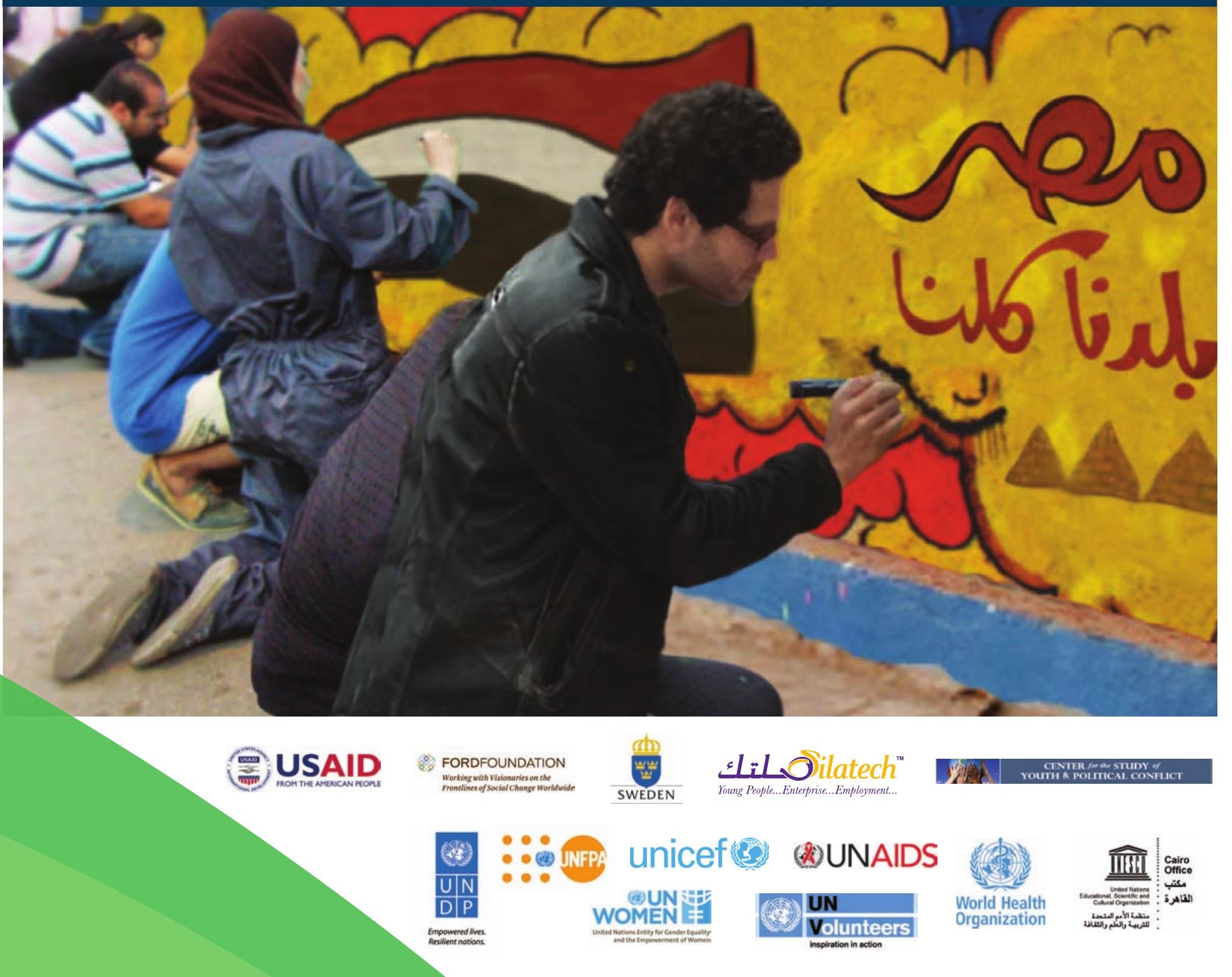



\section{PANEL SURVEY OF \\ YOUNG PEOPLE IN EGYPT \\ (SYPE) 2014 \\ Generating Evidence for Policy, Programs, and Research}

Edited by Rania Roushdy and Maia Sieverding 


\section{porularon Pr connch \\ Ideas. Evidence. Impact.}

The Population Council confronts critical health and development issues-from stopping the spread of HIV to improving reproductive health and ensuring that young people lead full and productive lives. Through biomedical, social science, and public health research in 50 countries, we work with our partners to deliver solutions that lead to more effective policies, programs, and technologies that improve lives around the world. Established in 1952 and headquartered in New York, the Council is a nongovernmental, nonprofit organization governed by an international board of trustees.

Population Council

One Dag Hammarskjold Plaza

New York, NY 10017

Population Council/Egypt

59 Misr-Helwan Agricultural Road, Maadi

PO Box 168, Maadi

Cairo, Egypt 11431

Tel. +2022525 5968

Fax: +20 225255962

popcouncil.org

Suggested citation: Roushdy, Rania and Maia Sieverding. 2015. "Panel survey of young people in Egypt 2014: Generating evidence for policy, programs, and research." Cairo: Population Council.

This is the final report of the 2014 Survey of Young People in Egypt. The opinions expressed herein are those of the authors and do not necessarily reflect the views of the initiative supporters.

Photo credits: Cover: Wolfgang Sterneck/Salma Abou Hussein; page 1: Imre Cikajlo;

page 9: Amr Nabil/AP; page 31: John Samples/Photoshare; page 51: kasra.co; page 69:

powerofforever.com; pages 95, 111, 127, and 143: Joel Carillet.

Any part of this publication may be photocopied without permission from the Population Council provided that copies are distributed without charge and that full source citation is provided. The Population Council would appreciate receiving a copy of any materials in which the text is used.

(c) 2015 The Population Council, Inc. 


\section{Contents}

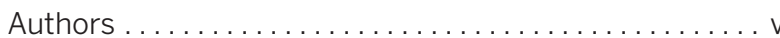

Study Team ......................... vi

Acknowledgements ....................... vii

Acronyms ........................... vii

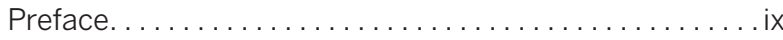

Foreword $\ldots \ldots \ldots \ldots \ldots \ldots \ldots \ldots \ldots \ldots \ldots \ldots \ldots \ldots$

Executive Summary .................... xii

\section{CHAPTER 1: INTRODUCTION AND BACKGROUND}

CHARACTERISTICS .......................... 1

1.1 Egypt in the post-revolutionary period......... 2

1.2 Overview of SYPE 2009 and SYPE $2014 \ldots \ldots \ldots .2$

1.3 Survey design and implementation ........... 3

1.4 The profile of young people in 2014 . . . . . . . . . . 6

CHAPTER 2: HEALTH OF EGYPTIAN YOUTH IN 2014: KNOWLEDGE, ATTITUDES, AND BEHAVIORS ........ 9

2.1 Introduction .......................... 10

2.2 Access to health care ................. 10

2.3 Self-rating of health and reported prevalence of chronic diseases and disability $\ldots \ldots \ldots \ldots \ldots 12$

2.4 Hygienic practices..................... 13

2.5 Health and the environment............. 13

2.6 Exposure to risk of injury and violence..... . . . . 14

2.7 Nutrition, dietary habits, and physical activity . . . 17

2.8 Use of tobacco, alcohol, and drugs .......... 19

2.9 Mental health and social development. .........20

2.10 Reproductive health . . . . . . . . . . . . . . . . . 21

2.11 Conclusion .........................29
CHAPTER 3: EDUCATIONAL EXPERIENCES OF YOUTH IN EGYPT: WHO ATTENDS SCHOOL, WHO SUCCEEDS, AND WHO STRUGGLES ......... 31

3.1 Introduction ......................... 32

3.2 Educational attainment and school completion. . . 32

3.3 Intergenerational educational mobility. ...... . . 34

3.4 Patterns of ever attending school . . . . . . . . . . 36

3.5 Youth experiences with literacy classes ....... 38

3.6 When do students exit school? .............. 39

3.7 Who are the youth currently in school? ........40 40

3.8 Struggles in school................... 41

3.9 School quality . . . . . . . . . . . . . . 42

3.10 Tutoring and family help during school . . . . . . . . 44

3.11 Conclusion ........................ 48

CHAPTER 4: YOUNG PEOPLE'S LABOR MARKET OUTCOMES DURING A PERIOD OF TRANSITION ... . 51

4.1 Introduction ........................ 52

4.2 Labor force participation................... 52

4.3 Employment structure . . . . . . . . . . . . 56

4.4 Unemployment .................... 61

4.5 Employment transitions . . . . . . . . . . 64

4.6 Entrepreneurship .....................65

4.7 Conclusion ............................. 67

CHAPTER 5: THE CHANGE IN INTERNATIONAL MIGRATION ASPIRATIONS OF EGYPTIAN YOUTH. . . . 69

5.1 Introduction ........................ 70

5.2 Youth migration aspirations in $2014 \ldots \ldots \ldots \ldots .71$

5.3 Changes in migration intentions: 2009 and 2014 . . 76

5.4 The January 25, 2011 revolution and migration intentions ......................... 78

5.5 Conclusion ............................ 79 
CHAPTER 6: MARRIAGE AND FAMILY FORMATION TRENDS AMONG YOUTH IN EGYPT . . . . . . . . . . . . . 81

6.1 Introduction . . . . . . . . . . . . . 82

6.2 Marital status among Egyptian youth, 2009

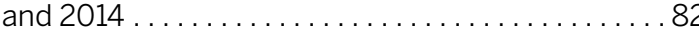

6.3 Age at marriage and early marriage . . . . . . . . . 84

6.4 Characteristics of youth marriages............ 86

6.5 Meeting and choosing a spouse. ........... 88

6.6 Quality of youth's marital relationships ..... . . . . 89

6.7 Cost of marriage $\ldots \ldots \ldots \ldots \ldots \ldots \ldots \ldots \ldots$

6.8 Desired number of children. . . . . . . . . . . . . 92

6.9 Conclusion ............................ 93

CHAPTER 7: THE YOUTH OF THE REVOLUTION: PARTICIPATION IN POLITICAL EVENTS FROM

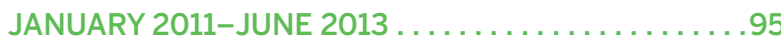

7.1 Introduction ....................... 96

7.2 Youth participation in political activism since January $2011 \ldots \ldots \ldots \ldots \ldots \ldots \ldots$

7.3 Participation of youth's social networks ....... 99

7.4 Reasons for nonparticipation. . . . . . . . . . . . . . 101

7.5 Media use for information on the January 25 revolution ............................ 101

7.6 Experience of violence .................... 102

7.7 Perceptions of January 25, 2011 and

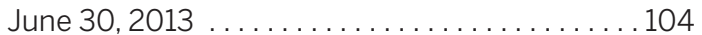

7.8 Youth participation in elections and referendums............................... 106

7.9 Conclusion ..............................109
CHAPTER 8: CIVIC ENGAGEMENT, POLITICAL ATTITUDES, AND YOUTH'S VISIONS FOR THE

FUTURE DURING EGYPT'S TRANSITION . . . . . . . . . . . . 111

8.1 Introduction . . . . . . . . . . . . . . . . . . . . 112

8.2 Youth opinion on priorities and threats facing the country.................. 112

8.3 Opinions on politics and political activism . . . . 114

8.4 Assessment of recent regimes . . . . . . . . . 115

8.5 Assessment of values in Egyptian society. . . . . . 117

8.6 The role of religion in politics, law, and personal life ............................ 118

8.7 Optimism about the future . . . . . . . . . . . . . . 119

8.8 Participation in volunteering and social groups ...................... 121

8.9 Participation in social debate . . . . . . . . . . . 124

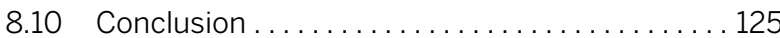

CHAPTER 9: CONTINUING CONSERVATISM: GENDER ATTITUDES AMONG EGYPTIAN YOUTH . . . 127

9.1 Introduction ....................... 128

9.2 Access to education, employment, and electoral politics ...................... 129

9.3 Household dynamics . . . . . . . . . . . . . . 132

9.4 Divorce ............................. 136

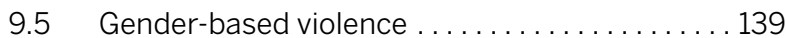

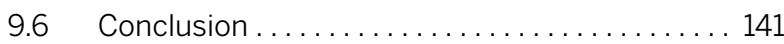

APPENDIXES ............................ . . . . . . . . .

Appendix A: Tables ........................ 145

Appendix B: Sampling error estimates of SYPE 2014 key indicators . . . . . . . . . . . . . . . . . . 217 


\section{Authors}

NAHLA ABDEL-TAWAB is Country Director, Population Council, Egypt

MOHAMMED ISMAIL is Professor of Statistics and Department Chair, Faculty of Economics and Political Science, Cairo University, Egypt

SARAH ISMAIL is Associate, Partners in Expanding Health Quality and Access, USA

CAROLINE KRAFFT is Assistant Professor of Economics, St. Catherine University, USA

DAFNI PAPOUTSAKI is a Teaching Fellow, Department of Economics, University of Southampton, United Kingdom

AHMED RAGAB is Assistant Lecturer of Economics, Faculty of Economics and Political Science, Cairo University, Egypt

NADA RAMADAN is a doctoral student, Department of Sociology, University of California Los Angeles and a former researcher with the Population Council, Egypt

ALI RASHED is Senior Researcher and Data Analyst, Population Council, Egypt

RANIA ROUSHDY is Senior Program Manager of the Poverty, Gender and Youth Program, Population Council, Egypt

COLETTE SALEMI is a consultant with the Population Council, Egypt

IRENE SELWANESS is Assistant Professor of Economics, Faculty of Economics and Political Science, Cairo University, Egypt

LILA SHEIRA is a consultant with the Population Council, Egypt

MAIA SIEVERDING is SYPE Lead Research Consultant and Research Officer (former),

Population Council, Egypt

JACKLINE WAHBA is Professor of Economics, Department of Economics, University of Southampton, United Kingdom 


\section{Study Team}

\author{
CENTRAL AGENCY FOR PUBLIC \\ MOBILIZATION AND STATISTICS (CAPMAS) \\ H.E. General Abou Bakr El Gendi \\ CAPMAS DIRECTOR \\ Dr. Ferial Abdel Kader \\ DEMOGRAPHER ADVISOR \\ Ms. Amal Aly Nour El-Din \\ HEAD SECTOR OF POPULATION STATISTICS AND \\ CENSUS \\ Ms. Amira Gamal El-Din \\ UNDERSECRETARY FOR POPULATION STUDIES \\ AND SOCIAL RESEARCH CENTER \\ Ms. Soaad Ahmed Eldawy \\ GENERAL MANAGER FOR STATISTICAL TRAINING \\ CENTER (FORMER) \\ Mr. Gamal Hashem \\ TRAINING AND IMPLEMENTATION OFFICER \\ Mr. Essam Fathallah \\ IT EXPERT
}

\section{POPULATION COUNCIL}

\section{Research Team}

Dr. Nahla Abdel-Tawab

COUNTRY DIRECTOR

Dr. Rania Roushdy

SYPE PRINCIPAL INVESTIGATOR

Mr. Ali Rashed

SENIOR DATA ANALYST

Dr. May Gadallah

SENIOR RESEARCH OFFICER

Dr. Maia Sieverding

RESEARCH OFFICER (FORMER)

Dr. Irene Selwaness

POSTDOCTORAL RESEARCH FELLOW (FORMER)

Ms. Rasha Hassan

RESEARCHER (FORMER)
Mr. Ahmed Ragab

RESEARCHER (FORMER)

Ms. Nada Ramadan

RESEARCHER (FORMER)

Interns and Research Assistants

Mr. Henar Elshemy

Ms. Monica Mamdouh

Ms. Nouran Chakra

Ms. Dina Ashraf

Communication, Coordination, and Finance

Mr. Amr Kotb

SENIOR FINANCIAL OFFICER

Ms. Hanan Tammam

SENIOR COMMUNICATION OFFICER

Ms. Gihan Hosny

SENIOR PROGRAM ADMINISTRATOR

Ms. Ayah EIDifrawy

PROGRAM ADMINISTRATOR

Desktop Publishing and Copy Editing

Mr. Nashwa Bahgat

Ms. Gihan Hosny

Mr. Robert Heidel

Mr. Michael Vosika

Arabic Copy Editing

Dr. Ahmed Zayed

Dr. May Gadallah

Arabic Translation

Dr. Manal Zakaria

Dr. Adel Shaaban

Dr. Soheir Mahfouz

\section{Cover Design}

Ms. Salma Abou Hussein

Mr. Mohamed El Sharkawy

Ms. Gihan Hosny 


\section{Acknowledgements}

The 2014 wave of the Panel Survey of Young People in Egypt (SYPE 2014) would not have been possible without the support and commitment of a number of individuals and institutions. His Excellency Minister Ashraf Al Araby has supported the survey throughout various phases and has shown keen interest in utilization of the results. The Central Agency for Public Mobilization and Statistics (CAPMAS) team, under the leadership and guidance of General Abou Bakr El Gendy, has competently and diligently managed all data collection and processing activities related to this survey and made valuable contributions during the review and pretesting of SYPE questionnaires.

Special thanks are due to the following organizations for their generous financial support of the 2014 SYPE: USAID, Ford Foundation, SIDA, UNFPA, UNICEF, UNDP, UN WOMEN, UN Volunteers, UNAIDS, UNESCO, WHO, Silatech, and University of Tennessee.

We are grateful to government officials, researchers, partners and youth leaders who contributed to updating the 2014 survey questionnaires during the series of consultative meetings held by the Population Council in April 2013. Special thanks go to Dr. Ragui Assaad, Professor of Public Policy at the University of Minnesota and former Regional Director of the Population Council's West Asia and North Africa office, who initiated the 2009 SYPE and who continued to provide technical guidance at various stages of 2009 and 2014 surveys.
We also gratefully acknowledge the contributions of Dr. Brian Barber, at the Center for the Study of Youth and Political Conflict, University of Tennessee, and his team of collaborators on the Jacobs Foundation- funded project, for their significant contribution to the civic engagement module of the SYPE 2014. The technical support provided by colleagues at partner UN agencies is deeply acknowledged.

SYPE - 2014 has been undertaken by Population Council /Egypt Poverty, Gender and Youth Program. Dr. Rania Roushdy, Senior Program Manager, deserves special thanks for capably leading all survey activities and compiling the final report. Our sincere gratitude goes to all authors who contributed to this report as well as Dr. Maia Sieverding who has thoroughly reviewed and edited earlier drafts of this report. Thanks are also extended to Mr. Ali Rashed for managing all data analysis activities, Ms. Aya El Defrawy for providing logistical and administrative support to the project, and Robert Heidel and Michael Vosika for the copyediting and design of this report.

Last but not least, we wish to extend our sincere thanks and gratitude to the young people who responded candidly and enthusiastically to the 2014 survey. We are hoping that results of this survey will contribute to policies and programs that help young people in Egypt realize their dreams and full potential.

NAHLA ABDEL-TAWAB, MD, DRPH Country Director 


\section{Acronyms}

\begin{tabular}{|c|c|}
\hline CAPMAS & $\begin{array}{l}\text { Central Agency for Public } \\
\text { Mobilization and Statistics }\end{array}$ \\
\hline EDHS & $\begin{array}{l}\text { Egypt Demographic and Health } \\
\text { Survey }\end{array}$ \\
\hline EGP & Egyptian pounds \\
\hline IDSC & $\begin{array}{l}\text { Information and Decision Support } \\
\text { Center }\end{array}$ \\
\hline IRB & Institutional Review Board \\
\hline LF & Labor Force \\
\hline DLF & Out of Labor Force \\
\hline PC & Population Council \\
\hline PSU & Primary Sampling Unit \\
\hline SD & Standard Deviation \\
\hline SYPE & Survey of Young People in Egypt \\
\hline UNDP & $\begin{array}{l}\text { United Nations Development } \\
\text { Programme }\end{array}$ \\
\hline UNFPA & United Nations Population Fund \\
\hline UNICEF & United Nations Children's Fund \\
\hline UNIFEM & $\begin{array}{l}\text { United Nations Development Fund } \\
\text { for Women }\end{array}$ \\
\hline VIO & Wealth quintiles \\
\hline
\end{tabular}




\section{Preface}

The youth phase is one of the most crucial times in a person's lifetime, in which an individual shifts from being a child to becoming an adult. It is the progression from the dependence on parents in livelihood matters and decision making to increasing independence. During this period, a person is exposed to experiences and information that help shape his/her own self-identity and personal beliefs and enables him/her to make choices and form judgments that would guide his/her present and future. It is also the transitional phase from school to the job market and all it holds of challenges, future aspirations and endless opportunities.

In any society youth constitute the engine of growth and development and they are the leaders of tomorrow. Today's youth shape the future of the country and take on the responsibility of meaningfully contributing to the rebuilding of our nation. Recent development experiences have demonstrated the pivotal role that youth play in achieving development goals.

Youth are considered reservoirs of strength, knowledge and infinite energy, hence they are capable of easily adapting to the rapid technological advancements happening around the world. Many societies seek to utilize these pulsating energies in increasing employment, aggregating production and achieving development goals through providing adequate job opportunities and creating an enabling environment for young people to be creative and innovative as well as involving them in the decision making process. On the other hand, marginalizing this population group during this critical phase of their life may in turn lead to negative outcomes both at the personal level and for society at large. Unemploy- ment, drug use, decadence and lack of a sense of citizenship and national belonging are some of the serious consequences of marginalizing youth. Therefore, it is of utmost importance to integrate youth in society through understanding their problems and assisting them in successfully addressing them.

The Egyptian population is exceptionally young with about $61 \%$ under the age of 30 ; and $40 \%$ of the population between the ages of 10 and 29 , being equally distributed among males and females. This population could be perceived as a challenge for the Egyptian government in providing education and health services, suitable housing and employment opportunities to accommodate the needs of this massive generation of young people. It could also be seen as a demographic opportunity of huge potential for achieving progress and prosperity for the country if those massive human resources are properly utilized and directed towards work, production and active participation in building this nation.

From this standpoint comes the importance of the Survey of Young People in Egypt (SYPE), which was first conducted in 2009. The survey is the first of its kind conducted on youth of ages between 10 and 29 and focuses on key aspects of their lives including education, employment, health, family formation, migration, reproductive health, social issues and civic/political participation. The second round of the survey was conducted in 2014 in the wake of major transitions that took place in Egypt with the outbreak of two youth-led revolutions (January 25, 2011 and June 30,2013 ) calling for freedom, social justice and equality. Moreover, the Survey gains additional importance from the fact that it attempts to un- 
derstand changes that occurred among Egyptian youth over the period between the two rounds through targeting the same group of respondents of the 2009 survey in 2014 to accurately document changes and progress in the status of these young people.

Preliminary findings of SYPE 2014 indicated that positive improvements have occurred in a number of areas compared to the 2009 round. A slight decrease in unemployment among this age group was noticeable as well as a reduction in rates of early marriage, although early marriage remains one of the major problems in our society. The gender gap in educational attainment has narrowed in the period between the two surveys. Despite political and economic instability between 2011-2013 youth desire to migrate has not changed between the two surveys while youth participation in social and political activities is on the rise.

Moreover, prevalence rates of female genital mutilation/cutting and sexual harassment appear to be declining. On the other hand, youth are increasingly seeing their immediate environment as polluted, and perceiving streets and public transportation as unsafe. SYPE has also highlighted that Egyptian youth aspire to improve their living conditions and to fight corruption and achieve freedom and democracy. While there is a general feeling of dissatisfaction with living conditions in Egypt over the last few years, young people expressed their optimism about the future.
With no doubt, the Egyptian youth have demonstrated their huge potential and capabilities that need to be invested in for reforming the nation and contributing to its welfare and prosperity. This entails providing youth with the necessary opportunities to acquire a broad range of competencies and creating a suitable environment that would ensure their skills development and political inclusion. Therefore, the Government of Egypt is expected to sustain their efforts in reaching these goals while youth are expected to work on strengthening their own skills and nurturing their innate capabilities for creativity and innovation.

To conclude, I would like to thank all those who contributed to this survey both at the Population Council and the Central Agency for Public Mobilization and Statistics (CAPMAS), for their efforts to complete this body of work. We hope the findings of this survey would assist in setting a roadmap to enhance the current situation of Egyptian youth and in delivering an array of related activities that would fulfill their aspirations and dreams for the future. We are hopeful that young people of Egypt will play a greater role in the development of our nation in the coming period.

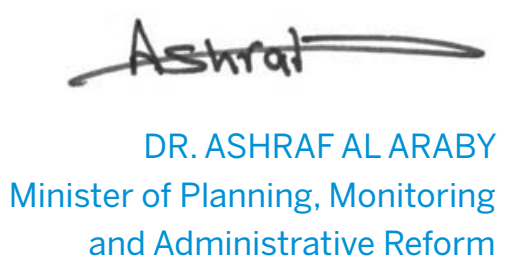




\section{Foreword}

For decades, the Population Council has generated evidence about the lives of young people in Egypt. In 1997, we fielded the ground-breaking Adolescence and Social Change in Egypt survey, which interviewed more than 9,000 young people. In 2009, we built on that foundation with the Survey of Young People in Egypt (SYPE). Council interviewers spoke to a nationally representative sample of around 15,000 young people between the ages of 10 and 29 from 11,000 householdsone of the largest surveys of young people in the Middle East and North Africa.

The results of these studies-which offered gender-disaggregated information on health, schooling, employment, civic engagement, and many other topics-were used to inform government policies for young people. They were also used to inform two of the Council's own pioneering programs, Ishraq and Neqdar Nasharek, to empower girls and young women in rural Upper Egypt.

Two years after data were collected for SYPE, young people electrified the world by playing an active part in demanding 'bread, freedom and social justice' and ousting Egypt's regime of 30 years. The intervening years have been turbulent.

In 2014, the Council re-interviewed more than 10,000 respondents from the original 2009 survey, a group now aged 13-35. This study offers a unique and valuable trove of data on the lives of young people in Egypt before and after the Revolution.

To develop effective programs and policies, governments and organizations need solid, reliable data. Given the tumult and change recently experienced in Egypt, this is true now more than ever. Egypt's population has a "youth bulge," which under the right circumstances could propel the country economically. But, without the right investments in young people's health and education, as well as in opportunities for productive livelihoods, their future prospects-and some might even say the future of Egypt-will be limited.

Information on the circumstances and outlook of young people in Egypt is urgently needed. In this report, you'll learn of young people's struggle for jobs and concerns about Egypt's economic situation, but also of their optimism about the future.

We are proud of the Population Council's long history in Egypt. We look forward to continuing to work hand in hand to improve the lives and secure the wellbeing of the Egyptian people.

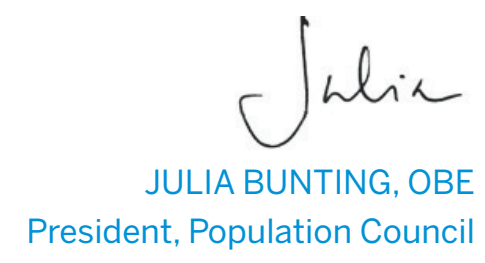




\section{Executive Summary}

\section{Background}

The 2009 Survey of Young People (SYPE) generated a unique source of data on the situation of youth in Egypt, covering a broad set of areas crucial to the transition to adulthood, including education, employment, migration, health, family formation, social issues, and civic and political participation. Given the unprecedented series of political changes that have occurred in Egypt since 2009, the Population Council designed and implemented the second wave of SYPE in 2014 in order to observe how Egyptian young people have been faring following this transitional period. The Population Council, in partnership with the Central Agency for Public Mobilization and Statistics (CAPMAS), collected the second round of data for the Survey of Young People in Egypt (SYPE) in 2013/2014, which re-interviewed the same sample of young people that were interviewed in 2009.

\section{SYPE 2009 interviewed a nationally representative sample of 15,029 young people aged 10-29 from 11,372 house- holds. SYPE 2014 was able to interview 10,916 (72.6\%) of those same young people (now aged 13-35).}

This yields a nationally representative panel dataset for both time periods. This report uses both waves of SYPE, and on several occasions exploits the panel structure of the new SYPE data to provide a before-and-after picture of the economic, social, political, and health situation of young people during this critical time in Egypt's history. SYPE is targeted to policymakers to assist them in developing evidence-based policies and programs to enhance the potential and well-being of Egyptian youth.

The characteristics of the SYPE 2014 respondents, as well as key results of SYPE and relevant policy implications, are summarized below.

\section{Main characteristics of SYPE respondents}

Due to the high fertility rates experienced in the 1980s, accompanied by a decline in child mortality, Egypt has been in a stage in its demographic transition characterized by a remarkable "youth bulge".

\section{IN 2009, SYPE REPORTED THAT:}

- $62 \%$ of the Egyptian population was below the age of 29 at the time of data collection and almost $40 \%$ were between ages 10-29.

- Among 10-29-year-olds, the highest percentage of young people $(44.7 \%)$ were in the 10-17 age group.

\section{FIVE YEARS LATER, RESULTS FROM}

SYPE 2014 INDICATE THAT:

- Almost $42 \%$ of the youth sample is now between the ages of 15 and 24 , and $16.8 \%$ of youth are now in the $30-35$ age group (which was outside the range of SYPE 2009.)

- Among the young population aged $13-35$, the percent of males $(51.2 \%)$ is slightly higher than that of females $(48.8 \%)$.

- The majority of young people are still residing in rural areas $(60.7 \%)$, as was the case in 2009.

- As was the case in 2009, most young people in 2014 reside in Lower Egypt (42.8\%) and Upper Egypt (36.7\%). The Urban Governorates comprise about $18.7 \%$ of the young population, while only $1.8 \%$ live in the Frontier Governorates. 


\section{Key SYPE results}

\section{Health and safety}

The health module of SYPE 2014 has shown some improvements between 2009 and 2014 as well as gaps that warrant prompt action. Overall, Egyptian youth consider themselves healthier in 2014 compared to 2009, with about half (48.4\%) of respondents indicating that their health was either "very good" or "excellent," compared to less than a third (29.4\%) in 2009.

An overall decrease in experience of sexual harassment has been noted among female youth aged $13-29$ (from $49.7 \%$ in 2009 to $42.8 \%$ in 2014 ). However, young girls 13-17 years witnessed a slight increase in exposure to sexual harassment (from $46.4 \%$ in 2009 to $49.5 \%$ in 2014).

Eating habits of young people, coupled with lack of physical exercise, expose them to a number of health risks. More than half of youth aged 13-35 (51.6\%) drink carbonated beverages 1-3 times per week, while more than one third (35\%) eat fast food 1-3 times per week. Female engagement in daily physical activity is considerably lower than that of males (40.8\% versus $67.0 \%$ ).

Knowledge of HIV/AIDS is low while stigma against people living with HIV is widespread. Slightly less than three-quarters of SYPE respondents know of HIV/AIDS (73.2\%); slightly more than one-third (35\%) know three to four modes of transmission, while fewer than one in five respondents are willing to interact with someone living with HIV/AIDS.

Fewer respondents (aged 15-29) in 2014 than in 2009 indicated that they were exposed to female genital mutilation/cutting (FGM/C) (79.5\% versus $87.5 \%$ ); however, more respondents in 2014 (7.1\%) refused to answer the question on their circumcision status. Seven out of ten male and female respondents plan to circumcise their future daughters.
Among SYPE respondents aged $13-35$, six out of ten know about family planning methods, with knowledge considerably higher among females than males (72\% versus 52\%). Current use of family planning among married young people is low compared to the national average of $58.5 \%$ reported in the 2014 Egypt Demographic and Health Survey.

\section{Education}

Primary school entry is now nearly universal. More than 95\% of youth aged 13-18 in 2014 had attended school. However, many youth do not complete the (mandatory) basic education. The percentage of young people completing preparatory school by age 16 ranges from a high percentage of $86.9 \%$ in Urban Lower Egypt to a lower percentage of $69.1 \%$ in the Frontier Governorates.

Although young people tend to be more educated compared to their parents, the education young people achieve is closely linked to their parents' education. The chance that a young person with an illiterate mother attends university is $12 \%$, while the chance that a young person with a universityeducated mother attends university is $93 \%$.

Egypt still has a long way to go in ensuring high-quality education for all students. Rote memorization is a more common approach to teaching than critical thinking. While $40.4 \%$ of students report teachers "always" want students to only memorize, just $10.5 \%$ report that teachers encourage students to form their own point of view and $9.5 \%$ report that teachers encourage students to express their opinions.

Private lessons and other forms of supplements to public education are increasingly common. For instance, while $47.5 \%$ of those aged 30-34 in 2014 took private lessons or support programs when they were in preparatory, $59.6 \%$ of those aged 13-18 in 2014 took private lessons or support programs during preparatory. 


\section{Employment}

Labor market conditions have seriously deteriorated during the transitional period. Although the standard unemployment rate for youth (aged 15-29) declined from 16.1\% in 2009 to $13.3 \%$ in 2014, this drop was not associated with an increase in employment levels but was due to an increase in the percent of youth who became discouraged and left the labor force.

Youth labor force participation decreased slightly from $37.9 \%$ in 2009 to $36.6 \%$ in 2014. Even among the non-students group of youth aged 15-29, a similar decline in total labor force participation was observed from $51.7 \%$ in 2009 to $49.6 \%$ in 2014 . Labor force participation declined among both non-student males (from $86.4 \%$ in 2009 to $79.4 \%$ in 2014) and females (from $18.0 \%$ in 2009 to $17.8 \%$ ).

A substantial share of wage-earning male and female youth were still engaged in informal jobs, with neither a contract nor social insurance benefits, albeit declining from $43.5 \%$ in 2009 to $30.6 \%$ in 2014. This decline in informal private sector employment was not associated with an equivalent increase in the share of the government or formal regular private wage work, but rather with an increase in the share of irregular wage work (from $21.7 \%$ to $26.3 \%$ ) and non-wage work ( $12.1 \%$ to $22.8 \%)$.

Indications of increased reliance on entrepreneurship as an alternative mean of entering or staying in the labor market during this difficult economic transition was observed. The percent of employers or self-employed youth increased between 2009 and 2014 from $3.7 \%$ to $13.1 \%$ among employed men and from $3.2 \%$ to $5.7 \%$ among employed women.

The percent of youth reporting being unemployed due to the unavailability of work declined from $69.2 \%$ in 2009 to $58.3 \%$ in 2014 . However, the percentage of both men and women reporting not finding jobs that match their experience or qualifications increased from $8.0 \%$ in 2009 to $13.8 \%$ in 2014 . Young women in 2014 were also two times as likely to say that they could not find a job with a suitable organization. This might be due to the heightened sense of insecurity that followed January 25, 2011 and June 30, 2013.

\section{Migration}

Despite political and economic instability in Egypt during the transitional period, the rate of international migration aspirations amongst youth did not change much between 2009 and 2014. More than 17.2\% of youth aged 15-29 aspired to migrate within the next five years in SYPE 2014, while in the 2009 survey $18.3 \%$ of youth aged 15-29 aspired to migrate in the future.

Egyptian male youth aged 15-29 were three times more likely (25.8\%) to aspire to migrate compared to female youth (7.8\%). Migration aspirations peaked at $28.1 \%$ for the middle age group (18-24) of young men and were lowest for the youngest age group.

Male youth (15-29) from rural areas were more likely to aspire to migrate (28.3\%) compared to those in urban areas $(23.3 \%)$ and to those in informal urban housing (16.2\%). Furthermore, the percentage of male youth (15-29) interested in migration was highest for university graduates at $30.3 \%$, as compared to $17.2 \%$ among illiterate youth.

Economic factors were the main drivers of migration among youth aged 18-29. Low income was the main push factor out of Egypt (44.0\%). Twothirds of youth blamed lack of job opportunities in Egypt for pushing them to aspire to migrate. Bad living conditions in Egypt (48.9\%) were another common push factor. Only $10.1 \%$ of youth blamed the political and security circumstances in Egypt for driving them to want to leave. 


\section{Marriage and family formation}

A large percentage of male youth marry in their late 20 s and early 30s. In 2014, 41.4\% of male youth aged 25-29 were married, compared to $74.8 \%$ of male youth aged $30-35$. Still, a quarter of young men remain unmarried into their early 30s. Female youth marry at younger ages; $3.7 \%$ of those $15-17$ were married, $32.4 \%$ of those aged 18-24 were married, $72.7 \%$ of those aged $25-29$, and $84.3 \%$ of those aged 30-35.

Female youth in rural areas continue to face the greatest risk of early marriage. Among married female youth aged $30-34$ in 2014, $23.0 \%$ of those in rural Upper Egypt had been married by age 16 and $11.2 \%$ of those in rural Lower Egypt.

Desired fertility has risen among both married and never-married youth. Never-married youth aged 15-29 desired an average of 2.6 children in 2009, compared to 2.9 in 2014. Currently married youth of the same age desired 2.8 children in 2009 and 3.1 in 2014.

\section{Political and civic participation}

As documented by SYPE 2009, only 16\% of respondents of voting age had ever voted in an election. Youth participation in national elections increased substantially since 2009, with turnout ranging from 52\% to 65\% in referendums and elections that took place between 2011 and 2012.

Youth participation in political activities (protesting, supporting protesters, strikes, participating in neighborhood watches, political and electoral organizing, etc.) was low between January $25^{\text {th }}$ 2011 and the SYPE 2014 interview, with only 7.4\% of youth reporting engaging in the mentioned activities. There was a substantial gender gap in participation in political activities, with $13.1 \%$ of male respondents participating compared to $1.5 \%$ of female respondents.
Youth participation in volunteer activities still remains low. In SYPE 2009, only $2.8 \%$ of youth ever volunteered during the year prior to the survey interview. Also, in SYPE 2014, only 3.6\% of youth reported that they had ever volunteered since the 2009 interview.

Youth's internet and media use increased dramatically between 2009 and 2014; in 2014, about 25\% of youth aged 15-29 reported having ever used the internet, compared to $10 \%$ in 2009 .

About $71.5 \%$ of youth stated that raising living standards should be the top priority for the country in 2014 , whereas $42.9 \%$ indicated that fighting corruption should be the second priority. When asked about the top threats facing the country, $63.2 \%$ of youth reported the lack of security as the first threat while $37.9 \%$ stated the economic crisis as the main second threat.

SYPE also asked youth to rate, on a scale from 1 to 10 their feelings about their lives and the state of the country five years from the time of the survey. The results show that youth display considerable optimism about the future.

\section{Attitudes toward gender equality}

Overall, gender attitudes remained highly conservative among Egyptian youth. As was the case in 2009, SYPE 2014 male respondents held more conservative outlooks than their female counterparts.

Youth have more egalitarian outlooks in the domains of education and electoral politics than in relation to women's access to jobs. Among youth aged $15-29,56.7 \%$ supported gender equality in education, and among youth aged $18-35,81.5 \%$ agreed with the right to vote for female family members, but $60.4 \%$ believed that men should have priority in employment opportunities when jobs are scarce. 
The percentage of youth aged 15-29 who support a woman's right to seek a divorce or khul has increased from $63.7 \%$ in 2009 to $71.4 \%$ in 2014. However, approximately two-thirds (63.7\%) of 2014 respondents aged 15-29 felt that their societies do not respect divorced women.

An alarming percentage of youth continued to justify gender-based violence in particular contexts. About $64.9 \%$ of SYPE 2014 respondents (aged 15-29) believed that a man could justifiably beat his wife if she "talked to another man." Almost 60\% of respondents of this age agreed that women who are sexually harassed in the streets "deserve" to be if their clothing is "provocative."

\section{Conclusions and policy implications}

A key aim of SYPE 2014 is to update the state of knowledge on adolescents and youth in Egypt and identify issues of importance to young people in the country's new political environment. SYPE also aims to support the development of evidence-based policies and programs to ensure that all young people have the opportunity to reach their full potential.

Taken together, the findings of the SYPE report indicate several key areas that deserve attention in order to work towards a brighter future for Egypt's young people. It is clear that the difficult economic conditions prevailing in Egypt since 2011 have hit youth particularly hard. In addition to their poorer labor market outcomes, youth's perceptions of the challenges and priorities facing their generation and the country show a strong preoccupation with ensuring a basic livelihood. Under these circumstances, ensuring better employment opportunities for youth must be a key priority in the future.
The results of the SYPE also reiterate the finding from 2009 that there are subpopulations of young people in Egypt who are consistently more disadvantaged in terms of key life opportunities. Young people, and particularly young women, in rural areas suffer from poorer educational outcomes and increased risk of negative practices such as early marriage and female genital mutilation/ cutting, and lower levels of engagement in political and civic life. Young women are also constrained by the highly conservative gender attitudes that many youth hold regarding their roles both inside and outside the home. Although development programs can and do target these most disadvantaged populations, policies to promote equality of opportunity for all youth are a more sustainable and far-reaching means to change outcomes on a national scale.

Finally, the 2014 SYPE presents one of the first nationally representative pictures of young people's involvement with the political and social processes that will shape the country's future. While there has been a dramatic improvement in youth's participation in elections, these analyses indicate that many youth still do not take part in other forms of engagement with civic life such as volunteering, group membership, and social discussion related to current events. In order for youth to contribute further to Egypt's transition, measures are needed to foster this generation's continued transition towards active citizenship.

RANIA ROUSHDY SYPE Principal Investigator MAIA SIEVERDING SYPE Research Consultant 


\section{$4 \quad$ Introduction and Background Characteristics}

RANIA ROUSHDY

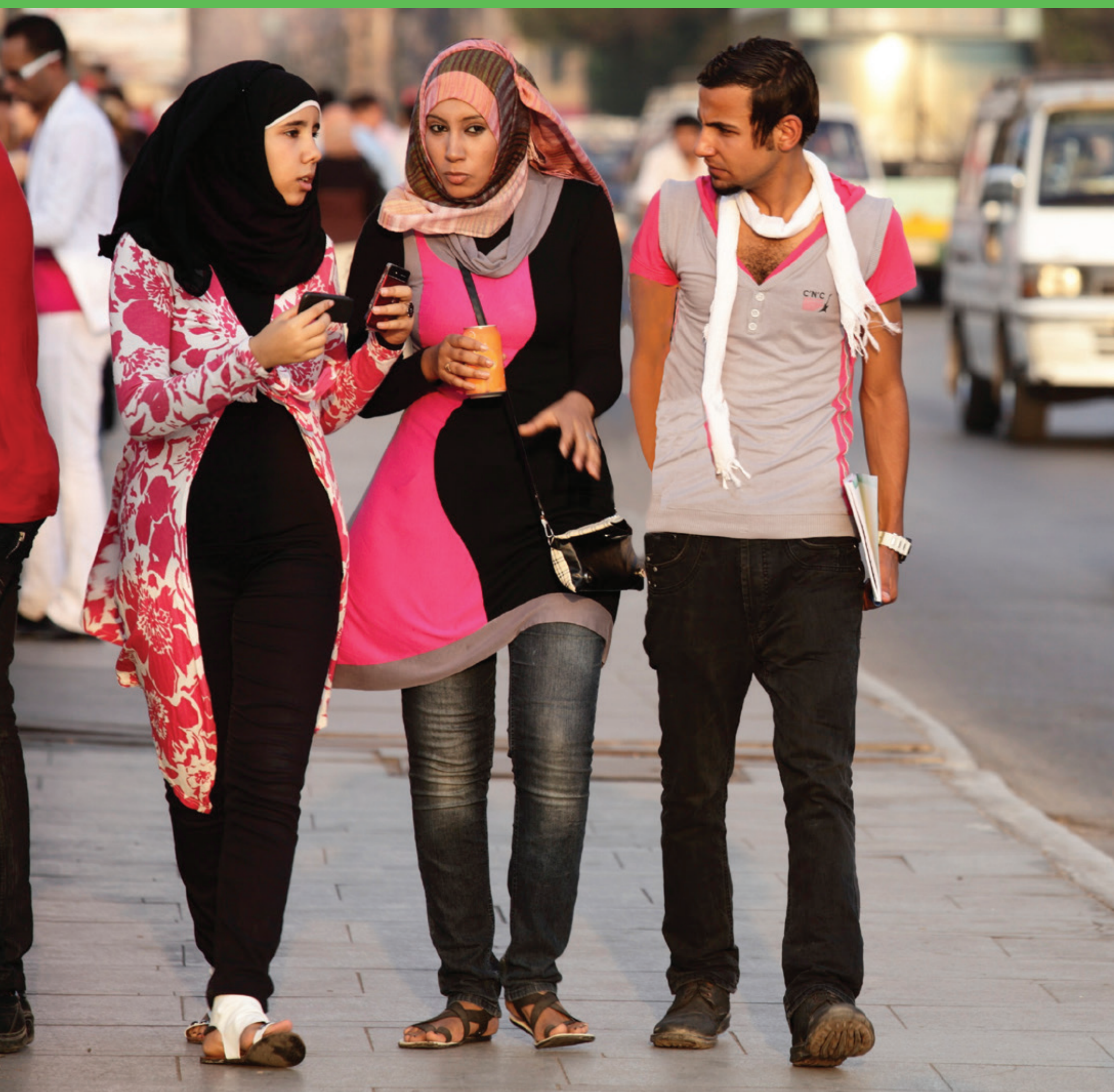


The five years that have passed since the Population Council's Survey of Young People in Egypt of 2009 (SYPE 2009) have proved to be a tumultuous period for the country. The year 2011 marked a historic year for Egyptian youth, as young people from around the country took an active role in the January 25 revolution.

Through their activism in early 2011, Egypt's young revolutionaries gained a platform to denounce their social and political marginalization, and demand their rights to freedom, justice, equality, and opportunity. This unprecedented voice for Egypt's youth pointed a national spotlight on many of the challenges that were found in the 2009 SYPE, including an educational system unresponsive to youth needs, difficult employment conditions, low civic and political engagement, and a social environment that denies youth access to essential information about their transition to adulthood.

\subsection{Egypt in the post- revolutionary period}

Since 2011, Egypt has undergone several political fluctuations and changes of power, with civil unrest and continued protests marking many events during the transition. Furthermore, the past four years have proven costly to Egypt's economic well-being and the labor market. Post-revolutionary political instability has resulted in the widespread divestment of foreign-owned firms, the declining value of the Egyptian pound, and a looming debt crisis the Egyptian state is still struggling to avoid (Kirkpatrick and Salah Amer 2011). The tumultuous climate has resulted in an enormous drop in revenues for particular economic sectors, such as tourism. Moreover, the return of large numbers of migrants from Libya and other countries in the region affected by the "Arab Spring" has also negatively affected the Egyptian labor market. ${ }^{1}$

1 The slowdown of Egypt's economy following the revolution has been widely covered in domestic and foreign media (New York Times 2011).
This post-revolutionary economic stagnation is expected to have resulted in a steady deterioration of job quality and increasing employment informality, in the context of labor market conditions that were already difficult for young entrants. Such economic challenges could not come at a worse time for Egypt's youth.

Like other countries in the region, Egypt is currently experiencing a demographic "youth bulge," meaning that the population of young people is significantly larger than other age groups. Although more highly educated than previous generations (Elbadawy 2009), this population of young people has struggled to achieve economic stability. Even prior to the 2011 uprisings, Egypt's youth constituted an estimated $90 \%$ of the country's unemployed (UNDP and INP 2010).

It is therefore vital to question how Egypt's youth are now faring in a significantly more unfavorable economic climate, and whether they are able to access the professional opportunities needed to work toward economic independence and complete key life transitions such as getting married and starting a family. At the same time, the transitional period may have opened up new opportunities to youth in other areas of life, most notably deeper engagement with media, politics, and civic life. Such questions regarding youth employment and civic participation in the current tumultuous era, along with potential changes in the institutions and decisions that shape the transition to adulthood, such as health and access to health care, quality of education, migration, marriage, and youth attitudes and life outlooks, are what this report seeks to better understand.

\subsection{Overview of SYPE 2009 and SYPE 2014}

The 2009 Survey of Young People in Egypt (SYPE) was fielded in May 2009 and collected data on several key areas of interest to youth, including education, employment, migration, health, family formation, social issues, and civic and political participation (Population Council 2010). In order to observe how young people have been faring during the transition period in Egypt in comparison to 2009, the Population Council designed the second 
wave of SYPE in 2014, which re-interviewed the same sample of young people who were interviewed in 2009. This yields a panel data set that spans the periods before and after the January 25 , 2011 revolution, and that is nationally representative for both time periods. This introductory chapter describes the SYPE sample design and implementation of the panel survey, and outlines the main background characteristics of young people aged 13-35 in Egypt in 2014 in order to provide a general background on the profile of youth in Egypt in 2014. The subsequent chapters then turn to an examination of specific topics of importance to youth during Egypt's transitional period.

\subsection{Survey design and implementation}

SYPE 2009 targeted young people aged 10-29, thus encompassing both "youth" and "adolescents." The SYPE team chose this age range in order to track young people throughout the complete duration of their transition to adulthood, allowing for an extended period to account for the phenomenon of delayed marriage and, in some cases, delayed transitions to productive work (Assaad and Barsoum 2007). The SYPE 2014 survey built a panel dataset by going back to re-interview the same sample of young people (now aged 14-35) interviewed in SYPE 2009 in all governorates of Egypt.

\section{Survey sample}

A brief explanation of the sampling design for the previous wave of SYPE is essential for understanding the 2014 SYPE sampling. SYPE 2009 is a uniquely comprehensive survey in that it is nationally representative, covering all the governorates in Egypt including the five frontier governorates, and was specifically designed for a priori inclusion of informal urban areas, also known as slums (or ashwaiyyat in Arabic). The Frontier Governorates and informal areas are often not covered in largescale surveys. The sample is designed so that the data are not only nationally representative, but also representative of Egypt's six major administrative regions: the Urban Governorates, rural Upper Egypt, urban Upper Egypt, rural Lower Egypt, urban Lower Egypt, and the Frontier Governorates.
By comparing the 2014 findings to the 2009 SYPE data, we gain a broad view of the ways in which the state of Egypt's young people has changed during the transitional period.

The 2009 SYPE sample is a stratified, multi-stage cluster sample. Sampling was determined using primary sampling units (PSUs) drawn from the master sample provided by the Central Agency for Public Mobilization and Statistics (CAPMAS), which was based on the 2006 national census. SYPE 2009 consisted of 455 PSUs, with 239 PSUs in rural areas and 216 PSUs in urban areas. Rural PSUs were divided equally between large and small villages, in order to accurately represent the diversity of rural demographics and account for peri-urbanization. Informal settlements were selected from a list developed by the Information and Decision Support Center of the Egyptian Cabinet of Ministers (IDSC).

The 2009 SYPE data collection and processing were conducted in collaboration with the IDSC. Out of the 11,372 households selected from the CAPMAS master sample for the 2009 SYPE sample, 20,200 young people were eligible to participate, and the Kish grid technique was used to draw a sample of 16,061 subjects from this pool of potential participants. In total, 15,029 of the sampled 16,061 young people were interviewed, with attrition primarily being due to the individual's refusal to participate or unavailability during data collection periods. See Population Council (2010) for more details on the 2009 SYPE sample and its sampling weights.

SYPE 2014 sampled the same young people who were part of the original sample of 15,029 individuals surveyed in 2009 . Of the 15,029 young people interviewed in 2009, data collectors managed to 
completely interview 10,916 (72.6\%) aged 13-35 for the SYPE 2014 study. ${ }^{2}$ Every effort was made to track down the current contact information of households and/or eligible young people who had changed their location since the 2009 interview. $^{3}$ Attrition was mainly due to family refusal to participate (9\%) as well as the relocation of respondents (14\%) who could not be tracked in 2014. As Figure 1.1 shows, $60 \%$ of the interviewed individuals were still in their original 2009 households, while $12.6 \%$ were found in split households. ${ }^{4}$ Weights based on the probability of non-response were constructed to adjust the sample of the 2014 SYPE for attrition. ${ }^{5}$

\section{Questionnaire design}

The 2014 SYPE questionnaire is based primarily on the 2009 survey, which was developed using qualitative data from focus group discussions and interviews with young people that determined the issues that were important to youth. In addition, the Council team consulted with different partners and research experts in each of the topics covered in the survey and completed an extensive overview of literature to further refine the 2009 questionnaire. In its semi-final stage, pretesting in selected PSUs in the Qalyubia, Cairo, and Giza governorates in March of 2009 helped the team further refine the survey before commencing nationwide data collection.

2 A few respondents reported being below age 14 at the time of the 2014 SYPE interview. These cases were left as is and included in the analysis of this report, after carefully checking their exact age.

3 During the SYPE 2014 data collection phase, a household was not interviewed (i.e., the household questionnaire was not filled out) if the eligible young person could not be located either in the original or in a split household.

4 A split household is defined in this 2014 SYPE panel as a household that was formed due to the move of at least one eligible young person out of his/her original 2009 household to form a new household after the 2009 interview.

5 Very few cases were reported as missing due to migration or death of an eligible young person. These cases were assigned to the "household not found" or "individual not found" categories. However, we suspect that some of the households that we were unable to track in 2014 may also have been missing due to the migration or death of household members. For more information on the calculation of attrition weights see Roushdy (2015).
FIGURE 1.1 SYPE 2014 interview results

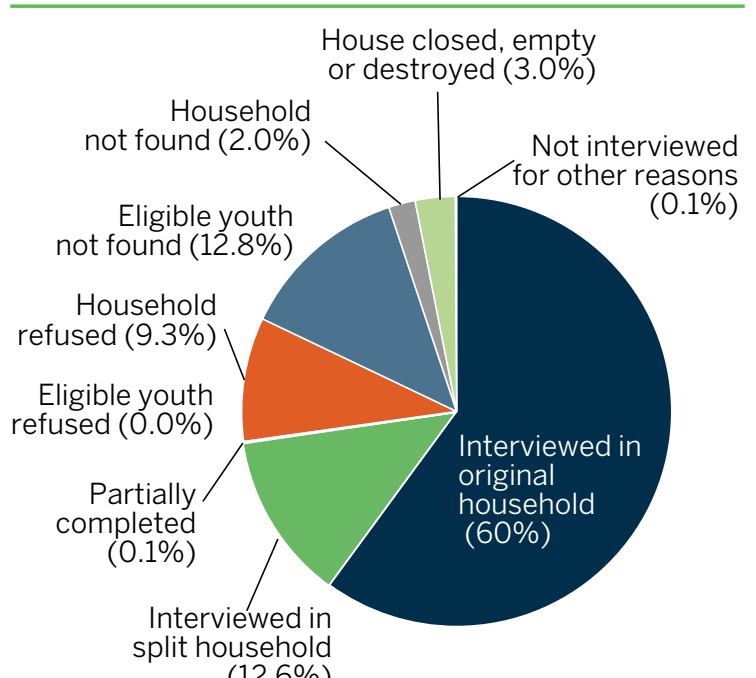

$(12.6 \%)$

The 2009 survey consisted of three questionnaires: a household questionnaire, an individual questionnaire focused on the respondent, and a community-level questionnaire. ${ }^{6}$ The household questionnaire assessed the demographic and socioeconomic characteristics of the subject's household, with the head of the household or an adult in the household interviewed for this section.

The 2009 individual questionnaire consisted of six versions designed specifically for different age groups and genders: males aged 10-14, females aged 10-14, males aged 15-21, females aged 15-21, males aged 22-29, and females aged 22-29. In 2014, we decided to design one all-inclusive version of the questionnaire using skip patterns whenever needed. Individual questionnaires for both rounds of SYPE covered the following key areas: education, work, family formation, health, migration, and civic and political participation.

In late 2012 and early 2013, the Population Council team began updating the SYPE 2009 household and individual questionnaires in consultation

6 The 2009 community-level questionnaire was used to assess characteristics of the subject's local community. This questionnaire was not administered as part of the 2014 SYPE due to budget constraints. 
with several partners and frequent SYPE users. ${ }^{7}$

The result is a more comprehensive version of these two questionnaires. The SYPE 2014 household questionnaire now includes additional information on migration, remittances, and household income and transfers. The SYPE 2014 individual questionnaire also added questions that cover new issues emerging since the January 25,2011 revolution, especially in relation to the civic engagement module, which focuses on four areas: civic and political participation, community values, gender role attitudes, and religiosity. The health, violence, risk, and safety module has been significantly updated as well to gain a broad picture of how youth's safety has changed since 2009, including exposure to health hazards, harassment, and physical violence. ${ }^{8}$

In June of 2013, a two-day pretesting of the full household and individual questionnaires was conducted. This pretesting included 60 households in the urban and slum areas of El-Sayeda Zeinab and Abdeen districts of Cairo. Pretesting helped the Council determine the expected duration of the full interview and identify problematic questions and misleading skip patterns in the questionnaires, which were then modified accordingly.

\section{Data collection and processing}

In early June 2013, the SYPE team conducted a week-long training for fieldworkers, and approxi-

7 In April of 2013, the Population Council team held several consultative meetings with experts in the fields covered by the different SYPE modules, SYPE partners and donors, and officials from relevant ministries to get additional feedback on the contents of each module of the updated version of the survey. These meetings significantly improved the design of the questionnaire.

8 In early August, the updated 2014 SYPE questionnaires were submitted to CAPMAS for legal approval, which was granted shortly after. Furthermore, as was the case in 2009, the 2014 SYPE study was approved by the Population Council's Institutional Review Board (IRB) prior to the commencement of fieldwork. The IRB reviews research involving human subjects to ensure that participants in such fieldwork are treated ethically and that participation does not compromise the participant's safety or well-being. This is especially important when a study involves minors, which is the case with SYPE.
SYPE 2014 questionnaires were updated to include additional information on existing topics such as migration, remittances, and household income, and on new issues related to civic engagement, gender role attitudes, and religiosity.

mately 115 interviewers and field supervisors participated. The training was conducted by CAPMAS and monitored by the Population Council. ${ }^{9}$ Prior to data collection in the non-frontier governorates, the fieldwork staff underwent a four-day refresher training course in November of 2013. In March 2014, the field staff again participated in a refresher course before conducting fieldwork in these governorates.

The SYPE 2014 data collection was conducted in collaboration with CAPMAS. Fieldwork in the non-frontier governorates started in late 2013 and continued until February 2014. However, the security situation in the frontier areas delayed research in the corresponding governorates. SYPE data collection in the Frontier Governorates started in March 2014 and was completed in June 2014.

Data collection was completed under the direct management of CAPMAS, which formed 18 field teams to conduct the SYPE. Field teams consisted of one supervisor, four interviewers, and one field editor. Two weeks after data collection began, CAP-

9 During the training, each question of the household and individual questionnaires was discussed in detail with the fieldworkers, who completed a written exam at the end of the training week. Based on the exam results, in addition to fieldworker's performance during the training, those with unsatisfactory performance were excluded from the SYPE data collection team. 
MAS formed office editing, callback center, coding, and data entry teams. The office editing team, which consisted of 50 experienced editors trained for the particular task, carefully reviewed each questionnaire received from the field to ensure that questionnaires did not contain missing or illogical data and that skip patterns were followed correctly. Identified errors were reported to the callback center team, which then contacted the interviewed families and individuals to gather the correct information. When the callback center team identified inconsistencies in the questionnaire responses and family responses on the phone, which happened in very few cases, the questionnaire was sent to the quality control team for further investigation.

Once all questionnaires were reviewed, a team of 15 CAPMAS data coders transformed all open-ended questions into codes. ${ }^{10}$ Finally, the reviewed and coded questionnaires were ready for data entry. Using a data entry interface designed specifically for SYPE 2014, the data entry team entered the data. The final clean data tape of the full SYPE 2014 data was submitted to the Population Council by CAPMAS in late September 2014.

\subsection{The profile of young people in 2014}

The SYPE sample aged by five years in the period between the 2009 and 2014 waves of the survey, a period of time that can encompass many life changes for a population that is in the midst of the transition to adulthood. In this section we therefore update the profile of youth background characteristics in 2014 , and discuss the implications of the sample aging for the analysis in the subsequent chapters.

Due to the high fertility rates experienced in the 1980s, accompanied by a decline in child mortality, Egypt has been experiencing a remarkable "youth bulge" in this stage of its demographic transition. Based on SYPE 2009, 62\% of the Egyptian popu-

10 In this step, the team used the recent CAPMAS official codebooks for occupation, economic activity, education certificate, school codes, and district of residence (shiakha/qism) and governorate. lation was below the age of 29 at the time of data collection and almost $40 \%$ were between the ages of 10 and 29. Among 10-29 year olds, the highest percentage of young people was in the age group from 10-17 in 2009 (44.7\%). Having aged by five years between the surveys, in SYPE 2014 almost $42 \%$ of the youth sample is now between the ages of 15 and $24 .{ }^{11}$ The sample has now largely aged out of the youngest age group from 10-14 that was captured in the SYPE 2009 , and $16.8 \%$ of youth are now in the 30-35 age group that was outside the range of the SYPE 2009.

This change in the distribution of young people by age group in 2014, as compared to 2009, certainly affects the distribution of other background characteristics of youth that depend on age, such as education level and labor market participation. Hence, one should be careful when comparing the distribution of youth by such background characteristics, even among the common age group of 15-29 in both surveys. ${ }^{12}$ The aging of the SYPE sample may also be associated with change in behavioral and attitudinal outcomes, such as uptake of risky health behaviors, attitudes toward gender roles, and youth's relationships with their families and communities. Thus, outcomes must also be compared across the 2009 and 2014 surveys with caution. For this reason, throughout the report the authors use a variety of approaches to compare between the two SYPE waves. Where possible, comparative analyses focus on the 15-29 age group that is common across the two surveys, using the two cross-sectional waves. In other analysis, authors rely on the panel dimension of SYPE to examine change in outcomes among the same group of youth as they age, for example in terms of labor market or marriage transitions.

11 See Assaad and Krafft (2015) for a detailed discussion of the youth bulge aging and its labor market effects.

12 For example, higher percentages of male youth might be fulfilling military service now than in 2009 , due to the relative increase in the percentage of youth who are above the age of 18 in 2014 than in 2009. This would in turn affect the youth labor force participation rate, as a relatively larger percentage of youth will be reported as out of labor force than in 2009. 
Table 1.1 presents the core demographic characteristics of the interviewed sample of youth in SYPE 2014. Among the young population aged $13-35$, the percentage of males (51.2\%) is slightly higher than that of females (48.8\%). In 2014, 64.8\% of 13-35-year-olds remain never married. The majority of young people are still residing in rural areas (60.7\%), as was the case in 2009. Nearly the same percentage of youth reside in informal urban areas in 2014 (9.8\%) as they did in 2009 (9.5\%); in contrast, fewer youth are now observed in urban areas (29.5\% in 2014 vs. $31.6 \%$ in 2009). Also, as in 2009, most young people reside in Lower Egypt (42.8\%) and Upper Egypt (36.7\%). The Urban Governorates comprise about $18.7 \%$ of the young population, while only $1.8 \%$ live in the Frontier Governorates as of 2014.
The following eight chapters of this report present detailed analysis and results of the SYPE data. The report uses both waves of SYPE, and on several occasions exploits the panel structure of the new SYPE data, to provide a before-and-after picture of the economic, social, political, and health situation of young people during this critical time period in Egypt's history. A key aim of this report is to identify issues of importance to young people in the country's new political environment in order to support policymakers in the development of evidence-based policies and programs to enhance the well-being of Egyptian youth and ensure that all young people have the opportunity to reach their full potential.

TABLE 1.1 Weighted and unweighted distribution of young people by main background characteristics, 2014

\begin{tabular}{|c|c|c|c|}
\hline & WEIGHTED \%* & WEIGHTED (N) & UNWEIGHTED (N) \\
\hline \multicolumn{4}{|l|}{ Gender } \\
\hline Male & 51.2 & $(5,586)$ & $(5,336)$ \\
\hline Female & 48.8 & $(5,330)$ & $(6,102)$ \\
\hline \multicolumn{4}{|l|}{ Age } \\
\hline $13-17$ & 20.4 & $(2,227)$ & $(2,196)$ \\
\hline $18-24$ & 39.5 & $(4,311)$ & $(4,158)$ \\
\hline $25-29$ & 23.3 & $(2,539)$ & $(2,564)$ \\
\hline $30-35$ & 16.8 & $(1,837)$ & $(1,998)$ \\
\hline \multicolumn{4}{|l|}{ Marital status } \\
\hline Never married & 64.8 & $(7,072)$ & $(6,313)$ \\
\hline Ever married & 35.2 & $(3,834)$ & $(4,593)$ \\
\hline \multicolumn{4}{|l|}{ Region } \\
\hline Urban Governorates & 18.7 & $(2,043)$ & $(2,064)$ \\
\hline Urban Lower Egypt & 11.6 & $(1,262)$ & $(1,217)$ \\
\hline Rural Lower Egypt & 31.2 & $(3,407)$ & $(3,426)$ \\
\hline Urban Upper Egypt & 8.0 & $(878)$ & $(639)$ \\
\hline Rural Upper Egypt & 28.7 & $(3,127)$ & $(2,621)$ \\
\hline Frontier Governorates & 1.8 & (199) & $(952)$ \\
\hline \multicolumn{4}{|l|}{ Urban-rural residence } \\
\hline Urban & 29.5 & $(3,221)$ & $(3,314)$ \\
\hline Rural & 60.7 & $(6,623)$ & $(6,506)$ \\
\hline Informal urban areas & 9.8 & $(1,072)$ & $(1,099)$ \\
\hline Total & 100.0 & $(10,916)$ & $(10,916)$ \\
\hline
\end{tabular}

*Weighted percentage is presented throughout this report, because it reflects the actual population, while the unweighted percentage reflects the sample. 


\section{References}

Assaad, Ragui and Ghada Barsoum. 2007. Youth Exclusion in Egypt: In Search of "Second Chances." Middle East Youth Initiative Working Paper, No. 2. Dubai: Wolfensohn Center for Development, Dubai School of Government, United Arab Emirates.

Assaad, Ragui and Caroline Krafft. 2015. "The Evolution of Labor Supply and Unemployment in the Egyptian Economy: 1998 -2012," in R. Assaad and C. Krafft (eds.), The Egyptian Labor Market in an Era of Revolution. Oxford, UK: Oxford University Press, pp. 1-26.

Elbadawy, Asmaa. 2009. "Education at a glance: Selected indicators based on the Egypt labor market surveys of 1988, 1998 and 2006," in Ragui Assaad (ed.), Egypt Labor Market: Revisited. Cairo: American University in Cairo Press, pp 117-155.

Kirkpatrick, David D. and Dina Salah Amer. 2011. "Egypt's Economy Slows to a Crawl; Revolt Is Tested." New York Times, 11 July. http://www.nytimes.com/2011/06/10/ world/middleeast/10egypt.html?emc=eta1.\&_r=0.

Population Council. 2010. The Survey of Young People in Egypt: Final Report. Cairo: Population Council, Egypt.

Roushdy, Rania. 2015. "Who Attrite during Political Transitions: Analysis of the Survey of Young People Attrition Weights," Population Council Working Paper Series. Cairo: Population Council, Egypt (forthcoming).

United Nations Development Program and the Institute of National Planning, Egypt. 2010. Egypt Human Development Report 2010: Youth in Egypt: Building our Future. Cairo: UNDP. 


\section{Health of Egyptian Youth in 2014: Knowledge, Attitudes, and Behaviors}

SARAH ISMAIL・NAHLA ABDEL-TAWAB • LILA SHEIRA

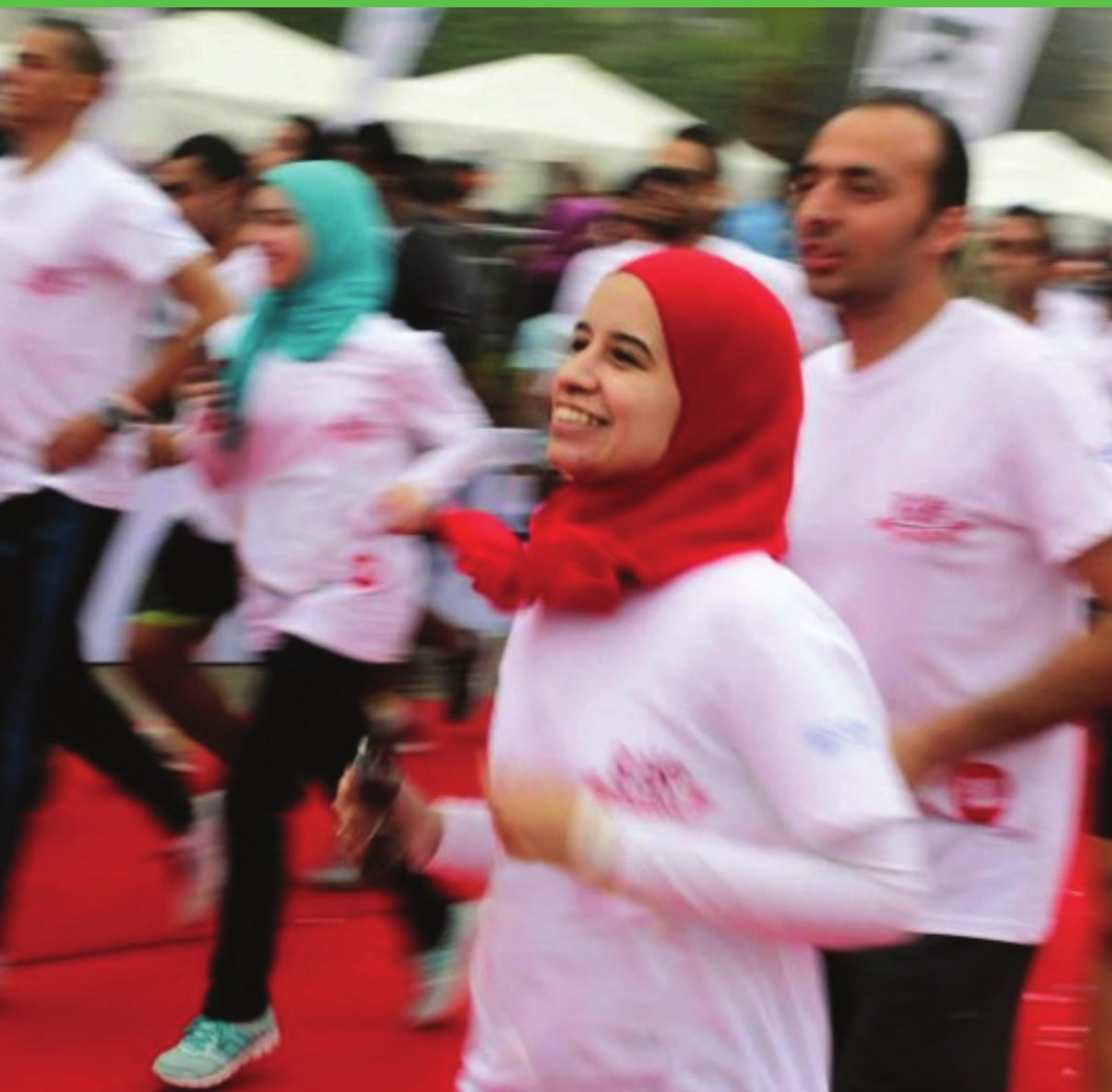


Young people's health attitudes and behaviors are central to their transition to adulthood and impact areas of their lives such as education, employment, family formation, and civic participation. Young people who are healthy are better able to successfully complete their education, lead productive lives, and contribute positively to their families, communities, and country. The health and development of young people have significant repercussions for their current and future well-being, as well as the health of their future children.

\subsection{Introduction}

The revolutions of January 25 and June 30 and subsequent political transitions may have impacted young people's health in a number of ways. Political instability and psychosocial stressors may have undermined youth livelihoods and increased their exposure to risk factors, thus leading to adverse health outcomes. On the other hand, the fact that recent political transitions were largely led by young people, and youth were recognized as the driving force behind those transitions, may have enhanced their sense of self-esteem and resilience and thus positively impacted the way they perceive their health. The 2014 SYPE provides a unique opportunity to examine change in a wide range of youth health indicators during Egypt's transitional period.

This chapter provides an overview of the situation of young people's health attitudes and behaviors in 2014 and makes comparisons with the 2009 data for key indicators. Overall, the 2014 health module included the same core questions asked of respondents in 2009. Those questions inquired about the respondent's general sense of well-being; access to health services; experience of disability and chronic diseases; hygienic practices such as washing hands and brushing teeth; perceptions of exposure to environmental pollution; road and transportation safety (including accidents and sexual harass- ment); nutrition and dietary habits; tobacco, alcohol and drug use; mental and psychological health; and reproductive health. A few additional questions were added in 2014 to measure knowledge of different modes of transmission of HIV/AIDS, use of antenatal care services, and contraceptive knowledge. Also, in 2014, as the cohorts of youth included in the SYPE sample were now older (aged 13-35), all participants answered all questions as there were no questions that were deemed inappropriate or irrelevant for a specific age group. However, different modules were used for male and female participants as appropriate.

In both 2009 and 2014, the health modules were built on international literature, a number of previously tested tools utilized in youth surveys elsewhere, and consultations with key experts in the field of youth and adolescent health. Tools utilized in the Youth Risk Behavior Surveillance (2007) and WHO Global School-based Student Health Survey (GHSH) were modified to suit the Egyptian context. It is also important to note that all assessments of health or nutritional status were based on respondents' self-reports, with no physical exams or blood tests undertaken.

\subsection{Access to health care}

Young people's ability to access health care when they need it and their health-seeking behaviors are important determinants of health outcomes. This section begins with an overview of youth access to and utilization of medical care.

\section{Usual source of medical care}

Respondents aged 13-35 were asked about where they usually go to receive care when they are ill (see Table A2.1). More than a third (38.9\%) of respondents went to a private clinic or hospital, while more than one-fourth (28.2\%) of respondents said that they do not seek care. Less than one-fifth (22.2\%) of respondents went to a government hospital.

There were several differences in usual source of medical care by background characteristics. More male youth (31.9\%) than female youth (24.3\%) 
reported not seeking health care. On the other hand, more female youth (43.4\%) reported attending a private clinic or hospital than their male peers (34.6\%). More than half of respondents in Frontier Governorates (52.4\%) reported not seeking any medical care compared to about one-fourth of respondents in the Urban Governorates (27.0\%). Similarly, more illiterate respondents (34.9\%) reported not seeking health care when feeling sick than do those who could read and write or who had more education.

To compare with SYPE 2009, we examined data for young people aged 15-29 in both surveys. Figure 2.1 shows that more young people in 2014 did not seek medical care when they got ill (28.5\% versus $11.1 \%$, respectively) while fewer young people utilized public facilities (22.7\% in 2014 versus $38.6 \%$ in 2009) or private clinics or hospitals (39.2\% in 2014 versus $45.8 \%$ in 2009).

Of respondents aged 13-35 who stated that they had been to a healthcare facility, male youth made an average of 1.3 visits in the previous six months, while female youth averaged 1.8 visits in the same period. The number of visits increased slightly by age and decreased by wealth (those in the lowest wealth quintile averaged 1.7 visits while those in the highest quintile averaged 1.4 visits). Older female youth had slightly more visits than their younger peers, and ever-married young women had more

FIGURE 2.1 Source of medical care for respondents aged 15-29, 2009 and 2014 (\%)

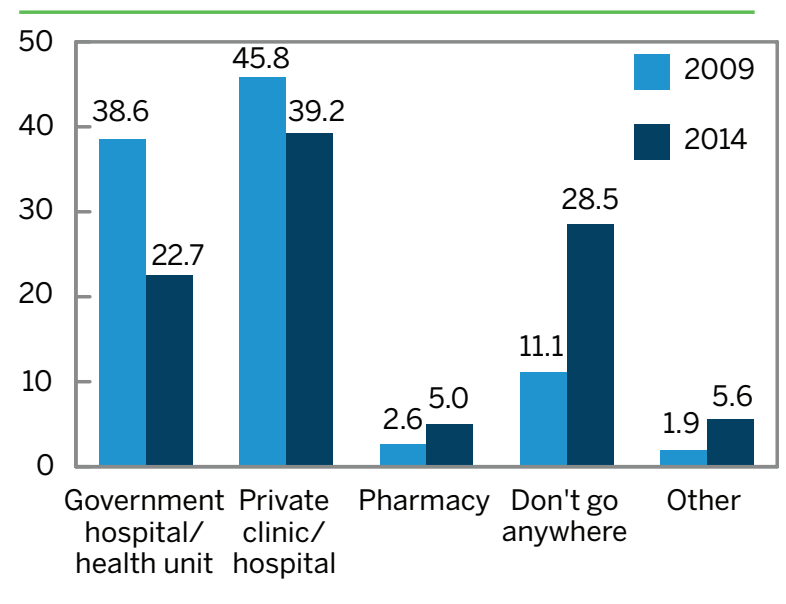

\author{
Young people's health is affected \\ by wider social, economic, and \\ political circumstances, which \\ may influence their access to \\ resources (e.g., health services \\ and financial resources), \\ exposure to risk factors \\ (e.g., pollutants and psychosocial \\ stress), or adoption of health- \\ compromising behaviors \\ (e.g., sedentary lifestyle and \\ early marriage).
}

visits than never-married women. These differences may reflect antenatal care or child-related visits among married women of childbearing age. Youth in the Frontier Governorates had fewer visits to health facilities than youth in other regions (data not shown).

The majority (88.9\%) of respondents aged 15-29 who sought health care in the last six months were able to reach the facility in less than 30 minutes. Mean travel time was 22.7 minutes, ranging from 17.5 minutes in urban Lower Egypt to 25.1 minutes in the Frontier Governorates. More than two-fifths (42.6\%) of respondents reported walking to their usual healthcare facility. For those who did not walk, the average reported cost of transportation to reach the most commonly used healthcare facility was 9 Egyptian pounds (EGP). Of those who did not walk, $8.6 \%$ of SYPE respondents paid EGP 1 or less, and $83.3 \%$ paid less than EGP 10 to get to their usual source of care (data not shown). As of June 2014, 1 USD = EGP 7.6. 


\section{Treatment and medication expenses}

For youth aged 13-35, the average amount of money spent on examination fees for medical care during their last visit was EGP 32.4, and the average amount spent on medication was EGP 53.3 (data not shown). On average, male youth paid more for medication and lab tests than did female youth (EGP 55.4 versus 50.9 and EGP 65.6 versus 49.6, respectively). Medical care fees paid by SYPE respondents were highest in the Urban Governorates (EGP 36.3) and lowest in the Frontier Governorates (EGP 25.1). Expenditures for medication were highest in urban Lower Egypt (EGP 62.1) and the Urban Governorates (EGP 61.1) and lowest in rural Upper Egypt (EGP 45.1) (data not shown).

As expected, fees paid and expenditures for medication increased with greater wealth. Those in the lowest wealth quintile paid the smallest amount (EGP 25.7 on average for fees, which was three times higher than the EGP 9.2 spent in 2009; EGP 42.7 was spent on medications) and those in the highest wealth quintile paid the highest amount (EGP 41.6 on average for fees and EGP 62.3 on medications). As for lab tests, female youth spent more than male youth and SYPE respondents in urban areas spent more.

\section{Use of medications without a prescription}

Taking medications without a prescription may result in inappropriate or unnecessary use of medications, and may be an indication that youth are not seeking medical care when they need it. About $24.2 \%$ of SYPE respondents aged $13-35$ reported having taken a medication without a prescription in the two weeks prior to the survey. Prevalence rates were similar across gender, age, and wealth quintile. However, rates were substantially different by region; the Urban Governorates had the highest usage (37.3\%) followed by rural Upper Egypt (24.8\%) with urban Lower Egypt demonstrating the lowest usage (16.7\%) (data not shown).

\subsection{Self-rating of health and reported prevalence of chronic diseases and disability}

The SYPE health module asked all respondents to self-evaluate their current health status. Overall, respondents expressed feeling healthy; about half (48.4\%) of youth indicated that their health was either "very good" or "excellent."

There was very little difference in self-perceived general health among respondents by gender, age group, or marital status. However, as wealth increased, the percentage of respondents who indicated that their health was either "very good" or "excellent" increased to reach $52.1 \%$ among respondents in the highest quintile compared to 45.0\% among respondents in the lowest quintile. Similarly, youth in the highest two education categories were more likely to indicate that they had either "very good" or "excellent" health (52.1\% of respondents who had completed post-secondary, and $52.3 \%$ of respondents who had completed university or more) than those respondents from the lowest two education levels (44.3\% of those respondents who were illiterate, and $45.6 \%$ of those who could only read and write) (data not shown).

Figure 2.2 shows the self-rating of health status among SYPE respondents aged 15-29 in 2009 and 2014. In 2014, a much larger proportion of respondents rated their health as very good or excellent

FIGURE 2.2 Self-rating of health status among SYPE respondents aged 15-29, 2009 and 2014 (\%)

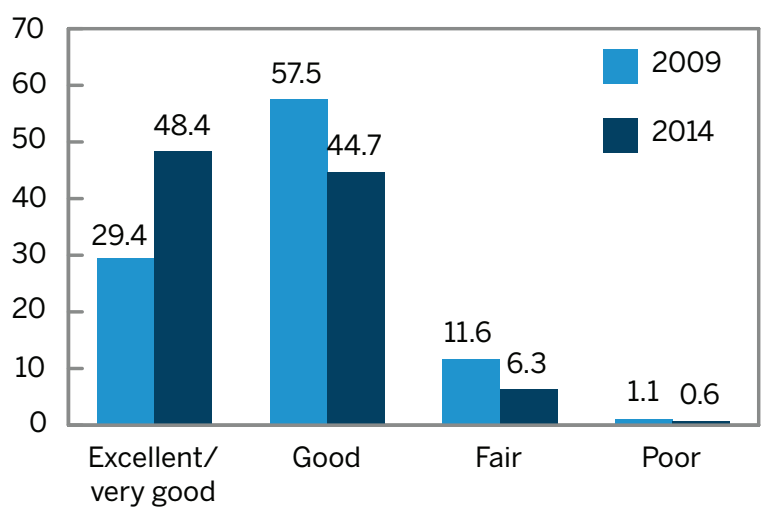


(48.4\% in 2014 versus $29.4 \%$ in 2009), while fewer respondents rated their health as good (44.7\% in 2014 versus $57.5 \%$ in 2009 ), fair (6.3\% versus $11.6 \%)$ or poor $(0.6 \%$ versus $1.1 \%)$.

\section{Chronic disease and disability}

One-fourth of SYPE respondents aged 13-35 reported suffering from at least one chronic disease. Very few young people reported having a disability (1.1\%). Of those youth who reported having a chronic disease or disability, $35.0 \%$ reported that their disability prevented them from fulfilling their regular responsibilities or getting married. However, among those with a disease or disability who attended school, only $4.4 \%$ reported that it had interrupted their attendance at school. Among SYPE respondents who reported having an illness or disability, $69.4 \%$ had never worked. Among those who had ever worked, $5.1 \%$ had to miss days of work because of their condition (data not shown).

\subsection{Hygienic practices}

Slightly more than one-half (54.6\%) of SYPE respondents aged $13-35$ cleaned their teeth with a toothbrush and toothpaste. A minority (3.3\%) used a siwaak, a traditional branch or twig used for teeth cleaning. More females (58.7\%) used a toothbrush than males (50.7\%), whereas more males used a siwaak (4.3\%) than females (2.3\%). Younger respondents were more likely to use a toothbrush and older respondents were more likely to use a siwaak. Toothbrush use was highest in the Urban Governorates (75.9\%) and urban Lower Egypt (75.8\%) and lowest in rural Upper Egypt (29.7\%) and urban Upper Egypt (34.0\%). Toothbrush use increased with wealth (Figure 2.3).

About $80.1 \%$ of SYPE respondents reported always $(62.5 \%)$ or often $(17.6 \%)$ washing their hands with soap after using the bathroom. As one would expect, rates of "always hand washing" increase with wealth quintile, literacy, and education. Also, more females than males reported washing hands often or always (83.0\% of females versus $77.2 \%$ of males).
FIGURE 2.3 Percentage of young people who brushed their teeth, by wealth quintile, 2014

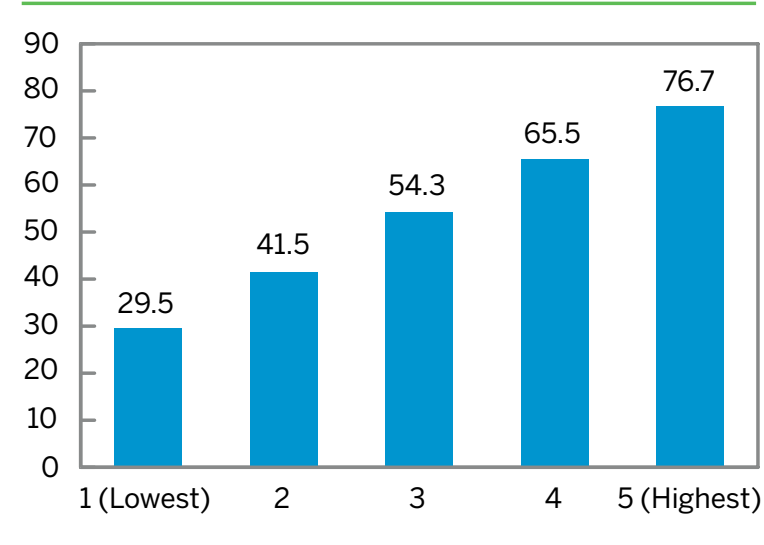

\subsection{Health and the environment}

SYPE respondents aged 13-35 were asked if they perceived any type of pollution in the area where they lived. About two thirds (67.7\%) of respondents perceived the environment around them as polluted. Perception of pollution tends to increase by wealth; $72.8 \%$ those in the highest wealth quintile versus $62.2 \%$ those in the lowest wealth quintile thought that the area where they lived was polluted. As one would expect, those who lived in metropolitan urban regions were most likely $(81.6 \%)$ to believe their surrounding environment to be polluted, and those living in the Frontier Governorates were least likely (32.0\%) to perceive this. There were no substantial differences by gender or age (data not shown).

Compared to 2009, substantially more young people aged 15-29 in 2014 perceived their environment as polluted compared with 2009 (67.7\% versus $29.6 \%$, respectively) (Figure 2.4). The percentage of female respondents 15-29 who perceived their environment as polluted more than tripled between 2009 and 2014 (20.6\% versus $68.0 \%$ respectively).

Youth also perceived a range of other environmental health risks in the area in which they lived. Among all SYPE respondents aged 13-35, 41.8\% thought that the streets were dirty or there was garbage in the streets, $43.3 \%$ thought that the air 
When asked about the specific impact of environmental pollution on their health, about two-thirds of respondents believed that pollution in

\section{their immediate environment affected their health.}

was polluted, $40.7 \%$ thought that the water was polluted, $19.5 \%$ thought that there was sewage or sanitation pollution in their areas, $15.9 \%$ thought that there was noise pollution, and $9.8 \%$ believed that there was pollution from pesticides.

Respondents who noted that their immediate environment was polluted were asked if this had affected their health. Among those respondents, $60.7 \%$ thought that the pollution affected their health. Slightly more respondents in the lower wealth quintiles thought that the pollution in their environment affected their health $(63.6 \%$ of youth in lowest wealth quintile compared to $58.2 \%$ of those in the highest wealth quintile). Those living in urban

FIGURE 2.4 Respondents aged 15-29 who perceived their environment as polluted, 2009 and 2014, (\%)

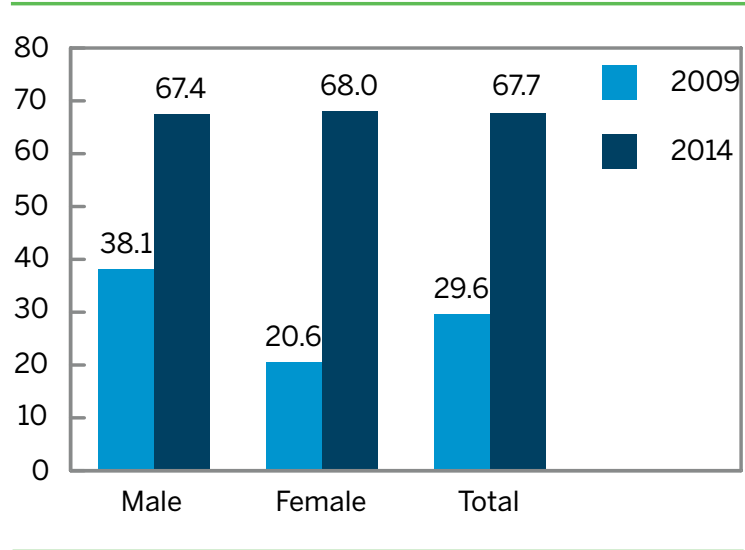

(64.5\%) and rural (60.4\%) areas were more likely to think that pollution affected their health than those living in informal urban areas (49.5\%). There were no substantial differences by gender or age.

When asked about the specific impact of environmental pollution on their health, about two-thirds of respondents believed that pollution in their immediate environment affected their health. Close to $63.0 \%$ indicated that the pollution affected their respiratory system, while others referred to digestive problems (30.3\%), kidney problems (19.9\%), eye infections (19.2\%), skin rashes (16.0\%), hearing problems (13.2\%), and liver problems (12.6\%). Although based on self-reports, the high percentage of youth who perceived that their environment negatively impacted their health suggests that policy measures to curb pollution and other environmental hazards are greatly needed.

\subsection{Exposure to risk of injury and violence}

\section{Risks in the use of transportation}

SYPE respondents aged 13-35 were asked about the most common means of transportation that they used. Public transportation (microbus, bus, metro, train, taxi, toktok, truck, and cart) was the most widely used form (79.5\%), the most popular being the microbus (55.9\%). Private transportation (bicycle, motorcycle, private car, walking, other) was used by the remaining $20.5 \%$. More male youth than female youth used microbuses (60.3\% vs. $51.2 \%$ ) while more female youth than male youth used taxis (2.5\% vs. $1.2 \%$ ) and toktoks (16.4\% vs. $10.6 \%$ ). Metro usage was equally distributed across gender. Walking was more common among younger than older respondents, whereas microbus usage was more common among older than younger respondents.

Young people aged 13-35 were asked about the most serious risks they face while on the street (not on transportation). More than two-thirds (70.2\%) indicated that there was at least one serious risk they faced on the street, including crowding (29.6\%), fast or reckless driving (20.4\%), and theft 
(9.5\%). Among female respondents, 6.3\% mentioned sexual harassment as the most serious risk they faced on the street.

Among SYPE respondents who most often used public transportation, the majority (81.6\%) felt that there was at least one form of risk they were exposed to while on transportation. Crowding was the risk most often mentioned (by $36.5 \%$ of those who ride public transportation), followed by fast and reckless driving (by 20.0\%), theft (10.3\%), pushing (by $6.6 \%$ of riders), aggressive drivers (1.9\%), and not having enough time to board and exit public transport (by $1.3 \%$ of riders).

Perceptions of risk on the street and on public transportation were compared among young people 15-29 in 2009 and 2014. More young people in 2014 compared to 2009 identified at least one risk on the street (70\% versus 60\%, respectively) and at least one risk on public transportation (82.4\% versus $71.2 \%)$.

\section{Safety measures in driving or riding bicycles or motorcycles}

The majority (90.0\%) of respondents whose primary mode of transportation was a bicycle had never used a helmet. The remainder of responses were equally distributed between rarely (5.5\%) and sometimes (4.5\%) using a helmet. As for motorcycle riders, very few (3.5\%) reported using a helmet often or regularly. The majority (74.1\%) reported never using a helmet, whereas $22.3 \%$ sometimes or rarely wear a helmet.

A small percentage (6.2\%) of SYPE respondents aged 18-35 drove a car. (This question was only asked of participants over age 18.) Only two in 10 young drivers (21.3\%) reported wearing a seatbelt often or regularly in 2014. Seatbelt use among passengers was even less common with less than one out of 25 (3.5\%) reporting regularly wearing a seatbelt as a passenger.

Seatbelt use dropped among both SYPE drivers and passengers between 2009 and 2014. Among drivers aged 18-29, "regular" seatbelt use dropped from $45.5 \%$ in 2009 to $21.3 \%$ in 2014 . Among passengers aged 13-29, regular seatbelt use dropped from $7.7 \%$ in 2009 to $3.5 \%$ in 2014 . (Figure 2.5 )

\section{Young people and violence}

Because violence is a major risk factor for young people in the region (Krug et al. 2002), the survey included questions on incidence of and exposure to violence. Risks were divided into engagement in a physical altercation and carrying any sort of weapon. This chapter covers violence in general; exposure to violence specifically related to political participation is covered in Chapter 7. Less than one-tenth of SYPE respondents (6.2\%) had been in a physical altercation in the past 12 months. Male

FIGURE 2.5 Seatbelt use among drivers aged 18-29 and passengers aged 13-29 in 2009 and 2014 (\%)

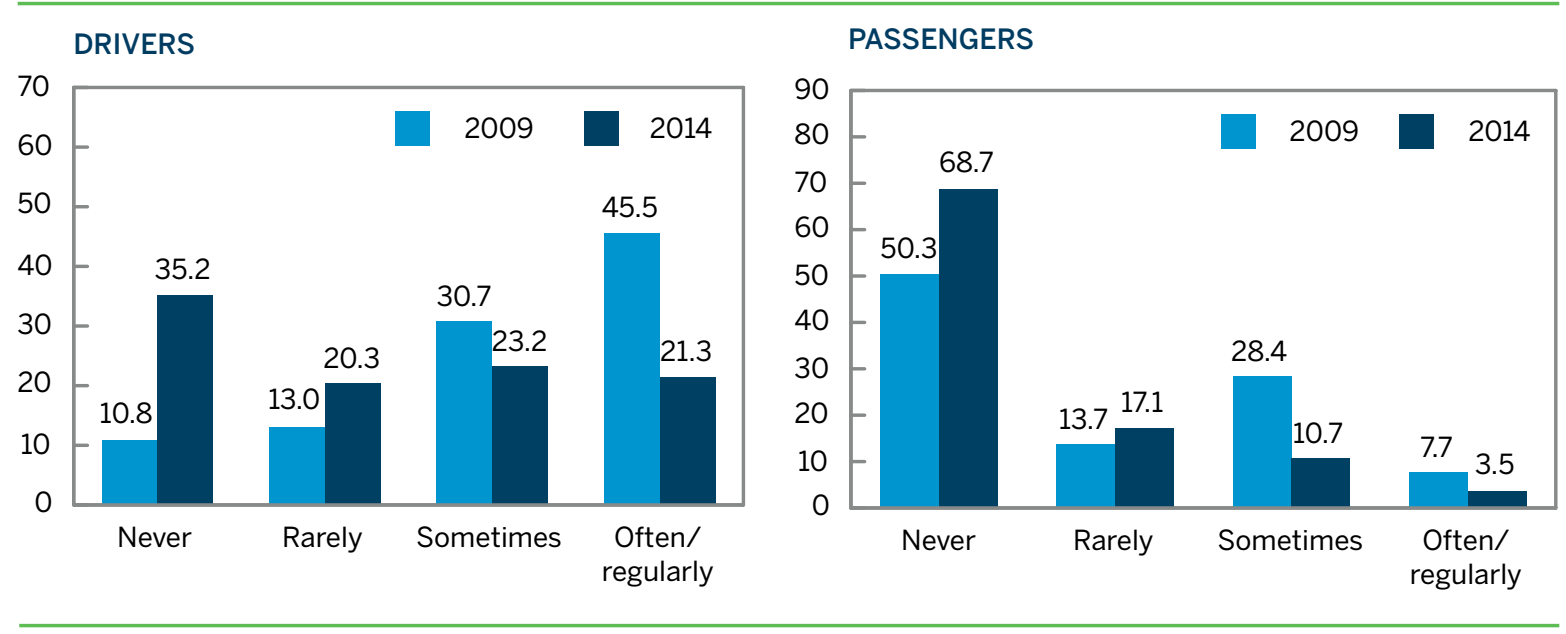


youth were four times more likely than female youth (9.8\% vs. $2.5 \%$ ) to be in a physical altercation. There were no substantial differences by age or wealth quintile (data not shown).

A small percentage (2.6\%) of SYPE respondents aged 13-35 carried a weapon for self-defense. The weapons most commonly carried were knives $(1.5 \%)$, followed by guns ( $0.3 \%)$. Male youth were four times more likely (4.1\%) to carry a weapon than females (1.1\%). There was a clear gender preference in weapon choice with male youth preferring to carry knives and guns and female youth preferring to carry pins. Weapons were most prevalent among those who lived in rural Upper Egypt (3.6\%), followed by urban Upper Egypt (3.2\%). Of those who carried a weapon, $29.1 \%$ reported using it in the past two years. Female youth were more likely to report using a weapon in the past two years; $33.5 \%$ of females who carried a weapon reported using it versus $28.1 \%$ of males.

\section{Exposure to injury and accidents}

Like violence, injury is a major health concern that disproportionately affects young people (Peden et al. 2008). The frequent exposure to injury or accidents is often seen as a sign of living in a risky environment or engaging in risky behavior. Among all SYPE respondents aged 13-35, 13.2\% reported having had an injury or accident happen to them in the past 12 months. A small percentage (3.3\%) had more than one incident in the previous year. The Urban Governorates had the highest rate of injury or accidents, while urban Upper Egypt and urban Lower Egypt had the lowest. More male youth than female youth reported having had an injury. Prevalence of injury in general was similar across age and wealth quintiles (data not shown).

Overall, more male youth than female youth reported having a deep cut, being in a collision, being in a car accident, or being in a fight. Car collisions were more common in the Urban Governorates than in other areas. Female youth reported more burns compared to male youth. Also, burns were most common in the Urban Governorates (data not shown).

\section{Sexual harassment}

All female respondents aged 13-35 were asked about their exposure to sexual harassment in the past six months. More than one-third of SYPE respondents (39.9\%) were exposed to some form of sexual harassment in 2014. As shown in Table A2.2, younger respondents aged 13-17 were more likely to experience sexual harassment than older age groups. Sexual harassment was most likely to happen in informal urban areas (61.6\%); it was reported at similar rates in the Urban Governorates (53.3\%), in urban Upper Egypt (50.2\%), and in urban Lower Egypt (50.1\%).

Among female SYPE respondents aged 13-35, $41.6 \%$ reported that someone had made a bad or inappropriate comment to them, $1.7 \%$ reported that someone had touched their private parts, less than $1.0 \%$ reported that someone made them touch his or her private parts, showed them a private part of his body, or that they had been hugged or kissed in a sexual way. None of the SYPE respondents reported an attempted rape (data not shown).

Strangers were by far the most commonly reported perpetrators of sexual harassment against young women; $40.9 \%$ of all female SYPE respondents (aged 13-34)-96.3\% of those who reported being sexually harassed-had experienced sexual harassment from a stranger, 3.3\% from an acquaintance; a smaller percentage reported harassment from a family member, co-worker, or teacher, and none from a boss. The most commonly reported location for sexual harassment was the street: of those females aged 15-29 who reported being sexually harassed, $86.3 \%$ reported being harassed on the street (36.7\% of all female SYPE respondents), $21.9 \%$ on transportation, $6.4 \%$ at the mall or market, $4.5 \%$ at school, 2.1\% in an abandoned place, and $1.2 \%$ at home. Harassment in the workplace or parks was not common. 
Only one-third (35.0\%) of female SYPE respondents (aged 15 -29) who had experienced sexual harassment told someone about their experience. Younger females were more likely to tell someone about their experience than older females: $44.2 \%$ of those aged 15-17 told someone, while only $26.9 \%$ of those aged $25-29$ did so. Female youth living in urban areas (42.7\%) were more likely to report being sexually harassed than those in rural areas (32.7\%) and informal urban areas (31.4\%). Female youth in the highest wealth quintile were most likely (43.5\%) to tell someone they were harassed. Of those respondents who told someone about being sexually harassed, $22.9 \%$ told a parent, $14.5 \%$ told a friend, $3.2 \%$ told another relative, and $0.2 \%$ told the police (data not shown).

To compare the results on sexual harassment in 2014 with those of 2009, while adjusting for aging of the survey population, we examined exposure to sexual harassment among respondents 13-29 in the two surveys. Figure 2.6 shows an overall decrease in experience of sexual harassment among female youth 13-29 (from 49.7\% in 2009 to $42.8 \%$ in 2014). This decline from 2009 to 2014 is most notable among respondents aged 25-29 (from $46.4 \%$ to $33.3 \%$ ) followed by those aged 18-24 (from 54.2\% to 44.8\%). On the other hand, 13-17-year-olds witnessed an increase in exposure to sexual harassment (from $46.4 \%$ in 2009 to $49.5 \%$ in 2014).

FIGURE 2.6 Exposure to sexual harassment among females aged 13-29, 2009 and 2014 (\%)

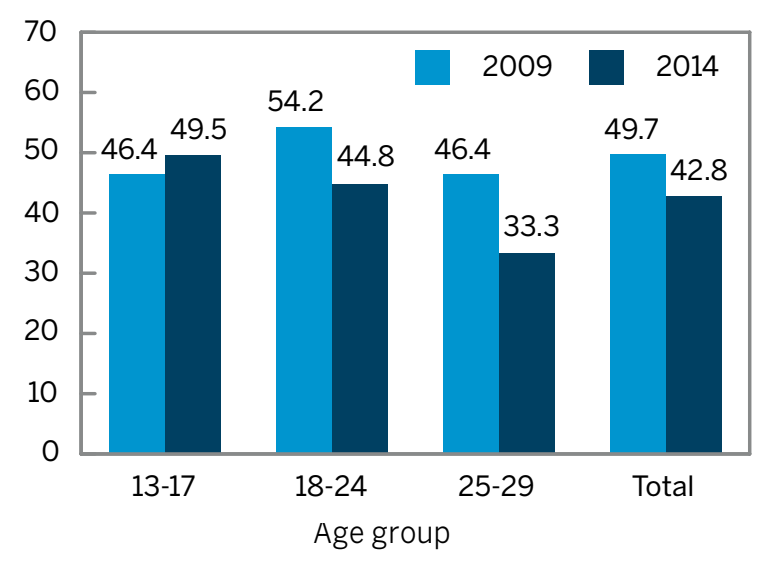

\section{More than one-third of female SYPE respondents aged $13-35$ were exposed to some form of sexual harassment in 2014.}

\subsection{Nutrition, dietary habits, and physical activity}

This section examines SYPE respondents' eating habits, nutritional intake of different types of food, as well as their perceptions of weight and daily exercise habits. Just under half of SYPE respondents 13-35 years indicated that they ate breakfast daily (45.2\%), followed by slightly more than a fourth (26.7\%) reporting "often" and a smaller percentage (21.8\%) reporting "sometimes." Female respondents were more likely than their male counterparts to eat breakfast on a regular basis ( $49.1 \%$ versus $41.4 \%$ always ate breakfast). Respondents from rural areas were the most likely to report "always" (49.7\%) compared to those from urban (39.7\%) and informal urban (33.3\%) areas. There were no substantial differences among age groups or wealth quintiles (data not shown).

Respondents were also asked about their daily intake of sweets, carbonated beverages, snacks, and fast food, revealing that a substantial percentage of youth engage in some unhealthy eating habits. Table A2.3 shows that more than half of young people $13-35$ years $(51.6 \%)$ drink carbonated beverages 1-3 times per week while $11.6 \%$ drink it more than three times per week. Young people who are 13-17 years, those who live in the Urban Governorates, and those who belong to the highest wealth quintile are more likely to consume carbonated drinks more than three times per week.

About one-third (35\%) of young people aged 13-35 eat fast food 1-3 times per week and nearly onetenth (8.4\%) eat it more than 3 times per week. Young males, those aged under 25, and those who 
live in urban governorates or who belong to the highest wealth quintile were more likely to consume fast food (Table A2.4).

There is a large evidence base indicating that diets with high salt intake, especially in lower-middle income and developing countries, are highly associated with increased rates of hypertension (Ibrahim and Dumasceno 2012). Hypertension is one of the main causes of cardiovascular disease, which is reaching epidemic percentages in the Middle East and North Africa, where deaths from stroke are predicted to double by 2030 (Tran, Mirzaei, and Leeder 2007). SYPE respondents were asked about their salt intake and preferences for salty foods. Overall, $32.8 \%$ of respondents indicated "yes" to the question "do you like your food to be very salty?" Those in the highest wealth quintile and those in urban and informal urban areas were more likely to prefer their food very salty than other respondents. There were no substantial differences by age or gender (data not shown).

SYPE participants were asked about the type of bread they usually eat. Respondents from the highest wealth quintile were three times as likely to report eating white (fino/shamy) bread (44.2\%) than those from the lowest quintile (16.3\%). Interestingly, consumption of brown, subsidized bread (subsidized balady) was highest amongst respondents in the highest wealth quintile (35.7\%), compared to just $23.0 \%$ of those in the lowest quintile. ${ }^{1}$ This underscores the need to revisit the current generalized subsidy system. Respondents from the lowest wealth quintile were more likely to report eating bread baked at home (61.7\%) than those from the highest (42.2\%) (data not shown).

The section on nutrition concluded with questions specifically for respondents who were still in school at any level, asking about their food intake while at school. Research has shown that nutrition during the school day, especially breakfast, is important for cognitive development and can impact test

1 Bread is among the main food items included in the government subsidy scheme. For information on the subsidy scheme in Egypt see Akhter et al. (2001). scores and other measures of academic performance (Rampersaud et al. 2005). The great majority (85.6\%) consumed food at school; just under two-thirds of respondents (64.9\%) indicated that they bought food at school, whereas a smaller percentage (18.9\%) consumed "homemade sandwiches" and a very small percentage mentioned a “school meal" (1.9\%).

\section{Perceptions of weight and obesity}

About three-fourths of respondents aged 13-35 (73.4\%) reported that their weight was "about the right weight," followed by $12.4 \%$ responding "slightly overweight" and $11.9 \%$ responding "slightly underweight." Female respondents were nearly twice as likely as male respondents to report their weight as being "slightly overweight" (16.3\% compared to $8.7 \%$ ) and three times as likely to report being "very overweight" as male youth (1.5\% compared to $0.5 \%$ ). As in 2009 SYPE, as age increased, the perception of being "slightly overweight" increased as well, with $15.9 \%$ of those in the oldest age category responding as such compared to just $7.6 \%$ of those in the youngest.

All SYPE respondents were asked if they were trying to lose, gain, maintain, or doing nothing about their weight. Nearly two-thirds responded that it "doesn't matter" (65.0\%) followed by $23.0 \%$ who responded that they were trying to "stay the same weight." Three times as many female youth (10.2\%) as male youth (3.4\%) wanted to "lose weight." Desire to lose weight also increased as wealth increased; nearly twice as many people in the highest wealth quintile $(8.7 \%)$ wanted to lose weight as those in the lowest (4.5\%). The same is true for residence: respondents from urban residences were almost twice as likely to want to lose weight (9.1\%) than those from rural (5.7\%) and informal urban (5.9\%) areas.

\section{Physical activity}

The survey included a series of questions asking SYPE respondents about their daily physical activities, including biking and walking, going to a gym, playing sports, or physical work on the job. Table A2.5 shows that nearly half (45.8\%) of SYPE 
respondents $13-35$ do not engage in physical activities daily. Nearly twice as many young women (59.2\%) did not exercise as men (33.0\%). SYPE participants aged 13-17 were more likely to indicate daily exercise (66.8\%) than the those aged 30-35 (49.0\%). Furthermore, respondents from informal urban areas were less likely to report participating in a daily physical activity (42.6\%) than their urban (55.3\%) or rural (55.6\%) counterparts. Participation in a daily physical activity was not substantially different by wealth or education level attained.

The most common response among those who did engage in daily exercise was "walking/bicycling to work/school" (43.9\%), followed by "my work involves a physical activity" (10.8\%) and "playing football on the street" (9.1\%). Male youth were much more likely to play sports in a youth center (7.1\% of all male respondents), play football on the street (17.2\%), or work in a job that requires physical activity (14.7\%), compared to female youth (0.8\%, 0.6\%, and $6.8 \%$, respectively). The most common response by women was "walk/bicycle to work/school," to which 35.1\% indicated that they did so on a daily basis (data not shown).

Engagement in daily physical activity among young people 15-29 was compared in the two surveys. Figure 2.7 shows a decline in engagement in daily physical activity for both young men and women 15-29 between 2009 and 2014.

FIGURE 2.7 Engagement in daily physical activity among youth aged 15-29, by gender, 2009 and 2014 (\%)

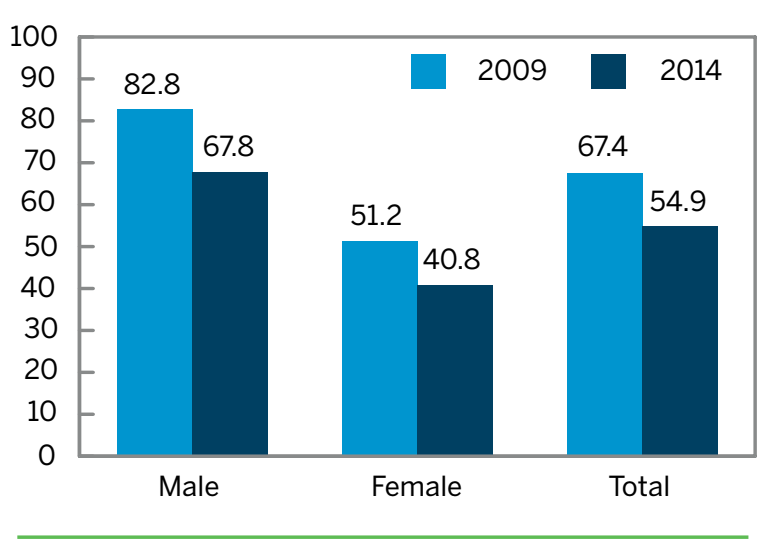

\subsection{Use of tobacco, alcohol, and drugs}

The questions regarding smoking first asked about other people's smoking habits, including those of family members, then about the respondent's own habits. The rationale for this sequencing was to get proximal data in case of reluctance to self-report about such sensitive issues. The same technique was also used to inquire about drug and alcohol use.

\section{Smoking}

Among SYPE respondents aged 13-35, one-third (30.9\%) reported having a father who smoked and very few $(0.7 \%)$ reported that their mothers smoked. The majority (60.7\%) reported that none of their siblings smoked, about one-third (35.0\%) said that few of their older siblings smoked, and $2.9 \%$ reported that all or most of their older siblings smoked.

Respondents were also asked whether their friends smoked and whether their spouses smoked. Responses varied by gender: $8.1 \%$ of female respondents had a close friend who smoked and $21.7 \%$ had a spouse who smoked, while $74.2 \%$ of males reported that their friends smoked and $1.8 \%$ that their spouses smoked. Nearly half (48.0\%) of young married females lived with a smoking husband. More than one-fourth (28.0\%) of male youth aged 13-35 reported currently smoking cigarettes (occasionally or regularly). Current smoking increased with age, from 5.6\% of 13-17-year-old males to $46.9 \%$ among 30-35-yearolds (data not shown).

About $7.3 \%$ of SYPE respondents have ever tried smoking shisha (hookah), and $2.5 \%$ said they smoked shisha regularly, whereas $90.2 \%$ had never smoked shisha. Smoking shisha regularly was similar by gender (2.6\% for males and $2.4 \%$ for females), however remarkably more male youth $(13.7 \%)$ reported trying shisha than female youth (0.5\%). Among male youth, regular shisha smoking was most prevalent in the 25-29-year-old age group (3.0\% regularly smoke shisha-down from $6.3 \%$ in 2009). Although more male youth (3.8\%) 
in the Frontier Governorates regularly smoked shisha than did males in other regions (all other regions are less than $2.8 \%$ ), trying shisha was least common (6.4\%) among males in Frontier Governorates compared to all other regions (other regions ranged from $11.4 \%$ to $16.1 \%$ ) (data not shown).

\section{Alcohol consumption and drug use}

All respondents were asked if any of their friends had consumed alcoholic drinks, such as beer, wine, or spirits, in the past 12 months. About $3.5 \%$ of respondents (6.2\% of males and $0.7 \%$ of females) replied that their friends had consumed alcohol. When asked about their own alcohol consumption, $1.0 \%$ reported they had consumed alcohol (1.9\% of male youth and $0.1 \%$ of female youth).

SYPE 2014 asked respondents aged 13-35 about their friends' drug use, their family members' drug use, and their own drug use. Overall $7.6 \%$ said their friends had tried drugs ( $14.2 \%$ of male youth and $0.8 \%$ of female youth). Fewer respondents (3.8\%) said that their family members had tried drugs overall ( $5.6 \%$ male and $1.9 \%$ female).

Very few (1.9\%) SYPE respondents aged 13-35 said that they had tried drugs (3.6\% of male youth and $0.1 \%$ of female youth). Actual drug use is probably underreported because more respondents reported that their family members had tried drugs, and even more reported that their friends had tried drugs. Among those respondents who reported that they had tried drugs, the most commonly used drug were weed (hashish) (77.7\%), marijuana (bango) $(40.2 \%)$, and pills (20.8\%).

The majority of SYPE respondents aged 13-35 (60.8\%) knew of campaigns to help people stop using drugs and smoking. The question about these campaigns was asked of both those who tried drugs and those who did not. Awareness of campaigns was slightly more common among male youth (63.1\%) than female youth (58.0\%). Respondents were most aware in the Urban Governorates (73.6\%) and least aware in urban Upper Egypt (49.8\%). Awareness of campaigns increased with education and wealth. Approximately half (48.3\%) of those who were aware of anti-drug campaigns thought that they were successful (data not shown).

\subsection{Mental health and social development}

The SYPE survey utilized the Self-Reporting Questionnaire (SRQ-20), developed by the World Health Organization to screen for common mental disorders in low-income and developing-world settings (Beusenberg and Orley 1994). The SRQ-20 is a group of 20 yes/no questions, and a respondent's score is the total number of questions to which he or she answers "yes." The tool is designed so that the higher the score, the more likely the respondent is to have a mental disorder. The cutoff value for the $\mathrm{SRQ}$, to suggest the presence of mental disorder, must be validated within a population by comparing scores of people who have been professionally diagnosed with mental illness with the scores of people diagnosed as having no mental illness (Beusenberg and Orley 1994).

A literature review for published studies using the SRQ-20 in Egypt yielded only one study, which used an SRQ-20 cutoff score of 8 or more as a positive screen for mental disorder (Vizcarra et al. 2004). Rahman et al. (2005) in Pakistan validated a cutoff score of 9 or greater. In Jordan, Daradkeh et al. (2006) used a cutoff point of greater than or equal to 7; and in Syria, Maziak et al. (2002) used a cutoff score of greater than or equal to 8 as a positive screening result for mental disorder. Thus, for the purposes of SYPE 2014, we used a cutoff score of 8.

Among the SYPE respondents, the average number of "yes" responses among the sample was 2.2 ( $S D \pm 3.2)$. On average, female respondents had a higher "yes" response rate (mean=2.7, $\mathrm{SD} \pm 3.6$ ) than male respondents (mean $=1.6, \mathrm{SD} \pm 2.6$ ). Respondents from the lowest wealth quintile had the highest number of SRQ-20 responses (mean=2.5); this score steadily decreased as wealth increased, with the highest wealth group having the lowest $\mathrm{SRQ}-20$ (mean=1.8,SD \pm 2.9 ). Also, there were modest differences in the SRQ-20 scores when broken down by residence; respondents from the Urban Governorates had the highest score (mean $=2.8$, $\mathrm{SD} \pm 3.8)$ followed by those from rural Upper Egypt (mean=2.4, SD \pm 3.3 ) and urban Upper Egypt (mean=1.8, SD \pm 2.5 ). 
Using a cutoff of 8 or greater as indicative of mental disorder, $7.1 \%$ of the SYPE respondents showed signs of a mental disorder. Female respondents were three times more likely to have signs of a mental disorder (10.5\%) than their male counterparts (3.9\%). ${ }^{2}$ Just as the average SRQ-20 score decreased as wealth increased, the percentages of those with a score greater than or equal to 8 decreased greatly as wealth increased; $9.4 \%$ of youth in the lowest quintile scored greater than or equal to 8 , compared to $5.1 \%$ of those from the highest quintile. The largest percentage of SYPE respondents with an SRQ-20 score greater than or equal to 8 were from the Urban Governorates (12.3\%) followed by those from rural Upper Egypt (7.8\%).

SYPE respondents were also asked whether or not they had a family history of mental illness. A total of $0.8 \%$ of respondents indicated that they did. A greater percentage of respondents from the Urban Governorates reported a family history of mental illness (1.9\%) than their counterparts in rural Lower Egypt (0.7\%) and rural Upper Egypt $(0.6 \%)$, who had the second and third highest percentages of reported family history of mental illness. Among those who reported a family history, $20.8 \%$ specified their mothers, followed by $20.5 \%$ who specified a sibling(s), and $15.7 \%$ who declined to specify.

\subsection{Reproductive health}

The reproductive health section of the SYPE consisted of a series of questions concerning menarche and puberty, relationships with the other sex, and knowledge of HIV/AIDS and other sexually transmitted infections. Additionally, female respondents were asked questions regarding exposure to female genital cutting, pregnancy, and childbirth. The module concluded with ever-married respondents being asked questions regarding their contraceptive knowledge and use.

2 These results should be interpreted with caution as some of the questions (e.g., "Do you often cry?" and "Are you easily frightened?") are less likely to be answered affirmatively by young men.

\section{Slightly more than half of the respondents were shocked, cried, and/or were afraid at menarche.}

\section{Experience of menarche}

Nearly all female respondents had already experienced the onset of menstruation (99.1\%), with the average age of menarche reported to be 12.9 years ( $S D \pm 1.4$ years). There were no large differences in age at menarche when broken down by wealth quintiles or by region. One-third of respondents who had experienced menarche (33.7\%) indicated that prior to menarche they did not know what menstruation was. This was slightly higher among rural respondents (37.3\%) than their counterparts from urban (28.0\%) or informal urban (27.9\%) areas (Table A2.6).

Slightly more than half of the respondents (51.3\%) were shocked, cried, and/or were afraid at menarche. Nearly one-fifth (18.5\%) of respondents were indifferent, and over one-fifth (21.5\%) did not know what to do. When disaggregated by education there were no major differences in reaction to menarche; however, there were differences by region. Respondents from urban Upper Egypt were nearly twice as likely to respond by being "shocked and afraid" (58.1\%) than their counterparts from the Frontier Governorates (32.7\%). Lastly, 8.6\% of respondents reported that they were happy to begin menstruating.

The majority of female respondents reported that they use sanitary pads while menstruating (79.1\%), followed by pieces of cloth (9.6\%) and special towels (9.4\%). When this question is examined by region, the responses change greatly; sanitary pad use is most common in urban Upper Egypt (93.4\%) and in the Urban Governorates (85.9\%) and decreased substantially in rural Upper Egypt and in the Frontier Governorates, to $72.8 \%$ and $73.4 \%$, respectively. Use of pieces of cloth was highest in rural Upper Egypt (15.6\%) followed by rural Lower Egypt (11.2\%) and lowest in the Urban Governorates 
(3.2\%). Not surprisingly, female respondents in the highest wealth quintile used sanitary pads the most (88.0\%) compared to those in the lowest quintile (65.4\%), and female respondents from the lowest quintile were much more likely to use pieces of cloth (21.0\%) than those from the highest quintile (2.5\%).

\section{Information and discussion about puberty}

The SYPE 2014 included a series of questions asking youth about their conversations with their parents, or other family members, about puberty and growing up. These questions were asked of all SYPE respondents. Just over one-third of the sample (34.2\%) had talked with a parent about puberty (Table A2.7). The most salient difference among subgroups of respondents was by gender; more than twice as many female respondents (47.5\%) than male respondents (21.6\%) had spoken with a family member about puberty. There were also substantial differences by education; $27.9 \%$ of illiterate respondents indicated that they had spoken with a family member about puberty, compared to $40.7 \%$ of those respondents who had a university education.

Respondents from the Frontier Governorates and Urban Governorates were more likely to have spoken with a family member (47.7\% and $44.8 \%$, respectively), while those in rural Upper Egypt were least likely to have done so (26.3\%). There were no major differences by age group. When disaggregated by wealth, there was a clear increase in the percentage of respondents who spoke to their parents or family members about puberty as wealth increased. Just over a fourth of respondents from the lowest quintile (26.9\%) had spoken with their parents about puberty, compared to $40.0 \%$ of those from the highest quintile.

Figure 2.8 shows that more SYPE respondents reported discussing puberty with their parents in 2014 than in 2009. In 2014, 33.9\% of 15-29-year-olds had spoken with family members about puberty, compared to 2009 , when just $28.5 \%$ reported that they had. While the percentage of female respondents who discussed puberty was almost equal in 2009 and 2014 (49.9\% and 47.6\%, respectively), the percentage of male respondents who had talked with their parents about puberty increased substantially from $8.1 \%$ in 2009 to $21.4 \%$ in 2014.
FIGURE 2.8 Percentage of youth (aged 15-29) who discussed puberty with their parents, by gender, 2009 and 2014

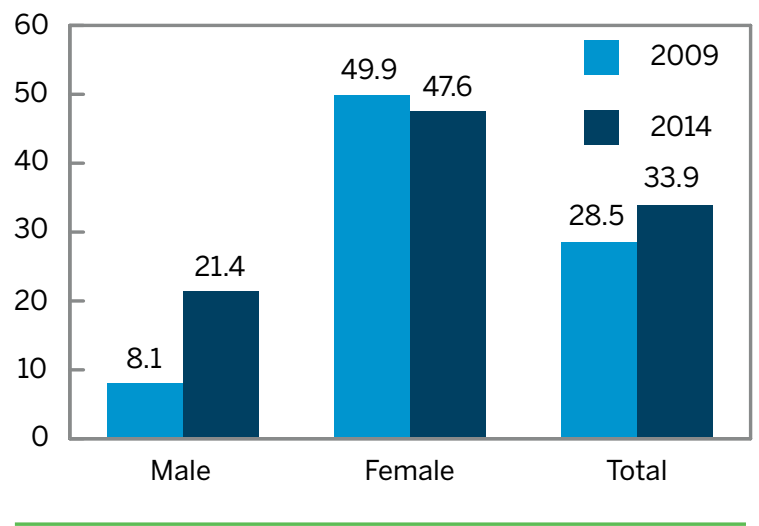

The survey continued with a series of questions asking respondents their opinions regarding the appropriate age, if ever, to talk to adolescents about puberty. The largest percentage of respondents (37.9\%) believed that this discussion should take place at the onset of menstruation/puberty. The second most common response was that no one should talk to youth about puberty, comprising $15.3 \%$ of respondents; more young men than women gave this answer. Furthermore, $10.5 \%$ of respondents believed that this conversation is best had at marriage. Finally, 10.7\% of the sample was unsure of the best age to discuss puberty (data not shown).

Youth were also asked about their main source of information regarding puberty. The most commonly cited source of information was "friends, neighbors, and/or relatives" (41.1\%), followed by "family" (26.5\%). When disaggregated by gender, $41.1 \%$ of female respondents indicated "family" compared to $12.5 \%$ of male respondents. For male respondents, $51.4 \%$ reported "friends, neighbors, and/or relatives" were their main source of puberty information. A substantial percentage of the sample (13.7\%) reported that their main source of information was films and cinema. When looking at information sources disaggregated by education, $15.6 \%$ of those with university-level education reported their main source to be a school curriculum, by far the largest among all education categories (data not shown).

Overall, $59.1 \%$ of youth indicated that the amount of information they received about puberty was 
sufficient. Slightly fewer male than female respondents believed that the information they received was sufficient (56.9\% versus $61.4 \%$, respectively). Generally, the older a respondent was, the more satisfied they were with the information they received. Younger respondents were more likely to say the information was insufficient (23.2\% of $13-17$-year-olds and $40.0 \%$ of $18-24$-yearolds) than their elder counterparts (14.9\% of 30-35-year-olds). Similarly, as wealth increased, respondents were more likely to report that the information they received was sufficient; $64.9 \%$ of respondents from the highest quintile, compared to $54.5 \%$ of those from the lowest, indicated that the information they received on puberty was sufficient (data not shown).

\section{Relationships with the other sex}

The SYPE survey had intended to inquire directly about young people's sexual relationships. However, due to the sensitivity of the topic and at the request of local authorities, the questions were asked in an indirect way, i.e., to inquire about relationships with the other sex.

All SYPE respondents were asked if they knew of girls or boys of their same age who had relationships with the opposite sex. The majority of respondents indicated "no" (69.1\%), while $11.3 \%$ answered "yes," 5.4\% refused to answer, and 14.2\% responded "I don't know." Males were somewhat more likely to report knowledge of such relationships than females $(14.2 \%$ versus $8.4 \%$, respectively). Also, respondents from rural Upper Egypt and higher wealth quintiles were more likely to report knowledge of such relationships.

A substantial percentage of respondents (42.3\%) indicated that youth in relationships usually met in parks, followed by cafés or restaurants (29.7\%). Parks were the most common meeting area among rural respondents (47.7\%) and the least for those from informal urban areas (26.5\%), who indicated that sports clubs and youth centers were the most common meeting areas (43.2\%). SYPE respondents who answered that they had heard of relationships with the other sex (11.3\%) were asked if they thought that the boys and girls had intimate relationships; $18.9 \%$ of the above respondents indicated "yes." Male respondents were nearly twice as likely as female respondents to answer "yes" (23.0\% vs. $11.8 \%$ ). Furthermore, respondents from urban areas were twice as likely to respond yes (30.6\%) as respondents from rural (14.1\%) or informal urban (14.4\%) areas (data not shown).

\section{Knowledge of HIV/AIDS and other sexually transmitted infections}

All survey respondents were asked if they had ever heard of sexually transmitted infections (STIs). Just over half of the sample (54.1\%) had, with substantially more male respondents (59.5\%) having heard of STIs than their female counterparts (48.3\%). Knowledge of STIs increased with wealth, with a larger percentage of youth in the highest wealth quintile (68.3\%) having heard of STIs than the lowest (41.3\%). Respondents in the youngest age group (13-17) were the least likely to have heard of STIs (39.5\%) compared to nearly equal knowledge among 18-24-year-olds (57.4\%), 25-29-year-olds (59.5\%), and 30-35-year-olds (56.4\%) (data not shown).

Similar to age, knowledge increased among respondents as their level of education increased. Among illiterate respondents, 20.3\% had heard of STIs, compared to $79.7 \%$ of respondents in the highest education level. There was also a large difference in knowledge of STIs among respondents from urban areas (62.7\%) and their rural (49.9\%) and informal urban area (53.8\%) counterparts.

When those who had heard of STIs were read a list of STIs, the STI most identified was human immunodeficiency virus (HIV) (97.3\%), followed by syphilis although at a much lower percentage (14.1\%). More than four out of five respondents (82.4\%) who had heard of STIs had heard of just one on the list presented (syphilis, gonorrhea, chlamydia, human papillomavirus, and human immunodeficiency virus), while very few respondents (1.6\%) had heard of all five (data not shown).

SYPE respondents who indicated that they had not heard of any sexually transmitted infections were asked, "Have you ever heard of AIDS?" Of those, $43.2 \%$ answered "yes." Altogether, those 
who indicated that they had heard of HIV or AIDS comprised $73.2 \%$ of the total sample. Just $59.6 \%$ of respondents from the youngest age group had heard of HIV or AIDS, compared to $76.3 \%$ of those in the oldest age group. Knowledge of HIV was highest among those in the highest wealth quintile (85.5\%) and lowest among those in the lowest quintile (61.9\%). Likewise, those with the least education were least likely to have heard of HIV or AIDS (43.5\%), with knowledge steadily increasing with education, reaching the maximum (92.6\%) among youth with a university education or higher. Regionally, respondents from the Urban Governorates were most likely to know of HIV or AIDS (86.5\%); the Frontier Governorates and urban Upper Egypt had the lowest and second lowest percentages (63.6\% and 63.4\%) (Table A.2.8).

Knowledge of HIV/AIDS decreased between 2009 and 2014. As shown in Figure 2.9, 85.5\% of 2009 SYPE respondents 15-29 had heard of HIV compared to $73.6 \%$ in 2014 . Knowledge decrease was common across both genders, although male youth 15-29 experienced a greater decrease between 2009 and 2014 (92.0\% versus $77.3 \%$, respectively) compared to female youth (78.7\% versus $69.4 \%$, respectively).

Respondents were asked to indicate the sources of information they had about HIV/AIDS. More than half (60.9\%) indicated that they had heard of HIV/ AIDS through media, radio, or cinema, followed by school (12.2\%) and friends (6.1\%). Both male and female respondents were equally likely to report school as a source of information; however, male respondents were nearly three times as likely $(73.2 \%)$ as female respondents (26.8\%) to report friends as a source (data not shown).

All of the respondents who indicated that they had heard of HIV or AIDS were asked if a series of eight mechanisms (of which six were correct and two were incorrect) could transmit the virus. The overwhelming majority of respondents correctly identified sexual relations (93.7\%) as a method to transmit HIV. Furthermore, a large percentage $(89.2 \%)$ of the sample correctly identified blood transfusion as a method of HIV transmission, as well as sharing of needles (79.9\%). On the other hand,
FIGURE 2.9 Percentage of youth (aged 15-29) who had heard of HIV/AIDS, by gender, 2009 and 2014

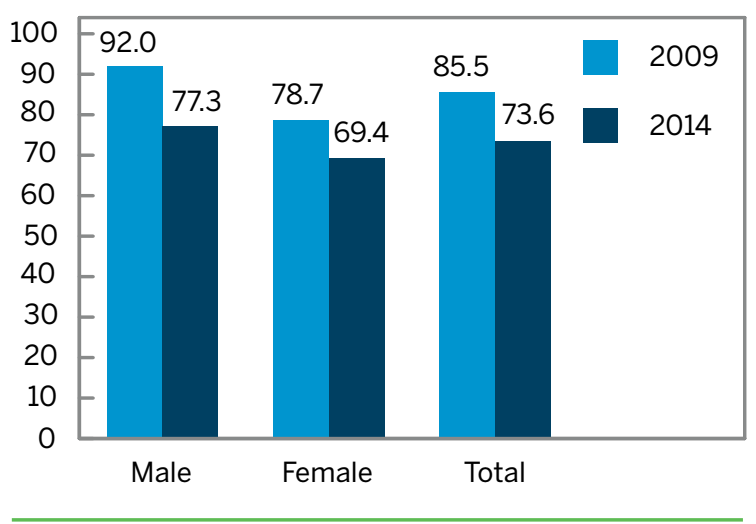

many respondents did not correctly identify vertical transmission from mother to child during pregnancy (only $32.5 \%$ indicated that this is a mechanism) or breastfeeding (only $24.6 \%$ indicated that this is a method) as modes of transmission. Nearly one-fifth (19.7\%) of the sample that knew of HIV or AIDS correctly identified all of the methods of transmission (14\% of the total sample). Those from the highest wealth quintiles were the most likely to be able to identify all of the mechanisms (25.9\%) compared to those from the lowest (15.7\%). A similar trend can be seen by education; the most highly educated respondents (university and above) were the most likely to identify all mechanisms (24.8\%) compared to the illiterate respondents, who were least likely (15.9\%) (data not shown).

Some respondents incorrectly answered that certain mechanisms could transmit HIV when in fact they cannot. For example, $16.8 \%$ of respondents answered that an insect bite could transmit HIV and $37.8 \%$ indicated that they did not know if this was a mode of transmission. A larger percentage (22.6\%) indicated that sharing food with someone living with HIV/AIDS was a mode of transmission and $37.5 \%$ responded that they did not know. For the most part, as level of education increased, respondents were better able to correctly identify methods of transmitting HIV. A small percentage (2.2\%) indicated that they had ever been tested for HIV.

Respondents were asked about their willingness to interact (i.e., shake hands or ride in a car) with 
someone who is HIV-infected. This question was intended to gauge both their knowledge of transmission and attitudes of stigma. Less than one-fifth of respondents (17.1\%) indicated that they would, a decrease from $21.1 \%$ who reported willingness in 2009 (data not shown). Male respondents were slightly more likely than female respondents to respond affirmatively (19.8\% compared to $13.8 \%$ ). Respondents who were illiterate were less likely to indicate "yes" (13.3\%) than those who completed vocational school, post-secondary studies, or university (15.0\%, 20.9\%, 23.3\%, respectively). Respondents from informal urban areas were slightly more likely to respond "yes" (19.8\%) than their rural and urban counterparts (17.5\% and $15.4 \%$, respectively).

\section{Knowledge and practice of female genital mutilation/cutting}

Female genital mutilation/cutting (FGM/C) is the practice of partial or total removal of the external female genitalia or other injury to the female genital organs for nonmedical reasons (UNICEF 2010). All SYPE respondents were asked if they had ever heard of female circumcision (khitan or tahara). A majority of the sample (94.0\%) had heard of FGM/C. More female respondents (98.3\%) had heard of FGM/C than male respondents (89.4\%). Regionally, respondents from rural and urban Upper Egypt were the most likely to have heard of FGM/C (96.3\% and 96.4\%, respectively); respondents from rural Lower Egypt were the least likely (92.0\%). As age increased, knowledge of FGM/C increased as well; while $11.3 \%$ of 13-17-year-olds had not heard of FGM/C, just $2.4 \%$ of those in the 30-35 year old age group had not heard of FGM/C (data not shown).

All female respondents aged 13-35 who indicated that they had heard of FGM/C were asked if they had undergone FGM/C. Of those, $80.5 \%$ responded that they had, $12.6 \%$ said they had not, and $7.0 \%$ refused to answer. Being cut was more common among rural female respondents (87.9\%) than their counterparts in informal urban (74.8\%) and urban areas (66.3\%). Respondents from rural Upper Egypt were the most likely to have undergone FGM/C (91.6\%), while those from the Urban Governorates were the least likely (55.6\%). The preva- lence of FGM/C decreased as education increased; $91.0 \%$ of illiterate respondents reported being circumcised, compared to $71.5 \%$ of university-educated respondents (Table A2.9).

As age increased, the percentage of respondents who indicated that they were cut did as well. Female respondents in the youngest age group (13-17) were the least likely to have undergone FGM/C (73.9\%), compared to the oldest age groups (85.7\%). Similarly, as wealth increased, respondents were much less likely to report being cut. Those from the lowest wealth quintile were more likely to report having been cut (87.2\%) compared to those in the highest wealth quintile (71.3\%).

Prevalence of FGM/C was compared among females aged 15-29 in both surveys. Figure 2.10 shows that fewer SYPE respondents in this age group indicated in 2014 that they were cut, compared to 2009 (79.5\% versus $87.5 \%$, respectively). However, more SYPE respondents in 2014 refused to answer this question. Possible reasons for this increase are discussed in this chapter's conclusion.

The mean age of female respondents who reported that they had undergone FGM/C was 9.4 years, with a standard deviation of \pm 3.0 years. FGM/C was performed at the youngest age in urban Upper Egypt (7.0 years, \pm 3.2 ), and performed later in the Urban Governorates (10.2 years, \pm 2.4 ) and urban Lower Egypt (9.8 years, \pm 2.6 ). There was no difference in age at FGM/C when disaggregated

FIGURE 2.10 Response of females aged 15-29 to question on their circumcision status, 2009 and $2014(\%)$

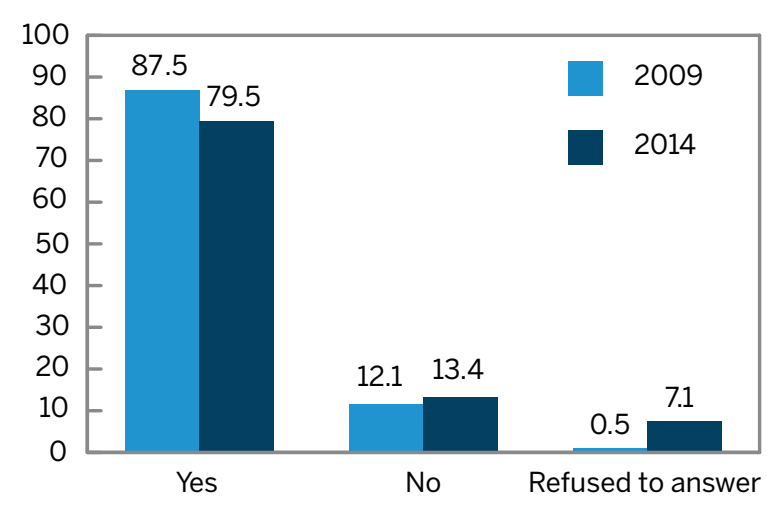


by wealth quintile. These results are slightly lower, yet consistent with both the 2009 SYPE and 2008 Egyptian Demographic and Health Survey, which reported the average age to be at 9.5 years and 10 years, respectively.

Respondents aged 13-35 who were cut indicated that doctors were the main providers of the procedure (43.8\%) followed by dayas/circumcision practitioners (42.6\%) and nurses (11.5\%). Younger respondents (13-17), those who live in urban governorates, those with a university degree and those who belong to the highest wealth quintile were more likely to be cut by a doctor than other groups of young women.

Nearly two-thirds (64.5\%) of all female respondents aged $13-35$ who were cut reported that the practice was performed at home or at another house. Home or another house was more common in rural areas (69.5\%) than urban (58.8\%) and informal urban (52.3\%) areas, although it was the most common place among all residential categories. On the other hand, urban respondents were far more likely to report a private hospital (11.5\%) than their counterparts from rural (2.7\%) and informal urban (1.0\%) areas (data not shown).

\section{Attitudes toward FGM/C}

SYPE respondents aged $13-35$ of both genders who had heard of FGM/C were asked a series of questions to ascertain their attitudes toward the practice. When asked if they believed that the practice was necessary, over half (61.3\%) answered that it was, compared to $21.2 \%$ who responded that it was not and the remaining $17.5 \%$ unsure. Female respondents were slightly more likely to respond that FGM/C was necessary (64.6\% of all female respondents compared to $57.8 \%$ of male respondents). However, more male than female respondents did not know whether the practice was necessary (22.2\% vs. $13.1 \%$, respectively). While two-thirds of respondents from the oldest age category (66.1\%) indicated "necessary," we see that as age decreases, fewer of the younger respondents indicated the same (53.3\%) (data not shown).
When assessed by region, $80.6 \%$ of respondents from urban Upper Egypt responded "necessary," compared to just $34.7 \%$ of those from the Urban Governorates. When disaggregated by both wealth and education level, several trends were noted. Over three-fourths of illiterate respondents responded that FGM/C was "necessary" (78.2\%), compared to half (50.0\%) of those who had a university education. Likewise, over three times as many respondents with a university education (32.8\%) reported FGM/C was "unnecessary" compared to illiterate respondents (11.1\%). Half of respondents from the highest wealth quintile (50.3\%) reported FGM/C as "necessary" compared to nearly three-fourths of those from the lowest quintile (70.9\%), although percentages of "I don't know" responses by wealth quintiles were fairly similar.

Attitudes of SYPE respondents aged 15-29 were compared in the two surveys (Figure 2.11). In 2014, slightly fewer respondents reported FGM/C to be "necessary" compared to 2009 (60.3\% versus $64.0 \%$ ). However, in 2014 more female than male respondents believed that FGM/C was necessary (63.2\% versus 57.4\%) while in 2009

FIGURE 2.11 Attitudes of male and female respondents aged $15-29$ regarding importance of FGM/C, 2009 and 2014 (\%)
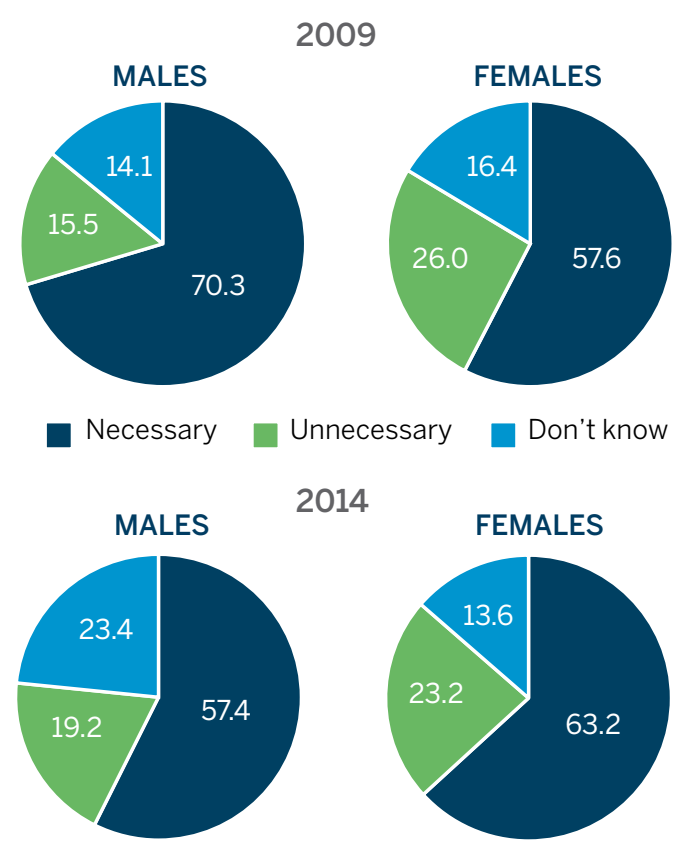
the opposite was true (70.3\% of male respondents versus $57.6 \%$ of female respondents). On the other hand, more male respondents in 2014 compared to 2009 did not know if the practice was necessary or not (23.4\% versus $14.1 \%$, respectively).

When asked why they believed that FGM/C was important, the most commonly cited reason was "customs and traditions" (56.7\%) followed by "religious reasons" (35.0\%) and "to get married" (5.3\%). Respondents from urban and rural Upper Egypt were much more likely to respond "customs and traditions" (74.5\% and $69.1 \%$, respectively) than those from urban and rural Lower Egypt (41.0\% and $41.1 \%$, respectively). Among respondents in the higher wealth quintiles, "religious reasons" were most often cited (48.2\%), whereas among those in the lowest, "customs and traditions" (67.3\%) were (data not shown).

When asked whether they intended to cut their daughters in the future, seven out of 10 SYPE respondents answered "yes." Fairly equal percentages of male (68.6\%) and female (70.7\%) respondents indicated that they intended to cut their daughters in the future (not shown).

\section{Pregnancy and childbirth}

This section of the health chapter addresses a series of questions related to pregnancy and childbirth. These questions were only asked of female SYPE respondents who indicated being "ever married" (35.1\%). Among those, a large majority (87.5\%) indicated that they had ever been pregnant. This number was similar across the regions of Egypt, being lowest (86.5\%) in rural Lower Egypt and highest (91.7\%) in the Urban Governorates. As expected, ever-married female respondents in the oldest age category, 30-35, had the highest percentage of respondents reporting ever being pregnant (96.1\%) compared to the youngest category, 13-17 (27.5\%). Similarly, $91.4 \%$ of illiterate respondents reported ever being pregnant, compared to $82.3 \%$ of respondents from the highest education category (university and above). Twice as many married female respondents from the highest wealth quintile reported never being pregnant (18.9\%) compared with those from the lowest (9.0\%).
Among ever-married female respondents, 16.5\% reported ever being pregnant before the age of 18 . Adolescent pregnancy was more common among female respondents from rural areas (19.7\% of all pregnancies were among adolescents) than informal urban (8.9\% of all pregnancies) and urban (8.1\%) areas. Likewise, $25.2 \%$ of pregnancies in rural Upper Egypt were among adolescents, whereas $8.4 \%$ of all pregnancies in the Urban Governorates were among adolescents. A quarter of pregnancies among respondents from the lowest wealth quintile (25.2\%) were among respondents under the age of 18; this is three times higher than the percent of adolescent pregnancies among respondents from the highest wealth quintile (8.7\%).

Among ever-married female respondents who indicated that they had ever been pregnant, $86.2 \%$ reported ever having a live birth. The average number of live births among ever-married female respondents aged 13-35 was 2.4 (standard deviation \pm 1.2 ). A small percentage (4.3\%) reported ever having a stillbirth; stillbirths were most common in rural areas (5.0\% of rural respondents who reported ever being pregnant indicated ever having a stillbirth) compared to those respondents from urban (3.0\%) or informal urban (2.5\%) areas. Furthermore, $11.7 \%$ of the respondents who had ever been married and pregnant indicated that they had ever had an abortion, either spontaneous or induced. Among all women who reported ever being pregnant, $2.0 \%$ indicated that they ever had an induced abortion (data not shown).

More than four-fifths of respondents who indicated that they had ever experienced pregnancy reported that they sought out antenatal care during their last pregnancy (84.2\%). When examined regionally there are a number of differences: respondents from the Frontier Governorates had the lowest percentage of reported antenatal care attendance (71.6\%) compared to respondents from urban Upper Egypt, who had the highest reported rate of seeking antenatal care (91.6\%). As expected, women from the highest wealth quintiles reported seeking antenatal care at higher rates (88.5\%) than those from the lowest quintile (74.1\%). Likewise, $93.0 \%$ of female respondents with a university edu- 
cation or above sought antenatal care, compared to $74.9 \%$ of their illiterate counterparts.

A large majority of women (83.1\%) indicated that a doctor assisted in the delivery of their last pregnancy. With regard to place of delivery, half of respondents (49.6\%) gave birth at a private facility, followed by $33.6 \%$ who gave birth at a public facility while $14.6 \%$ indicated that they gave birth at home.

Just under a third of respondents (32.5\%) indicated that their last delivery was by cesarean section. This rate of cesarean section in Egypt is twice as high as the $10-15 \%$ that is recommended by the World Health Organization (World Health Organization 1985). When examined regionally, half of respondents from the Urban Governorates reported cesarean delivery (49.9\%), compared to respondents from rural Upper Egypt who had the lowest percentage (26.5\%). A slight increase has been noted in rates of $\mathrm{C}$-section among young women 15-29 between 2009 and 2014 (32.6\% versus 34\%, respectively) (data not shown).

\section{Contraception}

All SYPE respondents aged 13-35, regardless of marital status, were asked if they knew of family planning methods that could delay or prevent pregnancy. Over half (61.5\%) of respondents indicated that they did. Over twothirds $(71.5 \%)$ of all female respondents knew of such methods, whereas slightly more than half of male respondents reported "yes" (52.0\%)
(Table A.2.10). Knowledge was highest among the oldest respondents (aged 30-35: 85.0\%) and lowest among the youngest (aged 13-17: 34.8\%). Regionally, respondents from rural Upper Egypt were most likely to have heard of contraceptive methods (67.6\%) and those from urban Upper Egypt the least (54.5\%). When disaggregated by education there was little variation. There was a steady increase in knowledge of methods as wealth quintile increased, although the difference between the lowest quintile and the highest was not large (59.0\% compared to $65.4 \%$, respectively). Lastly, when examined by marital status, married youth were twice as likely to know family planning methods as their unmarried counterparts (90.2\% versus $45.2 \%$, respectively) (data not shown).

The most commonly identified contraceptive method among all SYPE respondents aged 13-35 was oral contraceptive pills (OCPs), which $57.1 \%$ of respondents knew of. Intrauterine devices (IUDs) were the second most identified contraceptive method, with $50.3 \%$ of the sample reporting that they know of IUDs followed by injectables (42.7\%), subdermal implants (10.4\%) and condoms (9.3\%). Overall, female respondents had more knowledge of contraceptive methods than their male counterparts with the exception of male condoms (Figure 2.12).

On sources of information about contraceptives, the most commonly cited source of was healthcare providers (33.2\%), followed by radio and television (27.5\%) (data not shown).

FIGURE 2.12 Knowledge of selected family planning methods, by gender, 2014 (\%)

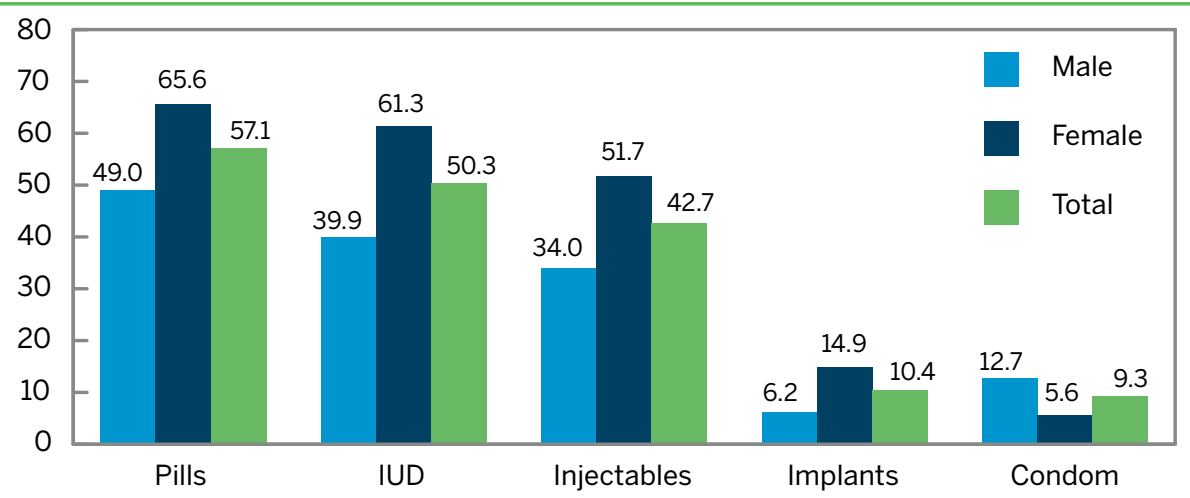


In the final section of the health module, all evermarried SYPE respondents were asked a series of questions about their or their spouse's (in the case of young men) contraceptive use history. Over half of ever-married respondents aged 13-35 (57.9\%) reported that they (or their spouse) had ever used a contraceptive method(s) to prevent or delay pregnancy. More female respondents (63.2\%) than male respondents (46.5\%) and more respondents from informal urban areas (63.5\%) than those in urban (58.5\%) and rural (56.9\%) areas answered affirmatively (data not shown).

It is noteworthy that more respondents in 2009 (75.0\%) indicated ever use of contraception. However, when a panel analysis was conducted to compare individual responses in the two survey rounds, it was found that $18.0 \%$ of participants who answered 'yes' to the question in 2009 answered 'no' to the same question in 2014. This discrepancy could be a result of inaccurate memory or misunderstanding of the question on either round.

Among currently married respondents aged 13-35, $42.6 \%$ indicated that they (or their spouse) were currently using a contraceptive method. Current use is lowest among 13-17-year-old married youth (10.1\%) and highest among 30-35-year-olds (50.9\%). The most commonly reported contraceptive method currently used among married respondents was the IUD (23.2\%) followed by OCPs (14.2\%) and injectable methods (6.8\%). Other methods (rhythm, male condoms, implants, and female sterilization) were altogether used by less than $1.0 \%$ of respondents. Participants in the 2009 survey were not asked about current use of contraception.

Married SYPE respondents who indicated that they were not currently using any contraceptive method were asked whether they (or their spouse) would consider using a contraceptive method in the future. Over half $(61.7 \%)$ of the respondents indicated that they would, while the remaining (38.3\%) replied "no." When asked to choose any number of reasons for this decision, the most cited reason was "I want to have children" (73.6\%) followed by "medical side effects" (15.5\%).

\subsection{Conclusion}

The health module of SYPE of 2014 has shed light on a number of issues that warrant policymakers' attention and prompt action. In addition, there have been some notable improvements between 2009 and 2014. Security issues have taken their toll on young people, as more young people in 2014 felt unsafe on the street and on public transportation. Decreased presence of police on the streets along with inadequate law enforcement had a negative influence on young people's personal safety. Today, fewer young people are using seatbelts when they drive or ride a car and more young people are carrying weapons.

Overall, young women aged 15-29 are still exposed to sexual harassment on the street and on public transportation in 2014, albeit in smaller numbers than in 2009. However, it is alarming to see that the youngest subset of girls (aged 13-17) have been increasingly exposed to sexual harassment compared to 2009. Besides posing a violation of girls' rights, sexual harassment may lead to further limitation of girls' mobility and their participation in public domains.

Eating habits of young people, coupled with lack of physical exercise, expose them to a number of health risks such as diabetes, hypertension, and obesity. Awareness-raising campaigns are needed to educate young people and their parents about the risks of excessive consumption of carbonated drinks and fast food. Limited engagement of young girls in physical activity may be due to reduced sense of safety on the street along with social norms that discourage girls from playing sports. Safe spaces (e.g., special hours at youth centers) need to be made available to enable young girls to play sports without fear of sexual harassment.

Discussion of pubertal changes by parents has improved between 2009 and 2014 but continues to be low, especially for male youth. Parents, teachers, healthcare providers, and religious leaders need to engage in more open dialog with young people to educate them about reproductive health matters. In the absence of credible sources of information, young people may turn to their peers, the internet, or mass media which may not necessarily provide accurate information. 
Young people, especially women, have limited knowledge about HIV or its modes of transmission. This knowledge has even declined between 2009 and 2014. Also, stigma associated with the disease is alarmingly high with less than one in five young people willing to interact with someone living with HIV. With such low levels of information and high stigma associated with the disease, young people may not be able to protect themselves, their spouses, or future offspring against HIV infection.

The prevalence of FGM/C continues to raise concerns, despite the fact that prevalence seems to have slightly declined between 2009 and 2014 . The increase in the percentage of participants who refused to answer the question about their circumcision status in 2014 warrants further investigation as it could suggest ambivalence about the practice or fear of legal implications for themselves or their parents. The fact that six out of 10 young people believe the practice is necessary calls for interventions that target young people (both male and female) early enough to help them question their own beliefs and misconceptions before they get married and subject their daughters to this practice.

Although overall awareness of family planning methods is reasonably high, it is less so among male youth, younger age groups (13-17 years) and those who are not married. Also, contraceptive use among currently married young people is relatively even among the older age group 30-35 years old (50.9\%) compared to $64.6 \%$ reported in the Egypt Demographic and Health Survey 2014. This may be due to the fact that SYPE 2014 includes both male and female respondents while EDHS only includes female respondents. Raising young people's awareness of the benefits of family planning for themselves, their families, and communities should be a priority and should target both male and female youth.

SYPE 2014 has shown a number of salient health needs among young people in Egypt. Addressing those health needs requires multisectorial interventions that involve government agencies, civil society, religious institutions, mass media, as well as parents. More importantly, those interventions should empower young people to be able to lead more healthy and productive lives.

\section{References}

Akhter, A., T. Gutner, H. Lofgren, and H. Bouis. 2001. "The Egyptian food subsidy system: Structure, performance, and options for reform," Research Report No. 119. Washington, DC: International Food Policy Research Institute.

Beusenberg, M. and J. Orley. 1994. A User's Guide to the Self-Reporting Questionnaire (SRQ). Geneva: World Health Organization: Division of Mental Health.

Daradkeh, T. K., A., Alawan, R. Al Ma'aitah, and S.A. Otoom. 2006. "Psychiatric morbidity and its sociodemographic correlates among women in Irbid, Jordan," Eastern Mediterranean Health Journal 12(S2): S107-S117.

Rampersaud, Gail C., Mark A. Pereira, Beverly L. Girard, Judi Adams, and Jordan D. Metzl. 2005. "Breakfast habits, nutritional status, body weight, and academic performance in children and adolescents," Journal of the American Dietetic Association 105(5): 743-760.

Ibrahim, M Mohsen and Albertino Damasceno. 2012. "Hypertension in developing countries," The Lancet 380(9841): 611-619.

Krug, E. G., Dahlberg, L. A., Mercy, J. A., Zwi, A. B., and Lozano, R. 2002. World Report on Violence and Health. Geneva: World Health Organization. http://whqlibdoc.who.int/publications/2002/ 9241545615_eng.pdf (English); http://whqlibdoc.who. int/publications/2002/9241545615_ara.pdf (Arabic). Accessed 23 November 2010.

Maziak, W. et al. 2002. "Socio-demographic correlates of psychiatric morbidity among low income women in Aleppo, Syria." Social Science \& Medicine 54: 1419-1427.

Rahman, A., Z. Iqbal, H. Lovel, and M.A. Shah. 2005. "Screening for postnatal depression in the developing world: A comparison of the WHO Self-Reporting Questionnaire (SRQ-20) and the Edinburgh Postnatal Depression Screen (EPDS)," Journal of Pakistan Psychiatric Society 2: 69-72.

Peden, M. et al. (eds.) 2008. World Report on Child Injury Prevention. Geneva: WHO. http://whqlibdoc. who.int/publications/2008/9789241563574_eng.pdf. Accessed 23 November 2010.

Tran, Jackie, Masoud Mirzaei, and Stephen Leeder. 2007. "Hypertension: Its prevalence and population-attributable fraction for mortality from stroke in the Middle East and North Africa," Circulation 122(2): 530.

UNICEF. 2010. The Dynamics of Social Change: Towards the Abandonment of Female Genital Mutilation/Cutting in Five African Countries. October. New York: United Nations.

Vizcarra, B., F. Hassan, W.M. Hunter, et al. 2004. “Partner violence as a risk factor for mental health among women from communities in the Philippines, Egypt, Chile, and India," Injury Control and Safety Promotion 11 (2): 125-129.

World Health Organization. 1985. "Appropriate technology for birth," Lancet 2(8452): 436-437. 


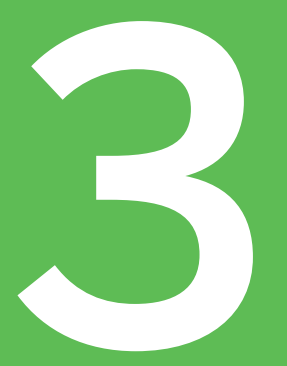

Educational Experiences of Youth in Egypt: Who Attends School, Who Succeeds, and Who Struggles

CAROLINE KRAFFT

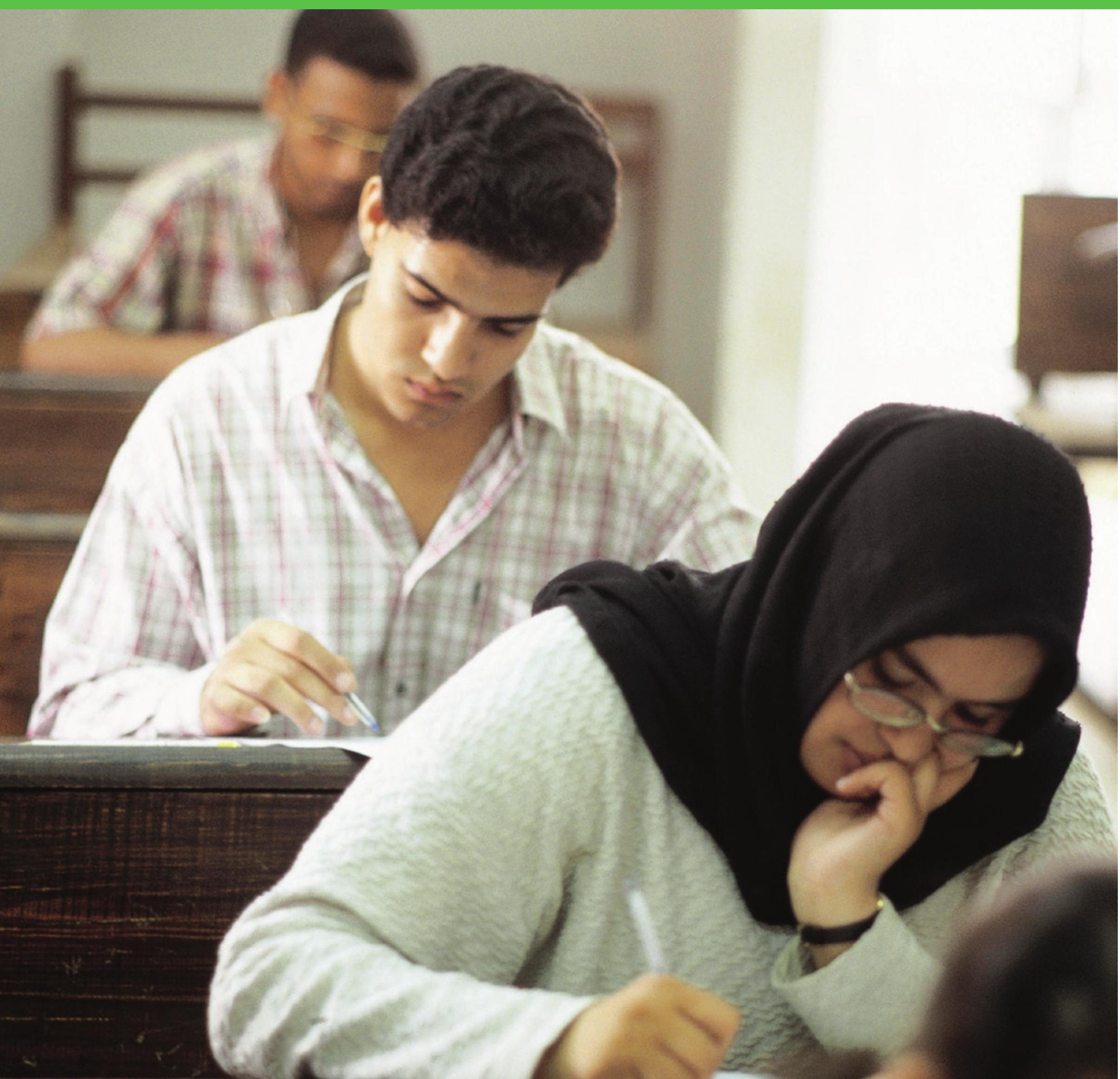


Education plays a key role in shaping human development and the opportunities that are available to young people. The economic and social development of a country is shaped by the educational outcomes of its youth population. It is important to understand the key challenges facing the Egyptian education system and the potential policy mechanisms for addressing these challenges.

\subsection{Introduction}

Egyptian youth are guaranteed a free education by the constitution. With the adoption of the January 2014 constitution, secondary education is becoming mandatory (Egypt State Information Service 2014), whereas previously only basic (primary and preparatory level) education was mandatory. Primary through higher education are provided free of charge; pre-primary education is not publicly provided for free (UNESCO International Bureau of Education 2006). The level of national expenditure on education has also been mandated in the constitution, at a minimum of $4 \%$ of the gross national product (GNP), to be gradually increased in line with the rise in global averages (Egypt State Information Service 2014).

This chapter analyzes a number of aspects of the educational experiences of young people in Egypt, relying on the 2009 and 2014 rounds of the Survey of Young People in Egypt (SYPE). Because the youth in the 2014 round of the SYPE are older (aged 13-35), comparisons across cohorts for youth who have completed school are now possible using the 2014 SYPE.

Although increasing numbers of youth have attended pre-primary kindergarten programs, most enter the Egyptian education system at the primary stage. On-time entry into primary school occurs at age six, and primary education consists of six grades. ${ }^{1}$ Upon completion of primary school, students are expected to proceed to preparatory education, starting at age 12 , for an additional three years. At the end of preparatory school and based on their scores during the preparatory stage, students are tracked into either general or vocational secondary education.

The lower-score, less prestigious vocational secondary track is almost always a terminal degree, although a few students continue to two-year post-secondary institutes, or even more rarely, four-year higher institutes or university programs (Krafft, Elbadawy, and Assaad 2013). The general secondary track entails an implicit guarantee of continuing to university. Both secondary programs generally take three years, although there are some five-year vocational secondary degrees. At the end of general secondary, test scores as well as students' tracks within general secondary determine the form and specialization of higher education that students can then attend. A small minority of university graduates will also continue for post-graduate studies (masters degrees or PhDs). Some higher education specializations within the university are also longer than the standard four years. Figure 3.1 shows the potential paths students might follow as they enter and then progress through the education system.

\subsection{Educational attainment and school completion}

Because the youth who participated in SYPE 2009 are now older, it is possible to consider not only the educational attainment of those youth old enough to have definitively left the school system, but also to consider how educational attainment has evolved over time. Figure 3.2 presents educational attainment for youth aged 25 and older by gender, comparing those youth 25-29 (the younger cohort) to those aged 30-35 (the older cohort) to

1 At the time when most SYPE respondents were attending primary school, it had been reduced to five years and is treated as such in the analyses of years of schooling. The sixth year of primary education has subsequently been restored (Shahine 2003). 
FIGURE 3. 1 Structure of the Egyptian education system, 2014

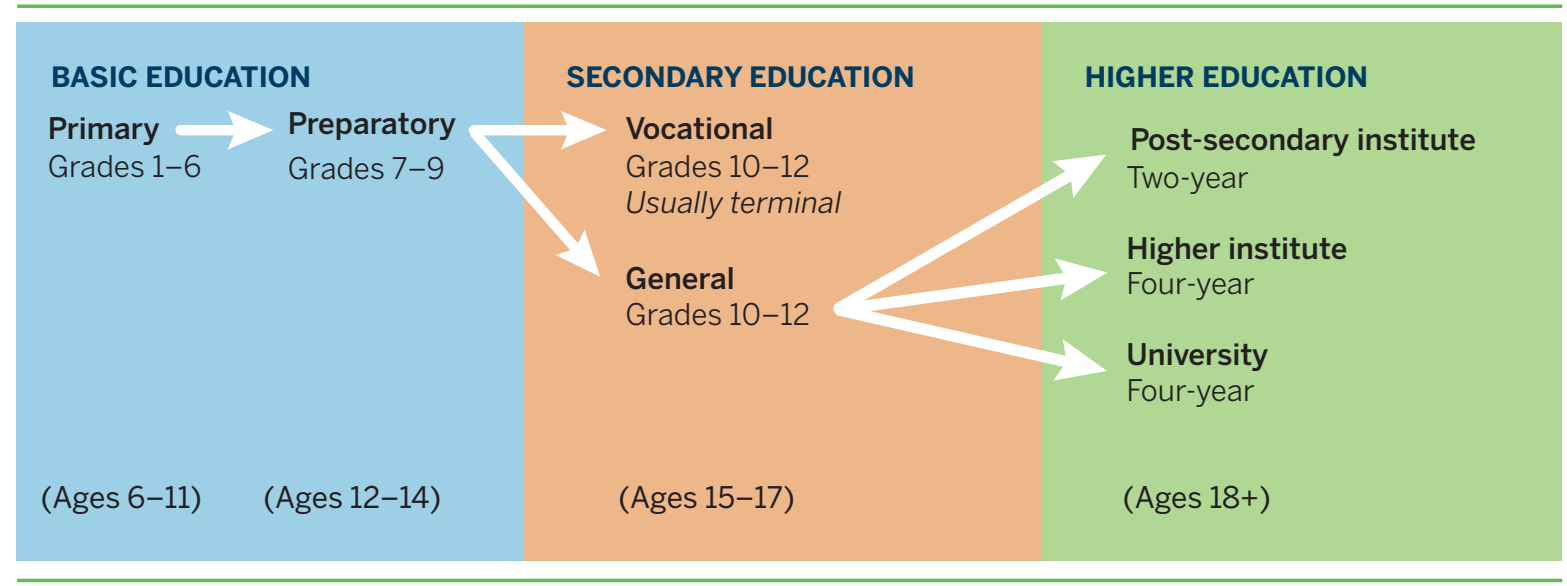

Note: Ages in parentheses are ideal, assuming on-time entry and no grade repetition.

show how education has been evolving over time. Illiteracy has been dropping over time, from 9\% among male youth aged 30-35 to 7\% among male youth aged 25-29. The level of illiteracy is much higher among female youth but rapid progress has also occurred. While $24 \%$ of $30-35$ year-old female youth were illiterate, illiteracy dropped to $18 \%$ among 25-29-year-old female youth.

The share of youth with only a primary education ranges from $8 \%$ to $12 \%$ depending on gender or age group. For both male and female youth the share with only a primary education has been decreasing over time as educational attainment has been rising. While $9 \%$ of female youth in both age groups attained a preparatory education, with no change across cohorts, this share has shrunk from $8 \%$ to $5 \%$ for male youth across cohorts. Since general secondary is rarely terminal, few youth ended up with this degree, but a rising share of youth have a vocational secondary degree as their final attainment, with $43 \%$ of male youth aged 25-29 and $37 \%$ of female youth aged 25-29 who attained a vocational secondary education. A small share (3-5\% of youth across groups) received a twoyear post-secondary degree. The fastest growing category is university and above; while $22 \%$ of male youth aged 30-35 completed a university educa-

FIGURE 3.2 Educational attainment of youth aged 25 and older, by gender and age group (\%), 2014

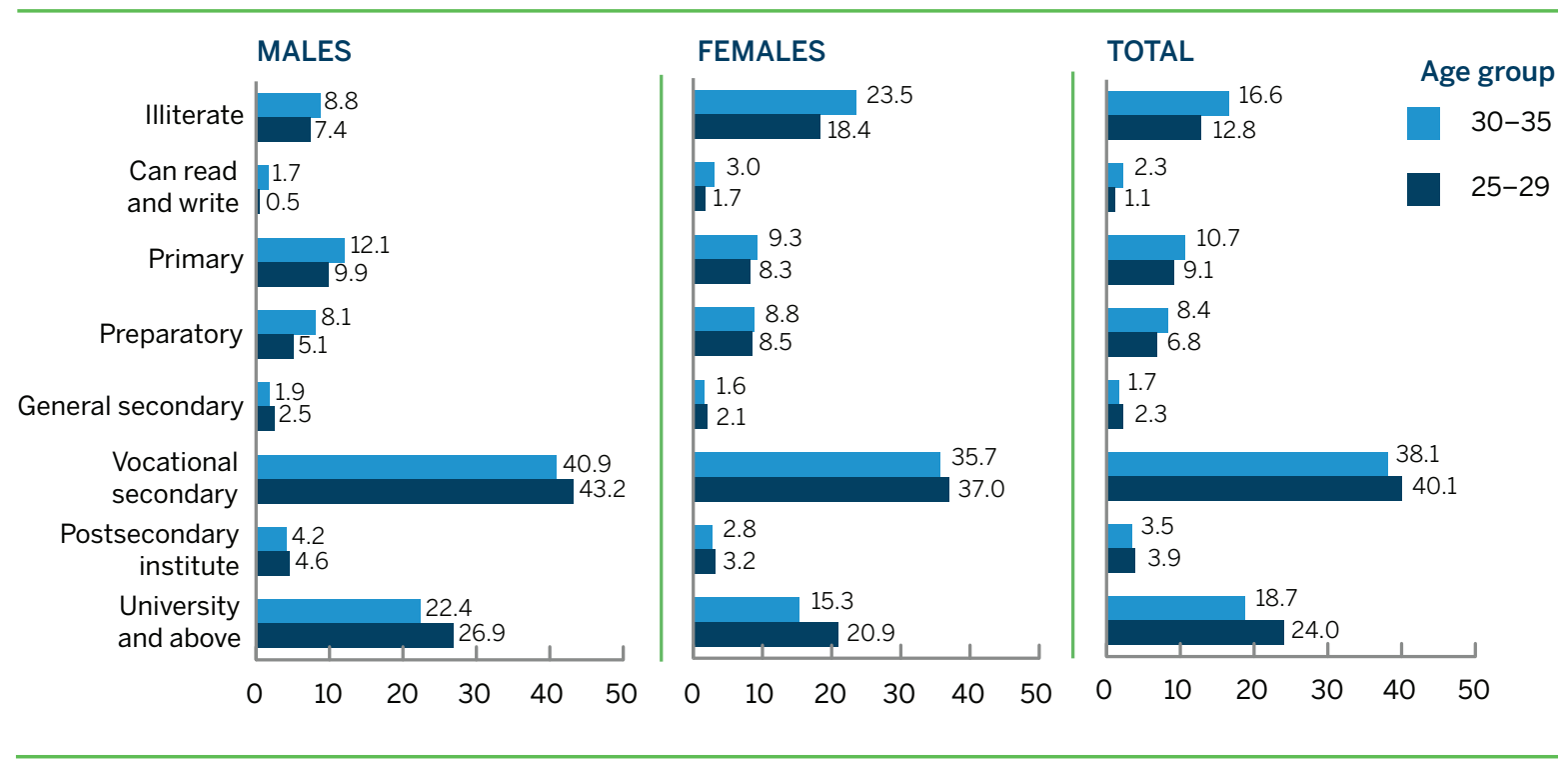


tion, $27 \%$ of male youth aged $25-29$ did so. Female youth have also seen large gains, from 15\% having completed a university education among those $30-35$ to $21 \%$ among those aged 25-29.

To understand progress through each stage of schooling, this section analyzes a generous definition of "on-time" completion; that is, completing primary by age 13 , completing preparatory by age 16 , completing secondary by age 19 , and completing higher education by age 23. Completion is considered to be finishing in the typical number of years, so as not to penalize those in longer programs while still assessing the common pattern. Analyses by a number of background characteristics are presented in Table A3.1. Differential patterns of completion by region evolve somewhat with education level (Figure 3.3). Urban Lower Egypt has the highest completion rates, particularly in preparatory and secondary; it is followed by the Urban Governorates, and then urban Upper Egypt. The Frontier Governorates have the lowest primary and preparatory completion rates, but did slightly better than rural Upper Egypt in secondary completion. The largest differentials were in university completion. Whereas $37 \%$ of youth in urban Lower Egypt and 34\% in Urban Governorates completed university, only 19\% in urban Upper Egypt, 16\% in rural Lower Egypt, 15\% in the Frontier Governorates, and $12 \%$ of those in rural Upper Egypt had completed a university education by age 23 .

\subsection{Intergenerational educational mobility}

Education can play an important role in society by providing socioeconomic mobility. When the education status of parents plays little or no role in determining children's outcomes, this is a sign of socioeconomic mobility or equality of opportunity. This mobility is important from both a social justice perspective and for incentivizing efforts in school. Although the expansion of educational opportunities has meant that many youth are more educated than their parents were, there remains a clear hierarchy when examining youth's educational attainment by father's and mother's education (Figure 3.4). The analysis of intergenerational mobility below focuses on youth 25 years or older, in order to ensure that youth have obtained their final educational status. ${ }^{2}$

Nearly one-fourth of the youth who had illiterate fathers were themselves illiterate, in contrast to

2 Among this group of youth, mother's education was as follows: $73 \%$ illiterate, $5 \%$ read and write, $8 \%$ primary, $3 \%$ preparatory, $1 \%$ general secondary, $6 \%$ vocational secondary or post-secondary institutes, and $4 \%$ higher education. Father's education was: 54\% illiterate, $13 \%$ read and write, $10 \%$ primary, $4 \%$ preparatory, $1 \%$ general secondary, $11 \%$ vocational secondary or post-secondary institutes, and $7 \%$ higher education (data not shown).

FIGURE 3.3 "On-time" school completion, by region, all youth (\%), 2014

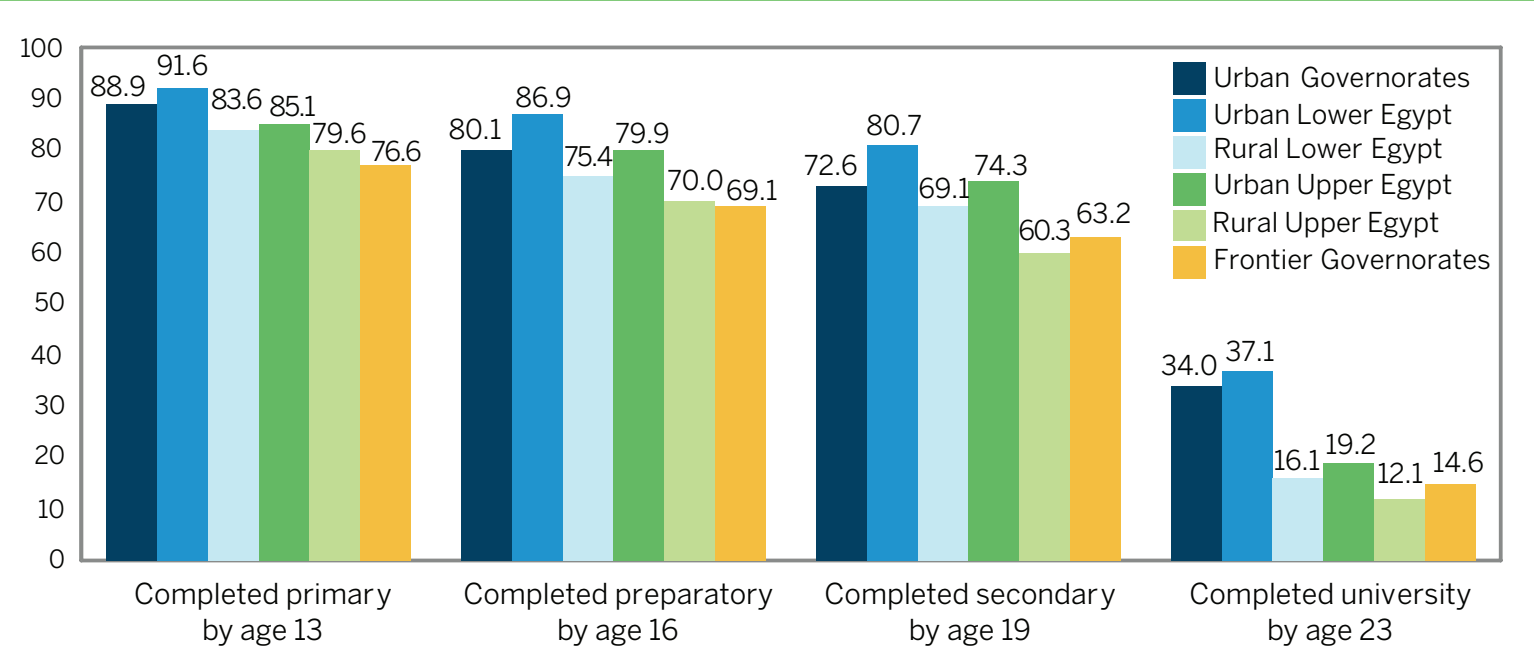

Note: Completion is among all youth and is not conditional upon having entered a level. 
FIGURE 3.4 Educational attainment of youth aged 25 and older, according to father's and mother's education, $2014(\%)$

\section{MOTHER'S EDUCATION LEVEL}

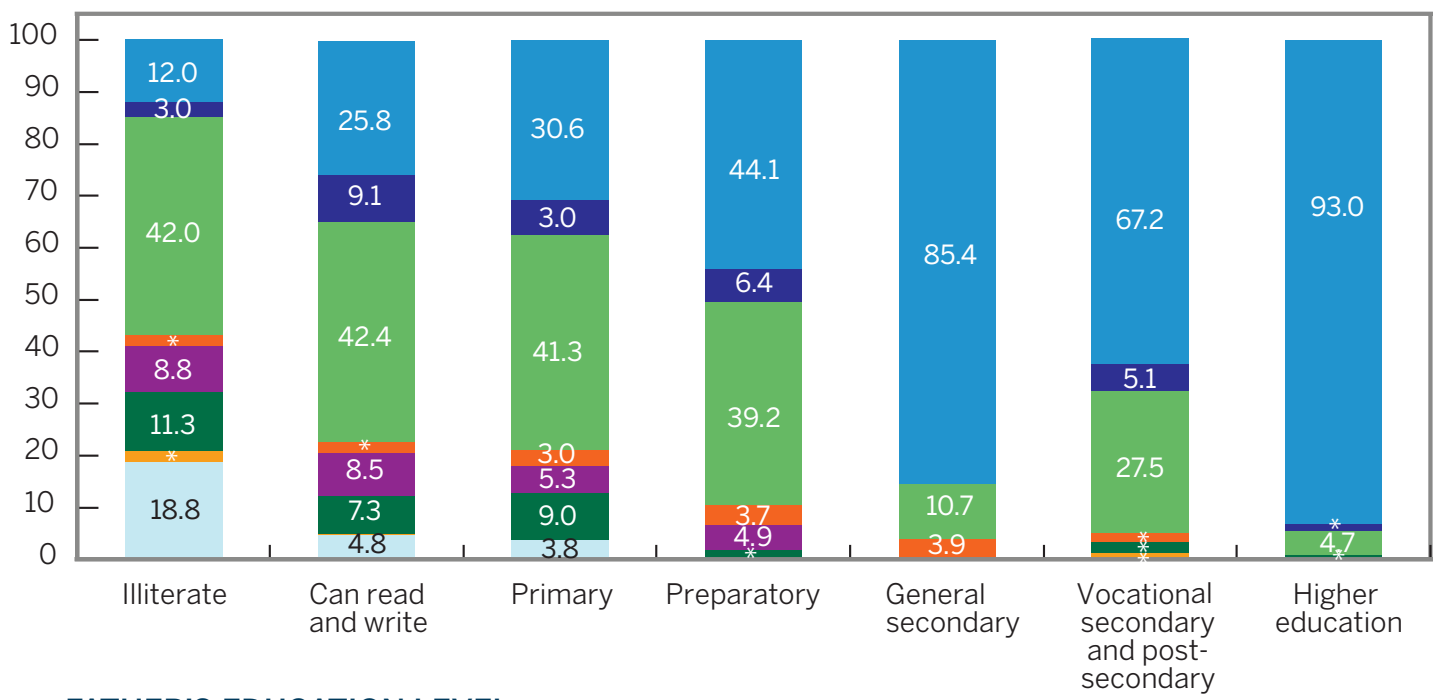

FATHER'S EDUCATION LEVEL

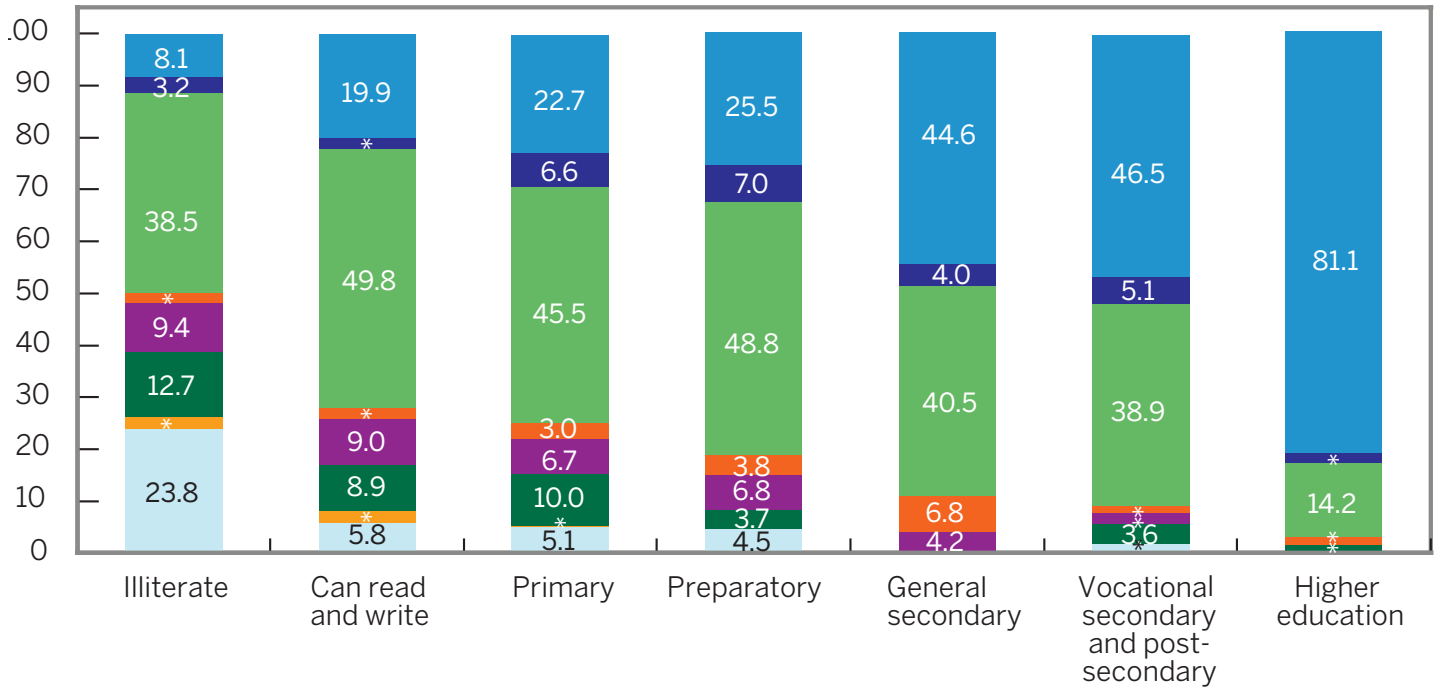

YOUTH'S EDUCATION LEVEL

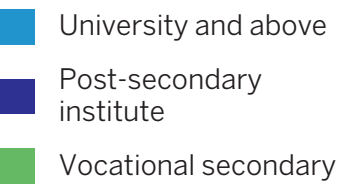
General secondary
Preparatory
Primary

only $6 \%$ of those whose fathers can read and write, and low or near zero shares of those whose fathers have higher levels of education. Another quarter of youth with illiterate fathers have some type of basic education. Most of the remainder (38\% of the total) attained a vocational secondary degree, whereas only $8 \%$ attended university. Very few youth moved from the bottom of the socioeconomic ladder into higher education. Youth from higher rungs of the socioeconomic ladder are decreasingly likely to have lower levels of education and more likely to have attended higher education. When fathers have higher education, there is an $81 \%$ chance that their children also attended university or above. 
Intergenerational differences are even sharper when looking at mother's education; more educated mothers were relatively less common, and even having a mother with a vocational secondary education raised the chances of university to twothirds. Around $93 \%$ of youth who have mothers with higher education have themselves attained a university education. In contrast, only $12 \%$ of youth with illiterate mothers attended university and above. In summary, although there has been an expansion of education, youth from families with higher socioeconomic status (those with educated parents) have very high chances of themselves receiving a university education, whereas those with uneducated or low educated parents have much lower chances, a clear sign of low socioeconomic mobility in Egyptian society.

\subsection{Patterns of ever attending school}

The primary historical challenge for the Egyptian education system has been getting youth to attend school. Although only a small minority of recent cohorts of youth never entered school as of 2014 , a substantial number of young people, particularly young women, have never been to school. This section examines the trends in who attended school and the reasons young people report for not having entered school, comparing youth from different backgrounds.

\section{Who attended school and who missed out?}

The SYPE sample of youth ages 10-29 in 2009, who were aged 13-35 in 2014, were born over the period spanning from just before 1980 to just before 2000. This generation of youth experienced a shift from a substantial minority of youth (approximately $20 \%$ of females and $10 \%$ of males) who never entered school, to nearly universal primary enrollment and gender parity (data not shown).

While less than $80 \%$ of female youth born in the 1980 s ever entered school, and only around 90\% of male youth, by the end of the 1990 s school entry rates were above $95 \%$ and approaching $100 \%$ for both genders.
FIGURE 3.5 Youth who never attended school, by region and gender (\%), 2014

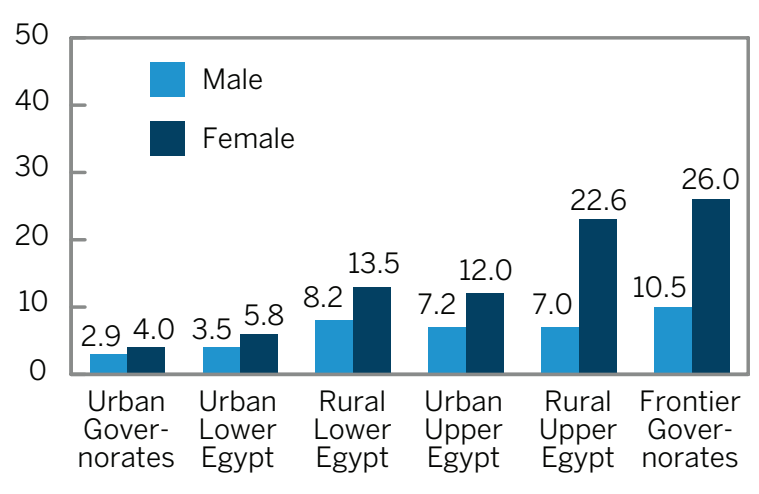

Rural youth, particularly rural female youth and those in Upper Egypt and the Frontier Governorates, were particularly likely to have never attended school (Figure 3.5). ${ }^{3}$ While only $3-4 \%$ of youth in the Urban Governorates never attended school, with only a small gap between male (3\%) and female youth (4\%), across rural areas around 7-8\% of male youth never attended school, and there is a large gender gap, with 13\% of female youth having never attended in rural Lower Egypt and 23\% in rural Upper Egypt. The highest rates of never attendance were in the Frontier Governorates, where $10 \%$ of male youth and $26 \%$ of female youth never attended school (Table A3.1).

In addition to large differences by region, there are substantial differences in terms of the chances of never attending school by parent's education. Essentially, having an educated mother, even one who can just read and write but did not complete any formal certificate, almost guaranteed that a youth attended school, with a particularly large difference for female youth; $10 \%$ of male youth with uneducated (illiterate) mothers never attended school, compared to $21 \%$ of female youth. Having a father with at least some education also

3 Region and place of residence are considered current residence, not necessarily the location where the educational experience in question took place. Analyses indicate that few SYPE respondents had moved from where they were born, making the current location essentially representative of the location of individuals' education experiences. 
increased the chances of attending school (see

Table A3.2).

A relatively small share of recent cohorts never attended school, but among poorer families even younger youth had a moderate chance of never attending school. For youth under age 18, Figure 3.6 presents the percentage of male and female youth in each wealth quintile that never attended school. Notably, it is the poorest male youth who did not attend school (9\%), and this is the group with the largest gender gap, albeit a reverse gender gap (only $6 \%$ of the poorest female youth never attended school). Around $6 \%$ of male youth and $4 \%$ of female youth in the second wealth quintile never attended school. Rates of never attendance become small (1\% or below) by the highest quintile.

\section{Why did some youth never attend school?}

A variety of barriers might preclude youth from attending school. Both supply factors, such as the availability of schools, and demand factors, such as parents' interest in education, could be contributing factors. Table 3.1 highlights (using 2009 data, since this was only asked in 2009) the different reasons youth aged 10-14 reported for having never attended school. This young cohort is likely to be most reflective of the current challenges youth face for not going to school. Table A3.3 presents the reasons by a host of background characteristics,

FIGURE 3.6 Youth under age 18 who never attended school, by household wealth quintile and gender, 2014 (\%)

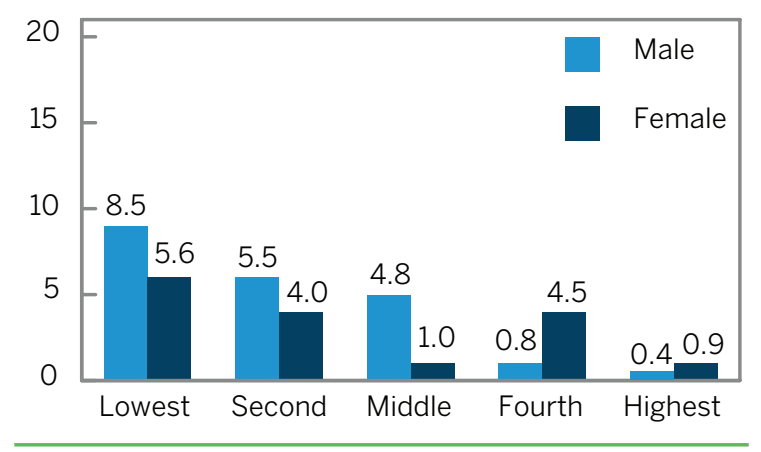

\section{The inability of the} household to afford education is the number one reason that the youngest out-of-school youth gave when asked why
they did not attend school.

including across cohorts, and some key findings of that table are also discussed here. The household being unable to afford education is the number one reason youth did not attend (a reason given by $43 \%$ of those aged 10-14 in 2009). As the share of youth never attending education has decreased, this reason has increased in prevalence, as has the share of youth giving health as a reason. Financial support for the poorest families to send their children to school, for instance conditional cash transfers, might help reduce never attendance

TABLE 3.1 Reasons reported for never attending school, youth aged 10-14, 2009 (\%)

\begin{tabular}{lc}
\hline Household can't afford & 42.9 \\
Parents didn't want & 27.8 \\
Health & 19.2 \\
I had to work & 8.1 \\
Customs and traditions & 8.1 \\
I didn't want to learn & 5.7 \\
Father wouldn't agree & 5.2 \\
To help with household chores & 2.5 \\
Helping family at work & 2.4 \\
School is too far & 1.9 \\
There was no school & 1.0 \\
No birth certificate & 1.0 \\
Too old & 0.0 \\
All teachers male & 0.0 \\
Marriage & 0.0 \\
\hline Note: Does not total to 100 because multiple reasons could be \\
reported by the same individual.
\end{tabular}


due to financial reasons. Improving accessibility of schools to youth with health conditions is also of increasing importance.

Parents not wanting to send children to school remained a barrier for $28 \%$ of the youngest youth. Father wouldn't agree and "customs and traditions" have also been decreasing, although were still contributing factors. The fourth most common reason was having to work, and helping the family in work and helping with household chores were also sometimes contributing factors. School supply is not a major factor; there was no school and school was too far were only occasionally reported to be the reason for nonattendance. The reason "I didn't want to learn" has also fallen over time, which may reflect a perceived increase in the necessity or value of education. Marriage, age, and teacher gender were not stated as factors more than a few times.

There are substantial gender differences in the reasons given for never attending school, with female youth particularly limited by parents' wishes and by customs and traditions. Male youth were more likely not to attend due to the need to work, not wanting to learn, or health. Cost, parental wishes, and the need to help at home disproportionately affect poorer youth. Youth in the bottom three wealth quintiles were also more likely to report multiple reasons, suggesting that multiple barriers may need to be addressed to get poorer youth into school.

\subsection{Youth experiences with literacy classes}

Youth illiteracy remains a substantial problem in Egypt, with two important components. First, many youth who never attended school are illiterate, and few have attended literacy courses or otherwise learned the basic literacy and numeracy skills that would open up important economic and social opportunities to them. Second, many youth who attended school for less than a primary education are not literate; around $50 \%$ of youth who attained only five years of school cannot read, 50\% cannot write, and $40 \%$ cannot do basic math (addition or subtraction) (Figure 3.7). Since youth may drop out
FIGURE 3.7 Literacy outcomes and literacy class attendance by years of school completed, for youth with less than a secondary education (\%), 2014

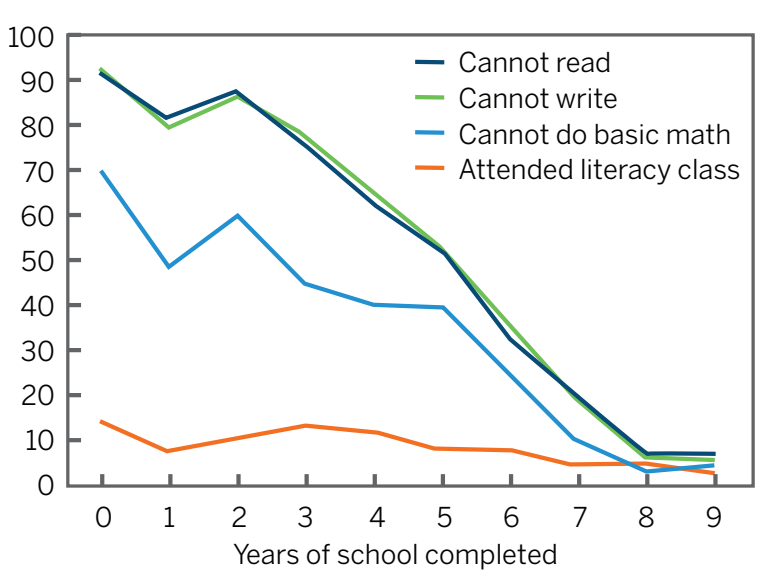

Note: Based on years attended, taking into account that some youth attended five-year primary and some youth attended six-year primary.

of school due to their struggles with the material, this does not necessarily mean that half of youth approaching the end of primary are illiterate, but it is a troubling sign in terms of the quality of the school system.

It is also notable that only $14 \%$ of youth with no schooling ever attended literacy classes. Ninety-two percent of youth who never attended school cannot read, 93\% cannot write, and 70\% cannot do basic math. The higher proficiency in basic math may be attributable to the fact that it is more likely to be picked up in every day life (i.e., selling or buying goods, counting objects) than are reading or writing. Relatively few of those who attended school but had only a few years of education (and are therefore likely to be illiterate) attended literacy classes; $10-13 \%$ of those with 2-4 years of school attended. This group may perceive literacy as more achievable, having attended a couple of years of school already. Table A3.4 presents the patterns of literacy classes and literacy outcomes by background characteristics. Notably, the share of the less educated receiving literacy classes does not vary substantially by region, although levels of illiteracy do vary. 
Among youth who did attend literacy classes, many remain illiterate. Additional analyses demonstrated that around half (51\%) of those who attained less than a secondary education and ever attended literacy classes can read, and half (49\%) can write. Around two-thirds (65\%) can do basic arithmetic. It is important to keep in mind that some of the youth who attended literacy classes likely picked up some of their skills outside of literacy classes. Therefore, that only half of those who attend literacy classes were literate suggests that less than half of youth who attended literacy classes in fact became literate as a result of the classes (data not shown).

\subsection{When do students exit school?}

Once they have entered the education system, male and female youth showed relatively similar progress through years of schooling. Figure 3.8 shows the proportion of youth remaining in school at each year among those who ever entered. ${ }^{4}$ The youth who did not remain in school may have exited because they have dropped out, failed out during a particular year or level, or completed the course of their schooling (for instance, stopping after completing a vocational secondary degree). Male youth were slightly more likely to continue to secondary (around eight years) ${ }^{5}$ than female youth, but female youth catch up in continuing to higher education after 11 years of schooling, and were actually slightly more likely to pursue post-graduate studies.

Not only has entry into school been improving over time, but persistence in school has improved (i.e., the dropout rate has decreased). Figure 3.9a

4 Because there are a number of current students in the SYPE data, survival analysis methods were used to account for the "right-censored" current students, so as to not count their current attainment as final, but to take into account that they have advanced at least to their current level.

5 In order to have the ends of levels at the same point for those who attended both five- and six-year primary, primary is always treated as five years for those who continued beyond that point.
FIGURE 3.8 Proportion of students remaining in school, according to years in school, by gender, 2014

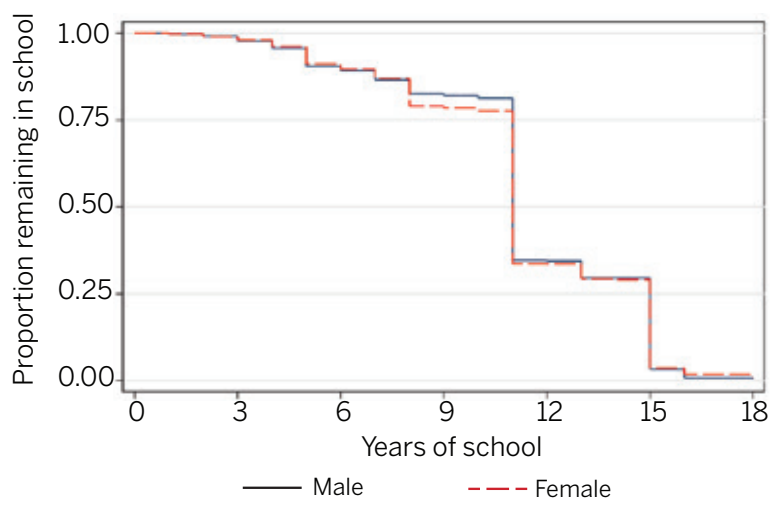

Note: Estimated using Kaplan-Meier method to account for right censoring (current students).

shows persistence in school by birth cohort. From the oldest generation (born in 1978-82) to the youngest (born in 1993-99) there have been clear improvements, but it is also clear that students continue to drop out at each year of basic and secondary education, as well as during transitions from one stage to the next. There has also been very little change in continuing to secondary education among the past few cohorts, and most of the decline in basic education drop out occurred in the primary stage. The chances of continuing to higher education have, however, been steadily increasing over time, with around $40 \%$ of those who went to school continuing for some form of higher education.

Depending on where they lived, youth who attended school faced different chances of continuing to higher levels of education (Figure 3.9b). Not only did youth in rural Upper Egypt face a lower chance of ever entering school, among those who did attend school more dropped out both during the course of a stage, and more stopped rather than continuing to the next level of schooling. Youth in urban Lower Egypt had the greatest persistence in school at every level, although the Urban Governorates catch up somewhat in the share-nearly $50 \%$ of those who enter school-continuing to higher education. 
FIGURE 3.9 Proportion of students remaining in school, according to years in school, by cohort, region, and father's education, 2014
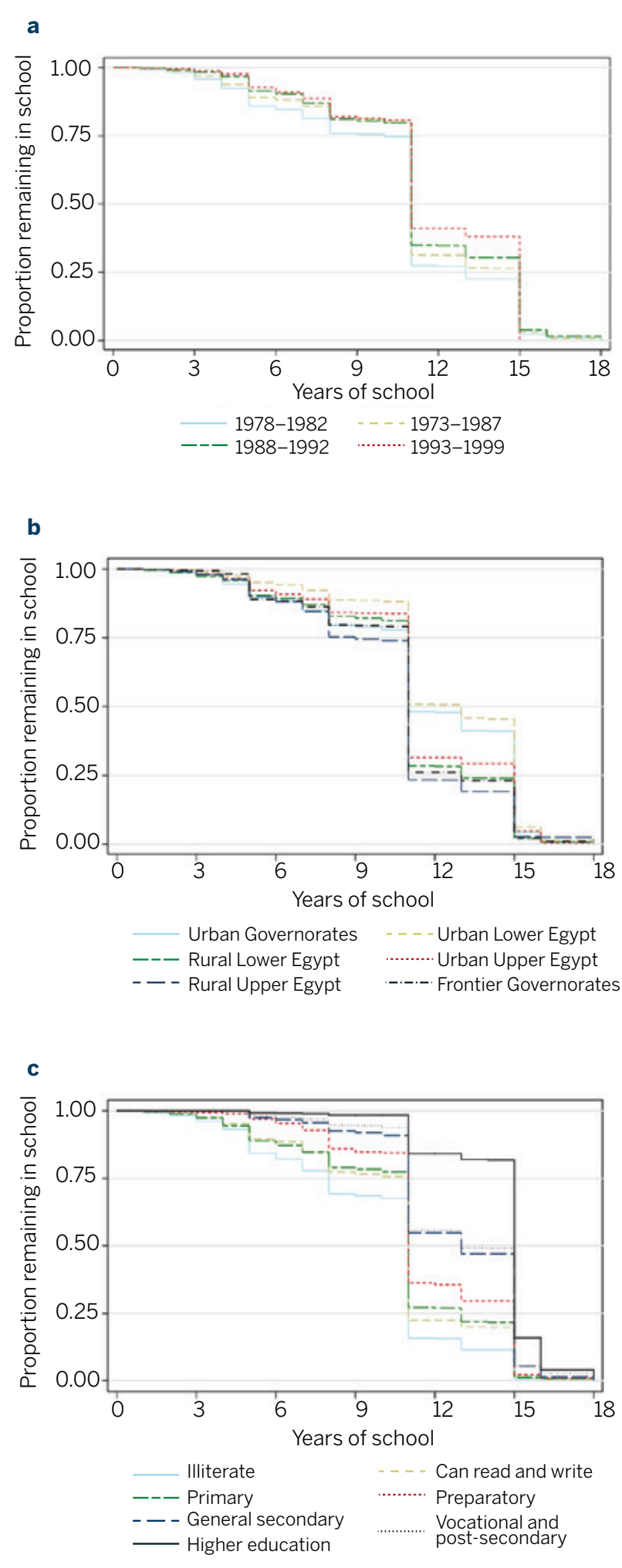

Note: Estimated using Kaplan-Meier method to account for right censoring (current students).
The largest differences in the chances of dropping out come from comparing youth in terms of their father's education (Figure 3.9c). Youth with educated fathers, particularly those with higher- or secondary-educated fathers, were highly unlikely to drop out through at least the end of secondary, and a majority continued for higher education. Those with illiterate fathers were the most likely to drop out at the end of each level, and were also, unlike those with fathers with higher education, likely to drop out in intervening years. Having a father who can simply read and write but has no formal certificate was associated with a substantial decrease in the chances of drop out. Overall, youth face very different chances of progressing through the school system or dropping out depending on their father's education, which likely represents their families' socioeconomic status and the parental resources that can support education.

Students in the SYPE sample who were no longer in school were asked why they left school. Selected (more common) reasons are broken down by background characteristics in Table A3.5. Notably, the most common reason given was having finished with one's studies (70\%). This was followed by not wanting to finish (13\%), school fees ( $5 \%)$, having to work (4\%), and not doing well in school (3\%). Those who left having attended at most primary or preparatory were unlikely to state that they had finished their studies. School fees, having to work, not wanting to finish school, and not doing well in school particularly contributed to those dropping out early.

\subsection{Who are the youth currently in school?}

A number of the analyses in the following section (and throughout the remainder of the chapter) rely on the samples of youth who were currently in school at the time of the SYPE survey. This section briefly summarizes the distribution of current students in the SYPE sample. Detailed information is available in Table A3.6. Overall, $27 \%$ of youth in the 2014 sample were current students. 
TABLE 3.2 Distribution of current students by education level and gender (\%), 2014

\begin{tabular}{lrr}
\hline & MALE & FEMALE \\
\hline Current primary & 0.6 & 0.2 \\
Preparatory & 18.7 & 18.4 \\
General secondary & 21.8 & 28.4 \\
Vocational secondary & 31.0 & 23.9 \\
Post-secondary institute & 1.8 & 2.0 \\
University and above & 26.2 & 27.1 \\
Total & 100.0 & 100.0 \\
\hline
\end{tabular}

Table 3.2 shows the distribution of levels by gender. Around $18-19 \%$ of youth who were current students were in preparatory. Although half of both male and female students were in secondary, male students were more likely to be in vocational secondary (31\%) than female youth (24\%). In contrast $22 \%$ of male current students were in general secondary and $28 \%$ of female current students in general secondary. This was in fact driven by a larger share of vocational secondary students being male and general secondary students being female, and suggests that in the future female youth might exceed male youth in their share of university students.

\subsection{Struggles in school}

This section examines two key issues within the education system that are likely to be important for the success of students, and that are indicators of the success of the school system in providing a quality education. First, absenteeism, or missing one or more days of school, and the reasons for absences are investigated. When students miss school, they learn less and may be unable to catch up to lost material, putting their educational progress at risk. Students may also decide to be absent if they perceive school not to be worthwhile. Second, this section examines repetition during the course of schooling. Students repeat a grade when they are unable to master the year's material, which is symptomatic of quality and inefficiency problems in the school system.
Forty percent of students said that their teachers always want students to memorize information; only $11 \%$ said they are always encouraged to form their own point of view.

\section{Absenteeism}

Overall, $61 \%$ of students were absent one or more days during the semester. The average number of days absent (among students who were absent) was 9. Table A3.7 presents the percentage of students absent, the mean days absent, and reasons for absence by background characteristics. ${ }^{6}$ Illness was the most common reason for absence (52\%). The second most common reason for absence was that students do not perceive benefit from school (28\%), followed by studying (22\%), working or helping with the family $(7 \%)$, and helping with housework (6\%). These reasons, along with private tutoring during the school day (5\%), demonstrate that absence is driven by low (perceived) value of attending school. When students miss school to study outside of school, this suggests that the value of education in school is subpar. Family reasons and distance to school contributed to some absences, but problems at

6 Absenteeism levels should be taken with caution due to the different timing when the SYPE 2014 was administered in each region as highlighted in Chapter 1 of this report. However, as shown in Table A3.7, variations by region of residence do not seem to be caused by the timing of data collection. Although SYPE was administered in the Frontier Governorates near the end of the 2014 school year, young people living in these governorates were slightly less likely to report being absent. The frequency of reporting absenteeism is actually lower in these governorates than in the Urban Governorates where the survey was first administered (early to midway through the 2014 school year). 
school were only rarely reasons for absence. Not benefiting from school was a particularly common reason at the secondary level, while studying and especially private tutoring were particularly prevalent at the general secondary level, when highstakes exams determine the track of university into which students can place.

\section{Grade repetition}

Grade repetition is common in Egypt, particularly at the preparatory and university levels. While $3 \%$ of those who attended school reported repeating in primary and 6\% during preparatory, this dropped to $4 \%$ in secondary before rising to $7 \%$ at the university level (rates and breakdown by background characteristics are shown in Table A3.8). There were differential rates of repetition by gender. Male youth were more likely to repeat than female youth, and this difference increased throughout the schooling system. Although female youth have historically had less access to school, they have greater success in progressing through the schooling system. Rural youth and those with less educated parents were particularly likely to repeat, suggesting that these groups struggled to succeed in school and may require additional support.

\subsection{School quality}

School quality is a complex and multi-dimensional concept; there are a variety of ways to measure school quality, such as in terms of inputs (such as class sizes), outcomes (such as learning or test scores), or opinions (youth satisfaction with their schooling). This section examines just a few measures of the many possible dimensions of quality. First, student opinions about their school experiences are examined, and second, school facility quality (as reported by students) is examined.

\section{Student opinions about educational experiences}

Youth who had ever been to school (or were current students) were asked their opinions about a number of different statements, in terms of whether the statement, in the youth's opinion, occurred never, sometimes, or always in their school. The results show a variation in student opinions. For instance, only $22 \%$ of students believed the rules were applied equally to all, and $25 \%$ thought this was never true. A similar distribution occurred for equal treatment of boys and girls. Only $24 \%$ of youth said that teachers never used corporal punishment (Figure 3.10).

By far the strongest opinions were on the topic of memorization; $40 \%$ of students said that teachers always want students to memorize information, and only $13 \%$ said this was never true. Rote memorization has been identified as a serious problem with education quality (and the productivity of education in the labor market) in the region (World Bank 2008, 2013). Critical thinking was not encouraged. Only $11 \%$ of students said students are always encouraged to form their own point of view, and $31 \%$ said this was never the case. Overall, as well as negative experiences such as unequal treatment of students and use of corporal punishment, students' opinions suggest that rote memorization is the norm and critical thinking is rare. Students who dropped out before entering preparatory school had more negative opinions about their school experiences than those who stayed longer in school. Comparisons with student opinions in 2009 suggest that these issues have been persistent challenges in the education system.

\section{School facilities}

Current students were also asked a number of questions about school facilities. One important measure is the use of multiple shifts (a morning shift and an afternoon shift, for instance), which is likely to contribute to less learning (a shorter school day) as well as to indicate overcrowding. All youth who ever attended a level were asked whether their school operated in shifts. Additionally, current students were asked about the physical conditions of their school facilities. Table A3.9 presents these indicators by a number of background characteristics. In Figure 3.11, these outcomes are presented by place of residence. Geographic differences were substantial, and likely indicate unequal investments or upkeep of schools across 
FIGURE 3.10 Opinions of students who ever attended school about school experiences, 2014 (\%)

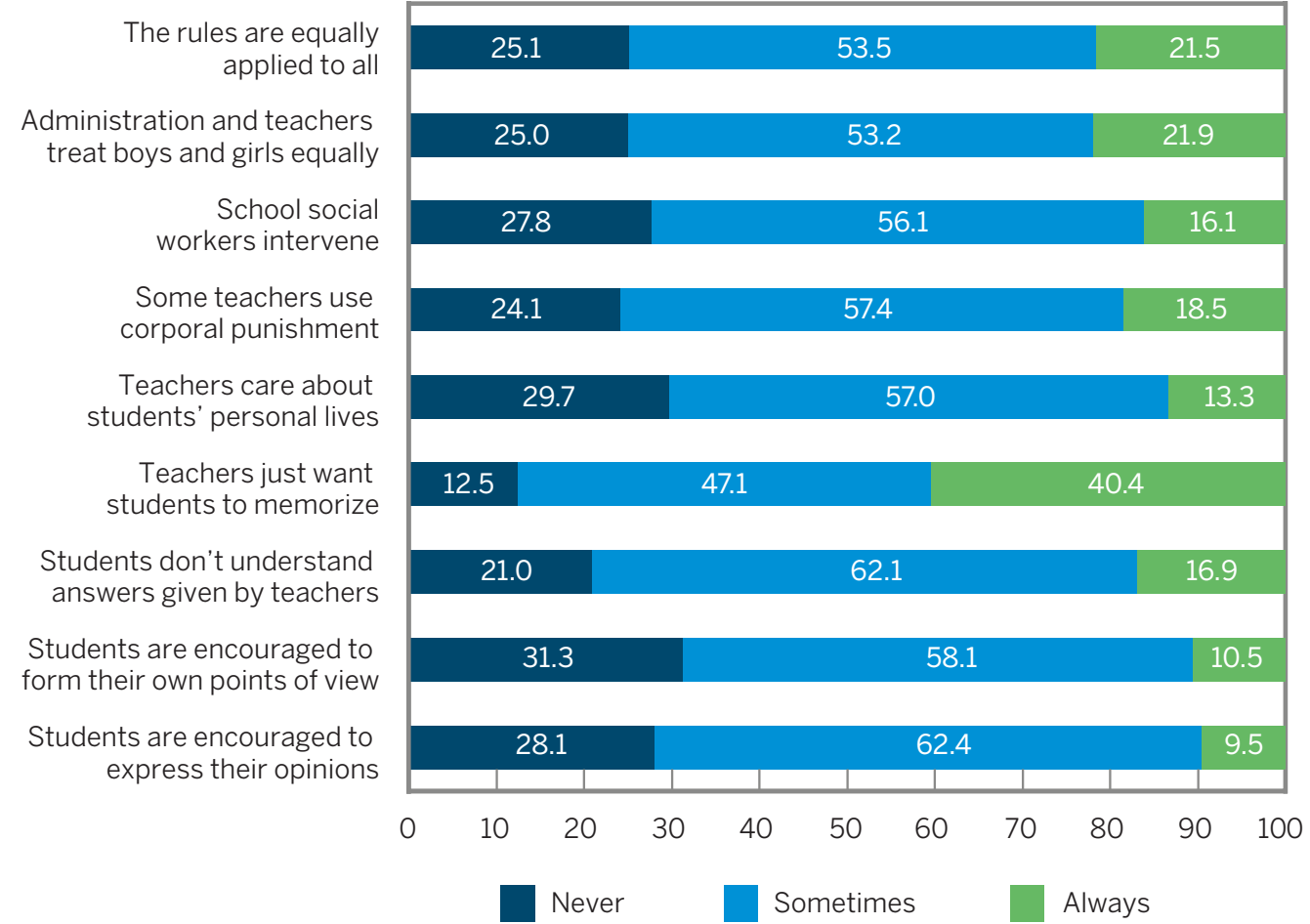

FIGURE 3.11 School facility quality measures by place of residence, 2014 (\%)

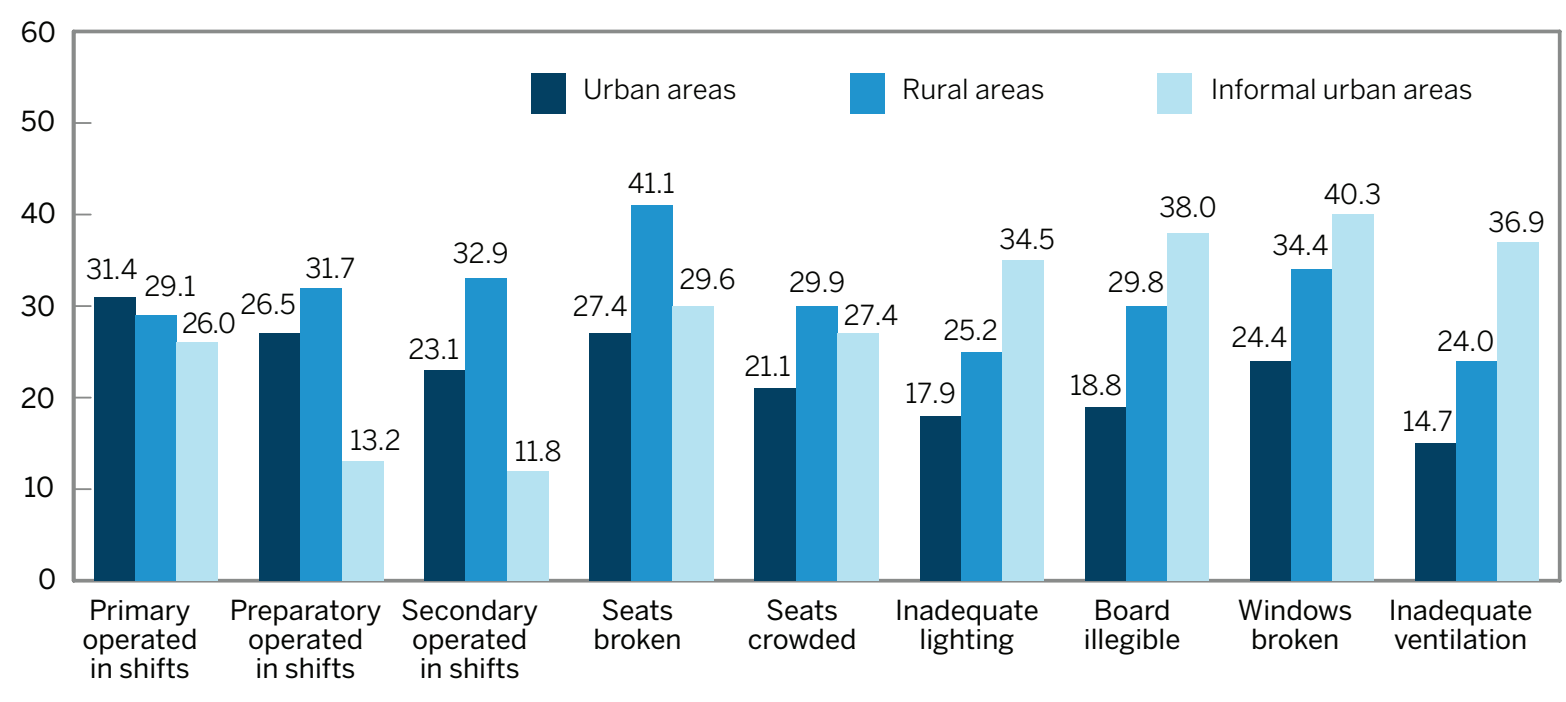

Note: Based on all youth who attended that level for whether schools operated in multiple shifts; all other measures current students in secondary and below. 
different areas of Egypt. Multiple shift schools at the primary stage were most common in urban areas, followed by rural areas and informal urban areas. At the preparatory and secondary stages, these problems were most common in rural areas, followed by urban and then informal urban areas.

Problems with physical facilities were also common, and comparisons with 2009 responses show that there has been little improvement in the facilities students experience. (Comparisons were undertaken by school level to ensure that the composition of students did not drive results). If anything, students reported that physical facilities were in worse condition in 2014. In 2014, 36\% of students reported that seats are broken, $27 \%$ reported crowding of seats and benches, $24 \%$ reported inadequate lighting, $27 \%$ reported that the board is in poor condition or illegible, $32 \%$ reported broken windows, and $22 \%$ reported inadequate ventilation.

Although these findings suggest that a substantial share (but not a majority) of facilities were in a poor state, there were substantial differences in the state of facilities by place of residence. Problems with seating were most prevalent in rural areas, while inadequate lighting, illegible boards, and broken windows were most prevalent in informal urban areas, where $35-40 \%$ of students reported these problems. Urban areas had better facilities, with the lowest rates of problems reported. Comparing 2009 and 2014, along with little improvement occurring in the facilities students experience, disparities have widened among urban areas, rural areas, and informal urban areas.

\subsection{Tutoring and family help during school}

The quantity and quality of education received in the classroom ought to be sufficient for students to succeed or excel in school. However, in Egypt, this may not be the case. Private and group tutoring are common, and may be a key component of good performance on high-stakes exams. This tutoring is expensive and, when undertaken by teachers, creates an incentive problem for educators, who may not adequately cover material in class in order to earn extra income providing tutoring (Assaad and Krafft, 2015; Elbadawy et al. 2009; Ille 2015). In the face of inadequate school quality, families may also help children with schoolwork, which can potentially contribute to inequality because the amount of help is dependent on the resources and education of parents.

\section{Private and group tutoring}

In Egypt, there are two types of tutoring: private lessons and support (help) groups or programs. Figure 3.12 presents the percentage of youth who took private lessons, support programs in school, and

FIGURE 3.12 Students' use of private lessons and support programs, by level, ages $<18$ and $30+, 2014(\%)$,

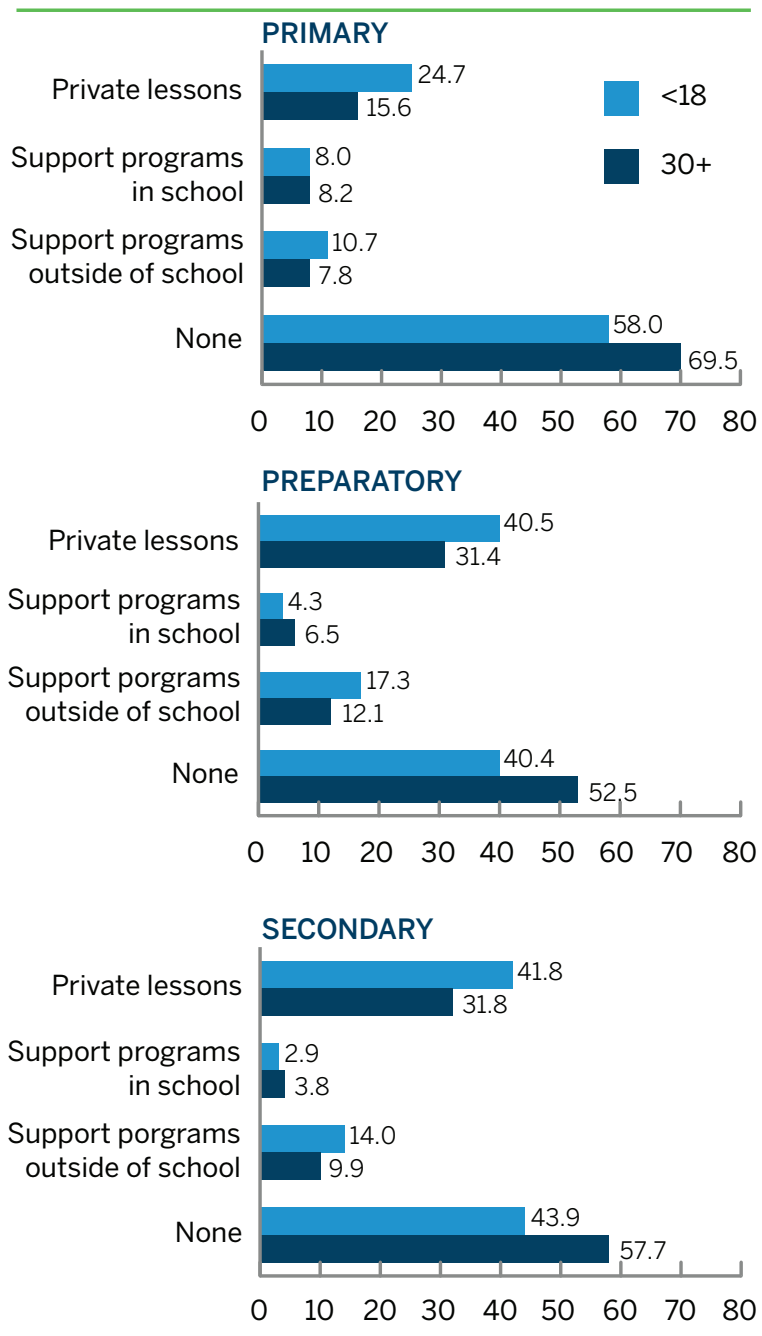

Note: Based on youth who ever attended the level indicated. 
support programs out of school, or none of these, at each level of school. Note that some students took multiple forms of private tutoring. Breakdowns by a number of characteristics are reported in Table A3.10. The figure compares youth age 18 and under to those age 30 and above to get a sense of trends in private tutoring over time. The prevalence of private tutoring was higher, and the share of youth with no help was lower, at every level among the younger age group. Use of private lessons during primary has risen from $16 \%$ to $25 \%$. Preparatory-level private lessons have risen from $31 \%$ to $41 \%$, and secondary lessons from $32 \%$ to $42 \%$. At the same time, support programs have remained relatively flat overall, with support programs out of school having grown, particularly at the preparatory and secondary levels, while those in school have fallen.

The use of private lessons is closely linked to families' socioeconomic background. Youth with more educated parents were more likely to receive tutoring. Wealthier students were more likely to receive tutoring, particularly private tutoring, and have higher expenditures when they do (Figure 3.13, further breakdown in Table A3.11). While only $25 \%$ of current students from the poorest quintile received private tutoring and $10 \%$ received group tutoring, $50 \%$ of current students from the highest quintile received private tutoring and $17 \%$ group tutoring. The average monthly cost of tutoring for those who did receive it was doubled for the highest quintile compared to the poorest, with the wealthiest having spent on average 414 EGP per month on private tutoring and 248 EGP per month on group tutoring.

Among students taking private tutoring, 54\% took lessons with a school teacher. The primary reason stated for doing so was that the teacher was a good teacher (74\%), followed by this being the teacher the student knows (15\%), preferring to take tutoring with the teacher who writes the exam (7\%), the teacher imposing it (3\%), or other reasons (1\%) (data not shown). Although incentive problems in terms of teachers not providing adequate education within school may be an issue, students did not usually perceive themselves as coerced into taking tutoring with their teachers. It is important to note that students may not be willing to report coercion even if they experience it.
FIGURE 3.13 Use and average monthly cost of private and group tutoring for current students in secondary or below, by wealth quintile, 2014

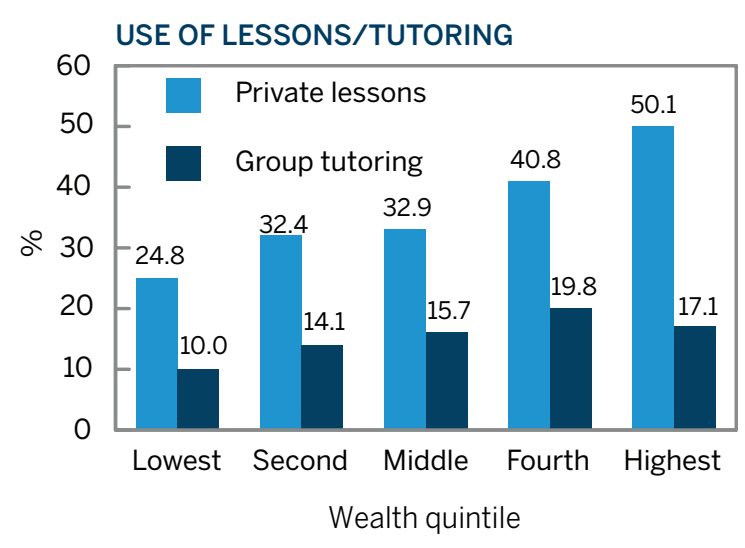

\section{AVERAGE MONTHLY COST}

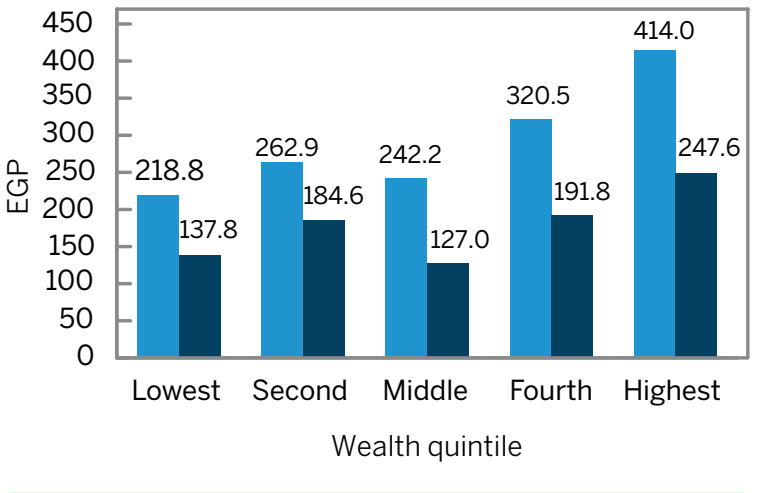

Note: Exchange rate is 1 USD = 7.6 EGP, as of June 2015 .

\section{Family help}

Students' chances of receiving help from their families also rise with their families' wealth (and education), compounding the disadvantages faced by students from less wealthy families. Figure 3.14 shows the proportion of youth who received help with school work from family, and, of those, the (possibly multiple) sources of help (further breakdown in Table A3.12). While just 7\% of youth from the poorest families received help with school work, $26 \%$ of youth from the richest families did so. Those receiving help were increasingly likely to receive assistance from their mother or father with increasing wealth, but poorer students who received help were more likely to get help from older siblings or other sources, which may reflect the fact that their parents were less likely to be educated and therefore able to provide help with schoolwork. 
FIGURE 3.14 Among current students in secondary school, those who received help with schoolwork and the source of that help, by wealth quintile, 2014 (\%)

\% RECEIVING HELP

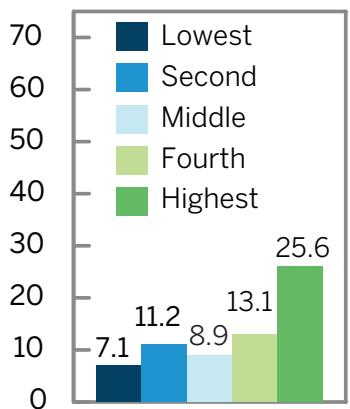

SOURCE OF SUPPORT (AMONG THOSE WHO RECEIVED HELP)

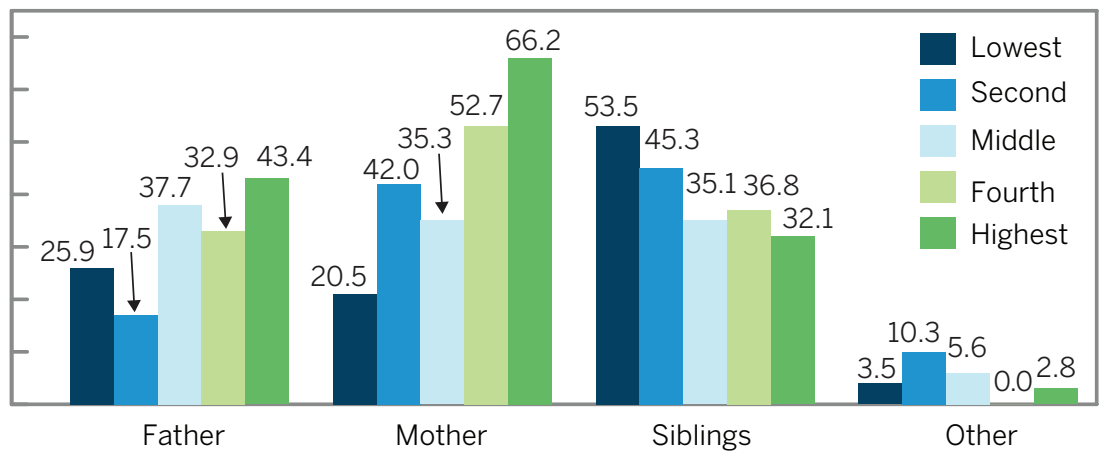

\section{Early childhood care and education}

Early childhood is the most important phase for human development. When children attend early childhood care or education (ECCE), it can help them do better in subsequent schooling and earn higher wages later in life (UNESCO 2006). ECCE can also help reduce the achievement gaps between children in the lowest and highest wealth quintiles, and inequality in later outcomes (Checchi and van de Werfhorst 2014; Jung and Hasan 2014). However, in Egypt, although ECCE has expanded over time, from $16 \%$ of those now age 30 and above to $35 \%$ of those youth now under 18, it is the children living in Urban Governorates who most likely attended ECCE (Table A3.13). Figure 3.15 shows the percentage of children who attended each type of ECCE (children could attend multiple types, or might attend none), by region and by mother's education. Approximately $58 \%$ of youth attended ECCE in the Urban Governorates, with $32 \%$ attending nursery and $28 \%$ attending kindergarten. In contrast, just 31\% of youth in urban Lower Egypt attended ECCE, and $20 \%$ or less in all other regions. ${ }^{7}$ Additionally, only $5-14 \%$ of youth attended kindergartens outside of the Urban Governorates, which may be related to differential public (as well as private) supply (El-Kogali and Krafft 2015; World Bank 2002).

7 In the 2014 round, youth who never went to school were not asked about their ECCE. Evidence from the 2009 round indicates that very few youth who never went to school attended ECCE (Krafft 2015).
It is primarily the children of educated parents (who are likely also wealthier) who attended ECCE. While only $12 \%$ of youth with illiterate mothers attended ECCE (7\% in nurseries, 4\% in kindergartens), $69 \%$ of those with mothers with higher education attended ECCE, with $21 \%$ going to nurseries and $51 \%$ to kindergartens. This unequal preparation for school-including unequal public investmentsis sure to contribute to subsequent inequality throughout the education system.

\section{Vocational secondary education}

A vocational secondary degree is the most common educational attainment among youth, with more than a third of youth (39\%) having attained this degree (Figure 3.2). The characteristics of vocational secondary education are therefore of particular importance to youth and the Egyptian economy. Vocational secondary education is the track to which lower-scoring students are relegated after the preparatory level. It has historically expanded in line with the supply of students rather than the demand for skills. Furthermore, the training, despite being named as vocational, does not necessarily provide students with skills that are relevant or up-to-date for the labor market (Krafft 2013; UNDP and Institute of National Planning 2010; World Bank 2007). Figure 3.16 describes the specializations of youth who attended vocational secondary, and also their experiences during vocational secondary, comparing age groups (and thus trends over time). Further breakdowns are presented in Table A3.14. 
FIGURE 3.15 Attendance in early childhood care and education, by region and mother's education, 2014 (\%)

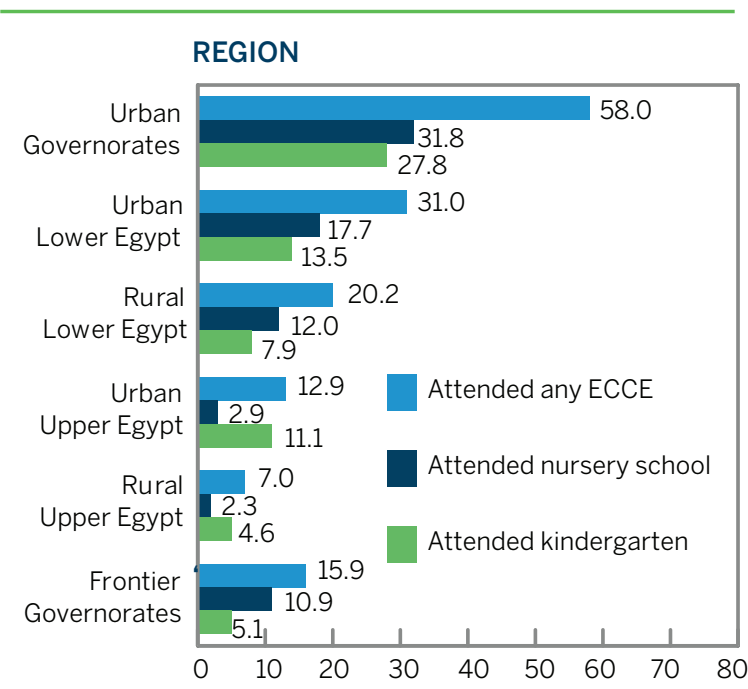

MOTHER'S EDUCATION LEVEL

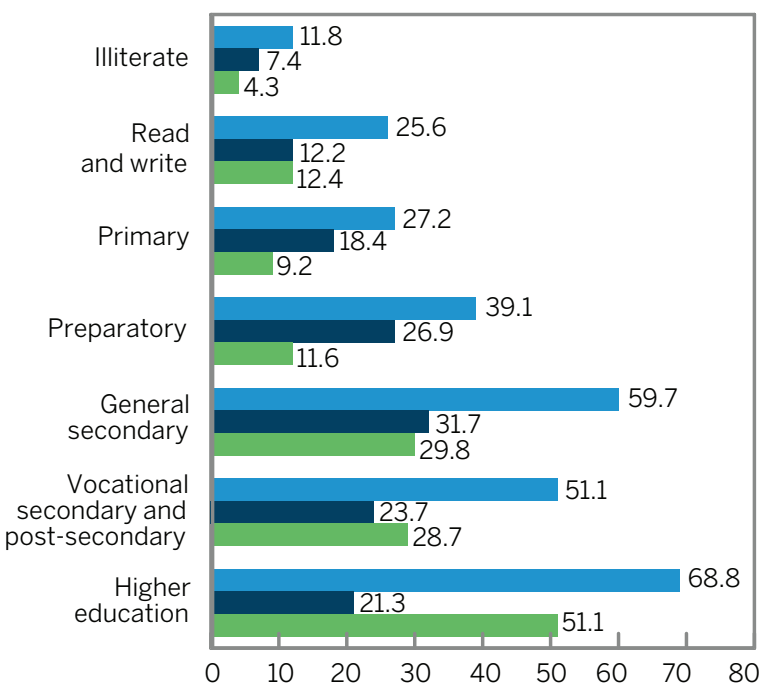

Notes: "Attended other" accounted for $1 \%$ or less. Based on all youth, but assuming that those who never went to school did not attend ECCE. Children could attend multiple types of ECCE.

There has been little change over time in the specializations of youth within vocational secondary, with $46 \%$ of all attendees specialized in the industrial track, $40 \%$ in the commercial track, $11 \%$ in the agricultural track, and 3\% in other tracks (including nursing and tourism). The lack of change in the distribution of specializations may indicate that the training supplied by vocational secondary is not responsive to labor demand. There has also been very little change across
A vocational secondary degree is the most common degree obtained by youth in Egypt. Improvements in vocational secondary education are necessary to increase the labor market relevance of this type of education.

cohorts in whether students experience handson training, with $48 \%$ of all age groups having experienced hands on training. The reported labor-market relevance of the hands-on training that youth receive has increased over time; among those 30 and above $47 \%$ of youth receiving hands-

FIGURE 3.16 Specialization and relevance of vocational secondary by age group, 2014 (\%)

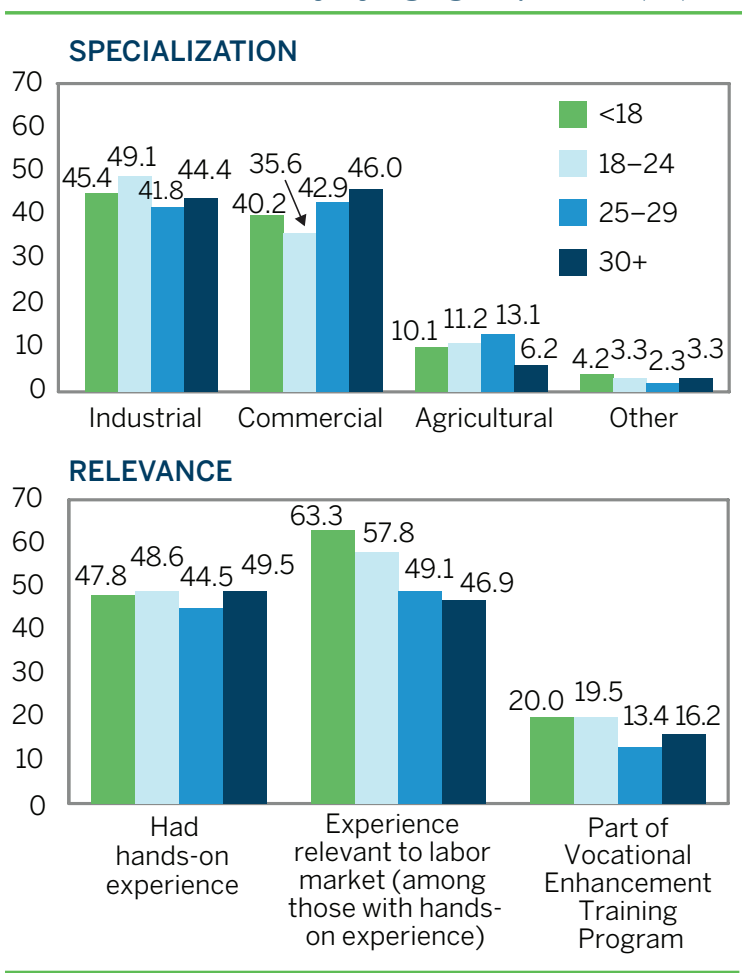

Note: Based on youth who ever attended vocational secondary. 
on experience reported that it was relevant, rising to $63 \%$ of youth under 18 reporting the same. However, it may be that younger youth have not had jobs yet and are optimistic but uninformed as to the labor market relevance of their training. The Egyptian program to enhance vocational training has expanded somewhat over time as well, from $16 \%$ of those 30 and above to $20 \%$ of those under 18. Overall, there have been at best small improvements in the labor-market relevance of vocational secondary education over time.

\section{Higher education}

Around one-fifth of Egyptian youth age 25 and older have a higher education degree (Figure 3.2). This section examines a number of issues specific to higher education in Egypt. Ideally, higher education would help support a knowledge economy and develop skilled workers prepared for the labor market. Table 3.3 shows the characteristics of and youth's experiences with higher education. Notably, $66 \%$ of youth attended higher education in the same city as their family ( $61 \%$ of male youth and $72 \%$ of female youth), suggesting that access to higher education was often linked to city of residence. Youth may have limited geographic choices, and also may not be able to choose their institution due to their test scores; only $54 \%$ of youth chose their institution, whereas the rest were limited by their test scores. Within higher education, students' experiences were mixed. Less than half (43\%) reported that

TABLE 3.3 Characteristics of and youth's experiences with higher education (\%), 2014

\begin{tabular}{lc}
\hline $\begin{array}{l}\text { Attended institution in same city where } \\
\text { family lives }\end{array}$ & 66.4 \\
Had a choice in which institution to attend & 53.6 \\
Professor discussed topics related to field & 43.4 \\
Professor discussed career options & 37.2 \\
Professor was respectful with students & 68.4 \\
Institution offered job-skills or & 36.4 \\
employment workshops related to field & \\
Felt that higher education prepared them & 81.4 \\
\hline
\end{tabular}

Note: Based on youth who ever attended higher education. professors engage students in discussions of topics related to the material. Only one-third reported that professors discuss career options (37\%) or that institutions offer job-skills or employment workshops relevant to their field (36\%). Professors were described as respectful with students by twothirds (68\%) of students. Despite the mixed quality of experiences in school, most students (81\%) believed that higher education prepared them for the labor market.

\subsection{Conclusion}

Egypt has made enormous progress over the past several decades in ensuring that youth enter school. Primary entry is now nearly universal, although there remains a small group of mainly poor youth from less educated families who still do not enter school. Increasingly, the challenge for Egypt is going to be ensuring that children succeed and learn in school.

The findings of this chapter suggest that Egypt has a long way to go before ensuring a high-quality education for all children. Problems with pedagogy, which emphasizes rote memorization rather than critical thinking, are one key quality issue. The relevance of education to the labor market is limited, with particular problems in vocational secondary education. The state of physical facilities is also a quality issue in Egypt. These and other factors likely contribute to Egypt's poor performance on international competitiveness assessments; for instance, in survey of business professionals, the country ranked 141 out of 144 in terms of the quality of basic education (Schwab 2014). The low quality of education in schools may contribute to the need for additional tutoring and family help, factors which also contribute to the many unequal opportunities different youth face in school.

Ideally, the education system is an institution that provides students with equal chances for success. However, youth have both different experiences in the education system and different educational outcomes depending on circumstances beyond their control. Youth face unequal chances for school access and success depending on their 
backgrounds; gender, region of residence, parental education, and household resources all shape the educational experiences of youth. Parents' education is strongly predicative of their children's outcomes, limiting the role of education in socioeconomic mobility. Thus, the education system, which ideally provides equal opportunities for all youth, is falling short of this goal.

A number of reforms might help address the challenges facing the Egyptian education system. Bringing additional resources into the education system may help, but the resources need to be carefully deployed. The mandate of the January 2014 constitution that education spending be $4 \%$ of gross national product (GNP) (Egypt State Information Service 2014) provides a unique opportunity to craft a number of carefully targeted initiatives. For instance, there is very unequal access to kindergartens, and government investment in pre-primary education could help children enter school on more equal footing, as well as be better able to succeed and persist in school (Krafft 2015).

The substantial problems with pedagogy in the schools, as demonstrated directly by students' reports of rote memorization and little critical thinking, as well as indirectly by absenteeism in order to study or due to not benefiting from school, are more challenging to redress. These problems are tied into a system of high-stakes testing, and revamping testing to better value critical thinking and other broadly applicable skills rather than a certain set of facts might help address both the quality of pedagogy and some of the issues related to private tutoring and inequality. Initiating such a change will also require retraining of current teachers and changing how future teachers are trained.

The future of Egypt's young people, and the social and economic development of the country as a whole, depend on expanding on Egypt's successes within education, and also addressing the large number of challenges, particularly in terms of quality and inequality, that persist within the school system.

\section{References}

Assaad, R. and C. Krafft. 2015. "Is Free Basic Education in Egypt a Reality or a Myth?" Egyptian Center for Economic Studies (ECES) Working Paper No. 179. Cairo: ECES

Checchi, D. and H.G. van de Werfhorst. 2014. "Educational Policies and Income Inequality." IZA Discussion Paper Series No. 8222. Bonn: IZA.

Egypt State Information Service. 2014. "Constitution of The Arab Republic of Egypt" (English Translation). Retrieved from http://www.sis.gov.eg/Newvr/ Dustor-en001.pdf.

El-Kogali, S., and C. Krafft 2015. Expanding Opportunities for the Next Generation: Early Childhood Development in the Middle East and North Africa. Washington, DC: World Bank.

Elbadawy, A., D. Ahlburg, R. Assaad, and D. Levison. 2009. "Private and Group Tutoring in Egypt: Where Is the Gender Inequality?" Paper Presented at the XXVI IUSSP International Population Conference. Marrakech, Morocco.

IIle, S. 2015. "Contrived Private Tutoring in Egypt: Quality Education in a Deadlock between Low Income, Status and Motivation." Egyptian Center for Economic Studies Working Paper No. 178. Cairo: ECES.

Jung, H. and A. Hasan. 2014. "The Impact of Early Childhood Education on Early Achievement Gaps: Evidence from the Indonesia Early Childhood Education and Development (ECED) Project." World Bank Policy Research Working Paper No. 6794. Washington, DC: World Bank.

Krafft, C. 2013. "Is School the Best Route to Skills: Returns to Vocational School and Vocational Skills in Egypt." Minnesota Population Center Working Paper Series No. 2013-09. Minneapolis, MN: Minnesota Population Center.

- - . 2015. "Increasing educational attainment in Egypt: The impact of early childhood care and education," Economics of Education Review 46: 127-143.

Krafft, C., A. Elbadawy, and R. Assaad. 2013. "Access within the higher education system: Evidence for more inequality of opportunity," in A. Elbadawy (ed.), Is There Equality of Opportunity under Free Higher Education in Egypt? (Arabic). Cairo: Population Council.

Schwab, K. 2014. The Global Competitiveness Report: 2014-2015. Geneva: World Economic Forum.

Shahine, G. 2003. “A system for Sisyphus," Al-Ahram Weekly Issue No. 648. Cairo: Al-Ahram. http://weekly. ahram.org.eg/2003/648/eg6.htm. Retrieval date: March 2015 
UNDP and Institute of National Planning. 2010. Egypt Human Development Report 2010. Cairo: UNDP and INP.

UNESCO. 2006. Education For All Global Monitoring Report 2007: Strong Foundations: Early Childhood Care and Education. Paris: UNESCO.

UNESCO International Bureau of Education. 2006. Egypt: Early Childhood Care and Education (ECCE) Programmes. Country Profile Prepared for the Education for All Global Monitoring Report 2007. Geneva: UNESCO IBE

World Bank. 2002. Arab Republic of Egypt Strategic Options for Early Childhood Education. Washington, DC: World Bank.

-- - 2007. Youth--An Undervalued Asset: Towards a New Agenda in the Middle East and North Africa: Progress, Challenges and Way Forward. Washington, DC: World Bank.

- - -2008. The Road Not Traveled: Education Reform in the Middle East and North Africa. Washington, DC: World Bank.

- - . 2013. Jobs for Shared Prosperity: Time for Action in the Middle East and North Africa. Washington, DC: World Bank. 


\section{Young People's Labor Market Outcomes During a Period of Transition}

RANIA ROUSHDY • IRENE SELWANESS

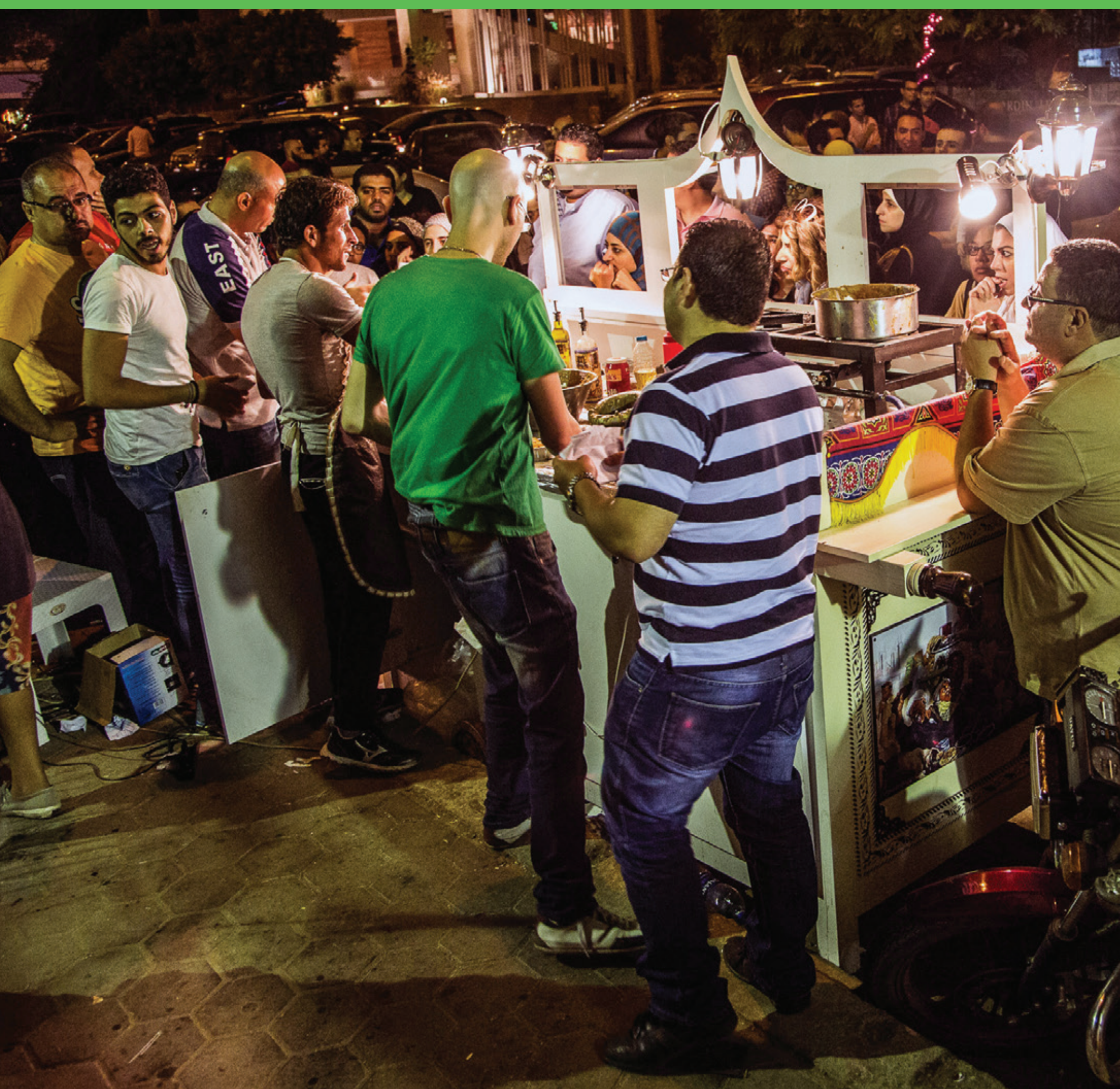


The difficult labor market conditions

following the January 25, 2011 revolution in

Egypt have been widely documented in the

media, but there are limited data to measure

the actual impact of post-revolutionary

economic conditions on young people. It is

vital to document the short-term adjustments

of the Egyptian labor market at this critical

time and their implications for youth labor

market outcomes.

\subsection{Introduction}

Historical international evidence has shown that several factors may determine the labor market effects of an economic downturn. Among those factors are the magnitude of the economic contraction, the role of existing labor market institutions, and the nature of the policy response (Verick 2010). Gender- and age-specific consequences of economic shocks might also be observed for women and youth, particularly in poor countries. During a recession, women may be simultaneously observed to increase their labor force participation (the added-worker effect) or to withdraw from the labor force (the discouraged-worker effect). The added-worker effect is often observed among middle-aged, married, and less educated women from poor households, who enter the labor force to maintain household income. The discouraged-worker effect primarily occurs among young, highly educated, single women working in the service sector (World Bank 2009; Roushdy and Gadallah 2012). ${ }^{1}$

1 For instance, during the Latin America debt crisis of the early 1980s and late 1990s, women's labor force participation increased in Peru, Costa Rica, and Argentina (see Cerutti 2000; Francke 1992; Leslie, Lycette, and Buvinic 1988). However, during the 1997 financial crisis in South Korea, young women working in clerical and service sectors were observed withdrawing from the labor market more than men (see Kim and Voos 2007).
This chapter uses the updated SYPE employment module to provide a detailed analysis of the impact of post-revolutionary economic shocks on the employment and unemployment situation of youth in Egypt, as well as how the revolution has affected job regularity and formality status among young workers. We focus on the market definition of the labor force, which encompasses all individuals engaged in economic activity for the purposes of market exchange or who are seeking such work. We also use the standard International Labour Office (ILO) definition of unemployment, which defines as unemployed all those who have not worked or been attached to a job during the week prior to the survey interview, who were willing and available for work, and were actively searching for work.

\subsection{Labor force participation}

According to the SYPE 2014 results, the overall labor force participation of youth aged 15-29 decreased slightly from $37.9 \%$ in 2009 to $36.6 \%$ in 2014. We find a slightly smaller percentage of male youth (61.4\% in 2009 vs. 57.8\% in 2014) now participating in the labor force, whereas the rate among female youth remains similar to the 2009 figure (13.4\% in 2009 vs. 13.3 in 2014). Total labor force participation was only slightly higher among the full 2014 sample of SYPE respondents of working age (15-35), at 40\%. Also, slightly higher levels were observed for both male (63.7\%) and female youth $(14.9 \%)$ when including young people aged 30-35 in the overall labor force participation rate (data not shown).

Since many youth are still studying, below we focus on the group of young people who had completed their education by 2014. Surprisingly, a similar decline in total labor force participation was also observed among nonstudents aged 15-29 (from $51.7 \%$ in 2009 to $49.6 \%$ in 2014). Labor force participation declined from $86.4 \%$ in 2009 to $79.4 \%$ in 2014 among nonstudent male youth, and stayed around the 2009 level (18\%) among nonstudent female youth in 2014. 
Nonstudent youth labor force participation rates for 2009 and 2014 are shown in Table 4.1. The decline in male labor force participation was cutting across all education levels, except among general secondary school graduates. In contrast, female labor force participation increased among illiterates, and primary, general secondary, and post-secondary school graduates. In 2014, male participation was highest among primary and preparatory school graduates, and lowest among those with university education and the illiterate group. For female youth, participation was highest among post-secondary school and university graduates and lowest among those with preparatory education and the illiterate group.

As expected, the observed decline in young men's labor force participation was driven by the never-married population. Never-married male youth experienced about an 11 percentage point decline in their labor force participation (from $85.6 \%$ in 2009 to $75.0 \%$ in 2014), compared to a 0.2 percentage point increase (from $95.1 \%$ in 2009 to $95.3 \%$ in 2014) among their married peers. For women, labor force participation declined slightly among both the never-married and married groups between 2009 and 2014. As is often highlighted in literature on the Egyptian labor market, married women's labor force participation is still substantially lower than that of never-married women (Assaad and El-Hamidi 2009).

\section{Among nonstudents, male labor force participation decreased across most education levels (except for general secondary school graduates), while female participation increased among illiterates, primary, general secondary, and post-secondary school graduates.}

\begin{abstract}
The positive relationship between household wealth and nonstudent youth labor force participation seen in 2009 was also observed in 2014, for both male and female youth (Figure 4.1). Whereas the 2014 drop in young men's economic activity held across all wealth quintiles, young women in both the lowest and the second wealth quintiles experienced an increase in their labor force participation of about 2 percentage points from 2009 to 2014 (from $11.9 \%$ and $13.6 \%$ in 2009 to $14.0 \%$ and $16.3 \%$ in 2014, respectively). This may be an added-worker effect which is often observed among women from poor households who enter the labor market during
\end{abstract}

TABLE 4.1 Nonstudent labor force participation, by education level and gender, 2009 and 2014 (\%)

\begin{tabular}{|c|c|c|c|c|c|c|c|c|c|}
\hline & \multirow{2}{*}{\multicolumn{3}{|c|}{$\begin{array}{c}2009 \\
\text { AGED 15-29 }\end{array}$}} & \multicolumn{6}{|c|}{2014} \\
\hline & & & & \multicolumn{3}{|c|}{ AGED 15-29 } & \multicolumn{3}{|c|}{ AGED 15-35 } \\
\hline & MALE & FEMALE & TOTAL & MALE & FEMALE & TOTAL & MALE & FEMALE & $\overline{\text { TOTAL }}$ \\
\hline \multicolumn{10}{|l|}{ Education level } \\
\hline Illiterate & 76.1 & 7.1 & 22.4 & 76.1 & 8.7 & 32.1 & 80.2 & 9.3 & 31.7 \\
\hline Can read and write* & - & - & - & 91.7 & 3.8 & 38.3 & 94.7 & 9.0 & 40.5 \\
\hline Primary & 89.3 & 9.9 & 54.1 & 84.9 & 12.7 & 54.2 & 87.5 & 13.5 & 55.4 \\
\hline Preparatory & 85.9 & 9.9 & 49.3 & 83.1 & 9.6 & 40.2 & 85.5 & 9.2 & 41.3 \\
\hline General secondary & 71.9 & 4.3 & 36.7 & 78.4 & 10.9 & 45.1 & 80.5 & 9.9 & 45.8 \\
\hline Vocational secondary & 86.8 & 17.7 & 54.5 & 78.2 & 15.3 & 50.8 & 81.1 & 16.6 & 52.2 \\
\hline Post-secondary institute & 90.5 & 35.1 & 64.9 & 78.5 & 43.3 & 63.8 & 83.1 & 41.7 & 65.7 \\
\hline University and above & 87.5 & 46.7 & 67.6 & 77.9 & 40.8 & 60.7 & 83.1 & 43.5 & 65.0 \\
\hline Total & 86.4 & 18.0 & 51.7 & 79.4 & 17.8 & 49.6 & 82.8 & 18.8 & 51.1 \\
\hline$(\mathrm{N})$ & $(3,260)$ & $(4,580)$ & $(7,840)$ & $(2,739)$ & $(3,278)$ & $(6,017)$ & $(3,527)$ & $(4,478)$ & $(8,005)$ \\
\hline
\end{tabular}

* For 2009, rates among nonstudents for this category not included due to small sample size. 
FIGURE 4.1 Nonstudent labor force participation rate according to wealth quintile and region, by gender, 2009 and 2014 (\%)

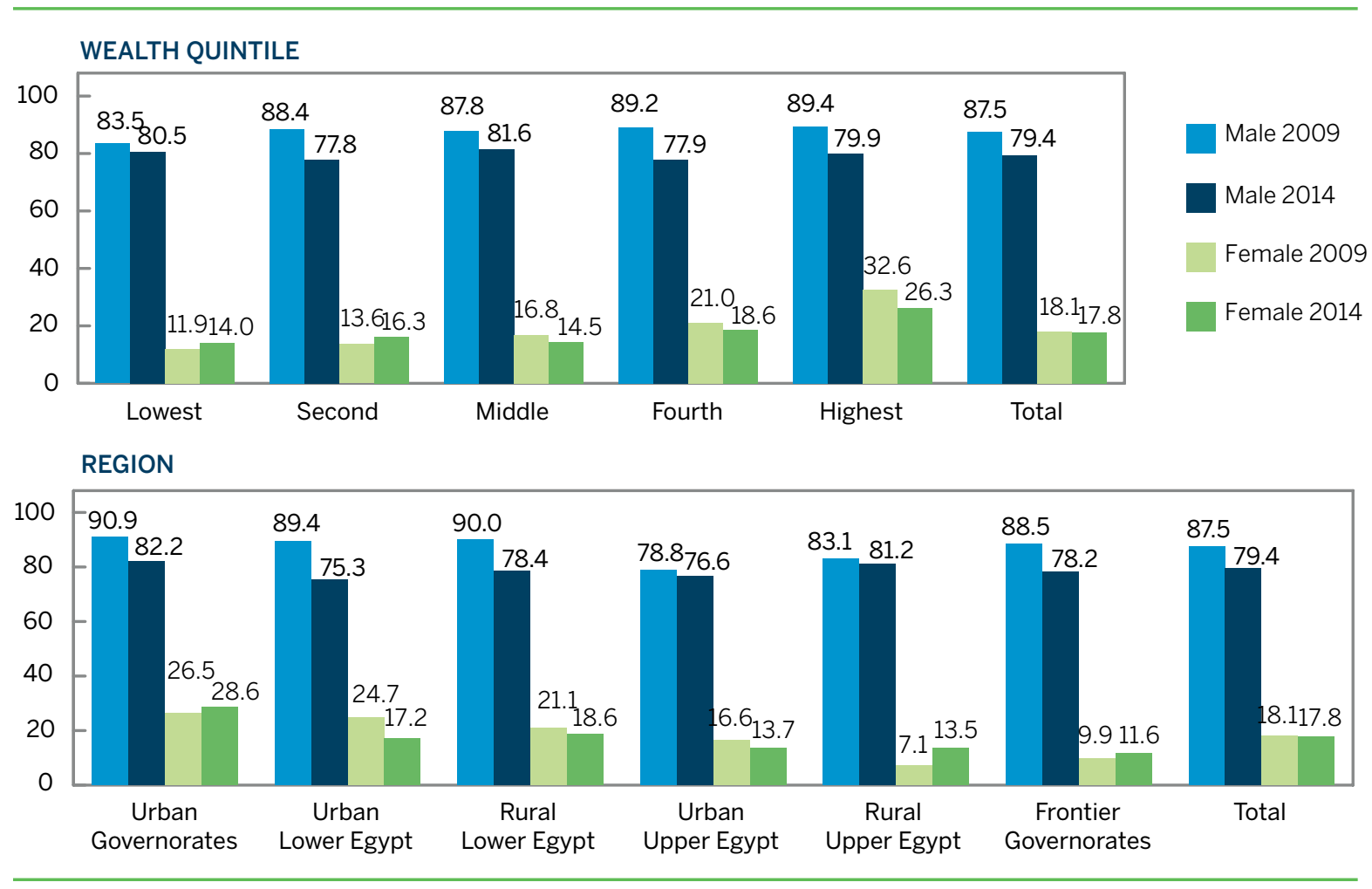

economic downturns to sustain household income; this added-worker effect was also observed in the Egyptian labor market during the global financial crisis (see Roushdy and Gadallah 2012).

Furthermore, there was regional variation in the changes seen in the nonstudent youth labor force participation rate during the 2009-2014 period. In 2009, the female labor force participation rate (aged 15-29) was strikingly low in rural Upper Egypt (7.1\%) and in the Frontier Governorates (9.9\%). However, in 2014 female activity almost doubled in rural Upper Egypt, reaching 13.5\%. Female labor force participation also increased in the Urban Governorates and the Frontier Governorates, but the other regions experienced a decline in female labor force participation rates from 2009 to 2014. As Figure 4.1 illustrates, female labor force participation is now the lowest in the Frontier Governorates (11.6\%) followed by rural (13.5\%) and urban Upper Egypt (13.7\%). Female youth are still most likely to be economically active in the metropolitan governorates. The decline in the male youth participation rate (aged 15-29) was prevalent across all regions of Egypt, with the largest decline witnessed in urban Lower Egypt. Male participation is now lowest in urban Lower Egypt and urban Upper Egypt, at 75.3\% and $76.6 \%$, respectively.

Overall, young people aged 15-29 living in urban Lower Egypt, who completed their education, experienced the largest decline in their youth labor force participation rate (from 55.5\% in 2009 to 45.6\% in 2014), while rural Upper Egypt enjoyed an almost 5 percentage point increase in its youth activity rate (from $41.3 \%$ to $45.7 \%$ ), which was mainly driven by the increase in female labor force participation in this region (data not shown). This increase might be due to the substantial development efforts directed toward employability projects for young people, and particularly for female youth, in rural Upper Egypt directly after the January 25, 2011 revolution. 
FIGURE 4.2 Labor force participation rate among all youth and nonstudent youth, by age and gender, 2009 and 2014 (\%)

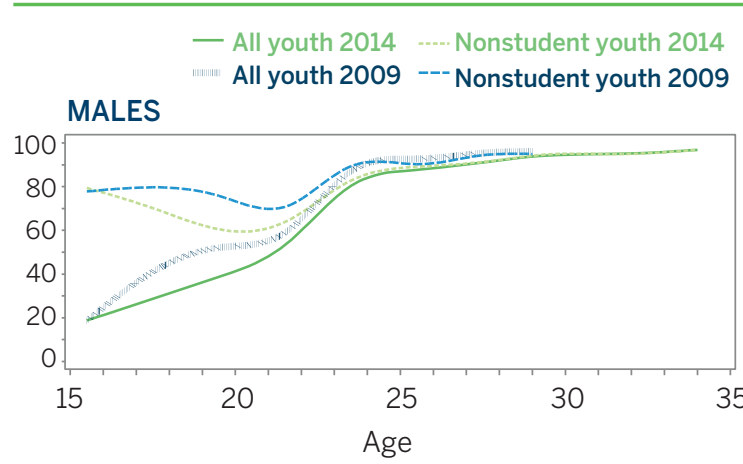

FEMALES

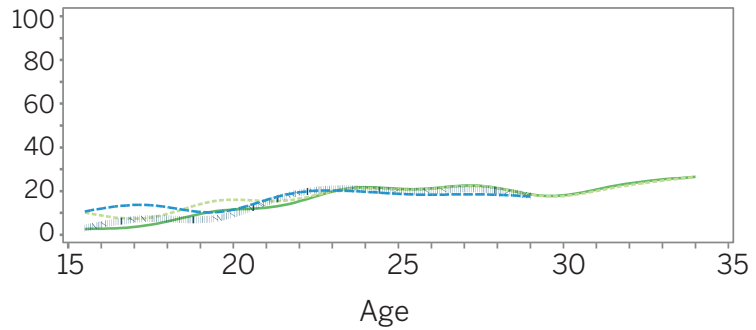

ALL

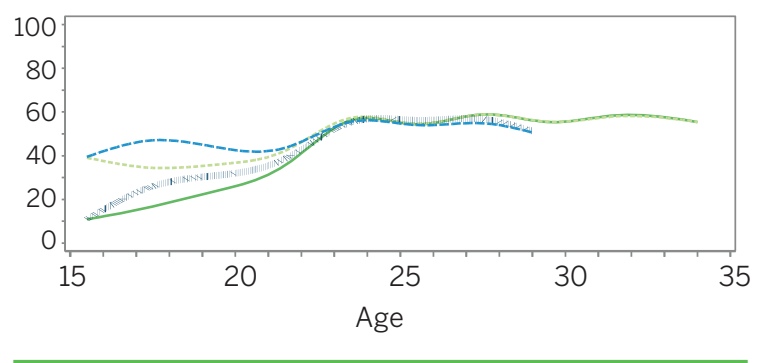

In order to control for the change in the age distribution of youth between the two waves of SYPE, we present labor force participation by single year of age among all youth and nonstudent youth in 2009 and 2014 (Figure 4.2). As is clear from the third panel of the figure, the decline in labor force participation among both the nonstudent group and all youth (aged 15-29) in 2014 appears to be mainly due to the substantial decline in the participation rate of the younger cohorts of youth aged 16-22. Similar trends are observed for the labor force participation rate using the broad definition of unemployment, which includes the discouraged unemployed in the labor force. Male youth labor force participation declined across all cohorts, while female youth participation was more stable between 2009 and 2014. The figure also shows that, based on the SYPE 2014 data, male labor force participation started converging with its 2009 levels by age 25. Also, surprisingly, female participation appeared to increase slightly after age 30 as compared to younger ages.

The decline in labor force participation observed in 2014, especially among young men and even among those who are no longer in school, indicates that youth are increasingly withdrawing into inactivity. To understand why this is happening, in Table 4.2 we present the reasons mentioned by nonstudents

TABLE 4.2 Nonstudent youth aged 15-29 who reported reasons for not wanting to work, by gender, 2009 and 2014 (\%)

\begin{tabular}{|c|c|c|c|c|c|c|}
\hline & \multicolumn{3}{|c|}{2009} & \multicolumn{3}{|c|}{2014} \\
\hline & MALE & FEMALE & TOTAL & MALE & FEMALE & TOTAL \\
\hline \multicolumn{7}{|l|}{ Reasons for not wanting to work } \\
\hline Housewife/taking care of the household & 0.0 & 92.9 & 82.9 & 2.7 & 61.9 & 50.5 \\
\hline Does not want to work* & 12.3 & 3.5 & 4.4 & 3.0 & 3.0 & 3.0 \\
\hline Temporarily disabled & 7.4 & 0.2 & 1.0 & 3.0 & 0.1 & 0.7 \\
\hline Permanently disabled & 12.5 & 0.8 & 2.1 & 3.4 & 0.5 & 1.0 \\
\hline On unpaid leave for at least one year & 0.3 & 0.0 & 0.0 & 0.2 & 0.0 & 0.0 \\
\hline Planning to travel/work abroad or immigrate & 2.2 & 0.0 & 0.2 & 1.2 & 0.0 & 0.3 \\
\hline No appropriate job opportunity* & 30.0 & 2.0 & 5.1 & 42.9 & 15.9 & 21.1 \\
\hline Parent/spouse refusal & - & - & - & 2.0 & 16.5 & 13.7 \\
\hline Other & 35.3 & 0.6 & 4.4 & 42.0 & 1.6 & 9.4 \\
\hline$(\mathrm{N})$ & $(289)$ & $(3,667)$ & $(3,956)$ & $(482)$ & $(2,628)$ & $(3,110)$ \\
\hline
\end{tabular}

*In SYPE 2014, more reasons for not wanting or not being available to work were listed in the questionnaires than in 2009. To facilitate comparability between the survey waves, the following reasons were grouped together in the 2014 columns: In the "Does not want to work" category, "religious reasons," "social norms," "do not need to work as family is well off," "none of my friends work," and "work is not fun" were included. For the "No appropriate job opportunity" category: "could not find the right job opportunity," "I have no appropriate skills to find a job," "I know I wouldn't find a good job," "I know I won't find a government job," and "no job with appropriate pay." were included. Finally, for the "Other" category, "military service" and "health problems" were included. 
for not wanting to work (and therefore not even looking for work) in 2009 and 2014 . $^{2}$

Although the percentage of young people who reported not wanting to work had declined from $4.4 \%$ in 2009 to $3.0 \%$ in 2014 , the percentage increased fourfold (from $5.1 \%$ to $21.1 \%$ ) for nonstudents who indicated that they were no longer willing to work because 1) type of job they aspire to no longer exists or 2) an appropriate job opportunity is unavailable ${ }^{3}$. Among male youth, the percentage of those who reported not wanting to work due to the unavailability of an appropriate job opportunity increased from 30.0\% in 2009 to $42.9 \%$ in 2014. This percentage grew even more for female youth, from $2.0 \%$ in 2009 to $15.9 \%$ in 2014 . The percentage of male youth reporting other reasons, including military service, also increased in 2014 (42.0\%) compared to 2009 (35.3\%). Hence, this provides some evidence that the observed decline in labor force participation is primarily due to young people becoming discouraged about finding the "right" job opportunity following the January 25, 2011 revolution and the subsequent economic downturn.

Table 4.2 also provides evidence that culture and patriarchal norms still represent important barriers to female labor market participation, with about $16.5 \%$ of young women mentioning that they do not want to work due to their parents' or spouse's refusal.

\subsection{Employment structure}

SYPE recorded the employment rate, job characteristics, and working conditions of young people who were employed in 2009 and 2014.

2 When including the full group of youth aged 15-29, whether currently studying or not, a similar trend in the reported reasons for not wanting to work is observed. However, about $45 \%$ of young people reported "being a full-time student" as the main reason for not wanting to work in both SYPE waves. Among young men, the percentage of those who reported this reason decreased from $79.9 \%$ in 2009 to $66.8 \%$ in 2014 . In contrast, more women reported not wanting to work because of being full-time student in 2014 (33\%) than in 2009 (29.6\%) (data not shown).

3 It is important to note that this is different from the discouraged unemployed. We will return to that concept in Section 4.4.
Alarmingly, the employment-to-population ratio ${ }^{4}$ appeared to be declining for young people (aged 15-29) at the time of the 2009 SYPE: while the 2006 Egypt Labor Market Panel Survey (ELMPS) recorded an employment rate of $57.0 \%$ for male youth and $14.1 \%$ for female youth aged $15-29$, the 2009 SYPE recorded employment rates of $54.0 \%$ among males and just 9.4\% among females in the same age group. According to the 2014 SYPE, this negative trend has continued even further, with the overall youth employment rate for ages 15-29 at $31.7 \%$ (declining from $32.2 \%$ in 2009), which represents a decline in the employment rate for both male (52.4\%) and female youth (9.0\%). The total employment rate among the full 2014 sample of SYPE respondents of working age (15-35) is only slightly higher (35.2\%). Among this group, the female employment rate is still low, at $10.5 \%$ compared to $58.6 \%$ for males (Table A4.1).

\section{Gender differences in type of employment}

Among young people (aged 15-29) with jobs, we find that the observed increase in nonwage work in 2014 was primarily due to the sharp increase in the share of unpaid family work among female youth, from $6.6 \%$ in 2009 to $21.0 \%$ in 2014 (Table 4.3). This rapid increase in female nonwage work might be due to the added-worker effect highlighted above. It might also be due to the above-mentioned expansion post-January 25 of employability projects for youth, particularly for female youth in rural Upper Egypt, who often take up unpaid family work and household micro-enterprises to sustain household income.

The percentage of male and female youth who were employers or self-employed increased between 2009 and 2014 , to $13.1 \%$ of employed males and $5.7 \%$ of females (from $3.7 \%$ and $3.2 \%$, respectively, in 2009). These findings may indicate that more youth have started turning to entrepreneurship as a means of entering or staying in the labor market

4 Employment rate or employment-to-population ratio is the ratio of currently employed youth in a given age group to the total youth population in the same age group. This measure is different from the labor force participation rate, which is the ratio between employed plus unemployed youth in a given age group to the total population of youth in the same age group. 
TABLE 4.3 Distribution of employed youth, by gender and type of employment, 2009 and 2014

\begin{tabular}{|c|c|c|c|c|c|c|c|c|c|}
\hline \multirow[b]{3}{*}{ TYPE OF EMPLOYMENT } & \multirow{2}{*}{\multicolumn{3}{|c|}{$\begin{array}{c}2009 \\
\text { AGED 15-29 } \\
\end{array}$}} & \multicolumn{6}{|c|}{2014} \\
\hline & & & & \multicolumn{3}{|c|}{ AGED 15-29 } & \multicolumn{3}{|c|}{ AGED 15-35 } \\
\hline & MALE & FEMALE & TOTAL & MALE & FEMALE & TOTAL & MALE & FEMALE & $\overline{\text { TOTAL }}$ \\
\hline \multicolumn{10}{|l|}{ Wage work } \\
\hline Public & 10.0 & 37.6 & 13.9 & 11.1 & 29.5 & 13.6 & 13.4 & 35.4 & 16.6 \\
\hline Formal private regular wage & 8.1 & 12.3 & 8.7 & 6.1 & 10.9 & 6.8 & 7.4 & 10.2 & 7.8 \\
\hline Informal private regular wage & 45.2 & 33.4 & 43.5 & 31.3 & 26.2 & 30.6 & 29.5 & 21.5 & 28.3 \\
\hline Irregular wage & 24.2 & 6.9 & 21.7 & 29.3 & 6.9 & 26.3 & 27.2 & 6.1 & 24.1 \\
\hline Total & 87.5 & 90.2 & 87.9 & 77.8 & 73.4 & 77.2 & 77.4 & 73.3 & 76.8 \\
\hline \multicolumn{10}{|l|}{ Nonwage work } \\
\hline Unpaid family worker & 8.8 & 6.6 & 8.5 & 9.1 & 21.0 & 10.7 & 7.3 & 18.6 & 9.0 \\
\hline Employer & 1.2 & 0.5 & 1.1 & 6.4 & 2.2 & 5.9 & 7.6 & 2.2 & 6.8 \\
\hline Self-employed & 2.5 & 2.7 & 2.5 & 6.7 & 3.5 & 6.2 & 7.6 & 6.0 & 7.4 \\
\hline $\begin{array}{l}\text { Total } \\
(\mathrm{N})\end{array}$ & $\begin{array}{c}12.5 \\
(2,626)\end{array}$ & $\begin{array}{r}9.8 \\
(550)\end{array}$ & $\begin{array}{c}12.1 \\
(3,176)\end{array}$ & $\begin{array}{r}22.2 \\
(2,075)\end{array}$ & $\begin{array}{l}26.6 \\
(362)\end{array}$ & $\begin{array}{c}22.8 \\
(2,437)\end{array}$ & $\begin{array}{r}22.6 \\
(2,803)\end{array}$ & $\begin{array}{l}26.8 \\
(547)\end{array}$ & $\begin{array}{c}23.2 \\
(3,350)\end{array}$ \\
\hline
\end{tabular}

during this difficult economy. We will return to this point in the section on entrepreneurship below.

Similar to 2009, young women were more likely to be working for the government than their male counterparts. Nevertheless, a substantial decline (about 8.1 percentage points) in the percentage of young women (aged 15-29) working in the public sector has been observed since $2009 .{ }^{5}$ Finally, the small percentage of male youth working in formal regular wage jobs in the private sector $(8.1 \%)$ in 2009 got even smaller in 2014 (6.1\%); the percentage of young women in this type of work declined between the two waves of the SYPE (12.3\% in 2009 versus $10.9 \%$ in 2014).

\section{Change in employment structure}

Working young people aged 15-29 experienced a notable decline in their prospects of wage work in 2014 as compared to the 2009 figures; correspondingly, participation in nonwage work almost doubled between the two waves of SYPE. More specifically, only $77.2 \%$ of employed youth aged $15-29$ worked for a wage in 2014 as compared to $87.9 \%$ in 2009

5 This may be a cohort effect, meaning that government jobs continue to become less available to new labor market entrants. Public sector jobs have declined since the early 1990s, when the Economic Reform Structural and Adjustment Program was adopted. This reform curbed new employment opportunities in the public sector and initiated the privatization of existing public enterprises (see Wahba and Mokhtar 2002). (a 10.7 percentage point decline), whereas $22.8 \%$ were nonwage workers in 2014 compared to only $12.1 \%$ in 2009 (Table 4.3).

A substantial drop in the percentage of young workers engaged in informal regular wage employment in the private sector was also observed. Overall, this share of youth employment decreased by almost 13 percentage points from $43.5 \%$ in 2009 to $30.6 \%$ in 2014. Nevertheless, a significant percentage of wage-earning male and female youth were still engaged in informal labor, with neither a contract nor social insurance benefits. The notable decline in youth's participation in regular informal private sector employment from 2009 to 2014 was not associated with an equivalent increase in the share of government or formal regular private wage work, but rather with an increase in the share of irregular wage work and nonwage work. The share of young people working in the formal private sector decreased from $8.7 \%$ to $6.8 \%$ and in the public sector (government and state owned enterprises) from $13.9 \%$ to $13.6 \%$, between 2009 and 2014. In contrast, the share of irregular wage employment, which is not only informal but also highly unstable, went up by about 4.6 percentage points (from $21.7 \%$ in 2009 to $26.3 \%$ in 2014). ${ }^{6}$

6 Similar employment trends were also found by Assaad and Krafft (2015), particularly the increase in irregular wage work, using the 2006 and 2012 Egypt Labor Market Panel Survey (ELMPS) data. 
Although young men and women were equally likely to hold permanent jobs in 2009, the percentage of men holding such jobs declined by almost 11 percentage points in 2014 and increased by about 12 percentage points among young women.

\section{Employment sectors}

Figure 4.3 shows the sector of economic activity for those young men and women aged 15-29 in 2009 and 2014 who were employed. As in 2009, the field of public services (including public administration, education, and healthcare, etc.) was most common for employed female youth in 2014; over one-third (35.0\%) of working young women were engaged in these forms of economic activity, as compared to only $5.2 \%$ of male youth. The economic activities most common for employed male youth included: wholesale, hotels and restaurants (20.0\%), agriculture, hunting and fishing (19.9\%), manufacturing, mining and electricity (19.5\%) and construction (19.1\%).

As expected, given the increase in the share of young female unpaid family workers in 2014 relative to 2009 , the share of young women working in the agriculture, hunting, and fishing sector went up from $11.8 \%$ in 2009 to $19.8 \%$ in 2014 (an 8 percentage point increase). These sectors and public services were the only two sectors that experienced an increase in the share of young working women. As for young men, the sectors that experienced an increasing share were the wholesale, hotels and restaurants, construction, and public services sectors. The economic activity of all working age respondents in the 2014 SYPE (15-35) is also presented in Figure 4.3. A similar structure of economic activity was observed among this full sample.

\section{Job characteristics}

As Table 4.4 shows, the percentage of employed youth in Egypt who hold a contract increased to $19.9 \%$ in 2014 , up from around $16.4 \%$ in 2009 . Both

FIGURE 4.3 Sectors of economic activity among youth, by gender, 2009 and 2014

\begin{tabular}{|c|c|c|c|c|c|c|c|c|c|c|}
\hline & \multicolumn{3}{|c|}{2009} & \multicolumn{6}{|c|}{2014} & \\
\hline 10 & YOUTH & AGED 1 & -29 & YOU & ГH AGED & $15-29$ & YOUT & H AGED & $15-35$ & \\
\hline 90 & 22.7 & & 21.1 & 19.9 & 19.8 & 19.8 & 18.2 & 19.0 & 18.3 & fishing \\
\hline 80 & & 15.3 & & & & & & & & $\begin{array}{l}\text { Manufacturing, mining, } \\
\text { and electricity }\end{array}$ \\
\hline 70 & 20.7 & & 19.9 & 19.5 & 14.0 & 18.8 & 20.1 & & 19.0 & Construction \\
\hline 60 & & 17 & 15.6 & 191 & 17.8 & 16.7 & 18.4 & & 15.9 & $\begin{array}{l}\text { Wholesale, hotels, and } \\
\text { restaurants }\end{array}$ \\
\hline 40 & & & & & 9.9 & & & & & and communications \\
\hline 30 & 16.2 & & & 20.0 & & |'. & 19 & & & $\begin{array}{l}\text { Financial, real estate, } \\
\text { and business }\end{array}$ \\
\hline 20 & 9.1 & 34.3 & 8.0 & 8.4 & 35.0 & 7.4 & 8.7 & 38.3 & $\begin{array}{l}1.6 \\
6.2\end{array}$ & Public services \\
\hline 10 & $\begin{array}{l}5.4 \\
5.1 \\
2.9\end{array}$ & 3.3 & 9.3 & $\begin{array}{l}4.7 \\
5.2 \\
3.3\end{array}$ & 17 & 9.2 & $\begin{array}{l}6.4 \\
3.1\end{array}$ & 20 & 11.0 & Other services \\
\hline & Male & Female & Total & Male & Female & Total & Male & Female & Total & \\
\hline
\end{tabular}


young men and women became more likely to hold a contract in 2014 (16.9\% for men vs. 39.3\% for women) than in 2009 (13.5\% for men vs. 33.8\% for women). Nevertheless, young working women were still more likely to have a contract with their employer than their male peers in 2014. Two-thirds of both male and female public sector workers have contracts; however, young women (16.2\%) were more than twice as likely to have a contract in the private sector as young men (7.2\%) in 2014 (data not shown).

Similarly, the percentage of young workers covered by social insurance increased from 15.6\% in 2009 to $18.5 \%$ in 2014 (see Roushdy and Selwaness 2014 for a description of the Egyptian social insurance system and how long it takes for young people to gain access to it.) Young working women not only kept their advantage in terms of having access to social insurance relative to young men, but the percentage of covered female youth workers increased by about 5.3 percentage points (from $30.5 \%$ in 2009 to $36.8 \%$ in 2014), compared to a 2.3 percentage point increase among young men (from $13.1 \%$ in 2009 to $15.4 \%$ in 2014). As has often been highlighted in the literature (Assaad and Barsoum
2007), this gender difference in the prevalence of both contracts and social insurance coverage is mainly due to the fact that women often either accept formal jobs or withdraw from the labor market (i.e., stay out of the labor force).

In terms of job stability, although young men and women were equally likely to hold permanent jobs in 2009, the percentage of men holding such jobs declined by almost 11 percentage points in 2014 and increased by about 12 percentage points among young women. In contrast, the percentage of young men holding casual (31.7\%) and seasonal (4.4\%) jobs substantially increased in 2014. During the transition period, young men also became more likely to work part-time (working less than 40 hours a week) in 2014 (21.6\%) than in 2009 (16.7\%). Among young people working part-time in 2014, 23.9\% mentioned that they were involuntarily working less than 40 hours due to the unavailability of full-time jobs or because they could not find work the rest of the day, compared to $18.9 \%$ in 2009 . The percentage of involuntary part-time workers (or visibly under-employed youth) increased from $22.5 \%$ to $28.4 \%$ among young men, while it decreased

TABLE 4.4 Job characteristics of employed youth aged 15-29, by gender, 2009 and 2014

\begin{tabular}{|c|c|c|c|c|c|c|}
\hline & \multicolumn{3}{|c|}{2009} & \multicolumn{3}{|c|}{2014} \\
\hline & MALE & FEMALE & ALL YOUTH & MALE & FEMALE & ALL YOUTH \\
\hline \multicolumn{7}{|l|}{ Formal job characteristics } \\
\hline Contract & 13.5 & 33.8 & 16.4 & 16.9 & 39.3 & 19.9 \\
\hline Social insurance & 13.1 & 30.5 & 15.6 & 15.4 & 36.8 & 18.5 \\
\hline \multicolumn{7}{|l|}{ Job stability } \\
\hline Permanent & 53.6 & 56.5 & 54.1 & 42.9 & 68.1 & 46.3 \\
\hline Full time & 83.3 & 58.5 & 79.6 & 78.4 & 57.9 & 74.4 \\
\hline Part time & 16.7 & 41.5 & 20.4 & 21.6 & 42.1 & 25.6 \\
\hline Temporary & 19.8 & 34.6 & 21.9 & 21.0 & 20.0 & 20.9 \\
\hline Seasonal & 1.5 & 3.2 & 1.8 & 4.4 & 3.7 & 4.3 \\
\hline Casual & 25.0 & 5.7 & 22.3 & 31.7 & 8.2 & 28.6 \\
\hline Work requires special skill & 50.6 & 42.2 & 49.4 & 30.8 & 21.8 & 29.5 \\
\hline \multicolumn{7}{|c|}{ Where did you learn that skill? } \\
\hline Formal education & 11.1 & 34.6 & 14.0 & 9.2 & 39.1 & 12.2 \\
\hline Vocational training & 26.3 & 45.0 & 28.6 & 13.0 & 23.0 & 14.0 \\
\hline Apprenticeship & 43.9 & 5.6 & 39.2 & 45.2 & 10.7 & 41.8 \\
\hline On the job training & 3.3 & 1.1 & 3.0 & 19.9 & 15.7 & 19.4 \\
\hline Family/self-trained & 11.5 & 6.8 & 11.0 & 11.9 & 11.4 & 11.9 \\
\hline Others & 3.9 & 6.9 & 4.3 & 0.9 & 0.0 & 0.8 \\
\hline$(\mathrm{N})$ & $(2,626)$ & $(550)$ & $(3,176)$ & $(2,085)$ & $(362)$ & $(2,447)$ \\
\hline
\end{tabular}


from $4.4 \%$ to $2.0 \%$ among young women between 2009 and 2014 (data not shown).

Hence, this provides evidence that the job stability of young men seems to be deteriorating in 2014 as compared to 2009, a trend characterized by lower access to permanent jobs, accompanied by a growing presence in seasonal, casual, and involuntary part-time permanent jobs. $^{7}$

In addition to job stability and formality status, SYPE asked young people several questions related to whether their job required a special skill and where they learned that skill. Table 4.4 shows that the share of young people whose job required special skills substantially declined in 2014 among both men and women, yet men were still more likely to be engaged in a job that required a skill than women. Among men, as of 2014 , the two main channels through which they learned their job skill were an apprenticeship (45.2\%) and the on-the-job training (19.9\%). This marks a change as compared to their situation in 2009, when vocational training played a larger role in providing young men with needed job skills (26.3\%), as compared to 2014 (13.0\%).

Training channels differed for young women, who reported that their trainings were primarily received through the education system (39.1\%) or vocational training (23.0\%) in 2014. Nevertheless, similar to men, the percentage of women reporting receiving skills through vocational training declined by half between 2009 and 2014. In contrast, the percentage of young people who learned their job skill on-the-job substantially increased from 3.0\% in 2009 to almost $20.0 \%$ in 2014 . This substantial increase was observed among both men and women. This may be an indication that the culture of providing on-the-job training has started to expand among employers in Egypt to substitute for

7 These results are in accordance with the increase in visible underemployment found by Assaad and Krafft (2015), which increased from $2.2 \%$ in 2006 to $6.7 \%$ in 2012 among the full working age population (15-64). SYPE revealed that visible underemployment among youth as a share of the standard labor force increased from $4.9 \%$ in 2009 to $7.0 \%$ in 2014 . the weak training provided to young people during formal education. ${ }^{8}$

\section{Working conditions}

Table A4.2 presents additional characteristics of employed youths' working conditions. As in 2009, youth of both genders were more likely to complain of maltreatment and harassment in the private than in the public sector. However, it is interesting to note that there is no substantial gender difference in the experience of harsh treatment by supervisors in either the public or private sector. Surprisingly, male youth were more likely to report annoyances and harassment than females. In contrast, female youth were more likely to report harassment during commuting time. This might be due to young women feeling less comfortable reporting harassment in their own workplaces, which is different from reporting harassment in public spaces such as on the street or transportation. As mentioned in the SYPE 2009 report (Population Council 2010), it might also be due to males understanding the term "harassment" differently than females. They might have thought it meant fighting or arguing or part of bad treatment at work. ${ }^{9}$

Both male and female youth were more likely to complain about long working hours, exhaustive workload, and hazardous work conditions in the private than in the public sector. Also, similar to 2009, the majority of young men and women still complained about their salary, particularly among those working in the private sector.

8 This change may be the by-product of the long-term efforts of the government and several local and international development agencies that aimed to provide solutions to the very well-known skill-mismatch problem of the Egyptian labor market among educated youth (see Assaad and Roushdy 2007). Many of these efforts focused on providing on-the-job-training for young people, through partnering with employers, particularly for youth with vocational education level. Yet, further impact evaluation research is needed to appropriately validate the effects of such efforts.

9 This section focuses on experience of harassment only as it relates to youth's employment conditions. For more information on the experience of harassment among all female youth, see Chapter 2. 


\subsection{Unemployment}

Using the standard market definition of unemployment, we find that the youth (aged 15-29) unemployment rate has declined from $16.1 \%$ in 2009 to about $13.3 \%$ in 2014 . This was mainly due to the decline of the male youth unemployment rate from $12.9 \%$ to $9.3 \%$ during the five-year period. In contrast, the female youth unemployment rate increased from $31.3 \%$ to $32.3 \%$ in 2014 . However, this decline in unemployment is not associated with an increase in the employment rate among males, but was rather due to the increase in the percentage of men who became discouraged and left the labor force. Similarly, the increase in the female unemployment rates concurs with the previously discussed increase in female labor force participation.

The broad unemployment rate (including both the discouraged unemployed youth who are not actively searching for a job and the youth actively searching) also declined from $21.6 \%$ in 2009 to $20.2 \%$ in 2014. The broad unemployment rate increased among females from $41.8 \%$ in 2009 to $45.6 \%$ in 2014 ; however, it declined from $16.8 \%$ to $13.8 \%$ among males. Since the observed decline in the standard unemployment rate among young men was more substantial than the decline in their broad unemployment rate, this indicates that more young men have become discouraged and stopped searching for employment since 2009. Hence, not only did young men withdraw to inactivity more frequently in 2014 than in 2009, but also those who were still available to work increasingly tended to cease looking for jobs.

Examining standard unemployment by age shows the difficulty that youth, and particularly female youth above the age of 18 , face in finding gainful employment. Most of youth in this group are firsttime labor market entrants. As Figure 4.4 shows, male unemployment increases with age among the youngest youth, peaking at about $15 \%$ by age 22 , and then drops and remains below $5 \%$ by age 28 . In contrast, female unemployment increases dramatically after age 19 and remains above 35\% until age 26. At this point, the female unemployment rate starts declining, parallel to the time when many
FIGURE 4.4 Youth unemployment rates, by single year of age and gender, 2009 and 2014

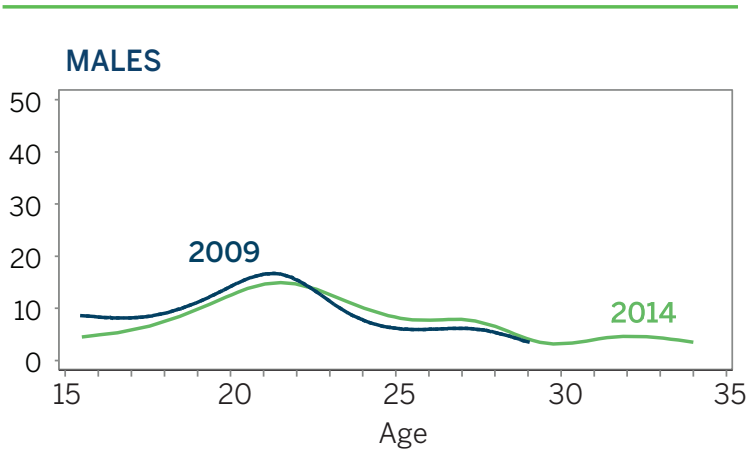

FEMALES

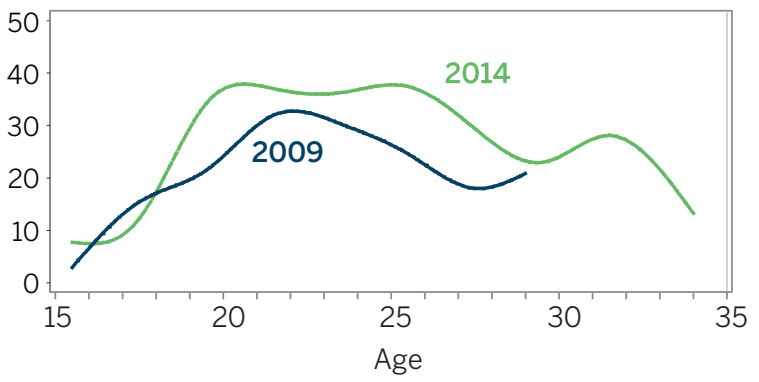

ALL

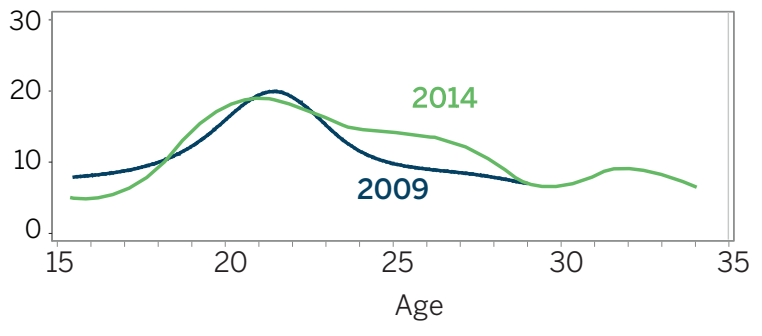

young women leave the labor force due to marriage and childbearing.

Figure 4.5 shows that unemployment remained a serious problem for educated youth. As in 2009 , the unemployment rate was highest among those who completed studies at a post-secondary institute, as well as youth with a university education or higher. Similar trends are observed among the full SYPE 2014 sample aged 15-35 (Table A4.1).

\section{Reasons for unemployment}

Although unavailability of work during the seven days before the SYPE interview still played a major factor in driving youth unemployment, both young men and women reported this reason less frequent- 
FIGURE 4.5 Unemployment by education level (standard definition), young people aged 15-29, 2009 and 2014
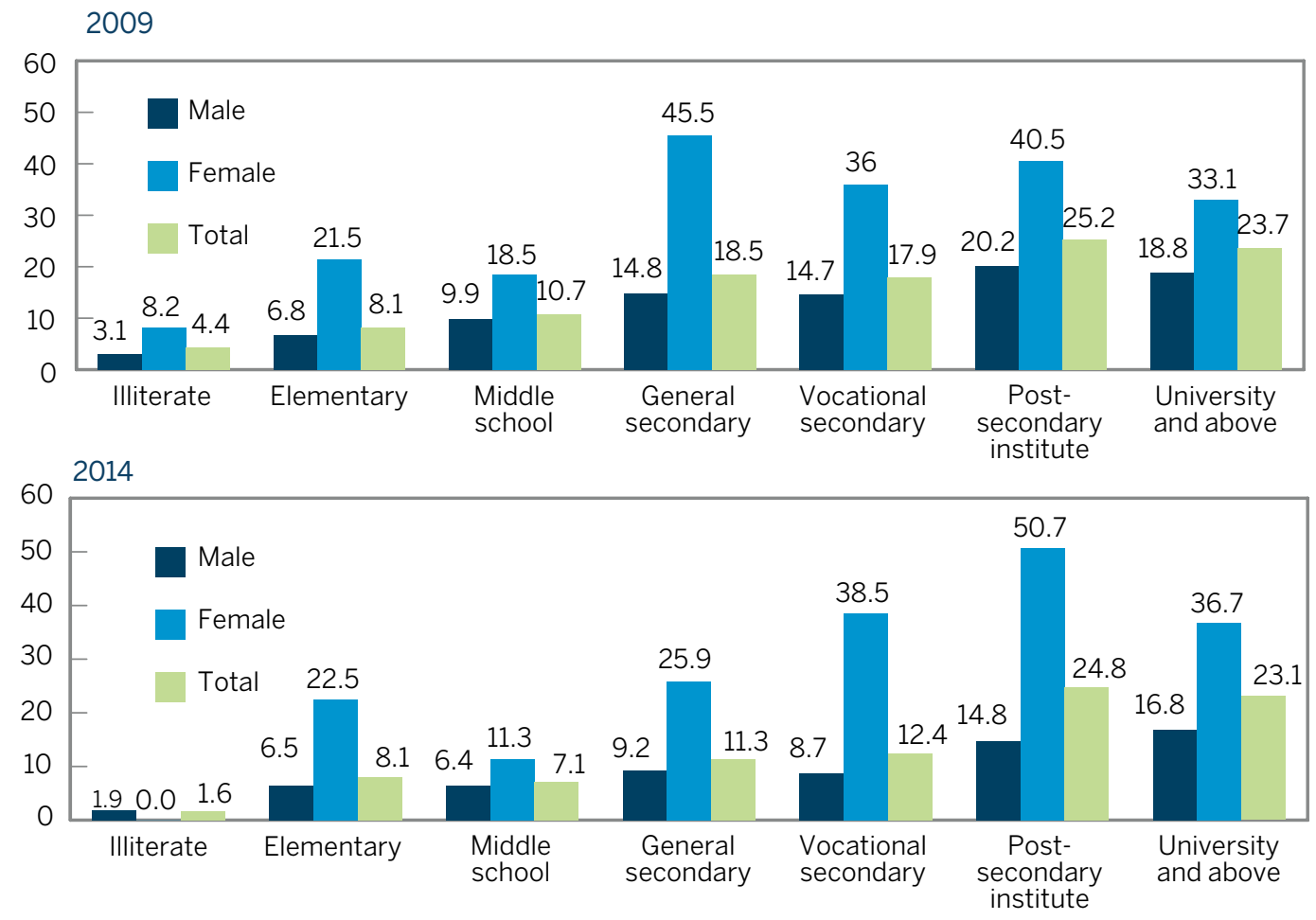

Note: "Can read and write" category is not included because there were fewer than 10 responses in both years for females. In 2014, $3.1 \%$ of males in this category reported being unemployed.

FIGURE 4.6 Self-reported reasons for being unemployed, unemployed youth aged 15-29 (broad definition), 2009 and 2014 (\%)

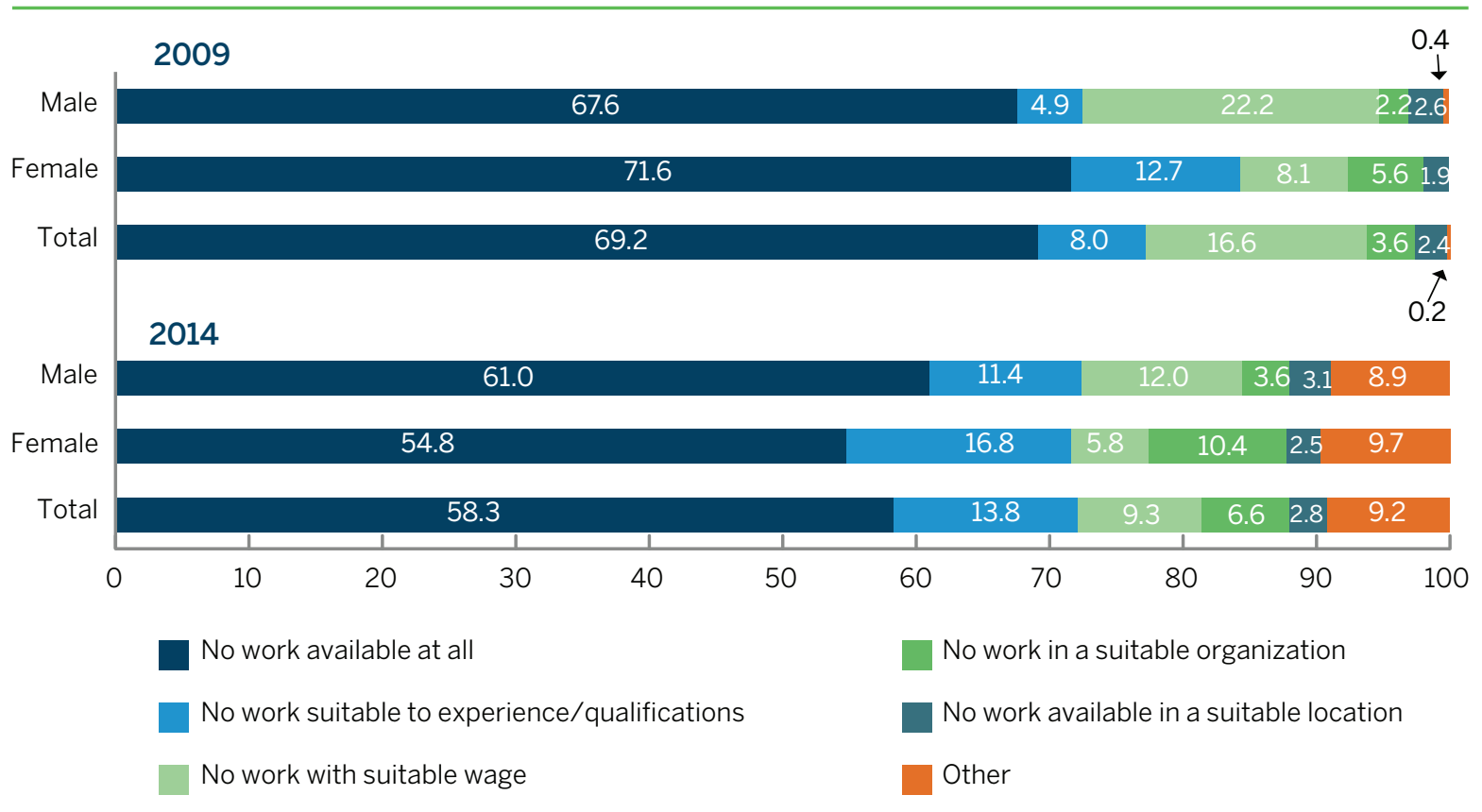


ly in 2014 than in 2009 (Figure 4.6). Furthermore, young women were no longer more likely to give this reason than men; on the contrary, only $54.8 \%$ of young women reported not working due to the unavailability of work, compared to $61.0 \%$ of young men in 2014. In contrast, the percentage of both men and women reporting not finding jobs that match their experience or qualifications increased substantially between 2009 and 2014. Young women in 2014 were nearly two times as likely as they were in 2009 to say that they could not find a job with a suitable organization. This might be due to the heightened sense of insecurity that followed the January 25, 2011 and June 30, 2013 events.

Table 4.5 focuses only on unemployed youth who were not searching for a job. Slightly less than half of discouraged unemployed youth $(47.2 \%)$ said that their main reason for not searching for a job was that they believed there were no jobs (compared to around a quarter in 2009). Contrary to the pattern for unemployed youth overall, among this discouraged unemployed group, young women remained more likely to report lack of jobs than their male peers (52.0\% versus $42.6 \%$, respectively). However, the percentage of discouraged male youth reporting this reason more than doubled in 2014 (42.6\%) as compared to 2009 (17.3\%). In addition, between 2009 and 2014, the percentage of discouraged unemployed who said that they were tired of looking for a job decreased among men from 30.1\% to $24.0 \%$, and from $9.8 \%$ to $7.7 \%$ among women.
The percentage of unemployed youth who reported registering in private employment offices almost tripled from 2009 to 2014.

\section{Searching for employment}

\begin{abstract}
Unemployed young people's methods of jobs search have changed between 2009 and 2014. Table A4.3 shows the percentage of youth who reported using a given search method among unemployed youth according to the broad market definition. In 2009, asking friends and relatives came out on top of search methods, whereas the second most frequently mentioned method was sending job applications or inquiring at job location. In 2014, asking friends and relatives still remained the most commonly used search method, albeit the percentage of youth using this search method declined among young men and increased among young women. The most commonly cited search method in 2014 was registration in government offices: $28.9 \%$ of young men and $31.2 \%$ of young women used this method. This marks an important difference with respect to 2009, when the percentage of
\end{abstract}

TABLE 4.5 Self-reported reasons for not searching for a job among discouraged unemployed youth aged 15-29, 2009 and 2014 (\%)

\begin{tabular}{|c|c|c|c|c|c|c|}
\hline & \multicolumn{3}{|c|}{2009} & \multicolumn{3}{|c|}{2014} \\
\hline & MALE & FEMALE & TOTAL & MALE & FEMALE & TOTAL \\
\hline Believe that there are no jobs & 17.3 & 34.9 & 25.5 & 42.6 & 52.0 & 47.2 \\
\hline Tired of looking for jobs & 30.1 & 9.8 & 20.7 & 24.0 & 7.7 & 16.0 \\
\hline Employers prefer males to females in hiring & 0.0 & 0.6 & 0.3 & 0.0 & 0.6 & 0.3 \\
\hline Do not know an effective way to look for a job & 21.3 & 17.7 & 19.7 & 5.6 & 8.5 & 7.0 \\
\hline Waiting for Ministry of Manpower hiring & 0.8 & 3.7 & 2.1 & 0.7 & 0.0 & 0.4 \\
\hline No government jobs & - & - & - & 4.2 & 7.4 & 5.7 \\
\hline I do not have the required skill/ training & 0.0 & 1.9 & 0.9 & 4.0 & 0.9 & 2.5 \\
\hline No suitable jobs & 10.2 & 12.4 & 11.2 & 7.2 & 3.7 & 5.5 \\
\hline Lack of connections & 5.1 & 1.9 & 3.6 & - & - & - \\
\hline Others & 15.2 & 17.0 & 16.1 & 11.7 & 19.3 & 15.4 \\
\hline Number of discouraged unemployed youth & $(121)$ & $(136)$ & $(257)$ & $(106)$ & $(117)$ & $(223)$ \\
\hline
\end{tabular}

$-=$ option not available in survey year. 
unemployed registered in government offices was only $9.4 \%$ of male youth and $20.5 \%$ of female youth. This is likely due to an announcement made by the first Minister of Finance after the January 25 revolution stating that government hiring would begin. Nearly eight million applications were mailed to the Ministry of Finance following the announcement. It is also interesting to note that the percentage of unemployed youth who reported registering in private employment offices almost tripled in 2014 for both males (23.8\%) and females (15.0\%), compared to 2009 (7.6\% and 6.2\%, respectively).

\subsection{Employment transitions}

In order to further analyze the employment situation of Egypt's youth, and in particular the decline in their unemployment and labor force participation rates, the transitions between different employment statuses from 2009 to 2014 are measured among youth who were aged 15-29 in 2009 (Table 4.6). In order to investigate all of the possible transitions, employment status is grouped into 12 categories: wage work in the public sector, regular formal wage work in the private sector, regular informal wage work in the private sector, irregular wage work, employer, self-employed, unpaid family work, unemployed actively searching for a job, unemployed not searching for a job (discouraged unemployed), student out of labor force, nonstudent out of labor force, and permanently disabled (also called out of manpower, which includes youth older than 15 who reported not wanting to work due to being permanently disabled).

As expected, the most stable category was the public sector, with around $67.4 \%$ of young public sector employees in 2009 retaining their jobs in 2014. Also, $75.8 \%$ of those who were not studying and out of labor force remained in this status, indicating that the majority of those who were not willing to work in 2009 did not change this preference in 2014. Many of these youth are young women who reported being housewives in both years, as shown in Table 4.2. All other statuses, including unpaid family work, nonwage work (employers and self-employed), irregular wage work, and regular informal and formal wage work in the private sector, were quite unstable. Among these less stable employment statuses, self-employed and unpaid family work were the most two volatile between 2009 and 2014.

TABLE 4.6 Transitions between employment statuses, from 2009 to 2014, among youth aged 15-29 in 2009 (\%)

\begin{tabular}{|c|c|c|c|c|c|c|c|c|c|c|c|c|c|}
\hline \multirow[b]{2}{*}{2009 STATUS } & \multicolumn{13}{|c|}{2014 STATUS } \\
\hline & $\begin{array}{l}\text { Public } \\
\text { sector }\end{array}$ & $\begin{array}{c}\text { Regular } \\
\text { formal } \\
\text { private }\end{array}$ & $\begin{array}{r}\text { Regular } \\
\text { informal } \\
\text { private }\end{array}$ & $\begin{array}{l}\text { Irregular } \\
\text { wage }\end{array}$ & $\begin{array}{l}\text { Em- } \\
\text { ployer }\end{array}$ & $\begin{array}{r}\text { Self- } \\
\text { em- } \\
\text { ployed }\end{array}$ & $\begin{array}{r}\text { Unpaid } \\
\text { family } \\
\text { worker }\end{array}$ & $\begin{array}{r}\text { Student } \\
\text { out of } \\
\text { labor } \\
\text { force }\end{array}$ & $\begin{array}{r}\text { Nonstu- } \\
\text { dent out } \\
\text { of labor } \\
\text { force }\end{array}$ & $\begin{array}{l}\text { Active } \\
\text { unem- } \\
\text { ployed }\end{array}$ & $\begin{array}{r}\text { Discour- } \\
\text { aged } \\
\text { unem- } \\
\text { ployed }\end{array}$ & $\begin{array}{c}\text { Out of } \\
\text { man- } \\
\text { power }\end{array}$ & Total \\
\hline Public sector & 67.4 & 3.4 & 4.1 & 3.5 & 4.1 & 1.1 & 0.4 & 1.5 & 8.8 & 3.8 & 2.0 & 0.0 & 100.0 \\
\hline Regular formal private & 18.1 & 29.2 & 18.5 & 5.6 & 8.7 & 2.0 & 1.1 & 2.9 & 7.6 & 3.8 & 1.7 & 0.7 & 100.0 \\
\hline Regular informal private & 6.4 & 6.2 & 30.9 & 19.2 & 7.1 & 7.8 & 1.8 & 1.2 & 12.8 & 4.6 & 1.9 & 0.3 & 100.0 \\
\hline Irregular wage & 7.1 & 4.0 & 20.5 & 28.8 & 7.3 & 8.6 & 4.6 & 1.6 & 11.9 & 2.9 & 2.6 & 0.2 & 100.0 \\
\hline Employer & 3.7 & 10.2 & 27.2 & 13.6 & 26.9 & 4.5 & 4.1 & 0.0 & 4.4 & 5.6 & 0.0 & 0.0 & 100.0 \\
\hline Self-employed & 10.5 & 3.6 & 12.4 & 21.6 & 6.8 & 13.6 & 3.8 & 2.9 & 18.5 & 1.6 & 4.8 & 0.0 & 100.0 \\
\hline Unpaid family worker & 4.0 & 2.9 & 16.3 & 20.2 & 8.4 & 9.7 & 12.3 & 2.6 & 12.6 & 6.6 & 4.3 & 0.0 & 100.0 \\
\hline Student out of labor force & 4.2 & 3.1 & 7.8 & 6.0 & 1.8 & 1.3 & 2.9 & 25.0 & 33.2 & 9.3 & 5.3 & 0.2 & 100.0 \\
\hline $\begin{array}{l}\text { Nonstudent out of labor } \\
\text { force }\end{array}$ & 2.3 & 0.7 & 3.4 & 3.9 & 1.1 & 1.6 & 3.0 & 0.5 & 75.8 & 4.1 & 3.4 & 0.2 & 100.0 \\
\hline Active unemployed & 10.4 & 7.0 & 19.0 & 10.4 & 3.0 & 4.6 & 2.5 & 0.8 & 27.8 & 9.4 & 4.2 & 0.8 & 100.0 \\
\hline Discouraged unemployed & 4.4 & 3.7 & 16.0 & 18.6 & 5.0 & 3.6 & 4.2 & 1.3 & 31.6 & 8.9 & 2.7 & 0.2 & 100.0 \\
\hline Out of manpower & 8.6 & 0.0 & 2.8 & 1.3 & 5.7 & 0.0 & 10.1 & 0.0 & 32.4 & 3.3 & 0.0 & 35.7 & 100.0 \\
\hline Total & 7.5 & 3.7 & 11.8 & 9.9 & 3.5 & 3.4 & 3.1 & 7.7 & 39.3 & 6.0 & 3.6 & 0.5 & 100 \\
\hline$(\mathrm{N})$ & $(583)$ & $(261)$ & $(816)$ & $(600)$ & $(248)$ & $(250)$ & (222) & $(556)$ & $(3,482)$ & $(434)$ & $(277)$ & $(26)$ & $(7,755)$ \\
\hline
\end{tabular}


Only $25.0 \%$ of youth who were students and out of the labor force in 2009 remained in this status in 2014. However, instead of making a successful school-to-work transition, an unexpectedly large share $(33.2 \%)$ of youth who were out of this status in 2014 transitioned into inactivity (nonstudent out of labor force). Only $27.1 \%$ of this group of 2009 students were working, and $14.6 \%$ were unemployed, in 2014. These figures are even more alarming if we focus only on the $75.0 \%$ of 2009 students who were no longer students in 2014. Among this latter group, which was mostly comprised of new labor market entrants, only $9.7 \%$ managed to find a job in the public (5.6\%) or private (4.1\%) formal sector in 2014, while $18.4 \%$ were employed in the informal regular (10.4\%) or irregular $(8.0 \%)$ sectors, $4.1 \%$ became either employers or self-employed workers and 3.9\% were unpaid family workers in 2014 (numbers not shown in table). In contrast, almost half of them (44.2\%) were not in the labor force, $7.1 \%$ were discouraged unemployed and $12.4 \%$ were active unemployed.

Another alarming finding is that $31.6 \%$ and $27.8 \%$ of discouraged unemployed and active unemployed in 2009, respectively, lost hope and became inactive (nonstudent out of labor force). Additionally, a large share of the self-employed in 2009 (18.5\%) became nonstudent out of labor force in 2014. In contrast, only a little more than half of discouraged and active unemployed youth, respectively, were working in 2014, most of whom ended up in the informal private regular or irregular wage sectors. Among the active (discouraged) unemployed, only $10.4 \%$ (4.4\%) got a public sector job and $7.0 \%$ (3.7\%) got a formal private sector job, while $29.4 \%$ (34.6\%) got an informal regular or irregular job and $10.1 \%$ (12.8\%) were nonwage workers. Similarly, the self-employed youth in 2009 were more likely to move to irregular (21.6\%) and regular informal work (12.4\%), than to the public (10.5\%) and formal private $(3.6 \%)$ sectors.

Employers in 2009 were most likely to shift to regular informal private sector wage employment (27.2\%) by 2014 , followed by irregular wage work (13.6\%), while $10.2 \%$ moved to the formal private sector and $3.7 \%$ to the public sector. Important shares of those who were regular but informal wage workers in the private sector in 2009 transitioned into irregular wage work (19.2\%) and nonwage work (16.7\%), compared to only $6.4 \%$ transitioning to the public sector and $6.2 \%$ to the formal private sector.

Furthermore, less than $30 \%$ of youth who were employed in the formal regular private sector in 2009 retained this status in 2014, while more than a third of this group of youth moved to the informal private sector (24.1\%) and nonwage work (11.8\%). Yet, it is interesting to see that about $18.1 \%$ of this group transitioned into the public sector in 2014 , as well as fewer than $6 \%$ transitioned to unemployment status and only $7.6 \%$ to out of the labor force.

Hence, the decline in youth labor force participation in 2014 was driven by important shares of the 2009 active unemployed, discouraged unemployed, students out of the labor force, and self-employed youth transitioning to inactivity during the last five years. Also, very few youth managed to transition from the informal wage and nonwage sectors to the public or formal private sectors between the two SYPE surveys.

\subsection{Entrepreneurship}

Given the tough labor market conditions prevailing in Egypt after the January 25, 2011 revolution, it is important to investigate whether young people considered creating employment opportunities for themselves through entrepreneurship during this period. The stated preference of young people aged 15-29 for establishing their own business, as opposed to being employed in a wage job, declined to $37.2 \%$ in 2014 from $53.6 \%$ in 2009 . Also, the percentage of youth who actually tried to establish their own business declined from 15.5\% in 2009 to about $9.3 \%$ of the total youth population in 2014 . The drop in the quest for entrepreneurship was more substantial among young males (23.0\% in 2009 vs. $13.2 \%$ in 2014) than among young females (7.7\% in 2009 vs. $5.0 \%$ in 2014). In contrast, the percentage of youth who in fact started their own business-the employers and the self-employedincreased from 1.2\% in 2009 to $4.0 \%$ in 2014 (data not shown). 
The reasons why youth who actually started their own business were interested in being entrepreneurs were similar between 2014 and 2009 (Figure 4.7). As a matter of fact, a large proportion of young entrepreneurs in 2014 (42.8\%) said they were motivated by the greater independence provided by self-employment activities. While female youth were more likely than male youth to report their inability to find a wage job as one of the main reasons behind their entrepreneurial activities in

FIGURE 4.7 Self-reported reasons for being entrepreneurs, among those who started their own business, youth aged 15-29 (\%)

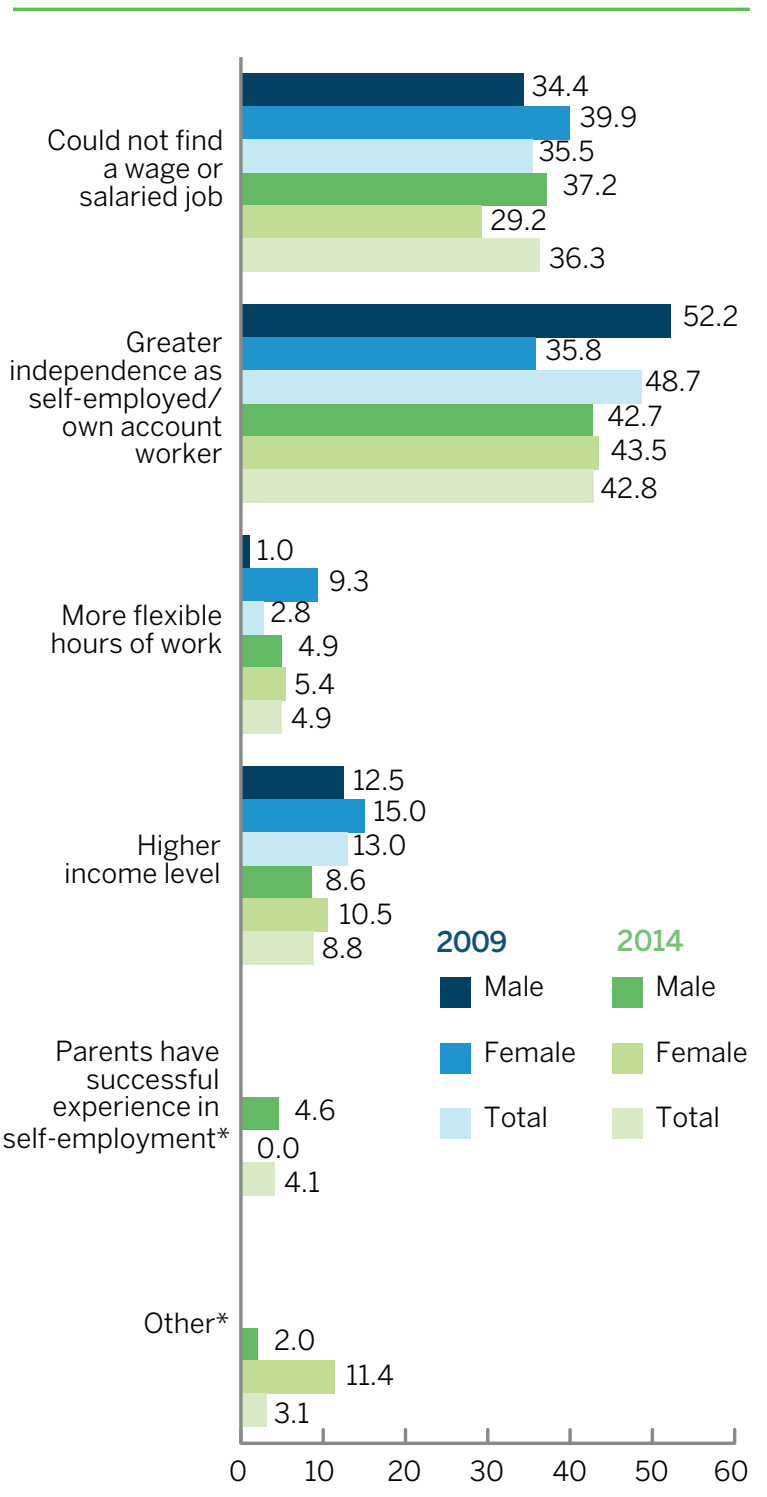

*These response options were not available in the SYPE 2009 questionnaire.
2009 (39.9\% versus $34.4 \%$ of males), this pattern was reversed in 2014 . About $37.2 \%$ of male youth reported this reason, compared to $29.2 \%$ among female youth.

In terms of the barriers to entrepreneurship, in 2014 lack of counseling and advice, followed by lack of financial services, represented the two most common challenges that young male entrepreneurs reported facing when starting their own businesses (Table 4.7). More specifically, around $26.5 \%$ of young male employers and self-employed reported that counseling and advice were the main problem they faced when starting-up their establishment, compared to only $10.0 \%$ in 2009 . The second most common challenge given by male entrepreneurs was financial services (17.1\%). This marked a change vis-à-vis the 2009 situation, when the lack of financial and credit services was the top challenge that young entrepreneurs faced (31.2\%). As for female entrepreneurs, their major constraint remained the lack of business information (19.9\%), as was found in 2009 (24.7\%). The lack of financial services was the next most commonly mentioned constraint among young female entrepreneurs in 2014 (14.8\%).

As for the source of funds used by young people who tried to establish their own business, savings-whether personal or family-basedwere the most common financial resource used in 2014. More specifically, $47.8 \%$ and $50.5 \%$ of male entrepreneurs relied on personal saving and family-based savings, respectively, to finance their business. Fewer women than men used personal savings (40.0\%), while they were as likely as men to rely on family savings (50.6\%). As for loans, young entrepreneurs had access to family loans (19.8\%) in 2014, yet they did not rely on other types of loans, such as micro-loans or banking loans. The need to develop adequate and supportive financial services to promote business start-up among young people is still one of the important areas of opportunity to address youth employability challenges in Egypt (see Sieverding 2012) (data not shown). 
TABLE 4.7 Self-reported barriers to entrepreneurship, among those who started their own business, young people aged 15-29, 2009 and 2014 (\%)

\begin{tabular}{|c|c|c|c|c|c|c|}
\hline & \multicolumn{2}{|c|}{ MALE } & \multicolumn{2}{|c|}{ FEMALE } & \multicolumn{2}{|c|}{ TOTAL } \\
\hline & 2009 & 2014 & 2009 & 2014 & 2009 & 2014 \\
\hline Business information & 12.2 & 13.2 & 24.7 & 19.9 & 14.9 & 14.0 \\
\hline Marketing services & 16.3 & 13.4 & 11.9 & 12.5 & 15.4 & 13.3 \\
\hline Financial services & 31.2 & 17.1 & 21.0 & 14.8 & 29.0 & 16.9 \\
\hline Accounting & 1.7 & 2.2 & 0.0 & 0.0 & 1.4 & 1.9 \\
\hline Legal services & 5.7 & 0.5 & 0.0 & 5.0 & 4.5 & 1.0 \\
\hline Counseling/advice & 10.0 & 26.5 & 9.2 & 10.2 & 9.8 & 24.6 \\
\hline Business training & 1.9 & 0.6 & 5.7 & 9.8 & 2.7 & 1.7 \\
\hline Skills training & 0.9 & 5.3 & 0.0 & 0.0 & 0.7 & 4.6 \\
\hline Access to technology & 2.3 & 1.2 & 0.0 & 0.0 & 1.8 & 1.1 \\
\hline Product development & 2.1 & 3.0 & 6.3 & 6.1 & 3.0 & 3.4 \\
\hline Access to utilities & 3.7 & 2.3 & 0.0 & 0.0 & 2.9 & 2.0 \\
\hline Single ownership, better to find a partner & 8.1 & - & 8.7 & - & 8.2 & - \\
\hline Nothing & - & 10.8 & - & 9.1 & - & 10.4 \\
\hline Other & 1.1 & 6.6 & 12.1 & 13.0 & 3.5 & 7.4 \\
\hline$(\mathrm{N})$ & $(91)$ & $(117)$ & $(31)$ & $(19)$ & $(122)$ & $(136)$ \\
\hline
\end{tabular}

$-=$ Response option was not available in survey year.

\subsection{Conclusion}

This chapter uses the rich data provided by the panel SYPE of 2009 and 2014 to update the state of knowledge on youth labor market outcomes in Egypt after the January 25, 2011 revolution. The results show that youth labor market conditions have deteriorated during the revolutionary era.

A quick investigation of the unemployment rate alone may lead to a faulty conclusion regarding youth well-being in the labor market in the aftermath of the January 25 revolution. A careful examination of other labor market indicators demonstrates that youth labor market outcomes have in fact seriously worsened since 2009. The decline in the unemployment rate was not associated with an increase in employment opportunities, but was rather due to the increase in the percentage of youth who became discouraged and left the labor force.

Young women and men (aged 15-29) both experienced a decline in their employment-to-population ratio between 2009 and 2014 (from 9.4\% to 9.0\% and from $54.0 \%$ to $52.4 \%$, respectively). Also, the share of employment in the government and in formal and informal regular wage jobs in the private sector has declined. This seems to have led many youth to shift to irregular wage jobs, which is the most vulnerable form of employment.

On the positive side, traces of increased reliance on entrepreneurship as an alternative means of entering or staying in the labor market during this difficult economic transition was observed. The percentage of employers or self-employed youth increased between 2009 and 2014 from 3.7\% to $13.1 \%$ among employed men and from $3.2 \%$ to $5.7 \%$ among employed women. However, $37.2 \%$ of male youth and $29.2 \%$ of female youth reported their inability to find a wage job as one of the main reasons behind their entrepreneurial activities.

Furthermore, the percentage of youth reporting being unemployed due to the unavailability of work declined from $69.2 \%$ in 2009 to $58.3 \%$ in 2014 . However, the percentage of both men and women reporting not finding jobs that match their experience or qualifications increased from 8.0\% in 2009 
to $13.8 \%$ in 2014 . Young women in 2014 were also two times as likely as they were in 2009 to say that they could not find a job with a suitable organization. This might be due to the heightened sense of insecurity that followed January 25, 2011 and June $30,2013$.

The observed decline in youth labor force participation in 2014 was driven by important shares of the 2009 students out of the labor force (33.2\%), active unemployed (27.8\%), and discouraged unemployed (31.6\%) youth transitioning into inactivity rather than to employment during the last five years.

This chapter provides evidence that labor market adjustments during economic downturns must be depicted beyond unemployment levels (Assaad and Krafft 2015). The increase in the percentage of discouraged youth and the harder transition to formal wage work provide compelling evidence of the more precarious working conditions that the young generations are facing following the Egyptian revolution.

\section{References}

Assaad, Ragui and Caroline Krafft. 2015. “The Evolution of Labor Supply and Unemployment in the Egyptian Economy: 1998 -2012," in The Egyptian Labor Market in an Era of Revolution, R. Assaad and C. Krafft (eds.). Oxford, UK: Oxford University Press, pp. 1-26.

Assaad, Ragui and Ghada Barsoum. 2007. "Youth Exclusion in Egypt: In Search of 'Second Chances.'” Middle East Youth Initiative Working Paper, No.2. Washington, DC: Publisher?

Assaad, Ragui and Fatma El-Hamidi. 2009. "Women in the Egyptian labor market," in The Egyptian Labor Market Revisited, Ragui Assaad (ed.). Cairo: American University in Cairo Press, pp. 217-257.

Assaad, Ragui and Rania Roushdy. 2007. “Poverty and the Labor Market in Egypt: A Review of Developments in the 1998-2006 period," Background Paper for Arab Republic of Egypt: Poverty Assessment Update. Cairo: The World Bank.

Cerutti, Marcela. 2000. “Economic reform, structural adjustment, and female labor force participation in Buenos Aires, Argentina," World Development 28 (5): 879-891.
Francke, Marfil. 1992. "Women and the Labor Market in Lima, Peru: Weathering Economic Crisis." Paper prepared for the International Center for Research on Women Seminar on Weathering Economic Crises: Women's Responses to the Recession in Latin America, Washington, DC, August 11.

Kim, Haejin and Paula B. Voos. 2007. "The Korean economic crisis and working women," Journal of Contemporary Asia 37(2): 190-208.

Leslie, Joanne, Margaret Lycette, and Mayra Buvinic. 1988. "Weathering Economic Crises: The Crucial Role of Women in Health," in Health, Nutrition and Economic Crises: Approaches to Policy in the Third World, David E. Bell and Michael R. Reich (eds.), Dover, MA.: Auburn House Publishing Company, pp. 307-348.

Mokhtar, May, and Jackeline Wahba. 2002. “Informalization of Labor in Egypt," in The Egyptian Labor Market in an Era of Reform Economy: Egypt in the 1990s, Assaad, R. (ed.). Cairo: The American University in Cairo Press, Cairo, Egypt, pp. 131-157.

Population Council. 2010. The Survey of Young People in Egypt: Final Report. Cairo: Population Council, Egypt.

Roushdy, Rania and May Gadallah. 2012. “Informality and Labor Market Dynamics during Economic Downturns: Evidence from Egypt." Gender and Work in the MENA Region Working Paper Series, No. 26, Cairo: Population Council, Egypt.

Roushdy, Rania and Irene Selwaness. 2014. "Duration to Coverage: Dynamics of Access to Social Security in the Egyptian Labor Market in the 1998-2012 Period," Economic Research Forum (ERF) Working Papers No. 836, Cairo: ERF, Egypt.

Sieverding, Maia. 2012. "Youth Perspectives on Entrepreneurship in Egypt: Barriers to Entrepreneurship as a Means to Combat Youth Unemployment," Policy Brief Series, No. 5. Cairo: Population Council, Egypt.

Verick, S. 2010. "Unraveling the Impact of the Global Financial Crisis on the South African Labor Market." Employment Working Paper no. 48. Geneva: International Labour Office.

World Bank. 2009. How Should Labor Market Policy Respond to the Financial Crisis? Washington, D.C.: World Bank, HD and PREM Labor Market Teams, April. 


\section{The Change in International Migration Aspirations of Egyptian Youth}

DAFNI PAPOUTSAKI • JACKLINE WAHBA

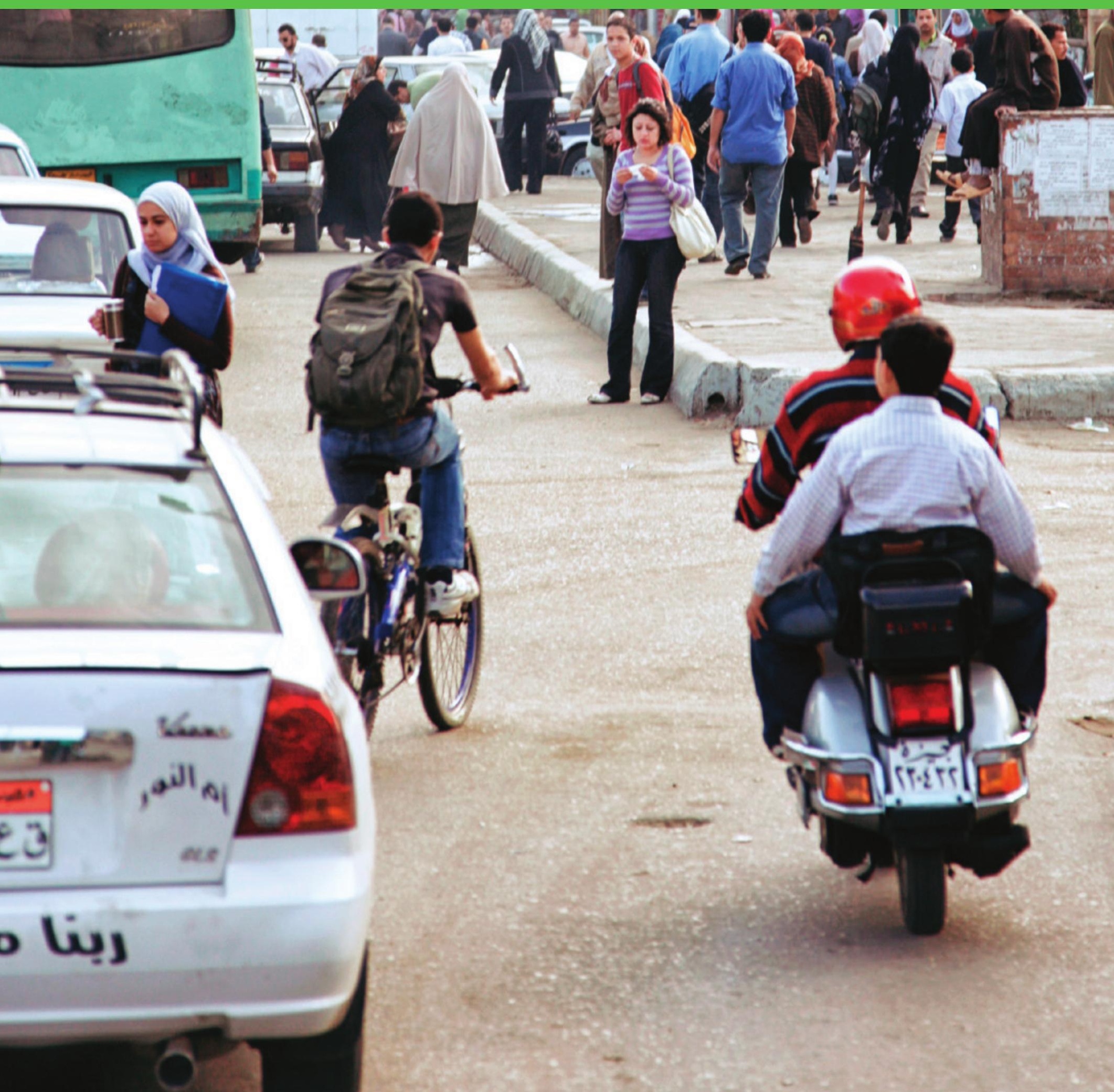


Migration continues to be an important issue for policymakers because of the economic, social, and cultural implications of large movements of people across international borders. Measuring young people's intentions to emigrate from Egypt is especially important because intentions are informative about the potential determinants and patterns of emigration.

\subsection{Introduction}

International migration has been a key feature of the Egyptian economy since the 1970s. According to the 2006 census, 3.9 million Egyptians were living abroad (CAPMAS 2009). In 2013, CAPMAS estimated the number of Egyptian migrants to be around 8 million (Sabry 2012). Furthermore, findings from the recent Egypt Labor Market Panel Survey (2012) highlight the importance of international migration as a backbone of the Egyptian economy; indeed, about $15 \%$ of Egyptian households had a returnee or a current migrant in 2012 (Wahba 2015).

Although there is extensive literature on factors that influence individual migration decisions, in most of those studies the determinants of migration examined are based on samples of individuals who have already migrated. Rarely do data exist on individuals before migration. Thus, some studies focus on migration intentions rather than actual migration in order to understand the factors behind potential migration. A few studies have focused on migration intentions in Egypt. For example, Zohry (2006) studied migration intentions to Europe of just over 1,550 males aged 18-40 in high migration prevalence areas in Cairo and Alexandria, and in four governorates in Lower Egypt and two in Upper Egypt. Van Dalen et al. (2005) used data from a multicountry study investigating the determinants and mechanisms of international migration to the European Union. However, both Zohry (2006) and van Dalen et al. (2005) only focused on Europe, whereas much Egyptian migration is to other Arab countries.
The collection of detailed, nationally representative data on migration intentions in the Survey of Young People in Egypt (SYPE 2009) provided researchers with a unique opportunity to study potential migration and the intention to migrate among Egyptian youth. Five years later, data collected from SYPE 2014 allows researchers to examine the changes in patterns and trends relative to 2009. In addition, it explores whether the January 25, 2011 revolution affected the international migration aspirations of youth in Egypt.

Youth's social networks are a key factor in the development of their migration aspirations; additionally, being a discouraged unemployed person has a positive effect on migration intentions, and wealthier persons were much more likely to choose Western countries as their preferred destination (Elbadawy 2010). In a study of job satisfaction and potential among Egyptian youth, Abdel Fattah (2012) found that migrant networks and the belief that seeking a job abroad will be the main solution to their problems (especially marriage) were the main factors driving migration aspirations. Another variable that significantly affected the probability of being a potential migrant was the need to continue in a job as well as being satisfied in the current job. On the other hand, Elbadawy, Said, and Wahba (2013) examined the reverse causality between migration intentions and investment in education.

The International Organization for Migration conducted a survey on migration intentions in 2011 following the January 25 revolution (IOM 2011). A total of 22,978 contacts were made, but of these only 1,417 successful interviews of young Egyptians between 15 and 29 years old in 17 governorates were eventually conducted between March and April 2011. The survey revealed that 750 of the youth aspired to migrate. It is not clear whether the sample or the timing of the survey was the reason behind this high rate of migration aspirations, given that previous surveys such as the push-pull factors in Europe (2000) or the SYPE (2009) suggested the migration aspiration rate among youth to be about $20 \%$.

It is important, however, to realize that migration intentions do not necessarily translate to actual migration as legal hurdles and financial constraints, 
among other barriers, reduce the opportunities and ability of potential migrants to realize their aspirations (see, for example, Constant and Massey 2002). Yet, migration intentions are still important in enabling us to understand the potential determinants of migration.

\subsection{Youth migration aspirations in 2014}

\section{Long-term migration aspirations}

Overall, 17.2\% of youth aged 15-29 in 2014 aspired to migrate within the next five years, referred to hereafter as long-term aspirations. On the other hand, short-term aspirations were, not surprisingly, lower at $8.9 \%$ since they were based on current migration intentions at the time of the survey in 2014. In 2009, $18.3 \%$ of youth aged $15-29$ aspired to migrate. However, it has to be noted that there was no time limit on intentions in the 2009 survey and hence the answers could have been referring to immediate, short-term, or long-term migration aspirations. ${ }^{1}$

Examining the correlates of long-term (five-year) migration intentions, the same patterns are observed for the total sample of youth (aged 13-35) and those aged 15-29 (see Table A5.1). It is obvious that in 2014 Egyptian male youth (15-29) tended to be three times more likely to aspire to migrate than female youth: $25.8 \%$ of male youth had intentions to migrate, compared to $7.8 \%$ of female youth. Unlike in 2009, aspirations to migrate did not decrease with age, in particular for male youth. In fact the

1 The question on aspiring to migrate was slightly different in each SYPE wave. In SYPE 2009, the question was "do you aspire to migrate to any country...?" without referring to a time period, while in 2014 the question was changed to "do you aspire to migrate now to any country...?"Also, an additional question on migration was included in 2014 SYPE: "What's your chance (in \%) of traveling within the next 5 years?" This question is useful in understanding long-term aspirations, as well as the potential likelihood of migrating within the next five years. However, the full set of questions related to migration destination and push and pull factors were only asked of those who replied that they aspire to migrate now. relationship between age and aspirations was an inverted U-shape (see Figure 5.1). Migration aspirations peaked for 18-24-year-olds. For male youth aged $15-29$, migration aspirations peaked at $28.1 \%$ for the middle age group and were lowest for the youngest age group. This was different from 2009 , when migration aspirations declined with age. Also, unlike in 2009, unmarried male youth (15-29) were no longer more likely to want to migrate (25.5\%) than married male youth (26.8\%).

Male youth aged 15-29 from rural areas were slightly more likely to aspire to migrate (28.3\%) compared to those in urban areas (23.3\%). However, male youth residing in informal urban areas were the least likely to aspire to migrate (16.2\%), which is

FIGURE 5.1 Long-term migration aspirations among youth aged 13-35, in 2009 and 2014 (\%)
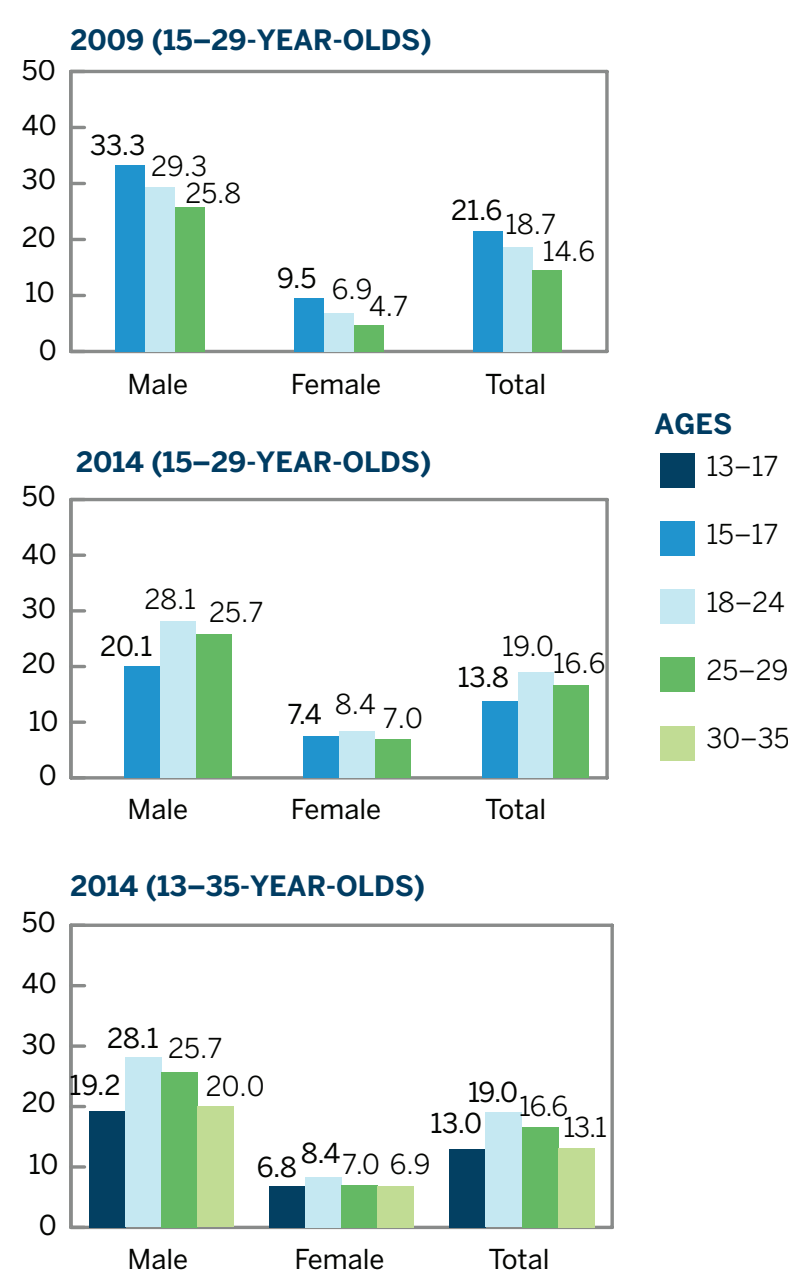


\section{In 2014, a clear increase} was seen in the prevalence of migration aspirations among youth from wealthier families, which was not the case in 2009 when there was no clear positive association between wealth and migration aspiration.

a change from 2009 when that group was the most likely to aspire to migrate. The opposite is true for female youth aged 15-29 in 2014, as those residing in rural areas were the least likely to aspire to migrate and those in informal housing had the highest rate of migration aspirations within urban areas.

Migration aspirations among youth increased with educational attainment. The percentage of 15-29-year-old male youth interested in migration was highest for university graduates, at 30.3\%, while for females secondary and university graduates had similar rates of aspirations (15.6\%). On the whole, the patterns of migration aspirations by education were similar to those of 2009.

On the other hand, a striking difference between 2009 and 2014 is that in 2014, there was a clear increase in aspiration prevalence as wealth rose, which was not the case in 2009, when there was no clear positive association between wealth and migration aspirations. Furthermore, the rate of migration aspirations among students (15-29) in 2014 was $17 \%$, compared to $22 \%$ in 2009 . Surprisingly, the intention to migrate among the unemployed (15-29) had not changed significantly (27\% in 2014 and $29 \%$ in 2009).

\section{Short-term migration aspirations}

Looking at the characteristics of those who aspired to migrate in the short run, several more interesting patterns emerge. Given that aspirations to migrate here refer to the intention to migrate immediately, not surprisingly the rate of aspirations is lower, at 8.9\% (see Table A5.2). The migration intention rate among male youth aged $15-29$ was $13.2 \%$ while among female youth it was $4.1 \%$. Furthermore, aspirations to migrate to the West were only $1.5 \%$, while aspirations to migrate to the Arab countries were $7.1 \%$ among $15-29$-year-old youth. It is worth noting that data from SYPE 2009 revealed a similar pattern of migration aspirations: $14.3 \%$ of youth aspired to migrate to an Arab country, compared to $3.9 \%$ who chose a Western country. In both surveys, preference for Arab countries was four times higher than for Western countries (SYPE 2009).

Patterns observed in the case of short-term aspirations are similar to those seen for long-term aspirations in terms of age, education, marital status, wealth, and employment status for both the 15-29 (Tables A5.2 and A5.3) and 13-35 (Table A5.4 and A5.5) youth populations. However, examining the pattern by destination indicates several interesting differences. Among male youth, although migration aspirations to Arab countries increased with age, aspirations to Western countries decreased with age, though the sample size is too small to confidently claim this decline with age in migration aspirations to Western countries is significant (see

FIGURE 5.2 Desired migration destinations (Arab versus Western countries) among males aged 15-29, by age and marital status, 2014 (\%)

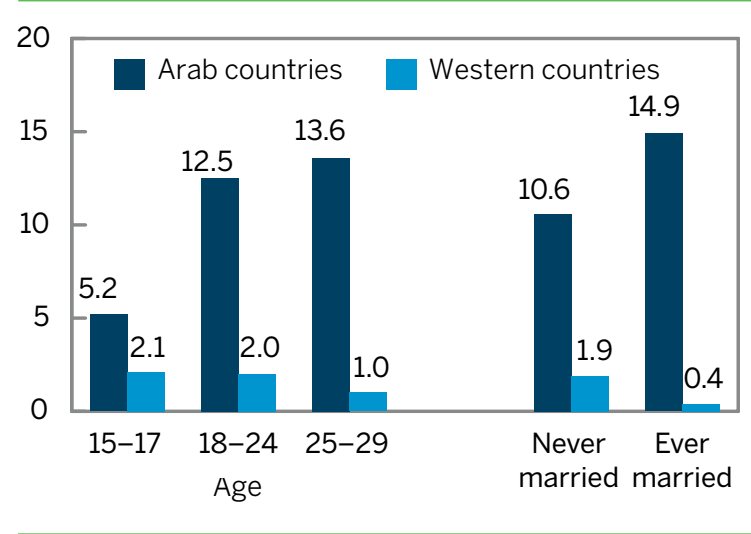


Figure 5.2). Similarly, married male youth indicated higher aspirations to migrate to Arab countries than never-married ones, the opposite of the pattern observed for migration aspirations to Western countries and also of patterns in 2009. Finally, male youths' aspirations to migrate to the West rose steadily with wealth, but not aspirations to migrate to Arab countries.

\section{Desired destinations for short-term migration aspirations in 2014}

Trends in preferred migration destinations among youth (aged 15-29) aspiring to migrate in the shortterm varied between rural and urban youth, as well as between genders. Figure 5.3 shows the preferred destination by urban-rural residence (15-29). Interestingly, $87.5 \%$ of aspiring migrant youth aged 15-29 chose Arab countries, while $12.5 \%$ indicated aspirations to migrate to Western countries. Moreover, about $38.7 \%$ of youth (15-29) in both urban and rural areas aspired to migrate to Saudi Arabia, while those in urban areas were twice as likely to aspire to migrate to Europe or to Australia/Canada/ USA, compared to those in rural areas.

Figure 5.3 also shows the preferred migration destinations by gender. Saudi Arabia was the most popular destination among aspiring migrant youth, but a higher percentage of female youth (31.8\%) aspired to migrate to Western countries, compared to $13.5 \%$ among male youth aged $15-29$. Similar patterns were observed for the total sample of youth aged 13-35 (see Table A5.6).

\section{Reasons for youth migration aspirations}

Most youth (93.0\%) who aspired to migrate said they would like to do so only temporarily. Indeed, the mean duration of intended stay abroad was 5 years. This is consistent with the majority of youth aspiring to migrate to Arab countries, where migration is typically temporary in nature, see e.g., Wahba (2015).

Table 5.1 summarizes the main reasons behind youth's (aged 18-29) migration aspirations by gender and residence; multiple answers were permitted. Low income was the main push factor out of Egypt (73.7\%): $44.0 \%$ believed income in Egypt was lower than abroad, and $29.7 \%$ wanted
FIGURE 5.3 Desired destinations for migration, among youth aged 15-29, according to urban-rural residence and gender, 2014 (\%)

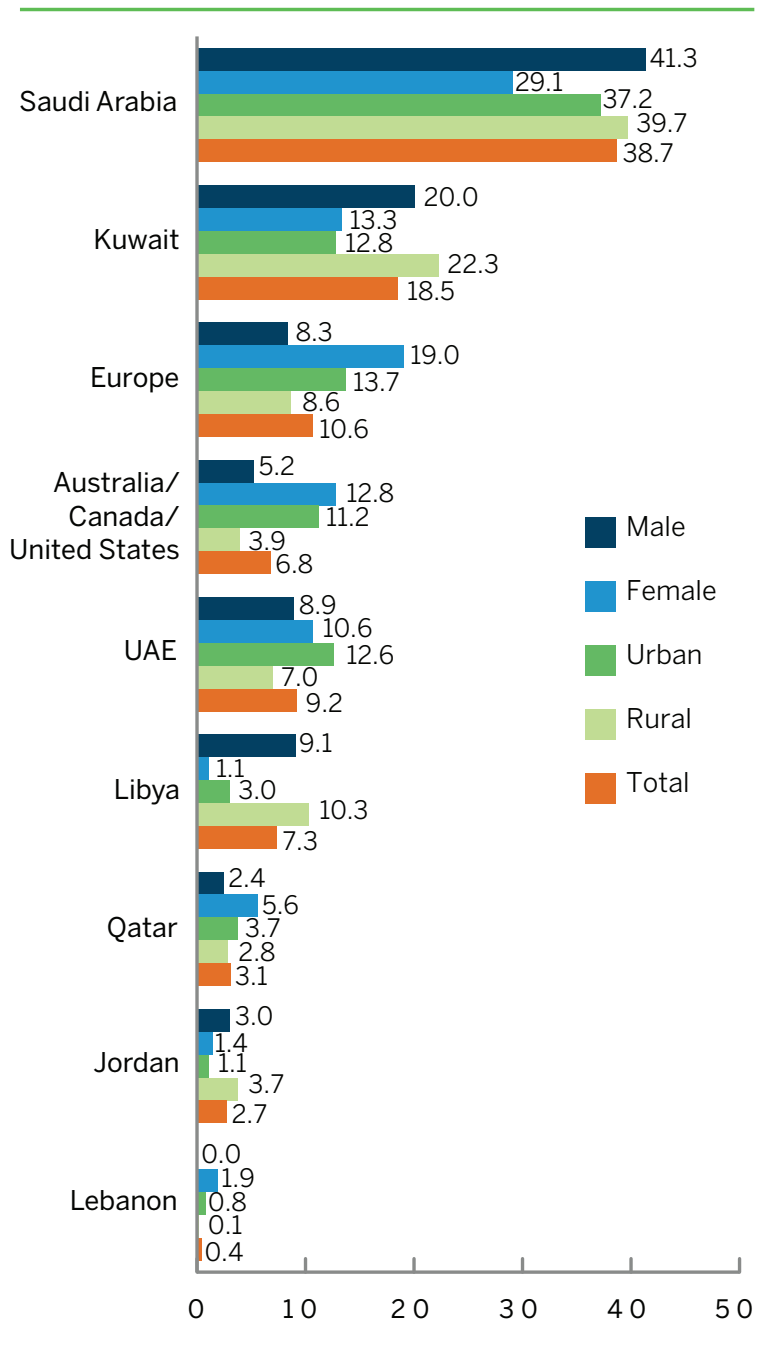

to migrate to earn more money. Two-thirds of youth blamed lack of job opportunities in Egypt for pushing them to aspire to migrate. Bad living conditions in Egypt (48.9\%) were another common push factor. Only $10.1 \%$ of youth blamed the political and security circumstances in Egypt for driving them to want to leave.

The pull factors were a mirror picture, with $72.3 \%$ saying that higher income abroad was driving their migration aspirations. Saving for marriage was another reason behind the intention to migrate. Overall, for male youth economic reasons were much stronger as both push and pull factors than political reasons or investment in human capital 
TABLE 5.1 Reasons given for wanting to migrate, among respondents (aged 18-29) who aspired to migrate in 2014 , by gender and urban/rural residence (\%)

\begin{tabular}{|c|c|c|c|c|c|c|c|c|c|}
\hline & \multicolumn{3}{|c|}{ MALE } & \multicolumn{3}{|c|}{ FEMALE } & \multicolumn{3}{|c|}{ TOTAL } \\
\hline & URBAN & RURAL & $\overline{\text { TOTAL }}$ & URBAN & RURAL & TOTAL & URBAN & RURAL & TOTAL \\
\hline \multicolumn{10}{|l|}{ Push factors } \\
\hline No job opportunities available in Egypt & 67.1 & 71.5 & 69.9 & 44.8 & 49.9 & 47.5 & 62.0 & 68.0 & 65.6 \\
\hline Income in Egypt is lower than abroad & 43.9 & 48.7 & 46.9 & 34.3 & 29.1 & 31.6 & 41.7 & 45.5 & 44.0 \\
\hline Bad living conditions in Egypt & 49.4 & 51.0 & 50.4 & 47.2 & 37.7 & 42.2 & 48.9 & 48.9 & 48.9 \\
\hline To escape family pressures and troubles & 3.0 & 3.0 & 3.0 & 13.1 & 4.7 & 8.7 & 5.4 & 3.3 & 4.1 \\
\hline Accompany family & 0.0 & 1.1 & 0.7 & 8.5 & 11.7 & 10.2 & 2.0 & 2.8 & 2.5 \\
\hline To help my family & 14.6 & 20.8 & 18.5 & 11.1 & 9.7 & 10.3 & 13.8 & 19.0 & 17.0 \\
\hline Don't know & 0.8 & 0.3 & 0.5 & 1.4 & 2.5 & 2.0 & 0.9 & 0.7 & 0.8 \\
\hline $\begin{array}{l}\text { No opportunities to gain information and } \\
\text { experience }\end{array}$ & 7.4 & 0.7 & 3.2 & 26.6 & 12.4 & 19.2 & 11.9 & 2.6 & 6.2 \\
\hline To earn money & 32.7 & 32.8 & 32.7 & 19.4 & 14.5 & 16.8 & 29.6 & 29.8 & 29.7 \\
\hline Political and security circumstances in Egypt & 10.7 & 8.6 & 9.4 & 15.7 & 10.8 & 13.1 & 11.9 & 9.0 & 10.1 \\
\hline Other & 1.0 & 0.0 & 0.4 & 10.5 & 4.9 & 7.6 & 3.2 & 0.8 & 1.7 \\
\hline \multicolumn{10}{|l|}{ Pull factors } \\
\hline I want to see other countries & 7.0 & 7.6 & 7.3 & 24.6 & 14.6 & 19.4 & 11.1 & 8.7 & 9.6 \\
\hline I want to live abroad & 9.1 & 5.9 & 7.1 & 13.1 & 10.3 & 11.6 & 10.1 & 6.6 & 7.9 \\
\hline I have relatives/friends there & 4.8 & 5.3 & 5.1 & 12.7 & 9.6 & 11.1 & 6.6 & 6.0 & 6.3 \\
\hline I have a job offer there & 5.6 & 4.9 & 5.1 & 7.7 & 0.0 & 3.7 & 6.1 & 4.1 & 4.9 \\
\hline I can study there & 6.5 & 1.7 & 3.5 & 29.9 & 19.5 & 24.5 & 11.9 & 4.6 & 7.5 \\
\hline Higher income abroad than in Egypt & 74.1 & 77.4 & 76.2 & 57.2 & 54.7 & 55.9 & 70.2 & 73.7 & 72.3 \\
\hline To save money for marriage & 47.4 & 51.5 & 50.0 & 7.9 & 6.4 & 7.1 & 38.2 & 44.2 & 41.8 \\
\hline To improve my knowledge & 12.9 & 2.3 & 6.2 & 34.2 & 21.0 & 27.3 & 17.8 & 5.4 & 10.2 \\
\hline Family reunion & 2.6 & 1.0 & 1.6 & 6.3 & 10.2 & 8.3 & 3.4 & 2.5 & 2.9 \\
\hline $\begin{array}{l}\text { Other } \\
(\mathrm{N})\end{array}$ & $\begin{array}{c}0.6 \\
(169)\end{array}$ & $\begin{array}{c}1.8 \\
(288)\end{array}$ & $\begin{array}{c}1.3 \\
(458)\end{array}$ & $\begin{array}{l}3.0 \\
(51)\end{array}$ & $\begin{array}{c}2.7 \\
(56)\end{array}$ & $\begin{array}{c}2.9 \\
(107)\end{array}$ & $\begin{array}{c}1.2 \\
(221)\end{array}$ & $\begin{array}{c}1.9 \\
(344)\end{array}$ & $\begin{array}{c}1.6 \\
(565)\end{array}$ \\
\hline
\end{tabular}

Note: Multiple answers allowed.

(studying abroad or improving one's knowledge).

On the other hand, for female youth, economic reasons were not as prominent as for males. Again, those aged 13-35 had similar patterns to the 18-29-year-olds (Table A5.7).

Almost half of the youth blamed bad living conditions for their desire to migrate. Figure 5.4 provides further insights into the quality of life in Egypt as a push factor in the emergence of migration plans. Household water shortages were positively correlated with youth's desire to migrate. Similarly, those who found it difficult to enjoy daily activities and those who were unable to play a useful part in life had higher migration aspirations. ${ }^{2}$ Also, those

2 These questions are part of the Self-Reporting Questionnaire (SRQ-20) developed by the World Health Organization to screen for common mental disorders. For more information see Chapter 2. who were most uncertain about the future were the ones who had the highest rates of aspirations to migrate. Thus, overall, life dissatisfaction seems to be another driver of migration aspirations among youth aged 18-29. Data for the larger age range of 13-35 are shown in Table A5.8.

\section{Sources of information and social networks}

Another important catalyst in migration, and perhaps in turning aspirations into actual migration, is the role played by social networks (friends and family). Table 5.2 reports youth's sources of information on the destinations they aspired to migrate to. Indeed, $41 \%$ of youth (aged 18-29) reported receiving information from relatives abroad (18.9\%) or friends (21.9\%) abroad. Aspiring youth (37.2\%) also had relatives or friends in Egypt 
FIGURE 5.4 Attitudes of respondents aged 18-29 about their quality of life in Egypt, according to short- or long-term migration aspirations, 2014 (\%)
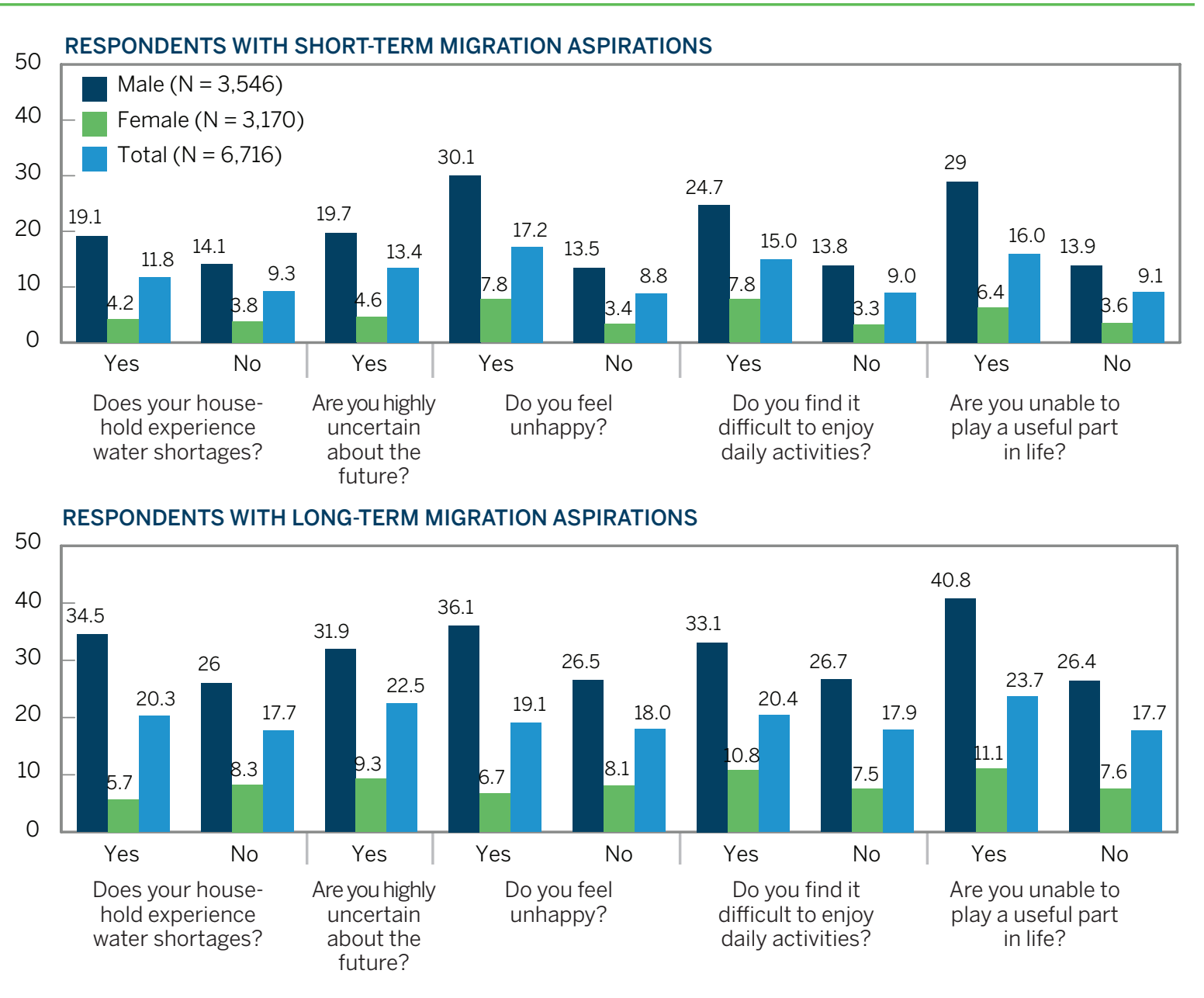

TABLE 5.2 Sources of information on migration destinations, among youth aged 18-29, 2014 (\%)

\begin{tabular}{|c|c|c|c|c|c|c|c|c|c|}
\hline \multirow[b]{2}{*}{ RECEIVED INFORMATION FROM } & \multicolumn{3}{|c|}{ ARAB COUNTRIES } & \multicolumn{3}{|c|}{ WESTERN COUNTRIES } & \multicolumn{3}{|c|}{ ANY DESTINATION } \\
\hline & URBAN & RURAL & TOTAL & URBAN & RURAL & TOTAL & URBAN & RURAL & TOTAL \\
\hline Relatives abroad & 16.9 & 20.8 & 19.4 & 12.9 & 21.3 & 16.7 & 16.2 & 20.6 & 18.9 \\
\hline Relatives in Egypt & 19.9 & 14.8 & 16.6 & 7.8 & 4.1 & 6.1 & 17.0 & 13.8 & 15.0 \\
\hline Egyptian friends abroad & 19.5 & 25.0 & 23.0 & 16.2 & 19.7 & 17.8 & 18.4 & 24.1 & 21.9 \\
\hline Friends in Egypt & 21.7 & 23.4 & 22.8 & 10.9 & 24.8 & 17.1 & 20.4 & 23.3 & 22.2 \\
\hline Internet & 6.4 & 1.6 & 3.4 & 29.9 & 17.7 & 24.4 & 10.9 & 3.6 & 6.5 \\
\hline Governments & 0.0 & 0.7 & 0.5 & na & na & na & 0.0 & 0.6 & 0.4 \\
\hline General reading & 4.0 & 3.7 & 3.8 & 6.8 & 6.7 & 6.7 & 4.5 & 4.1 & 4.3 \\
\hline Media (TV, radio, newspapers) & 10.6 & 8.2 & 9.1 & 14.0 & 5.8 & 10.3 & 11.4 & 8.3 & 9.5 \\
\hline Embassies/consulates & 0.4 & 0.3 & 0.3 & na & na & na & 0.3 & 0.2 & 0.3 \\
\hline Other & 0.6 & 1.6 & 1.3 & 1.5 & 0.0 & 0.8 & 0.9 & 1.4 & 1.2 \\
\hline$(\mathrm{N})$ & $(168)$ & (299) & $(467)$ & $(48)$ & (39) & $(87)$ & $(221)$ & $(344)$ & (565) \\
\hline
\end{tabular}




\section{The most important push factors for youth to migrate were lack of employment opportunities and poor living conditions, while the most important pull factor was higher wages abroad than in Egypt.}

who were sources of information, some of whom might be return migrants. Not surprisingly, age did not change the pattern of the sources of information on destinations (Table A5.9 shows data for youth aged 13-35). Overall, as found in previous studies, official sources such as governments and embassies or consulates provided very little information to aspiring migrants. However, an interesting difference emerged between 2009 and 2014, as Table 5.3 shows that the percentage of urban youth using the internet for getting information on their destinations has increased substantially.

With regard to the types of people that youth expected they would need to rely upon when trying to migrate (Table 5.4), social networks, consisting

TABLE 5.3 Sources of information on all migration destinations among 18-29-year-olds, 2009 and 2014 (\%)

\begin{tabular}{|c|c|c|c|c|c|c|}
\hline & \multicolumn{2}{|c|}{ URBAN } & \multicolumn{2}{|c|}{ RURAL } & \multicolumn{2}{|c|}{ TOTAL } \\
\hline & 2009 & 2014 & 2009 & 2014 & 2009 & 2014 \\
\hline Friends/relatives & 73.2 & 72.0 & 84.9 & 81.7 & 79.9 & 78.0 \\
\hline Internet & 3.8 & 10.9 & 1.8 & 3.6 & 2.7 & 6.5 \\
\hline Governments & 0.4 & 0.0 & 0.3 & 0.6 & 0.4 & 0.4 \\
\hline General readings & 2.8 & 4.5 & 1.9 & 4.1 & 2.3 & 4.3 \\
\hline $\begin{array}{l}\text { Media (TV, radio, } \\
\text { newspapers) }\end{array}$ & 19.6 & 11.4 & 10.7 & 8.3 & 14.5 & 9.5 \\
\hline $\begin{array}{l}\text { Other } \\
(\mathrm{N})\end{array}$ & $\begin{array}{r}0.3 \\
(523)\end{array}$ & $\begin{array}{c}1.2 \\
(221)\end{array}$ & $\begin{array}{r}0.4 \\
(699)\end{array}$ & $\begin{array}{r}1.6 \\
(344)\end{array}$ & $\begin{array}{r}0.3 \\
(1222)\end{array}$ & $\begin{array}{r}1.5 \\
(565)\end{array}$ \\
\hline
\end{tabular}

TABLE 5.4 Sources of expected help in migrating, among 18-29-year-olds, 2014 (\%)

\begin{tabular}{lccc}
\hline & $\begin{array}{c}\text { ARAB } \\
\text { COUNTRIES }\end{array}$ & $\begin{array}{c}\text { WESTERN } \\
\text { COUNTRIES }\end{array}$ & $\begin{array}{c}\text { ANY DES- } \\
\text { TINATION }\end{array}$ \\
\hline Relatives abroad & 27.2 & 27.2 & 27.2 \\
Relatives in Egypt & 48.4 & 56.9 & 49.6 \\
Egyptian friends & & & \\
abroad & 10.8 & 9.1 & 10.5 \\
Friends in Egypt & 6.7 & 4.9 & 6.4 \\
Migration brokers & 3.2 & na & 2.8 \\
Other & 3.8 & 2.0 & 3.5 \\
(N) & $(203)$ & $(38)$ & $(241)$ \\
\hline
\end{tabular}

of both friends and relatives at home and abroad, were found to be the main channels. Only $2.8 \%$ of youth (aged 18-29) reported that migration brokers-agents who help in migration and job finding-would help them. Similar patterns are observed for youth (aged 13-35) in terms of reliance on social networks to help in the migration process (Table A5.10).

To sum up, the most important push factors for youth to migrate were lack of employment opportunities and poor living conditions, while the most important pull factor was higher wages abroad than in Egypt. The majority of youth sought information about their preferred migration destination from their family and friends who were living abroad. Saudi Arabia remained the most popular destination. To a large extent these patterns were similar to what was found by the IOM in 2011. The main difference is that the prevalence of migration aspirations was much smaller than in the IOM Survey or SYPE 2009, an issue we will examine next.

\subsection{Changes in migration intentions: 2009 and 2014}

This section investigates the changes in migration aspiration trends between 2009 and 2014. We use the panel aspect of the SYPE data, where we focus first on those youth (aged 15-29) who aspired to migrate in 2009 and check whether in 2014 they had changed their long-term migration plans. 
TABLE 5.5 Panel analysis: Respondents' long-term intention to migrate, measured in 2009 and again in $2014^{*}$, by gender (\%)

\begin{tabular}{|c|c|c|c|c|}
\hline \multicolumn{2}{|c|}{$\begin{array}{c}\text { DID NOT HAVE } \\
\text { LONG-TERM } \\
\text { ASPIRATIONS IN } 2014 \\
\end{array}$} & \multirow[t]{2}{*}{$\begin{array}{c}\text { HAD LONG-TERM } \\
\text { ASPIRATIONS IN } 2014\end{array}$} & \multirow[t]{2}{*}{$\begin{array}{l}\text { MISSING } \\
\text { IN } 2014\end{array}$} & \multirow[t]{2}{*}{ (N) } \\
\hline Total & & & & \\
\hline $\begin{array}{l}\text { Aspired to migrate in } 2009 \\
\text { Did not aspire to migrate in } 2009 \\
\text { (N) }\end{array}$ & $\begin{array}{c}50.2 \\
61.5 \\
(6,469)\end{array}$ & $\begin{array}{r}18.2 \\
9.8 \\
(1,204)\end{array}$ & $\begin{array}{c}31.6 \\
28.8 \\
(3,168)\end{array}$ & $\begin{array}{r}(1,746) \\
(9,095) \\
(10,841)\end{array}$ \\
\hline $\begin{array}{l}\text { Wanted to go to an Arab country in } 2009 \\
\text { Wanted to go to a Western country in } 2009\end{array}$ & $\begin{array}{l}51.3 \\
45.5\end{array}$ & $\begin{array}{l}18.0 \\
19.4\end{array}$ & $\begin{array}{l}30.7 \\
35.7\end{array}$ & $\begin{array}{r}(1,344) \\
(387)\end{array}$ \\
\hline \multicolumn{5}{|l|}{ Male } \\
\hline $\begin{array}{l}\text { Aspired to migrate in } 2009 \\
\text { Did not aspire to migrate in } 2009 \\
\text { (N) }\end{array}$ & $\begin{array}{c}49.2 \\
54.3 \\
(2,545)\end{array}$ & $\begin{array}{c}21.4 \\
17.7 \\
(901)\end{array}$ & $\begin{array}{l}29.4 \\
28.1 \\
(1,370)\end{array}$ & $\begin{array}{l}(1,352) \\
(3,464) \\
(4,816)\end{array}$ \\
\hline $\begin{array}{l}\text { Wanted to go to an Arab country in } 2009 \\
\text { Wanted to go to a Western country in } 2009\end{array}$ & $\begin{array}{l}50.6 \\
54.2\end{array}$ & $\begin{array}{r}20.8 \\
7.0\end{array}$ & $\begin{array}{l}28.6 \\
38.8\end{array}$ & $\begin{array}{r}(1,071) \\
(273)\end{array}$ \\
\hline \multicolumn{5}{|l|}{ Female } \\
\hline $\begin{array}{l}\text { Aspired to migrate in } 2009 \\
\text { Did not aspire to migrate in } 2009 \\
\text { (N) }\end{array}$ & $\begin{array}{c}53.8 \\
65.9 \\
(3,924)\end{array}$ & $\begin{array}{c}7.1 \\
4.9 \\
(303)\end{array}$ & $\begin{array}{c}39.1 \\
29.2 \\
(1,798)\end{array}$ & $\begin{array}{r}(394) \\
(5,631) \\
(6,025)\end{array}$ \\
\hline $\begin{array}{l}\text { Wanted to go to an Arab country in } 2009 \\
\text { Wanted to go to a Western country in } 2009\end{array}$ & $\begin{array}{r}43.1 \\
51.3\end{array}$ & $\begin{array}{r}24.1 \\
8.0\end{array}$ & $\begin{array}{l}32.9 \\
40.7\end{array}$ & $\begin{array}{l}(274) \\
(113)\end{array}$ \\
\hline
\end{tabular}

* Among youth who were between the ages of 15 and 29 when they were first interviewed in 2009.

Table 5.5 shows the number and percentage of youth by aspiration status in 2009 and 2014 , where aspirations in 2014 refer to long-term intentions to migrate and those not tracked (missing) in 2014 are also included. Only $18.2 \%$ of youth who aspired to migrate in 2009 still aspired to migrate in the long run in 2014. At the same time, $9.8 \%$ of the youth who did not want to migrate in 2009 changed their mind and wanted to migrate by 2014 . However, it is worth noting that $31.6 \%$ of those who aspired to migrate in 2009 were not tracked in 2014, but at the same time a similar percentage (28.8\%) of the youth who did not aspire to migrate in 2009 were missing in 2014. This suggests that it was unlikely that those missing in 2014 were missing due to having already migrated. Indeed, the SYPE questionnaire has information on members of the household who migrated and returned between 2009 and 2014: only 26 of the youth who aspired to migrate in 2009 did in fact migrate for six continuous months and return between 2009 and 2014. Moreover, 178 households in 2014 had current migrants, but we do not know whether those current migrants were aspirers in 2009. It is also possible that households migrated in their entirety, though those are potentially a small number. Only nine households were not tracked in 2014 because they moved overseas.

Table 5.5 also shows that the percentage of youth who aspired to migrate to the West in 2009 and were missing in 2014 was higher than the percentage of youth who aspired to migrate to Arab countries (35.7\% compared to $30.7 \%$ ). Yet it is important to note that the number of those who aspired to migrate to the West was rather small.

Furthermore, in order to check the change in migration plans, we examine those who aspired to migrate in 2009 and aspired to migrate in the shortterm in 2014. Not surprisingly, when we consider short-term migration plans, only $10.3 \%$ of the youth who aspired to migrate in 2009 still wanted to migrate in the short-run in 2014, as seen in Table A5.11. Overall, this evidence suggests that it would 
be unlikely that the number of nontracked youth and the change in migration intentions between 2009 and 2014 are due to actual migration.

\subsection{The January 25, 2011 revolution and migration intentions}

This section explores whether the January 25, 2011 revolution in Egypt affected young people's migration aspirations. Although one might speculate that the political instability and marked economic slowdown would push youth to consider migrating, the rest of the Arab region has also experienced political turbulence, including Libya, which was a popular destination for Egyptian migrants, and this might have discouraged potential migrants. At the same time, the global economic downturn has affected Western economies and their attractiveness, given the high unemployment rates and economic austerity.

In the 2014 SYPE, all youth were asked whether the January 25 revolution affected their migration plans. Figure 5.5 shows the impact of the revolution on youth (aged 18-29), on the long-term aspirers who planned to migrate within the next five years, and on the short-term aspirers who were contemplating migration in 2014. Similar patterns are observed for youth 13-35 (Table A5.12). Overall, the revolution seemed to have had a marginal impact on young Egyptians' migration intentions. About $91.2 \%$ of youth aged $18-29$ said that the revolution had nothing to do with their migration intentions. The remainder were split almost equally between those who were more in favor of migration after the revolution and those who were no longer thinking about migration because of the revolution.

Among those male youth who had long-term plans to migrate, $20.7 \%$ changed their mind in favor of migration after the revolution and only $5.5 \%$ of male youth long-term aspirers were thinking less about migrating. On the other hand, of those youth who were short-term aspirers, 31.9\% attributed the change in their thinking in favor of migration to the revolution.

Table 5.6 focuses on the short-term migration aspirers and shows that $41.9 \%$ of youth aged $18-29$ years old who aspired to migrate started thinking about migration after the revolution. Furthermore,

FIGURE 5.5 Responses to the question "Has the revolution changed your decision with respect to migration?", youth aged 18-29, 2014 (\%)

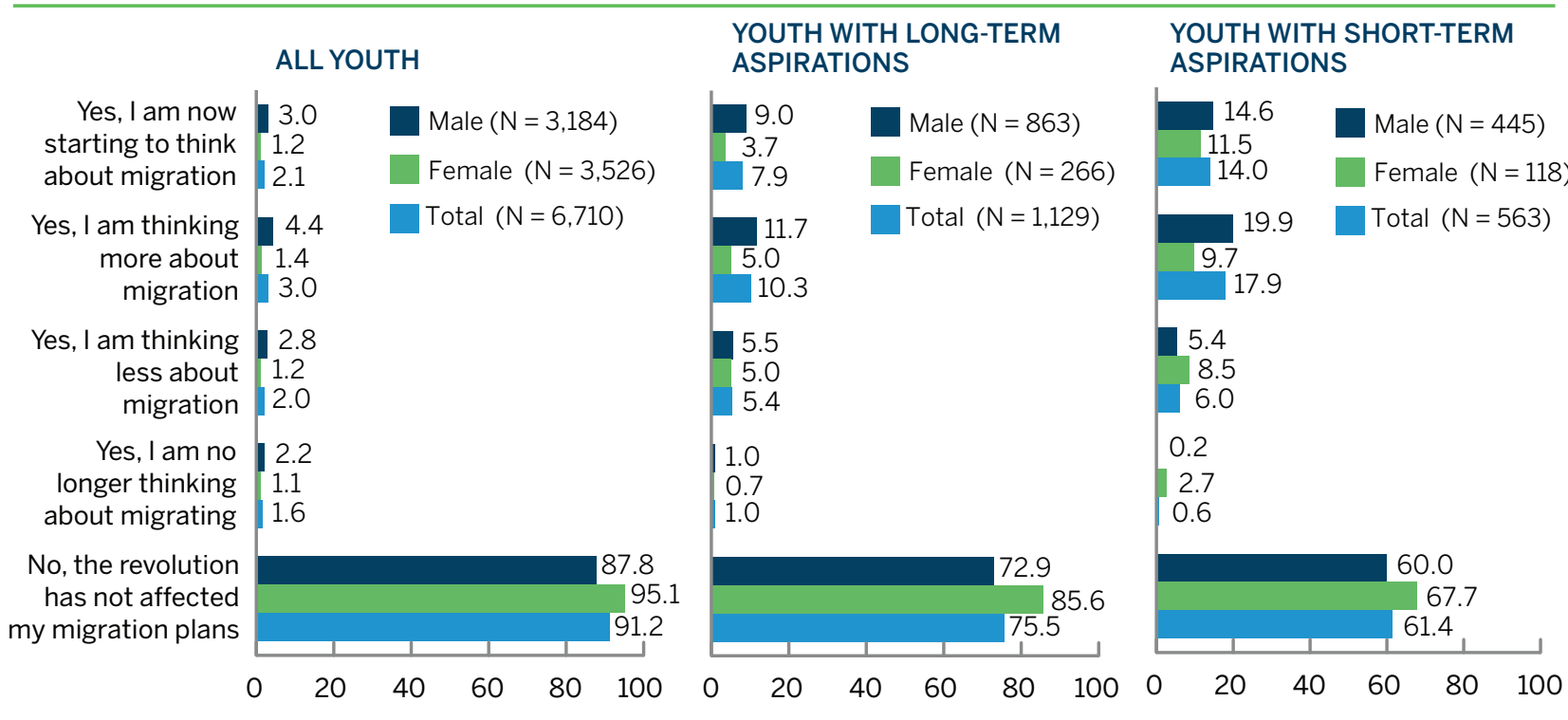

Total $(\mathrm{N})$ for all youth = 6,710; $(\mathrm{N})$ for long-term =1,129; $(\mathrm{N})$ for short-term = 563 . 
TABLE 5.6 The impact of the revolution on youth with short-term plans to migrate, youth aged 18-29, $2014(\%)^{*}$

MALE FEMALE TOTAL

$\begin{array}{lrrr}\begin{array}{l}\text { When did you start } \\ \text { thinking about migration? }\end{array} & & & \\ \text { Before the revolution } & 57.5 & 60.7 & 58.1 \\ \text { After the revolution } & 42.5 & 39.4 & 41.9 \\ \text { (N) } & 458 & 107 & 565\end{array}$

Have you taken any steps to migrate or is it just an idea?

\begin{tabular}{lrrr}
$\begin{array}{l}\text { Yes, I have started to take } \\
\quad\end{array}$ & 10.7 & 7.0 & 10.0 \\
$\quad \begin{array}{l}\text { Nteps } \\
\quad \text { take steps }\end{array}$ & 31.3 & 19.4 & 29.1 \\
It is just an idea & 57.9 & 73.7 & 60.9 \\
Has anyone influenced your & & & \\
decision to migrate? & & & \\
Yes & 18.8 & 21.7 & 19.4 \\
No & 81.2 & 78.3 & 80.6 \\
Who has most influenced & & & \\
your decision? & & & \\
My father abroad & 7.3 & 6.9 & 7.2 \\
My mother abroad & 0.0 & 2.6 & 0.6 \\
Other relatives abroad & 31.1 & 11.5 & 26.9 \\
Egyptian friends abroad & 38.4 & 32.4 & 37.1 \\
My father in Egypt & 6.6 & 5.8 & 6.4 \\
My mother in Egypt & 0.9 & 0.0 & 0.7 \\
Other relatives in Egypt & 2.7 & 13.6 & 5.0 \\
Friends in Egypt & 10.3 & 11.7 & 10.6 \\
Foreign spouse & 0.6 & 11.5 & 2.9 \\
Migration brokers & 0.9 & 0.0 & 0.7 \\
Current/ex local employer & 1.2 & 0.0 & 0.9 \\
An educational institution & 0.0 & 4.1 & 0.9 \\
(N) & $(83)$ & $(23)$ & $(106)$ \\
\hline Only youth who aspired to migrate & & &
\end{tabular}

*Only youth who aspired to migrate.

$10.0 \%$ started taking steps to migrate; $10.7 \%$ among males and $7.0 \%$ among females. For $80.6 \%$ of these youth, no one influenced their intention to migrate but for the remaining $19.4 \%$, relatives and friends abroad had been influential in changing youths' migration plans. For the full sample of youth (13-35) a slightly higher percentage (82.3\%) reported that no one had influenced their intention to migrate (see Table A5.13).

\subsection{Conclusion}

This chapter examines migration aspirations among Egyptian youth during and after the political changes Egypt has experienced since 2011. The rate of migration aspirations among youth did not change much between 2009 and 2014 when looking at youth aspiring to migrate within the next five years. When looking at short-term migration plans among youth, unsurprisingly, the percentage of aspiring migrants in 2014 was about half that of long-term aspirers. Youth were asked in particular whether the January 25, 2011 revolution sparked their migration plans or aspirations, but it appears that the revolution only had a marginal positive impact on youth's aspirations to migrate. It is possible that those who felt strongly about the political and economic situation after 2011 have already migrated and we are not able to observe them in 2014. However, it is also possible that given that other Arab countries, such as in Libya, were going through political instability and the global economic downturn during the same period, migration aspirations have been dampened. The IOM survey conducted after January 25, 2011 also found that the revolution did not seem to have directly influenced the decision of Egyptian youth to migrate.

In terms of patterns of migration aspirations, males and the more educated tended to have higher aspiration rates. Despite the political instability in Egypt, economic factors were the main drivers of migration. Again, similar results were found by the IOM (2011) in terms of job and income loss acting as primary push factors for youth who reported intentions to migrate after the revolution. In addition, social networks (family and friends) continued to play a prominent role in providing information on migration and help in migrating.

It is important to note that most migration aspirations do not materialize. Indeed, actual migration depends on many factors: personal, financial constraints, migration policies, and opportunities. According to a recent study by Docquier et al. (2014), based on 138 countries, one in five educated potential migrants becomes an actual migrant, and only one out of 20 less educated potential 
migrants actually migrates. Nonetheless, migration aspirations are useful in understanding the determinants of migration.

A few points are worth highlighting from a policy perspective. First, although migration intentions are informative in explaining the determinants and possibly the patterns of migration, they are not accurate in predicting actual emigration rates. In order to solicit more concrete information on migration intentions, it would be useful to find out whether intentions are accompanied by any actions to realize such intentions, such as acquiring a passport, saving, or looking for a job abroad. Second, economic factors are the most important push factor for Egyptian youth despite the recent political turmoil. Finally, despite the lack of increase in migration aspirations among youth between 2009 and 2014, international migration remains a dream of many young male youth in Egypt.

\section{References}

Abdel Fattah, D. 2012. "Satisfaction at the Workplace and Potential Migration among Egyptian Youths." Paper submitted to Middle East Economic Association Meetings in Alexandria June 24-26.

CAPMAS. 2009. Housing and Population Census, 2006. Cairo: CAPMAS.

Constant, Amelie and Douglas S. Massey. 2002. "Return migration by German guestworkers: Neoclassical versus new economic theories," International Migration 40(4): 5-38.

Docquier, F. ,G. Peri. and I. Ruyssen. 2014. “The Cross-Country Determinants of Potential and Actual Migration" International Migration Review, 48: S37S99.

Elbadawy, A. 2010. "Migration Aspirations among Young People in Egypt: Who Desires to Migrate and Why?" Economic Research Forum Conference paper, Antalya, Turkey.

Elbadawy, A., M. Said, and J. Wahba. 2013. "Migration Aspirations and Education among Youth in Egypt: Evidence from Survey of Young People, 2009" mimeo.

IOM. 2011. “Egypt after January 25: Survey of Youth Migration Intentions." Cairo: IOM.

Population Council, 2010. Survey of Young People in Egypt: Final Report. Cairo: Population Council, Egypt.
Sabry, Bassem. 2012. "A guide to Egypt's challenges: Overpopulation." Alahram online, 16 August. http://english.ahram.org.eg/NewsContent/1/0/49602/Egypt/ Overpopulation.aspx. Accessed 20 January 2015.

Wahba, Jackline. 2015. “Through the keyhole: International migration in Egypt," in The Egyptian Labor Market in an Era of Revolution, R. Assaad and C. Krafft (eds.). Oxford: Oxford University Press, pp. 198 -217.

Van Dalen, Hendrik P., George Groenewold, and Tineke Fokkema. 2005. "The effect of remittances on emigration intentions in Egypt, Morocco, and Turkey," Population Studies: A Journal of Demography, 59(3): 375-392.

Zohry, Ayman. 2006. Attitudes of Egyptian Youth towards Migration to Europe. Cairo: IOM. 


\section{Marriage and Family Formation Trends among Youth in Egypt}

MAIA SIEVERDING • AHMED RAGAB

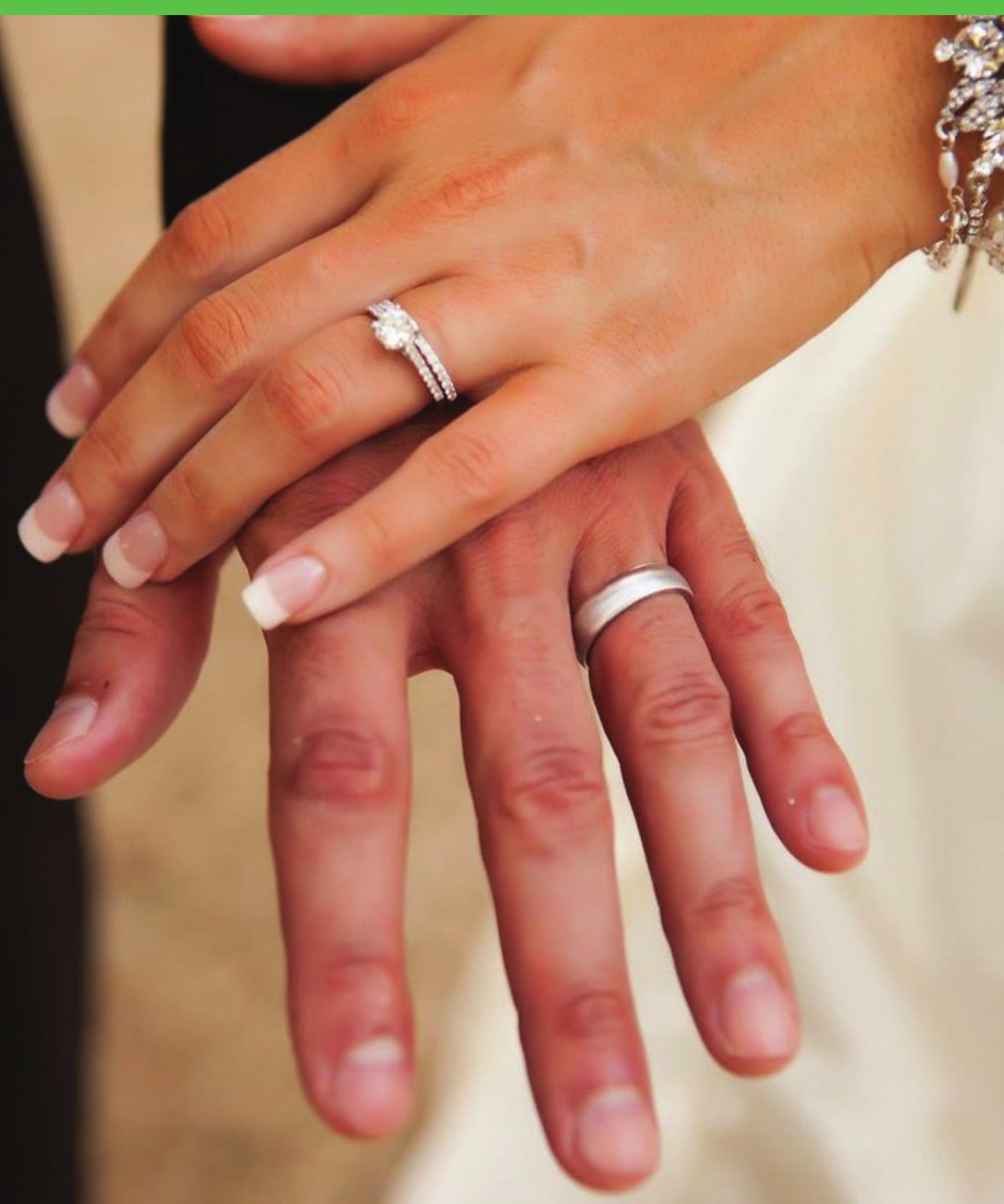




\section{Entry into marriage is a key aspect of the transition to adulthood, and an important marker of adult status in Egyptian society. In some regions, young people are waiting longer to get married for various reasons. Despite this trend, some female youth in Egypt remain at risk of early marriage and the numerous negative outcomes that are associated with entering adulthood too early.}

\subsection{Introduction}

Marriage delay among young people, due in part to the high cost of marriage, has been identified as part of the phenomenon of "waithood," or stalled transitions to adulthood, in Egypt as well as elsewhere in the Middle East and North Africa (Dhillon and Yousef 2009; Singerman 2007). Yet at the same time that marriage delay has received increasing attention, there are subpopulations of female youth in Egypt who remain at risk of early marriage (Brady et al. 2007; Lee-Rife et al. 2012). In this chapter, we update the description of young Egyptians' transition into marriage provided by SYPE 2009, addressing which types of youth enter marriage when, as well as a variety of characteristics of young people's marriages.

The aging of the SYPE sample between 2009 and 2014 allows for a broader look at youth's transitions into marriage, as a larger percentage of the sampled youth have now married. Because marriage is a state that most young people enter into only once and do not exit (rates of divorce and separation among this young population are very low), many of the youth marriages that we observe in 2014 were the same marriages we observed in 2009. In order to differentiate between these marriages and the youth who have married since the last SYPE wave, we use the longitudinal dimension of SYPE to construct a variable reflecting year of marriage. This variable for marriage cohort identifies the youth who were married between the two SYPE rounds (2010-2014), so that they can be compared with youth who married during a similar period of time prior to the 2009 wave (marriage years 2005-2009), and youth who married 10 years or more prior to the survey (marriage years 2004 or earlier). Analysis by marriage cohort is thus a key means by which we examine trends in the transition into marriage.

\subsection{Marital status among Egyptian youth, 2009 and 2014}

Table 6.1 shows that in $201437.8 \%$ of female youth and $15.1 \%$ of male youth aged $15-29$ were married (and $1.0 \%$ and $0.2 \%$ of young women and men were previously married, respectively). Breaking down the percentage of married youth by gender and age group indicates that the marriage rate for young men aged 24 and below has been low since 2009 , with $6.7 \%$ of young men aged $18-24$ married and none of the male youth aged 15-17. Marriage rates for young men increased substantially in their late 20 s, with $41.4 \%$ of young men in the age group 25-29 being currently married. These figures were similar to those found for youth aged 15-29 in the 2009 SYPE. However, the aging of the SYPE sample from 2009 to 2014 allows for an additional examination of trends in youth entry into marriage at later ages; for 30-35-year-olds, the percentage of men who were currently married in 2014 rose to $74.8 \%$ (with fewer than $1.0 \%$ previously married). In sum, three quarters of young men appear to enter into marriage in the decade between 25 and 35 years of age, but an additional quarter of young men remained unmarried as of age 35.

Compared to the large percentage of young men who marry in their late 20s, young women tend to marry earlier: $32.4 \%$ of female youth aged $18-24$ and $72.7 \%$ of those aged 25-29 were married, and another $1.7 \%$ had been previously married. This represents a drop in marriage prevalence of about 3.0 and 6.0 percentage points, respectively, from the same age groups of young women in 2009. Corresponding with their generally younger transition into marriage, the increase in marriage prevalence among the 30-35-year-old age group in 2014 was not as sharp for young women (at $84.3 \%$ currently married and $3.8 \%$ previously married) as for young 
men, relative to the $25-29$ age group. This also indicates that a smaller percentage of young women than young men (about $12.0 \%$ ) remain never-married in their early 30s.

In $2014,0.3 \%$ of male youth and $1.5 \%$ of female youth had been but were not currently married, constituting $1.0 \%$ of the ever-married male and $3.2 \%$ of the ever-married female youth in the sample. Additionally, $1.6 \%$ of currently married male youth and $1.3 \%$ of currently married female youth were in their second marriage. Due to the small number of previously married youth in the sample (22 male and 43 female), the remainder of the chapter drops these youth from the analysis, focusing only on currently and never-married youth, as was done in the analysis of SYPE 2009 (Population Council 2010).

\section{Composition of recently married youth}

Using the two SYPE waves, we can examine the characteristics of youth who got married between 2009 and 2014, which gives an indication of which youth were more likely to marry during this period. Nearly half (46.7\%) of married youth in 2014 were
Compared to a large proportion of young men who marry in their late 20s, young women tend to marry earlier: $32.4 \%$ of female youth aged $18-24$ and $72.7 \%$ aged 25-29 were married in 2014 , and another $1.7 \%$ had been previously married.

newly married in the second SYPE wave, i.e. they had married between 2010 and 2014. An additional 29.0\% were married between 2005 and 2009 (the time of the first SYPE wave), and $24.3 \%$ had been married since 2004 or earlier (data not shown).

TABLE 6.1 Marital status of youth surveyed, by gender and age group, 2009 and 2014 (\%)

\begin{tabular}{|c|c|c|c|c|c|c|}
\hline & \multicolumn{3}{|c|}{2009} & \multicolumn{3}{|c|}{2014} \\
\hline & $\begin{array}{r}\text { NEVER } \\
\text { MARRIED }\end{array}$ & $\begin{array}{r}\text { CURRENTLY } \\
\text { MARRIED }\end{array}$ & $\begin{array}{r}\text { PREVIOUSLY } \\
\text { MARRIED }\end{array}$ & $\begin{array}{r}\text { NEVER } \\
\text { MARRIED }\end{array}$ & $\begin{array}{r}\text { CURRENTLY } \\
\text { MARRIED }\end{array}$ & $\begin{array}{r}\text { PREVIOUSLY } \\
\text { MARRIED } \\
\end{array}$ \\
\hline \multicolumn{7}{|l|}{ Males } \\
\hline Ages 15-17 & 100.0 & 0.0 & 0.0 & 99.8 & 0.0 & 0.0 \\
\hline $18-24$ & 95.1 & 4.9 & 0.0 & 93.2 & 6.7 & 0.1 \\
\hline 25-29 & 58.2 & 41.5 & 0.3 & 58.1 & 41.4 & 0.6 \\
\hline $30-35$ & - & - & - & 24.4 & 74.8 & 0.8 \\
\hline Total aged 15-29 & 86.8 & 13.1 & 0.1 & 84.7 & 15.1 & 0.2 \\
\hline Total aged 15-35 & - & - & - & 73.2 & 24.0 & 0.3 \\
\hline \multicolumn{7}{|l|}{ Females } \\
\hline Ages 15-17 & 97.7 & 2.3 & 0.0 & 95.8 & 3.7 & 0.3 \\
\hline $18-24$ & 63.7 & 35.2 & 1.1 & 66.7 & 32.4 & 0.9 \\
\hline $25-29$ & 18.8 & 78.7 & 2.5 & 25.6 & 72.7 & 1.7 \\
\hline $30-35$ & - & - & - & 11.9 & 84.3 & 3.8 \\
\hline Total 15-29 & 58.5 & 40.2 & 1.3 & 61.2 & 37.8 & 1.0 \\
\hline Total 15-35 & - & - & - & 50.3 & 45.1 & 1.5 \\
\hline \multicolumn{7}{|l|}{ All youth } \\
\hline Total aged 15-29 & 73.0 & 26.4 & 0.7 & 73.4 & 26.0 & 0.6 \\
\hline Total aged 15-35 & - & - & - & 62.0 & 34.3 & 0.9 \\
\hline (N) Ages 15-29 & $(7,438)$ & $(3,460)$ & (78) & $(5,789)$ & $(2,775)$ & (53) \\
\hline (N) Ages 15-35 & - & - & - & $(6,017)$ & $(4,507)$ & (92) \\
\hline
\end{tabular}


As shown in Table $6.2,55.7 \%$ of youth who married between the SYPE waves were in the age group 18-24 in 2009. A substantial percentage (26.2\%) of female youth who married were in the age group 15 - 17 in 2009, whereas almost all of the other male youth who married (34.7\%) were in the age group 25 - 29 in 2009. In terms of education, the percentage of recently married youth who had low educational attainment-mainly primary and preparatory education-was higher than the percentage of youth who have these levels as their final attainment (Chapter 3). This suggests that, particularly among young women, earlier exit from school is associated with the likelihood of marriage. A large percentage of youth who married also had vocational secondary education, which is likely related to the large percentage of youth who have this as their final educational attainment (Chapter 3). Interestingly, the percentage of male youth who married who had a university education was higher than that of female youth, which may be

TABLE 6.2 Characteristics of youth married between 2010 and 2014, by age, education, and wealth quintile, 2009 (\%)

\begin{tabular}{lrrr}
\hline & MALE & FEMALE & TOTAL \\
\hline Age group & & & \\
10-14 & 0.8 & 15.2 & 8.3 \\
15-17 & 4.2 & 26.2 & 15.7 \\
18-24 & 60.4 & 51.5 & 55.7 \\
25-29 & 34.7 & 7.1 & 20.3 \\
Education level & & & \\
Illiterate & 4.1 & 9.4 & 6.9 \\
Can read and write & 0.0 & 3.1 & 1.6 \\
Primary & 11.4 & 21.6 & 16.7 \\
Preparatory & 14.7 & 23.4 & 19.3 \\
General secondary & 9.3 & 11.3 & 10.3 \\
Vocational secondary & 38.6 & 21.6 & 29.7 \\
Post-secondary institute & 3.9 & 1.5 & 2.6 \\
University and above & 18.1 & 8.1 & 12.9 \\
Wealth quintile & & & \\
Lowest & 21.5 & 25.3 & 23.5 \\
Second & 20.9 & 22.7 & 21.8 \\
Middle & 25.8 & 26.3 & 26.1 \\
Fourth & 18.4 & 15.0 & 16.6 \\
Highest & 13.4 & 10.7 & 12.0 \\
Total & 47.8 & 52.2 & 100.0 \\
(N) & $(835)$ & $(1,250)$ & $(2,085)$ \\
\hline & & & \\
\hline
\end{tabular}

related to men's later average ages at marriage. Finally, among both male and female youth, a larger percentage of those who married between 2010 and 2014 were in the lower wealth quintiles (which by definition contain $20.0 \%$ of the overall sample). This is likely related to the higher educational attainment of wealthier youth, and therefore delay of marriage among this population.

\subsection{Age at marriage and early marriage}

SYPE 2014 asked youth their opinions on the ideal marriage age for men and women, revealing substantial gender differences. (This question on ideal marriage age was not asked in SYPE 2009.) The large majority of youth (79.2\%) said that the ideal age at marriage for a young woman was between 18 and 24 (Figure 6.1). Whereas 5.5\% said that the ideal marriage age for females was younger than 18 , only $9.8 \%$ gave an age between 25 and 29. Youth opinion on the ideal age at marriage for young men was much more varied, with 30.5\% answering "between ages 18 and 24" and just over half answering "between ages 25 and 29. An additional $11.3 \%$ thought the ideal age at marriage for men was 30 or older, but less than $1.0 \%$ gave an age below age 18 .

Actual median ages at marriage among the SYPE sample in 2014 generally accorded with these ideals (for the full set of background characteristics see Table A6.1). In order to examine median age at mar-

FIGURE 6.1 Perceived ideal age at marriage among youth aged $13-35$ (\%)

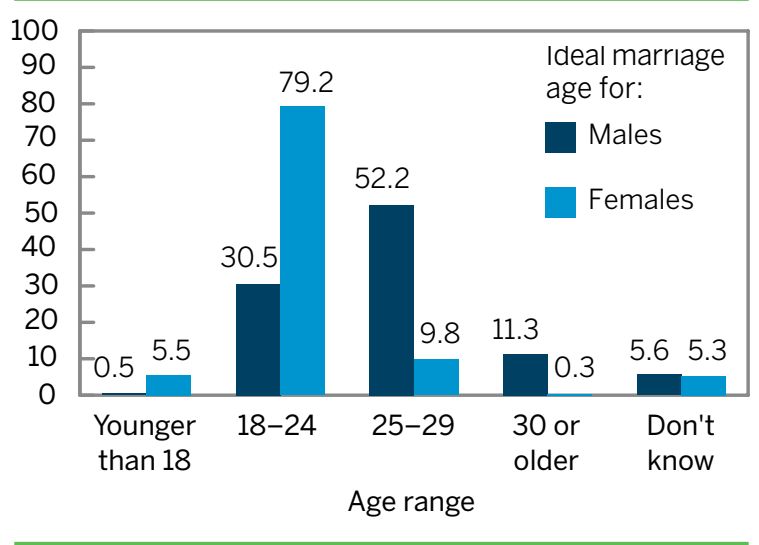


riage, we restricted the analysis to youth aged 25 and older, as estimates for younger youth are likely to be biased downward. Still, even at these older ages, it is important to note that some youth remain unmarried. Among married youth aged 25-29 in 2014, male youth had married at a median age of 25 and female youth at age 20. Among youth aged 30-35, the median age at marriage was no different for females but increased to 26 among male youth, reflecting the fact that a much larger percentage of male youth remained unmarried at older ages.

Focusing on youth aged 30-35 in 2014, median ages at marriage were lowest for female youth in rural areas, with female youth in rural Upper Egypt marrying the youngest at a median age of 19 (Table 6.3). Less educated youth also tend to

TABLE 6.3 Median age at marriage among youth aged 30-35, by selected background characteristics, 2014

\begin{tabular}{lccc}
\hline & MALE & FEMALE & TOTAL \\
\hline Region & & & \\
Urban Governorates & 27 & 21 & 24 \\
Urban Lower Egypt & 26 & 21 & 23 \\
Rural Lower Egypt & 26 & 20 & 22 \\
Urban Upper Egypt & 25 & 21 & 23 \\
Rural Upper Egypt & 25 & 19 & 21 \\
Frontier Governorates & 25 & 21 & 23 \\
Education level & & & \\
Illiterate & 24 & 19 & 20 \\
Can read and write & 24 & 18 & 18 \\
Primary & 25 & 19 & 21 \\
Preparatory & 22 & 18 & 20 \\
General secondary & 26 & 19 & 24 \\
Vocational secondary & 25 & 20 & 22 \\
Post-secondary institute & 26 & 23 & 24 \\
University and above & 28 & 23 & 26 \\
Employment status & & & \\
Employed & 26 & 20 & 25 \\
Unemployed & 29 & 21 & 23 \\
Out of labor force & 25 & 20 & 20 \\
Marriage cohort & & & \\
2010-2014 & 29 & 28 & 29 \\
2005-2009 & 25 & 23 & 24 \\
Before 2004 & & 20 & 19 \\
Total & & & \\
(N) & & & \\
\hline & & & \\
\hline & 26 & $(1,085)$ & $(1,731)$ \\
\hline
\end{tabular}

marry younger, although the relationship between education and age at marriage is clearer for young women. The most notable pattern among young men is that those with a university education or above tend to marry later than youth of all other educational attainments, at a median age of 28 years. Among female youth, those with less than a vocational secondary education had median ages at marriage below 20. For those with a tertiary education, however, median age at marriage rose to 23. Median age at marriage rose consistently with wealth for both young men and women, which likely reflects that wealthier youth are more likely to have higher educational attainments (Chapter 3), particularly as we would expect that wealthier youth are likely more able to cover the costs of marriage (data not shown). On the other hand, it is possible that wealth correlates with material expectations for marriage (see Section 6.7). Unemployed male youth had a higher median age at marriage (29) than their peers who were employed (26), which may similarly be related to the difficulty of saving for marriage without a job. Turning to marriage cohort, as we might expect, youth who were married in earlier years were much younger than youth who married in the few years prior to the survey. Male youth who were married by 2004 had a median age at marriage of 21, compared to 29 years among male youth who married between 2010 and 2014. Among female youth, the median age at marriage for those married before 2004, from 2005-2009 and 2010-2014 increased steadily from 19 to 23 to 28 years, respectively.

Early marriage has been widely shown to be detrimental to young women's health and socioeconomic outcomes (Lee-Rife et al. 2012). As suggested by these patterns in median age at marriage, early marriage in Egypt is concentrated among female youth in certain regions. In Table 6.4, we compare the percentage of married youth aged 25-29 in 2009 and 2014 who were married before certain ages. ${ }^{1}$ Whereas marriage rates before the

1 The percentage of youth married before a certain age is cumulative. For example, the percentage married before age 16 includes those who were married before age 15, etc. We restrict this analysis to the older age groups in order to avoid censoring. 
TABLE 6.4 Percentage of married youth aged 25-29 who reported being married at an early age, 2009 and 2014

\begin{tabular}{lccccc}
\hline & \multicolumn{2}{c}{ MALES } & & \multicolumn{2}{c}{ FEMALES } \\
\cline { 2 - 3 } \cline { 5 - 6 } & $\mathbf{2 0 0 9}$ & $\mathbf{2 0 1 4}$ & & $\mathbf{2 0 0 9}$ & $\mathbf{2 0 1 4}$ \\
\hline Married & & & & & \\
before age: & & & & & \\
15 & 0.1 & 0.1 & & 3.6 & 1.7 \\
16 & 0.1 & 0.1 & & 8.3 & 4.2 \\
18 & 1.9 & 0.7 & & 23.9 & 21.1 \\
20 & 7.8 & 2.6 & & 48.2 & 45.6 \\
\hline
\end{tabular}

legal age of 18 were negligible ( $0.1 \%$ or less) among married male youth in $2014,1.7 \%$ of married female youth aged 25-29 in 2014 had been married before age $15,4.2 \%$ before age 16 , and $21.1 \%$ before age 18 (the legal age of marriage in Egypt). As compared to married youth aged 25-29 in 2009, this represented a decline in the prevalence of early marriage among young women. This was particularly true for marriage before age 16 , which halved from $8.3 \%$ of married female youth aged 25-29 in 2009 to $4.2 \%$ in $2014 .{ }^{2}$

Breaking down these rates of early marriage by background characteristics furthermore shows a strong concentration of early marriage among girls in rural areas, and particularly rural Upper Egypt, as was also the case in 2009. As shown in Figure 6.2, among married female youth aged 25-29 in 2014, 33.3\% of those residing in rural Upper Egypt were married before age 18 , compared to just under $10 \%$ of those in the Urban Governorates and urban Lower Egypt. However, comparison with 2009 again shows that the prevalence of early marriage declined in all regions except urban Upper Egypt. The largest declines in the percentage of young women who were married before 18 between 2009 and 2014 were seen in rural Lower Egypt and the Frontier Governorates, which are also the regions in which early marriage is most prevalent.

2 There is some possibility of increased misreporting of actual marriage age, as the legal age of marriage for women was changed from 16 years to 18 years in 2008. If SYPE respondents became more aware of this change as time progressed, they may have been more reluctant to report having married prior to the new legal age.
FIGURE 6.2 Percentage of married female youth aged 25-29 who were married before age 18, by region, 2009 and 2014 (\%)

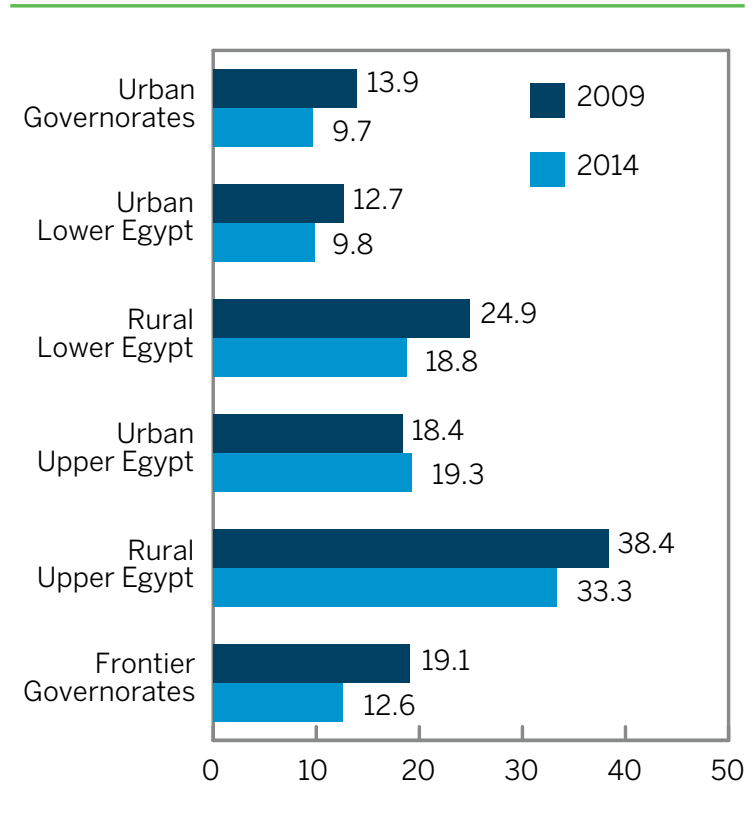

In addition to these regional trends, about half of female youth aged 25-29 (45.7\%) in 2014 who had been married before age 18 were illiterate (data not shown), which is disproportionately large compared to the percentage of female youth in these age groups who are illiterate (Chapter 3 ). This corresponds to the concentration of early married female youth in rural areas, where educational attainment tends to be lower, but also highlights the protective effects of education in terms of marriage; female youth who marry tend to withdraw from school, and conversely, those who stay in school may be less likely to marry (Brady et al. 2007).

\subsection{Characteristics of youth marriages}

The characteristics of young people's marriages may have important implications for the dynamics of their relationship. This is particularly true for young women, as marriage to a relative, co-residence with in-laws, and large age gaps between women and their husbands may all be associated with lower female autonomy. Relying on the new cohort of marriages established between the two 
SYPE waves, this section examines trends in these factors in young people's marriages.

Consanguinity, or marriage to a relative, has been declining over time among youth of both genders. Overall, $27.4 \%$ of married youth in 2014 were married to a relative, down from $33.9 \%$ of those married in 2009. This corresponds with the decrease in consanguinity among more recent marriages: Among youth married before $2004,33.2 \%$ of males and $30.4 \%$ of females reported being married to a relative. In contrast, among youth married between 2010 and 2014 , only $24.2 \%$ of males and $25.6 \%$ of females were in a consanguineous marriage (data not shown). Among youth aged $15-29,46.4 \%$ of consanguineous marriages in 2014 were to first cousins, compared to $59.2 \%$ in 2009 , and did not vary by gender (data not shown).

Consanguinity is most common among earlymarrying girls, as $35.1 \%$ of girls married before age 18 and $33.3 \%$ of girls married before age 16 in 2014 were married to a relative (data not shown). By region, consanguinity is most prevalent in Upper Egypt and the Frontier Governorates; in the latter, $42.5 \%$ of all marriages are consanguineous (Figure 6.3; Table A6.2 in the Appendix). Consanguinity is

FIGURE 6.3 Prevalence of consanguineous marriages, by region and gender, 2014 (\%)

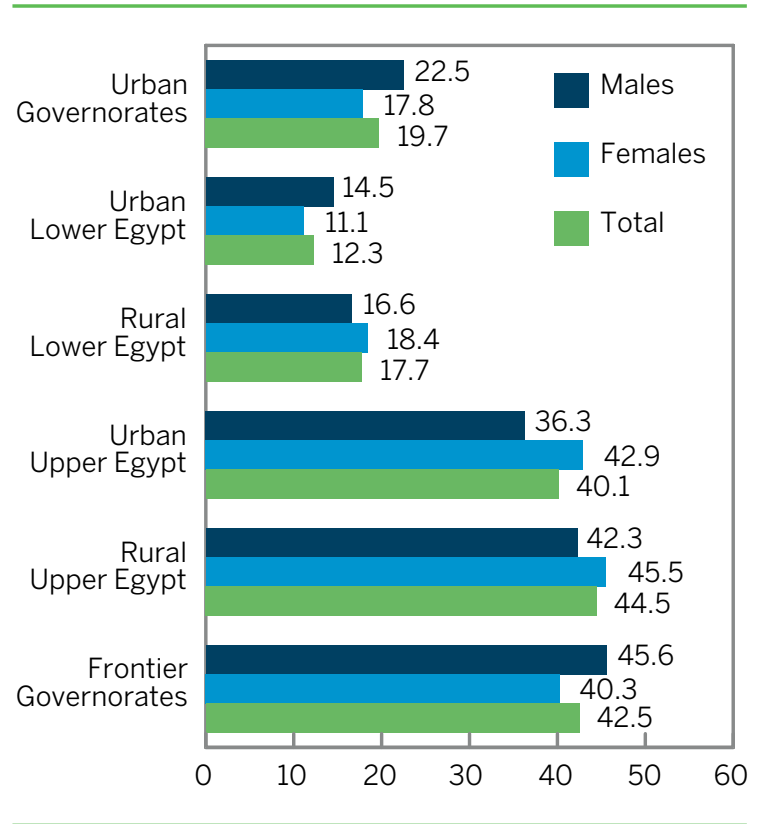

also most common in rural areas, where almost one-third of marriages are consanguineous. More highly educated youth are less likely to marry a relative, with $16.8 \%$ of those who completed a university degree in consanguineous marriages as compared to $32.2 \%$ of those who were illiterate in 2014 . Youth in lower wealth quintiles were similarly more likely to marry a relative. Finally, although consanguineous marriage remains quite common among young people, it has become less common among more recent youth marriages; $24.9 \%$ of youth married between 2010 and 2014 married a relative, compared to $30.8 \%$ of those married before 2004 . However, it is important to note that this may be due to the aging of the SYPE sample, as youth who married young were more likely to marry a relative.

In the marriages of young people as of 2014, the husband was, on average, 5.2 years older than the wife; the median husband-wife age gap was five years among young married women and 4 years among young married men. In over $30 \%$ of marriages, the husband was 6 to 10 years older than the wife, and the husband was 11 or more years older than the wife in $9.4 \%$ of marriages (Table 6.5). Such large spousal age gaps were more frequent in the marriages of young women, as more than $13.0 \%$ of young women compared to less than $3.0 \%$ of young men were married to husbands or wives who are at least 11 years older. As with consanguinity, large spousal age gaps were more common among girls who married young; $22.5 \%$ of girls married by age 16 had husbands aged 11 years older or more, and $20.7 \%$ of girls married by age 18 . By region, the largest spousal age gaps were found in rural areas in both Lower and Upper Egypt, which

TABLE 6.5 Reported age gap between husbands and wives, among youth aged $13-35$, $2014(\%)$

\begin{tabular}{lr}
\hline & $\%$ \\
\hline Husband is 1-5 years older than wife & 47.7 \\
Husband is 6-10 years older than wife & 32.5 \\
Husband is 11 or more years older than wife & 9.4 \\
No age gap & 5.9 \\
Wife is older than husband & 4.5 \\
\hline
\end{tabular}




\section{Rural youth were also more likely than urban youth to live with the spouse's family after marriage, whereas youth living in informal urban areas were most likely to live in an independent house.}

is also where young marriage is most common for female youth (data not shown).

The SYPE data show that marriage in Egypt is traditionally patrilocal. Whereas $32.1 \%$ of married male youth reported that they lived with their own family upon marriage, only $2.4 \%$ of female youth did so (Table A6.3). Comparable percentages of married youth lived with their spouse's family; $32.2 \%$ of females and $11.7 \%$ of males. The majority of married youth $-56.0 \%$ of male youth and $64.9 \%$ of female youth-lived independently upon marriage. The youngest married youth, particularly males, were more likely to live with their families than were older married youth; $34.8 \%$ of married males aged 18-24 lived with their own families upon marriage compared to $28.3 \%$ of $30-35$-year-olds. Rural youth were also more likely than urban youth to live with the spouse's family upon marriage, whereas youth living in informal urban areas were most likely to live in an independent house upon marriage. Youth with higher educational attainment and from higher wealth quintiles were more likely to live independently, which is unsurprising given that socioeconomic status is associated with the ability to afford separate housing. Just over two-thirds $(67.8 \%)$ of male youth in the highest wealth quintile and $80.1 \%$ of female youth lived independently upon marriage.

\subsection{Meeting and choosing a spouse}

Marriage matching among youth mostly takes place through social networks rather than in institutional settings (Table A6.4). Among married youth, $42.7 \%$ met their spouse through personal (friends and acquaintances) networks, and 53.5\% through broader social (relatives and neighbors) networks. As shown in Figure 6.4, 46.7\% of

FIGURE 6.4 How married youth aged 13-35 met their spouse, by education level, 2014 (\%)

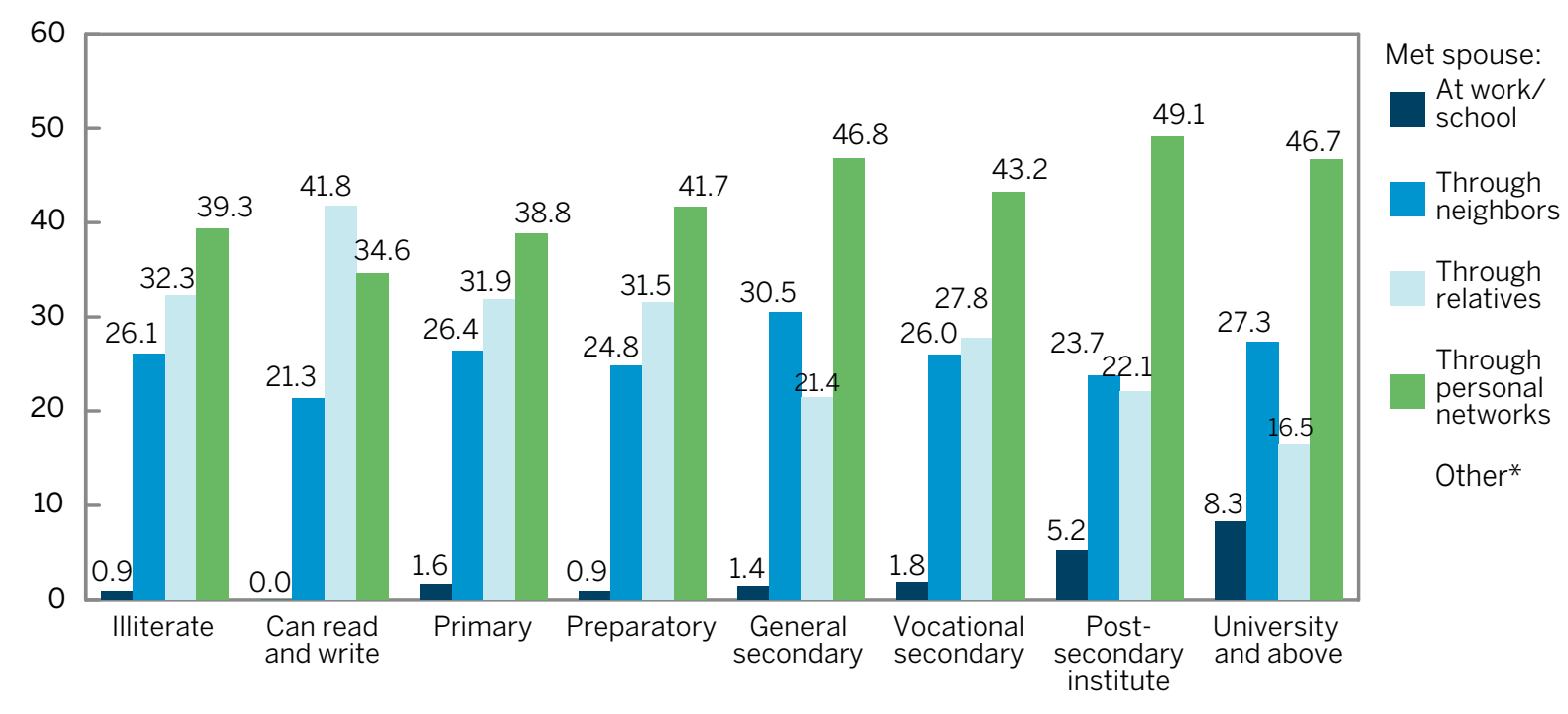

* "Other" accounted for less than $2 \%$ of responses for all education levels except for "can read and write" (2.4\%). 
university-educated youth reported meeting their spouse through personal networks, compared to $39.3 \%$ of illiterate youth. Personal networks were more commonly reported by higher-educated, wealthier, and urban young people as the means through which they met their spouses, as compared to relatives, which were a more common means among less-educated, poorer, and rural young people, particularly in Upper Egypt and the Frontier Governorates.

When SYPE respondents were asked who made the final decision about their marriage, $32.1 \%$ of married youth said that they made the decision themselves, $38.7 \%$ made the decision jointly with parents, and $29.2 \%$ said someone else alone made the decision for them (Table A6.5). Female youth were much more likely to report having no say over their marriage; $14.2 \%$ of young married men, compared to $37.4 \%$ of young married women said that somebody else alone decided about their marriage for them (Table 6.6). Younger youth were also more likely to have had someone decide about their marriage for them; whereas 39.2\% of married youth aged 13-17 (nearly all of whom are young women) had no say in their marriage decision, this was the case for $25.5 \%$ of married youth aged 30-35. Less educated and poorer youth were also less likely to have had a say in their marriage decision.

TABLE 6.6 Degree of youth (aged 13-35) involvement in their final decision to marry, by gender, 2014 (\%)

\begin{tabular}{lcc}
\hline & MALES & FEMALES \\
\hline Youth made the decision him/herself & $\mathbf{5 4 . 1}$ & 20.2 \\
$\begin{array}{l}\text { Someone else made the decision } \\
\begin{array}{l}\text { Parents and youth made the } \\
\text { decision jointly }\end{array}\end{array}$ & $\mathbf{3 7 . 4}$ \\
\hline
\end{tabular}

\subsection{Quality of youth's marital relationships}

SYPE 2014 also included an expanded set of questions about the quality of youth's marital relationships that can provide additional insight into family life and personal autonomy among young people.
Overall among married youth aged 13-35, 53.7\% agreed that they had a free and independent marital relationship, and an additional $22.3 \%$ strongly agreed (full set of responses in Table A6.6). However, agreement with this statement varied substantially by level of education, region of residence, and wealth. For example, whereas $32.1 \%$ of youth with a university education or above strongly agreed that they were free and independent in their marriage, only $15.1 \%$ of illiterate youth said so. Youth with lower educational attainments were more likely to be neutral in their response to this question.

Youth were also asked to respond to a series of negative statements about their marital relationship. When posed the statement, "My spouse does not respect me," $81.6 \%$ of youth disagreed or strongly disagreed, with disagreement more prevalent in urban areas (Table A6.7). Just over $22 \%$ of youth in the Frontiers Governorates and $17.4 \%$ of those in informal urban areas were neutral with regard to this statement. When posed the stronger statement, "My spouse treats me harshly," $81.0 \%$ of youth disagreed or strongly disagreed with this statement, and only 5.5\% agreed or strongly agreed. Disagreement was lowest among the youngest married youth aged $13-17$, at $66.5 \%$, compared to about $80-82 \%$ among all other age groups. Disagreement was also lower among the least educated and poorest youth.

Married youth aged 13-35 were also asked about their communication with their spouses on a number of topics (Table A6.8). Whereas $73.9 \%$ of youth discussed their future plans with their spouses "often" or "daily", a smaller percentage of couples (69.4\%) talk about their work or study problems with their spouses. A greater percentage of youth (83.4\%) communicated with their spouses about how things were going in their daily life, and a similar percentage (80.6\%) discussed their current or future children. Only $66.3 \%$ of married youth said that they discussed their marital sexual relations with their spouses, suggesting that this may be a sensitive subject even among couples.

Interestingly, male youth were consistently 2 to 8 percentage points more likely to report discussing 
all of these topics with their spouse than were female youth (Figure 6.5). Older, more educated, and wealthier youth also reported more frequent marital communication. Young people residing in informal urban areas were also more likely to report frequent marital communication; there was at least a 7 percentage-point gap between informal and urban or rural areas for each of the five marital communication topics.

\subsection{Cost of marriage}

The high cost of marriage in Egypt is a topic of frequent popular discussion, and has been linked to increasing age at marriage and stalled transitions to adulthood (Singerman 2007; Dhillon and Yousef 2009). Young people in Egypt are expected to establish an independent home or unit within a family home upon marriage. The SYPE 2009, as well as other studies, has shown that about two-thirds of the costs of establishing the joint residence for the new couple and celebrating the marriage typically fall on the groom's side, with the other third falling on the bride's side. As in 2009, the SYPE 2014 collected data from married youth on the main categories of marriage expenditures, except for housing. These included the costs of furniture, appliances, first stock of food and other goods for the new residence, the bride's trousseau (gihaz), and the celebrations

FIGURE 6.5 Youth reporting frequent discussions with their spouse on a variety of topics, by gender, 2014 (\%)

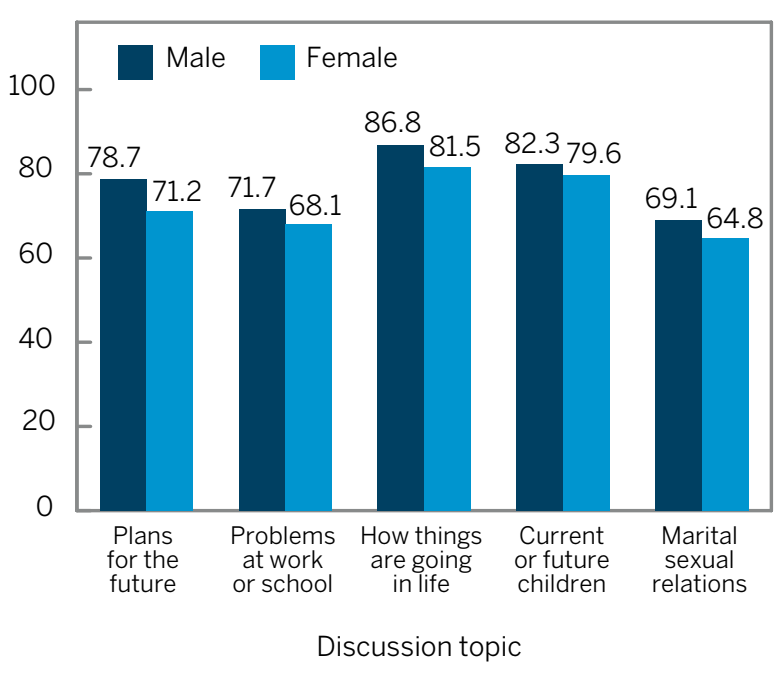

(typically including an engagement party as well as a wedding). In addition, respondents were asked about the value of the shabka, or the jewelery presented to the bride.

Comparing trends in the value of the shabka and total cost of marriage across marriage cohorts can give a sense of change in marriage costs over time, although these must be interpreted with some caution because, as discussed above, youth who married later were typically older and more educated. These factors likely contributed to the fact that the total reported value of the shabka among youth who married between 2010 and 2014 was just under 7,000 EGP, compared to about 5,000 EGP among youth who married from 2005-2009, and 4,000 EGP among youth who married prior to $2004^{3}$ (Figure 6.6).

However, it is also possible that the devaluation of the pound during Egypt's transitional period affected the price paid for the shabka, or that expenditures are in fact rising in real terms. As expected, the total value of the shabka also increased with wealth quintile, from about 4,300 LE among the youth in the lowest wealth quintile to 7,500 among those in the highest. The value of the shabka also generally increased with education, but, in contrast, decreased with age, at over 7,300 LE among those aged 13-17 compared to under 5,000 LE among those aged 30 and above (see Table A6.9).

Similar to trends in the value of the shabka, the total cost of marriage (excluding housing and the shabka) increased among more recent youth marriages, from about 25,000 LE among those married prior to 2004 to nearly 40,000 LE among those married from 2010-2014. The increase in total cost of marriage by wealth quintiles was also sharper than the increase in the value of the shabka, which may reflect greater variation in youth's material expectations for their new dwelling. The cost of marriage for youth with a university education or above was also more than double that for illiter-

3 These shabka values have not been adjusted for inflation. 
FIGURE 6.6 Mean reported cost of bride's shabka and total marriage cost, youth aged $13-35$, by wealth quintile and marriage cohort, 2014

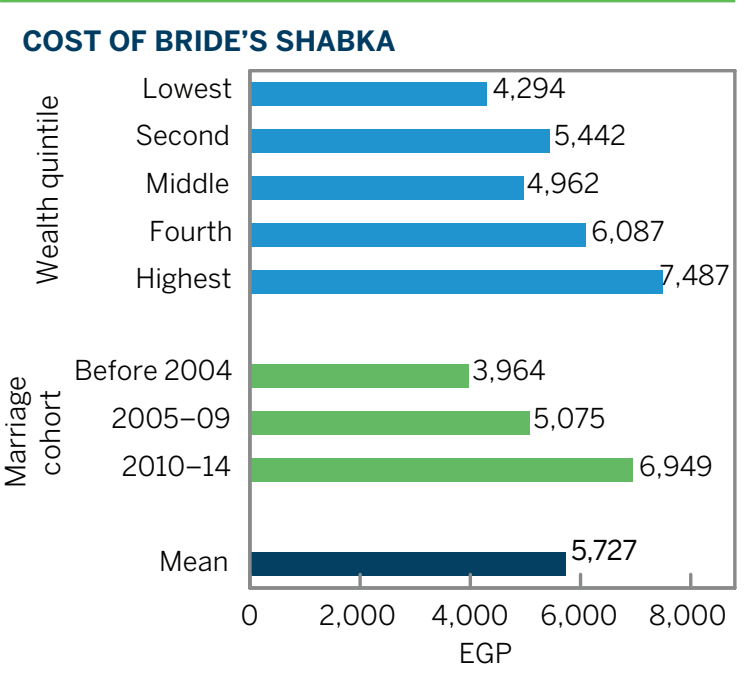

TOTAL COST OF MARRIAGE

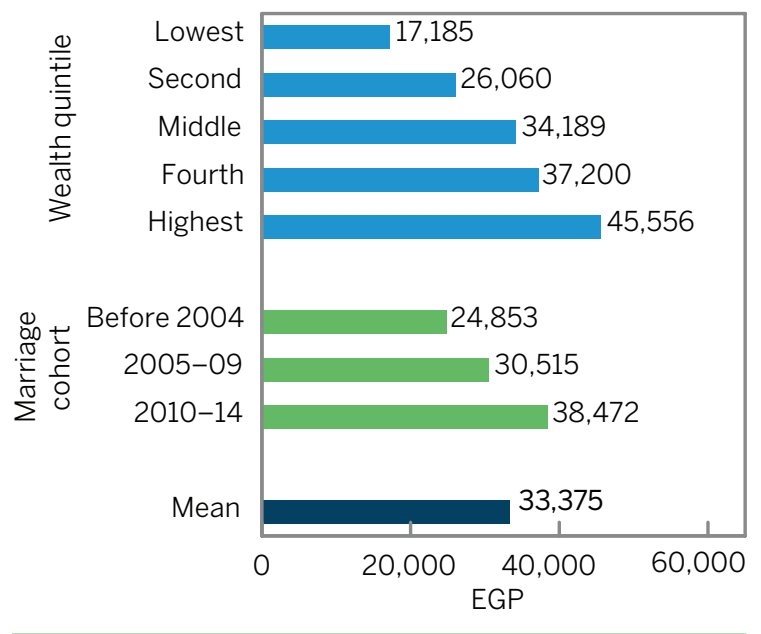

Note: As of June 2014, the exchange rate was: 1 USD $=7.6$ EGP.

ate youth (Table A6.9). This corresponds with the finding above that educated and wealthier youth are more likely to live independently upon marriage, and therefore to spend more on establishing a separate residence.

\section{Perceived barriers to marriage}

Given the substantial burden that saving for marriage represents for young people in Egypt, SYPE also asked respondents about their perceptions of the problems facing youth trying to marry. As shown in Figure 6.7, in 2014 youth (aged 15-29) were more likely to perceive a range of factors to be problems as compared to 2009. Although the percentage mentioning housing was nearly the same across both survey years, at about $70 \%$, in 2014 youth were more likely to perceive other components of the cost of marriage as a problem. They were also more likely to say that youth "want everything," or that their material expectations for marriage are too high. In terms of employment, which is particularly important to young men's ability to save for marriage and demonstrate marriageability, substantially larger percentages of youth cited problems in 2014. For example, whereas $10.4 \%$ of youth in 2009 said that the instability of jobs is a problem for youth trying to marry, by 2014 this had risen to $25.0 \%$ of youth. This may reflect the declining labor market conditions for youth during the transitional period, as discussed in Chapter 4.

FIGURE 6.7 Youth's perceptions of the problems they face in trying to marry, youth aged 15-29, 2009 and 2014 (\%)

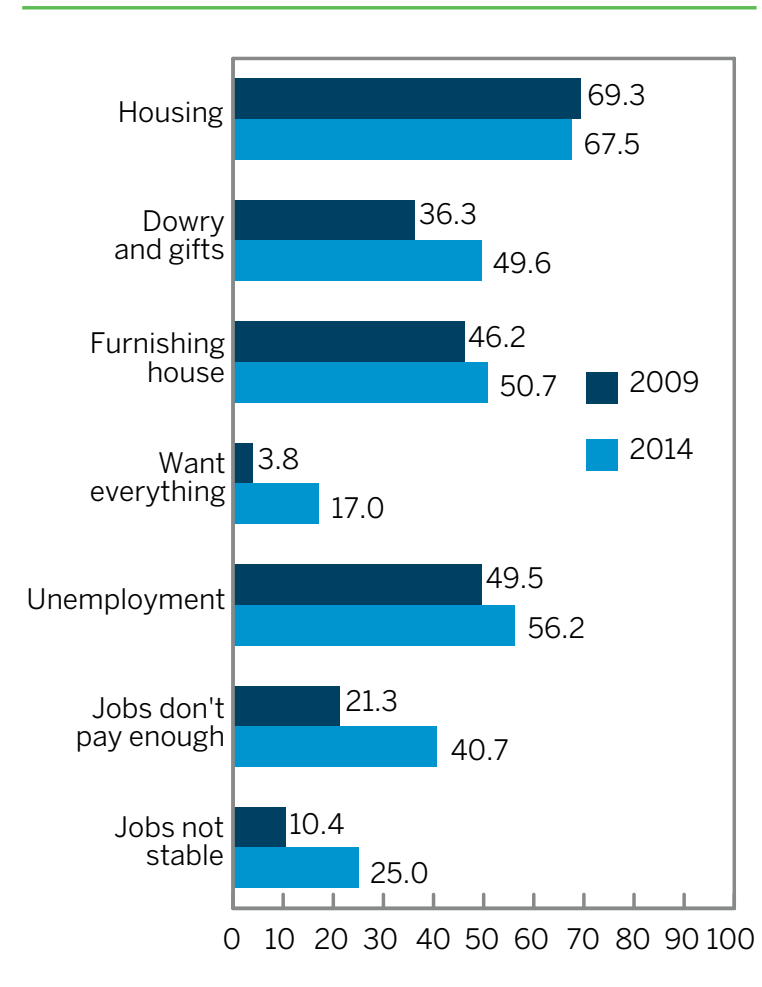


Increases in desired fertility for both males and females were consistent across wealth quintiles. This trend in desired fertility could have important implications for future fertility rates.

\section{Potential solutions to marriage barriers}

Youth's greater concern with problems facing young people trying to marry in 2014 was matched by a greater percentage who agreed that different potential solutions were options for addressing these problems. Notably, the percentage of youth suggesting greater financial support from both the bride's and the groom's family increased from 2009 to 2014 , from $16.6 \%$ to $31.4 \%$ for the bride's family and from $24.4 \%$ to $42.5 \%$ for the groom's family (Figure 6.8). The already high percentage of youth who thought that the government should provide support for marriage also increased further, from $59.5 \%$ to $64.5 \%$. The percentage of youth suggesting means of reducing marriage costs, namely doing without some things and living with family, also increased.

\subsection{Desired number of children}

Finally, as in 2009, SYPE asked all youth what they thought the ideal number of children is for a couple to have. Surprisingly, the results show a universal increase in desired number of children among youth as compared to 2009. Among never-married youth aged 15-29, the average desired number of children increased from 2.6 in 2009 to 2.9 in 2014 , and among married youth of the same age it increased from 2.8 children to 3.1 (3.2 among youth aged 13-35 in 2014). As shown in Figure 6.9, this
FIGURE 6.8 Youth's indications of possible solutions to the problems they face in trying to marry, youth aged 15-29, 2009 and 2014 (\%)

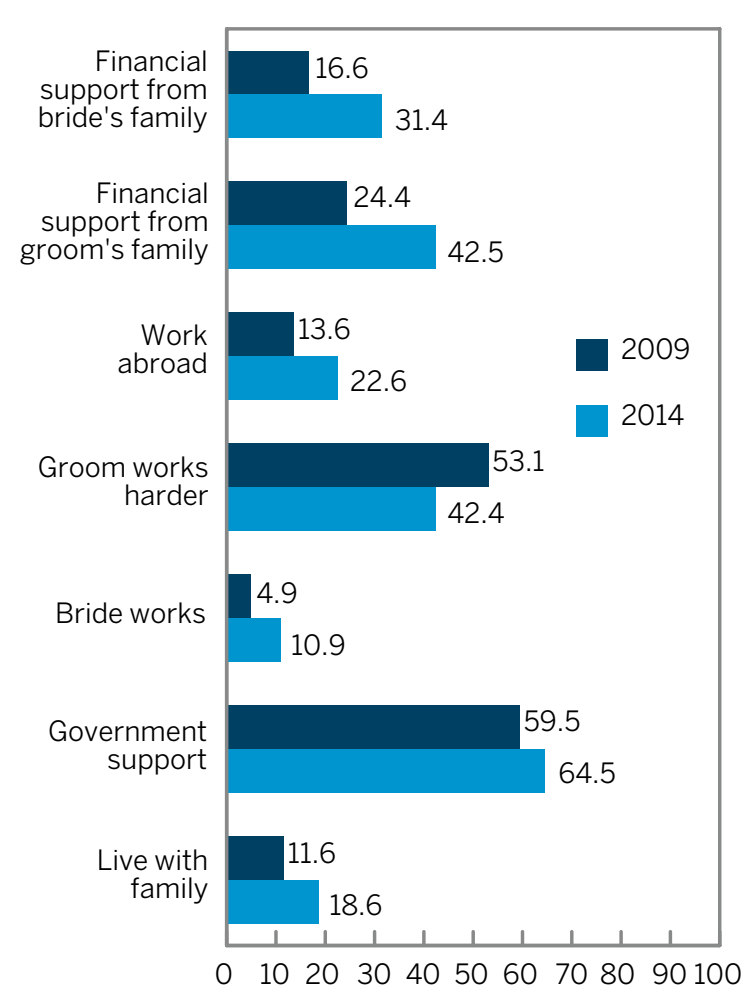

FIGURE 6.9 Desired number (mean) of children among married and unmarried youth aged 15-29, by gender, 2009 and 2014

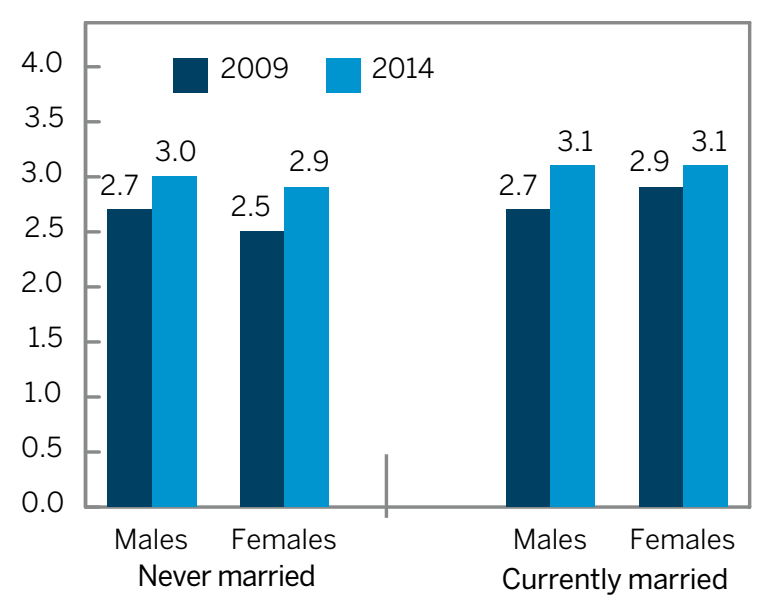


increase held across both genders regardless of marital status.

The increase in desired number of children also held across all wealth quintiles, educational levels, and regions of residence (Table A6.10). Among married youth aged 15-29, the largest increase in desired fertility was seen in urban Upper Egypt (from 2.9 to 3.5 children), whereas the Frontiers Governorates was the only region in which desired fertility remained unchanged. Among never-married youth, desired fertility increased by 0.5 children in both rural and urban Upper Egypt. Increases in desired fertility were quite consistent across wealth quintiles, at 0.3-0.4 children among married youth, and around 0.1 children for never-married youth in most quintiles. This trend in desired fertility could have important implications for future fertility rates.

\subsection{Conclusion}

The 2014 Panel Survey of Young People in Egypt allows for a broad look at Egyptian youth's transition into marriage, as the SYPE sample has now aged and a larger percentage of respondents have married. The analysis in this chapter reveals that the transition to marriage looks quite different for different subpopulations of Egyptian youth, with implications for the policies and programs that could help ensure that youth experience a timely and successful transition to marriage when and to whom they choose.

On one hand, young women in Egypt remain at risk of early marriage, particularly in rural areas and in Upper Egypt. Although the prevalence of early marriage appears to be declining among younger cohorts of women, substantial percentages still marry before the legal age of 18 . In addition, over a third of married young women report that they had no say in their decision to marry. There is therefore a need for continued programs to prevent early marriage, and to ensure the protection of young women's right to decide when they marry and to whom.
At the same time, there is a population of more educated youth, and particularly young men, who experience a comparatively late transition into marriage. Young men's transition into marriage is more concentrated than young women's, with a large majority marrying during their late 20 s and early 30s. Still, a quarter of young men aged 30-35 remain unmarried. Given the social significance of marriage as a marker of adulthood in Egypt, this raises the question of whether young men (and thus their potential spouses) remain unmarried not by choice but due to constraining factors. One such factor may be the high cost of marriage, which appears to be increasing even further among recent marriages (or among the subgroups of youth who are marrying later). That youth have increasingly felt the pressure of marriage costs under the difficult economic conditions prevailing during Egypt's transitional period is demonstrated by the higher percentage of youth reporting that young people face problems in trying to marry as compared to 2009. Measures to make marriage financially accessible to young people may thus be key to ensuring their successful transition to adulthood.

Finally, the number of children that youth wish to have has increased almost universally across gender, marital status, and other background characteristics since 2009. This finding agrees with the finding of lower contraceptive use among currently married youth (Chapter 2 ), but requires further investigation in order to understand some of the mechanisms that may be causing youth to want larger families than in 2009. If this increase in desired fertility proves to be a long-term trend, it has significant implications for a variety of national development indicators (see, e.g. Krafft and Assaad 2014), and points to the need for youth to have better access to education and information on family planning. 


\section{References}

Brady, Martha, Ragui Assaad, Barbara Ibrahim, Abeer Salem, and Rania Salem. 2007. "Providing New Opportunities to Adolescent Girls in Socially Conservative Settings: The Ishraq Program in Rural Upper Egypt." New York: Population Council.

Dhillon, Navtej and Tarik Yousef, eds. 2009. Generation in Waiting: The Unfulfilled Promise of Young People in the Middle East. Washington, DC: Brookings Institution Press.

Krafft, Caroline and Ragui Assaad. 2014. "Beware of the Echo: The Impending Return of Demographic Pressures in Egypt." Economic Research Forum Policy Perspective No. 12. Cairo: ERF.

Lee-Rife, Susan, Anju Malhotra, Ann Warner, and Allison McGonagle Glinski. 2012. "What works to prevent child marriage: A review of the evidence," Studies in Family Planning 43(4): 287-303.

Population Council. 2010. "Survey of Young People in Egypt.” Cairo: Population Council.

Singerman, Diane. 2007. “The Economic Imperatives of Marriage: Emerging Practices and Identities among Youth in the Middle East." Middle East Youth Initiative Working Paper, No. 6. Washington, DC: Wolfensohn Center for Development and Dubai School of Government. 


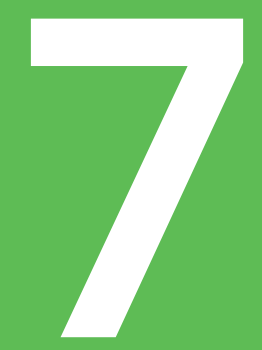

The Youth of the Revolution: Participation in Political Events from January 2011-June 2013

MAIA SIEVERDING • NADA RAMADAN

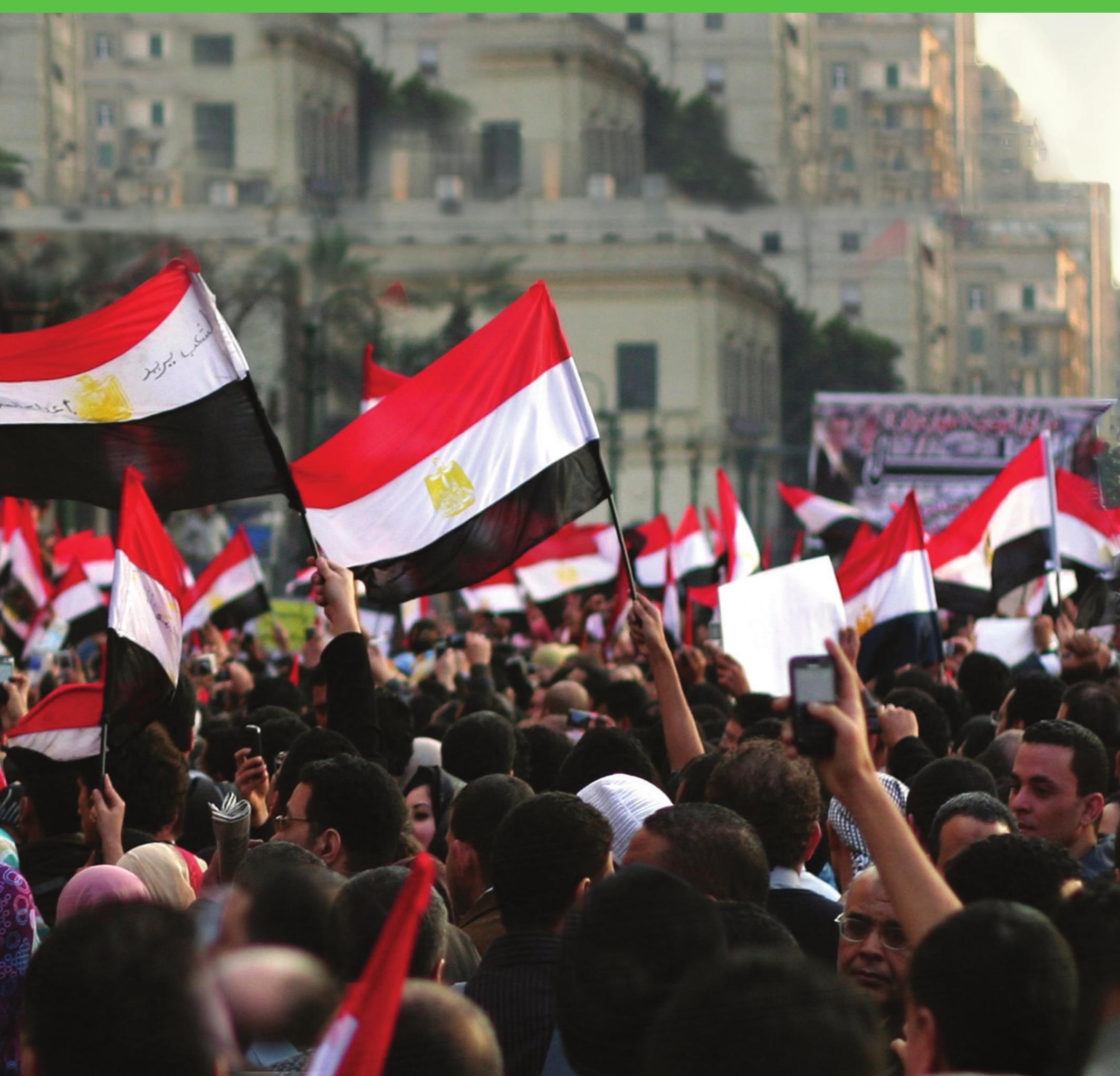


On January 25, 2011, protesters began an 18-day struggle against the Mubarak regime that brought new attention to Egyptian youth in the media, society, and politics. Young people have been widely viewed as a catalyst of the revolution through their public activism in virtual and physical spaces. They used social media, street protests, neighborhood protection committees, social services for demonstrators, and creative forms of artistic expression to express their grievances and call for change.

\subsection{Introduction}

The central role of youth in sparking the January 25 revolution was particularly compelling given the low rates of youth participation in political groups, voting, and volunteerism prior to this time. In 2009, the first round of the SYPE found youth to be politically apathetic and disengaged. Only $16 \%$ of all youth age 18-29 had voted in a previous election, and less than $1 \%$ belonged to a political party. Less than 5\% of Egyptian young people age 15-29 were members of a group or organization in 2009, and fewer than 3\% reported having participated in volunteer activities, mainly providing assistance to the poor (Population Council 2010).

As few nationally representative data have been available on youth's involvement in the January 25 revolution and subsequent events, the apparent dramatic shift from apathy to activism led to pressing questions about the current state of civic and political participation among youth: What were the actual participation rates of youth in revolutionrelated activism and who participated? For what reasons did many young people choose not to participate in the political events that started with the January 25, 2011 movement? Which youth were more or less likely to vote in the elections and referendums held during Egypt's transition? SYPE 2014 presents a unique opportunity to answer these questions on the national level, and to present a new portrait of youth activism and civic engagement during Egypt's transition.
Due to the wealth of data that SYPE collected on this topic, in this chapter we focus on youth participation in political events and processes, namely protests and other street-based activism, political organizing, and voting behavior. In the subsequent chapter we turn to volunteerism and participation in social groups, as well as youth's social and political opinions about a range of current events and issues.

Due to the multitude of changes that have occurred in the political arena since 2009, the SYPE 2014 civic engagement module substantially revised the series of questions related to civic participation, including participation in volunteer work, organizational membership, affiliation with political parties, and participation in elections. A new set of questions about participation in the events between January 25, 2011 and June 30, 2013 was also included in order to capture the extent and types of involvement among youth of different backgrounds. The set of questions asked in SYPE 2009 regarding media use was also updated, to attempt to measure the extent to which youth used media as vehicles to advance a political cause or as tools to remain informed and engaged citizens.

\subsection{Youth participation in political activism since January 2011}

Since the events of January 25, 2011, Egypt has witnessed an enormous change in the ways in which citizens claim their political rights and express their grievances. An analysis of which groups of youth actually participated in protests, and how they engaged in the tumultuous political processes of the past three years, is necessary in order to shed more light on the dynamics of this transitional period. The 2014 SYPE asked respondents about their participation in protests, activities to support protesters, strikes, neighborhood watches (legan shaabeya), and any violent forms of resistance since the onset of the January 25 revolution. Youth were also asked whether they had participated in any form of political or electoral organizing, including participating in or donating money to political 
parties, signing petitions, contacting politicians, or participating in electoral campaigns. ${ }^{1}$

Surprisingly, we find that participation in such activities among SYPE respondents was low, with only $7.4 \%$ of youth reporting that they had participated in any of the above-mentioned events since January 25 (Figure 7.1). Due to the low percentage of youth reporting participation in any of the types of political organizing, we aggregated all of these types into one measure; still, only $1.2 \%$ of youth reported participation in any type of political organizing. Just over 6\% of youth reported participating in a neighborhood watch, which was the most common form of participation. Contrasting the picture painted by extensive media coverage, only $1.3 \%$ of youth reported participating in a protest at any point from January 25 , 2011 through the time of the survey. (See Table A7.1 for the full set of participation patterns.)

There was some overlap between youth who took part in these different forms of activity, although the majority did not participate in more than one type of activity. About a quarter of youth who had participated in a protest also reported participat-

1 SYPE 2014 respondents who did not answer all questions in the series about participation in revolutionary activities, networks' participation in the revolution, personal exposure to violence, and participation in elections are dropped from these respective analyses. Otherwise, we would be making the assumption that nonresponse is equivalent to a "no," which is likely to be misleading, particularly for activities that youth may have been reluctant to report.
The 2014 Panel Survey of Young People in Egypt provides a unique opportunity to present a new portrait of youth activism and civic engagement during Egypt's transition.

ing in political organizing and vice versa. Although nearly half of youth who participated in a protest also participated in a neighborhood watch, because the latter group was larger, $90 \%$ of those who joined a neighborhood watch reported that they did not protest. As fewer than $1 \%$ of youth reported participating in activities to help protesters, strikes, or events involving violence, we do not present any further results on these types of activism alone due to the small sample size.

Understanding the socioeconomic makeup of those who participated in the protests can help reveal what dominated the agendas of those who participated. As shown in Figure 7.1, there was a substantial gender gap in participation in revolutionary activities, with $13.1 \%$ of male respondents participating compared to $1.5 \%$ of female respondents. This gender gap was somewhat expected due to the social, economic,

FIGURE 7.1 Youth participation in revolutionary activity since January 2011, by gender and age, 2014 (\%)

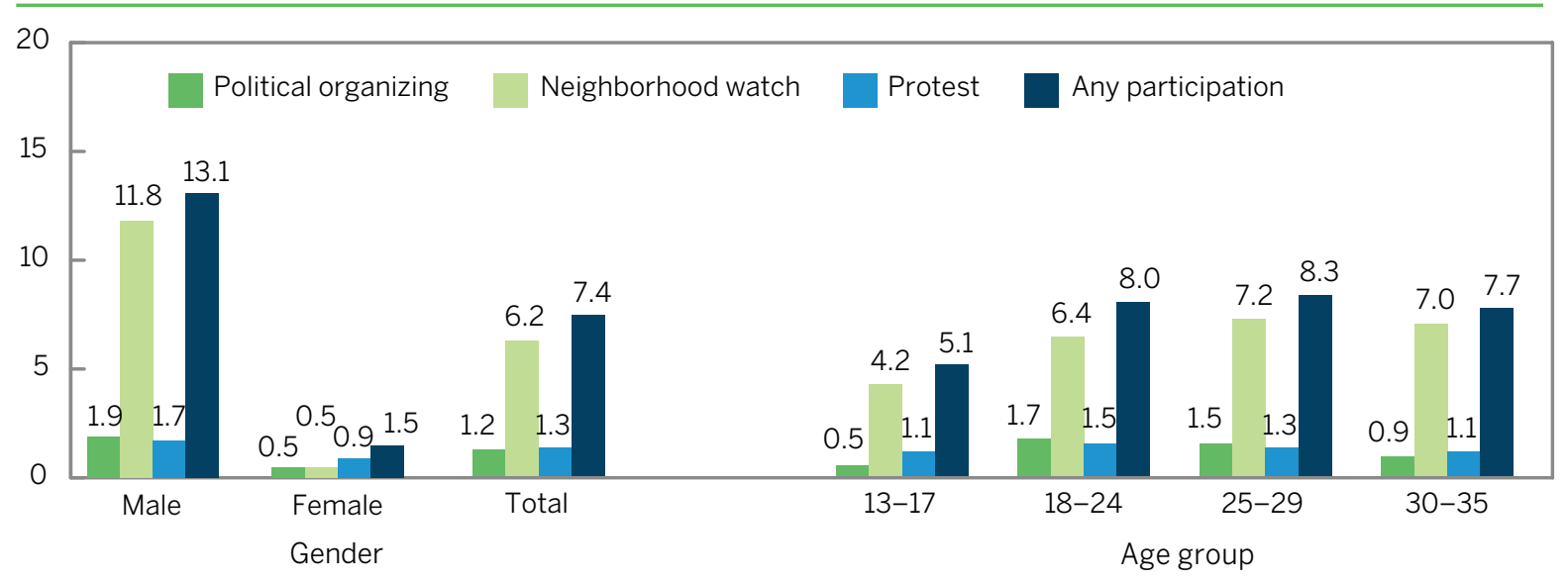


political, and security factors that may bar women from fully participating in the public sphere, particularly in open street protests and similar events, but stands in contrast to the extensive media discussion about female youth's participation in protests and other events. Disaggregated by gender, $11.8 \%$ of male youth report being part of neighborhood watches, which were organized during the 18 days of the 2011 revolution to protect homes from baltagiyya ("thugs") who took advantage of the security vacuum, compared to less than half a percent of female youth. The highest rate of female youth participation in any single activity was protesting (0.9\%), followed by political organizing (0.5\%), but these numbers were still lower than the participation rates of male youth in the same activities (at $1.7 \%$ and $1.9 \%$, respectively).

Along with difference in participation rates by gender, involvement in revolutionary activity varied greatly by residence; $13.9 \%$ of youth from the Urban Governorates participated in any form of activity, compared to lows of $2.6 \%$ in the Frontier Governorates and rural Upper Egypt and $2.1 \%$ in urban Upper Egypt (Figure 7.2). The type of revolutionary activity youth participated in also varied slightly depending on area of residence. While youth involvement in neighborhood watches was most common in urban areas (9.3\%), it was least common in informal urban settlements (3.5\%). Involvement in protests also varied slightly by residence: $3.0 \%$ of urban-based youth reported participating in demonstrations, compared to $0.6 \%$ of rural-based youth and almost $1 \%$ of youth living in informal areas. These patterns are expected since protests, as well as the violence that motivated neighborhood watches to form, were concentrated in Cairo and other major urban areas.

A positive correlation exists between youth's education level and the likelihood of participating in some form of political activism. Illiterate youth were the least active, with a participation rate of $2.6 \%$, compared to those who received university and graduate level education who reported the highest participation rate of $12.2 \%$ (Figure 7.3). This pattern may reflect a variety of factors, including network effects among youth with similar characteristics, the concentration of protests around universities, or the fact that urban populations, among whom participation rates were higher, tend to be better educated (see Chapter 3). Similarly, there was a positive relationship between household wealth and political activism; $10.7 \%$ of young people in the highest wealth quintile participated in revolutionary activity, as opposed to $3.8 \%$ of those from the lowest wealth quintile. The relationship between wealth and participation held across all types of participation measured. For example, $2.3 \%$ of youth from the highest wealth quintile participated in protests, and 1.4\% from the fourth quintile, compared to only $0.3 \%$ from the lowest wealth quintile. That there was greater participation from the youth

FIGURE 7.2 Youth participation in revolutionary activity since January 2011, by residence, 2014 (\%)

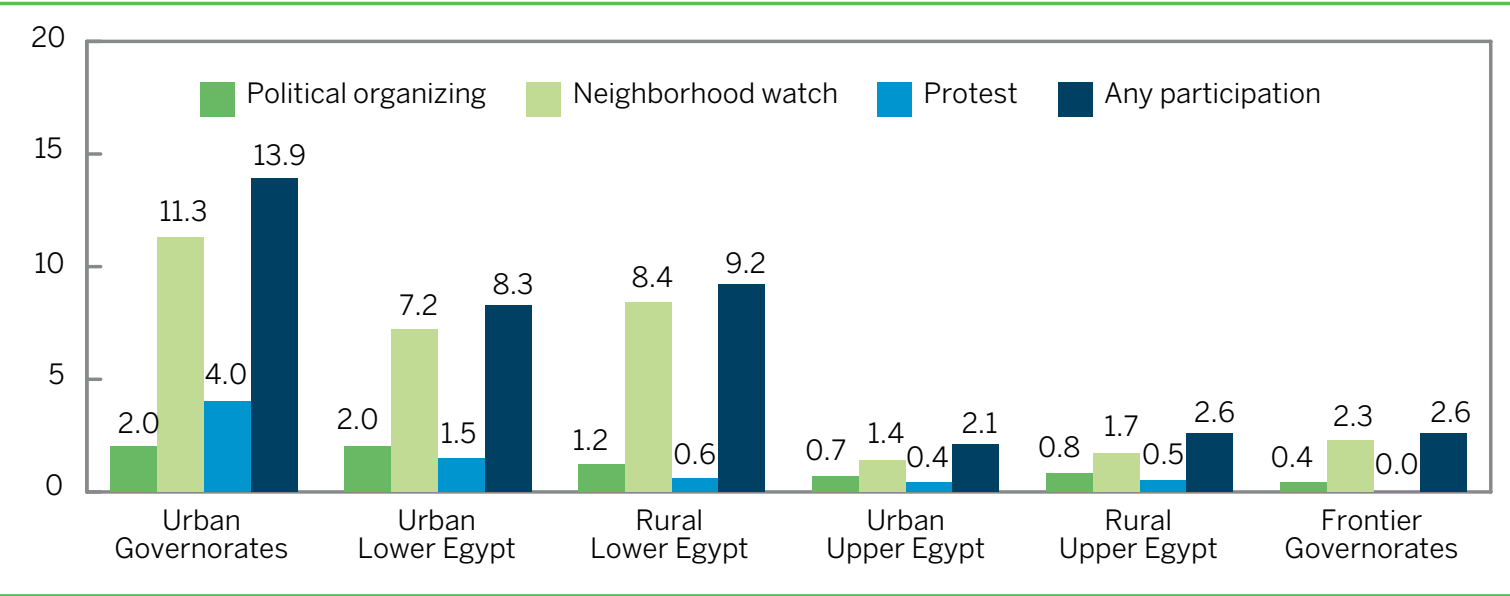


FIGURE 7.3 Youth participation in revolutionary activity since January 2011, by education level, $2014(\%)$

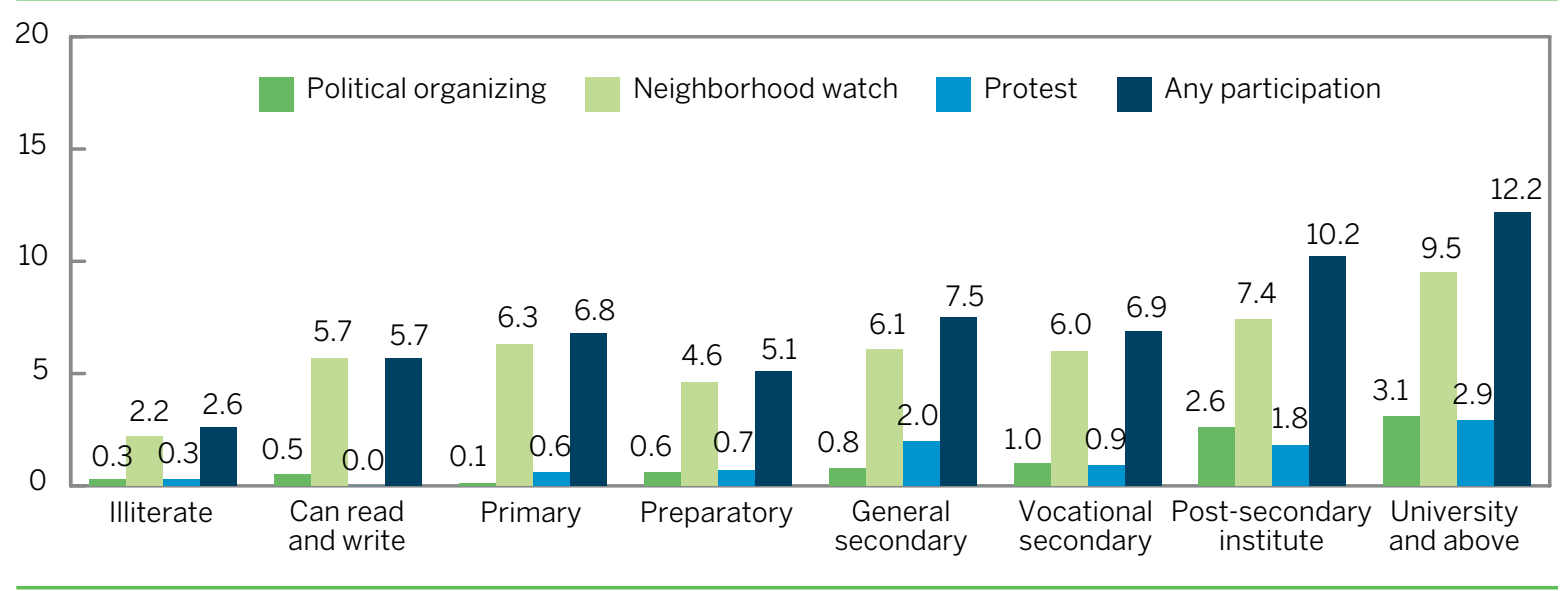

in the highest wealth quintiles in the January 25 revolution may indicate that these participants understood the revolution as a struggle for civil and political freedoms and not simply as one of economic grievances.

Unemployed youth were more likely to participate in protests (2.5\%) than employed youth (1.7\%), which may be a result of these youth having more free time, but may also reflect greater disillusionment or dissatisfaction with their life circumstances. A similar pattern held for political organizing, helping protesters and, interestingly, participating in strikes, even though these youth reported not having a job. Youth who were out of the labor force had much lower rates of participation in all types of activities, likely because this group is predominantly composed of female youth. However, likely due to the occurrence of protests at universities since January 25, 2011, youth who were out of the labor force but in school reported a somewhat higher participation rate in revolutionary activity (7.0\%).

\subsection{Participation of youth's social networks}

The consistently low participation rates reported by the generation termed the "youth of the revolution" are quite surprising, and raise the question of whether youth may have underreported their participation in revolutionary activity due to the politically sensitive climate characterizing the period during which SYPE 2014 data was collected from late July 2013 through early 2014 . This period included crackdowns on certain political parties, as well as the passage of a restrictive protest law in November 2013. Even though respondents were repeatedly reminded of their anonymity, they may have been hesitant to self-report their activism during this period of uncertainty.

What leads us to suspect that youth underreported their revolutionary activism is the higher rates of participation that respondents reported for other people in their lives. SYPE 2014 asked youth to rate the frequency of their parents', closest sibling's, and closest friend's participation in organizing or other "indirect" forms of activism (such as participating in night watches), or direct forms of activism such as strikes. ${ }^{2}$ Whereas youth's self-reported involvement in any of these types of revolutionary activity is low, respondents indicated higher rates of participation for all of these groups of family members and friends (Figure 7.4, full set of characteristics in Table A7.2). For example,

2 For young people's networks, SYPE defined organizational types of activism as activities such as participating in a political party, donating money to a political organization, or signing a petition. Night watches and protests were classified as "indirect" or supportive activism. Examples of "direct" activism included joining sit-ins or strikes. 
FIGURE 7.4 Youth's reports of their own and their networks' participation in any revolutionary activity, by gender, 2014 (\%)

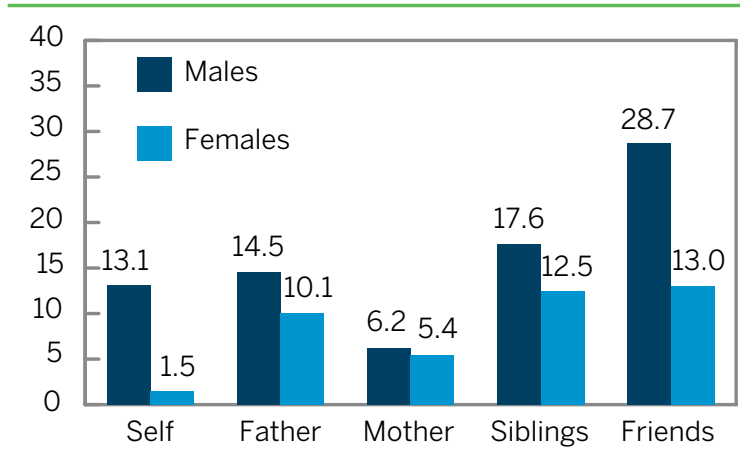

whereas only $13.1 \%$ of male respondents selfreported their own participation in any form of revolutionary activity, $28.7 \%$ of male youth reported their closest friends, $17.6 \%$ their siblings, and $14.5 \%$ their fathers as having participated in some form of revolutionary activity. Of all their social networks, male respondents reported only their mothers, with a participation rate of $6.2 \%$, as being less active than themselves. There was a smaller but still notable gap between male youth's reporting of their networks' participation in direct forms of activism and their own participation in protests (1.7\%); for example, $14.9 \%$ reported that their friends participated in direct activism, 3.3\% their fathers, and 2.7\% their mothers (Table A7.2).

As for female respondents, although only $1.5 \%$ had reported themselves as participating in any form of activity, they indicated that their fathers (10.1\%), mothers (5.4\%), siblings (12.5\%), and friends (13.0\%) had all been more active than themselves. They similarly reported that their networks were more active than themselves in both indirect and direct forms of activism. The fact that youth, across background characteristics, consistently reported higher participation rates among their networks-including their mothers, despite the gender norms that restrict women's participation-strongly suggests underreporting of youth's own participation. Interestingly, the reported participation of youth's networks in rural Lower Egypt and the Frontier Governorates is also particularly high (Table A7.2).
FIGURE 7.5 Youth's reports of their networks' participation in various revolutionary activities, by youth's own participation level, 2014 (\%)

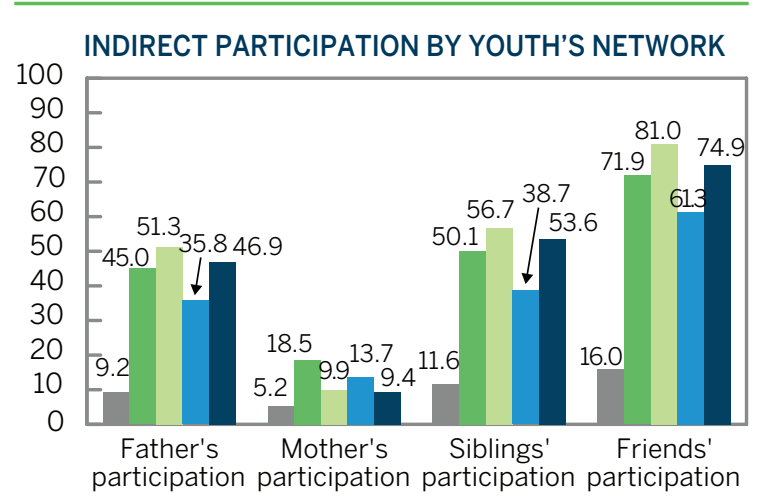

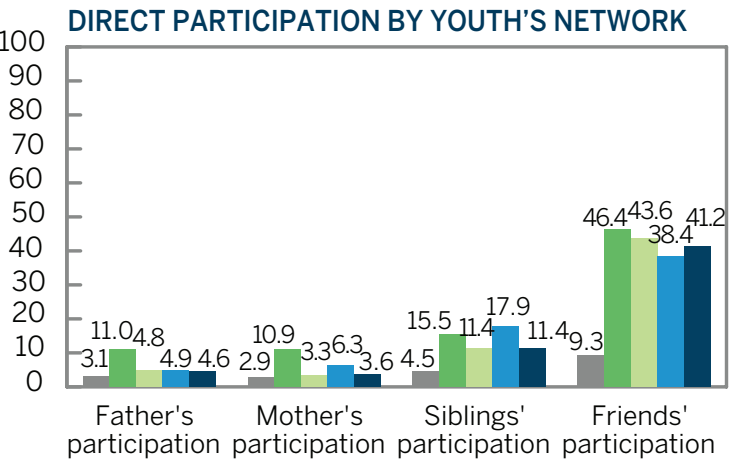

These data also show strong network effects in terms of participation. In other words, youth who participated in revolutionary activity were more likely to report that their friends and family also participated. For example, whereas less than $10 \%$ of inactive youth report their fathers as having participated in some form of revolutionary activity, this increases to $45 \%$ of youth who participated in political organizing and $36 \%$ of those who participated in a protest (Figure 7.5). Reported participation among the friends and siblings of youth who themselves participated is even higher. Interestingly, youth who protested reported that their parents were mainly involved in indirect forms of activity, whereas rates of participation in direct activity among their friends and siblings was substantially higher than among those of youth who did not protest. 


\subsection{Reasons for nonparticipation}

Despite the possibility that respondents underreported their political activism, many youth also said that they chose not to participate in revolutionary activities or were barred from being politically active by their families. As shown in Figure 7.6, $29.1 \%$ of youth reported that they did not participate in any revolutionary activity because they were confused about what was happening and could not decide if it was right or wrong to participate. Just under $19 \%$ of respondents indicated that they were not against the former regime and had no interest in participating in the uprising to undermine it, suggesting diversity in youth's opinion on the need for the January 25 revolution. About 16\% of nonparticipants did not join because they felt that their participation would not make a difference in changing the turn of events, and $14.5 \%$ gave other reasons.

Finally, despite the fact that youth reported higher rates of participation among some types of family members than they did for themselves, $27.4 \%$ of respondents said that their mother or father prohibited them from participating in the events. Younger youth, as might be expected, were more likely to report that they did not participate due to parents' opposition (Table A7.3). Youth in higher wealth quintiles were also more likely to give this reason, and less likely to report "other" as their reason for nonparticipation.
The main reasons youth reported for not participating also varied depending on where they were located. Whereas $42.4 \%$ of nonparticipants from the Urban Governorates blamed their parents for their lack of participation, only $18.4 \%$ from rural Upper Egypt cited this reason. This difference may be due to the higher level of revolutionary activity in the Urban Governorates, thus warranting greater opposition from parents. It could also be that youth in the Urban Governorates were more interested in participating than their peers elsewhere, so parental opposition was their main reason for nonparticipation as opposed to other factors. Fairly similar percentages of youth across the different regions did not participate because they felt they would not make a difference, ranging from about $13 \%$ to $17 \%$. However, youth from Upper Egypt and rural Lower Egypt were more likely to say that they did not participate because they were not against the prior regime, reaching $25.4 \%$ among youth from urban Upper Egypt.

\subsection{Media use for information on the January 25 revolution}

Awareness of current events and social, economic, or political issues facing a country can be strongly influenced by the media. However, the democratization of media with the spread of the Internet, and the growing popularity of new forms of social media, have also provided for more decentralized

FIGURE 7.6 Youth's reasons for nonparticipation in revolutionary activity, by region , 2014 (\%)

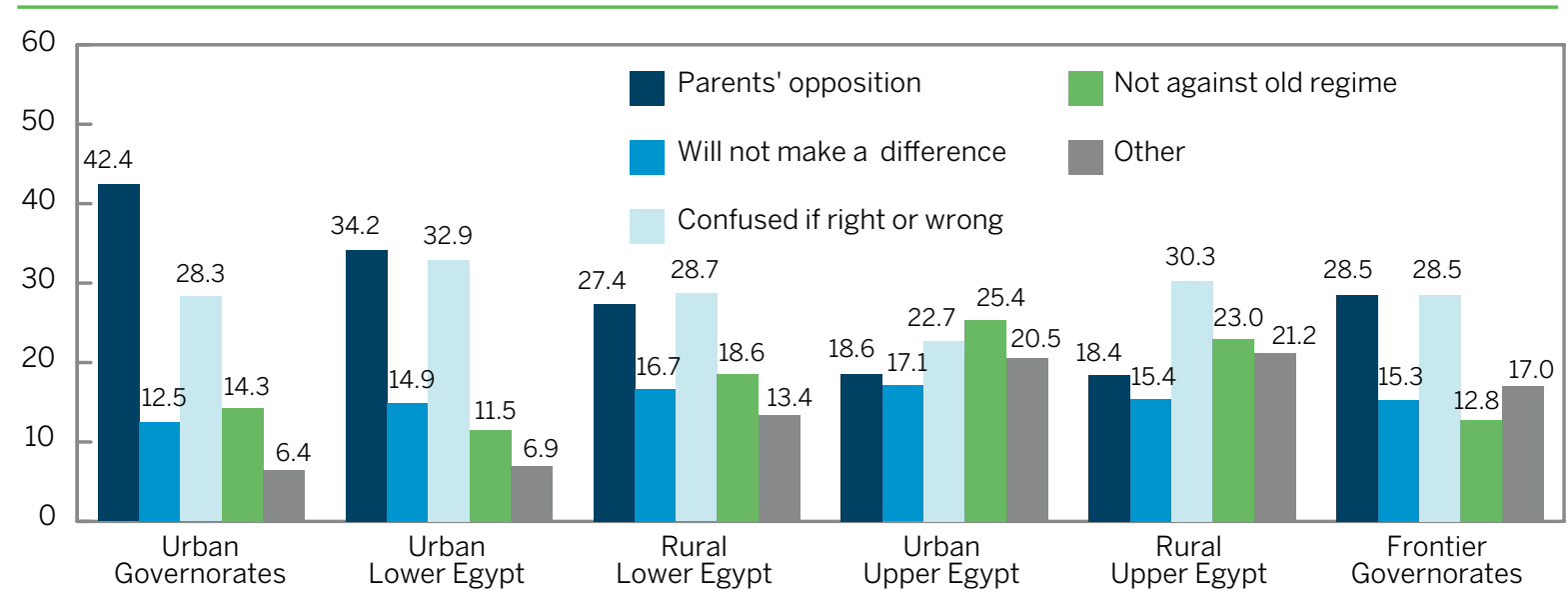

Note: Multiple answers allowed. 
Results from SYPE indicate that internet use among youth increased dramatically in the five years between surveys, jumping from less than $10 \%$ in 2009 to $25 \%$ in 2014.

forums for Egyptians to share information and debate political events. There has been a particular focus on the role played by social media in helping instigate and organize the uprisings that have taken place across the Middle East and North Africa since the Arab Spring. Thus, understanding how youth use media is crucial when attempting to draw conclusions about the factors and mechanisms that produced the January 25 revolution and other moments of political mobilization.

In 2009, SYPE asked young people about the frequency of their use of different media to obtain news and information, and found low usage. Over $70 \%$ of youth aged $15-29$ reported that they never used any form of media as a source of news, and fewer than 10\% had ever used the Internet. Yet SYPE indicates that youth's internet and media use increased dramatically from 2009 to 2014; in 2014, a quarter of youth aged 15-29 (25.1\%) reported having ever used the internet $(23.4 \%$ of all youth). Also, about $80 \%$ of youth reported that at least one type of media was important or very important to them for getting information about the January 25 revolution (data not shown).

SYPE 2014 asked youth to rank the importance of different sources of information to them regarding the January 25 revolution on a scale of 1 to 10 . On average, youth rated television as the most important source with an 8.2 rating (Table 7.1). Radio and newspapers both received a 4.7 rating, news shared through the Internet and Facebook were rated 4.5 and 4.4, respectively, and Twitter 3.9. The workplace was also rated at 3.9, and family and friends at 5.6, indicating that, with regards to the revolution, word- of-mouth was an important source of information for youth in addition to media.

There was little variation by socioeconomic or demographic background characteristics in youth's ratings of the importance of different sources of information on January 25. However, as shown in Table 7.1, youth who participated in revolutionary activities had different patterns of media usage, and gave higher importance ratings to a wider variety of information sources. Youth who participated in political organizing or protests were more likely to report internet news and social media such as Facebook and Twitter as sources of information. For example, protesters and political organizers rated Facebook's importance at 7.1 and 6.9, respectively. Youth who participated in political organizing rated radio, newspapers, and word-of-mouth sources such as family and work higher than both youth overall and protesters did.

\subsection{Experience of violence}

Egypt has suffered through the most intense political unrest in its recent history in the four years since the January 25, 2011 revolution, leading Egyptians to be exposed to new levels of violence both in the media and potentially in person. Although the impact that this unrest may have on youth is unknown, a first step is to measure youth's direct

TABLE 7.1 Youth's rating (mean) of the importance of different media sources of information about January 25 , by participation in revolutionary activities (scale of 1 to 10 )

\begin{tabular}{lccc}
\hline SOURCE & $\begin{array}{c}\text { ALL } \\
\text { YOUTH }\end{array}$ & $\begin{array}{c}\text { POLITICAL } \\
\text { ORGANIZERS }\end{array}$ & $\begin{array}{c}\text { PRO- } \\
\text { TESTERS }\end{array}$ \\
\hline TV & 8.2 & 8.1 & 7.3 \\
Friends/family & 5.6 & 7.5 & 6.6 \\
Newspaper & 4.7 & 6.1 & 4.9 \\
Radio & 4.7 & 5.4 & 4.1 \\
Internet news & 4.5 & 7.1 & 6.4 \\
Facebook & 4.4 & 6.9 & 7.1 \\
Twitter & 3.9 & 5.7 & 5.5 \\
Work & 3.9 & 5.9 & 4.6 \\
Pamphlets & 3.5 & 4.9 & 4.0 \\
Meetings & 3.3 & 4.8 & 3.9 \\
Text message & 3.3 & 4.4 & 3.8 \\
Email & 3.3 & 4.5 & 4.3 \\
\hline
\end{tabular}


and indirect exposure to violence during Egypt's transition. As shown in Table 7.2, the SYPE results indicate that nearly all youth witnessed violence on TV during the period from the start of the January 25,2011 revolution to the time of the survey; $98.5 \%$ of all respondents reported witnessing violence on television at least once during this time. Just under one-third reported seeing violence on social media during the same period. Male youth, youth in the middle age ranges (13-29-year-olds), urban youth, and youth with post-secondary education were more likely to report having witnessed violence on social media.

Youth were also asked whether they had seen someone injured or killed in person during the peri- od from the start of the January 25, 2011 revolution to the time of the survey. Overall, $18.3 \%$ reported having seen someone injured and $7.2 \%$ having seen someone killed. However, the frequency with which youth witnessed violence in these forms varied substantially; nearly all youth who had seen violence on TV said that they saw this "many times" or "a few times," and the majority of youth reported seeing violence on TV. Of those who witnessed violence in person, slightly over half also said that they saw this "many times" or "a few times." Of those youth who reported seeing someone killed in person, over half said they saw this just once and the rest more frequently. Again, male youth, youth in the middle age groups, and those with post-secondary education

TABLE 7.2 Youth exposure to violence perpetrated against others, January 25, 2011 to time of the survey, by background characteristics and participation in revolutionary activity, 2014 (\%)

\begin{tabular}{|c|c|c|c|c|}
\hline & ONTV & $\begin{array}{l}\text { SOCIAL } \\
\text { MEDIA }\end{array}$ & $\begin{array}{l}\text { SAW SOMEONE } \\
\text { INJURED IN PERSON }\end{array}$ & $\begin{array}{l}\text { SAW SOMEONE } \\
\text { KILLED IN PERSON }\end{array}$ \\
\hline \multicolumn{5}{|l|}{ Gender } \\
\hline Male & 98.4 & 37.6 & 24.0 & 9.6 \\
\hline Female & 98.5 & 24.5 & 12.3 & 4.7 \\
\hline \multicolumn{5}{|l|}{ Age group } \\
\hline 13-17 & 98.8 & 32.1 & 14.9 & 5.2 \\
\hline $18-24$ & 98.4 & 34.8 & 20.0 & 8.4 \\
\hline $25-29$ & 98.3 & 29.6 & 18.9 & 7.7 \\
\hline $30-35$ & 98.3 & 24.0 & 17.3 & 6.0 \\
\hline \multicolumn{5}{|l|}{ Region } \\
\hline Urban Governorates & 99.1 & 54.9 & 32.5 & 9.0 \\
\hline Urban Lower Egypt & 99.0 & 37.3 & 22.7 & 10.9 \\
\hline Rural Lower Egypt & 97.3 & 29.9 & 17.7 & 7.7 \\
\hline Urban Upper Egypt & 98.5 & 23.5 & 6.8 & 4.0 \\
\hline Rural Upper Egypt & 99.1 & 16.7 & 10.3 & 4.0 \\
\hline Frontier Governorates & 98.2 & 33.4 & 29.5 & 20.8 \\
\hline \multicolumn{5}{|l|}{ Education level } \\
\hline Illiterate & 96.6 & 8.7 & 7.7 & 3.3 \\
\hline Can read and write & 99.1 & 17.4 & 10.7 & 1.9 \\
\hline Primary & 98.5 & 15.0 & 14.8 & 6.2 \\
\hline Preparatory & 99.1 & 20.2 & 13.9 & 4.8 \\
\hline General secondary & 98.5 & 45.9 & 18.4 & 7.0 \\
\hline Vocational secondary & 98.4 & 24.5 & 17.3 & 7.0 \\
\hline Post-secondary institute & 99.5 & 46.5 & 30.9 & 11.8 \\
\hline University and above & 98.7 & 60.4 & 27.7 & 11.0 \\
\hline \multicolumn{5}{|c|}{ Youth participation in revolution } \\
\hline No participation & 98.3 & 28.4 & 16.9 & 6.7 \\
\hline Any participation & 99.9 & 65.8 & 35.9 & 13.1 \\
\hline Political organizing & 100.0 & 78.5 & 53.9 & 21.7 \\
\hline Neighborhood watch & 99.9 & 63.7 & 33.6 & 13.1 \\
\hline Protest & 100.0 & 80.9 & 62.1 & 22.8 \\
\hline Total & 98.5 & 31.2 & 18.3 & 7.2 \\
\hline$(\mathrm{N})$ & $(10,890)$ & $(10,889)$ & $(10,890)$ & $(10,888)$ \\
\hline
\end{tabular}


were more likely to report seeing either of these forms of violence.

Youth reports of having witnessed violence in person also varied by region (Table 7.2). Youth in the Frontier Governorates witnessed the highest level of violence, with $29.5 \%$ reporting that they had seen someone injured and $20.8 \%$ reporting that they had seen someone killed. This high rate may be explained by the increasing activity of militants in the Sinai Peninsula since the January 25 revolution. Youth in the Urban Governorates and urban Lower Egypt also witnessed relatively high rates of violence. Youth in rural Upper Egypt were least likely to report having personally witnessed violence, with $10.3 \%$ having seen someone injured and $4.0 \%$ had seen someone killed.

Similar to the low reported rates of participation in protests and other events, and somewhat in contrast to the results presented above, few youth reported that they had ever been directly exposed to violence on the streets, whether since January 25,2011 or before the revolution. As shown in Table $7.3,5.0 \%$ of youth report having ever been the victim of a form of violence. The most common among these, verbal abuse, was experienced by $3.4 \%$ of youth, whereas $1.7 \%$ of all youth reported being exposed to tear gas, $1.0 \%$ said they had been hit or kicked, and $0.8 \%$ said that they had a family member or friend injured. Fewer than half a percent of youth reported being exposed to other forms of violence, including being shot at, detained, or having a friend or family member killed, so we did not disaggregate these numbers further due to the small sample sizes.

Direct exposure to all reported types of violence was higher among males than among females, although exposure to different types of violence was more common in different regions. Overall, youth in the Urban Governorates were most likely to report exposure to any violence, at 7.9\%. As expected, however, youth who participated in any form of revolutionary activity, including political organizing or a neighborhood watch, were substantially more likely to report exposure to all kinds of violence than youth who had not participated in any form of activity.

The types of violence that youth were exposed to before and after the January 25 revolution appear to be quite different. Whereas only $38.6 \%$ of youth who reported verbal abuse said that this had happened since the start of the revolution, and $22.3 \%$ of those who reported being kicked or hit, nearly all of the youth who were exposed to tear gassing or saw a friend or family member injured reported that this occurred since the revolution. Youth were also much more likely to report that the latter forms of violence were perpetrated by a state force, whether the police, military, or other agency.

These low reports of direct exposure to street violence should also be taken with caution, as they provide additional evidence that youth may have underreported their participation in revolutionary activities in SYPE. For example, the fact that $98.5 \%$ of youth exposed to tear gas reported that this occurred since the revolution suggests that these youth were likely gassed during a protest. Although it is possible that youth were exposed to tear gas while simply observing a protest, the fact that $73 \%$ of the youth who reported being gassed said that they had not participated in any protests may also point to underreporting of their participation in revolutionary activity. Furthermore, the high percentage of youth who report having seen someone killed or injured in person, relative to the rates of self-reported participation, seems inconsistent. The large discrepancy between these reported figures suggests that these youth may in fact have been at protests or other events where they witnessed violence.

\subsection{Perceptions of January 25, 2011 and June 30, 2013}

Two regime changes have occurred in Egypt over the past four years that were not brought about by elections: the ousting of long-term President Hosni Mubarak after the 18 days of 2011, and the deposing of President Muhammad Morsi in the summer of 2013 . To better understand how youth felt about these historical events, SYPE 2014 attempted to assess youth's perceptions of the goals of both January 25, 2011 and June 30, 2013, as well as whether or not they supported the event. It is important to remember that youth's responses 
TABLE 7.3 Youth aged 13-35 reporting having been the victim of violence, by selected background characteristics, participation in revolutionary activity, and when violence occurred, 2014 (\%)

\begin{tabular}{|c|c|c|c|c|c|}
\hline & $\begin{array}{l}\text { ANY FORM } \\
\text { OF VIOLENCE }\end{array}$ & $\begin{array}{l}\text { VERBAL } \\
\text { ABUSE }\end{array}$ & $\begin{array}{l}\text { HIT OR } \\
\text { KICKED }\end{array}$ & $\begin{array}{l}\text { TEAR } \\
\text { GASSED }\end{array}$ & $\begin{array}{l}\text { FAMILY MEMBER OR } \\
\text { FRIEND INJURED }\end{array}$ \\
\hline \multicolumn{6}{|l|}{ Gender } \\
\hline Male & 7.3 & 4.8 & 1.6 & 2.6 & 1.3 \\
\hline Female & 2.6 & 1.9 & 0.4 & 0.7 & 0.2 \\
\hline \multicolumn{6}{|l|}{ Age group } \\
\hline $13-17$ & 4.5 & 3.7 & 1.1 & 1.0 & 0.3 \\
\hline $18-24$ & 5.5 & 3.5 & 1.1 & 2.0 & 0.7 \\
\hline $25-29$ & 5.4 & 3.6 & 1.2 & 1.8 & 1.2 \\
\hline $30-35$ & 3.8 & 2.2 & 0.5 & 1.6 & 0.8 \\
\hline \multicolumn{6}{|l|}{ Region } \\
\hline Urban Governorates & 7.9 & 3.1 & 0.7 & 5.2 & 2.1 \\
\hline Urban Lower Egypt & 1.9 & 1.0 & 0.5 & 1.1 & 0.3 \\
\hline Rural Lower Egypt & 3.9 & 3.0 & 0.7 & 0.9 & 0.4 \\
\hline Urban Upper Egypt & 6.0 & 4.7 & 0.8 & 1.5 & 0.3 \\
\hline Rural Upper Egypt & 5.4 & 4.6 & 1.8 & 0.6 & 0.4 \\
\hline Frontier Governorates & 4.1 & 1.2 & 0.4 & 0.6 & 3.0 \\
\hline \multicolumn{6}{|l|}{ Youth participation in revolution } \\
\hline No participation & 3.3 & 2.8 & 0.8 & 0.4 & 0.3 \\
\hline Any participation & 25.7 & 10.6 & 3.4 & 17.1 & 6.0 \\
\hline Political organizing & 38.3 & 13.3 & 2.4 & 26.1 & 13.4 \\
\hline Neighborhood watch & 24.5 & 9.8 & 3.6 & 17.3 & 5.6 \\
\hline Protest & 41.0 & 13.6 & 5.0 & 35.4 & 5.1 \\
\hline Total & 5.0 & 3.4 & 1.0 & 1.7 & 0.8 \\
\hline$(\mathrm{N})$ & $(10,890)$ & $(10,890)$ & $(10,798)$ & $(10,721)$ & $(10,792)$ \\
\hline (N who responded "yes") & (500) & (322) & $(92)$ & (169) & (98) \\
\hline $\begin{array}{l}\text { Experienced this form of violence } \\
\text { after January 25, } 2011\end{array}$ & $\mathrm{~N} / \mathrm{A}$ & 38.6 & 22.3 & 98.1 & 96.5 \\
\hline $\begin{array}{l}\text { This form of violence was perpetrated } \\
\text { by state forces (police, military, etc.) }\end{array}$ & $\mathrm{N} / \mathrm{A}$ & 8.2 & 9.2 & 68.4 & 58.5 \\
\hline
\end{tabular}

were shaped by the events that followed both of these regime changes, which included political instability and an economic downturn. Youth's understandings of and support for January 25, 2011 and June 30, 2013 with the hindsight of two years and several months, respectively, may therefore be different from responses they would have given at the time of these events.

SYPE 2014 asked to what degree the goals of the January 25 and June 30 events were clear to them. Whereas $37.4 \%$ of youth found the goals of the January 25 "very clear", a higher percentage, 43.2\%, found the goals of June 30 "very clear" (Figure 7.7). For each of these events, over $40 \%$ of youth said that they found the goals "somewhat clear," indicating a fairly high degree of confusion among youth as to what both movements were about.
Only $17.2 \%$ of youth found the goals of January 25 unclear, compared to $14.2 \%$ of youth who found the goals of June 30 unclear. Youth in the higher wealth quintiles generally tended to report greater clarity on the goals of both events compared to their peers in lower quintiles (Table A7.4); however, this relationship may be driven by education, as more educated youth also tended to report greater clarity on the goals. Youth from the Frontier Governorates generally reported lower levels of clarity on the goals of both events. Male youth were more likely to report that they were "very clear" on the goals of both January 25 and June 30 compared to female youth, who were more likely than male youth to report that they were "very unclear" about the goals of both events. 
FIGURE 7.7 Youth's reported degree of clarity on the goals of January 25, 2011 and June 30, 2013, by education level, 2014 (\%)

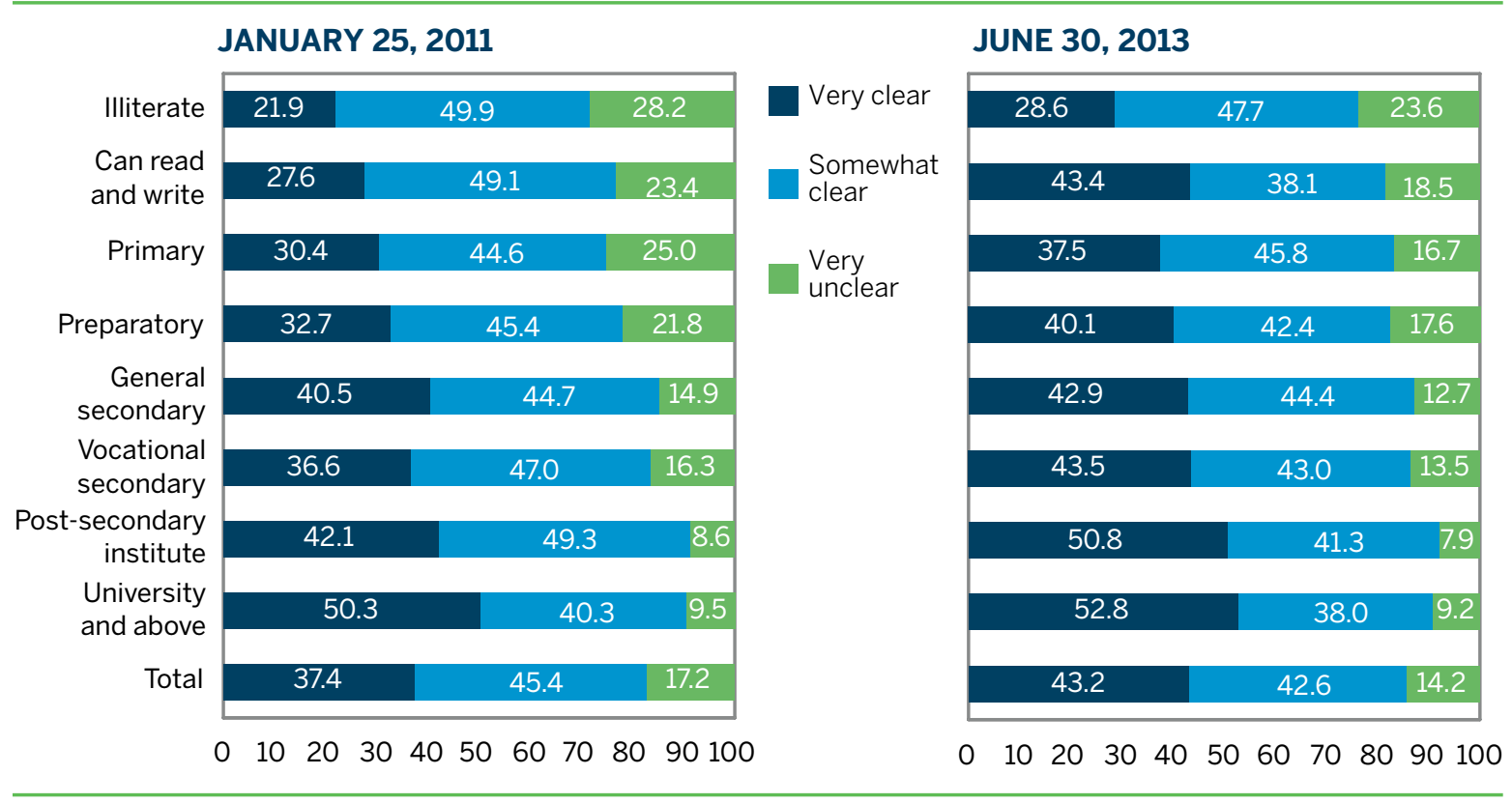

\subsection{Youth participation in elections and referendums}

Under the Mubarak regime, the National Democratic Party maintained an effective monopoly on political power, and elections were tightly controlled. In this context, youth participation in elections was low, as documented by SYPE 2009 , which found that only $16 \%$ of respondents of voting age had ever voted in an election. With the opening of the political process after January 25, millions of Egyptians were eager to vote and the media reported much higher turnout rates for the elections and referendums that occurred from 2011 through 2012. SYPE 2014 allows us to calculate for the first time youth's self-reported turnout for these elections, and examine variation in turnout rates across different groups of young people.

Youth were asked whether they voted in six rounds of elections or referendums in SYPE 2014. The first was the constitutional referendum held in March 2011, under the Supreme Council of Armed Forces, which set the stage for parliamentary and presidential elections to replace the transitional government. Parliamentary elections were held in two rounds at the end of 2011, although these candidates were later to be dismissed in June 2012 by the Supreme Constitutional Court, which ruled that the election was unconstitutional. In May 2012, the first round of the presidential election was held, which resulted in a second runoff round in June 2012 that brought Muhammad Morsi to power. Under former President Morsi, a second constitutional referendum was then held in 2012. SYPE 2014 was conducted before the latest presidential elections in May 2014 that brought the current President, Abdel Fatah al-Sisi, to power, so data on youth participation in this last election are not available.

Figure 7.8 presents self-reported turnout for the 2011 and 2012 constitutional referendums, parliamentary, and presidential elections, for youth aged 20 and older. Although the legal voting age in Egypt is 18 , because SYPE reported on elections and referendums taking place one to two years prior to the survey, many of the younger youth were ineligible to vote at the time of the election. In order to focus on turnout and reasons for not voting among youth who were eligible across the elections reported, we therefore drop these youngest cohorts of 18- and 19-year-olds. Self-reported turnout rates for youth by all background characteristics and revolutionary activity are presented in Table A7.5. 
FIGURE 7.8 Youth's self-reported turnout in referendums and elections from 2011-2012, by gender and wealth quintile, 2014 (\%)

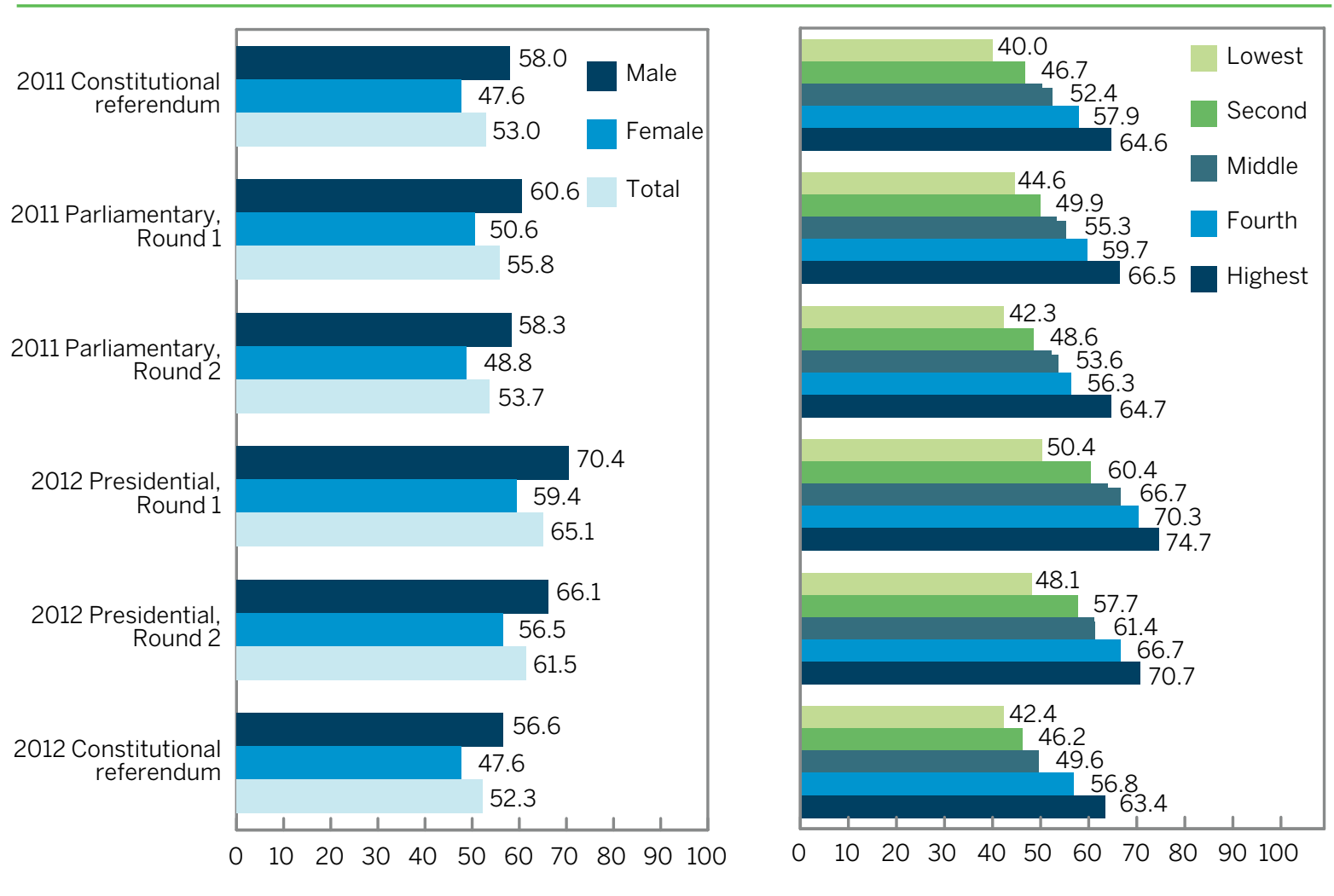

Youth participation in national elections increased substantially since 2009, with turnout ranging from $52 \%$ to $65 \%$. As expected, youth turnout was highest for the presidential elections, with $65.1 \%$ voting in the first round and $61.5 \%$ in the second round. Youth participation was higher than the reported overall voter turnout rates of $46 \%$ and $52 \%$, respectively, for these two elections (Carter Center 2012). Youth turnout was the lowest in the two constitutional referendums, both around 53\%. For the 2011 and 2012 referendums, this mirrored the low overall turnout of $41 \%$ and $32 \%$ respectively, but, as demonstrated by these figures, was still higher than turnout rates for the general population (Sabry 2012).

Youth voting behavior since the January 25, 2011 revolution varies by a number of background characteristics. Female youth consistently had a turnout rate of about 10 percentage points lower than male youth. Turnout also differed by region; voter turnout was generally lowest among eligible youth in urban and rural Upper Egypt, followed by the Frontier
Governorates. Turnout was highest in urban Lower Egypt, followed by the Urban Governorates. For example, in the 2012 constitutional referendum, $70.1 \%$ of youth in urban Lower Egypt voted, compared to $40.3 \%$ in rural Upper Egypt, and $45.9 \%$ in urban Upper Egypt.

Turnout was consistently around 6-9 percentage points higher among youth aged 30 and older compared to those aged 20-24, with youth aged 25-29 falling in the middle. Correspondingly, married youth consistently participated more than their unmarried peers in all referendums and elections. Even though the government often announced public holidays during elections to encourage participation, employment status also seems to affect voting levels, with unemployed youth consistently voting at a higher rate than employed youth. Public-sector wage employees consistently had higher turnout rates than private wage and self-employed workers, with nonwage workers consistently having the lowest turnout rates. These patterns may be driven by the educational composition of different types 


\section{Youth participation in national elections increased substantially since 2009, with turnout ranging from $52 \%$ to $65 \%$.}

of workers, as increasing education and wealth show similar associations with higher turnout rates. Whereas between $28-41 \%$ of illiterate youth turned out for each election, the turnout rate among youth with postsecondary education ranged from 65$80 \%$, or nearly double the rate of the least educated youth. Similarly, voter turnout rates increase with wealth quintile-in Round 1 of the 2012 presidential elections, $50.4 \%$ of youth in the lowest wealth quintile participated in elections compared to $74.7 \%$ of youth from the highest wealth quintile (Figure 7.8).

The turnout results also demonstrate that youth's revolutionary activity was associated with their likelihood of voting, as we might expect. Across all of the elections and referendums, youth who did not participate in any revolutionary activity were less likely to have voted than youth who participated in any form of revolutionary activity. For example, 50.5\% of youth who did not participate in any revolutionary activity voted in the 2011 constitution referendum, whereas $79.8 \%$ of youth who reported having participated in some form of revolutionary activity voted. Finally, youth's support of the January 25 and June 30 events were also associated with their turnout rates. Those who reported that they supported January 25 consistently turned out at rates of about 20 percentage points higher than youth who reported that they did not support January 25. Similarly, higher degrees of support for the events of June 30 were consistently associated with higher turnout rates. These findings suggest that youth who were unhappy with the direction of Egypt's transition may have been less likely to engage in the political process and exercise their right to vote.

Since these results suggest that there were subpopulations of youth who have been less enfranchised by the political processes following the January 25 revolution, we conducted an additional analysis of the consistency of youth's turnout across the six elections and referendums. As shown in Table 7.4, 29.3\% of youth reported that they did not vote in any of these six elections, whereas $41.4 \%$ reported that they voted in all six (results by the full set of background characteristics are presented in Table A7.6), reflecting considerable diversity in youth involvement in the political process.

The patterns of nonparticipation in any elections were consistent with youths' self-reported turnout rates, and suggest some concerning findings regarding the disenfranchisement of certain groups of youth. In particular, $35.2 \%$ of female youth reported that they never voted compared to $23.8 \%$ of male youth, suggesting that young women were considerably less involved in the electoral process. This is consistent with the finding that a sizable percentage of youth in some regions do not support women voting (Chapter 9), and suggests that gender norms may have been a barrier to young women's political participation at the voting booth as well as in the streets. On the other hand, as discussed below, fe-

TABLE 7.4 Youth who report never and always voting from 2011-2012, by selected background characteristics, 2014 (\%)

\begin{tabular}{lcc}
\hline & $\begin{array}{c}\text { NEVER } \\
\text { VOTED }\end{array}$ & $\begin{array}{r}\text { ALWAYS } \\
\text { VOTED }\end{array}$ \\
Gender & & \\
Male & 23.8 & 45.4 \\
Female & 35.2 & 37.1 \\
Region & & \\
Urban Governorates & 26.5 & 45.5 \\
Urban Lower Egypt & 14.8 & 59.9 \\
Rural Lower Egypt & 26.8 & 42.4 \\
Urban Upper Egypt & 32.4 & 37.3 \\
Rural Upper Egypt & 38.9 & 30.9 \\
Frontier Governorates & 34.0 & 38.2 \\
Education level & & \\
Illiterate & & \\
Can read and write & 54.7 & 20.6 \\
Primary & 31.5 & 31.2 \\
Preparatory & 37.4 & 31.5 \\
General secondary & 38.3 & 32.2 \\
Vocational secondary & 32.4 & 37.5 \\
Post-secondary institute & 26.9 & 40.8 \\
University and above & 17.8 & 54.3 \\
Total & 16.6 & 57.5 \\
\hline & 29.3 & 41.4 \\
\hline
\end{tabular}


male youth were also more likely to report that they did not vote because they "don't care."

Youth in Upper Egypt and the Frontier Governorates were also more likely to report that they never voted, as were the less educated. Whereas over half of illiterate youth reported that they had never voted, only $17 \%$ of youth with a post-secondary education had never voted. Poorer youth were also less engaged with the political process, with $42 \%$ in the lowest wealth quintile reporting that they had never voted compared to $21 \%$ of those in the highest wealth quintile. Similar to the results on turnout, youth who participated in revolutionary activities and those who supported January 25 and June 30 were less likely to say that they had never voted.

Youth who did not vote in the elections and referendums were also asked why they chose not to (Figure 7.9; full results by background characteristics and revolutionary activity found in Table A7.7). Responses suggest that nonparticipating youth were either apathetic about or dissatisfied with the political process. For the 2011 constitutional referendum,

FIGURE 7.9 Reasons for not voting in the 2012 presidential election, by gender and wealth quintile, 2014 (\%)

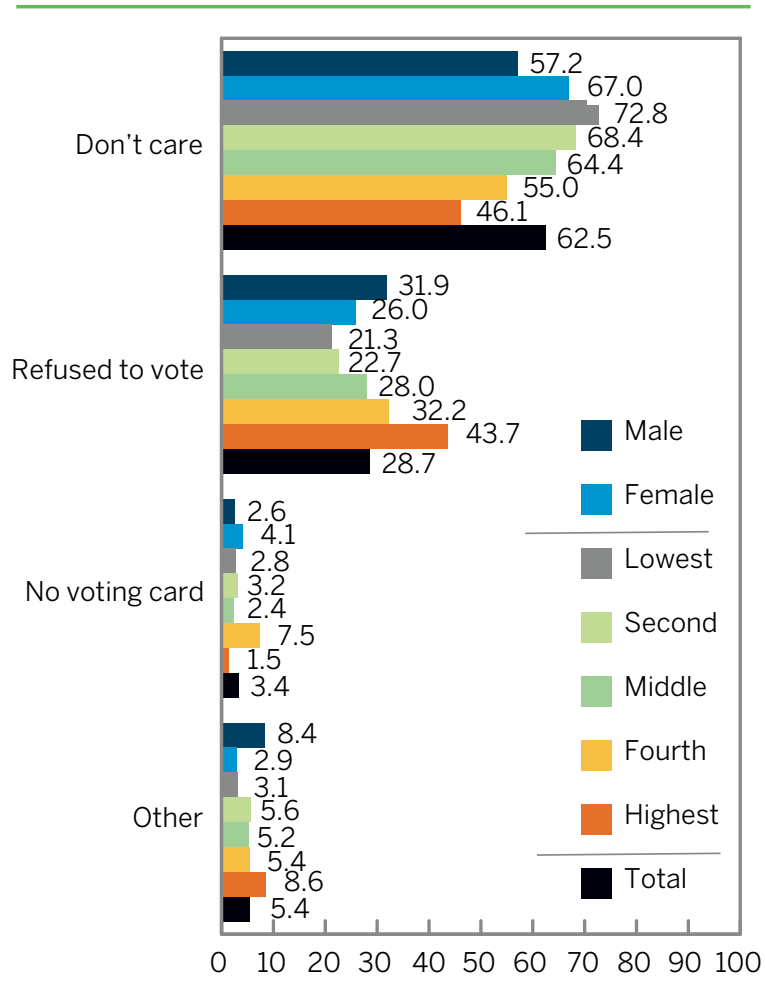

2011 parliamentary elections, and 2012 presidential election, between $62 \%$ and $70 \%$ of those who did not vote said that they did not participate in the election because they "don't care." Another 23-29\% said that they refused to participate in a particular election, with the 2011 constitutional referendum at the lower end of this range and the 2012 presidential election at the higher end. Only about $3 \%$ of youth who did not vote in each election reported that this was due to lack of a voter card, and 3-5\% cited other reasons for not voting. Female youth and poorer and less educated youth were generally more likely to report that they did not vote because they don't care, whereas more educated youth and those in higher wealth quintiles were more likely to say that they had refused to participate.

Finally, SYPE asked youth whether they intend to vote in the next election (Table A7.6). It is important to note that at the time the survey was administered, it was unclear what that election would be. Youth responses display a high degree of openness to and interest in further participation in the political process, with only $6.1 \%$ saying that they did not intend to vote compared to $47.3 \%$ who said that they did intend to vote. At the same time, there was considerable ambivalence among youth regarding their potential electoral choices, with a nearly equal percentage of youth $(46.6 \%)$ saying that they would "maybe" vote in the next election. A more recent poll conducted prior to the parliamentary elections scheduled for March 2015, which were later delayed, suggests even more strongly that youth overall are still interested in continuing to formally participate in the political process. In mid-January 2015, the Egyptian Center for Public Opinion Research (Baseera) polled the public on their political views; $79 \%$ said they intend to participate, including $72 \%$ of youth aged 18-29 (Osman 2015).

\subsection{Conclusion}

Since the January 25, 2011 revolution, Egypt has experienced a tumultuous transition, including a series of power shifts, and waves of civil unrest and protests. With these events, Egypt has also witnessed an enormous change in the ways in which youth claim their political rights, express their citizenship, and call for change, transforming the channels through which the government and the country's youth interact. Since 
the January 25 revolution, national discourse has also shifted to praise the "youth of the revolution" and to stress the importance of investing in the needs and aspirations of youth and creating the space for them to politically engage.

The data from SYPE 2014 present a more complex picture regarding youth participation in the transitional process that began on January 25, 2011 than we might expect based on media and social discourse. Self-reported participation in revolutionary activities was low among youth, and much of this activity was participation in the less political neighborhood watches as opposed to protests or political organizing. At the same time, the fact that respondents indicated higher rates of participation for family members and friends suggests that the political climate at the time of the survey may have prevented respondents from fully reporting their political behavior, raising concerns about freedom of expression that we will return to in the next chapter.

Two areas in which the SYPE data did show substantial change were in youth's use of media and participation in elections. Use of media to obtain news increased dramatically among youth from 2009 to 2014 , as did ever-use of the internet. Although the majority of youth rely on TV for their news, youth who were politically active were more likely to use social media tools to inform, mobilize, and create communities more than other youth. Youth participation in national elections has also increased substantially since 2009. These findings suggest an increase in youth involvement with current events and the formal political process, even though self-reported participation in revolutionary activities was lower than expected.

However, the SYPE results also raise concerns that there are sub-populations of youth who have been less enfranchised by the political processes that began with the January 25 revolution. Female youth, those less educated, and poorer youth were consistently less likely to report participation in revolutionary activities and in electoral processes, suggesting that these groups of youth face barriers to political engagement. Participation is also concentrated in urban areas in northern Egypt, with youth from rural Upper Egypt and the Frontier Governorates reporting lower rates of participation in political events and processes. Encouraging the participation of these groups of youth in the political process is key to generating a truly democratic transition.

Finally, SYPE results suggest a greater diversity of opinion among youth about the January 25 revolution and subsequent events than might be expected based on media reports. A substantial percentage of youth reported that they did not participate in the events of January 25 because they were confused about the goals or were not against the old regime, results that are consistent with the fact that a quarter of youth said that they did not support the January 25 revolution. Youth opinion about the events of June 30, 2013 was even more split, with higher percentages of youth expressing lack of clarity about the goals and mixed support of the events. Furthermore, lack of interest in elections was the most commonly cited reason for not voting among youth, suggesting that confusion over or opposition to the events taking place on Egypt's streets may lead youth to avoid the formal political processes that accompanied the transition. In the subsequent chapter, we turn to youth's assessments of the state of Egypt and their own lives in order to further explore how this diversity of opinion may affect young people's hope for the future and engagement in activities to improve their communities and country.

\section{References}

Carter Center. 2012. "Presidential Election in Egypt: Final Report." Atlanta: The Carter Center. www.cartercenter. org/resources/pdfs/news/peace_publications/election_reports/egypt-final-presidential-elections-2012. pdf. Accessed 20 January 2015.

Dunne, Michele and Scott Williamson. 2014. "Egypt's Unprecedented Instability by the Numbers." Carnegie Endowment for International Peace, 24 March. www.carnegieendowment.org/2014/03/24/egypt-sunprecedented-instability-by-numbers/h5j3. Accessed 20 January 2015.

Mungin, Lateef. 2011. "Amnesty: Egypt far from justice over unrest that killed more than 800." CNN, 19 May. Accessed 20 January 2015.

Osman, Maged. 2015. "Political Conditions in Egypt: Press Release." Baseera. January. www.baseera.com.eg/pdf_ poll_file_en/participation\%20in\%20parliamentary\%20 elections-\%20En.pdf. Accessed 25 April 2015.

Population Council. 2010. Survey of Young People in Egypt Final Report. Cairo: Population Council.

Sabry, Bassem. 2012. "The meaning of Egypt's referendum," Al Monitor, 23 December. www.al-monitor.com/ pulse/originals/2014/01/egypt-referendum-constitution-evaluation.html. Accessed 20 January 2015. 


\section{Civic Engagement, Political Attitudes, and Youth's Visions for the Future During Egypt's Transition}

NADA RAMADAN • MAIA SIEVERDING

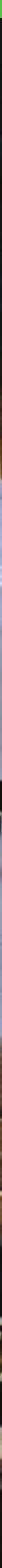


Young people's opinions about Egypt's transition-and their interest in taking part in national development during this critical period-affect their outlooks toward the future and their involvement with their peers, communities, and country. At the same time, young people's perceptions of how Egypt's transition has affected their lives may have important implications for this generation's transition to adulthood.

\subsection{Introduction}

Young people's active engagement in social and political change will be key to the success of Egypt's transition. It is therefore important to examine their responses to the January 25 revolution and subsequent events, in terms of opinions, attitudes, and actions, in order to better understand how to encourage their civic engagement.

In this chapter, we examine young people's opinions on social, economic, and political issues facing Egypt during its transition, and the extent to which they are active in trying to bring about change in their communities and the country more broadly. Although the majority of the questions in the civic engagement module of SYPE 2014 were new and based on events that occurred after SYPE 2009 was conducted, there are some questions that allow us to compare youth civic engagement and perceptions of social values across the two survey rounds.

We examine young people's opinions about what the priorities for the country should be at this point in time, including the importance of continuing the January 25 revolutionary movement, and the most important issues and threats facing Egypt today. We look at youth confidence in politicians and in their own ability to effect political change, We also capture youth's assessment of the three most recent Egyptian regimes on a variety of indicators related to democracy, development, and the rule of law. We discuss youth participation in political and volunteer activities since the 2009 SYPE, including their understanding of the definition of volunteerism, their participation in social groups, and reasons for joining those groups.

\subsection{Youth opinion on priorities and threats facing the country}

Nearly three years after January 25, 2011, youth's assessments of the revolutionary movement's success and its continued importance for Egypt were quite mixed. As shown in Figure 8.1, nearly half of youth agreed or strongly agreed with the statement that Egypt "needed reform, but not the January 25 revolution." At the same time, youth by and large did not think that January 25 had achieved the reforms that Egypt needed, with only $23 \%$ agreeing with this statement. In addition, whereas over half of the youth agreed that the January 25 revolution was urgent when it began, and an additional $30 \%$ said that they were neutral on this point, youth opinion on the continued urgency of the revolution in 2013 was

FIGURE 8.1 Youth opinion on the urgency and success of the January 25 revolution, 2014 (\%)

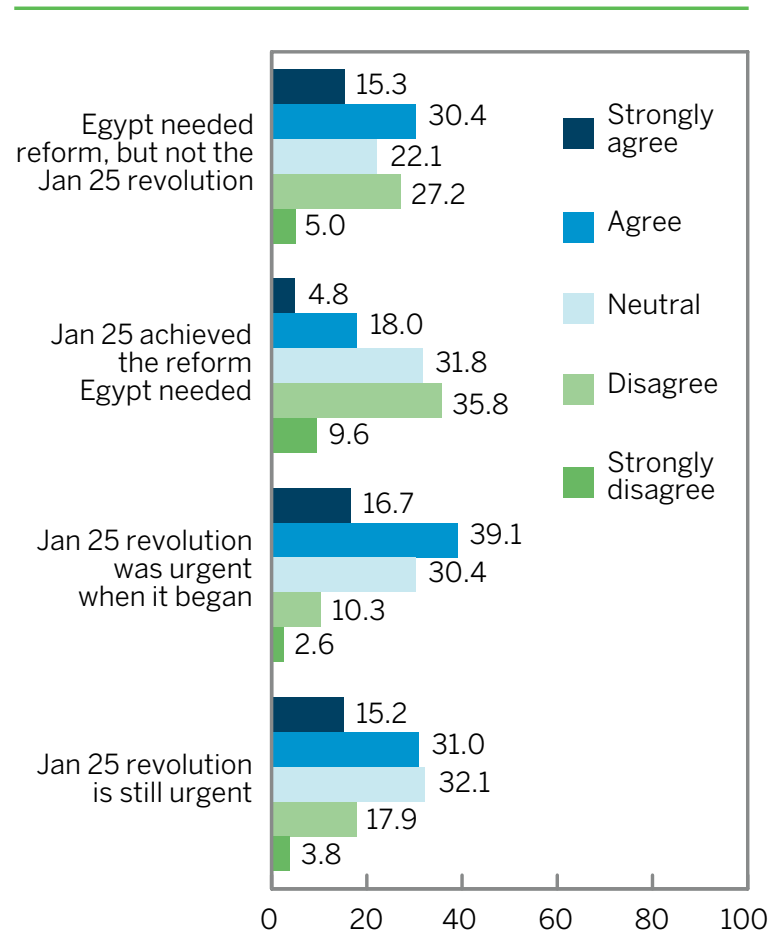


more mixed. Nearly a quarter of youth disagreed that the January 25 movement remained urgent in 2014 , compared to only $13 \%$ who disagreed that the revolution was urgent when it began. These findings suggest that while youth were-and the majority continued to be-eager to see reform in Egypt, in the aftermath of the economic and political chaos post-January 25, 2011, many were unsure as to whether the revolution was an effective means of generating that change.

In contrast to their mixed opinions on the continued importance of the revolution as a solution to Egypt's problems, youth opinion on the two main priorities for the country in 2014 was quite unified and varied little by background characteristics. An overwhelming $71.5 \%$ of respondents stated that raising living standards was the top priority for the country (Figure 8.2), likely reflecting the impact of Egypt's worsening economic situation in the aftermath of the revolution. As indicated in Chapter 4, youth labor market conditions have in fact seriously deteriorated since the January 25 revolution, and youth continue to be the most disadvantaged group in the Egyptian labor market in terms of unemployment rates, earnings, and job security and stability (Assaad and Krafft 2015). Under these conditions, economic concerns have clearly eclipsed political ones in terms of the improvements youth would like

FIGURE 8.2 Youth opinion on the top two priorities for the country, 2014 (\%)

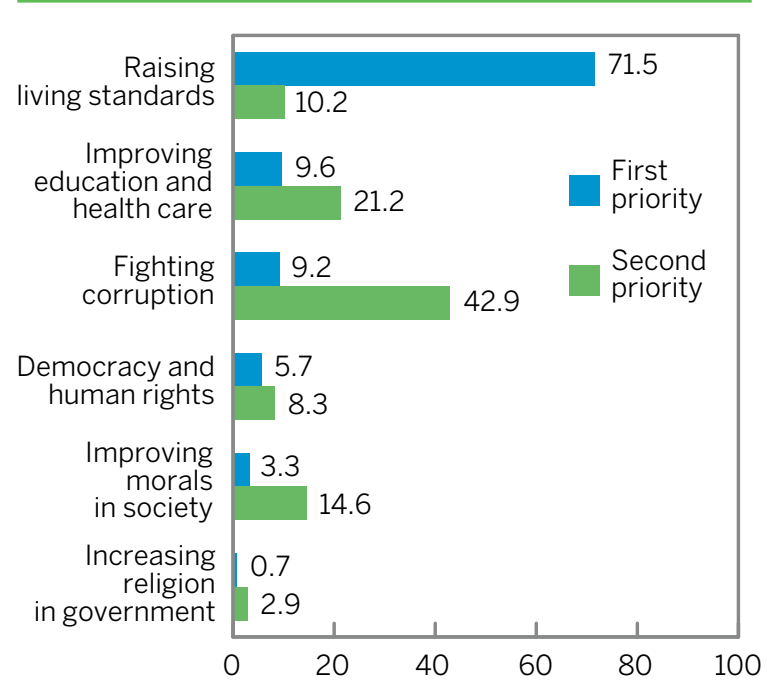

Economic concerns have clearly eclipsed political ones in terms of the improvements Egyptian youth would like to see in the country.

to see in the country; an additional $9.6 \%$ of youth ranked improving education and healthcare as the top priority, which is also linked to the priority of improving living standards and securing basic needs.

Nine percent of youth ranked fighting corruption as the top priority for the country, and $42.9 \%$ ranked this as the second priority. However, only 5.7\% believed improving democracy and human rights was the top priority for improving the state of the country, and $8.3 \%$ that it was the second priority. This suggests that youth's political concerns over Egypt's transition are focused on equality of opportunity and the need to reduce the private use of public resources, which again ties back to the overwhelming concern for improving livelihoods. That prioritization of democracy and basic human rights trailed far behind these other issues is concerning in terms of what it suggests about youth willingness to put pressure on the government to protect their freedoms and independence during this period of transition.

Finally, increasing the influence of religion on politics and the law was by far the lowest priority among youth, with $0.7 \%$ ranking it as a top priority while only $2.9 \%$ ranked it as the second. As we discuss in the following section, this confirms a general pattern in the SYPE data suggesting that Egyptian youth, particularly in the immediate aftermath of former President Morsi's turbulent year in power, show skepticism toward a political role for religion.

Given youth's focus on raising living standards as the top priority for Egypt, we also analyze questions that asked youth to assess a series of statements on economic policies. On a scale of 1 to 10 , with 1 
being "income should be more equal" and 10 "we need large income differences as economic incentives," youth on average placed themselves at 4.0, more in favor of income equality. Youth also placed greater responsibility on the government to provide for the population (1) than for people to take more responsibility to provide for themselves (10), on average rating themselves a 3.7 on this scale. Correspondingly, youth also leaned toward the opinion that the government should tax the rich to redistribute income. When comparing the statements that private ownership of business and industry should be increased (1) with the view that government ownership should be increased (10), youth again leaned toward public ownership of industries, at 5.8. Taken together, these statements indicate that youth favor a strong role for government in the economy, which was previously the situation in Egypt prior to the adoption of the Economic Reform and Structural Adjustment program in the early 1990s (Assaad 1997).

Youth opinion on the top two threats facing the country similarly reflects a strong preoccupation with daily quality of life (Figure 8.3). A large majority

FIGURE 8.3 Youth opinion on the top two threats facing the country, 2014 (\%)

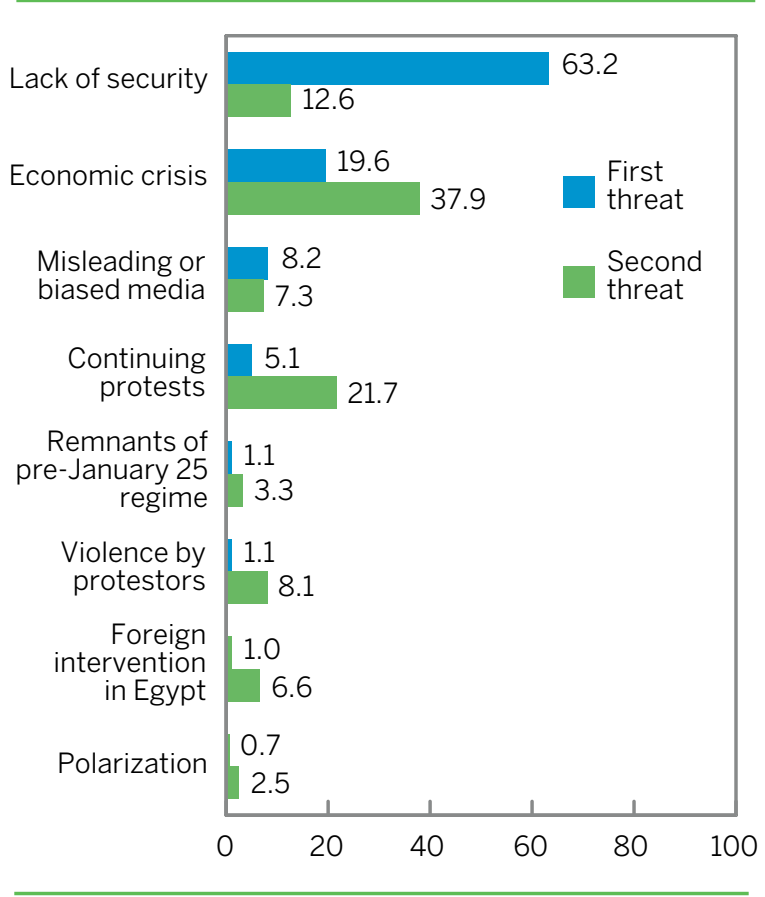

of youth (63.2\%) reported lack of security as the main threat facing the country, demonstrating a high sense of vulnerability to the insecurity in the country since January 25 . Another $19.6 \%$ of youth rated economic crisis as the main threat to the country and 38\% named this the second most important threat, consistent with youth identification of issues related to improving living standards as the main priority for the country.

The influence of misleading or biased media on national affairs or public opinion (8.2\%), and ongoing protests (5.1\%) were considered by a small percentage of youth to be the top threat facing the country. Polarization (0.7\%), violence by protesters $(1.1 \%)$, the continued existence of remnants of the Mubarak regime (1.1\%), and foreign intervention in Egypt's affairs (1.0\%) were not generally considered to be the important threat to the country. However, the danger of continuing protests (21.7\%) ranked above the lack of security (12.6\%) as the second greatest threat. Violence by protesters (8.1\%), misleading or biased media (7.3\%), and the risk of foreign intervention in Egypt (6.6\%) were also somewhat more commonly mentioned as the second greatest threat to the country. Youth viewed the polarization of Egyptian society as the least important threat facing the country overall.

\subsection{Opinions on politics and political activism}

Along with measuring youth participation in political organizing and electoral processes, SYPE 2014 assessed youth's degree of confidence that they themselves, politicians, political parties, and social movements could bring about change in national affairs. The results indicate that youth had little faith in the effectiveness of politicians and their ability to deliver on their campaign promises; $36.3 \%$ of youth agreed and $43.9 \%$ strongly agreed that most politicians make a lot of promises, but do not actually deliver, whereas only $3.6 \%$ disagreed and $0.8 \%$ strongly disagreed with this statement (Figure 8.4). However, a majority of youth did believe that political parties have the ability to influence citizens to vote: about $65 \%$ agreed with this statement, where- 
FIGURE 8.4 Youth opinion on politicians and the ability to effect political change, 2014 (\%)

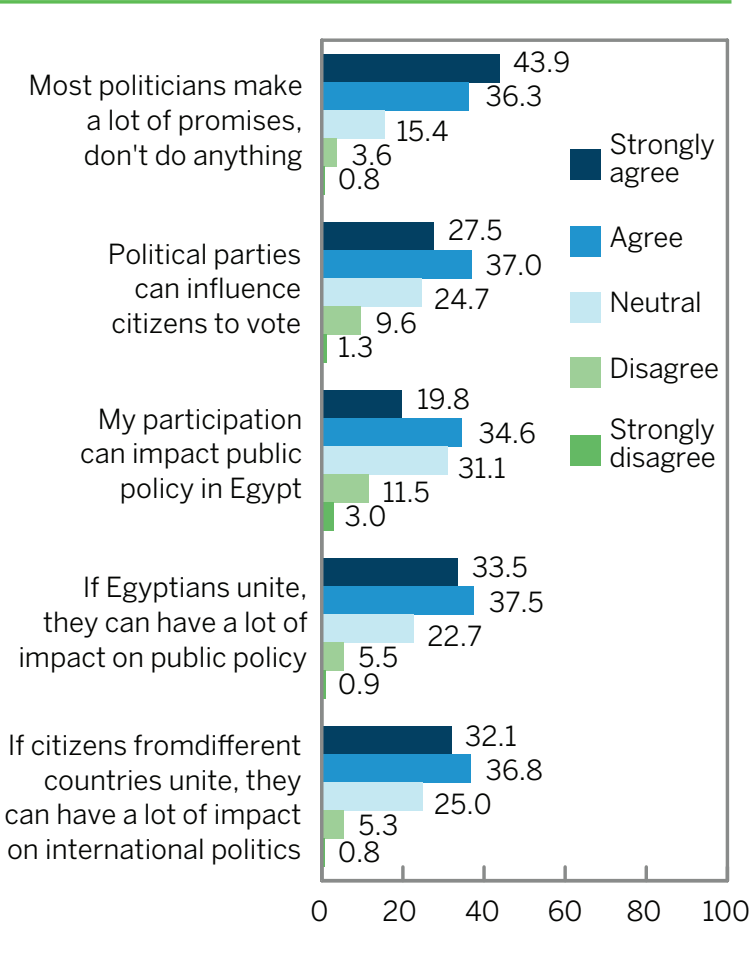

as about $10 \%$ disagreed. Youth's perspective that political parties have the ability to change voting behavior is likely influenced by the opening of the political space since January 25 and the creation of a number of new parties, and may be related to the dramatic increase in youth participation in national elections noted in Chapter 7. It is not clear, however, whether youth viewed this influence of political parties positively or negatively.

To assess youth's confidence in their own ability to become catalysts of change, SYPE 2014 asked whether they felt that their political participation could impact public policy. Just over a third of youth agreed that their participation could have an impact, and $19.8 \%$ strongly agreed with this statement. Another third of youth were neutral on this point, but fewer than $15 \%$ disagreed or strongly disagreed. These results suggest that youth are generally positive toward their own capacity to effect political change. This may be reflected in the higher voter turnout rates observed among youth in 2014 compared to 2009, but is somewhat sur- prising given the low rates of actual engagement in political organizing found in the previous chapter.

A larger percentage of youth also believed in the ability of national and international movements to influence the country's affairs. When asked if they agreed with the statement that when Egyptians unite they could have a great impact on public policy, just over $70 \%$ agreed or strongly agreed, whereas fewer than $7 \%$ disagreed. A similar percentage of youth believed in the impact of international movements on international policies. These findings suggest that the increasing interconnectedness of citizens through media, and the cross-national influence of the Arab Spring, may have influenced youth opinion on the political efficacy of global movements. In combination with youth people's general distrust of politicians, these responses also suggest that youth place greater faith in grassroots-based movements and their ability to change national and international politics than they place in the political establishment. Given the success of the January 25 movement in achieving regime change in Egypt, this may not be surprising, despite youth's uncertainty over whether January 25 succeeded in achieving its more broad-based goals.

\subsection{Assessment of recent regimes}

On a scale from 1 to 5 , with 1 being very bad and 5 being excellent, SYPE also asked youth to assess the three most recent Egyptian regimes on a variety of indicators related to democracy, development, and the rule of law. The three regimes were the pre-January 25 regime under former President Mubarak, the regime during the year prior to SYPE under former President Morsi (June 2012 to June 2013), and the present regime at the time of the SYPE data collection. During that period, The Supreme Council of Armed Forces, led by Abdel Fatah El-Sisi, announced that Adli Mansour, the head of the Supreme Constitutional Court, would be leading a transitional government until presidential elections. President El-Sisi was officially appointed as the country's president on June 8, 2014 following those elections. Thus, even though the interim gov- 
ernment that led the transitional period is closely associated with President Sisi, youth's assessments were of the interim government and may have changed under the elected government.

Figure 8.5 shows that, in terms of freedom of expression, youth rated the current government the highest (2.9) followed by the Morsi regime (2.2), and then the Mubarak regime with the lowest level of freedom of expression (2.0). The pattern for freedom to join a political party was similar. Youth on average also rated the current regime (2.7) better than the previous regimes in providing the space for "ordinary people" to have an influence on government. Youth believed that they had slightly greater influence on the government during Morsi's regime (2.0) than Mubarak's (1.8).

FIGURE 8.5 Youth assessment of three past regimes, on a scale of 1 (very bad) to 5 (excellent), 2014 (mean)

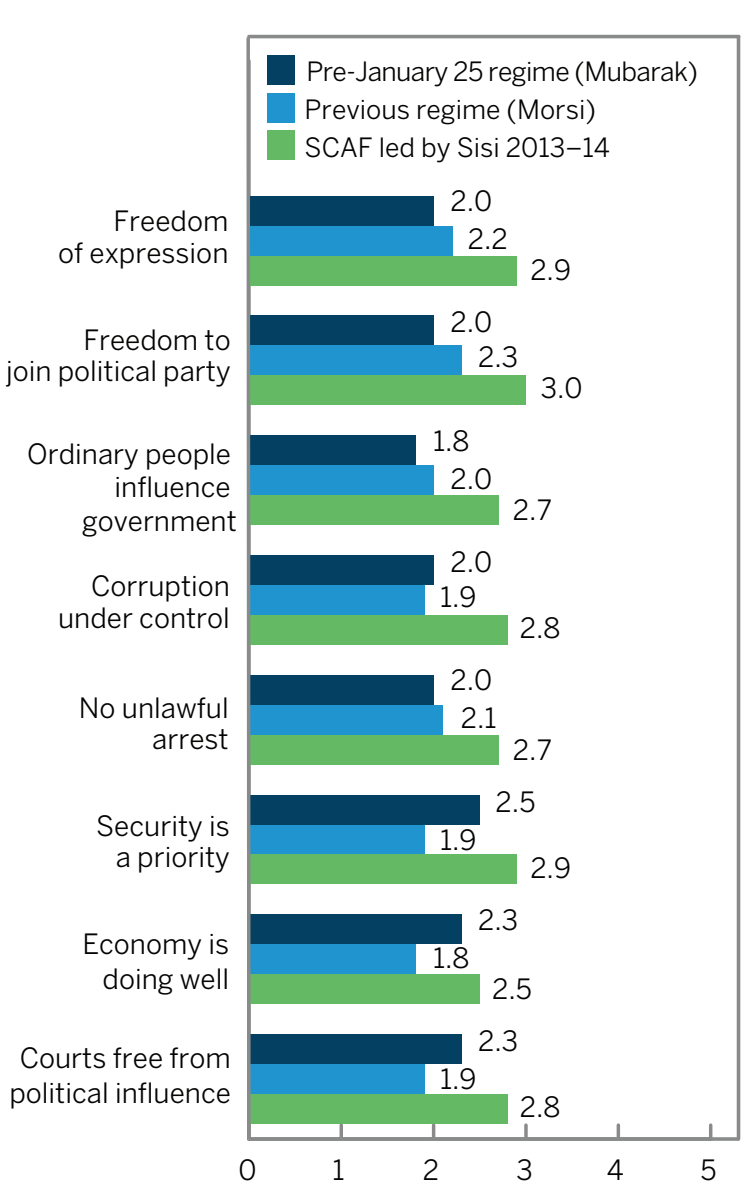

In terms of corruption and rule of law, the current regime also outperformed the other regimes in terms of keeping corruption under control (2.8). Youth perceived Mubarak's and Morsi's regimes to be very similar in terms of corruption (2.0 and 1.9, respectively). The present regime was also rated higher in terms of no unlawful arrest, at 2.7, whereas the Morsi and Mubarak regimes were again rated nearly the same, at 2.1 and 2.0, respectively. Youth were also asked to rate to what extent they thought courts were free from political influence. Whereas the present regime was rated at 2.8, the Mubarak regime, at 2.3, outperformed the Morsi regime on this indicator.

Turning to security and the economy, the two issues that youth perceived to be the most important for Egypt at the time of the survey, the present regime at the time of SYPE was also rated the highest. However, on both indicators the Mubarak regime clearly came out ahead of the Morsi regime, with youth rating Mubarak's regime 2.5 in terms of prioritizing preventing crime and maintaining order compared to 1.9 for Morsi's regime. Youth also thought that the previous regime under Morsi performed worse economically (1.8) than the pre-January 25 government (2.3), while the present regime was given a slightly higher rating (2.5).

Based on these patterns, it is clear that youth believed that in the early days the transitional government was performing better than previous regimes. Although youth indicated that there was consistently more space for freedom of expression and political affiliation in regimes after the January 25 revolution, on factors related to security, the economy, and corruption they perceived a worsening situation under former President Morsi compared to Mubarak, before the situation improved under the transitional government. It is important to keep in mind, however, that youth generally gave low ratings to all three regimes, with no regime receiving an average rating higher than 3.0 out of 5.0 on any measure. This indicates that youth are still dissatisfied with their government on a range of issues, and are looking for a more open regime with robust national policies. 


\subsection{Assessment of values in Egyptian society}

To understand how to increase youth engagement in national development and civic life, it is also crucial to understand their opinions on social affairs. In this section, we therefore turn to youth evaluations, on a scale of 1 to 10 , of the existence of certain values in Egyptian society (Table 8.1). On average, youth ranked the importance of becoming financially well-off as the most prevalent value in society, with a 6.8 rating out of 10. Youth also felt that Egyptian society values the importance of becoming well educated, which was given a 6.4 rating. Both of these values suggest an emphasis on securing a stable future, which may reflect the situation of economic insecurity that youth seemed to feel. A sense of responsibility (6.0), religious faith (5.9), and the value of hard work (5.7) were also perceived to be quite prevalent in society.

In terms of tolerance, respondents rated the value of "tolerance for others" at 5.7 and religious tolerance at 5.4. Youth believed that the tolerance toward opposing political views was lower, with

TABLE 8.1 Youth assessments of the presence of specific values in Egyptian society, on a scale of 1 (absent) to 10 (present), 2014

\begin{tabular}{lc}
\hline & MEAN RATING \\
\hline Importance of wealth & 6.8 \\
Importance of education & 6.4 \\
Sense of responsibility & 6.0 \\
Religious faith & 5.9 \\
Tolerance of others & 5.7 \\
Hard work & 5.7 \\
Independence & 5.5 \\
Religious tolerance & 5.4 \\
Helping community & 5.3 \\
Rule of law & 5.0 \\
Financial thrift & 4.9 \\
Transparency in transitions & 4.5 \\
Political tolerance & 4.5 \\
\hline Existence of corruption & 7.3 \\
\hline
\end{tabular}

Results indicate that youth are still dissatisfied with their government on a range of issues, and are looking for a more open regime with robust national policies.

a rating of 4.5. We examine the issue of political discussion and openness to others' political opinions in greater detail in Section 8.8. Along with the lower level of political tolerance, youth also felt that transparency in transitions (4.5) and the rule of law (5.0), both indications of a positive transitional path to democracy, were values that were not as apparent in Egyptian society. Variation in perceptions of these values was quite minor across most background characteristics. The greatest variation was across region, but exceeded one point on the scale in only a few cases.

Fairness in the functioning of institutions and the distribution of opportunity and reward are also important indicators of social values; youth perspectives on these topics were captured in SYPE through several questions related to corruption, bribery, and wasta (nepotism). The last line of Table 8.1 shows youth's rating of the level of corruption in public institutions, which at 7.3 was higher than their average rating of the presence of any of the values discussed above. In terms of direct experience with corruption, $18.4 \%$ of youth reported having seen a bribe paid during the past year.

Youth also perceive wasta, or the use of personal connections to obtain jobs or favors, to be quite common in Egyptian society. Fifty-five percent of youth said that jobs are obtained by wasta "to a large extent," and an additional 30\% said that jobs are obtained by wasta "sometimes." Only $2 \%$ of youth said that jobs are not obtained by wasta, and 
the remaining $12 \%$ said that they did not know. In personal experience, $28.7 \%$ of youth reported having witnessed the use of wasta during the past year alone (data not shown).

Perhaps due to their perceptions of the high levels of corruption in society and relatively lower levels of certain social values, youth also expressed low levels of generalized trust. When asked whether, generally speaking, most people can be trusted, only $21.3 \%$ said yes, whereas $78.6 \%$ of youth said that one must be very careful in dealing with other people. Youth in urban areas were more likely to be wary of dealing with other people (84\%) compared to those in rural areas (78\%) and informal areas (70\%), but variation on other background characteristics, including gender and age, was minimal (data not shown).

Despite the low level of trust, youth overall were more trusting of society in 2014 than in 2009. Whereas in 2009, $90.3 \%$ of youth said that one must be very careful in dealing with other people, in $201478.6 \%$ said that one must be careful. This trend toward increased generalized trust is particularly interesting given the increase in instability in Egypt during this period. Similarly, the ratings of the comparable group of youth aged 15-29 across SYPE 2009 and 2014 show, on average, a very slight improvement in the perception that positive social values are found in society (Table 8.2).

TABLE 8.2 Assessments of youth aged 15-29 of the presence of specific values in society, on a scale of 1 (very low) to 10 (pervasive), comparison between 2009 and 2014 (mean)

\begin{tabular}{lcc}
\hline & $\mathbf{2 0 0 9}$ & $\mathbf{2 0 1 4}$ \\
\hline Sense of responsibility & 5.8 & 6.0 \\
Hard work & 5.7 & 5.7 \\
Tolerance of others & 5.7 & 5.7 \\
Religious faith & 5.8 & 5.9 \\
Independence & 5.3 & 5.4 \\
Financial thrift & 4.9 & 4.9 \\
\hline
\end{tabular}

\subsection{The role of religion in politics, law, and personal life}

With the rise and fall of the Morsi regime and the rewriting of the Constitution in 2012 and again in 2014, there has been intense social debate over the role of religion in Egypt's political affairs. To gain a better understanding of youth opinion on this subject, SYPE 2014 asked respondents a series of questions related to what the role of religion should be in the political and public sphere. When asked whether they agreed with the statement that men of religion should not influence how people decide about political matters, $36.7 \%$ of youth agreed and $36.2 \%$ strongly agreed, whereas only $11 \%$ disagreed or strongly disagreed (Figure 8.6). An overwhelming $70 \%$ of youth also agreed that mosques and churches should not be used to influence people's political decisions, whereas only $10 \%$ disagreed. These findings indicate that the majority of youth disapprove of religious personalities or institutions aiming to influence their followers' political opinions.

FIGURE 8.6 Youth opinion on the role of religion in politics (\%)

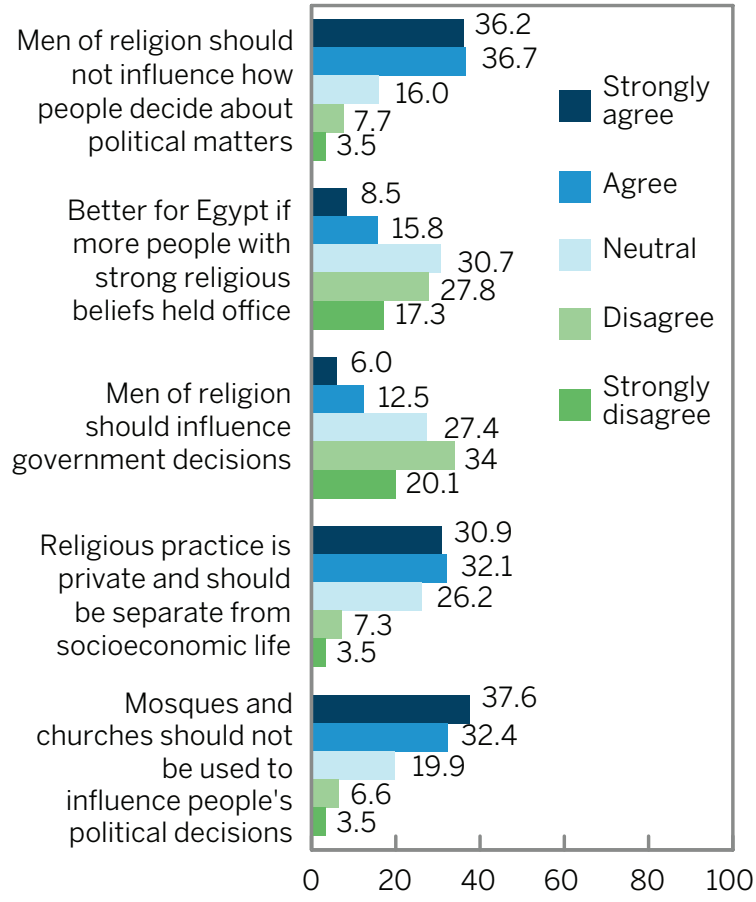


On the other hand, youth held mixed opinions on whether it would be better for Egypt if more people with strong religious beliefs held public office. Just under half of youth disagreed with this statement, $30.7 \%$ were neutral and about $25 \%$ agreed. Youth opinion on the statement that men of religion should be able to influence government decisions was similar, although a larger percentage of youth disagreed with this statement. These results are in contrast to those of a similar question asked by Gallup in 2011, shortly after the January 25 revolution. In that poll, $69 \%$ of Egyptians said that religious leaders should advise those in authority on writing national legislation, $14 \%$ said they should have full authority in writing national legislation, and only $9 \%$ said religious leaders should not have any authority at all ( $8 \%$ either refused the question or said they did not know) (Gallup 2011).

Although the Gallup poll was conducted among Egyptians aged 15 years and older and is not directly comparable with SYPE, this rather sharp difference suggests that public opinion may have become more resistant toward the engagement of religious leaders in governmental decisions during the transitional period. These indications that the majority of youth do not support a strong role for religion in political and socioeconomic life are also particularly interesting in light of the fact that AlAzhar, considered by many Muslims worldwide to be the highest authority in Sunni Islamic thought and Islamic jurisprudence, as well as the Coptic Church, has traditionally had influence over public policies that intersect with religious matters, such as personal status law.

In order to compare with youth's view of the role of religion in political and public life, we next turn to a series of questions about religion in young people's personal lives. In 2009, when SYPE asked youth if they viewed themselves as religious, regardless of whether they attend religious classes, the vast majority ( $85.5 \%$ ) of young people aged 15-29 identified themselves as religious; $2.7 \%$ identified themselves as very religious, and $11.8 \%$ said they were not religious. In 2014, when asked the same question, a slightly greater proportion of youth aged 15-29 (88.1\%) viewed themselves as religious, $4.8 \%$ viewed themselves as very religious, and a lower percentage $(7.0 \%)$ reported that they were not religious.

When asked how often they went to mosque or church in 2009, about two-thirds of youth reported attending more than once a day. In 2014, the question was changed to ask about the frequency of prayer regardless of attending a house of worship, but nevertheless suggested similar adherence to daily prayers, with $73.0 \%$ of youth saying that they prayed daily "always" or "most of the time." The increase from 2009 is likely attributable at least in part to the change in wording, as many youth may pray at home. Only $6.4 \%$ of youth said that they rarely or never prayed daily (data not shown).

In order to assess youth reliance on religious media, SYPE 2014 asked if they watch or listen to religious programs on the radio or television. Youth practice was quite mixed; $11.4 \%$ never listened to religious media, $57.2 \%$ rarely or sometimes listened, $17.8 \%$ listened most of the time, and the remaining $12.8 \%$ always listened to religious programs. As for studying religious texts, youth seem to be less frequent in their practice $-6.4 \%$ reported that they never read the Bible or Quran, $60.0 \%$ rarely or sometimes read their respective texts, $17.0 \%$ read most of the time, and $15.8 \%$ always. In addition, $82.4 \%$ of youth reported always fasting during Ramadan or Lent. Thus, youth's general view that religious leaders and institutions should not have a strong role in political life seems unlikely to be related to any change in their self-reported personal religiosity, as the majority perceive themselves to be religious and practice their faith quite regularly (data not shown).

\subsection{Optimism about the future}

Youth's assessments of the state of the country following the January 25 revolution and the subsequent events may affect their sense of hope not only for Egypt's future, but also for their own lives. SYPE asked youth to rate, on a scale from 1 (worst) to 10 (best), their feelings about their lives and the state of the country during four periods in time. As shown in Figure 8.7, trends in the two are closely related. On average, youth rate both their own lives 
FIGURE 8.7 Youth assessment of the state of their own lives and the country during different periods, on a scale of 1 (worst) to 10 (best), 2014 (mean)

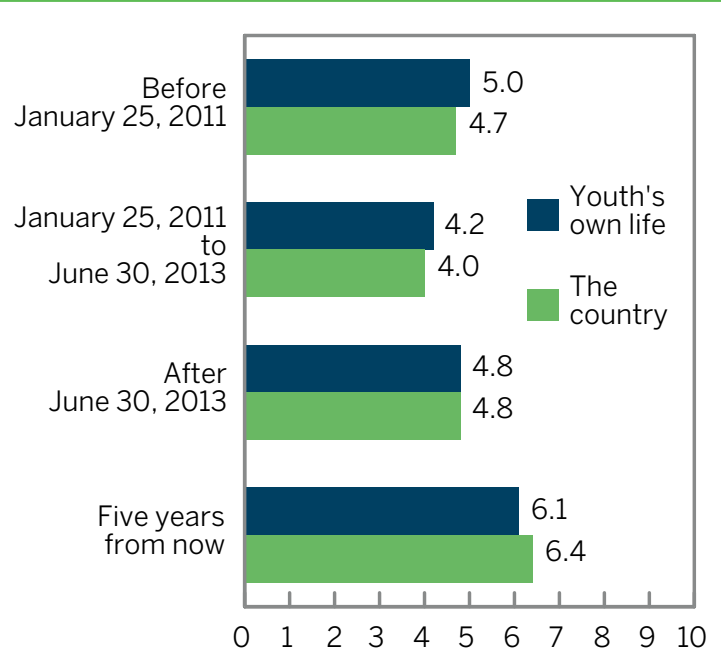

(5.0) and the state of the country (4.7) as having been better prior to the revolution than after. They rated the worst period for both themselves and the country to be from January 25, 2011 to June 30, 2013 , at lows of 4.2 and 4.0, respectively. Although both indicators increased to 4.8 for the period after June 30,2013 , it is notable that, on average, youth still found their own lives to have been better prior to the revolution. These ratings may be affected by youth concerns with lack of security and poor economic conditions following the revolution, as highlighted in the sections above. Youth do display considerable optimism about the future, however, as their predictions for their own lives five years from the time of the survey averaged 6.1, and for the state of the country 6.4. Despite their concerns over conditions during Egypt's transitional period, youth do therefore appear to have hope that the country will emerge from this period with better prospects for the country as a whole.

Although they expressed optimism about the trajectory of their own lives and the state of Egypt in five years, youth also said that the events of the revolution would negatively affect their own futures. When posed the statement "the events following the revolution will negatively affect my future," $28.0 \%$ of youth strongly agreed, $33.7 \%$ agreed and another $29.0 \%$ were neutral. Fewer than 10\% of youth disagreed or strongly disagreed with the statement. Youth in the Urban Governorates and informal urban areas were particularly likely to agree that the events following the revolution would affect them negatively, as were youth with post-secondary education and wealthier youth. Interestingly, youth who had participated in revolutionary activities were the most likely to say that the events would negatively affect their futures, with $75.2 \%$ agreeing or strongly agreeing. This may reflect the direct consequences of exposure to violence or political targeting of youth who played an active role in the revolution, or these youth may be more pessimistic and feel that the revolution has not achieved its goals (data not shown).

These somewhat contradictory findings on youth optimism about the future and their sense that the revolution would negatively affect the future may be explained in part by the fact that youth expressed a fairly high degree of uncertainty about the future. On a scale from 1 (very certain) to 10 (very uncertain), youth overall rated their level of certainty about their future lives at 7.0. Male youth expressed slightly lower levels of certainty (7.1) than female youth (6.9), and youth in the Urban and Frontier Governorates were somewhat less certain about their futures (7.3 and 7.2, respectively) than other youth. Youth from urban Upper Egypt expressed the greatest level of certainty about their future, at 6.5, whereas youth from the other regions all expressed levels of certainty around 7.0 (data not shown).

Certainty about the future was negatively correlated with education, with university-educated youth expressing the lowest certainty (7.1) and illiterate youth the highest (6.6), which may reflect youth's perceptions of the opportunities open to them. Wealth was also generally correlated with certainty, although the relationship was not as clear. Perhaps not surprisingly, unemployed youth (7.4) also expressed greater uncertainty about the future than youth who were employed (7.1) or out of the labor force (6.9). Youth who had participated in any revolutionary activity since January 25 also expressed greater uncertainty (7.5) than those who had not participated (7.0) (data not shown). 


\subsection{Participation in volunteering and social groups}

Following the 18 days of the January 25 revolution, there was widespread media coverage of youth engaging in activities to improve their communities and environment, leading to a common impression that youth participation in volunteering and organized social groups increased from the low levels prior to the revolution. Table 8.1, however, suggests that youth participation in voluntary activities still remained low, with only $3.6 \%$ of youth reporting that they had ever volunteered since participating in SYPE 2009. SYPE asked youth about volunteering in charitable, educational, community development, fundraising, and other volunteer activities. Due to the low overall rates of volunteering, we do not disaggregate by the type of activity. ${ }^{1}$

1 SYPE 2014 respondents who did not answer all questions in the series about volunteering and group membership are dropped from these respective analyses. Otherwise, we would be making the assumption that nonresponse is equivalent to a "no," which is likely to be misleading, particularly for activities that youth may have been reluctant to report.
Table 8.3 breaks down the percentage of youth volunteering by the period during which they reported volunteering (rates by the full set of background characteristics are presented in A8.1). Volunteer rates for the period from SYPE 2009 to January 25, 2011 were actually slightly higher, at 3.0\%, than rates for the year following January 25 (2.7\%) and the second year of the revolution (2.8\%), which was the same rate youth reported for the year prior to SYPE 2009. Furthermore, many of the youth who reported volunteering did so consistently across the three periods. In other words, there appears to be a small percentage of youth who are committed to volunteering regularly whereas the large majority of youth never participated in voluntary activities in any of the periods measured. This finding contrasts sharply with the perception of a surge of volunteer activity among youth in the months following January 25.

Youth who participated in volunteer activity - charitable, educational, community development, and other activities - also appear to have some overlap with the small group of youth who reported participating in revolutionary activities, which here are defined as political organizing or activities that took place on the streets such as protests (see

TABLE 8.3 Youth who reported that they volunteered, by gender and participation in revolutionary activity, SYPE 2009 and 2014 (\%)

\begin{tabular}{|c|c|c|c|c|c|c|}
\hline & \multicolumn{4}{|c|}{$\begin{array}{l}\text { VOLUNTEER RATES } \\
\text { (YOUTH AGED 13-35) }\end{array}$} & \multicolumn{2}{|c|}{$\begin{array}{l}\text { VOLUNTEER RATES } \\
\text { (YOUTH AGED 15-29) }\end{array}$} \\
\hline & $\begin{array}{r}\text { April } \\
2009- \\
\text { January } \\
25,2011\end{array}$ & $\begin{array}{r}\text { In the } \\
\text { year } \\
\text { following } \\
\text { January } \\
25,2011\end{array}$ & $\begin{array}{r}\text { From Janu- } \\
\text { ary } 25,2012 \\
\text { to the time } \\
\text { of } \\
\text { the survey }\end{array}$ & $\begin{array}{r}\text { Ever } \\
\text { volun- } \\
\text { teered } \\
\text { since } \\
\text { SYPE } \\
2009\end{array}$ & $\begin{array}{r}\text { Ever } \\
\text { volunteered } \\
2009-2014\end{array}$ & $\begin{array}{r}\text { Volun- } \\
\text { teered in } \\
\text { year prior } \\
\text { to SYPE } \\
2009\end{array}$ \\
\hline \multicolumn{7}{|l|}{ Gender } \\
\hline Male & 3.8 & 3.5 & 3.6 & 4.5 & 4.5 & 4.3 \\
\hline Female & 2.2 & 1.8 & 1.9 & 2.4 & 2.7 & 1.3 \\
\hline \multicolumn{7}{|c|}{ Youth participation in revolution } \\
\hline No participation & 2.0 & 1.7 & 1.8 & 2.4 & & \\
\hline Any participation & 14.6 & 14.0 & 14.3 & 16.5 & & \\
\hline Political organizing & 29.3 & 30.7 & 33.0 & 34.4 & & \\
\hline Neighborhood watch & 14.4 & 13.9 & 14.0 & 16.3 & & \\
\hline Protest & 17.3 & 17.5 & 18.8 & 19.3 & & \\
\hline Total & 3.0 & 2.7 & 2.8 & 3.5 & 3.6 & 2.8 \\
\hline$(\mathrm{N})$ & $(8,844)$ & $(8,844)$ & $(8,844)$ & $(8,844)$ & $(7,011)$ & $(10,976)$ \\
\hline
\end{tabular}


Chapter 7). The rate of volunteerism among youth who reported partaking in revolutionary activity was $16.5 \%$, compared to $2.4 \%$ among nonparticipants. Youth who participated in political organizing were particularly likely to report volunteering (34.4\%), which suggests that some of these volunteer activities may have been organized by their political groups or parties.

There was a gender gap in volunteer activity among all SYPE 2014 youth aged 13-35, as with participation in the revolution, with $4.5 \%$ of male youth reporting having ever volunteered since the time of SYPE 2009 compared to $2.4 \%$ of female youth. Youth with higher educational attainment were more likely to have volunteered, with up to $7.1 \%$ of youth with tertiary education reporting having volunteered. Volunteer rates among youth with less than a preparatory education were less than $1.0 \%$ (Table A8.1). Volunteering similarly increased with wealth, and, like participation in the revolution, was higher among unemployed youth (6.1\%) than those with employment (4.4\%) or who were out of the labor force (2.7\%), likely reflecting the greater time available to these youth to engage in such activities. Rates of volunteering among the 15-29 age group, which is the group directly comparable with SYPE 2009, are overall very similar.

In order to explore further the surprisingly low rates of volunteering among Egyptian youth following the revolution, we turn to the questions in SYPE about what volunteering means, and youth perceptions about why their peers may or may not participate (data not shown). According to the United Nations, volunteering is defined as "contributions that individuals make as nonprofit, nonwage, and noncareer action for the well-being of their neighbors, and society as large"-a definition that is rather broad and encompasses many forms of collective action (United Nations 1999). When asked about the best definition for volunteering, youth largely associated the concept with charitable activity, with $57.6 \%$ saying that volunteering meant "providing assistance for the poor and marginalized." Fourteen percent of youth said that volunteering meant "bringing people together and building solidarity," and $13 \%$ believed it meant "helping people to develop their skills." Only 6\% of youth identified "empowering individuals and communities" or "encouraging active citizenship" as the best definition for volunteering.

Youth who themselves participated in volunteer activities were more likely to identify bringing people together (22\%) and encouraging active citizenship $(12 \%)$ as the best definition of volunteering as opposed to youth who did not volunteer (13\% and 5\%, respectively), suggesting that participation in volunteer activities is associated with an understanding of volunteerism as extending beyond charity.

Although SYPE did not ask youth who had volunteered since 2009 why they did so, SYPE did ask all respondents why they think youth participate in volunteer activities (multiple answers were possible). Differences in these responses between youth who had and had not volunteered similarly suggest that youth who volunteer are more likely to see volunteerism as a form of active citizenship. Whereas $20 \%$ of youth who had never volunteered saw "being an active citizen or having a role in society" as a reason why youth participate in volunteerism, $39 \%$ of volunteers cited this as a motivation. Volunteers were also more likely to see this form of engagement as a means of gaining work experience (35\%) compared to nonvolunteers (23\%), as well as to enhance their personal development (12\% compared to 3\%). They were also more likely to cite supporting world peace and development as a motivation (27\% compared to 12\%). However, nonvolunteers were more likely to cite helping others (62\%) as a motivation to volunteer as opposed to youth volunteers (57\%) (data not shown).

SYPE also asked all youth why they thought youth would choose not to volunteer (multiple answers were possible). The most common reasons were related to economic pressures, with half of youth citing "no spare time" to volunteer and 47\% believing that youth were busy "searching for money." Seventeen percent cited lack of security as a reason and $23 \%$ believed that youth were being discouraged by their family. Poor or little information about volunteering was seen as a less important factor, with a "negative view of 
volunteer work" seen as a potential reason by $12 \%$ of youth, lack of opportunities to volunteer by $13 \%$ and "never been asked to volunteer" by $14 \%$. Youth opinions on what might encourage youth to volunteer (multiple responses possible) matched with the reasons they had cited for the lack of participation; 56\% mentioned having more spare time and 58\% mentioned having more money (data not shown).

Another form of engagement in civic life is participation in formal associations or clubs, whether or not these have an explicit social or political agenda. Interestingly, youth indicated higher rates of youth membership in social or political groups in 2009 , at $4.9 \%$, than the $2.8 \%$ found in 2014 (2.9\% among youth aged 15-29; Table 8.4). However, this may be due in part to the fact that the list of prompts used in the 2009 survey was different from that used in 2014, and named more types of groups individually. ${ }^{2}$

SYPE 2014 asked youth whether they were a member of any community of cultural associations, NGOs, sports clubs, unions or syndicates, political parties or movements, or unregistered informal groups. As shown in Table 8.4, only $2.8 \%$ responded that they were; $2.1 \%$ of youth were members of one of these types of groups and $0.7 \%$ were members of two or more groups. Of the different types of associations or groups, sports clubs were by far the most common, with $1.9 \%$ of youth reporting membership in such a club compared to less than $1 \%$ for all of the other types of associations (rates by the full set of background characteristics are presented in Table A8.2). As with volunteering, group membership was more common among male youth, and more educated and wealthier youth.

2 The same list of groups was used in both survey years, but in 2009 each type of group was provided as a separate survey item whereas in 2014 youth were prompted with five overall categories (community or cultural associations, sports clubs, unions/syndicates, political organizations, and unregistered informal groups), which had the individual group types listed as examples.
TABLE 8.4 Youth participation in groups and associations, by period and background characteristics, 2009 and 2014 (\%)

\begin{tabular}{|c|c|c|c|}
\hline & $\begin{array}{r}\text { YOUTH } \\
\text { AGED } \\
13-35 \\
\text { IN } \\
2014\end{array}$ & $\begin{array}{r}\text { YOUTH } \\
\text { AGED } \\
15-29 \\
\text { IN } \\
2014\end{array}$ & $\begin{array}{r}\text { YOUTH } \\
\text { AGED } \\
15-29 \\
\text { IN } 2009\end{array}$ \\
\hline \multicolumn{4}{|l|}{ Gender } \\
\hline Male & 4.1 & 4.2 & 6.6 \\
\hline Female & 1.5 & 1.5 & 3.2 \\
\hline \multicolumn{4}{|l|}{ Education } \\
\hline Illiterate & 0.0 & 0.0 & 0.5 \\
\hline Can read and write & 0.0 & 0.0 & 10.9 \\
\hline Primary & 1.0 & 1.1 & 3.4 \\
\hline Preparatory & 1.3 & 0.8 & 4.4 \\
\hline General secondary & 6.5 & 6.5 & 11.9 \\
\hline Vocational secondary & 1.4 & 1.5 & 2.0 \\
\hline Post-secondary institute & 4.5 & 4.7 & 3.2 \\
\hline University and above & 7.0 & 6.8 & 13.0 \\
\hline \multicolumn{4}{|l|}{$\begin{array}{l}\text { Youth participation in } \\
\text { revolution }\end{array}$} \\
\hline No participation & 1.4 & 1.4 & - \\
\hline Any participation & 20.8 & 21.1 & - \\
\hline Political organizing & 37.4 & 36.8 & - \\
\hline Neighborhood watch & 19.3 & 19.6 & - \\
\hline Protest & 35.0 & 36.7 & - \\
\hline Total & 2.8 & 2.9 & 4.9 \\
\hline$(\mathrm{N})$ & $(10,861)$ & $(8,579)$ & $(10,976)$ \\
\hline
\end{tabular}

Likewise, group membership was substantially more common among youth who participated in revolutionary activity (20.8\%) compared to youth who did not participate (1.4\%). The particularly high rates of group membership among youth who participated in political organizing (37.4\%) is likely related to the inclusion of political parties in the list of associations SYPE asked about. However, the percentage of youth who reported being a member of a political party or association $(0.3 \%)$ was lower than the percentage reporting participation in political organizing in Chapter 7 (1.3\%). This may indicate that not all youth who participated in organizing consider themselves a formal member of a group, or that there was also underreporting of participation in political parties and other formal political associations. In general, these results confirm that citizens who participate 
in one area of civic engagement are more likely to get involved in another.

SYPE also asked youth who reported being members of a group or association why they chose to participate in that group. These reasons varied by the type of organization, with "to help others" most commonly cited for charitable and community groups (41\%), "play sports" for sports clubs (52\%), "to cope with a problem" for unions/syndicates (32\%), "to achieve the goals of the revolution" for the few youth reporting membership in a political party or group (47\%), and "to help others" for the similarly small number of youth engaged in other types of groups (48\%) (data not shown).

\subsection{Participation in social debate}

Another indication of youth responses to the events following January 25, 2011 is their engagement in public debate about the political, social, and economic issues facing the country. Youth perceptions of their own level of engagement with current events, in different ways, are captured in Figure 8.8. Youth, on average, expressed a higher degree

FIGURE 8.8 Youth assessment of their own engagement with current events and community development, 2014 (\%)

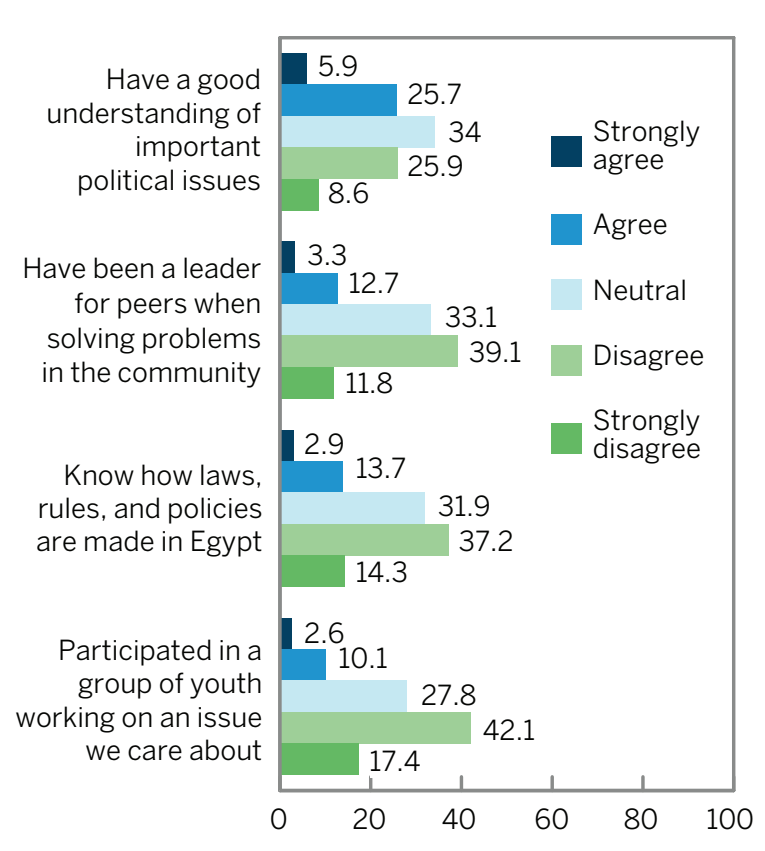

of confidence in their understanding of important political issues in the country than of how laws and policies are made. Just over $30 \%$ of youth agreed or strongly agreed that they had a good understanding of political issues, whereas only $13.7 \%$ of youth agreed that they understand how laws are made and $2.9 \%$ strongly agreed. Nearly half of youth did not feel that they know how laws and policies are formed in the country. Youth responses to statements on their active engagement with current events also show fairly low levels of engagement, with only $16.0 \%$ agreeing that they have been a leader among their peers when solving problems in the community and $12.7 \%$ saying that they have participated in a group of youth working on an issue that they care about. Nevertheless, these rates are higher than those found for participation in revolutionary activity, volunteering, or social groups, suggesting that youth perceive themselves to be engaged in their communities in less formal ways.

Along with their generally low confidence in their understanding of current politics and policy issues, and despite the perception that public debate surrounding politics has expanded during this contentious period, many youth do not appear to discuss politics frequently. Those who do report engaging in political debate primarily discuss politics with their friends, with just over $50 \%$ of youth saying that they discuss politics with their friends at least "sometimes" (Figure 8.9). About $42 \%$ of youth reported discussing politics at least sometimes with their siblings, whereas youth were less likely to speak about politics with their mother or father.

The majority of youth (62.2\%) reported that they never speak with other acquaintances about politics, suggesting some caution about discussing politics with anyone other than close friends and family. This is borne out by youth opinion on the degree to which engaging in political debate can sway their or others' opinions. Forty-three percent of youth responded that they "avoid talking about politics because no one will ever be convinced of another's opinion," and an additional $25 \%$ said that they would listen to another person but not express their own opinion. Only $16 \%$ said that they would try to convince someone else of their opinion, and $11 \%$ 
FIGURE 8.9 Frequency of youth's discussion of current events or politics with particular people, 2014 (\%)

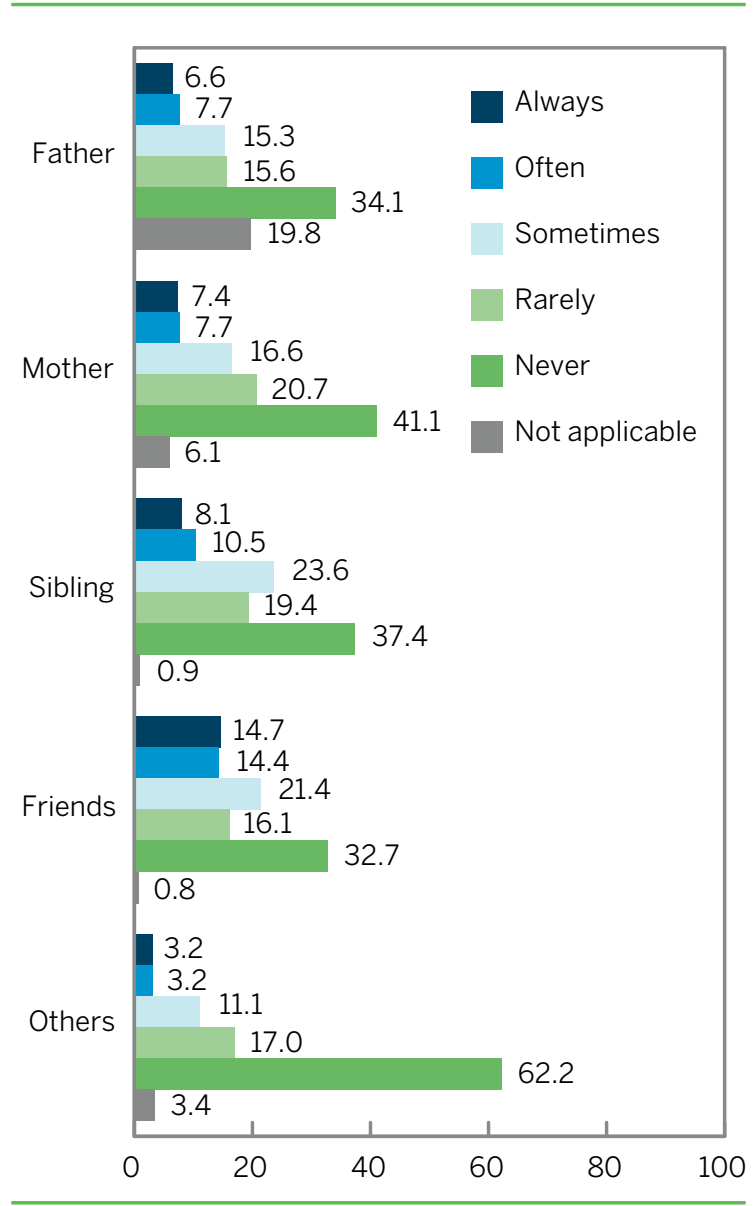

that they were themselves willing to be convinced by another's opinion (data not shown).

\subsection{Conclusion}

Civic participation is essential for youth to make a successful transition to meaningful adult roles in which they can participate fully in society and contribute to community and national development. Following the January 25, 2011 movement, there is a perception that Egyptians now have a greater sense of duty to be civically engaged and help change the direction of their nation. This chapter attempted to provide a deeper understanding of the dynamics surrounding youth civic engagement in this politically uncertain climate, and of how their engagement has taken shape in this period com- pared to the very low levels of civic engagement found in 2009.

The SYPE results demonstrate that youth believed that the January 25 revolution movement was needed when it began. However, given the economic, social, and political instability they have faced since 2011, they have mixed feelings on whether the movement is still urgent or is the most effective method to bring about reform. By contrast, in terms of what needs to change in Egypt, youth were quite unified on the priorities for the country moving forward, and the top priority was economic stability and improving the standard of living. Youth concern over economic conditions appears to have crowded out other issues such as ensuring democracy and human rights, and many youth confess to having low levels of understanding of how the political and legal systems function, despite the many reforms that have been debated and implemented during this period.

Furthermore, despite the perception that youth, with a renewed sense of patriotism and duty to help reform the country, have been more active in volunteering since the revolution, the SYPE data show that this is not in fact the case. Youth participation in volunteering has remained unchanged since 2009 , and their participation in social groups has actually declined. Furthermore, youth who participate in one area of civic engagement are more likely to get involved in other forms-including participation in revolutionary activities - suggesting that there is a small population of civically active youth and a much larger population who do not participate in any forms of civic engagement. Additionally, youth reported in SYPE that in fact they do not discuss politics frequently, and when they do, they discuss with their friends and their siblings. The majority of youth reported that they never speak with other acquaintances about politics, which is perhaps attributable to the fact that many youth perceive the political environment to be polarized and express low levels of overall social trust.

Low levels of civic participation reflect a strong disconnect between what youth believe will generate change in Egypt and their own actions, which is of 
great concern for Egypt's transition. In terms of the actors and strategies that youth believe can bring about reform, they have little faith in politicians to deliver on their promises of progress. Youth perceive high levels of corruption in society and relatively lower levels of certain social values, including the values of transparency and tolerance that are key to Egypt's current transition. In addition, youth expressed a high level of dissatisfaction with all three recent regimes' performance on a variety of economic, political, and security issues. In contrast, around half of the respondents agreed or strongly agreed that they themselves have the ability to make an impact on public policy, which is surprising given their low rates of actual engagement in revolutionary activity reported in the previous chapter as well as the low rates of volunteerism and group membership found in this chapter.

One hopeful finding is that youth display considerable optimism about the future, and expect both their own lives and the state of the country to be better five years from the time of the survey than they were before the January 25 revolution. However, in order to achieve this positive vision, youth participation in political and social debate and events must be fostered. As political and governance structures are reformed during this transitional period, the government and civil society must provide ways for the voices of youth to be meaningfully heard, their needs addressed, and to create spaces for them to contribute and help address the country's challenges.

\section{References}

Assaad, Ragui. 1997. “The effects of public sector hiring and compensation policies on the Egyptian labor market." The World Bank Economic Review 11 (1): 85-118.

Assaad, Ragui and Caroline Krafft (eds.). 2015. The Egyptian Labor Market in an Era of Revolution. Oxford: Oxford University Press.

Corporation for National and Community Service. 2011. "Report Shows Majority of Americans Civically Engaged in their Communities." www.nationalservice. gov/newsroom/press-releases/2011/reportshows-majority-americans-civically-engaged-theircommunities. Accessed January 20, 2014.
Gallup. 2011. “Egypt from Tahrir to Transition: Egyptians on their Assets and Challenges and What Leaders Should Do about It." www.gallup.com/ poll/157046/egypt-tahrir-transition.aspx. Accessed January 20, 2014.

Korayem, Katima. 1997. “Egypt's Economic Reform and Structural Adjustment," The Egyptian Center for Economic Studies. www.eces.org.eg/Publication. aspx?ld=209. Accessed January 20, 2014.

United Nations. 1999. "International year of the volunteer 2001, background note," United Nations Volunteers, Bonn: UNV. 


\section{Continuing Conservatism: Gender Attitudes among Egyptian Youth}

COLETTE SALEMI • ALI RASHED

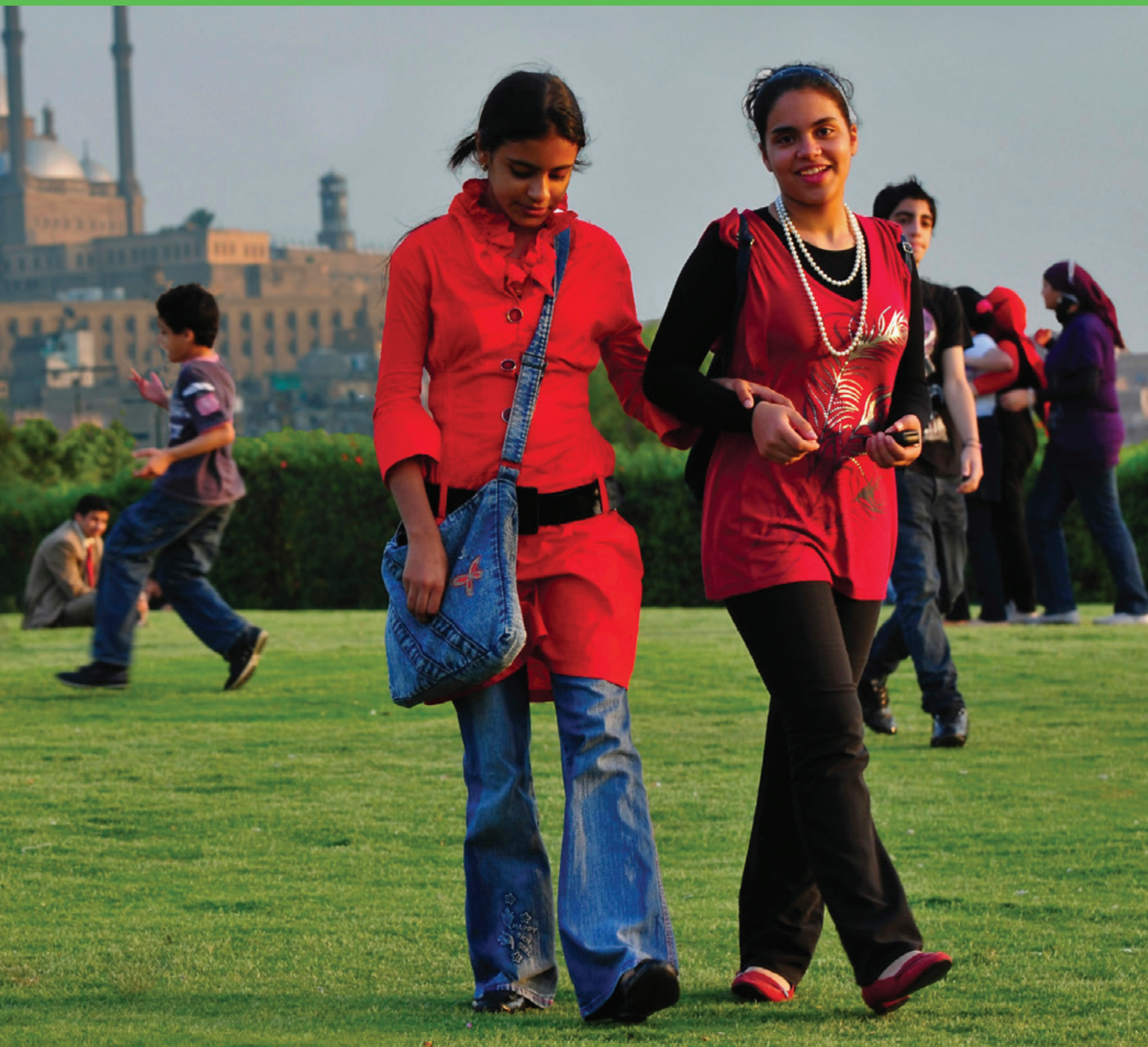


Society's attitudes about gender and gender roles have a direct impact on many spheres of life, including how household duties are assigned, how decisions are made, and how power in relationships is balanced. These attitudes also affect a woman's right to seek divorce, her access to institutions such as schools, the labor market, and electoral politics, and her risk of experiencing genderbased violence.

\subsection{Introduction}

Because of the important effect that gender attitudes have on the lives of young people, the 2009 SYPE measured Egyptian youth's attitudes toward gender roles and dynamics. The outcomes indicated that young Egyptians aged 15-29 maintained notably conservative attitudes, with young men proving more conservative than women and with attitudes varying considerably by region. While the 2009 data illustrated the positive association between educational attainment and youth outlooks on gender equality, the results also captured alarming degrees of acceptance of gender-based violence and domestic abuse, even among female respondents (El Kogali, Krafft, and Sieverding 2011). To assess whether outlooks have changed since 2009, we explore the 2014 SYPE results related to youth perspectives on gender roles and gender equality.

The 2014 questionnaire included the same questions related to gender as the 2009 questionnaire, with two notable modifications. Firstly, in light of the augmented importance of voter participation in elections and constitutional referendums since January 25, 2011, the 2014 SYPE collected data on youth outlooks regarding women voting. Second, for several of the metrics explored in this chapter-including those related to gender and access to education, household dynamics, and sexual harassment-the question design was modified in 2014. In the 2009 survey, respondents were given the options of "agree," "disagree," and "don't know" to indicate their views on these topics. In order to capture a broader variation in youth opinions, the 2014 questionnaire used a 5-point Likert scale instead; respondents could therefore chose "strongly agree," "agree," "neither agree nor disagree," "disagree," or "strongly disagree" to the same statements designed to capture gender attitudes among the SYPE sample. One should be careful when comparing the results of this scale to 2009 outcomes. There is a considerable difference between respondents indicating that they "don't know" (in 2009) and respondents stating that they "neither agree nor disagree"(in 2014).

Assessing the 2009 and 2014 results, we suspect that some of those who disagreed or agreed in 2009 would have selected "neither agree nor disagree" had they been given the option. This suggests that youth may be unsure where they stand on certain points related to gender norms and gender equality and that their opinions may become more defined later in life. The expanded scale used to measure these questions in 2014 has captured more of these dynamics. On several occasions, this chapter aggregates "strongly agree" and "agree" into one value label, and we do the same for the "strongly disagree" and "disagree" responses, to facilitate interpretation.

We restrict the comparative analysis in this chapter to gender attitudes that did not undergo such questionnaire modification. Also, our analysis primarily focuses on 2014 respondents aged 15-29-which allows for accurate comparison to 2009 outcomes when appropriate-but at times incorporates a sub-sample aged 13-35, to capture variation by age. The SYPE 2009 and 2014 outcomes are all provided in the Appendix, which covers SYPE respondents aged 15-29 in 2009 and 2014, as well as respondents aged $13-35$ in 2014. ${ }^{1}$

1 The one exception to the age groups outlined above pertains to voting rights. The 2014 SYPE asked only youth aged 18 and older about their views of women voting because 18 is the legal voting age in Egypt. Thus, we report outcomes in the Appendix for respondents aged $18-29$ and aged $18-35$. 


\subsection{Access to education, employment, and electoral politics}

\section{Educating female vs. male youth}

To observe how young Egyptians perceive gender equality in education, respondents in both SYPE waves (2009 and 2014) were asked to indicate if they believed that educating boys is more important than educating girls. The complete table of outcomes is included in Table A9.1. Among 2014 respondents aged 15-29, over half (56.7\%) disagreed with the idea that educating boys is more important than educating girls, while $27.8 \%$ believed that the education of male youth is in fact more important and $15.5 \%$ were undecided (Figure 9.1). As was the case in 2009, we observe notable variation by gender; $67.2 \%$ of female respondents (aged 15-29) were supportive of equal rights to education regardless of gender, compared to $47.1 \%$ of male respondents in 2014.

The 2014 data suggest that there is a positive correlation between educational attainment and youth support of equal access to education for girls and boys (Table A9.1). Young people with no education proved the least supportive; among illiterate respondents aged 15-29, 36.6\% believed that educating boys is more important than educating girls while $41.8 \%$ disagreed. By contrast, youth with tertiary attainment proved the most supportive. Observing youth aged $15-29$, we find that $63.8 \%$
The SYPE data suggest that there is a positive correlation between educational attainment and Egyptian youth's support of equal access to education for girls and boys.

of those with a post-secondary degree and $67.3 \%$ of those with university attainment believed that educating girls is as important as educating boys.

Attitudes about the importance of educating girls in relation to boys also varied by region. The 2014 responses indicate that young people residing in the Frontier and Urban Governorates held the most conservative views about gender and education, as $41.0 \%$ of respondents in the Frontier Governorates and $37.3 \%$ in the Urban Governorates believed that educating boys is more important than educating girls. On the other hand, respondents in urban and rural Lower Egypt demonstrated the strongest support of equal rights to education in 2014; we find that $60.5 \%$ of rural-based and $63.6 \%$ of urban-based respondents in Lower Egypt (aged 15-29) were supportive of equal access to education.

FIGURE 9.1 Agreement of youth aged 15-29 with the statement, "educating boys is more important than educating girls," by gender and wealth quintile, 2014 (\%)

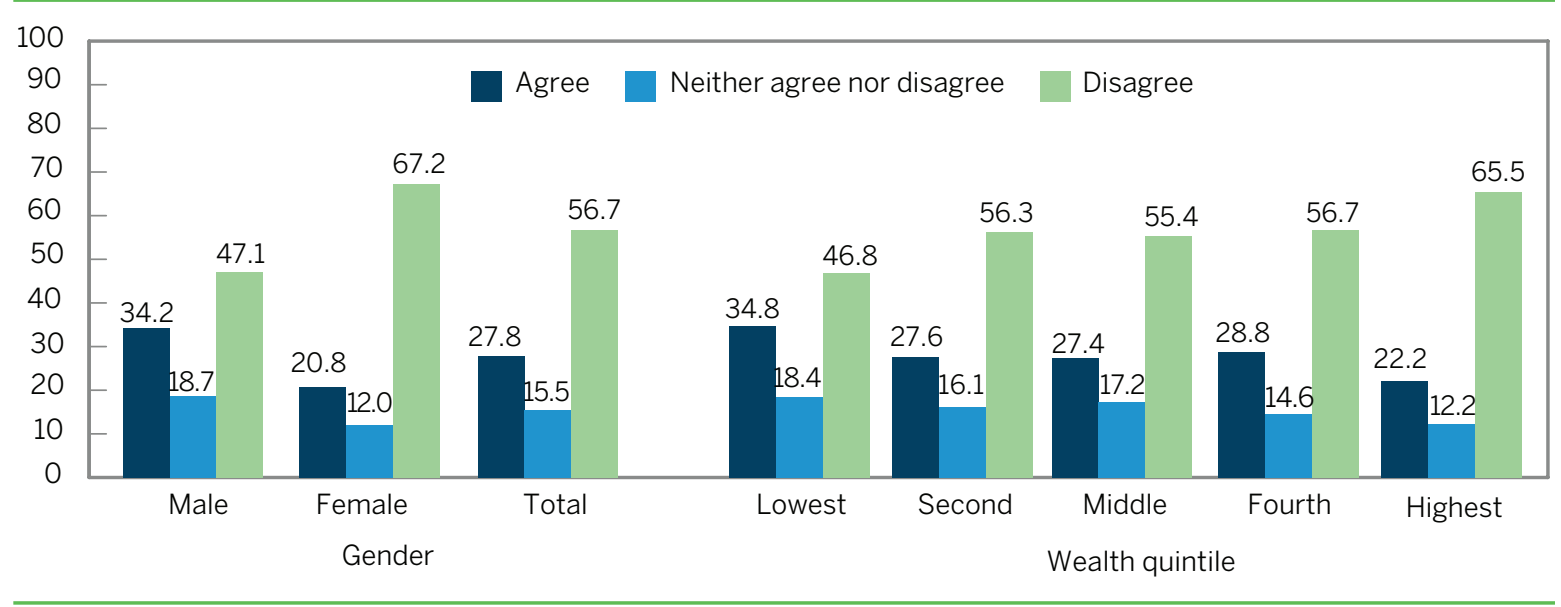


FIGURE 9.2 Agreement of youth aged 15-29 with the statement, "when job opportunities are scarce, priority must go to men over women," by gender and residence, 2014 (\%)

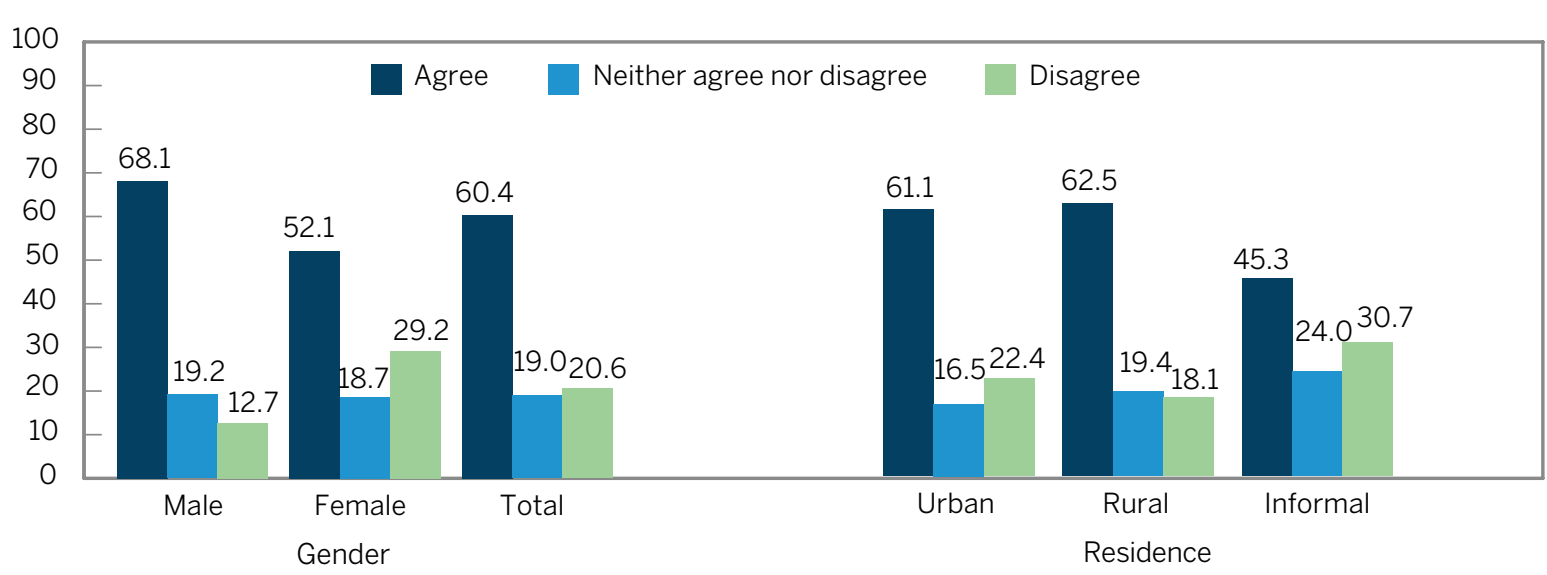

As was the case in 2009, the 2014 results suggest that as household wealth increases, support for a girl's right to education increases (Figure 9.1). Observing respondents aged 15-29, we find that youth from the lowest wealth quintile held the most conservative views, with $46.8 \%$ of respondents demonstrating their support of gender equality in access to education and 34.8\% agreeing that educating boys is more important than educating girls. We observe rising support of equality in education with each increase in wealth quintile and find that among respondents in the highest wealth quintile, $65.5 \%$ of youth supported equal access to education. This was nearly 20 percentage points higher than their counterparts in the lowest quintile.

\section{Job priority}

Both waves of the SYPE asked respondents to indicate if they believed that men should get jobs over women when professional opportunities are scarce (for all outcomes, see Table A9.2). ${ }^{2}$ Among respondents aged 15-29 in the 2014 SYPE, 60.4\%

2 This question used the Likert 5-point scale in 2014. Unlike other gender attitudes questions, respondents had the option to "agree," "disagree," or choose "neither (agree nor disagree)" in 2009. Although respondents had the "neither" option in the 2009 questionnaire, we should still be cautious when directly comparing the 2009 and 2014 statistics due to differences in question design (3-point scale in 2009 versus 5-point scale in 2014) and different question placement in the two surveys. supported male job priority, $20.6 \%$ disagreed, and $19.0 \%$ were undecided. As demonstrated by Figure 9.2, female respondents were more likely to advocate for equal access to work than their male counterparts in both SYPE waves. Nevertheless, we find that the majority of male (68.1\%) and female (52.1\%) respondents supported male job priority in 2014.

While youth support of male job priority was high at all education levels, SYPE respondents with higher educational attainment were more supportive of equal access to job opportunities in 2014 (Table A9.2). Observing the 15-29-year-old group, we find that respondents with general secondary attainment were the most likely to support equal access to work regardless of gender (31.9\%) followed by those with university attainment (28.0\%). By contrast, only $12.7 \%$ of illiterate youth supported equal access to employment in 2014.

We additionally observe some variation in youth outlooks by region and residence. Young people (aged 15-29) in rural areas were considerably less supportive of gender equality in access to work than those residing in informal areas; $18.1 \%$ of rural respondents and $30.7 \%$ of respondents in informal areas indicated their support of equal access to jobs in 2014 (Figure 9.2). Regionally, we find that respondents (aged 15-29) in rural Lower Egypt (16.4\%) and the Frontier Governorates (15.4\%) were the least likely to support equal 
access to professional opportunities. Unlike their rural counterparts, respondents from urban Lower Egypt were the most supportive, with just over one-quarter (26.6\%) demonstrating their support of equal access to job opportunities regardless of gender.

\section{The right to vote}

The updated civic participation module of the 2014 SYPE asked respondents aged 18 and older if they believed that the women in their families should be allowed to participate in elections (full set of outcomes in Table A9.3). The large majority of young people (81.5\%) aged $18-35$ supported the right of female family members to vote. Support of women voting was high among both male (81.9\%) and female (81.1\%) SYPE respondents (aged 18-35).

As shown in Figure 9.3, the majority of youth at each education level supported women voting, but there was some variation by educational attainment. Illiterate youth (aged 18-35) proved the least supportive of women voting, with $68.6 \%$ agreeing with the right of female relatives to participate in elections and referendums. This was approximately 20 percentage points lower than youth with tertiary degrees $(88.8 \%$ of respondents with post-secondary and $89.9 \%$ of respondents with university attainment) or with general secondary school attainment (85.3\%).

With regard to region and residence, young people (aged 18-35) living in informal areas were the most supportive of women voting (90.5\%), followed by urban areas (83.4\%), while the percentage of young people supporting a woman's right to vote was lowest in rural areas (79.3\%) (Table A9.3). While still in the majority, youth (aged 18-35) in the Frontier Governorates and rural Upper Egypt were the least supportive of women voting, with $70.7 \%$ and $73.8 \%$ of young people agreeing with the right of their female family members' to vote in these regions, respectively. This was considerably lower than in urban Lower Egypt, where $89.6 \%$ of respondents expressed their support of women voting in 2014.

There also appeared to be a positive relationship between household wealth and youth support of women voting. Those (aged 18-35) from the lowest
FIGURE 9.3 Responses of youth aged 18-35 to the question, "Do you agree that female family members should vote in elections and referendums?", by education level and region, 2014 (\%)

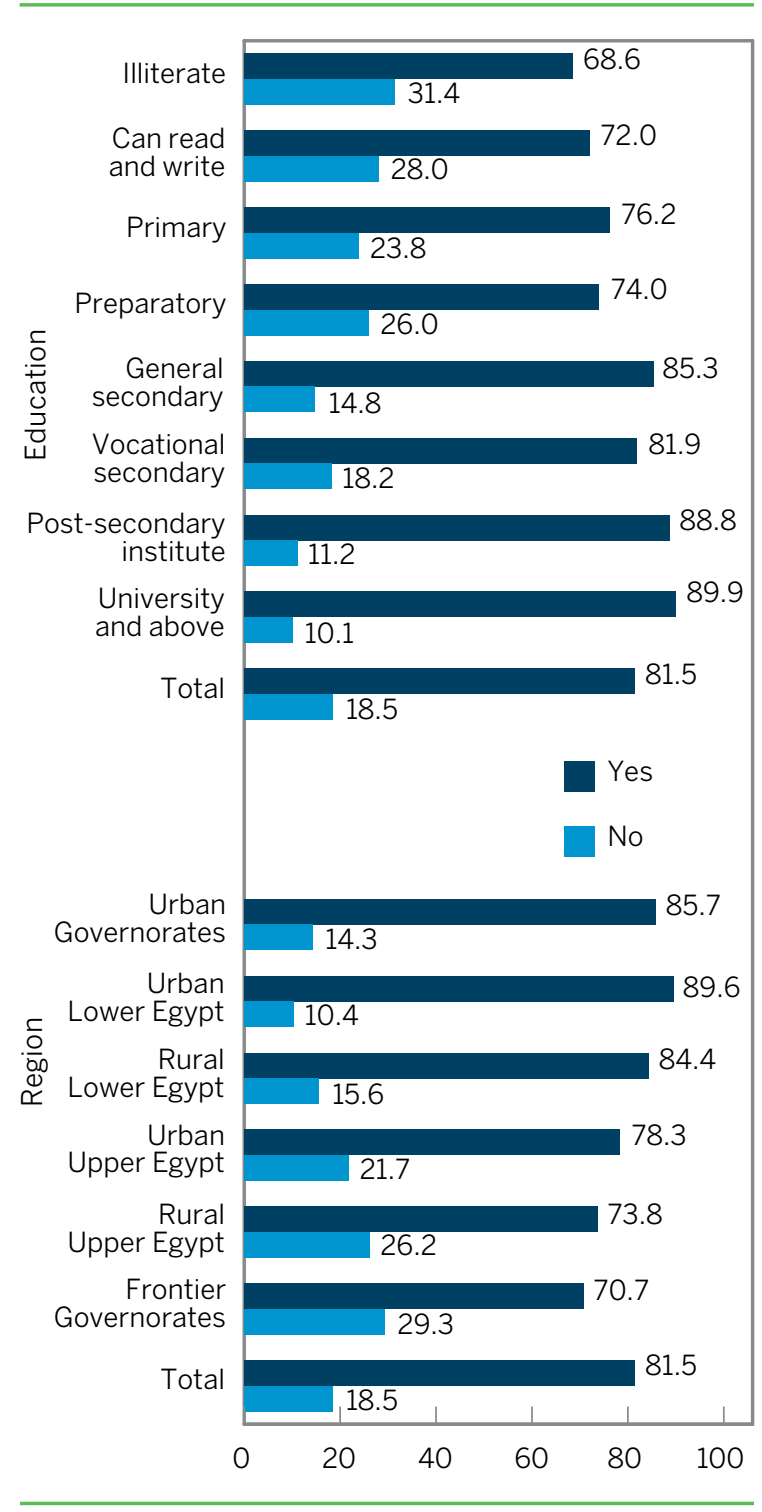

wealth quintile appeared notably more conservative than other wealth quintiles on this point, with $69.9 \%$ agreeing and $30.1 \%$ disagreeing with a woman's right to participate in elections and referendums. Among the other wealth quintiles, support of a woman's right to vote exceeded $80 \%$ of respondents. We observe the most liberal views among youth in the highest wealth quintile, among whom $88.7 \%$ (aged 18-35) agreed with the right of female family members to vote. 


\subsection{Household dynamics}

\section{Authority and obedience among siblings}

To better examine gendered household dynamics, both waves of the SYPE asked respondents to indicate whether they believed that a girl was obligated to obey her brother even if he was younger than she. All outcomes are provided in Table A9.4. As was the case in 2009, SYPE 2014 respondents (aged 15-29) demonstrated conservative responses to this question, with nearly two-thirds $(60.6 \%)$ of youth agreeing with these household gender norms and only $12.9 \%$ of youth disagreeing. Additionally, one-quarter (26.4\%) of respondents were on the fence, neither agreeing nor disagreeing with inequality of authority among siblings. As is demonstrated by Figure 9.4, male respondents were more likely to support a brother's authority over his sisters than their female counterparts; over two-thirds (67.5\%) of male respondents indicated this in the 2014 SYPE, compared to approximately one-half (53.1\%) of female respondents.

While support of a brother's authority over his sisters was high regardless of residence, youth residing in informal areas proved the most likely to support gender equality in this context, with $21.3 \%$ of respondents (aged 15-29) rejecting the notion that a girl must obey her younger brother, compared to $13.8 \%$ of urban and $11.2 \%$ of rural youth. Respondents in rural Upper Egypt held the most conservative views, with only $10.3 \%$ disagreeing and over two-thirds (67.8\%) agreeing with male superiority in between-sibling authority. By contrast, the largest percent of youth disagreed with this statement in the Urban Governorates and urban Lower Egypt, where $16.5 \%$ and $15.9 \%$ of respondents (aged 15-29) disagreed with a brother's authority over his siblings, respectively.

Outlooks remained conservative regardless of educational attainment, though we do find that respondents with the lowest levels of education were the least likely to support equality among siblings, which was also the case in 2009. Among SYPE 2014 respondents aged 15-29, only $9.7 \%$ of illiterate youth and $9.0 \%$ of youth with a primary education disagreed with a brother's authority over his sisters even if he is younger. At the other end of the educational spectrum, 18.4\% of SYPE 2014 respondents with university attainment disagreed with such household inequality among siblings. Nevertheless, the majority of youth at all education levels supported a brother's authority over his sisters regardless of the brother's age.

Conservative outlooks on household inequality among siblings cut across all wealth quintiles as well, though there did appear to be a relationship between household wealth and youth outlooks on this topic. While $68.5 \%$ of respondents aged $15-29$ in the lowest wealth quintile supported a brother's authority over his sisters, we find that $60.8 \%$ of respondents

FIGURE 9.4 Agreement of youth aged 15-29 with the statement, "A girl must obey her brother, even if he is younger" by gender and region, 2014 (\%)

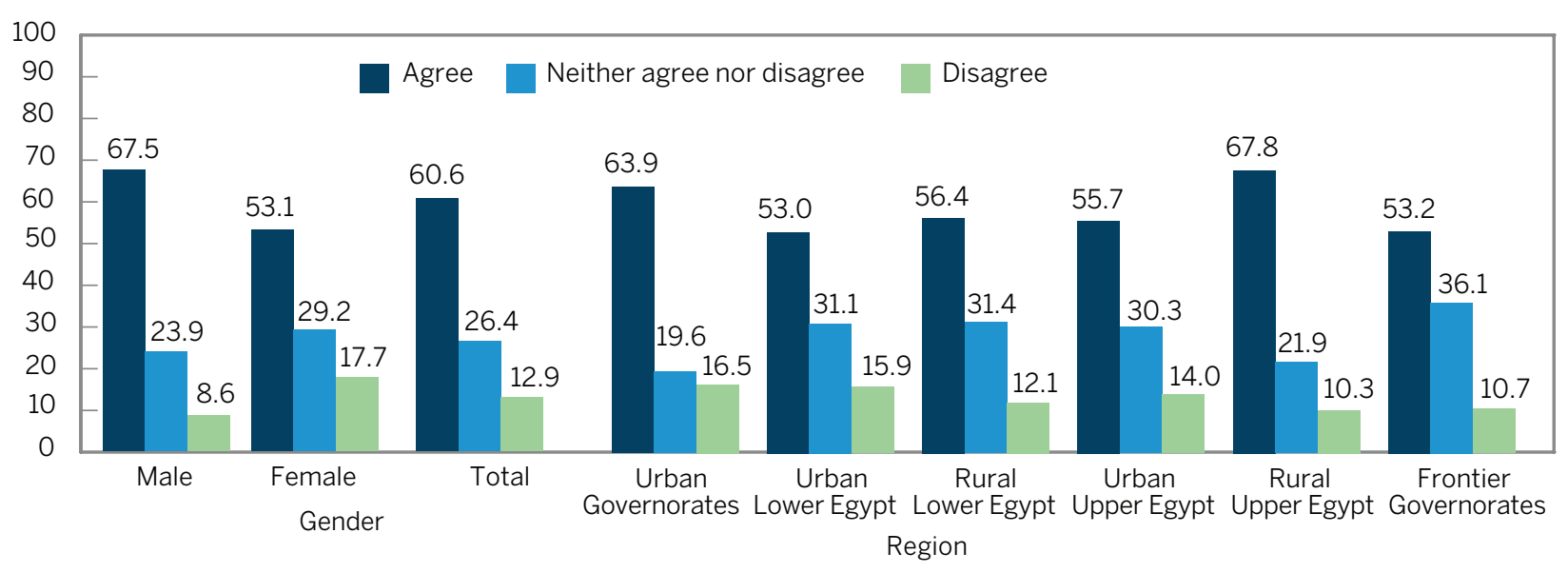


in the middle quintile and $55.6 \%$ of respondents in the highest wealth quintile were in agreement.

\section{Gender and household duties}

To further understand youth perspectives on gender norms within the family, the 2009 and 2014 SYPE questionnaires asked respondents if they felt that boys should contribute to household chores as much as girls. All outcomes are included in Table A9.5. Among respondents aged 15-29, over one-quarter (27.8\%) of respondents agreed that boys and girls should contribute to household chores equally, $41.9 \%$ disagreed, and $30.3 \%$ neither agreed nor disagreed. As was observed in 2009, female respondents proved considerably more likely to agree that boys and girls should contribute to chores equally: $36.1 \%$ of female respondents (aged 15-29) indicated this in 2014, compared to $20.3 \%$ of male respondents (Figure 9.5).

Observing outcomes by residence, we notice that among respondents aged 15-29, those living in informal areas were considerably more likely to support equal chores for girls and boys than their rural counterparts; $40.5 \%$ of youth living in informal areas agreed that boys should contribute to chores as much as girls do, compared to $31.6 \%$ of respondents in urban areas and $24.0 \%$ in rural areas. This differs from the 2009 outcomes, when there was little variation by residence. However, the 2014 re- sults on youth perspectives of gendered household duties were consistent with the outcomes regarding authority among siblings, where we similarly observed more egalitarian outlooks among youth in informal areas and more conservative views among rural young people.

Regionally, once again rural Upper Egypt and the Frontiers Governorates held the most conservative views. Youth (aged 15-29) living in rural Upper Egypt and the Frontier Governorates were the least supportive of boys and girls contributing to household chores equally, with only $20.4 \%$ of respondents in the Frontiers and $22.4 \%$ of respondents in rural Upper Egypt agreeing that boys should help with chores as much as girls. By contrast, respondents living in the Urban Governorates were the most supportive, with $36.7 \%$ agreeing with equal chores for girls and boys. This is not surprising in light of the outcomes noted above, i.e. the highest disagreement of a brother's authority over his sisters in the Urban Governorates in 2014.

Youth (aged 15-29) attitudes about gender and household responsibilities varied by educational level, but there did not appear to be a consistent correlation between level of schooling and support for boys contributing to chores (Figure 9.5). In 2014 , only $21.0 \%$ of illiterate respondents, $25.1 \%$ of respondents with primary education, and $25.6 \%$ of respondents with vocational secondary attainment

FIGURE 9.5 Youth (aged 15-29) agreement with the statement, "Boys should help with household chores as much as girls do", by gender and education level, 2014 (\%)

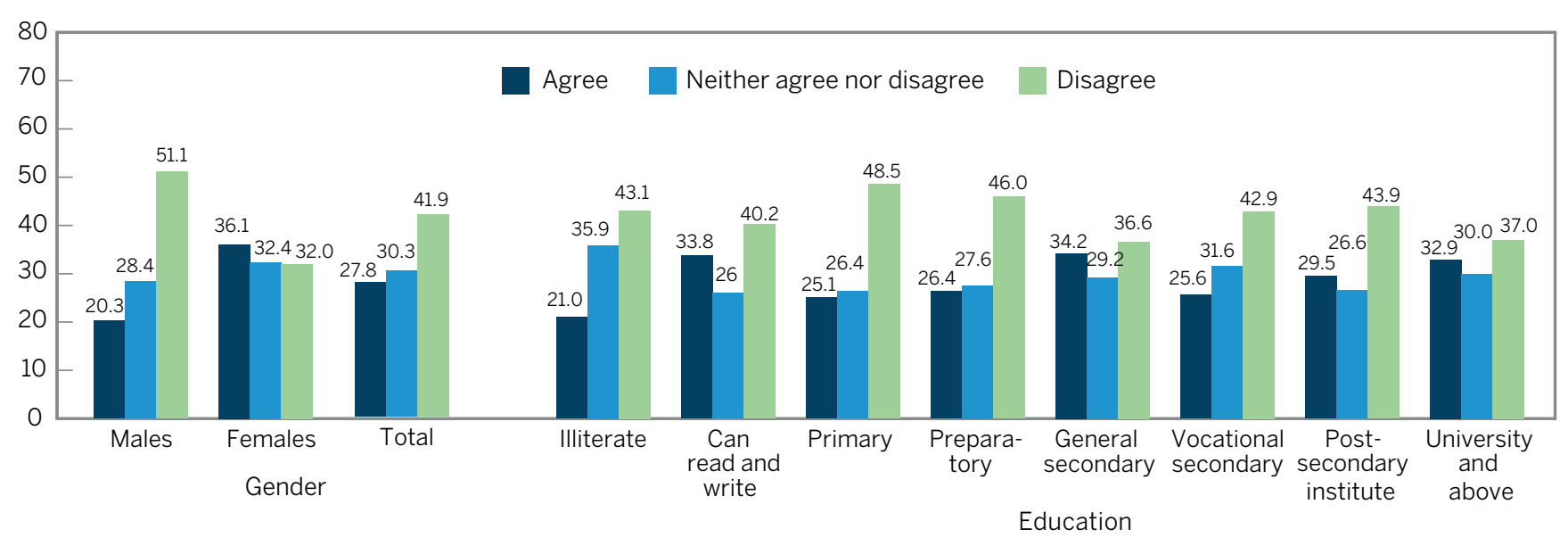




\section{There was considerable variation but no clear correlation between educational attainment and views on household financial decision making.}

agreed with boys' equal participation in household tasks. Conversely, we observe the highest support of equal household responsibilities for boys and girls among those with general secondary and university attainment, with $34.2 \%$ of respondents who completed the general secondary track and 32.9\% of university degree-holding respondents agreeing that boys and girls should contribute to household chores equally.

\section{Financial decision making between spouses}

To evaluate youth perceptions of household decision making authority between spouses, both waves of the SYPE asked respondents to indicate whether they thought that the husband exclusively should decide on how money is spent (See Table A9.6).
Overall, nearly half (47.4\%) of 2014 youth aged 15-29 agreed, while a smaller percentage (23.9\%) disagreed. Over one-quarter (28.7\%) of youth were undecided. Figure 9.6 provides outcomes by gender for 2014. We find that male youth (55.2\%) were considerably more likely than female youth (38.9\%) to believe that financial decision making should be solely in the hands of the husband.

In 2014, we find the strongest support for male control over household spending in rural Upper Egypt, where $55.1 \%$ of respondents (aged 15-29) agreed with the statement and only $20.5 \%$ of respondents disagreed. We observe less conservative views in Lower Egypt regarding a husband's control over household finances, with $43.3 \%$ of urban and $41.7 \%$ of rural youth in this region in agreement, while approximately one-quarter $(24.7 \%$ in urban areas and $24.5 \%$ in rural areas) expressed their disagreement.

We observe considerable variation but no clear correlation between educational attainment and views on household financial decision making. Illiterate youth (aged 15-29) maintained the most conservative outlooks, with over half (54.3\%) agreeing that financial decision making should be exclusively the role of the male household head. Inversely, youth agreement was lowest among those with general secondary and university attainment, at $41.0 \%$ and $38.1 \%$, respectively. While this might suggest that there is a positive relation-

FIGURE 9.6 Agreement of youth aged 15-29 with the statement, "only the husband should decide how household money is spent", by gender and employment status, 2014 (\%)

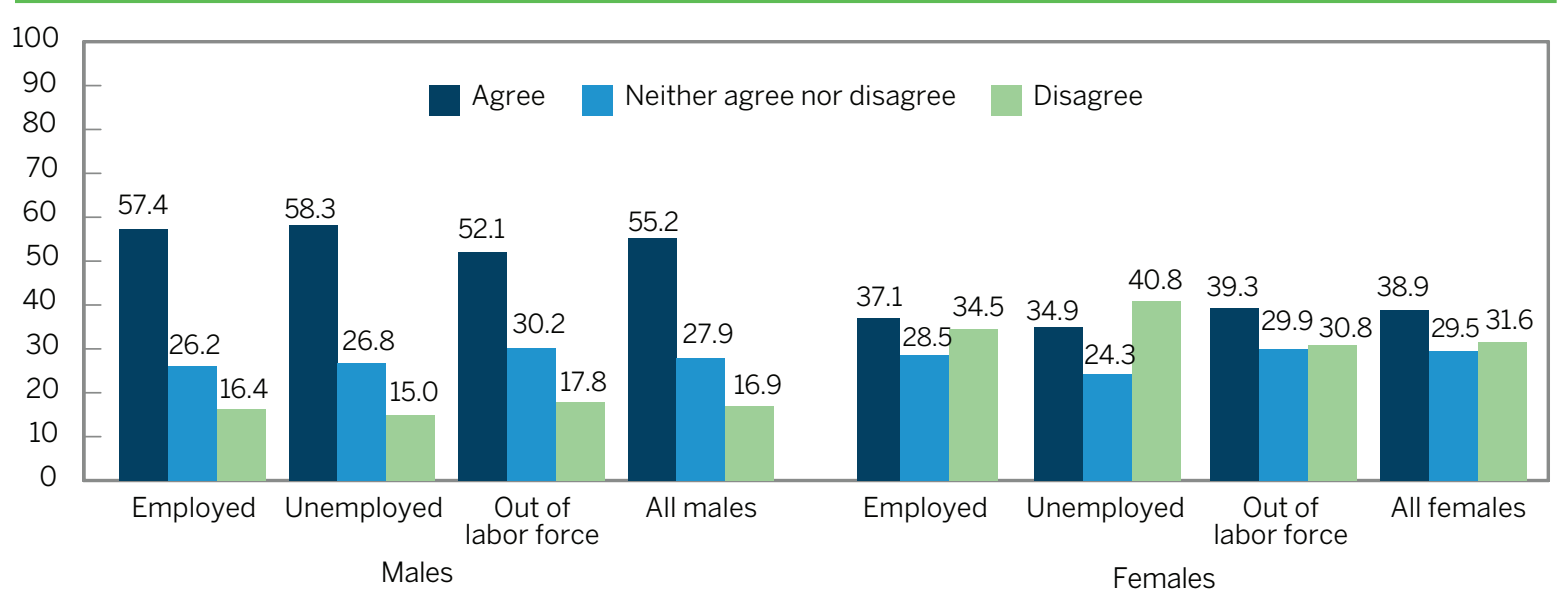


ship between schooling and youth perspectives on equal financial decision making authority between spouses, we also observe conservative views among those with higher levels of attainment. Notably, $50.7 \%$ of youth aged $15-29$ with vocational secondary and $49.3 \%$ with post-secondary attainment agreed that only the husband should decide how household money is spent. It also appears that there was a relationship between youth attitudes about household financial decision making and socioeconomic status. Over half (54.5\%) of youth from the lowest wealth quintile agreed with a husband's control over household spending. Conversely, $40.2 \%$ of those in the highest quintile were in agreement.

Analyzing this variable by employment status, it appears that for 2014 respondents aged 15-29, employed youth (54.7\%) were more likely to support a husband's control over financial decisionmaking than unemployed youth $(48.9 \%)$ or young people out of the labor force (43.7\%). When we disaggregate by gender (Figure 9.6), we find that unemployed male respondents aged 15-29 were slightly more likely to support male domination over household financial decisionmaking than those out of the labor force or employed. Conversely, unemployed females (aged 15-29) proved slightly less likely to agree that husbands should control household spending, compared to their female counterparts who were out of the labor force or employed.

\section{Obtaining permission from spouse}

The final SYPE indicator that assessed youth attitudes toward household dynamics concerned the question of whether a woman must obtain permission from her husband "before doing anything" (see Table A9.7). As was the case in 2009, we find that exceptionally high percentages of youth agree with this. Among respondents aged 15-29 in 2014, 76.3\% were in agreement, while a rather small percentage (6.0\%) disagreed and approximately $17.7 \%$ were undecided. Observing outcomes by gender (Figure 9.7), male respondents $(78.8 \%)$ were slightly more likely than female respondents (73.6\%) to agree, but youth support of the idea that a woman must obtain her
FIGURE 9.7 Agreement of youth aged 15-29 with the statement, "a woman must obtain permission from her spouse before doing anything", by gender, 2014 (\%)

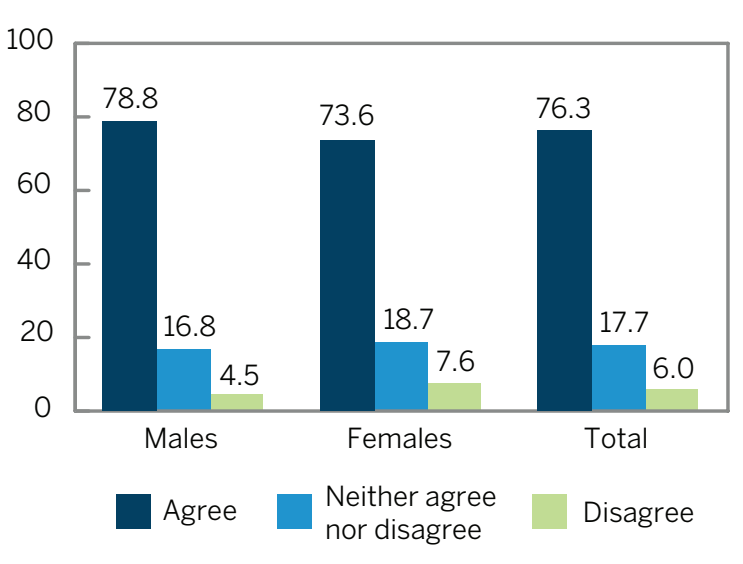

husband's permission before "doing anything" was high regardless of gender.

There was slight variation in outlooks by educational attainment, but there was no clear correlation between schooling and perspectives on this matter. In fact, youth (aged 15-29) with post-secondary attainment demonstrated the most conservative views, with $81.3 \%$ agreeing that a wife must have her spouse's permission for any activity. We additionally observe conservative outlooks among those with preparatory education (79.6\%) and primary education (78.6\%). While university-educated youth were the least likely to agree that a woman must have her husband's permission before "doing anything", we still find that the majority (71.7\%) were in agreement.

Analyzing the 2014 outcomes by residence, we observe the most conservative views in urban and rural areas (77.1\% and $77.5 \%$ respectively) but less conservative outlooks among youth in informal areas (66.4\%). Observing youth attitudes by region, we find that agreement was highest in rural Upper Egypt, where $82.2 \%$ of youth respondents supported the idea that a woman must obtain her husband's permission before "doing anything." Agreement was lower in urban Lower Egypt (70.6\%) and in the Frontier Governorates (71.6\%). 
Observing 2014 youth outlooks on the need for spousal permission by wealth, we also find that strong agreement cuts across all wealth quintiles, and there does appear to be a weak relationship between wealth and youth outlooks on this matter. Those from the lowest wealth quintile were most likely to be in favor (80.8\%), and we find that respondent agreement with inequality between spouses slowly declines as we move to higher wealth quintiles. Despite this apparent correlation, youth agreement was still very high among the second highest and highest quintiles, at $74.6 \%$ and $75.7 \%$, respectively.

\subsection{Divorce}

\section{Women's right to ask for divorce}

The 2009 and 2014 SYPE questionnaires allow us to compare youth outlooks on a woman's right to separate from her husband through divorce or khul. ${ }^{3}$ Outcomes by all background characteristics are provided in Table A9.8. Overall, the majority of 2014 respondents aged 15-29 (71.4\%) supported a woman's right to separate from her husband. Youth support has increased since 2009, when agreement among SYPE respondents was measured at $63.7 \%$ among those aged $15-29$. As was the case in 2009, female respondents (81.0\%) proved more likely to support a woman's right to divorce than male respondents (62.5\%) in 2014 (Figure 9.8).

Similar to the 2009 outcomes, wealthier young people were more likely to support a woman's right to divorce than young people from lower wealth quintiles. Over three-quarters (77.8\%) of respondents (aged 15-29) from the highest wealth quintile agreed with a woman's right to divorce, compared to $65.6 \%$ of youth from the lowest quintile. Youth support of a woman's right to divorce grew among youth in all wealth quintiles between the 2009 and 2014 wave of the SYPE.

3 Amendments to personal status laws passed in January 2000 interpret khul as the following: a woman has the right to separate from her husband, regardless of the circumstance, as long as she "renounces her dower and all her financial rights" (Sonneveld 2004).
FIGURE 9.8 Responses of youth aged 15-35 to the question, "do you think a woman has the right to ask for a separation (divorce or khul?), by gender (2009 and 2014) and marital status (2014), (\%)

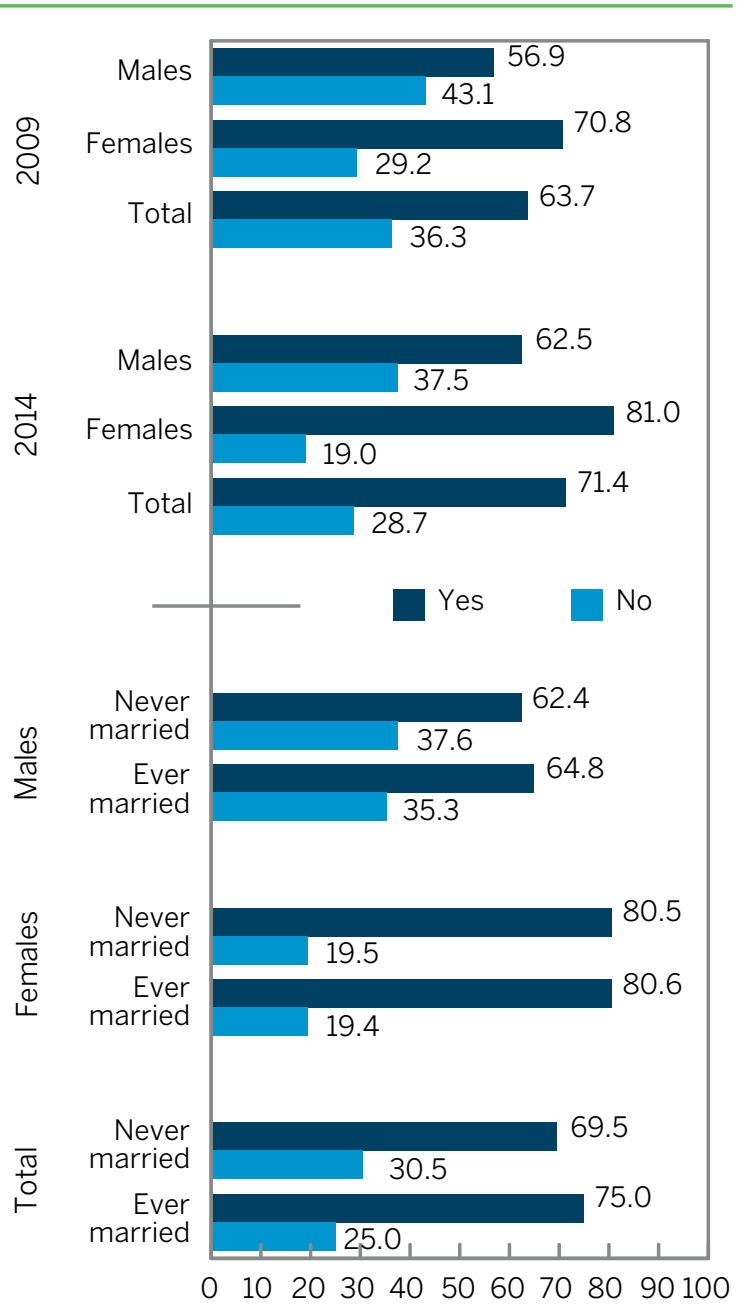

Attitudes about a woman's right to divorce varied by educational level: $61.2 \%$ of illiterate youth (aged 15-29) supported a woman's right to divorce, and with each step upward in educational attainment, we find increasing percentages of youth in support. Among those with university attainment, the large majority (78.1\%) were in favor in 2014. Comparing the 2009 and 2014 SYPE rounds, we find growing support for a woman's right to separate from her husband at all educational levels except among youth with post-secondary education. 
Observing 2014 outcomes by marital status, we find that ever-married youth were more likely to be in favor of a woman's right to divorce than never-married youth. Among 2014 respondents aged $15-35,{ }^{4}$ we find that $69.5 \%$ of never-married respondents supported a women's right to pursue divorce while three quarters (75.0\%) of ever-married respondents agreed that women should be allowed to request divorce. As Figure 9.8 illustrates, ever-married female youth were as likely to support a woman's right to divorce as their never-married counterparts, while we observe slightly higher support among the ever-married males than their never-married counterparts.

Regionally, we find that young people (aged 15-29) from the Frontier Governorates (56.5\%) and urban Upper Egypt (65.9\%) were the least likely to support a woman's right to divorce in 2014, while support was highest in the Urban Governorates (73.8\%). It is important to note here that youth support of this right has grown considerably in rural Upper Egypt, an area of the country often characterized by conservative norms. While support increased in all regions between the two survey waves, it jumped from $59.5 \%$ of respondents (aged 15-29) in rural Upper Egypt in 2009 to nearly three-quarters (72.7\%) of respondents in 2014.

\section{Circumstances in which divorce is justified}

The SYPE also asked youth to indicate circumstances in which women and men have the right to pursue divorce. For married women, SYPE respondents aged 15-29 most frequently supported the following reasons: if a wife hates her husband (78.1\%), if her husband marries another woman (74.8\%), if her spouse beats her regularly (71.4\%),

4 We observe trends among the 2014 respondents aged 15-35 in order to capture in our analysis older youth who are more likely to be married. Outcomes for SYPE ever-married and never-married respondents aged 15-29 in both the 2009 and 2014 survey rounds are also included in Table A9.8. and if her husband "knows" 5 another woman (69.4\%). While respondents perceived frequent domestic violence as grounds for divorce, only a minority (21.8\%) of 2014 respondents aged 15-29 believed that a woman has the right to seek divorce after the first time she is beaten by her husband (see Table A9.9).

Comparing 2009 and 2014 responses, we notice that while youth support of a woman's right to seek divorce has remained consistent for many of the circumstances addressed, the percentage of respondents (aged 15-29) who believed that a woman is justified in divorcing her husband if he does not adequately provide for her and her children dropped from nearly half (47.2\%) of respondents in 2009 to $36.4 \%$ in 2014 . The percentage of respondents who believed that it is appropriate for a wife to separate from her husband if he "tries to take her money" also declined between the two survey waves (from $60.3 \%$ in 2009 to $52.9 \%$ in 2014).

Table A9.10 provides youth perspectives on the circumstances in which a man has the right to divorce his wife, as reported by SYPE respondents. In 2014 , the most widely supported reason for a man to seek divorce among respondents aged 15-29 was if his wife "knew" another man (91.0\%) or if he hates his wife (71.2\%). These trends were similar to the 2009 responses, though we note a small decline in youth support of a man divorcing his wife if he hates her (from $79.6 \%$ in 2009 to $71.2 \%$ in 2014) or if she does not take care of the children (from $45.6 \%$ in 2009 to $38.7 \%$ in 2014).

Comparing 2014 outlooks on the circumstances in which men as opposed to women can justifiably pursue divorce, we notice equivalent expectations for husbands and wives in some cases but some evidence of double standards. For example,

5 The direct translation from the SYPE questionnaire is "if he knows another one (woman)." In this context, "knowing" another woman is not explicitly sexual, though it may likely be interpreted as such by respondents. 
nearly three-quarters of SYPE 2014 respondents aged 15-29 agreed that a wife or a husband can justifiably pursue divorce if he/she hates his/her spouse. We see similarly equivalent expectations pertaining to the circumstances in which a spouse suffers from sexual dysfunction or cannot have children.

Expectations vary more when we focus on the circumstance in which a spouse "knows" another (Figure 9.9). Overall, the majority of youth considered this grounds for divorce for both husbands and wives, but it is worth noting that while roughly three- quarters (69.4\%) believed that a man's "knowing" another woman is a justifiable reason for his wife to divorce him, 9 out of 10 respondents stated that a wife's "knowing" another was grounds for her husband divorcing her.

\section{Public perceptions of divorced women}

The SYPE 2014 results suggest that divorced women are still not seen positively in Egyptian society (Table A9.11). Among 2014 respondents aged $15-29,63.7 \%$ (62.9\% of male and $64.6 \%$

FIGURE 9.9 Agreement of youth aged 15-29 with a husband's or wife's decision to pursue divorce if his/her spouse "knows" another, by gender, 2014 (\%)

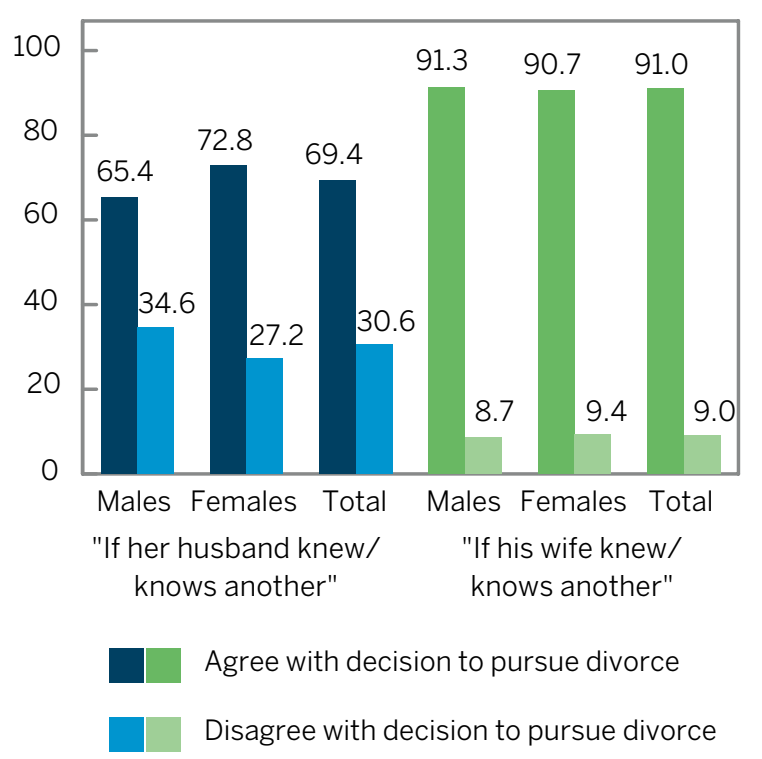

FIGURE 9.10 Responses of youth aged 15-29 to the question: "Do you think that society perceives divorced women respectfully?", by region and education, 2014 (\%)

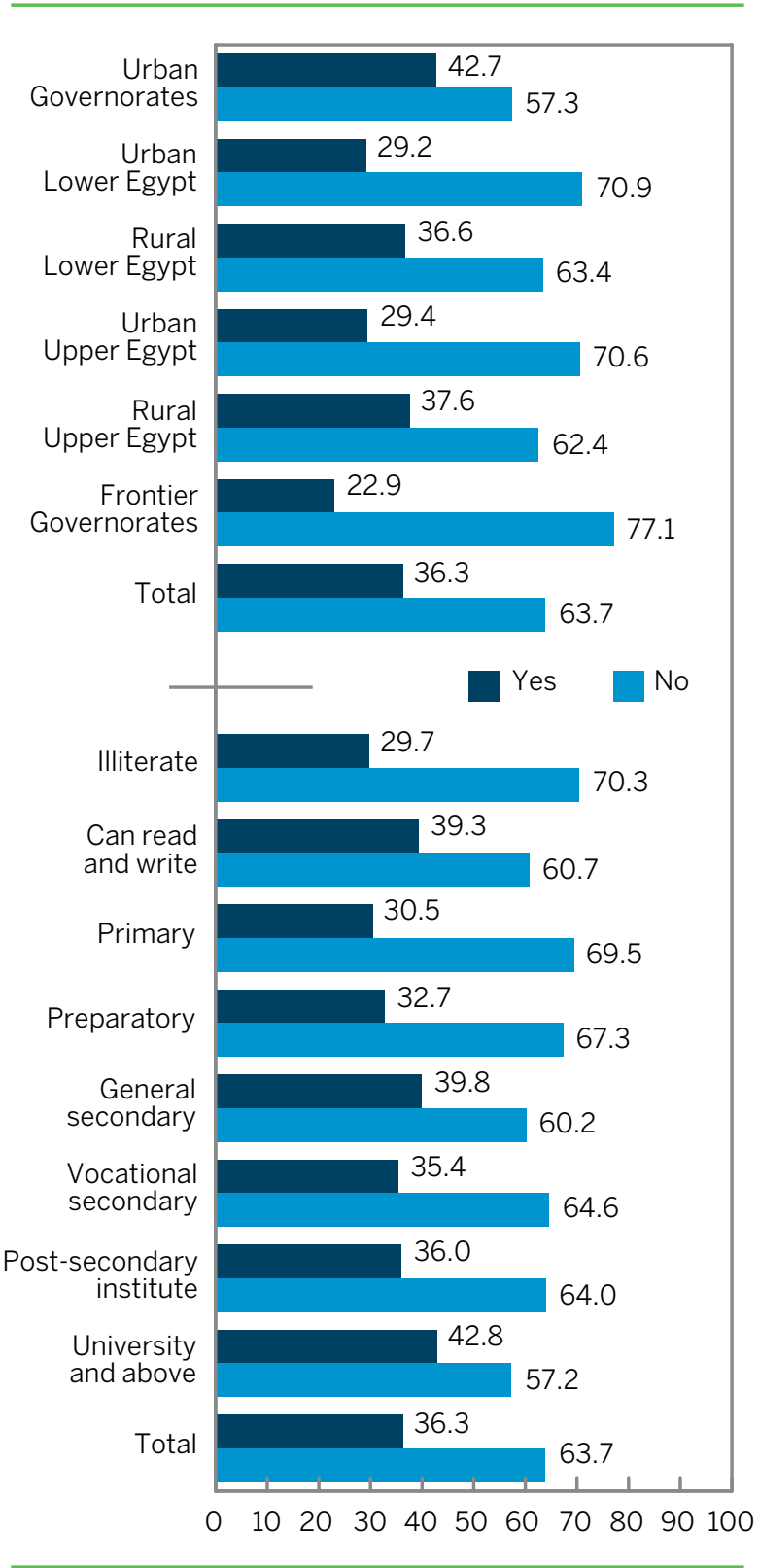

of female respondents) indicated that they do not think that society sees divorced women respectfully. These results are quite similar to 2009 , when $67.1 \%$ of respondents $(65.8 \%$ of males and $68.6 \%$ of females) stated that they did not believe society perceived divorced female with respect. 
We observe some variation by years of schooling (Figure 9.10). Young people (aged 15-29) with university (57.2\%) and general secondary (60.2\%) attainment proved less likely to believe that divorced females are not socially respected. Conversely, illiterate respondents (70.3\%) and respondents with primary education (69.5\%) were more likely to state that their societies do not respect divorced women.

Disaggregating 2014 responses by wealth quintile, we note slight but not drastic variation in outlooks. Respondents in the higher wealth quintiles were slightly less likely to believe that divorced women are disrespected by society, with $59.2 \%$ of respondents (aged 15-29) in the highest and $61.5 \%$ of those in the second highest quintiles disagreeing with the question. Respondents from the middle (68.2\%) and lowest (65.9\%) wealth quintiles proved more likely to believe that society disrespects divorced females.

In terms of residence, we find that youth who live in informal areas were the most likely to believe that society perceives divorced female negatively; $75.9 \%$ of youth (aged 15-29) living in informal areas indicated this, compared to $61.0 \%$ of youth in urban and $63.1 \%$ in rural areas. We also observe variation by region. Youth (aged 15-29) in the Frontier Governorates (77.1\%) and urban Lower Egypt (70.9\%) were the most likely to report that their society is not respectful toward divorced females. On the other hand, young people in the Urban Governorates were the least likely to report that society disrespected divorced females, with nearly one-half (57.3\%) aged 15-29 saying this in 2014 .

Interestingly we find that a smaller percentage of youth in rural Upper Egypt believed that society is disrespectful toward divorced women, with $62.4 \%$ of 2014 respondents aged 15-29 agreeing with this sentiment. This is surprising, as the SYPE data also suggested that young people living in these areas were the least supportive of divorce (as discussed in the previous section).

\section{While still alarmingly high, the percentage of Egyptian youth who felt that a man was justified in beating his wife if she "talked to another man" declined from $74 \%$ in 2009 to $65 \%$ in 2014.}

\subsection{Gender-based violence}

\section{Wife battery}

The SYPE 2009 and 2014 questionnaires asked respondents to indicate the contexts in which they feel it is justifiable for a husband to beat his wife. Table A9.12 provides the results overall and by gender for both SYPE waves. Similar to 2009 outcomes, the most commonly supported reason for wife battery reported by 2014 respondents (aged 15-29) was if a man's wife "talked" to another man; $64.9 \%$ of respondents considered this justifiable grounds for a husband to physically assault his spouse. While alarmingly high, respondent support of wife battery in this context has declined since 2009 , when $74.0 \%$ of SYPE respondents aged 15-29 considered a wife "talking to other men" as a justifiable reason for a husband to beat her.

Comparing the results from the 2009 and 2014 surveys, we notice that youth support of wife battery has declined for other circumstances as well. For example, one-quarter (25.5\%) of 2009 respondents (aged 15-29) agreed that a man could beat his wife if she argued with him. In 2014, this figure dropped to $18.9 \%$ of respondents of this age. Similarly, while one-third (33.0\%) of 2009 SYPE respondents (aged 15-29) agreed that wife battery 
FIGURE 9.11 Responses of youth aged 15-29 to the question, "do you believe that women who are harassed in the streets deserve to be if they are dressed provocatively?" by gender and region, 2014 (\%)

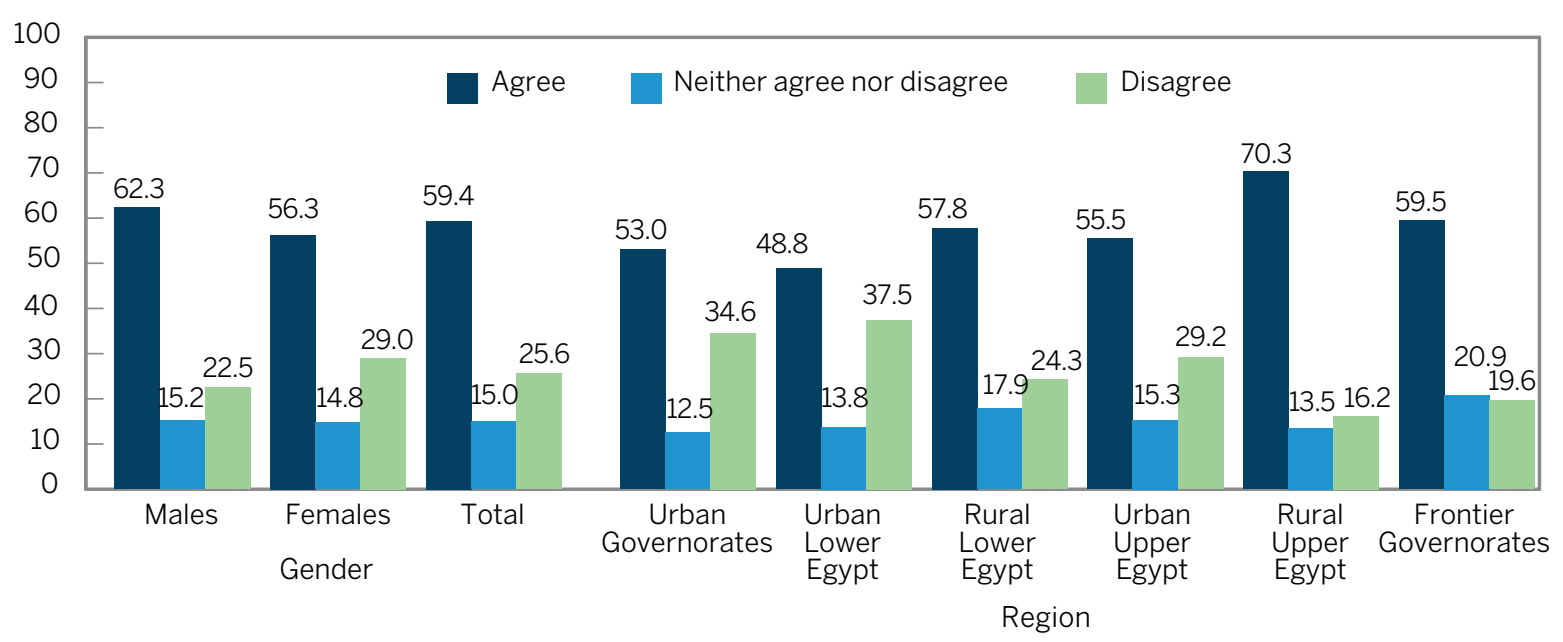

was justified if the wife wasted her husband's money, less than one-quarter (22.8\%) of respondents supported this in 2014.

As was the case in 2009, young men were more likely to approve of wife battery in each circumstance than young women in 2014. For example, while $13.9 \%$ of 2014 female respondents aged 15-29 believed that a man has the right to beat his wife if she argues with him, nearly twice as many male respondents $(23.4 \%)$ saw this is a justifiable reason. Similarly, while $58.4 \%$ of 2014 female respondents aged 15-29 thought that a man could beat his wife if she "talked" to other men, $70.9 \%$ of male respondents agreed with this statement.

\section{Sexual harassment}

The SYPE questionnaires asked respondents if they agreed or disagreed with the statement that women who dress "provocatively" in public spaces deserve to be harassed. ${ }^{6}$ (The full set of outcomes are provided in Table A9.13). We find that the majority of respondents aged

6 This question utilized the Likert 5-point scale in 2014. In 2009, respondents only had the option to "agree," "disagree," or indicate that they "don't know."
15-29 (59.4\%) agreed with this statement while one-quarter (25.6\%) disagreed with it. Figure 9.11 provides the 2014 outcomes by gender and region. The results are not surprising: male respondents (62.3\%) were more likely to argue that women dressed "provocatively" in the streets "deserve" to be harassed than female respondents (56.3\%); nevertheless, over one-half of female respondents aged 15-29 agreed with the statement in 2014.

In terms of location youth residing in informal areas were the least likely to agree that sexual harassment is justified due to a woman's attire; nearly one-half (48.2\%) of respondents aged 15-29 in these areas were in disagreement with the statement in 2014. These perspectives on sexual harassment from informal areas were quite different from those of young people in urban areas (where only $29.3 \%$ disagreed) and in rural areas (where only $20.4 \%$ disagreed).

Observing outcomes by region, we find that young people in rural Upper Egypt indicated that they were the most likely to agree that sexual harassment is justified by attire, with $70.3 \%$ of respondents aged 15-29 indicating this in 2014. Conversely, youth in urban Lower Egypt were 
the least likely to agree that women were to be blamed for the harassment they experience in the streets; over one-third (37.5\%) of respondents aged 15-29 in this region disagreed that women dressing provocatively in public spaces "deserved" to be harassed.

There was some variation in youth (aged 15-29) outlooks when we disaggregated by educational attainment, but we do not find a clear correlation between schooling and youth perspectives on sexual harassment. Those with university attainment were the least likely to blame the victim of sexual harassment because of her "provocative" attire, though one-half (50.9\%) did agree with the statement in 2014. By contrast, respondents who are illiterate (65.1\%), possessed a primary school education (65.6\%) or preparatory attainment (62.1\%) proved more likely to blame the victim of sexual harassment in public places and agree that a woman "deserved" harassment if dressed "provocatively."

\subsection{Conclusion}

Gender attitudes among Egyptian youth remained highly conservative for nearly all of the indicators examined in this chapter. Our analysis highlighted numerous cases where, despite some variation by demographic characteristics, conservative gender attitudes among youth cut across regions, residence, wealth quintiles, and education levels. As was the case in 2009, male youth held more conservative outlooks than female youth and, in many instances, higher educational attainment appeared to lead to more egalitarian views regarding gender roles and rights. Youth gender attitudes varied considerably by location, and we frequently find that young people residing in informal or urban areas have the most liberal outlooks, whereas their rural counterparts hold more conservative views. Regionally, young people in the Frontier Governorates and rural Upper Egypt continued to maintain highly conservative perspectives on gender, while Egyptian youth in rural Lower Egypt often proved more open to gender equality.
The conservatism of youth attitudes toward gender roles varied across the broad domains examined in this chapter. In the social, economic and political sphere, youth gender attitudes were somewhat varied. While the majority of SYPE respondents supported women voting, and while over half of respondents supported equal rights to education, outlooks on the labor market were quite different, with the majority of respondents supporting male job priority. Although support for gender equality has positive implications for women's political participation, it demonstrates that programs to support gender-equitable attitudes toward education and the labor market are still needed, and suggests that the value of women's participation in the labor market in particular is underappreciated by many youth.

We find that respondents' support of gender inequality in the household remained high, as the majority of young people continued to support male sibling authority over sisters, a male spouse's full control over household spending, and a wife's need to seek spousal approval before "doing anything". Household duties proved additionally gendered, with large percentages of SYPE respondents rejecting the idea that boys and girls should contribute equally to household chores. This finding indicates that attitudes toward gender equality in the home lag even behind those toward gender equality in the public sphere, which has negative implications for women's autonomy. Similar to 2009 outcomes, many Egyptian youth also continued to demonstrate support for domestic violence in particular contexts, and the majority of Egyptian young people still considered sexual harassment the victim's fault. These alarming findings highlight the need for broadbased campaigns against gender-based violence both inside and outside the home.

On a positive note, our analysis additionally highlighted growing support of a woman's right to ask for divorce, with a large majority of young people now supporting this in 2014. This may be related to legal changes in Egypt as well as changes in social norms. Nevertheless, according 
to SYPE youth, divorced women continue to face social marginalization in Egyptian communities, demonstrating the need for further progress in terms of acceptance of divorce. Finally, although views remained conservative overall, the five-point Likert scale captured the considerable uncertainty that many Egyptian youth feel over questions of gender roles and rights. These outlooks may evolve and become more defined as respondents come of age, though it remains to be seen whether those on the fence will gravitate toward gender equality or will develop more conservative outlooks.

\section{References}

El-Kogali, Saffaa, Caroline Krafft, and Maia Sieverding. 2011. "Attitudes toward gender roles," Survey of Young People in Egypt, Final Report. Cairo: Population Council West Asia and North Africa Office.

Sonneveld, Nadia. 2004. "The implementation of the 'Khul Law' in Egyptian courts: Some preliminary results," Rechet van de Islam 21, pp. 21-35. 


\section{Appendixes}

8

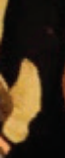

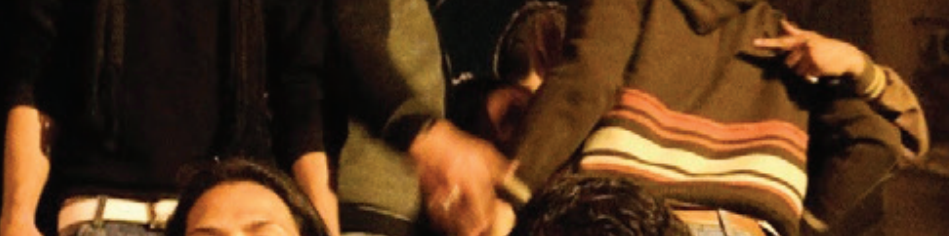

42
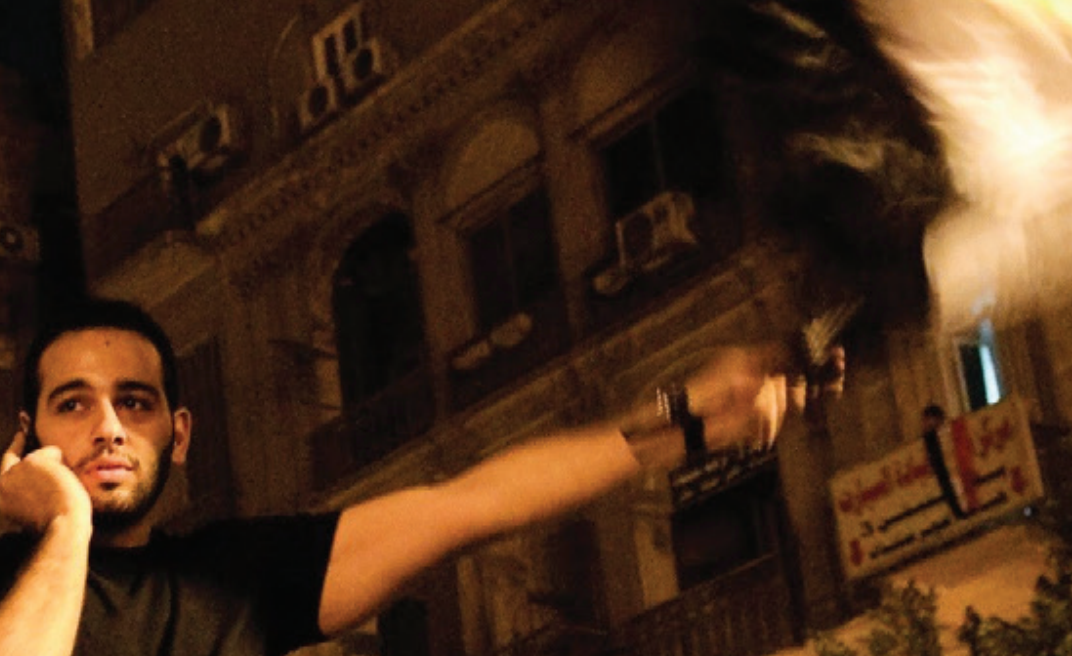

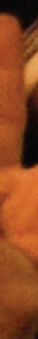

y.2.

1) 215

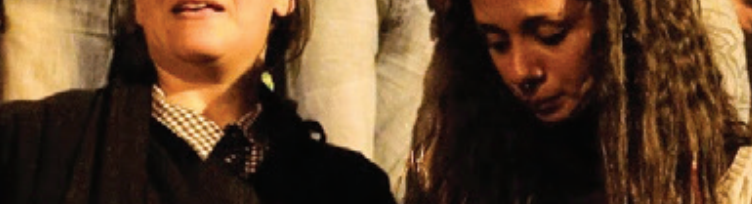

i 䜹
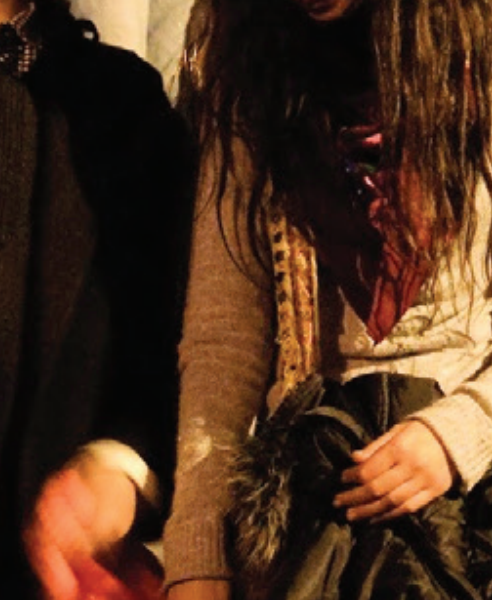

Appendix A

Tables 

TABLE A2.1 Usual source of medical care by background characteristics, among youth aged 13-35, 2014, (\%)

\begin{tabular}{|c|c|c|c|c|c|c|c|}
\hline & $\begin{array}{c}\text { HEALTH } \\
\text { INSURANCE }\end{array}$ & $\begin{array}{c}\text { PUBLIC } \\
\text { FACILITIES }\end{array}$ & PHARMACY & $\begin{array}{c}\text { PRIVATE } \\
\text { FACILITIES }\end{array}$ & OTHER & $\begin{array}{c}\text { DON'T GO } \\
\text { ANYWHERE }\end{array}$ & TOTAL \\
\hline \multicolumn{8}{|l|}{ Gender } \\
\hline Male & 5.1 & 20.5 & 6.0 & 34.6 & 2.0 & 31.9 & 100.0 \\
\hline Female & 3.1 & 24.1 & 4.0 & 43.4 & 1.2 & 24.3 & 100.0 \\
\hline \multicolumn{8}{|l|}{ Age group } \\
\hline $13-17$ & 8.9 & 19.9 & 4.5 & 36.1 & 1.8 & 28.8 & 100.0 \\
\hline $18-24$ & 2.5 & 21.6 & 5.2 & 40.3 & 1.4 & 29.1 & 100.0 \\
\hline $25-29$ & 2.9 & 23.1 & 5.2 & 39.9 & 1.9 & 27.2 & 100.0 \\
\hline $30-35$ & 3.8 & 25.4 & 4.8 & 37.8 & 1.4 & 26.9 & 100.0 \\
\hline \multicolumn{8}{|l|}{ Urban-rural residence } \\
\hline Urban & 5.6 & 20.7 & 3.1 & 39.2 & 2.6 & 28.9 & 100.0 \\
\hline Rural & 3.8 & 23.6 & 5.5 & 39.8 & 1.0 & 26.4 & 100.0 \\
\hline Informal & 1.4 & 18.8 & 7.6 & 32.5 & 2.1 & 37.7 & 100.0 \\
\hline \multicolumn{8}{|l|}{ Region } \\
\hline Urban Governorates & 6.6 & 23.7 & 1.8 & 37.7 & 3.2 & 27.0 & 100.0 \\
\hline Urban Lower Egypt & 4.1 & 19.2 & 2.9 & 41.5 & 1.3 & 30.9 & 100.0 \\
\hline Rural Lower Egypt & 5.7 & 24.4 & 3.1 & 39.3 & 1.1 & 26.5 & 100.0 \\
\hline Urban Upper Egypt & 0.5 & 13.3 & 11.9 & 32.9 & 2.6 & 38.9 & 100.0 \\
\hline Rural Upper Egypt & 1.8 & 22.6 & 8.3 & 41.1 & 1.0 & 25.3 & 100.0 \\
\hline Frontier Governorates & 3.0 & 23.3 & 1.2 & 19.5 & 0.6 & 52.4 & 100.0 \\
\hline \multicolumn{8}{|l|}{ Educational level } \\
\hline Illiterate & 1.1 & 30.4 & 4.8 & 27.5 & 1.3 & 34.9 & 100.0 \\
\hline Can read and write & 0.9 & 25.6 & 7.4 & 38.8 & 5.0 & 22.3 & 100.0 \\
\hline Primary & 1.2 & 34.3 & 5.0 & 31.2 & 0.9 & 27.5 & 100.0 \\
\hline Preparatory & 5.4 & 27.4 & 5.4 & 32.4 & 1.2 & 28.2 & 100.0 \\
\hline General secondary & 9.1 & 14.0 & 3.4 & 46.1 & 1.8 & 25.7 & 100.0 \\
\hline Vocational secondary & 3.4 & 23.0 & 5.7 & 38.5 & 1.6 & 27.9 & 100.0 \\
\hline Post-secondary institution & 4.7 & 18.4 & 7.7 & 42.3 & 1.9 & 25.1 & 100.0 \\
\hline University and above & 4.9 & 12.6 & 3.6 & 48.9 & 1.8 & 28.1 & 100.0 \\
\hline \multicolumn{8}{|l|}{ Wage work } \\
\hline Waged & 4.8 & 20.7 & 6.9 & 37.1 & 1.9 & 28.7 & 100.0 \\
\hline Employer/self-employed & 1.9 & 24.5 & 6.8 & 35.8 & 1.6 & 29.4 & 100.0 \\
\hline Unpaid & 1.2 & 31.9 & 6.2 & 32.1 & 0.7 & 28.0 & 100.0 \\
\hline Unemployed & 1.0 & 26.6 & 4.4 & 40.1 & 1.2 & 26.9 & 100.0 \\
\hline Nonstudent out of labor force & 0.9 & 26.7 & 3.8 & 39.6 & 1.2 & 27.8 & 100.0 \\
\hline Student out of labor force & 9.3 & 15.1 & 4.3 & 41.2 & 1.9 & 28.1 & 100.0 \\
\hline \multicolumn{8}{|l|}{ Wealth quintile } \\
\hline Lowest & 2.3 & 32.3 & 6.5 & 25.9 & 1.3 & 31.8 & 100.0 \\
\hline Second & 3.3 & 25.3 & 7.6 & 34.5 & 1.2 & 28.2 & 100.0 \\
\hline Middle & 4.8 & 24.3 & 5.1 & 39.6 & 1.7 & 24.6 & 100.0 \\
\hline Fourth & 4.6 & 19.1 & 3.6 & 41.5 & 1.3 & 29.9 & 100.0 \\
\hline Richest & 5.2 & 12.7 & 2.6 & 50.2 & 2.3 & 27.0 & 100.0 \\
\hline Total & 4.1 & 22.2 & 5.0 & 38.9 & 1.6 & 28.2 & 100.0 \\
\hline
\end{tabular}


TABLE A2.2 Exposure to sexual harassment among females aged 13-35, 2014 (\%)

\begin{tabular}{|c|c|c|c|}
\hline & AGES 13-35, 2014 & AGES 13-29, 2014 & AGES 13-29, 2009 \\
\hline \multicolumn{4}{|l|}{ Age group } \\
\hline $13-17$ & 49.5 & 49.5 & 46.4 \\
\hline $18-24$ & 44.8 & 44.8 & 54.2 \\
\hline 25-29 & 33.3 & 33.3 & 46.4 \\
\hline 30-35 & 27.1 & & \\
\hline \multicolumn{4}{|l|}{ Urban-rural residence } \\
\hline Urban & 47.7 & 50.3 & 61.9 \\
\hline Rural & 32.6 & 35.6 & 40.9 \\
\hline Informal & 61.6 & 65.0 & 63.0 \\
\hline \multicolumn{4}{|l|}{ Region } \\
\hline Urban Governorates & 53.3 & 56.5 & 72.1 \\
\hline Urban Lower Egypt & 50.1 & 52.7 & 63.3 \\
\hline Rural Lower Egypt & 32.1 & 35.1 & 52.9 \\
\hline Urban Upper Egypt & 50.2 & 52.1 & 36.4 \\
\hline Rural Upper Egypt & 33.6 & 36.5 & 27.4 \\
\hline Frontier Governorates & 28.5 & 30.4 & 37.9 \\
\hline \multicolumn{4}{|l|}{ Educational level } \\
\hline Illiterate & 22.6 & 23.5 & 28.0 \\
\hline Can read and write & 20.1 & 25.9 & 23.3 \\
\hline Primary & 34.5 & 37.9 & 41.3 \\
\hline Preparatory & 41.4 & 43.1 & 54.0 \\
\hline General secondary & 50.4 & 51.2 & 69.2 \\
\hline Vocational secondary & 39.2 & 42.5 & 51.9 \\
\hline Post-secondary institution & 48.5 & 51.6 & 64.2 \\
\hline University and above & 48.5 & 49.3 & 66.6 \\
\hline \multicolumn{4}{|l|}{ Wealth quintile } \\
\hline Lowest & 35.3 & 38.7 & 32.2 \\
\hline Second & 40.2 & 43.3 & 44.1 \\
\hline Middle & 43.1 & 46.1 & 47.5 \\
\hline Fourth & 39.1 & 41.6 & 58.8 \\
\hline Richest & 41.4 & 43.7 & 67.8 \\
\hline Total & 39.9 & 42.8 & 49.7 \\
\hline$(\mathrm{N})$ & $(5,821)$ & $(4,639)$ & $(6,819)$ \\
\hline
\end{tabular}


TABLE A2.3 Percentage of youth aged 13-35 consuming carbonated drinks, by background characteristics, 2014

\begin{tabular}{|c|c|c|c|}
\hline & NEVER & $\begin{array}{c}\text { 1-3 TIMES PER } \\
\text { WEEK }\end{array}$ & $\begin{array}{c}\text { MORE THAN } 3 \text { TIMES } \\
\text { PER WEEK }\end{array}$ \\
\hline \multicolumn{4}{|l|}{ Age group } \\
\hline $13-17$ & 31.6 & 53.4 & 15.1 \\
\hline $18-24$ & 34.7 & 53.1 & 12.3 \\
\hline $25-29$ & 39.5 & 50.7 & 9.8 \\
\hline $30-35$ & 44.3 & 47.4 & 8.2 \\
\hline \multicolumn{4}{|l|}{ Gender } \\
\hline Males & 33.5 & 53.9 & 12.6 \\
\hline Females & 40.2 & 49.2 & 10.6 \\
\hline \multicolumn{4}{|l|}{ Urban-rural residence } \\
\hline Urban & 26.7 & 56.4 & 16.9 \\
\hline Rural & 42.2 & 48.6 & 9.2 \\
\hline Informal & 33.9 & 56.1 & 10.1 \\
\hline \multicolumn{4}{|l|}{ Region } \\
\hline Urban Governorates & 24.2 & 56.3 & 19.5 \\
\hline Urban Lower Egypt & 34.2 & 51.7 & 14.1 \\
\hline Rural Lower Egypt & 39.9 & 49.7 & 10.4 \\
\hline Urban Upper Egypt & 29.5 & 62.7 & 7.8 \\
\hline Rural Upper Egypt & 44.2 & 47.7 & 8.2 \\
\hline Frontier Governorates & 43.6 & 50.6 & 5.7 \\
\hline \multicolumn{4}{|l|}{ Educational level } \\
\hline Illiterate & 56.3 & 39.4 & 4.3 \\
\hline Can read and write & 43.9 & 53.3 & 2.8 \\
\hline Primary & 46.7 & 45.6 & 7.8 \\
\hline Preparatory & 41.0 & 49.8 & 9.2 \\
\hline General secondary & 23.7 & 55.3 & 21.0 \\
\hline Vocational secondary & 38.3 & 52.2 & 9.5 \\
\hline Post-secondary institution & 28.1 & 55.9 & 16.0 \\
\hline University and above & 24.7 & 57.6 & 17.7 \\
\hline \multicolumn{4}{|l|}{ Wealth quintile } \\
\hline Lowest & 50.9 & 44.1 & 5.0 \\
\hline Second & 42.4 & 50.6 & 7.0 \\
\hline Third & 34.3 & 54.4 & 11.3 \\
\hline Fourth & 32.7 & 54.3 & 13.0 \\
\hline Highest & 26.3 & 53.9 & 19.8 \\
\hline Total & 36.8 & 51.6 & 11.6 \\
\hline$(\mathrm{N})$ & $(4,136)$ & $(5,534)$ & $(1,233)$ \\
\hline
\end{tabular}


TABLE A2.4 Percentage of youth consuming fast food, by background characteristics, 2014 (ages 13-35)

\begin{tabular}{|c|c|c|c|}
\hline & NEVER & $\begin{array}{l}\text { 1-3 TIMES } \\
\text { PER WEEK }\end{array}$ & $\begin{array}{c}\text { MORE THAN } 3 \text { TIMES } \\
\text { PER WEEK }\end{array}$ \\
\hline \multicolumn{4}{|l|}{ Age group } \\
\hline 13-17 & 53.6 & 36.4 & 10.0 \\
\hline $18-24$ & 54.3 & 36.2 & 9.6 \\
\hline $25-29$ & 58.3 & 35.0 & 6.7 \\
\hline 30-35 & 63.5 & 30.5 & 6.1 \\
\hline \multicolumn{4}{|l|}{ Gender } \\
\hline Males & 48.3 & 41.6 & 10.1 \\
\hline Females & 65.4 & 28.1 & 6.6 \\
\hline \multicolumn{4}{|l|}{ Urban-rural residence } \\
\hline Urban & 44.2 & 43.2 & 12.6 \\
\hline Rural & 63.3 & 30.4 & 6.4 \\
\hline Informal & 52.8 & 38.7 & 8.5 \\
\hline \multicolumn{4}{|l|}{ Region } \\
\hline Urban Governorates & 38.7 & 46.0 & 15.3 \\
\hline Urban Lower Egypt & 52.1 & 37.7 & 10.2 \\
\hline Rural Lower Egypt & 60.3 & 32.6 & 7.1 \\
\hline Urban Upper Egypt & 55.5 & 39.4 & 5.1 \\
\hline Rural Upper Egypt & 66.1 & 28.2 & 5.7 \\
\hline Frontier Governorates & 61.9 & 31.9 & 6.2 \\
\hline \multicolumn{4}{|l|}{ Educational level } \\
\hline Illiterate & 74.5 & 23.0 & 2.6 \\
\hline Can read and write & 64.8 & 34.2 & 1.1 \\
\hline Primary & 65.5 & 28.3 & 6.2 \\
\hline Preparatory & 63.3 & 29.9 & 6.8 \\
\hline General secondary & 45.9 & 40.5 & 13.5 \\
\hline Vocational secondary & 59.3 & 33.7 & 7.0 \\
\hline Post-secondary institution & 47.2 & 42.5 & 10.3 \\
\hline University and above & 40.8 & 45.6 & 13.6 \\
\hline \multicolumn{4}{|l|}{ Wealth quintile } \\
\hline Lowest & 70.2 & 24.7 & 5.2 \\
\hline Second & 62.3 & 32.7 & 5.0 \\
\hline Third & 55.9 & 35.7 & 8.4 \\
\hline Fourth & 51.0 & 39.6 & 9.4 \\
\hline Highest & 46.3 & 40.6 & 13.1 \\
\hline Total & 56.6 & 35.0 & 8.4 \\
\hline$(\mathrm{N})$ & $(6,334)$ & $(3,660)$ & (909) \\
\hline
\end{tabular}


TABLE A2.5 Percentage of youth engaged in any daily physical activity, by background characteristics

\begin{tabular}{|c|c|c|c|}
\hline & 2014 (AGES 13-35) & 2014 (AGES 15-29) & 2009 (AGES 15-29) \\
\hline \multicolumn{4}{|l|}{ Age group } \\
\hline 13-17 & 66.8 & 66.9 & 82.0 \\
\hline $18-24$ & 53.1 & 53.1 & 64.7 \\
\hline $25-29$ & 48.9 & 48.9 & 60.2 \\
\hline $30-35$ & 49.0 & & \\
\hline \multicolumn{4}{|l|}{ Gender } \\
\hline Males & 67.0 & 67.8 & 82.8 \\
\hline Females & 40.8 & 40.8 & 51.2 \\
\hline \multicolumn{4}{|l|}{ Urban-rural residence } \\
\hline Urban & 55.3 & 56.3 & 69.5 \\
\hline Rural & 55.6 & 55.9 & 66.0 \\
\hline Informal & 42.6 & 44.4 & 68.7 \\
\hline \multicolumn{4}{|l|}{ Region } \\
\hline Urban Governorates & 55.9 & 57.5 & 69.5 \\
\hline Urban Lower Egypt & 44.6 & 46.2 & 73.5 \\
\hline Rural Lower Egypt & 57.1 & 57.9 & 73.7 \\
\hline Urban Upper Egypt & 56.1 & 56.1 & 63.2 \\
\hline Rural Upper Egypt & 54.3 & 54.2 & 56.8 \\
\hline Frontier Governorates & 39.4 & 40.5 & 59.5 \\
\hline \multicolumn{4}{|l|}{ Educational level } \\
\hline Illiterate & 44.1 & 43.8 & 46.3 \\
\hline Can read and write & 49.6 & 49.3 & 71.8 \\
\hline Primary & 49.6 & 48.7 & 74.6 \\
\hline Preparatory & 55.9 & 53.9 & 75.2 \\
\hline General secondary & 65.1 & 65.8 & 73.5 \\
\hline Vocational secondary & 55.2 & 56.7 & 62.5 \\
\hline Post-secondary institution & 55.0 & 56.4 & 61.7 \\
\hline University and above & 53.4 & 53.5 & 63.9 \\
\hline \multicolumn{4}{|l|}{ Wealth quintile } \\
\hline Lowest & 52.6 & 54.1 & 63.6 \\
\hline Second & 53.6 & 54.2 & 63.9 \\
\hline Third & 54.0 & 53.7 & 69.7 \\
\hline Fourth & 55.7 & 56.2 & 69.2 \\
\hline Highest & 54.9 & 56.1 & 70.4 \\
\hline Total & 54.2 & 54.9 & 67.4 \\
\hline$(\mathrm{N})$ & $(5,578)$ & $(4,480)$ & $(7,110)$ \\
\hline
\end{tabular}


TABLE A2.6 Reactions to menarche among females aged 13-35, by background characteristics (\%)

\begin{tabular}{|c|c|c|c|c|c|c|c|}
\hline & $\begin{array}{c}\text { SHOCKED/ } \\
\text { CRIED/AFRAID }\end{array}$ & HAPPY & INDIFFERENT & $\begin{array}{l}\text { DIDN'T KNOW } \\
\text { WHAT TO DO }\end{array}$ & OTHER & $\begin{array}{l}\text { DON'T } \\
\text { KNOW }\end{array}$ & TOTAL \\
\hline \multicolumn{8}{|l|}{ Age group } \\
\hline $13-17$ & 52.0 & 8.8 & 18.7 & 20.5 & 0.0 & 0.0 & 100.0 \\
\hline $18-24$ & 50.5 & 9.0 & 17.4 & 22.9 & 0.1 & 0.0 & 100.0 \\
\hline $25-29$ & 51.2 & 8.9 & 18.4 & 21.4 & 0.1 & 0.0 & 100.0 \\
\hline $30-35$ & 52.3 & 7.3 & 20.6 & 19.7 & 0.1 & 0.1 & 100.0 \\
\hline \multicolumn{8}{|l|}{ Urban-rural residence } \\
\hline Urban & 50.5 & 9.0 & 20.3 & 20.2 & 0.1 & 0.0 & 100.0 \\
\hline Rural & 52.4 & 7.5 & 17.4 & 22.6 & 0.1 & 0.0 & 100.0 \\
\hline Informal & 47.4 & 14.5 & 19.8 & 18.1 & 0.0 & 0.2 & 100.0 \\
\hline \multicolumn{8}{|l|}{ Region } \\
\hline Urban Governorates & 46.7 & 8.6 & 25.1 & 19.6 & 0.1 & 0.0 & 100.0 \\
\hline Urban Lower Egypt & 49.8 & 8.9 & 19.2 & 22.0 & 0.0 & 0.1 & 100.0 \\
\hline Rural Lower Egypt & 51.4 & 9.1 & 18.8 & 20.8 & 0.0 & 0.0 & 100.0 \\
\hline Urban Upper Egypt & 58.1 & 16.4 & 9.9 & 15.6 & 0.0 & 0.0 & 100.0 \\
\hline Rural Upper Egypt & 54.0 & 5.6 & 15.6 & 24.6 & 0.2 & 0.0 & 100.0 \\
\hline Frontier Governorates & 32.7 & 15.3 & 30.2 & 21.8 & 0.0 & 0.0 & 100.0 \\
\hline \multicolumn{8}{|l|}{ Educational level } \\
\hline Illiterate & 52.2 & 8.6 & 19.8 & 19.4 & 0.0 & 0.1 & 100.0 \\
\hline Can read and write & 50.6 & 11.7 & 20.2 & 17.5 & 0.0 & 0.0 & 100.0 \\
\hline Primary & 54.0 & 7.5 & 16.6 & 21.6 & 0.2 & 0.0 & 100.0 \\
\hline Preparatory & 54.1 & 5.8 & 18.6 & 21.5 & 0.0 & 0.0 & 100.0 \\
\hline General secondary & 52.6 & 8.2 & 17.7 & 21.3 & 0.2 & 0.0 & 100.0 \\
\hline Vocational secondary & 51.6 & 10.0 & 16.6 & 21.7 & 0.2 & 0.0 & 100.0 \\
\hline Post-secondary institution & 50.2 & 8.9 & 13.4 & 27.6 & 0.0 & 0.0 & 100.0 \\
\hline University and above & 46.7 & 8.8 & 22.8 & 21.8 & 0.0 & 0.0 & 100.0 \\
\hline \multicolumn{8}{|l|}{ Wage work } \\
\hline Waged & 52.5 & 6.3 & 25.1 & 16.2 & 0.0 & 0.0 & 100.0 \\
\hline Employer/self-employee & 49.5 & 3.5 & 22.7 & 22.9 & 1.4 & 0.0 & 100.0 \\
\hline Unpaid & 55.5 & 4.1 & 23.4 & 17.0 & 0.0 & 0.0 & 100.0 \\
\hline Unemployed & 48.7 & 4.9 & 19.9 & 26.2 & 0.4 & 0.0 & 100.0 \\
\hline Nonstudent out of labor force & 51.6 & 9.1 & 17.5 & 21.8 & 0.1 & 0.0 & 100.0 \\
\hline Student out of labor force & 50.5 & 9.6 & 18.5 & 21.4 & 0.0 & 0.0 & 100.0 \\
\hline \multicolumn{8}{|l|}{ Wealth quantile } \\
\hline Lowest & 57.4 & 9.1 & 14.2 & 18.9 & 0.3 & 0.1 & 100.0 \\
\hline Second & 49.7 & 8.3 & 17.7 & 24.4 & 0.0 & 0.0 & 100.0 \\
\hline Middle & 48.5 & 11.3 & 18.1 & 22.0 & 0.2 & 0.0 & 100.0 \\
\hline Fourth & 50.2 & 8.1 & 20.5 & 21.3 & 0.0 & 0.0 & 100.0 \\
\hline Richest & 51.0 & 6.7 & 21.6 & 20.7 & 0.0 & 0.0 & 100.0 \\
\hline Total & 51.3 & 8.6 & 18.5 & 21.5 & 0.1 & 0.0 & 100.0 \\
\hline
\end{tabular}


TABLE A2.7 Percentage of youth who discussed puberty with their parents, by background characteristics

2014 (AGES 13-35) 2014 (AGES 15-29) 2009 (AGES 15-29)

\begin{tabular}{|c|c|c|c|}
\hline \multicolumn{4}{|l|}{ Age group } \\
\hline $13-17$ & 34.9 & 34.7 & 27.6 \\
\hline $18-24$ & 33.7 & 33.7 & 28.8 \\
\hline $25-29$ & 33.6 & 33.6 & 28.7 \\
\hline $30-35$ & 35.3 & & \\
\hline \multicolumn{4}{|l|}{ Gender } \\
\hline Males & 21.6 & 21.4 & 8.1 \\
\hline Females & 47.5 & 47.6 & 49.9 \\
\hline \multicolumn{4}{|l|}{ Urban-rural residence } \\
\hline Urban & 40.3 & 40.1 & 32.7 \\
\hline Rural & 30.2 & 29.7 & 25.5 \\
\hline Informal & 40.9 & 41.5 & 32.6 \\
\hline \multicolumn{4}{|l|}{ Region } \\
\hline Urban Governorates & 44.8 & 45.5 & 34.9 \\
\hline Urban Lower Egypt & 39.8 & 39.3 & 30.5 \\
\hline Rural Lower Egypt & 33.4 & 32.8 & 26.4 \\
\hline Urban Upper Egypt & 29.7 & 29.2 & 29.4 \\
\hline Rural Upper Egypt & 26.3 & 26.2 & 24.3 \\
\hline Frontier Governorates & 47.7 & 47.8 & 32.0 \\
\hline \multicolumn{4}{|l|}{ Educational level } \\
\hline Illiterate & 27.9 & 26.4 & 29.5 \\
\hline Can read and write & 36.2 & 34.4 & 28.1 \\
\hline Primary & 31.5 & 29.3 & 24.1 \\
\hline Preparatory & 32.6 & 32.2 & 26.7 \\
\hline General secondary & 39.3 & 39.3 & 32.8 \\
\hline Vocational secondary & 31.7 & 31.2 & 27.8 \\
\hline Post-secondary institution & 40.5 & 40.9 & 32.2 \\
\hline University and above & 40.7 & 40.7 & 34.4 \\
\hline \multicolumn{4}{|l|}{ Wealth quintile } \\
\hline Lowest & 26.9 & 26.3 & 21.9 \\
\hline Second & 29.9 & 29.6 & 26.4 \\
\hline Third & 31.9 & 31.2 & 26.8 \\
\hline Fourth & 40.7 & 40.1 & 31.3 \\
\hline Highest & 40.0 & 40.3 & 36.8 \\
\hline Total & 34.2 & 33.9 & 28.5 \\
\hline$(N)$ & $(4,047)$ & $(3,175)$ & $(3,434)$ \\
\hline
\end{tabular}


TABLE A2.8 Percentage of youth who knew of HIV/AIDS, by background characteristics

\begin{tabular}{|c|c|c|c|}
\hline & 2014 (AGES 13-35) & 2014 (AGES 15-29) & 2009 (AGES 15-29) \\
\hline \multicolumn{4}{|l|}{ Age group } \\
\hline $13-17$ & 59.6 & 62.1 & 80.6 \\
\hline $18-24$ & 77.2 & 77.2 & 87.2 \\
\hline $25-29$ & 76.1 & 76.1 & 86.4 \\
\hline $30-35$ & 76.3 & & \\
\hline \multicolumn{4}{|l|}{ Gender } \\
\hline Males & 77.4 & 77.3 & 92.0 \\
\hline Females & 68.8 & 69.4 & 78.7 \\
\hline \multicolumn{4}{|l|}{ Urban-rural residence } \\
\hline Urban & 80.7 & 81.2 & 91.5 \\
\hline Rural & 70.3 & 70.7 & 81.3 \\
\hline \multicolumn{4}{|l|}{ Region } \\
\hline Urban Governorates & 86.5 & 86.5 & 92.5 \\
\hline Urban Lower Egypt & 74.2 & 74.3 & 92.1 \\
\hline Rural Lower Egypt & 71.9 & 72.2 & 83.9 \\
\hline Urban Upper Egypt & 63.4 & 65.4 & 87.9 \\
\hline Rural Upper Egypt & 68.9 & 69.6 & 78.5 \\
\hline Frontier Governorates & 63.6 & 64.4 & 79.3 \\
\hline \multicolumn{4}{|l|}{ Educational level } \\
\hline Informal & 68.7 & 68.3 & 91.0 \\
\hline Illiterate & 43.5 & 41.8 & 46.0 \\
\hline Can read and write & 56.6 & 53.4 & 53.4 \\
\hline Primary & 58.6 & 57.0 & 74.4 \\
\hline Preparatory & 57.9 & 59.2 & 86.3 \\
\hline General secondary & 78.9 & 78.5 & 97.3 \\
\hline Vocational secondary & 76.7 & 75.5 & 92.4 \\
\hline Post-secondary institution & 91.3 & 90.7 & 97.1 \\
\hline University and above & 92.6 & 92.3 & 97.8 \\
\hline \multicolumn{4}{|l|}{ Wealth quintile } \\
\hline Lowest & 61.9 & 62.6 & 72.9 \\
\hline Second & 69.9 & 70.5 & 80.4 \\
\hline Third & 72.2 & 72.4 & 86.2 \\
\hline Fourth & 73.5 & 73.7 & 92.7 \\
\hline Highest & 85.5 & 85.3 & 95.9 \\
\hline Total & 73.2 & 73.6 & 85.5 \\
\hline$(\mathrm{N})$ & $(7,923)$ & $(6,303)$ & $(9,237)$ \\
\hline
\end{tabular}


TABLE A2.9 Percentage of circumcised females, by background characteristics

\begin{tabular}{|c|c|c|c|}
\hline & 2014 (AGES 13-35) & 2014 (AGES 15-29) & 2009 (AGES 15-29) \\
\hline \multicolumn{4}{|l|}{ Age group } \\
\hline $13-17$ & 73.9 & 74.0 & 81.8 \\
\hline $18-24$ & 79.3 & 79.3 & 87.4 \\
\hline $25-29$ & 84.1 & 84.1 & 92.1 \\
\hline $30-35$ & 85.7 & & \\
\hline \multicolumn{4}{|l|}{ Urban-rural residence } \\
\hline Urban & 66.3 & 65.1 & 75.3 \\
\hline Rural & 87.9 & 87.5 & 94.4 \\
\hline Informal & 74.8 & 71.9 & 84.1 \\
\hline \multicolumn{4}{|l|}{ Region } \\
\hline Urban Governorates & 55.6 & 53.3 & 70.5 \\
\hline Urban Lower Egypt & 74.1 & 71.9 & 80.9 \\
\hline Rural Lower Egypt & 84.6 & 83.6 & 94.2 \\
\hline Urban Upper Egypt & 88.7 & 87.8 & 91.4 \\
\hline Rural Upper Egypt & 91.6 & 91.5 & 94.9 \\
\hline Frontier Governorates & 73.7 & 73.2 & 69.2 \\
\hline \multicolumn{4}{|l|}{ Educational level } \\
\hline Illiterate & 91.0 & 91.4 & 95.6 \\
\hline Can read and write & 84.1 & 90.8 & 90.7 \\
\hline Primary & 85.9 & 85.3 & 91.1 \\
\hline Preparatory & 83.0 & 84.4 & 85.6 \\
\hline General secondary & 66.0 & 65.9 & 71.7 \\
\hline Vocational secondary & 83.4 & 82.3 & 93.1 \\
\hline Post-secondary institution & 75.7 & 72.5 & 90.9 \\
\hline University and above & 71.5 & 71.4 & 75.4 \\
\hline \multicolumn{4}{|l|}{ Wealth quintile } \\
\hline Lowest & 87.2 & 86.6 & 95.5 \\
\hline Second & 83.5 & 82.4 & 95.1 \\
\hline Third & 83.2 & 82.6 & 94.4 \\
\hline Fourth & 78.9 & 77.7 & 86.8 \\
\hline Highest & 71.3 & 70.3 & 62.1 \\
\hline Total & 80.5 & 79.5 & 87.5 \\
\hline$(\mathrm{N})$ & $(5,725)$ & $(4,375)$ & $(5,837)$ \\
\hline
\end{tabular}


TABLE A2.10 Percentage of respondents aged 13-35 who knew family planning methods that could delay or prevent pregnancy, by background characteristic

\begin{tabular}{|c|c|c|c|c|c|c|}
\hline & $\begin{array}{c}\text { KNEW } \\
\text { ANY METHOD }\end{array}$ & PILLS & IUD & $\begin{array}{l}\text { INJECT- } \\
\text { ABLES }\end{array}$ & IMPLANTS & CONDOMS \\
\hline \multicolumn{7}{|l|}{ Age group } \\
\hline 13-17 & 34.8 & 34.0 & 25.4 & 21.1 & 3.3 & 3.4 \\
\hline $18-24$ & 56.0 & 53.8 & 46.2 & 39.8 & 9.1 & 9.5 \\
\hline $25-29$ & 73.9 & 69.1 & 63.1 & 54.2 & 14.4 & 11.5 \\
\hline $30-35$ & 85.0 & 78.2 & 74.4 & 61.1 & 17.0 & 13.3 \\
\hline \multicolumn{7}{|l|}{ Gender } \\
\hline Male & 52.0 & 49.7 & 40.6 & 34.7 & 6.3 & 13.0 \\
\hline Female & 71.5 & 67.0 & 62.7 & 53.0 & 15.4 & 5.8 \\
\hline \multicolumn{7}{|l|}{ Urban-rural residence } \\
\hline Urban & 59.9 & 56.5 & 48.2 & 39.7 & 9.5 & 12.7 \\
\hline Rural & 63.4 & 59.7 & 52.9 & 45.5 & 10.7 & 8.3 \\
\hline Informal & 54.5 & 53.3 & 51.4 & 43.7 & 14.4 & 7.2 \\
\hline \multicolumn{7}{|l|}{ Region } \\
\hline Urban Governorates & 61.6 & 57.4 & 49.1 & 37.6 & 7.6 & 12.7 \\
\hline Urban Lower Egypt & 56.4 & 54.2 & 50.6 & 39.7 & 11.1 & 10.2 \\
\hline Rural Lower Egypt & 59.6 & 54.3 & 50.2 & 36.8 & 7.3 & 7.7 \\
\hline Urban Upper Egypt & 54.5 & 53.9 & 46.3 & 48.9 & 17.2 & 8.8 \\
\hline Rural Upper Egypt & 67.6 & 65.6 & 56.1 & 54.9 & 14.4 & 8.8 \\
\hline Frontier Governorates & 59.2 & 56.7 & 48.1 & 43.6 & 11.0 & 15.6 \\
\hline \multicolumn{7}{|l|}{ Educational level } \\
\hline Illiterate & 69.1 & 64.3 & 57.7 & 52.7 & 15.3 & 4.6 \\
\hline Can read and write & 80.1 & 75.1 & 62.2 & 48.9 & 14.7 & 7.3 \\
\hline Elementary & 59.7 & 59.7 & 52.3 & 42.6 & 7.5 & 7.8 \\
\hline Middle & 63.1 & 50.1 & 43.5 & 37.2 & 8.7 & 6.6 \\
\hline General secondary & 54.1 & 43.4 & 34.6 & 26.9 & 5.1 & 5.1 \\
\hline Vocational secondary & 62.3 & 58.9 & 52.1 & 44.4 & 10.1 & 8.7 \\
\hline Post-secondary institution & 69.2 & 66.6 & 61.1 & 52.3 & 15.1 & 16.8 \\
\hline University and above & 64.8 & 61.8 & 56.4 & 47.2 & 13.6 & 16.4 \\
\hline \multicolumn{7}{|l|}{ Wealth quintile } \\
\hline Lowest & 59.0 & 56.6 & 46.5 & 44.0 & 12.3 & 6.3 \\
\hline Second & 59.4 & 56.1 & 49.7 & 42.6 & 11.0 & 9.0 \\
\hline Middle & 62.7 & 58.9 & 54.7 & 45.3 & 10.5 & 7.9 \\
\hline Fourth & 60.0 & 56.7 & 49.0 & 40.2 & 8.8 & 9.1 \\
\hline Richest & 65.4 & 61.6 & 55.9 & 45.5 & 10.9 & 14.1 \\
\hline Total & 61.5 & 58.1 & 51.4 & 43.6 & 10.7 & 9.5 \\
\hline$(\mathrm{N})$ & (10.903) & $(10,916)$ & $(10,916)$ & $(10,916)$ & $(10,916)$ & $(10,916)$ \\
\hline
\end{tabular}


TABLE A3.1 School completion rates among all youth, by background characteristics, 2014 (\%)

\begin{tabular}{|c|c|c|c|c|}
\hline & $\begin{array}{l}\text { COMPLETED } \\
\text { PRIMARY BY } \\
\text { AGE } 13\end{array}$ & $\begin{array}{c}\text { COMPLETED } \\
\text { PREPARATORY BY } \\
\text { AGE } 16\end{array}$ & $\begin{array}{l}\text { COMPLETED } \\
\text { SECONDARY BY } \\
\text { AGE } 19\end{array}$ & $\begin{array}{c}\text { COMPLETED } \\
\text { UNIVERSITY BY } \\
\text { AGE } 23\end{array}$ \\
\hline \multicolumn{5}{|l|}{ Gender } \\
\hline Male & 87.6 & 79.2 & 73.3 & 23.1 \\
\hline Female & 81.0 & 73.3 & 64.5 & 19.3 \\
\hline \multicolumn{5}{|l|}{ Age group } \\
\hline$<18$ & 93.6 & 78.6 & $\mathrm{n} / \mathrm{a}$ & $\mathrm{n} / \mathrm{a}$ \\
\hline $18-24$ & 88.3 & 80.9 & 72.6 & 23.4 \\
\hline $25-29$ & 78.3 & 74.1 & 69.0 & 22.7 \\
\hline $30+$ & 72.3 & 66.8 & 61.0 & 17.8 \\
\hline \multicolumn{5}{|l|}{ Urban-rural residence } \\
\hline Urban & 89.4 & 82.2 & 75.8 & 33.6 \\
\hline Rural & 81.4 & 72.5 & 64.7 & 14.1 \\
\hline Informal urban areas & 87.5 & 81.9 & 74.2 & 25.9 \\
\hline \multicolumn{5}{|l|}{ Region } \\
\hline Urban Governorates & 88.9 & 80.1 & 72.6 & 34.0 \\
\hline Urban Lower Egypt & 91.6 & 86.9 & 80.7 & 37.1 \\
\hline Rural Lower Egypt & 83.6 & 75.4 & 69.1 & 16.1 \\
\hline Urban Upper Egypt & 85.1 & 79.9 & 74.3 & 19.2 \\
\hline Rural Upper Egypt & 79.6 & 70.0 & 60.3 & 12.1 \\
\hline Frontier Governorates & 76.6 & 69.1 & 63.2 & 14.6 \\
\hline \multicolumn{5}{|l|}{ Mother's education } \\
\hline Illiterate & 76.7 & 67.2 & 58.9 & 11.0 \\
\hline Can read and write & 90.8 & 82.7 & 77.4 & 24.3 \\
\hline Primary & 92.4 & 84.4 & 79.4 & 27.8 \\
\hline Preparatory & 97.2 & 90.0 & 88.5 & 40.2 \\
\hline General secondary & 100.0 & 99.1 & 95.4 & 76.5 \\
\hline $\begin{array}{l}\text { Vocational secondary and } \\
\text { post-secondary }\end{array}$ & 99.1 & 97.1 & 95.5 & 57.9 \\
\hline Higher education & 99.7 & 99.0 & 99.4 & 88.7 \\
\hline \multicolumn{5}{|l|}{ Father's education } \\
\hline Illiterate & 71.2 & 60.5 & 52.0 & 7.5 \\
\hline Can read and write & 86.7 & 77.8 & 70.8 & 17.9 \\
\hline Primary & 89.4 & 81.2 & 75.3 & 19.4 \\
\hline Preparatory & 96.2 & 89.2 & 81.8 & 27.9 \\
\hline General secondary & 98.9 & 95.1 & 88.0 & 44.4 \\
\hline $\begin{array}{l}\text { Vocational secondary and } \\
\text { post-secondary }\end{array}$ & 97.8 & 94.4 & 91.6 & 44.7 \\
\hline Higher education & 99.6 & 98.7 & 98.2 & 75.9 \\
\hline Total & 84.4 & 76.3 & 69.0 & 21.2 \\
\hline$(\mathrm{N})$ & $(10,907)$ & $(10,072)$ & $(8,253)$ & $(5,654)$ \\
\hline
\end{tabular}


TABLE A3.2 Percentage of youth who never attended school, by background and gender, 2014

\begin{tabular}{|c|c|c|c|}
\hline & MALE & FEMALE & TOTAL \\
\hline \multicolumn{4}{|l|}{ Age group } \\
\hline$<18$ & 4.0 & 3.1 & 3.5 \\
\hline $18-24$ & 5.0 & 9.6 & 7.1 \\
\hline $25-29$ & 7.9 & 20.0 & 13.8 \\
\hline $30+$ & 10.2 & 26.2 & 18.7 \\
\hline \multicolumn{4}{|l|}{ Urban-rural residence } \\
\hline Urban & 3.4 & 5.0 & 4.2 \\
\hline Rural & 7.7 & 18.4 & 13.0 \\
\hline Informal urban areas & 6.1 & 10.2 & 8.2 \\
\hline \multicolumn{4}{|l|}{ Region } \\
\hline Urban Governorates & 2.9 & 4.0 & 3.4 \\
\hline Urban Lower Egypt & 3.5 & 5.8 & 4.7 \\
\hline Rural Lower Egypt & 8.2 & 13.5 & 10.7 \\
\hline Urban Upper Egypt & 7.2 & 12.0 & 9.5 \\
\hline Rural Upper Egypt & 7.0 & 22.6 & 15.0 \\
\hline Frontier Governorates & 10.5 & 26.0 & 18.0 \\
\hline \multicolumn{4}{|l|}{ Mother's education } \\
\hline Illiterate & 10.0 & 21.2 & 15.7 \\
\hline Can read and write & 2.9 & 4.3 & 3.6 \\
\hline Primary & 2.2 & 0.7 & 1.6 \\
\hline Preparatory & 0.5 & 0.4 & 0.4 \\
\hline General secondary & 0.0 & 0.0 & 0.0 \\
\hline Vocational secondary and post-secondary & 0.3 & 0.2 & 0.3 \\
\hline Higher education & 0.0 & 0.2 & 0.1 \\
\hline \multicolumn{4}{|l|}{ Father's education } \\
\hline Illiterate & 13.3 & 26.7 & 20.1 \\
\hline Can read and write & 3.2 & 9.5 & 6.5 \\
\hline Primary & 1.5 & 5.3 & 3.2 \\
\hline Preparatory & 2.2 & 2.3 & 2.3 \\
\hline General secondary & 0.0 & 2.6 & 1.1 \\
\hline Vocational secondary and post-secondary & 1.0 & 0.8 & 0.9 \\
\hline Higher education & 0.0 & 0.0 & 0.0 \\
\hline Total & 6.3 & 13.7 & 9.9 \\
\hline$(\mathrm{N})$ & $(5,070)$ & $(5,837)$ & $(10,907)$ \\
\hline
\end{tabular}




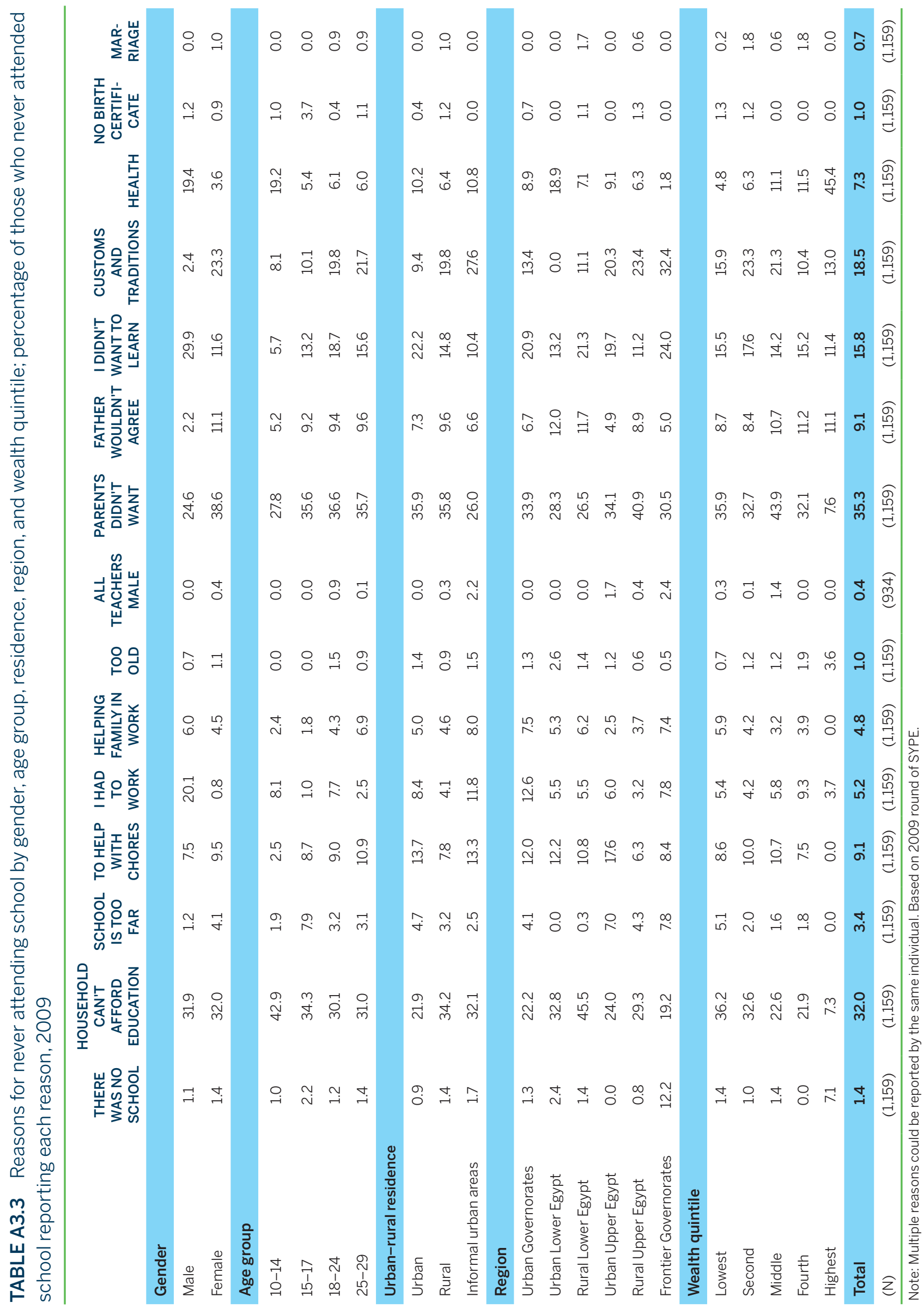


TABLE A3.4 Percentage of youth with less than a secondary education who attended literacy classes, cannot read, cannot write, and cannot do basic math, by background characteristics, 2014

\begin{tabular}{|c|c|c|c|c|}
\hline & $\begin{array}{c}\text { ATTENDED } \\
\text { LITERACY CLASSES }\end{array}$ & CANNOT READ & CANNOT WRITE & $\begin{array}{l}\text { CANNOT DO } \\
\text { BASIC MATH }\end{array}$ \\
\hline \multicolumn{5}{|l|}{ Gender } \\
\hline Male & 6.1 & 45.1 & 45.2 & 31.0 \\
\hline Female & 11.2 & 51.5 & 52.1 & 38.4 \\
\hline \multicolumn{5}{|l|}{ Age group } \\
\hline$<18$ & 4.0 & 23.5 & 23.1 & 17.3 \\
\hline $18-24$ & 6.7 & 48.3 & 48.6 & 35.7 \\
\hline $25-29$ & 13.9 & 66.2 & 66.8 & 46.9 \\
\hline $30+$ & 13.8 & 64.3 & 65.9 & 45.7 \\
\hline \multicolumn{5}{|l|}{ Urban-rural residence } \\
\hline Urban & 8.3 & 38.9 & 38.3 & 26.6 \\
\hline Rural & 8.9 & 52.9 & 53.5 & 39.3 \\
\hline Informal urban areas & 10.8 & 40.3 & 42.4 & 24.4 \\
\hline \multicolumn{5}{|l|}{ Region } \\
\hline Urban Governorates & 9.7 & 36.9 & 36.3 & 20.9 \\
\hline Urban Lower Egypt & 7.9 & 30.7 & 33.8 & 28.8 \\
\hline Rural Lower Egypt & 7.1 & 49.9 & 51.0 & 37.0 \\
\hline Urban Upper Egypt & 7.9 & 53.2 & 52.3 & 34.9 \\
\hline Rural Upper Egypt & 10.5 & 55.1 & 55.2 & 41.3 \\
\hline Frontier Governorates & 7.1 & 55.7 & 55.1 & 35.0 \\
\hline \multicolumn{5}{|l|}{ Mother's education } \\
\hline Illiterate & 10.1 & 55.4 & 56.1 & 40.0 \\
\hline Can read and write & 5.7 & 36.7 & 32.4 & 25.0 \\
\hline Primary & 4.7 & 29.6 & 31.8 & 22.2 \\
\hline Preparatory & 1.9 & 19.1 & 15.5 & 14.7 \\
\hline General secondary & 0.0 & 20.7 & 20.7 & 20.7 \\
\hline Vocational secondary and post-secondary & 4.8 & 7.8 & 7.0 & 5.0 \\
\hline Higher education & 8.3 & 12.5 & 9.6 & 4.8 \\
\hline \multicolumn{5}{|l|}{ Father's education } \\
\hline Illiterate & 9.5 & 59.0 & 59.5 & 42.6 \\
\hline Can read and write & 12.0 & 39.8 & 40.6 & 26.9 \\
\hline Primary & 9.1 & 37.3 & 37.6 & 27.7 \\
\hline Preparatory & 4.7 & 26.1 & 28.7 & 18.7 \\
\hline General secondary & 3.5 & 5.4 & 8.9 & 5.4 \\
\hline Vocational secondary and post-secondary & 4.3 & 17.3 & 15.9 & 13.4 \\
\hline Higher education & 4.5 & 3.9 & 4.7 & 4.7 \\
\hline \multicolumn{5}{|l|}{ Education status } \\
\hline None & 13.7 & 92.2 & 93.0 & 69.8 \\
\hline Current primary & 15.5 & 41.6 & 36.7 & 27.1 \\
\hline Current preparatory & 2.9 & 4.9 & 3.7 & 1.8 \\
\hline Attended primary & 9.8 & 59.6 & 60.3 & 41.5 \\
\hline Attended preparatory & 6.1 & 14.8 & 15.5 & 9.4 \\
\hline Total & 6.1 & 14.8 & 15.5 & 9.4 \\
\hline$(\mathrm{N})$ & $(3,638)$ & $(3,638)$ & $(3,638)$ & $(3,638)$ \\
\hline
\end{tabular}

Note: Being defined as able to read is a "yes" response to the question on being able to read a letter or newspaper. Being defined as able to write is a "yes" response to the question on writing a letter. Being defined as able to do basic math is a "yes" response to the question on a simple arithmetic operation (addition or subtraction). 


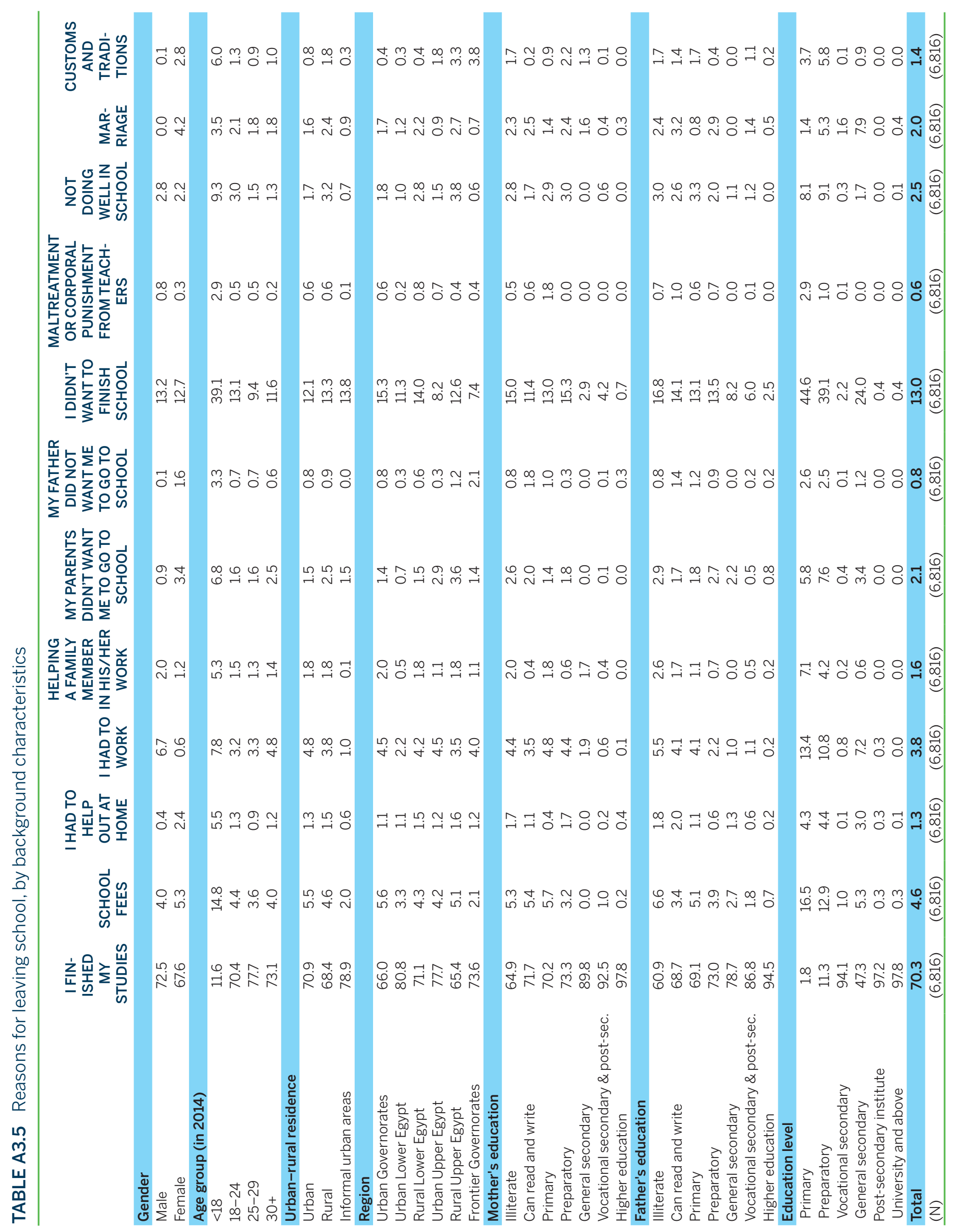


TABLE A3.6 Distribution of education level of current students, by background, 2014, percent

\begin{tabular}{|c|c|c|c|c|c|c|c|}
\hline & $\begin{array}{c}\text { CUR- } \\
\text { RENT } \\
\text { PRIMARY }\end{array}$ & $\begin{array}{l}\text { CURRENT } \\
\text { PREPARATO- } \\
\text { RY }\end{array}$ & $\begin{array}{c}\text { CURRENT } \\
\text { VOCATIONAL } \\
\text { SECONDARY }\end{array}$ & $\begin{array}{c}\text { CURRENT } \\
\text { GENERAL } \\
\text { SECOND- } \\
\text { ARY }\end{array}$ & $\begin{array}{l}\text { CURRENT } \\
\text { ABOVE } \\
\text { INTERME- } \\
\text { DIATE }\end{array}$ & $\begin{array}{l}\text { CURRENT } \\
\text { UNIVERSITY } \\
\text { AND ABOVE }\end{array}$ & TOTAL \\
\hline Male & 0.6 & 18.7 & 31.0 & 21.8 & 1.8 & 26.2 & 100.0 \\
\hline Female & 0.2 & 18.4 & 23.9 & 28.4 & 2.0 & 27.1 & 100.0 \\
\hline$<18$ & 0.6 & 29.6 & 33.9 & 35.0 & 0.1 & 0.9 & 100.0 \\
\hline $18-24$ & 0.0 & 1.5 & 18.6 & 9.6 & 4.9 & 65.4 & 100.0 \\
\hline $25-29$ & 0.0 & 0.0 & 2.5 & 0.0 & 0.7 & 96.8 & 100.0 \\
\hline $30+$ & 0.0 & 0.0 & 0.0 & 0.0 & 0.0 & 100.0 & 100.0 \\
\hline Informal urban areas & 0.0 & 15.7 & 24.1 & 29.1 & 1.0 & 30.2 & 100.0 \\
\hline \multicolumn{8}{|l|}{ Region of residence } \\
\hline Urban Governorates & 0.8 & 17.0 & 18.4 & 28.9 & 2.8 & 32.0 & 100.0 \\
\hline Urban Lower Egypt & 0.0 & 14.6 & 20.0 & 28.4 & 1.3 & 35.6 & 100.0 \\
\hline Rural Lower Egypt & 0.2 & 20.2 & 30.8 & 24.5 & 1.7 & 22.5 & 100.0 \\
\hline Urban Upper Egypt & 0.0 & 13.5 & 24.3 & 30.3 & 1.1 & 30.8 & 100.0 \\
\hline Rural Upper Egypt & 0.6 & 21.2 & 36.0 & 18.7 & 2.0 & 21.6 & 100.0 \\
\hline Frontier Governorates & 2.2 & 21.5 & 31.5 & 22.0 & 0.9 & 22.0 & 100.0 \\
\hline \multicolumn{8}{|l|}{ Mother's education } \\
\hline $\begin{array}{l}\text { Vocational secondary } \\
\text { and post-secondary }\end{array}$ & 0.2 & 16.2 & 16.7 & 34.3 & 1.5 & 31.1 & 100.0 \\
\hline Higher education & 0.0 & 8.9 & 5.6 & 40.4 & 1.2 & 43.8 & 100.0 \\
\hline \multicolumn{8}{|l|}{ Father's education } \\
\hline Illiterate & 0.6 & 26.5 & 40.0 & 14.2 & 1.2 & 17.4 & 100.0 \\
\hline Can read and write & 0.9 & 18.0 & 34.7 & 27.1 & 1.7 & 17.7 & 100.0 \\
\hline Primary & 0.5 & 18.1 & 40.8 & 15.9 & 3.5 & 21.1 & 100.0 \\
\hline Preparatory & 0.9 & 21.8 & 36.4 & 14.8 & 2.5 & 23.6 & 100.0 \\
\hline General secondary & 0.0 & 33.6 & 26.4 & 9.9 & 5.0 & 25.0 & 100.0 \\
\hline $\begin{array}{l}\text { Vocational secondary } \\
\text { and post-secondary }\end{array}$ & 0.2 & 17.2 & 21.7 & 31.3 & 1.8 & 27.8 & 100.0 \\
\hline Higher education & 0.0 & 8.4 & 7.1 & 38.6 & 1.4 & 44.6 & 100.0 \\
\hline Total & 0.4 & 18.6 & 27.7 & 24.9 & 1.9 & 26.6 & 100.0 \\
\hline$(\mathrm{N})$ & (11) & $(537)$ & $(800)$ & (734) & $(54)$ & (734) & $(2,870)$ \\
\hline
\end{tabular}




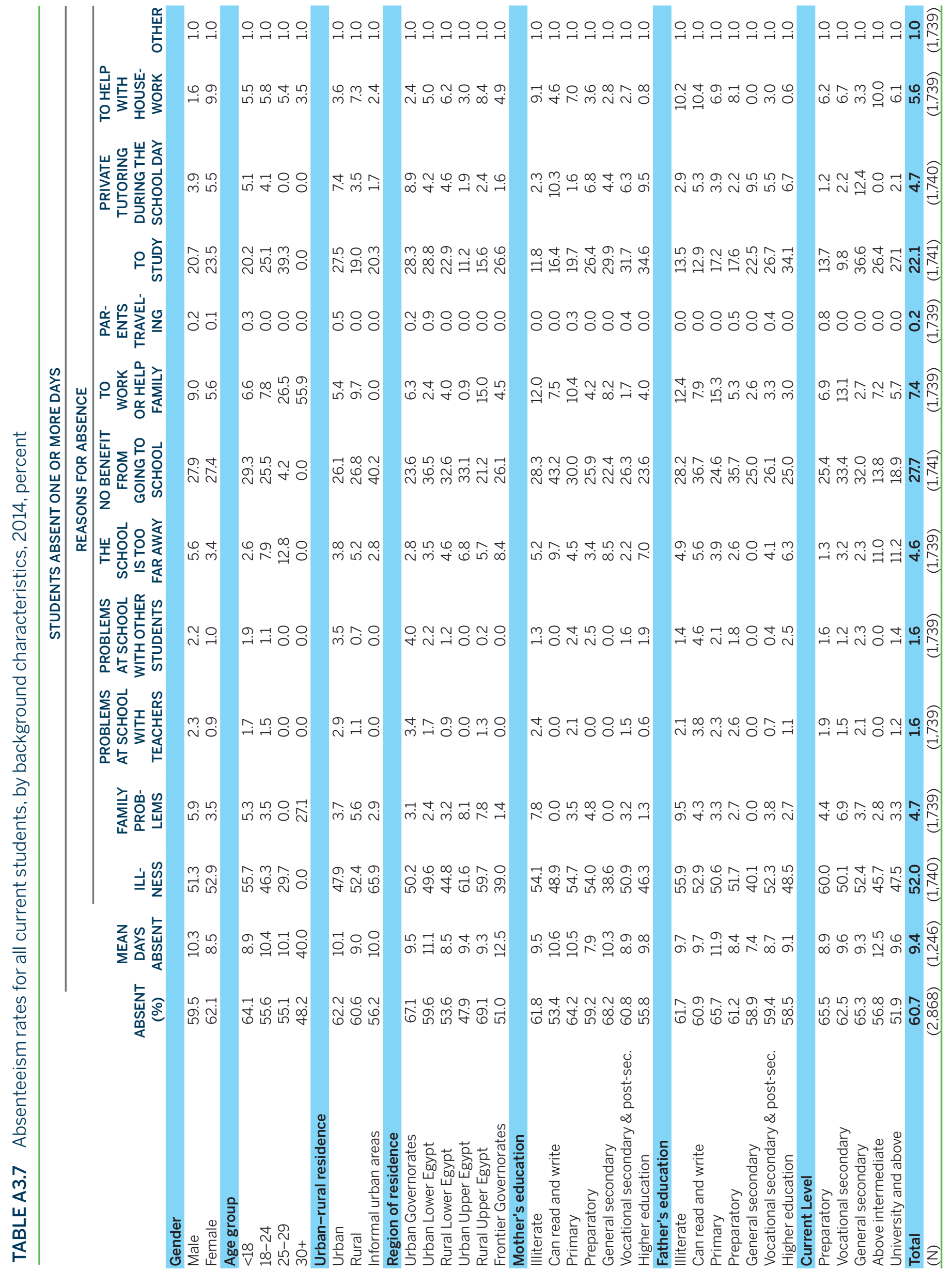


TABLE A3.8 Grade repetition among all youth, by level and background characteristics, 2014, percent

\begin{tabular}{|c|c|c|c|c|}
\hline & $\begin{array}{l}\text { REPEATED AT } \\
\text { PRIMARY LEVEL }\end{array}$ & $\begin{array}{c}\text { REPEATED AT } \\
\text { PREPARATORY LEVEL }\end{array}$ & $\begin{array}{c}\text { REPEATED AT } \\
\text { SECONDARY LEVEL }\end{array}$ & $\begin{array}{c}\text { REPEATED AT } \\
\text { UNIVERSITY LEVEL }\end{array}$ \\
\hline \multicolumn{5}{|l|}{ Gender } \\
\hline Male & 3.9 & 7.5 & 5.5 & 10.1 \\
\hline Female & 2.6 & 5.0 & 1.9 & 3.2 \\
\hline \multicolumn{5}{|l|}{ Age group } \\
\hline$<18$ & 3.5 & 3.7 & 0.0 & 0.0 \\
\hline $18-24$ & 3.4 & 7.2 & 4.5 & 5.5 \\
\hline $25-29$ & 3.0 & 6.0 & 3.4 & 6.7 \\
\hline $30+$ & 3.2 & 7.1 & 3.0 & 9.4 \\
\hline \multicolumn{5}{|l|}{ Urban-rural residence } \\
\hline Urban & 2.7 & 5.1 & 3.3 & 6.6 \\
\hline Rural & 3.7 & 7.6 & 4.6 & 8.8 \\
\hline Informal urban areas & 2.5 & 2.5 & 1.4 & 2.2 \\
\hline \multicolumn{5}{|l|}{ Region of residence } \\
\hline Urban Governorates & 3.8 & 5.2 & 3.7 & 9.3 \\
\hline Urban Lower Egypt & 1.6 & 2.5 & 1.2 & 1.7 \\
\hline Rural Lower Egypt & 3.4 & 5.5 & 3.1 & 5.7 \\
\hline Urban Upper Egypt & 1.7 & 6.0 & 3.8 & 1.1 \\
\hline Rural Upper Egypt & 4.0 & 10.1 & 6.6 & 13.8 \\
\hline Frontier Governorates & 2.2 & 3.0 & 2.6 & 1.8 \\
\hline \multicolumn{5}{|l|}{ Mother's education } \\
\hline Illiterate & 4.3 & 8.6 & 4.2 & 7.7 \\
\hline Can read and write & 4.0 & 6.2 & 3.1 & 5.3 \\
\hline Primary & 3.7 & 5.7 & 6.0 & 9.0 \\
\hline Preparatory & 0.9 & 5.1 & 3.2 & 10.2 \\
\hline General secondary & 0.0 & 0.0 & 1.5 & 6.7 \\
\hline Vocational secondary and post-secondary & 0.8 & 2.0 & 2.5 & 5.6 \\
\hline Higher education & 0.2 & 0.5 & 1.6 & 5.0 \\
\hline \multicolumn{5}{|l|}{ Father's education } \\
\hline Illiterate & 4.6 & 8.8 & 3.8 & 6.2 \\
\hline Can read and write & 4.0 & 6.5 & 4.7 & 5.6 \\
\hline Primary & 4.9 & 9.6 & 5.5 & 11.0 \\
\hline Preparatory & 2.5 & 5.7 & 2.7 & 17.3 \\
\hline General secondary & 2.5 & 4.0 & 3.8 & 2.6 \\
\hline Vocational secondary and post-secondary & 1.0 & 2.7 & 3.0 & 6.6 \\
\hline Higher education & 0.8 & 1.8 & 3.5 & 4.3 \\
\hline Total & 3.3 & 6.3 & 3.8 & 7.0 \\
\hline$(\mathrm{N})$ & $(9,677)$ & $(8,252)$ & $(5,733)$ & $(1,469)$ \\
\hline
\end{tabular}

Note: Based on all youth ever attended that level. 
TABLE A3.9 School facility quality measures, by background of student, 2014, percent

\begin{tabular}{|c|c|c|c|c|c|c|c|c|c|}
\hline & $\begin{array}{l}\text { PRIMARY } \\
\text { IN } \\
\text { SHIFTS }\end{array}$ & $\begin{array}{c}\text { PREPARA- } \\
\text { TORY IN } \\
\text { SHIFTS }\end{array}$ & $\begin{array}{l}\text { SECOND- } \\
\text { ARY IN } \\
\text { SHIFTS }\end{array}$ & $\begin{array}{c}\text { SEATS } \\
\text { BROKEN }\end{array}$ & $\begin{array}{c}\text { SEATS } \\
\text { CROWDED }\end{array}$ & $\begin{array}{l}\text { INADE- } \\
\text { QUATE } \\
\text { LIGHTING }\end{array}$ & $\begin{array}{l}\text { BOARD } \\
\text { ILLEGI- } \\
\text { BLE }\end{array}$ & $\begin{array}{c}\text { WIN- } \\
\text { DOWS } \\
\text { BROKEN }\end{array}$ & $\begin{array}{l}\text { INADE- } \\
\text { QUATE } \\
\text { VENTILA- } \\
\text { TION }\end{array}$ \\
\hline \multicolumn{10}{|l|}{ Gender } \\
\hline Male & 29.3 & 28.7 & 26.3 & 38.8 & 27.1 & 24.5 & 28.6 & 34.8 & 21.9 \\
\hline Female & 29.8 & 27.6 & 29.0 & 32.6 & 26.9 & 23.0 & 25.6 & 28.6 & 22.9 \\
\hline Urban & 31.4 & 26.5 & 23.1 & 27.4 & 21.1 & 17.9 & 18.8 & 24.4 & 14.7 \\
\hline Rural & 29.1 & 31.7 & 32.9 & 41.1 & 29.9 & 25.2 & 29.8 & 34.4 & 24.0 \\
\hline Informal urban areas & 26.0 & 13.2 & 11.8 & 29.6 & 27.4 & 34.5 & 38.0 & 40.3 & 36.9 \\
\hline \multicolumn{10}{|l|}{ Region } \\
\hline Urban Upper Egypt & 13.4 & 14.6 & 14.6 & 21.4 & 25.7 & 28.0 & 25.7 & 29.5 & 27.1 \\
\hline Rural Upper Egypt & 29.4 & 31.8 & 32.9 & 45.4 & 30.2 & 23.0 & 27.1 & 30.9 & 21.6 \\
\hline Frontier Governorates & 13.6 & 12.6 & 7.5 & 22.8 & 18.5 & 25.0 & 25.7 & 27.2 & 19.4 \\
\hline \multicolumn{10}{|l|}{ Mother's education } \\
\hline Illiterate & 31.9 & 30.2 & 31.9 & 39.4 & 30.3 & 27.5 & 30.9 & 33.2 & 24.3 \\
\hline Can read and write & 28.7 & 31.6 & 25.4 & 40.7 & 37.3 & 26.1 & 29.3 & 39.1 & 25.9 \\
\hline Primary & 30.1 & 30.3 & 30.0 & 41.7 & 27.1 & 25.2 & 25.3 & 37.0 & 20.9 \\
\hline Preparatory & 29.4 & 25.9 & 23.4 & 36.8 & 27.0 & 21.6 & 30.8 & 40.2 & 18.6 \\
\hline Can read and write & 31.6 & 28.0 & 31.5 & 48.1 & 31.5 & 27.4 & 25.0 & 37.5 & 18.6 \\
\hline Primary & 31.9 & 31.4 & 31.6 & 45.2 & 25.5 & 25.1 & 28.8 & 37.2 & 22.8 \\
\hline Preparatory & 31.0 & 28.7 & 35.5 & 33.6 & 23.9 & 22.2 & 26.5 & 32.1 & 24.9 \\
\hline General secondary & 27.8 & 26.4 & 20.2 & 37.0 & 31.2 & 31.9 & 28.5 & 38.6 & 26.1 \\
\hline $\begin{array}{l}\text { Vocational secondary and } \\
\text { post-secondary }\end{array}$ & 27.4 & 26.4 & 24.1 & 35.0 & 27.5 & 24.3 & 28.9 & 32.4 & 24.2 \\
\hline Higher education & 19.1 & 19.4 & 13.9 & 23.1 & 16.6 & 11.7 & 15.6 & 19.8 & 17.1 \\
\hline Total & 29.5 & 28.2 & 27.5 & 35.9 & 27.0 & 23.8 & 27.2 & 31.9 & 22.3 \\
\hline$(\mathrm{N})$ & $(9,666)$ & $(8,781)$ & $(7,262)$ & $(2,055)$ & $(2,055)$ & $(2,055)$ & $(2,055)$ & $(2,055)$ & $(2,055)$ \\
\hline
\end{tabular}

Note: Based on all youth who attended that level for whether schools operated in multiple shifts; all other measures based on current students. 


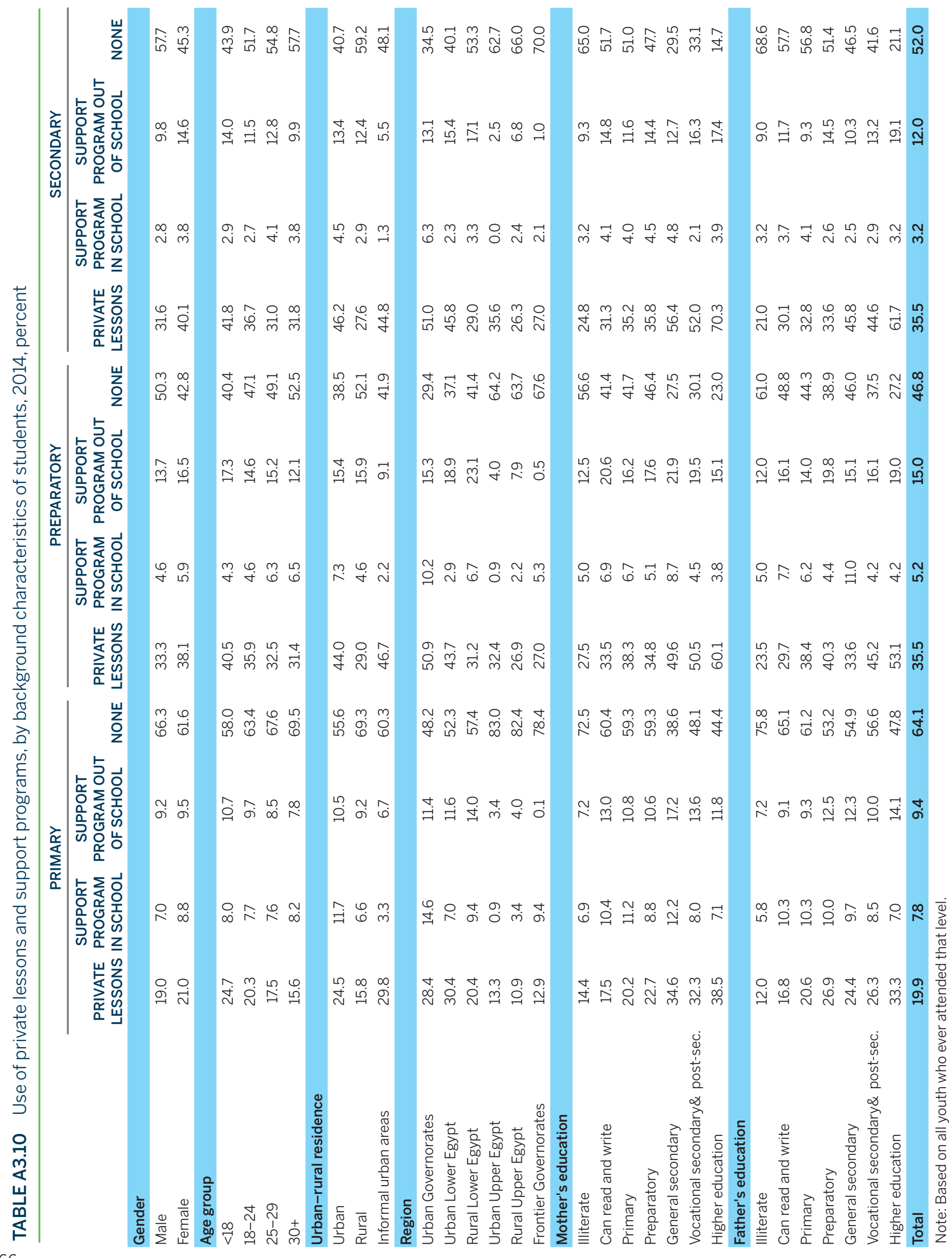


TABLE A3.11 Tutoring prevalence and average costs in Egyptian pounds (EGP), current students in secondary or below, 2014

\begin{tabular}{|c|c|c|c|c|}
\hline & \multicolumn{2}{|c|}{ PRIVATE LESSONS } & \multicolumn{2}{|c|}{ GROUP TUTORING } \\
\hline & $(\%)$ & $\begin{array}{l}\text { AVERAGE COST, IF } \\
\text { USING (EGP) }\end{array}$ & $(\%)$ & $\begin{array}{l}\text { AVERAGE COST, IF } \\
\text { USING (EGP) }\end{array}$ \\
\hline \multicolumn{5}{|l|}{ Gender } \\
\hline Male & 31.3 & 307.1 & 13.1 & 169.2 \\
\hline Female & 44.5 & 325.5 & 18.7 & 202.6 \\
\hline \multicolumn{5}{|l|}{ Urban-rural residence } \\
\hline Urban & 49.3 & 402.5 & 18.8 & 229.3 \\
\hline Rural & 29.5 & 219.5 & 15.3 & 158.7 \\
\hline Informal urban areas & 51.1 & 424.0 & 8.6 & 237.6 \\
\hline \multicolumn{5}{|l|}{ Region } \\
\hline Urban Governorates & 54.3 & 447.2 & 20.2 & 255.7 \\
\hline Urban Lower Egypt & 43.9 & 391.1 & 20.6 & 196.4 \\
\hline Rural Lower Egypt & 32.6 & 205.7 & 21.1 & 129.9 \\
\hline Urban Upper Egypt & 49.2 & 330.2 & 2.7 & 185.4 \\
\hline Rural Upper Egypt & 26.0 & 237.0 & 8.6 & 247.8 \\
\hline Frontier Governorates & 32.4 & 390.8 & 2.1 & 191.6 \\
\hline \multicolumn{5}{|l|}{ Mother's education } \\
\hline Illiterate & 24.5 & 253.3 & 10.2 & 132.1 \\
\hline Can read and write & 33.5 & 241.4 & 24.3 & 187.2 \\
\hline Primary & 31.0 & 353.4 & 17.3 & 133.0 \\
\hline Preparatory & 35.8 & 267.0 & 20.6 & 110.9 \\
\hline General secondary & 56.8 & 351.9 & 29.9 & 140.2 \\
\hline Vocational secondary and post-secondary & 49.9 & 302.2 & 19.6 & 260.6 \\
\hline Higher education & 70.3 & 481.4 & 16.7 & 271.4 \\
\hline \multicolumn{5}{|l|}{ Father's education } \\
\hline Illiterate & 20.3 & 234.1 & 13.3 & 150.0 \\
\hline Can read and write & 29.1 & 253.1 & 13.8 & 169.7 \\
\hline Primary & 29.2 & 319.9 & 13.8 & 170.2 \\
\hline Preparatory & 34.6 & 284.3 & 15.2 & 115.5 \\
\hline General secondary & 32.3 & 268.2 & 9.4 & 88.5 \\
\hline Vocational secondary and post-secondary & 48.0 & 315.0 & 17.0 & 216.9 \\
\hline Higher education & 60.8 & 403.5 & 21.6 & 239.9 \\
\hline \multicolumn{5}{|l|}{ Wealth quintile } \\
\hline Lowest & 24.8 & 218.8 & 10.0 & 137.8 \\
\hline Second & 32.4 & 262.9 & 14.1 & 184.6 \\
\hline Middle & 32.9 & 242.2 & 15.7 & 127.0 \\
\hline Fourth & 40.8 & 320.5 & 19.8 & 191.8 \\
\hline Highest & 50.1 & 414.0 & 17.1 & 247.6 \\
\hline \multicolumn{5}{|l|}{ Education status } \\
\hline Current preparatory & 35.2 & 194.2 & 18.8 & 128.0 \\
\hline Current vocational secondary & 11.8 & 239.4 & 8.8 & 161.9 \\
\hline $\begin{array}{l}\text { Current general } \\
\text { secondary }\end{array}$ & 67.8 & 381.3 & 21.1 & 244.4 \\
\hline TOTAL & 37.4 & 317.3 & 15.7 & 188.1 \\
\hline$(N)$ & $(2,082)$ & $(2,082)$ & $(797)$ & $(294)$ \\
\hline
\end{tabular}

Note: Statistics for current primary students $(\mathrm{N}=14)$ were omitted due to small sample size. 
TABLE A3.12 Percentage receiving help with schoolwork and help source (if help received), current students in secondary and below, 2014

\begin{tabular}{|c|c|c|c|c|c|}
\hline & \multirow[b]{2}{*}{$\begin{array}{l}\text { RECEIVED } \\
\text { HELP }\end{array}$} & \multicolumn{4}{|c|}{$\begin{array}{l}\text { AMONG THOSE RECEIVING HELP } \\
\end{array}$} \\
\hline & & $\begin{array}{l}\text { HELP FROM } \\
\text { FATHER }\end{array}$ & $\begin{array}{l}\text { HELP FROM } \\
\text { MOTHER }\end{array}$ & $\begin{array}{c}\text { HELP FROM } \\
\text { OLDER SIBLINGS }\end{array}$ & $\begin{array}{l}\text { HELP FROM } \\
\text { OTHER }\end{array}$ \\
\hline \multicolumn{6}{|l|}{ Gender } \\
\hline Male & 12.1 & 37.8 & 47.9 & 39.9 & 3.9 \\
\hline Female & 16.2 & 33.4 & 56.2 & 34.7 & 3.6 \\
\hline \multicolumn{6}{|l|}{ Urban-rural residence } \\
\hline Urban & 19.0 & 34.1 & 61.8 & 31.3 & 4.8 \\
\hline Rural & 11.6 & 37.0 & 41.8 & 47.2 & 2.9 \\
\hline Informal urban areas & 13.6 & 32.2 & 69.1 & 5.8 & 3.4 \\
\hline \multicolumn{6}{|l|}{ Region } \\
\hline Urban Governorates & 18.5 & 30.6 & 58.8 & 25.2 & 3.0 \\
\hline Urban Lower Egypt & 22.2 & 41.5 & 61.7 & 24.0 & 5.3 \\
\hline Rural Lower Egypt & 12.7 & 52.6 & 51.9 & 36.4 & 3.0 \\
\hline Urban Upper Egypt & 10.6 & 22.1 & 86.3 & 44.0 & 7.2 \\
\hline Rural Upper Egypt & 10.4 & 14.3 & 27.2 & 62.8 & 2.8 \\
\hline Frontier Governorates & 6.7 & 42.1 & 58.4 & 25.6 & 15.4 \\
\hline \multicolumn{6}{|l|}{ Mother's education } \\
\hline Illiterate & 6.9 & 21.3 & 20.6 & 57.6 & 6.6 \\
\hline Can read and write & 12.7 & 28.0 & 43.6 & 54.2 & 0.0 \\
\hline Primary & 11.9 & 24.6 & 31.3 & 62.4 & 0.0 \\
\hline Preparatory & 14.2 & 29.9 & 29.1 & 52.6 & 19.9 \\
\hline General secondary & 30.7 & 54.3 & 31.6 & 18.1 & 9.4 \\
\hline Vocational secondary and post-secondary & 19.2 & 45.2 & 71.0 & 22.9 & 0.7 \\
\hline Higher education & 33.5 & 37.3 & 74.1 & 24.5 & 2.1 \\
\hline \multicolumn{6}{|l|}{ Father's education } \\
\hline Illiterate & 5.8 & 11.5 & 22.5 & 61.6 & 16.4 \\
\hline Can read and write & 6.5 & 40.2 & 61.0 & 55.5 & 0.0 \\
\hline Primary & 11.0 & 11.2 & 30.4 & 52.3 & 2.9 \\
\hline Preparatory & 11.0 & 13.3 & 44.5 & 41.2 & 9.0 \\
\hline General secondary & 22.0 & 56.8 & 87.1 & 31.6 & 0.0 \\
\hline Vocational secondary and post-secondary & 16.3 & 36.0 & 62.3 & 31.2 & 1.7 \\
\hline Higher education & 32.5 & 53.4 & 56.6 & 28.2 & 1.5 \\
\hline \multicolumn{6}{|l|}{ Wealth quintile } \\
\hline Lowest & 7.1 & 25.9 & 20.5 & 53.5 & 3.5 \\
\hline Second & 11.2 & 17.5 & 42.0 & 45.3 & 10.3 \\
\hline Middle & 8.9 & 37.7 & 35.3 & 35.1 & 5.6 \\
\hline Fourth & 13.1 & 32.9 & 52.7 & 36.8 & 0.0 \\
\hline Highest & 25.6 & 43.4 & 66.2 & 32.1 & 2.8 \\
\hline \multicolumn{6}{|l|}{ Education status } \\
\hline Current preparatory & 16.7 & 34.2 & 61.2 & 28.9 & 2.9 \\
\hline Current vocational secondary & 6.6 & 26.7 & 42.2 & 47.5 & 7.3 \\
\hline Current general secondary & 20.0 & 39.5 & 51.5 & 37.8 & 3.0 \\
\hline TOTAL & 14.0 & 35.4 & 52.4 & 37.1 & 3.7 \\
\hline$(\mathrm{N})$ & $(2,059)$ & (279) & (279) & (279) & (279) \\
\hline
\end{tabular}

Note: Statistics for current primary students $(\mathrm{N}=14)$ were omitted due to small sample size. 
TABLE A3.13 Early childhood care or education (ECCE) attendance and types, by background characteristics of youth, 2014, percent

\begin{tabular}{|c|c|c|c|c|}
\hline & $\begin{array}{c}\text { ATTENDED ANY } \\
\text { ECCE }\end{array}$ & $\begin{array}{l}\text { ATTENDED } \\
\text { NURSERY }\end{array}$ & $\begin{array}{c}\text { ATTENDED } \\
\text { KINDERGARTEN }\end{array}$ & $\begin{array}{l}\text { ATTENDED } \\
\text { OTHER }\end{array}$ \\
\hline \multicolumn{5}{|l|}{ Gender } \\
\hline Male & 23.1 & 11.7 & 11.4 & 0.3 \\
\hline Female & 25.1 & 14.1 & 11.7 & 0.5 \\
\hline \multicolumn{5}{|l|}{ Age group (in 2014) } \\
\hline$<18$ & 34.7 & 18.0 & 17.3 & 0.5 \\
\hline $18-24$ & 25.0 & 12.8 & 12.6 & 0.4 \\
\hline $25-29$ & 18.8 & 11.0 & 8.0 & 0.3 \\
\hline $30+$ & 16.3 & 9.1 & 7.0 & 0.3 \\
\hline \multicolumn{5}{|l|}{ Urban-rural residence } \\
\hline Urban & 46.4 & 23.7 & 23.8 & 0.4 \\
\hline Rural & 13.8 & 7.4 & 6.3 & 0.4 \\
\hline Informal urban areas & 20.6 & 14.1 & 7.3 & 0.1 \\
\hline \multicolumn{5}{|l|}{ Region } \\
\hline Urban Governorates & 58.0 & 31.8 & 27.8 & 0.4 \\
\hline Urban Lower Egypt & 31.0 & 17.7 & 13.5 & 0.4 \\
\hline Rural Lower Egypt & 20.2 & 12.0 & 7.9 & 0.5 \\
\hline Urban Upper Egypt & 12.9 & 2.9 & 11.1 & 0.0 \\
\hline Rural Upper Egypt & 7.0 & 2.3 & 4.6 & 0.3 \\
\hline Frontier Governorates & 15.9 & 10.9 & 5.1 & 0.2 \\
\hline \multicolumn{5}{|l|}{ Mother's education } \\
\hline Illiterate & 11.8 & 7.4 & 4.3 & 0.2 \\
\hline Can read and write & 25.6 & 12.2 & 12.4 & 1.2 \\
\hline Primary & 27.2 & 18.4 & 9.2 & 0.5 \\
\hline Preparatory & 39.1 & 26.9 & 11.6 & 0.8 \\
\hline General secondary & 59.7 & 31.7 & 29.8 & 0.0 \\
\hline Vocational secondary and post-secondary & 51.1 & 23.7 & 28.7 & 0.6 \\
\hline Higher education & 68.8 & 21.3 & 51.1 & 0.2 \\
\hline \multicolumn{5}{|l|}{ Father's education } \\
\hline Illiterate & 9.8 & 6.3 & 3.4 & 0.2 \\
\hline Can read and write & 17.7 & 10.5 & 6.2 & 0.9 \\
\hline Primary & 23.5 & 16.4 & 7.1 & 0.5 \\
\hline Preparatory & 32.6 & 21.5 & 11.3 & 0.6 \\
\hline General secondary & 48.0 & 18.8 & 31.2 & 0.0 \\
\hline Vocational secondary and post-secondary & 40.0 & 19.9 & 21.4 & 0.3 \\
\hline Higher education & 56.5 & 19.7 & 38.6 & 0.5 \\
\hline Total & 24.1 & 12.8 & 11.5 & 0.4 \\
\hline$(\mathrm{N})$ & $(10,887)$ & $(10,887)$ & $(10,887)$ & $(10,887)$ \\
\hline
\end{tabular}

Note: Based on all youth, but assuming that those who never went to school did not attend ECCE. Multiple types of ECCE possible. 
TABLE A3.14 Vocational secondary specializations and experiences, by background characteristics, 2014, percent

\begin{tabular}{|c|c|c|c|c|c|c|c|}
\hline & \multicolumn{4}{|c|}{ SPECIALIZATION } & \multicolumn{3}{|c|}{ HAD HANDS-ON EXPERIENCE } \\
\hline & $\begin{array}{l}\text { INDUS- } \\
\text { TRIAL }\end{array}$ & $\begin{array}{l}\text { COM- } \\
\text { MERCIAL }\end{array}$ & $\begin{array}{l}\text { AGRICUL- } \\
\text { TURAL }\end{array}$ & OTHER & $\begin{array}{l}\text { HANDS- } \\
\text { ON EXPE- } \\
\text { RIENCE }\end{array}$ & $\begin{array}{c}\text { RELEVANT } \\
\text { TO LABOR } \\
\text { MARKET }\end{array}$ & $\begin{array}{c}\text { PART OF VOC. } \\
\text { ENHANCE. } \\
\text { TRAINING }\end{array}$ \\
\hline \multicolumn{8}{|l|}{ Gender } \\
\hline Male & 56.2 & 27.2 & 14.6 & 2.1 & 51.5 & 54.3 & 18.6 \\
\hline Female & 32.4 & 57.4 & 5.6 & 4.6 & 42.5 & 55.0 & 16.0 \\
\hline \multicolumn{8}{|l|}{ Age group (in 2014) } \\
\hline$<18$ & 45.4 & 40.2 & 10.1 & 4.2 & 47.8 & 63.3 & 20.0 \\
\hline $18-24$ & 49.1 & 36.5 & 11.2 & 3.3 & 48.6 & 57.8 & 19.5 \\
\hline $25-29$ & 41.8 & 42.9 & 13.1 & 2.3 & 44.5 & 49.1 & 13.4 \\
\hline $30+$ & 44.4 & 46.0 & 6.3 & 3.3 & 49.5 & 46.9 & 16.2 \\
\hline \multicolumn{8}{|l|}{ Urban-rural residence } \\
\hline Urban & 48.7 & 39.8 & 6.1 & 5.4 & 49.5 & 61.5 & 24.7 \\
\hline Rural & 45.0 & 39.5 & 13.2 & 2.3 & 47.4 & 52.3 & 14.9 \\
\hline Informal urban areas & 43.7 & 47.0 & 6.2 & 3.1 & 43.8 & 48.9 & 14.9 \\
\hline \multicolumn{8}{|l|}{ Region } \\
\hline Urban Governorates & 49.1 & 40.4 & 1.8 & 8.8 & 53.7 & 65.7 & 30.3 \\
\hline Urban Lower Egypt & 53.9 & 35.6 & 8.6 & 1.9 & 51.4 & 43.5 & 17.9 \\
\hline Rural Lower Egypt & 51.5 & 36.3 & 9.7 & 2.5 & 51.9 & 49.6 & 14.1 \\
\hline Urban Upper Egypt & 35.2 & 52.5 & 11.3 & 1.0 & 31.3 & 68.0 & 11.9 \\
\hline Rural Upper Egypt & 36.5 & 43.9 & 17.5 & 2.1 & 42.0 & 56.7 & 15.7 \\
\hline Frontier Governorates & 62.7 & 27.8 & 7.0 & 2.5 & 57.3 & 44.4 & 18.4 \\
\hline \multicolumn{8}{|l|}{ Mother's education } \\
\hline Illiterate & 41.4 & 44.0 & 12.2 & 2.4 & 44.4 & 50.8 & 15.6 \\
\hline Can read and write & 54.7 & 36.9 & 6.1 & 2.3 & 52.3 & 52.6 & 14.0 \\
\hline Primary & 48.1 & 37.6 & 10.4 & 3.9 & 53.9 & 53.6 & 18.0 \\
\hline Preparatory & 60.2 & 29.1 & 7.1 & 3.7 & 53.3 & 69.9 & 26.8 \\
\hline General secondary & 43.7 & 41.8 & 11.6 & 2.9 & 34.8 & 59.3 & 16.3 \\
\hline $\begin{array}{l}\text { Vocational secondary and post- } \\
\text { secondary }\end{array}$ & 57.4 & 30.3 & 6.0 & 6.3 & 54.3 & 66.2 & 24.1 \\
\hline Higher education & 55.1 & 25.6 & 7.9 & 11.5 & 61.0 & 56.0 & 31.8 \\
\hline \multicolumn{8}{|l|}{ Father's education } \\
\hline Illiterate & 39.7 & 46.2 & 11.8 & 2.3 & 43.2 & 50.5 & 13.9 \\
\hline Can read and write & 43.9 & 41.1 & 12.8 & 2.2 & 48.1 & 51.5 & 15.1 \\
\hline Primary & 50.8 & 34.4 & 10.8 & 4.1 & 51.0 & 57.4 & 19.8 \\
\hline Preparatory & 51.3 & 35.0 & 10.3 & 3.5 & 47.0 & 56.7 & 16.5 \\
\hline General secondary & 48.8 & 34.6 & 9.6 & 6.9 & 56.5 & 51.4 & 27.8 \\
\hline $\begin{array}{l}\text { Vocational secondary and post- } \\
\text { secondary }\end{array}$ & 53.1 & 36.4 & 6.7 & 3.8 & 52.9 & 60.0 & 22.4 \\
\hline Higher education & 53.8 & 28.9 & 9.3 & 8.1 & 55.4 & 59.5 & 30.9 \\
\hline \multicolumn{8}{|l|}{ Currently employed } \\
\hline No & 41.0 & 47.6 & 8.3 & 3.0 & 44.0 & 55.1 & 17.5 \\
\hline Yes & 53.3 & 29.0 & 14.2 & 3.4 & 53.2 & 53.9 & 17.3 \\
\hline Total & 45.9 & 40.3 & 10.6 & 3.2 & 47.6 & 54.5 & 17.5 \\
\hline$(\mathrm{N})$ & $(4,342)$ & $(4,342)$ & $(4,342)$ & $(4,342)$ & $(4,342)$ & $(2,151)$ & $(4,342)$ \\
\hline
\end{tabular}

Note: Based on all youth who ever attended vocational secondary. 
TABLE A3.15 Characteristics and youth's experiences in higher education, by background characteristics, 2014, percent

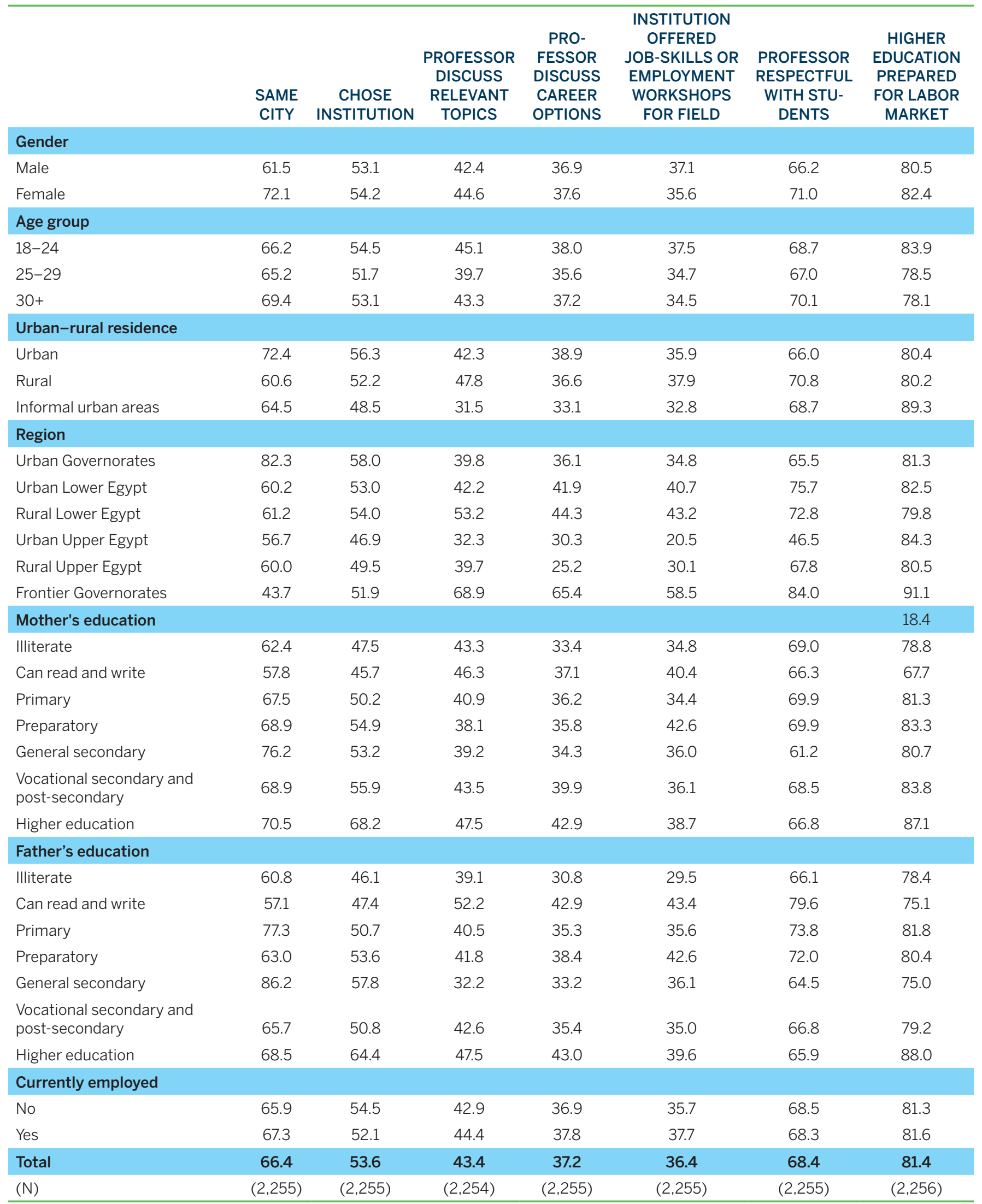

Notes: Age group $<18$ omitted due to small sample size. Based on all youth who ever attended higher education. 
TABLE A4.1 Labor force participation, unemployment and employment, by main background characteristics, youth aged 15-35, 2014 (\%)

\begin{tabular}{|c|c|c|c|c|c|c|c|c|c|}
\hline & \multicolumn{3}{|c|}{$\begin{array}{l}\text { LABOR FORCE } \\
\text { PARTICIPATION }\end{array}$} & \multicolumn{3}{|c|}{$\begin{array}{c}\text { UNEMPLOYMENT } \\
\text { (STANDARD DEFINITION) }\end{array}$} & \multicolumn{3}{|c|}{ EMPLOYMENT } \\
\hline & MALE & FEMALE & TOTAL & MALE & FEMALE & TOTAL & MALE & FEMALE & TOTAL \\
\hline \multicolumn{10}{|l|}{ Age group } \\
\hline $15-17$ & 21.2 & 2.7 & 12.0 & 4.4 & 7.1 & 4.7 & 20.3 & 2.5 & 11.5 \\
\hline $18-24$ & 55.0 & 13.6 & 35.8 & 12.3 & 34.3 & 16.2 & 48.2 & 8.9 & 30.0 \\
\hline $25-29$ & 90.2 & 21.0 & 56.3 & 7.0 & 32.7 & 11.7 & 83.9 & 14.1 & 49.7 \\
\hline $30+$ & 95.1 & 21.9 & 56.4 & 3.7 & 22.1 & 7.5 & 91.6 & 17.0 & 52.2 \\
\hline \multicolumn{10}{|l|}{ Urban-rural residence } \\
\hline Urban & 63.5 & 18.6 & 42.1 & 9.8 & 24.7 & 12.9 & 57.3 & 14.0 & 36.7 \\
\hline Rural & 65.0 & 13.8 & 40.0 & 7.5 & 31.9 & 11.6 & 60.1 & 9.4 & 35.3 \\
\hline Informal urban areas & 56.6 & 11.3 & 33.7 & 5.4 & 33.8 & 10.1 & 53.6 & 7.5 & 30.3 \\
\hline \multicolumn{10}{|l|}{ Region } \\
\hline Urban Governorates & 65.4 & 21.2 & 44.5 & 10.3 & 21.8 & 12.9 & 58.7 & 16.5 & 38.8 \\
\hline Urban Lower Egypt & 56.9 & 14.5 & 35.8 & 9.4 & 31.0 & 13.8 & 51.6 & 10.0 & 30.9 \\
\hline Rural Lower Egypt & 63.8 & 14.6 & 40.6 & 9.7 & 38.4 & 14.6 & 57.6 & 9.0 & 34.7 \\
\hline Urban Upper Egypt & 60.2 & 10.0 & 36.0 & 4.0 & 34.2 & 8.1 & 57.8 & 6.6 & 33.0 \\
\hline Rural Upper Egypt & 66.1 & 13.1 & 39.2 & 5.1 & 25.0 & 8.5 & 62.8 & 9.8 & 35.9 \\
\hline Frontier Governorates & 67.0 & 10.1 & 39.4 & 7.3 & 39.6 & 11.3 & 62.1 & 6.1 & 35.0 \\
\hline \multicolumn{10}{|l|}{ Education level } \\
\hline Illiterate & 80.2 & 9.3 & 31.7 & 2.4 & 2.9 & 2.5 & 78.3 & 9.0 & 30.9 \\
\hline Can read and write & 94.7 & 9.0 & 40.5 & 1.9 & 0.0 & 1.7 & 92.9 & 9.0 & 39.9 \\
\hline Primary & 86.8 & 13.5 & 55.1 & 5.3 & 21.0 & 7.0 & 82.2 & 10.6 & 51.3 \\
\hline Preparatory & 62.5 & 8.2 & 33.4 & 5.7 & 11.5 & 6.5 & 59.0 & 7.2 & 31.3 \\
\hline General secondary & 19.8 & 2.3 & 10.6 & 7.5 & 24.1 & 9.4 & 18.3 & 1.8 & 9.6 \\
\hline Vocational secondary & 68.1 & 13.8 & 44.2 & 7.3 & 37.7 & 11.5 & 63.1 & 8.6 & 39.1 \\
\hline Post-secondary institute & 65.9 & 31.7 & 51.3 & 11.6 & 46.6 & 20.8 & 58.3 & 16.9 & 40.6 \\
\hline University and above & 57.0 & 29.5 & 44.2 & 14.3 & 31.0 & 19.5 & 48.8 & 20.4 & 35.6 \\
\hline \multicolumn{10}{|l|}{ Marital status } \\
\hline Never married & 53.2 & 15.2 & 38.2 & 10.9 & 31.5 & 14.2 & 47.4 & 10.4 & 32.8 \\
\hline Married & 95.6 & 14.6 & 43.1 & 3.1 & 27.4 & 8.4 & 92.6 & 10.6 & 39.5 \\
\hline \multicolumn{10}{|l|}{ Wealth quintiles } \\
\hline Lowest & 68.7 & 13.0 & 40.7 & 6.2 & 22.7 & 8.8 & 64.4 & 10.0 & 37.1 \\
\hline Second & 68.1 & 13.8 & 41.5 & 5.5 & 24.4 & 8.6 & 64.4 & 10.5 & 38.0 \\
\hline Middle & 65.1 & 12.7 & 39.2 & 9.1 & 27.5 & 12.0 & 59.2 & 9.2 & 34.5 \\
\hline Fourth & 61.5 & 14.3 & 39.1 & 8.8 & 41.2 & 14.4 & 56.1 & 8.4 & 33.5 \\
\hline Highest & 57.3 & 19.8 & 39.5 & 10.6 & 30.1 & 15.2 & 51.2 & 13.8 & 33.5 \\
\hline Total & 63.7 & 14.9 & 40.0 & 8.0 & 29.5 & 11.9 & 58.6 & 10.5 & 35.2 \\
\hline$(N)$ & $(4,941)$ & $(5,680)$ & $(10,621)$ & $(4,941)$ & $(5,680)$ & $(10,621)$ & $(4,941)$ & $(5,680)$ & $(10,621)$ \\
\hline
\end{tabular}


TABLE A4.2 Percentage of young people aged 15-29 reporting specific working conditions, by gender and public/private sector, 2014

\begin{tabular}{|c|c|c|c|c|c|c|}
\hline & & LE & FEN & ALE & TOT & \\
\hline & PUBLIC & PRIVATE & PUBLIC & PRIVATE & PUBLIC & PRIVATE \\
\hline $\begin{array}{l}\text { Do you experience any of the } \\
\text { following in your work? }\end{array}$ & & & & & & \\
\hline Harsh treatment from supervisor(s) & 6.5 & 11.8 & 6.0 & 9.7 & 6.3 & 11.6 \\
\hline Long working hours & 14.8 & 29.2 & 6.9 & 21.7 & 12.4 & 28.3 \\
\hline Low wage & 30.2 & 38.0 & 19.9 & 35.2 & 27.1 & 37.7 \\
\hline No annual paid leave & 6.0 & 25.3 & 4.6 & 16.3 & 5.5 & 24.1 \\
\hline No paid sick leave & 4.3 & 26.0 & 4.8 & 19.2 & 4.4 & 25.2 \\
\hline No paid maternity leave & 7.6 & 7.9 & 4.8 & 10.9 & 6.1 & 8.8 \\
\hline Exhaustive workload & 20.0 & 29.1 & 11.4 & 29.5 & 17.4 & 29.1 \\
\hline Long commute time & 14.4 & 12.8 & 10.2 & 11.6 & 13.1 & 12.6 \\
\hline Annoyances from colleagues/supervisor & 7.5 & 7.5 & 3.9 & 8.9 & 6.4 & 7.7 \\
\hline Harassment from colleagues/supervisor & 0.0 & 3.9 & 0.0 & 0.0 & 0.0 & 2.6 \\
\hline Annoyances from customers/clients & 6.4 & 12.4 & 1.2 & 10.5 & 4.7 & 12.2 \\
\hline Harassment from customers/clients & 4.2 & 3.6 & 0.0 & 0.4 & 1.9 & 2.6 \\
\hline Hazardous work conditions & 10.4 & 14.3 & 1.1 & 3.5 & 7.5 & 13.0 \\
\hline Harassment during commute & 0.9 & 2.1 & 1.3 & 3.8 & 1.1 & 2.6 \\
\hline Wage not paid after finishing a task & 2.0 & 6.0 & 0.0 & 3.3 & 1.4 & 5.7 \\
\hline Wage not specified at the beginning of job & 1.4 & 6.0 & 0.8 & 2.7 & 1.2 & 5.7 \\
\hline Others & 1.6 & 2.9 & 0.0 & 2.7 & 1.2 & 2.9 \\
\hline$(N)$ & $(236)$ & $(1,849)$ & $(125)$ & $(237)$ & $(361)$ & $(2,086)$ \\
\hline
\end{tabular}

TABLE A4.3 Young people's methods of job search: Percent reporting that they used the method, broad definition of unemployment, youth aged 15-29, 2009 and 2014

\begin{tabular}{|c|c|c|c|c|c|c|}
\hline & \multicolumn{3}{|c|}{2009} & \multicolumn{3}{|c|}{2014} \\
\hline & MALE & FEMALE & TOTAL & MALE & FEMALE & TOTAL \\
\hline Registered in a private office & 7.6 & 6.2 & 7.1 & 23.8 & 15.0 & 19.9 \\
\hline Registered in a government office & 9.4 & 20.5 & 13.8 & 28.9 & 31.2 & 29.9 \\
\hline Entered a government job competition & 9.4 & 28.5 & 17.0 & 16.0 & 18.4 & 17.0 \\
\hline Sent job application & 26.5 & 24.4 & 25.6 & 16.7 & 20.2 & 18.2 \\
\hline Inquired at work location & 22.8 & 8.4 & 17.1 & 14.8 & 12.8 & 13.9 \\
\hline Advertised in newspapers & 0.8 & 1.0 & 0.9 & 3.4 & 3.2 & 3.3 \\
\hline Applied to job advertised in newspapers & 11.4 & 6.2 & 9.3 & a & a & a \\
\hline Applied to job advertised in newspapers/on the internet & a & a & a & 12.7 & 11.4 & 12.1 \\
\hline Registered online in an employment office & - & - & - & 5.6 & 4.3 & 5.0 \\
\hline Asked friends or relatives for help & 40.6 & 21.0 & 32.8 & 32.9 & 24.6 & 29.2 \\
\hline Contacted employer & 17.7 & 4.3 & 12.4 & 16.0 & 6.2 & 11.6 \\
\hline Contacted contractor & 4.1 & 0 & 2.5 & 9.2 & 0.0 & 5.2 \\
\hline Waited at worker gathering locations & 2.7 & 0 & 1.6 & 4.6 & 0.0 & 2.6 \\
\hline Searched for private project (land, equipment) & 1.6 & 0.6 & 1.2 & 3.8 & 0.0 & 2.1 \\
\hline Arranged to get financing for private project & 0.7 & 1.1 & 0.8 & 2.3 & 0.0 & 1.3 \\
\hline Used land line in any of above methods & 47.0 & 24.1 & 38.9 & 8.5 & 6.4 & 7.5 \\
\hline Used mobile phone in any of above methods & 45.1 & 20.4 & 36.3 & 33.5 & 15.9 & 25.7 \\
\hline$(\mathrm{N})$ & $(381)$ & $(330)$ & $(711)$ & (331) & $(300)$ & (631) \\
\hline
\end{tabular}

a "On the internet" was added to this question for SYPE 2014.

$-=$ Response option was not available in survey year. 
TABLE A5.1 Long-term migration aspiration rates among youth aged 13-35, 2009 and 2014, percent

\begin{tabular}{|c|c|c|c|c|c|c|c|c|c|}
\hline & \multicolumn{3}{|c|}{ 13-35 YEARS (2014) } & \multicolumn{3}{|c|}{ 15-29 YEARS (2014) } & \multicolumn{3}{|c|}{ 15-29 YEARS (2009) } \\
\hline & MALE & FEMALE & TOTAL & MALE & FEMALE & TOTAL & MALE & FEMALE & TOTAL \\
\hline \multicolumn{10}{|l|}{ Age group } \\
\hline $13-17$ & 19.2 & 6.8 & 13.0 & - & - & - & - & - & - \\
\hline $15-17$ & - & - & - & 20.1 & 7.4 & 13.8 & 33.3 & 9.5 & 21.6 \\
\hline $18-24$ & 28.1 & 8.4 & 19.0 & 28.1 & 8.4 & 19.0 & 29.3 & 6.9 & 18.7 \\
\hline $25-29$ & 25.7 & 7.0 & 16.6 & 25.7 & 7.0 & 16.6 & 25.8 & 4.7 & 14.6 \\
\hline $30-34$ & 20.0 & 6.9 & 13.1 & - & - & - & - & - & - \\
\hline \multicolumn{10}{|l|}{ Urban-rural residence } \\
\hline Urban & 22.9 & 7.7 & 15.7 & 23.3 & 8.1 & 16.2 & 25.4 & 8.9 & 17.3 \\
\hline Rural & 26.6 & 7.0 & 16.9 & 28.3 & 7.3 & 18.3 & 30.7 & 5.3 & 18.2 \\
\hline Informal urban areas & 16.7 & 9.9 & 13.3 & 16.2 & 9.7 & 12.9 & 34.7 & 9.7 & 22.0 \\
\hline \multicolumn{10}{|l|}{ Region } \\
\hline Urban Governorates & 22.0 & 9.8 & 16.2 & 22.3 & 10.2 & 16.6 & 24.3 & 8.9 & 16.9 \\
\hline Urban Lower Egypt & 23.5 & 10.0 & 16.8 & 22.5 & 9.9 & 16.3 & 31.5 & 7.9 & 19.4 \\
\hline Rural Lower Egypt & 28.2 & 5.0 & 17.1 & 30.0 & 5.7 & 18.9 & 30.6 & 5.1 & 18.2 \\
\hline Urban Upper Egypt & 18.0 & 2.6 & 10.5 & 20.2 & 3.2 & 12.0 & 32.1 & 11.7 & 21.8 \\
\hline Rural Upper Egypt & 24.8 & 9.0 & 16.8 & 26.6 & 8.8 & 17.8 & 31.3 & 5.6 & 18.5 \\
\hline Frontier Governorates & 20.2 & 6.0 & 13.3 & 18.5 & 7.2 & 13.0 & 17.5 & 4.5 & 11.2 \\
\hline \multicolumn{10}{|l|}{ Education level } \\
\hline Illiterate & 16.5 & 4.0 & 8.0 & 17.2 & 3.3 & 8.1 & 21.0 & 1.2 & 5.6 \\
\hline Can read and write & 7.1 & 3.3 & 4.7 & 3.5 & 0.6 & 1.7 & 10.9 & 0.0 & 4.8 \\
\hline Primary & 23.4 & 4.9 & 15.3 & 25.8 & 5.3 & 17.2 & 24.4 & 5.3 & 15.6 \\
\hline Preparatory & 21.5 & 4.8 & 12.5 & 24.3 & 4.1 & 13.5 & 29.8 & 6.8 & 19.3 \\
\hline General secondary & 23.2 & 9.6 & 16.1 & 22.2 & 10.0 & 15.8 & 29.1 & 13.4 & 22.1 \\
\hline Vocational secondary & 25.1 & 5.9 & 16.6 & 26.5 & 6.0 & 17.7 & 31.9 & 5.8 & 19.6 \\
\hline Post-secondary institute & 19.6 & 7.8 & 14.5 & 20.0 & 8.2 & 15.0 & 28.4 & 9.9 & 19.9 \\
\hline University and above & 30.0 & 15.2 & 23.1 & 30.3 & 15.6 & 23.4 & 32.5 & 12.4 & 22.5 \\
\hline \multicolumn{10}{|l|}{ Marital status } \\
\hline Never married & 25.1 & 8.3 & 18.3 & 25.5 & 8.5 & 18.8 & 30.9 & 8.9 & 22.3 \\
\hline Ever married & 22.8 & 6.6 & 12.3 & 26.8 & 6.7 & 12.7 & 19.4 & 4.1 & 7.9 \\
\hline \multicolumn{10}{|l|}{ Wealth quintile } \\
\hline Lowest & 18.7 & 3.6 & 11.1 & 20.1 & 3.6 & 12.2 & 30.4 & 3.6 & 17.0 \\
\hline Second & 21.8 & 6.2 & 14.1 & 23.8 & 5.9 & 15.2 & 25.9 & 5.3 & 15.8 \\
\hline Middle & 25.4 & 8.6 & 17.0 & 26.4 & 8.7 & 17.6 & 30.8 & 5.3 & 18.8 \\
\hline Fourth & 25.1 & 8.0 & 17.0 & 25.8 & 8.4 & 17.9 & 31.1 & 8.9 & 20.2 \\
\hline Highest & 30.1 & 10.6 & 20.8 & 30.9 & 11.4 & 21.7 & 28.4 & 11.8 & 19.9 \\
\hline \multicolumn{10}{|l|}{ Employment status } \\
\hline Employment & 24.7 & 10.3 & 22.6 & 26.6 & 11.3 & 24.6 & 28.2 & 10.0 & 25.6 \\
\hline Unemployment & 39.9 & 10.2 & 27.3 & 39.5 & 9.4 & 27.4 & 37.2 & 15.6 & 29.4 \\
\hline Nonstudent out of labor force & 22.3 & 7.0 & 11.8 & 22.9 & 7.4 & 12.8 & 34.4 & 3.6 & 8.1 \\
\hline Student out of labor force & 21.0 & 10.2 & 15.7 & 21.7 & 11.0 & 16.5 & 30.0 & 12.4 & 22.2 \\
\hline Total & 24.5 & 7.5 & 16.2 & 25.8 & 7.8 & 17.2 & 29.4 & 6.9 & 18.3 \\
\hline$(\mathrm{N})$ & $(5,073)$ & $(5,843)$ & $(10,916)$ & $(4,147)$ & $(4,476)$ & $(8,623)$ & $(5,513)$ & $(5,328)$ & $(10,841)$ \\
\hline
\end{tabular}


TABLE A5.2 Short-term migration aspiration rates among youth aged 15-29, 2014, percent

\begin{tabular}{|c|c|c|c|c|c|c|c|c|c|}
\hline & \multicolumn{3}{|c|}{ MALES } & \multicolumn{3}{|c|}{ FEMALES } & \multicolumn{3}{|c|}{ TOTAL } \\
\hline & $\begin{array}{l}\text { ARAB } \\
\text { COUN- } \\
\text { TRIES }\end{array}$ & $\begin{array}{c}\text { WESTERN } \\
\text { COUN- } \\
\text { TRIES }\end{array}$ & $\begin{array}{c}\text { ANY } \\
\text { DESTINA- } \\
\text { TION }\end{array}$ & $\begin{array}{l}\text { ARAB } \\
\text { COUN- } \\
\text { TRIES }\end{array}$ & $\begin{array}{c}\text { WESTERN } \\
\text { COUN- } \\
\text { TRIES }\end{array}$ & $\begin{array}{c}\text { ANY } \\
\text { DESTINA- } \\
\text { TION }\end{array}$ & $\begin{array}{l}\text { ARAB } \\
\text { COUN- } \\
\text { TRIES }\end{array}$ & $\begin{array}{l}\text { WESTERN } \\
\text { COUN- } \\
\text { TRIES }\end{array}$ & $\begin{array}{c}\text { ANY } \\
\text { DESTINA- } \\
\text { TION }\end{array}$ \\
\hline \multicolumn{10}{|l|}{ Age group } \\
\hline 15-17 & 5.2 & 2.1 & 7.5 & 2.1 & 2.2 & 4.6 & 3.6 & 2.1 & 6.0 \\
\hline $18-24$ & 12.5 & 2.0 & 14.6 & 2.9 & 1.5 & 4.5 & 8.1 & 1.7 & 10.0 \\
\hline $25-29$ & 13.6 & 1.0 & 15.0 & 2.4 & 0.4 & 2.8 & 8.2 & 0.7 & 9.1 \\
\hline \multicolumn{10}{|l|}{ Urban-rural residence } \\
\hline Urban & 10.1 & 2.8 & 13.3 & 3.8 & 2.5 & 6.5 & 7.1 & 2.7 & 10.1 \\
\hline Rural & 12.4 & 1.3 & 13.7 & 2.2 & 0.8 & 3.1 & 7.5 & 1.1 & 8.7 \\
\hline Informal urban areas & 7.9 & 1.2 & 9.7 & 1.6 & 0.6 & 2.6 & 4.7 & 0.9 & 6.0 \\
\hline \multicolumn{10}{|l|}{ Region } \\
\hline Urban Governorates & 9.9 & 3.3 & 13.6 & 5.0 & 3.1 & 8.7 & 7.6 & 3.2 & 11.3 \\
\hline Urban Lower Egypt & 9.9 & 2.4 & 13.1 & 1.5 & 1.1 & 2.6 & 5.7 & 1.7 & 7.9 \\
\hline Rural Lower Egypt & 13.4 & 1.7 & 15.1 & 2.0 & 0.7 & 2.6 & 8.1 & 1.2 & 9.4 \\
\hline Urban Upper Egypt & 9.2 & 0.8 & 10.1 & 2.0 & 1.3 & 3.3 & 5.7 & 1.1 & 6.8 \\
\hline Rural Upper Egypt & 11.5 & 0.8 & 12.5 & 2.5 & 1.0 & 3.6 & 7.0 & 0.9 & 8.1 \\
\hline Frontier Governorates & 3.5 & 0.3 & 4.3 & 1.2 & 0.0 & 1.2 & 2.4 & 0.1 & 2.8 \\
\hline \multicolumn{10}{|l|}{ Education level } \\
\hline Illiterate & 6.8 & 0.4 & 7.2 & 1.1 & 0.0 & 1.1 & 3.1 & 0.1 & 3.3 \\
\hline Can read and write & 12.0 & 0.0 & 12.0 & 1.4 & 0.0 & 1.4 & 5.6 & 0.0 & 5.6 \\
\hline Primary & 15.2 & 0.7 & 16.3 & 0.0 & 0.0 & 0.0 & 8.8 & 0.4 & 9.4 \\
\hline Preparatory & 7.7 & 1.7 & 9.8 & 0.9 & 0.0 & 1.0 & 4.0 & 0.8 & 5.1 \\
\hline General secondary & 7.1 & 2.2 & 9.7 & 2.1 & 3.8 & 6.6 & 4.5 & 3.0 & 8.1 \\
\hline Vocational secondary & 12.7 & 1.2 & 13.9 & 1.8 & 0.6 & 2.5 & 8.0 & 1.0 & 9.0 \\
\hline Post-secondary institute & 14.1 & 2.1 & 16.2 & 7.1 & 2.7 & 9.8 & 11.1 & 2.4 & 13.5 \\
\hline University and above & 11.4 & 3.2 & 15.0 & 6.3 & 3.0 & 9.4 & 9.0 & 3.1 & 12.4 \\
\hline \multicolumn{10}{|l|}{ Marital status } \\
\hline Never married & 10.6 & 1.9 & 12.8 & 2.9 & 1.9 & 5.0 & 7.5 & 1.9 & 9.7 \\
\hline Ever married & 14.9 & 0.4 & 15.8 & 2.1 & 0.4 & 2.5 & 5.9 & 0.4 & 6.5 \\
\hline \multicolumn{10}{|l|}{ Wealth quantile } \\
\hline Lowest & 10.8 & 0.6 & 12.0 & 1.5 & 0.7 & 2.1 & 6.3 & 0.6 & 7.2 \\
\hline Second & 10.5 & 1.2 & 11.9 & 1.7 & 0.9 & 2.8 & 6.3 & 1.0 & 7.5 \\
\hline Middle & 11.4 & 1.7 & 13.1 & 1.8 & 1.0 & 3.1 & 6.6 & 1.4 & 8.1 \\
\hline Fourth & 10.7 & 2.3 & 13.3 & 1.8 & 1.2 & 3.1 & 6.6 & 1.8 & 8.6 \\
\hline Highest & 12.7 & 2.4 & 15.4 & 5.5 & 2.5 & 8.2 & 9.3 & 2.5 & 12.0 \\
\hline \multicolumn{10}{|l|}{ Employment status } \\
\hline Employment & 13.8 & 1.0 & 15.1 & 5.9 & 1.1 & 7.0 & 12.7 & 1.0 & 14.0 \\
\hline Unemployment & 23.4 & 4.1 & 27.9 & 6.8 & 2.4 & 9.2 & 16.8 & 3.4 & 20.4 \\
\hline Nonstudent out of labor force & 6.6 & 2.2 & 9.1 & 2.1 & 1.3 & 3.5 & 3.6 & 1.6 & 5.4 \\
\hline Student out of labor force & 4.4 & 2.8 & 7.4 & 3.9 & 3.2 & 7.4 & 4.2 & 3.0 & 7.4 \\
\hline Total & 11.3 & 1.7 & 13.2 & 2.6 & 1.3 & 4.1 & 7.1 & 1.5 & 8.9 \\
\hline$(\mathrm{N})$ & $(436)$ & $(70)$ & $(516)$ & $(103)$ & $(56)$ & $(165)$ & $(539)$ & $(126)$ & $(681)$ \\
\hline
\end{tabular}


TABLE 5.3 Characteristics of short-term migration aspirers (aged 15-29)*, 2014, percent

\begin{tabular}{|c|c|c|c|c|c|c|}
\hline & \multicolumn{2}{|c|}{ MALES } & \multicolumn{2}{|c|}{ FEMALES } & \multicolumn{2}{|c|}{ TOTAL } \\
\hline & $\begin{array}{c}\text { ARAB } \\
\text { COUNTRIES }\end{array}$ & $\begin{array}{l}\text { WESTERN } \\
\text { COUNTRIES }\end{array}$ & $\begin{array}{c}\text { ARAB } \\
\text { COUNTRIES }\end{array}$ & $\begin{array}{l}\text { WESTERN } \\
\text { COUNTRIES }\end{array}$ & $\begin{array}{c}\text { ARAB } \\
\text { COUNTRIES }\end{array}$ & $\begin{array}{l}\text { WESTERN } \\
\text { COUNTRIES }\end{array}$ \\
\hline \multicolumn{7}{|l|}{ Age group } \\
\hline $15-17$ & 69.4 & 27.8 & 44.5 & 46.9 & 60.0 & 35.0 \\
\hline $18-24$ & 85.4 & 13.4 & 64.9 & 32.6 & 81.1 & 17.5 \\
\hline $25-29$ & 90.6 & 6.5 & 86.4 & 13.6 & 89.9 & 7.6 \\
\hline \multicolumn{7}{|l|}{ Urban-rural residence } \\
\hline Urban & 75.9 & 21.1 & 57.9 & 38.9 & 70.4 & 26.5 \\
\hline Rural & 89.9 & 9.1 & 70.7 & 27.3 & 86.7 & 12.2 \\
\hline Informal urban areas & 81.7 & 12.1 & 61.2 & 22.4 & 77.1 & 14.4 \\
\hline \multicolumn{7}{|l|}{ Region } \\
\hline Urban Governorates & 73.1 & 24.2 & 57.5 & 35.9 & 67.4 & 28.4 \\
\hline Urban Lower Egypt & 75.4 & 18.0 & 58.6 & 41.4 & 72.6 & 21.9 \\
\hline Rural Lower Egypt & 88.2 & 11.4 & 74.2 & 25.8 & 86.4 & 13.2 \\
\hline Urban Upper Egypt & 91.8 & 8.2 & 59.9 & 40.1 & 84.4 & 15.6 \\
\hline Rural Upper Egypt & 92.2 & 6.2 & 68.0 & 28.4 & 86.8 & 11.1 \\
\hline Frontier Governorates & 82.4 & 6.0 & 100.0 & 0.0 & 86.1 & 4.7 \\
\hline \multicolumn{7}{|l|}{ Education level } \\
\hline Illiterate & 94.5 & 5.5 & 100.0 & 0.0 & 95.7 & 4.3 \\
\hline Can read and write & 100.0 & 0.0 & 100.0 & 0.0 & 100.0 & 0.0 \\
\hline Primary & 93.4 & 4.4 & na & na & 93.4 & 4.4 \\
\hline Preparatory & 77.9 & 17.4 & 88.8 & 0.0 & 79.0 & 15.7 \\
\hline General secondary & 72.9 & 22.1 & 31.7 & 58.0 & 55.2 & 37.5 \\
\hline Vocational secondary & 90.9 & 8.7 & 71.9 & 23.6 & 88.6 & 10.5 \\
\hline Post-secondary institute & 86.9 & 13.1 & 72.6 & 27.4 & 82.5 & 17.5 \\
\hline University and above & 75.5 & 21.2 & 67.2 & 32.0 & 72.5 & 25.1 \\
\hline \multicolumn{7}{|l|}{ Marital status } \\
\hline Never married & 83.1 & 15.3 & 58.3 & 38.3 & 78.0 & 20.0 \\
\hline Ever married & 94.2 & 2.5 & 81.8 & 14.3 & 90.8 & 5.7 \\
\hline \multicolumn{7}{|l|}{ Wealth quantile } \\
\hline Lowest & 90.0 & 5.2 & 68.9 & 31.1 & 87.0 & 8.9 \\
\hline Second & 88.4 & 9.9 & 61.2 & 31.7 & 83.5 & 13.9 \\
\hline Middle & 86.8 & 13.2 & 58.6 & 32.6 & 81.4 & 16.9 \\
\hline Fourth & 80.6 & 17.2 & 57.9 & 39.5 & 76.9 & 20.9 \\
\hline Highest & 82.7 & 15.9 & 67.6 & 30.6 & 77.8 & 20.6 \\
\hline \multicolumn{7}{|l|}{ Employment status } \\
\hline Employment & 91.4 & 6.8 & 84.2 & 15.8 & 90.9 & 7.4 \\
\hline Unemployment & 83.9 & 14.7 & 74.3 & 25.7 & 82.1 & 16.7 \\
\hline Nonstudent out of labor force & 72.9 & 24.8 & 58.7 & 36.6 & 66.9 & 29.8 \\
\hline Student out of labor force & 60.0 & 37.9 & 52.2 & 43.6 & 56.2 & 40.7 \\
\hline Total & 85.2 & 12.9 & 64.1 & 32.4 & 80.6 & 17.2 \\
\hline$(\mathrm{N})$ & $(436)$ & $(70)$ & (103) & $(56)$ & $(539)$ & $(126)$ \\
\hline
\end{tabular}

* Respondents (15-29 years) who aspired to migrate in 2014. 
TABLE A5.4 Short-term migration aspiration rates among youth aged 13-35, 2014, percent

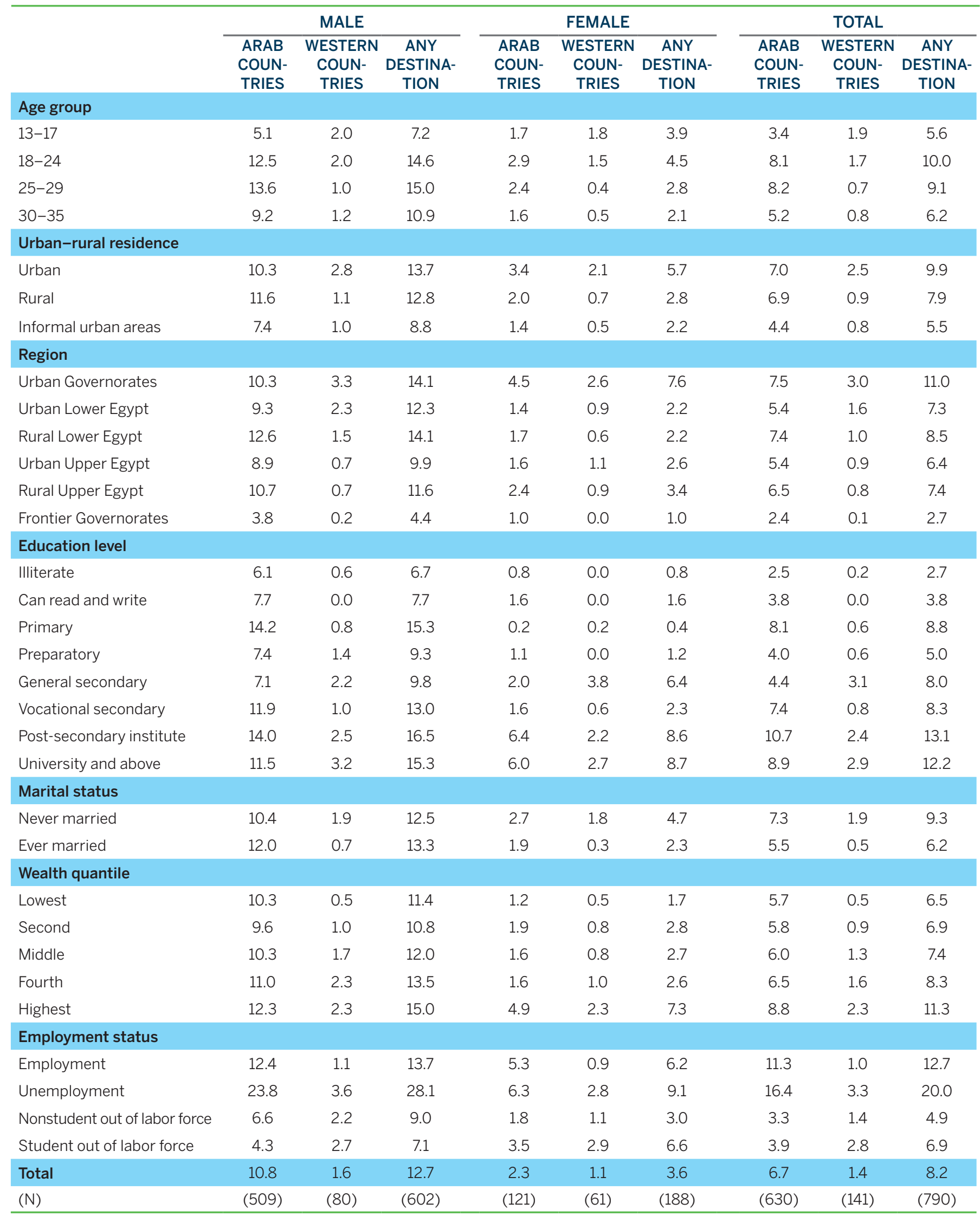


TABLE A5.5 Characteristics of short-term migration aspirers (aged 13-35), 2014, percent

\begin{tabular}{|c|c|c|c|c|c|c|}
\hline & \multicolumn{2}{|c|}{ MALE } & \multicolumn{2}{|c|}{ FEMALE } & \multicolumn{2}{|c|}{ TOTAL } \\
\hline & $\begin{array}{c}\text { ARAB } \\
\text { COUNTRIES }\end{array}$ & $\begin{array}{l}\text { WESTERN } \\
\text { COUNTRIES }\end{array}$ & $\begin{array}{c}\text { ARAB } \\
\text { COUNTRIES }\end{array}$ & $\begin{array}{l}\text { WESTERN } \\
\text { COUNTRIES }\end{array}$ & $\begin{array}{c}\text { ARAB } \\
\text { COUNTRIES }\end{array}$ & $\begin{array}{c}\text { WESTERN } \\
\text { COUNTRIES }\end{array}$ \\
\hline \multicolumn{7}{|l|}{ Age group } \\
\hline $13-17$ & 70.2 & 27.2 & 44.5 & 46.9 & 61.1 & 34.2 \\
\hline $18-24$ & 85.4 & 13.4 & 64.9 & 32.6 & 81.1 & 17.5 \\
\hline $25-29$ & 90.6 & 6.5 & 86.4 & 13.6 & 89.9 & 7.6 \\
\hline $30-35$ & 90.6 & 6.5 & 86.4 & 13.6 & 89.9 & 7.6 \\
\hline \multicolumn{7}{|l|}{ Urban-rural residence } \\
\hline Urban & 75.2 & 20.8 & 59.5 & 37.7 & 70.9 & 25.4 \\
\hline Rural & 90.5 & 8.5 & 71.6 & 26.6 & 87.2 & 11.6 \\
\hline Informal urban areas & 83.2 & 11.7 & 63.6 & 21.0 & 79.2 & 13.6 \\
\hline \multicolumn{7}{|l|}{ Region } \\
\hline Urban Governorates & 73.1 & 23.3 & 59.4 & 34.7 & 68.6 & 27.0 \\
\hline Urban Lower Egypt & 75.3 & 19.0 & 60.9 & 39.1 & 73.2 & 22.0 \\
\hline Rural Lower Egypt & 89.0 & 10.3 & 74.6 & 25.4 & 87.2 & 12.2 \\
\hline Urban Upper Egypt & 90.3 & 6.9 & 59.9 & 40.1 & 84.2 & 13.6 \\
\hline Rural Upper Egypt & 92.4 & 6.1 & 69.5 & 27.5 & 87.1 & 11.1 \\
\hline Frontier Governorates & 86.1 & 4.7 & 100.0 & 0.0 & 88.5 & 3.9 \\
\hline \multicolumn{7}{|l|}{ Education level } \\
\hline Illiterate & 91.8 & 8.2 & 100.0 & 0.0 & 93.5 & 6.5 \\
\hline Can read and write & 100.0 & 0.0 & 100.0 & 0.0 & 100.0 & 0.0 \\
\hline Primary & 92.9 & 5.4 & 41.9 & 58.1 & 91.9 & 6.4 \\
\hline Preparatory & 79.5 & 14.9 & 93.5 & 0.0 & 81.3 & 12.9 \\
\hline General secondary & 72.5 & 22.8 & 31.0 & 58.9 & 55.1 & 38.0 \\
\hline Vocational secondary & 91.5 & 7.9 & 70.4 & 25.6 & 88.9 & 10.0 \\
\hline Post-secondary institute & 84.7 & 15.3 & 74.4 & 25.6 & 81.8 & 18.2 \\
\hline University and above & 75.0 & 21.0 & 68.8 & 30.5 & 73.0 & 24.1 \\
\hline \multicolumn{7}{|l|}{ Marital status } \\
\hline Never married & 83.3 & 15.2 & 58.2 & 38.5 & 78.3 & 19.9 \\
\hline Ever married & 89.9 & 5.6 & 82.5 & 14.6 & 88.1 & 7.7 \\
\hline \multicolumn{7}{|l|}{ Wealth quantile } \\
\hline Lowest & 90.2 & 4.5 & 70.5 & 29.5 & 87.6 & 7.7 \\
\hline Second & 89.0 & 9.5 & 65.6 & 28.8 & 84.3 & 13.4 \\
\hline Middle & 85.9 & 14.1 & 61.3 & 30.4 & 81.5 & 17.1 \\
\hline Fourth & 81.4 & 16.8 & 61.4 & 36.3 & 78.4 & 19.7 \\
\hline Highest & 81.9 & 15.3 & 67.1 & 31.3 & 77.4 & 20.2 \\
\hline \multicolumn{7}{|l|}{ Employment status } \\
\hline Employment & 90.0 & 7.7 & 85.2 & 14.8 & 89.6 & 8.2 \\
\hline Unemployment & 84.9 & 12.8 & 68.8 & 31.2 & 81.7 & 16.4 \\
\hline Nonstudent out of labor force & 73.7 & 24.2 & 60.3 & 35.4 & 68.1 & 28.9 \\
\hline Student out of labor force & 60.2 & 37.8 & 52.2 & 43.6 & 56.4 & 40.5 \\
\hline Total & 85.0 & 12.7 & 65.5 & 31.3 & 80.9 & 16.6 \\
\hline (N) & (509) & (80) & (121) & (61) & (630) & $(141)$ \\
\hline
\end{tabular}


TABLE A5.6 Desired destinations for migration among youth aged 13-35, 2014, percent

\begin{tabular}{|c|c|c|c|c|c|}
\hline & \multicolumn{2}{|c|}{ RESIDENCE } & \multicolumn{2}{|c|}{ GENDER } & \multirow[b]{2}{*}{ TOTAL } \\
\hline & URBAN & RURAL & MALE & FEMALE & \\
\hline Saudi Arabia & 37.6 & 42.1 & 42.7 & 31.1 & 40.2 \\
\hline Kuwait & 14.1 & 20.7 & 19.3 & 13.0 & 17.9 \\
\hline UAE & 11.7 & 7.1 & 8.7 & 10.3 & 9.0 \\
\hline Libya & 2.5 & 9.5 & 8.0 & 1.4 & 6.6 \\
\hline Qatar & 4.1 & 2.5 & 2.7 & 5.0 & 3.2 \\
\hline Jordan & 1.4 & 4.5 & 3.4 & 2.2 & 3.2 \\
\hline Lebanon & 0.7 & 0.1 & 0.0 & 1.7 & 0.4 \\
\hline Europe & 13.3 & 8.3 & 8.1 & 18.7 & 10.4 \\
\hline Australia/Canada/US & 10.6 & 3.6 & 5.1 & 12.1 & 6.6 \\
\hline$(\mathrm{N})$ & (331) & $(459)$ & (623) & (167) & $(790)$ \\
\hline
\end{tabular}

TABLE A5.7 Selected reasons* for migration among youth aged $13-35$, by gender and residence, 2014**, \%

\begin{tabular}{|c|c|c|c|c|c|c|c|c|c|}
\hline & \multicolumn{3}{|c|}{ MALE } & \multicolumn{3}{|c|}{ FEMALE } & \multicolumn{3}{|c|}{ TOTAL } \\
\hline & URBAN & RURAL & TOTAL & URBAN & RURAL & TOTAL & URBAN & RURAL & TOTAL \\
\hline \multicolumn{10}{|l|}{ Push factors } \\
\hline No job opportunities available in Egypt & 62.7 & 67.1 & 65.4 & 45.0 & 46.7 & 45.8 & 58.0 & 63.6 & 61.3 \\
\hline Income in Egypt is lower than abroad & 43.5 & 48.4 & 46.5 & 26.0 & 31.1 & 28.4 & 38.9 & 45.4 & 42.7 \\
\hline Bad living conditions in Egypt & 47.9 & 52.0 & 50.4 & 40.9 & 37.4 & 39.3 & 46.1 & 49.5 & 48.0 \\
\hline To escape from family pressures and troubles & 4.3 & 3.6 & 3.9 & 10.7 & 6.5 & 8.7 & 6.0 & 4.1 & 4.9 \\
\hline Accompany family & 0.0 & 0.8 & 0.5 & 5.1 & 13.3 & 9.1 & 1.4 & 3.0 & 2.3 \\
\hline To help my family & 15.8 & 18.2 & 17.3 & 6.7 & 9.2 & 7.9 & 13.4 & 16.7 & 15.3 \\
\hline Don't know & 0.6 & 0.2 & 0.4 & 7.6 & 1.8 & 4.8 & 2.4 & 0.5 & 1.3 \\
\hline $\begin{array}{l}\text { No opportunities to gain information and } \\
\text { experience }\end{array}$ & 7.9 & 0.8 & 3.6 & 22.8 & 10.0 & 16.7 & 11.9 & 2.4 & 6.4 \\
\hline To earn money & 30.6 & 35.2 & 33.4 & 19.3 & 16.4 & 17.9 & 27.6 & 32.0 & 30.1 \\
\hline Political and security circumstances in Egypt & 8.5 & 9.5 & 9.1 & 12.0 & 12.4 & 12.2 & 9.5 & 10.0 & 9.8 \\
\hline Other & 1.0 & 0.6 & 0.7 & 7.1 & 7.6 & 7.4 & 2.6 & 1.8 & 2.1 \\
\hline$(\mathrm{N})$ & (244) & (379) & (623) & (87) & $(80)$ & (167) & (331) & (459) & (790) \\
\hline \multicolumn{10}{|l|}{ Pull factors } \\
\hline I want to see other countries & 9.1 & 7.9 & 8.3 & 34.1 & 17.8 & 26.3 & 15.7 & 9.6 & 12.1 \\
\hline I want to live abroad & 8.9 & 5.6 & 6.9 & 12.8 & 9.7 & 11.3 & 9.9 & 6.3 & 7.8 \\
\hline I have relatives/friends there & 5.4 & 6.3 & 5.9 & 8.5 & 10.8 & 9.6 & 6.2 & 7.1 & 6.7 \\
\hline I have a job offer there & 6.7 & 5.7 & 6.1 & 5.4 & 0.0 & 2.8 & 6.3 & 4.7 & 5.4 \\
\hline I can study there & 6.8 & 1.7 & 3.7 & 29.3 & 23.3 & 26.4 & 12.7 & 5.4 & 8.5 \\
\hline Higher income abroad than in Egypt & 73.9 & 76.0 & 75.2 & 46.7 & 50.8 & 48.7 & 66.7 & 71.6 & 69.6 \\
\hline To save money for marriage & 38.5 & 49.2 & 45.0 & 5.5 & 6.7 & 6.1 & 29.8 & 41.8 & 36.8 \\
\hline To improve my knowledge & 11.4 & 3.4 & 6.6 & 23.2 & 21.1 & 22.2 & 14.5 & 6.5 & 9.9 \\
\hline Family reunion & 1.8 & 0.8 & 1.2 & 4.5 & 10.4 & 7.4 & 2.5 & 2.4 & 2.5 \\
\hline Other & 2.3 & 2.0 & 2.1 & 2.5 & 2.0 & 2.2 & 2.4 & 2.0 & 2.2 \\
\hline (N) & (244) & (379) & (623) & (87) & $(80)$ & (167) & (331) & (459) & (790) \\
\hline
\end{tabular}

*Multiple answers allowed.

**only respondents (13-35 years) who aspired to migrate. 
TABLE A5.8 Quality of life in Egypt and migration aspirations by gender among youth aged 13-35, 2014, percent

\begin{tabular}{|c|c|c|c|c|c|c|}
\hline & \multicolumn{3}{|c|}{ SHORT-TERM ASPIRATION RATES } & \multicolumn{3}{|c|}{ LONG-TERM ASPIRATION RATES } \\
\hline & MALE & FEMALE & TOTAL & MALE & FEMALE & TOTAL \\
\hline \multicolumn{7}{|c|}{ Household owns agricultural land (in rural areas) } \\
\hline Yes & 10.0 & 2.9 & 6.9 & 27.0 & 10.5 & 19.9 \\
\hline No & 14.0 & 2.8 & 8.2 & 26.4 & 6.0 & 15.9 \\
\hline$(\mathrm{N})$ in rural areas & $(3,301)$ & $(3,195)$ & $(6,496)$ & $(3,301)$ & $(3,195)$ & $(6,496)$ \\
\hline \multicolumn{7}{|c|}{ Household experiences water shortages } \\
\hline Yes & 15.5 & 3.4 & 9.4 & 29.9 & 5.6 & 17.7 \\
\hline No & 12.2 & 3.6 & 8.0 & 23.6 & 7.9 & 16.0 \\
\hline \multicolumn{7}{|c|}{ Uncertainty about future } \\
\hline 1 (Low) & 10.9 & 2.8 & 7.2 & 17.7 & 3.9 & 11.4 \\
\hline 2 & 10.6 & 1.9 & 6.1 & 23.1 & 7.2 & 14.8 \\
\hline 3 & 11.7 & 3.7 & 7.7 & 23.3 & 7.5 & 15.4 \\
\hline 4 & 13.4 & 4.8 & 9.2 & 28.7 & 9.7 & 19.3 \\
\hline 5 (High) & 17.0 & 3.4 & 10.8 & 28.0 & 7.1 & 18.6 \\
\hline \multicolumn{7}{|c|}{ Do you feel unhappy? } \\
\hline Yes & 25.0 & 6.3 & 14.1 & 31.4 & 6.6 & 16.9 \\
\hline No & 11.6 & 3.2 & 7.6 & 23.9 & 7.6 & 16.1 \\
\hline \multicolumn{7}{|c|}{ Do you find it difficult to enjoy daily activities? } \\
\hline Yes & 19.1 & 6.5 & 11.7 & 32.7 & 9.7 & 19.1 \\
\hline No & 12.1 & 3.1 & 7.8 & 23.8 & 7.2 & 15.9 \\
\hline \multicolumn{7}{|c|}{ Are you unable to play a useful part in life? } \\
\hline Yes & 24.9 & 5.5 & 13.4 & 37.0 & 10.5 & 21.3 \\
\hline No & 12.0 & 3.4 & 7.9 & 23.8 & 7.2 & 15.9 \\
\hline \multicolumn{7}{|c|}{ Do you feel that you are worthless? } \\
\hline Yes & 16.2 & 4.7 & 9.6 & 24.3 & 5.7 & 13.6 \\
\hline No & 12.5 & 3.5 & 8.2 & 24.6 & 7.6 & 16.4 \\
\hline Total & 12.7 & 3.6 & 8.2 & 24.5 & 7.5 & 16.2 \\
\hline$(\mathrm{N})$ & $(5,582)$ & $(5,325)$ & $(10,907)$ & $(5,582)$ & $(5,325)$ & $(10,907)$ \\
\hline
\end{tabular}


TABLE A5.9 Sources of information on destinations among youth aged 13-35, 2014, percent

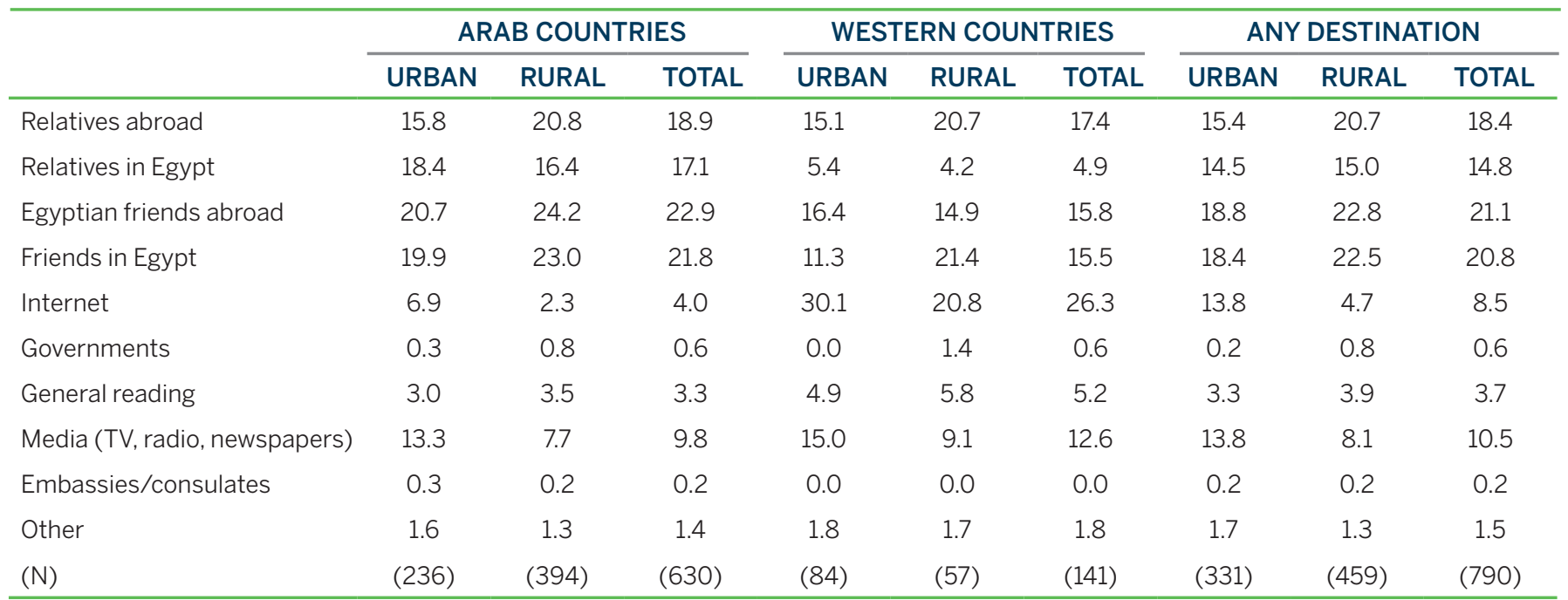

TABLE A5.10 Sources of expected help in migrating among youth aged 13-35, 2014, percent

\begin{tabular}{lccc}
\hline & ARAB COUNTRIES & WESTERN COUNTRIES & ANY DESTINATION \\
\hline Relatives abroad & 26.4 & 29.8 & 26.9 \\
Relatives in Egypt & 50.2 & 56.0 & 51.1 \\
Egyptian friends abroad & 10.4 & 7.2 & 9.9 \\
Friends in Egypt & 6.7 & 3.0 & 6.4 \\
Migration brokers & 2.9 & 0.0 & 2.3 \\
Consulate & 0.3 & 1.3 & 0.5 \\
Other & 3.0 & 2.7 & 2.9 \\
(N) & $(264)$ & $(62)$ & $(330)$ \\
\hline
\end{tabular}


TABLE A5.11 Panel analysis: 2009-2014 by gender, short-term aspirations in 2014*, percent

\begin{tabular}{|c|c|c|c|c|}
\hline & $\begin{array}{c}\text { DID NOT HAVE } \\
\text { SHORT-TERM } \\
\text { ASPIRATIONS IN } 2014\end{array}$ & $\begin{array}{c}\text { HAD SHORT-TERM } \\
\text { ASPIRATIONS IN } \\
2014\end{array}$ & MISSING IN 2014 & $(\mathrm{~N})$ \\
\hline \multicolumn{5}{|l|}{ Total } \\
\hline Aspired to migrate in 2009 & 58.1 & 10.3 & 31.6 & $(1,746)$ \\
\hline Did not aspire to migrate in 2009 & 66.7 & 4.6 & 28.8 & $(9,095)$ \\
\hline (N) & $(7,077)$ & (596) & $(3,168)$ & $(10,841)$ \\
\hline Wanted to go to an Arab country in 2009 & 59.3 & 10.0 & 30.7 & $(1344)$ \\
\hline - Wanted to go to a Western country in 2009 & 53.5 & 11.4 & 35.1 & $(387)$ \\
\hline \multicolumn{5}{|l|}{ Male } \\
\hline Aspired to migrate in 2009 & 58.5 & 12.1 & 29.4 & $(1,352)$ \\
\hline Did not aspire to migrate in 2009 & 62.9 & 9.1 & 28.1 & $(3,464)$ \\
\hline$(\mathrm{N})$ & $(2,968)$ & $(478)$ & $(1,370)$ & $(4,816)$ \\
\hline Wanted to go to an Arab country in 2009 & 59.9 & 11.5 & 28.6 & $(1071)$ \\
\hline - Wanted to go to a Western country in 2009 & 52.6 & 14.6 & 32.9 & (273) \\
\hline \multicolumn{5}{|l|}{ Female } \\
\hline Aspired to migrate in 2009 & 56.6 & 4.3 & 39.1 & (394) \\
\hline Did not aspire to migrate in 2009 & 69.0 & 1.8 & 29.2 & $(5,631)$ \\
\hline$(\mathrm{N})$ & $(4,104)$ & (118) & $(1,798)$ & $(6,025)$ \\
\hline Wanted to go to an Arab country in 2009 & 56.8 & 4.4 & 38.8 & $(274)$ \\
\hline - Wanted to go to a Western country in 2009 & 55.8 & 3.5 & 40.7 & $(113)$ \\
\hline
\end{tabular}

* Youth who were between the ages 15-29 when they were first interviewed in 2009.

TABLE A5.12 The revolution and migration plans in 2014 (youth aged 13-35), percent

\begin{tabular}{|c|c|c|c|c|c|c|c|c|c|}
\hline & \multicolumn{3}{|c|}{ ALL YOUTH } & \multicolumn{3}{|c|}{ LONG-TERM ASPIRERS } & \multicolumn{3}{|c|}{ SHORT-TERM ASPIRERS } \\
\hline & MALE & FEMALE & TOTAL & MALE & FEMALE & TOTAL & MALE & FEMALE & TOTAL \\
\hline \multicolumn{10}{|l|}{$\begin{array}{l}\text { Do you think the revolution } \\
\text { changed your decision with respect } \\
\text { to migration? }\end{array}$} \\
\hline $\begin{array}{l}\text { Yes, I am now starting to think about } \\
\text { migration }\end{array}$ & 2.3 & 1.0 & 1.7 & 7.5 & 3.2 & 6.5 & 13.2 & 10.8 & 12.7 \\
\hline I am thinking more about migration & 3.9 & 1.5 & 2.7 & 11.1 & 5.4 & 9.8 & 20.0 & 11.1 & 18.1 \\
\hline I am thinking less about migration & 2.4 & 1.1 & 1.8 & 5.2 & 3.8 & 4.9 & 6.0 & 6.0 & 6.0 \\
\hline $\begin{array}{l}\text { Yes, I am no longer thinking about } \\
\text { migration }\end{array}$ & 1.9 & 1.2 & 1.6 & 1.3 & 0.7 & 1.1 & 0.1 & 1.8 & 0.5 \\
\hline $\begin{array}{l}\text { No, the revolution has nothing to do with } \\
\text { migration }\end{array}$ & 89.4 & 95.2 & 92.2 & 75.0 & 86.8 & 77.6 & 60.7 & 70.4 & 62.7 \\
\hline (N) & $(5,063)$ & $(5,832)$ & $(10,895)$ & $(1,228)$ & (423) & $(1,651)$ & (602) & (186) & (788) \\
\hline
\end{tabular}


TABLE A5.13 The revolution and short-term migration aspirers (youth aged 13-35)*, 2014, percent

\begin{tabular}{|c|c|c|c|}
\hline & MALE & FEMALE & TOTAL \\
\hline \multicolumn{4}{|c|}{ When did you start thinking about migration? } \\
\hline Before Revolution & 57.9 & 63.6 & 59.1 \\
\hline After Revolution & 42.2 & 36.4 & 40.9 \\
\hline$(\mathrm{N})$ & $(622)$ & $(167)$ & $(789)$ \\
\hline \multicolumn{4}{|c|}{ Have you taken any steps to migrate or is it just an idea? } \\
\hline Yes, I have started to take steps & 11.5 & 6.8 & 10.5 \\
\hline No, I have not started to take steps yet & 29.2 & 19.8 & 27.2 \\
\hline It is just an idea & 59.3 & 73.4 & 62.3 \\
\hline \multicolumn{4}{|c|}{ Has anyone influenced your decision to migrate? } \\
\hline Yes & 18.2 & 15.8 & 17.7 \\
\hline No & 81.8 & 84.2 & 82.3 \\
\hline \multicolumn{4}{|l|}{ Who has most influenced your decision? } \\
\hline My father abroad & 5.8 & 9.6 & 6.5 \\
\hline My mother abroad & 0.0 & 2.4 & 0.4 \\
\hline Other relatives abroad & 29.9 & 10.4 & 26.2 \\
\hline Egyptian friends abroad & 41.9 & 32.2 & 40.1 \\
\hline My father in Egypt & 5.2 & 5.3 & 5.2 \\
\hline My mother in Egypt & 0.7 & 0.0 & 0.6 \\
\hline Other relatives in Egypt & 4.1 & 12.3 & 5.7 \\
\hline Friends in Egypt & 10.4 & 10.6 & 10.5 \\
\hline Foreign spouse & 0.4 & 13.5 & 2.9 \\
\hline Migration brokers & 0.7 & 0.0 & 0.6 \\
\hline Current/ex local employer & 0.9 & 0.0 & 0.7 \\
\hline An educational institution & 0.0 & 3.7 & 0.7 \\
\hline$(\mathrm{N})$ & $(110)$ & $(26)$ & $(136)$ \\
\hline
\end{tabular}

* Only youth who aspired answered. 
TABLE A6.1 Median age at marriage among youth aged 25-29 and 30-35, by background characteristics, 2014

\begin{tabular}{|c|c|c|c|c|c|c|}
\hline & \multicolumn{3}{|c|}{ YOUTH AGED 25-29 } & \multicolumn{3}{|c|}{ YOUTH AGED 30-35 } \\
\hline & MALE & FEMALE & TOTAL & MALE & FEMALE & TOTAL \\
\hline \multicolumn{7}{|l|}{ Region } \\
\hline Urban Governorates & 25 & 21 & 23 & 27 & 21 & 24 \\
\hline Urban Lower Egypt & 25 & 21 & 22 & 26 & 21 & 23 \\
\hline Rural Lower Egypt & 25 & 20 & 22 & 26 & 20 & 22 \\
\hline Urban Upper Egypt & 26 & 21 & 24 & 25 & 21 & 23 \\
\hline Rural Upper Egypt & 24 & 19 & 21 & 25 & 19 & 21 \\
\hline Frontier Governorates & 24 & 20 & 22 & 25 & 21 & 23 \\
\hline \multicolumn{7}{|l|}{ Urban-rural residence } \\
\hline Urban & 25 & 21 & 23 & 27 & 21 & 24 \\
\hline Rural & 24 & 19 & 21 & 25 & 19 & 21 \\
\hline Informal urban areas & 24 & 21 & 22 & 25 & 20 & 23 \\
\hline \multicolumn{7}{|l|}{ Education level } \\
\hline Illiterate & 24 & 18 & 19 & 24 & 19 & 20 \\
\hline Can read and write & 25 & 19 & 20 & 24 & 18 & 18 \\
\hline Primary & 24 & 18 & 21 & 25 & 19 & 21 \\
\hline Preparatory & 24 & 20 & 21 & 22 & 18 & 20 \\
\hline General secondary & 24 & 20 & 22 & 26 & 19 & 24 \\
\hline Vocational secondary & 25 & 20 & 22 & 25 & 20 & 22 \\
\hline Post-secondary institute & 26 & 20 & 23 & 26 & 23 & 24 \\
\hline University and above & 25 & 23 & 24 & 28 & 23 & 26 \\
\hline \multicolumn{7}{|l|}{ Employment status } \\
\hline Employed & 25 & 21 & 24 & 26 & 20 & 25 \\
\hline Unemployed & 25 & 19 & 21 & 29 & 21 & 23 \\
\hline Out of labor force & 25 & 20 & 20 & 25 & 20 & 20 \\
\hline \multicolumn{7}{|l|}{ Wealth quintile } \\
\hline Lowest & 24 & 19 & 20 & 24 & 19 & 20 \\
\hline Second & 24 & 20 & 22 & 25 & 20 & 22 \\
\hline Middle & 25 & 20 & 21 & 25 & 20 & 22 \\
\hline Fourth & 25 & 20 & 23 & 26 & 20 & 22 \\
\hline Highest & 25 & 22 & 24 & 27 & 22 & 24 \\
\hline \multicolumn{7}{|l|}{ Marriage cohort } \\
\hline 2010-2014 & 25 & 23 & 24 & 29 & 28 & 29 \\
\hline 2005-2009 & 22 & 19 & 20 & 25 & 23 & 24 \\
\hline Before 2004 & 19 & 17 & 17 & 21 & 19 & 19 \\
\hline Total & 25 & 20 & 22 & 26 & 20 & 22 \\
\hline$(\mathrm{N})$ & $(555)$ & $(1,176)$ & $(1,731)$ & $(646)$ & $(1,085)$ & $(1,731)$ \\
\hline
\end{tabular}


TABLE A6.2 Prevalence of consanguineous marriage, by background characteristics and marriage cohort, youth aged 13-35, 2014

\begin{tabular}{|c|c|c|c|}
\hline & MALES & FEMALES & TOTAL \\
\hline \multicolumn{4}{|l|}{ Age group } \\
\hline $13-17$ & 0.0 & 37.1 & 36.3 \\
\hline $18-24$ & 34.3 & 28.8 & 29.9 \\
\hline $25-29$ & 23.5 & 27.1 & 25.7 \\
\hline $30+$ & 26.1 & 28.1 & 27.2 \\
\hline \multicolumn{4}{|l|}{ Region } \\
\hline Urban Governorates & 22.5 & 17.8 & 19.7 \\
\hline Urban Lower Egypt & 14.5 & 11.1 & 12.3 \\
\hline Rural Lower Egypt & 16.6 & 18.4 & 17.7 \\
\hline Urban Upper Egypt & 36.3 & 42.9 & 40.1 \\
\hline Rural Upper Egypt & 42.3 & 45.5 & 44.5 \\
\hline Frontier Governorates & 45.6 & 40.3 & 42.5 \\
\hline \multicolumn{4}{|l|}{ Urban-rural residence } \\
\hline Urban & 23.3 & 21.1 & 22.0 \\
\hline Rural & 27.3 & 31.6 & 30.2 \\
\hline Informal urban areas & 25.8 & 20.1 & 22.2 \\
\hline \multicolumn{4}{|l|}{ Education level } \\
\hline Illiterate & 29.0 & 33.0 & 32.2 \\
\hline Can read and write & 42.7 & 41.5 & 41.8 \\
\hline Primary & 32.8 & 31.1 & 31.8 \\
\hline Preparatory & 22.0 & 34.8 & 31.4 \\
\hline General secondary & 22.2 & 21.0 & 21.4 \\
\hline Vocational secondary & 28.7 & 27.6 & 28.0 \\
\hline Post-secondary institute & 27.8 & 17.7 & 22.1 \\
\hline University and above & 16.1 & 17.3 & 16.8 \\
\hline \multicolumn{4}{|l|}{ Employment status } \\
\hline Employed & 25.9 & 31.2 & 26.9 \\
\hline Unemployed & 22.3 & 15.4 & 17.6 \\
\hline Out of labor force & 31.6 & 28.4 & 28.5 \\
\hline \multicolumn{4}{|l|}{ Wealth quintile } \\
\hline Lowest & 33.9 & 37.4 & 36.3 \\
\hline Second & 29.7 & 32.3 & 31.4 \\
\hline Middle & 28.9 & 27.2 & 27.8 \\
\hline Fourth & 23.4 & 25.6 & 24.8 \\
\hline Highest & 18.3 & 19.6 & 19.1 \\
\hline \multicolumn{4}{|l|}{ Marriage cohort } \\
\hline 2010-2014 & 24.2 & 25.6 & 24.9 \\
\hline 2005-2009 & 27.5 & 29.3 & 28.7 \\
\hline Before 2004 & 33.2 & 30.4 & 30.8 \\
\hline Total & 26.1 & 28.3 & 27.4 \\
\hline$(\mathrm{N})$ & $(366)$ & (954) & $(1,320)$ \\
\hline
\end{tabular}


TABLE A6.3 Location of residence at first marriage, by background characteristics and marriage cohort, youth aged $13-35,2014$, percent

\begin{tabular}{|c|c|c|c|c|c|c|c|c|}
\hline & \multicolumn{2}{|c|}{$\begin{array}{c}\text { LIVED WITH OWN } \\
\text { FAMILY }\end{array}$} & \multicolumn{2}{|c|}{$\begin{array}{l}\text { LIVED WITH } \\
\text { SPOUSE'S FAMILY }\end{array}$} & \multicolumn{2}{|c|}{$\begin{array}{c}\text { LIVED WITH } \\
\text { SOMEONE ELSE }\end{array}$} & \multicolumn{2}{|c|}{ LIVED ALONE } \\
\hline & MALE & FEMALE & MALE & FEMALE & MALE & FEMALE & MALE & FEMALE \\
\hline \multicolumn{9}{|l|}{ Age group } \\
\hline $13-17$ & & 4.6 & & 33.1 & & 0.0 & & 62.4 \\
\hline $18-24$ & 34.8 & 2.4 & 9.4 & 30.8 & 0.0 & 0.4 & 55.8 & 66.5 \\
\hline $25-29$ & 35.9 & 3.1 & 11.0 & 33.3 & 0.3 & 0.4 & 52.8 & 63.2 \\
\hline $30-35$ & 28.3 & 1.6 & 12.9 & 32.1 & 0.1 & 0.8 & 58.7 & 65.6 \\
\hline \multicolumn{9}{|l|}{ Region } \\
\hline Urban Governorates & 22.0 & 4.9 & 10.7 & 16.3 & 0.3 & 0.5 & 67.0 & 78.3 \\
\hline Urban Lower Egypt & 13.9 & 0.8 & 11.4 & 11.1 & 0.0 & 0.2 & 74.7 & 87.9 \\
\hline Rural Lower Egypt & 28.7 & 1.8 & 12.1 & 29.6 & 0.4 & 0.8 & 58.8 & 67.8 \\
\hline Urban Upper Egypt & 53.4 & 0.5 & 5.8 & 30.2 & 0.0 & 1.2 & 40.8 & 68.1 \\
\hline Rural Upper Egypt & 43.8 & 2.8 & 14.2 & 49.8 & 0.0 & 0.2 & 42.0 & 47.2 \\
\hline Frontier Governorates & 40.6 & 2.5 & 6.7 & 22.7 & 0.0 & 0.7 & 52.7 & 74.1 \\
\hline \multicolumn{9}{|l|}{ Urban-rural residence } \\
\hline Urban & 29.9 & 3.7 & 10.2 & 20.5 & 0.2 & 0.3 & 59.7 & 75.5 \\
\hline Rural & 35.1 & 2.2 & 12.8 & 39.2 & 0.2 & 0.5 & 51.9 & 58.1 \\
\hline Informal urban areas & 18.7 & 0.6 & 9.0 & 9.2 & 0.0 & 1.0 & 72.3 & 89.2 \\
\hline \multicolumn{9}{|l|}{ Education level } \\
\hline Illiterate & 48.7 & 44.4 & 13.0 & 0.7 & 0.5 & 52.0 & 37.7 & 100.0 \\
\hline Can read and write & 44.2 & 1.2 & 13.3 & 39.8 & 0.0 & 0.0 & 42.6 & 59.1 \\
\hline Primary & 36.3 & 2.4 & 13.7 & 39.0 & 0.0 & 0.7 & 49.9 & 57.9 \\
\hline Preparatory & 29.9 & 3.7 & 13.4 & 42.6 & 0.0 & 0.7 & 56.7 & 53.0 \\
\hline General secondary & 44.9 & 2.2 & 13.5 & 24.7 & 0.0 & 0.0 & 41.6 & 73.1 \\
\hline Vocational secondary & 31.4 & 2.0 & 12.7 & 29.3 & 0.2 & 0.4 & 55.8 & 68.3 \\
\hline Post-secondary institute & 16.3 & 1.5 & 13.3 & 12.5 & 0.0 & 0.0 & 70.5 & 86.0 \\
\hline University and above & 25.9 & 2.0 & 6.5 & 13.0 & 0.4 & 0.4 & 67.2 & 84.7 \\
\hline \multicolumn{9}{|l|}{ Employment status } \\
\hline Employed & 31.0 & 3.2 & 12.0 & 28.7 & 0.1 & 0.5 & 57.0 & 67.7 \\
\hline Unemployed & 53.2 & 1.1 & 4.7 & 26.4 & 4.6 & 0.0 & 37.5 & 72.5 \\
\hline Out of labor force & 40.0 & 2.4 & 11.3 & 32.9 & 0.0 & 0.5 & 48.8 & 64.2 \\
\hline \multicolumn{9}{|l|}{ Wealth quintile } \\
\hline Lowest & 43.5 & 1.9 & 15.2 & 48.6 & 0.3 & 1.1 & 41.0 & 48.4 \\
\hline Second & 44.7 & 3.6 & 11.1 & 37.5 & 0.0 & 0.3 & 44.2 & 58.6 \\
\hline Middle & 30.4 & 2.4 & 12.2 & 31.3 & 0.3 & 0.6 & 57.1 & 65.7 \\
\hline Fourth & 24.7 & 2.2 & 11.6 & 28.2 & 0.4 & 0.2 & 63.3 & 69.4 \\
\hline Highest & 22.5 & 1.9 & 9.7 & 17.8 & 0.0 & 0.3 & 67.8 & 80.1 \\
\hline Total & 32.1 & 2.4 & 11.7 & 32.2 & 0.2 & 0.5 & 56.0 & 64.9 \\
\hline$(N)$ & $(370)$ & (69) & $(143)$ & $(960)$ & (3) & $(15)$ & $(834)$ & $(2,108)$ \\
\hline
\end{tabular}


TABLE A6.4 How married youth aged 13-35 met their spouse, by background characteristics and marriage cohort, 2014, percent

\begin{tabular}{|c|c|c|c|c|c|}
\hline & $\begin{array}{l}\text { WORK/ } \\
\text { SCHOOL }\end{array}$ & NEIGHBORS & RELATIVES & $\begin{array}{l}\text { PERSONAL } \\
\text { NETWORKS }\end{array}$ & OTHER \\
\hline \multicolumn{6}{|l|}{ Gender } \\
\hline Male & 3.0 & 31.0 & 25.8 & 39.4 & 0.8 \\
\hline Female & 2.5 & 23.4 & 28.2 & 44.5 & 1.5 \\
\hline \multicolumn{6}{|l|}{ Age group } \\
\hline $13-17$ & 1.2 & 25.5 & 36.3 & 34.4 & 2.6 \\
\hline $18-24$ & 2.1 & 25.6 & 29.9 & 41.4 & 1.1 \\
\hline $25-29$ & 3.4 & 26.7 & 25.5 & 43.2 & 1.2 \\
\hline $30-35$ & 2.4 & 25.7 & 27.1 & 43.6 & 1.2 \\
\hline \multicolumn{6}{|l|}{ Region } \\
\hline Urban Governorates & 5.3 & 31.2 & 19.7 & 43.2 & 0.7 \\
\hline Urban Lower Egypt & 5.0 & 23.8 & 12.3 & 57.8 & 1.2 \\
\hline Rural Lower Egypt & 1.9 & 30.4 & 17.6 & 48.3 & 1.8 \\
\hline Urban Upper Egypt & 2.6 & 15.0 & 40.1 & 41.9 & 0.4 \\
\hline Rural Upper Egypt & 1.5 & 21.1 & 44.3 & 31.9 & 1.1 \\
\hline Frontier Governorates & 1.2 & 29.9 & 42.5 & 26.2 & 0.2 \\
\hline \multicolumn{6}{|l|}{ Urban-rural residence } \\
\hline Urban & 5.0 & 29.1 & 22.0 & 43.0 & 0.9 \\
\hline Rural & 1.7 & 26.2 & 30.0 & 40.6 & 1.5 \\
\hline Informal urban areas & 3.5 & 17.8 & 22.2 & 56.2 & 0.4 \\
\hline \multicolumn{6}{|l|}{ Education level } \\
\hline Illiterate & 0.9 & 26.1 & 32.3 & 39.3 & 1.5 \\
\hline Can read and write & 0.0 & 21.3 & 41.8 & 34.6 & 2.4 \\
\hline Primary & 1.6 & 26.4 & 31.9 & 38.8 & 1.4 \\
\hline Preparatory & 0.9 & 24.8 & 31.5 & 41.7 & 1.2 \\
\hline General secondary & 1.4 & 30.5 & 21.4 & 46.8 & 0.0 \\
\hline Vocational secondary & 1.8 & 26.0 & 27.8 & 43.2 & 1.2 \\
\hline Post-secondary institute & 5.2 & 23.7 & 22.1 & 49.1 & 0.0 \\
\hline University and above & 8.3 & 27.3 & 16.5 & 46.7 & 1.3 \\
\hline \multicolumn{6}{|l|}{ Employment status } \\
\hline Employed & 4.1 & 28.6 & 26.6 & 39.9 & 0.8 \\
\hline Unemployed & 2.0 & 28.8 & 17.6 & 47.9 & 3.6 \\
\hline Out of labor force & 1.7 & 24.1 & 28.5 & 44.3 & 1.4 \\
\hline \multicolumn{6}{|l|}{ Wealth quintile } \\
\hline Lowest & 1.6 & 24.6 & 36.4 & 36.0 & 1.4 \\
\hline Second & 1.5 & 27.7 & 31.5 & 38.4 & 1.0 \\
\hline Middle & 2.5 & 24.6 & 27.8 & 44.1 & 1.0 \\
\hline Fourth & 2.9 & 27.6 & 24.7 & 43.5 & 1.3 \\
\hline Highest & 4.4 & 25.6 & 18.7 & 49.8 & 1.5 \\
\hline Total & 2.7 & 26.1 & 27.4 & 42.7 & 1.2 \\
\hline$(\mathrm{N})$ & (117) & $(1,234)$ & $(1,298)$ & $(2,011)$ & $(60)$ \\
\hline
\end{tabular}


TABLE A6.5 Married youth aged 13-35 who made the final decision to marry their spouse themselves, by background characteristics and marriage cohort, 2014, percent

\begin{tabular}{|c|c|c|c|}
\hline & MYSELF ALONE & $\begin{array}{l}\text { SOMEONE ELSE } \\
\text { ALONE }\end{array}$ & $\begin{array}{c}\text { MYSELF AND } \\
\text { PARENTS JOINTLY }\end{array}$ \\
\hline \multicolumn{4}{|l|}{ Gender } \\
\hline Male & 54.1 & 14.2 & 31.7 \\
\hline Female & 20.2 & 37.4 & 42.4 \\
\hline \multicolumn{4}{|l|}{ Age group } \\
\hline $13-17$ & 26.3 & 39.2 & 34.5 \\
\hline $18-24$ & 26.1 & 34.6 & 39.4 \\
\hline $25-29$ & 32.8 & 29.0 & 38.2 \\
\hline $30+$ & 35.5 & 25.5 & 39.0 \\
\hline \multicolumn{4}{|l|}{ Region } \\
\hline Urban Governorates & 50.7 & 14.1 & 35.2 \\
\hline Urban Lower Egypt & 26.0 & 29.6 & 44.4 \\
\hline Rural Lower Egypt & 33.8 & 32.5 & 33.7 \\
\hline Urban Upper Egypt & 18.9 & 18.0 & 63.2 \\
\hline Rural Upper Egypt & 25.3 & 35.4 & 39.4 \\
\hline Frontier Governorates & 32.1 & 32.1 & 35.8 \\
\hline \multicolumn{4}{|l|}{ Urban-rural residence } \\
\hline Urban & 43.4 & 17.3 & 39.3 \\
\hline Rural & 29.8 & 33.9 & 36.3 \\
\hline Informal urban areas & 20.4 & 25.8 & 53.7 \\
\hline \multicolumn{4}{|l|}{ Education level } \\
\hline Illiterate & 22.8 & 41.2 & 36.0 \\
\hline Can read and write & 27.8 & 30.5 & 41.7 \\
\hline Primary & 36.0 & 30.5 & 33.6 \\
\hline Preparatory & 30.9 & 33.3 & 35.8 \\
\hline General secondary & 37.9 & 28.7 & 33.4 \\
\hline Vocational secondary & 30.6 & 28.0 & 41.4 \\
\hline Post-secondary institute & 36.2 & 23.5 & 40.4 \\
\hline University and above & 41.8 & 18.5 & 39.7 \\
\hline \multicolumn{4}{|l|}{ Employment status } \\
\hline Employed & 50.5 & 17.4 & 32.1 \\
\hline Unemployed & 26.1 & 29.2 & 44.7 \\
\hline Out of labor force & 20.0 & 37.3 & 42.8 \\
\hline \multicolumn{4}{|l|}{ Wealth quintile } \\
\hline Lowest & 25.5 & 35.1 & 39.4 \\
\hline Second & 30.5 & 29.7 & 39.8 \\
\hline Middle & 31.8 & 30.7 & 37.5 \\
\hline Fourth & 35.8 & 28.1 & 36.1 \\
\hline Highest & 35.7 & 23.8 & 40.5 \\
\hline Total & 32.1 & 29.2 & 38.7 \\
\hline$(\mathrm{N})$ & $(1,459)$ & $(1,443)$ & $(1,818)$ \\
\hline
\end{tabular}




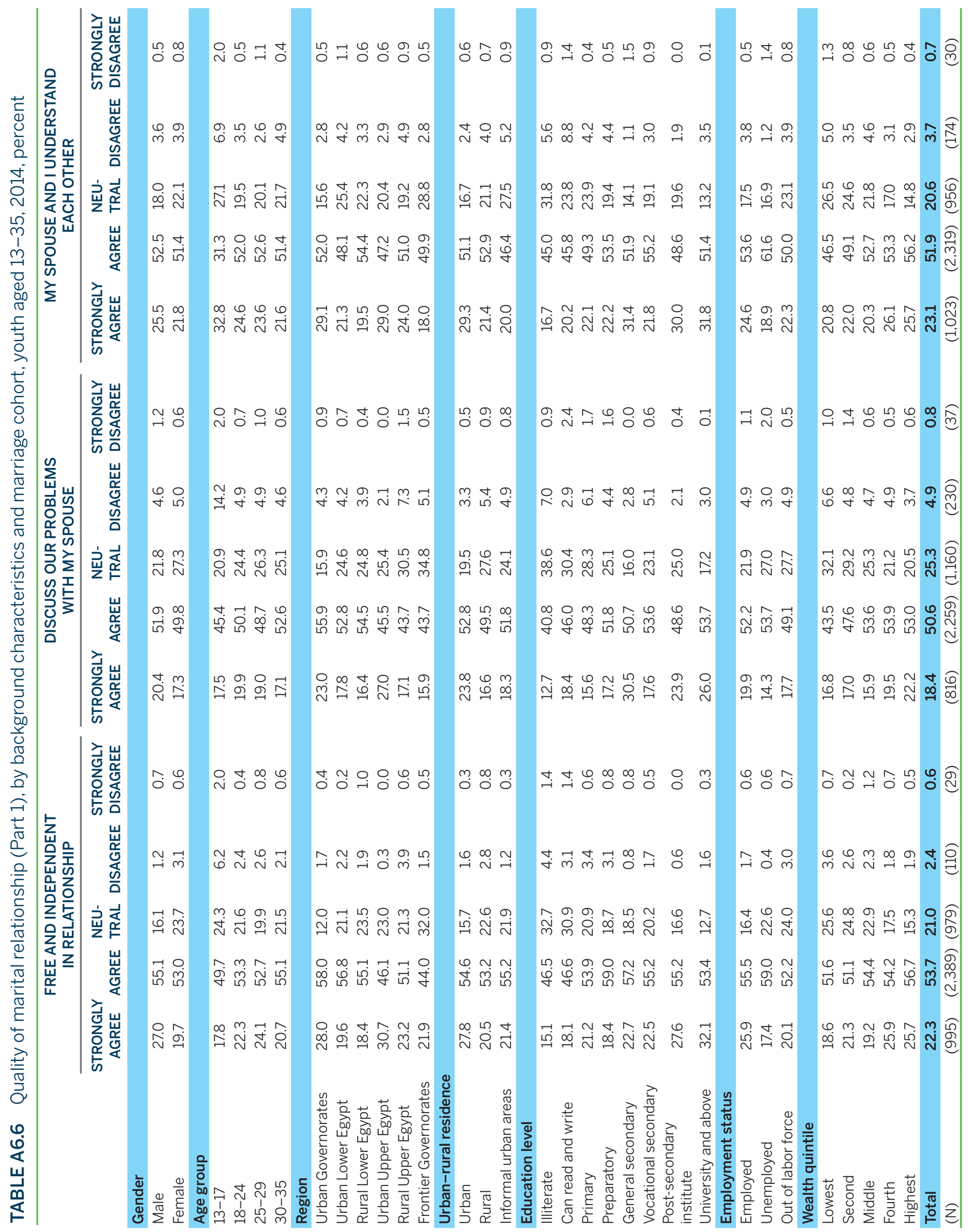




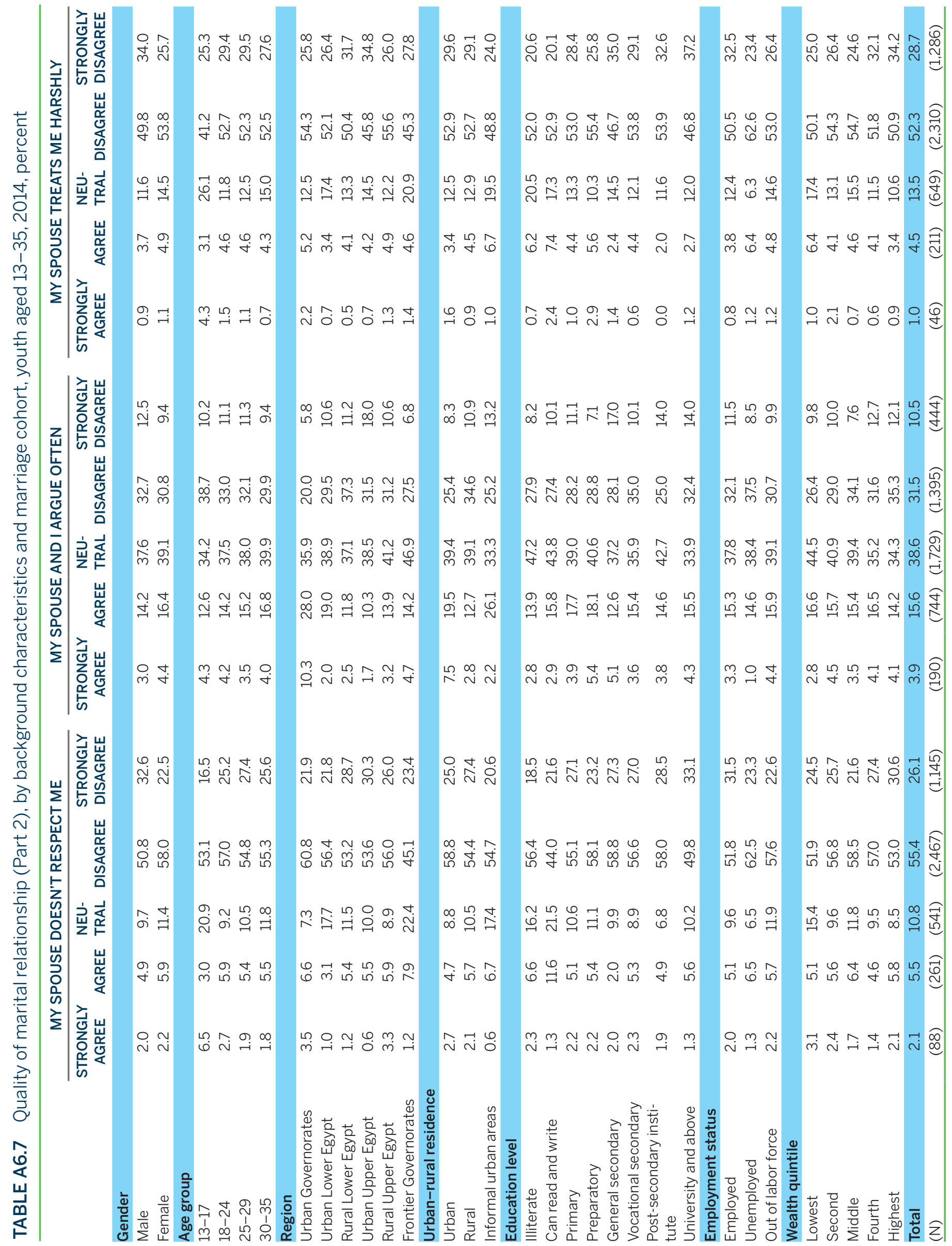


TABLE A6.8 Percentage of youth aged 13-35 who talk "often" or "daily" with their spouse on selected topics, 2014

\begin{tabular}{|c|c|c|c|c|c|}
\hline & $\begin{array}{l}\text { PLANS FOR } \\
\text { THE FUTURE }\end{array}$ & $\begin{array}{l}\text { PROBLEMS } \\
\text { AT WORK OR } \\
\text { SCHOOL }\end{array}$ & $\begin{array}{c}\text { HOW } \\
\text { THINGS ARE } \\
\text { GOING IN } \\
\text { YOUR LIFE }\end{array}$ & $\begin{array}{l}\text { CURRENT } \\
\text { OR FUTURE } \\
\text { CHILDREN }\end{array}$ & $\begin{array}{c}\text { MARITAL } \\
\text { SEXUAL } \\
\text { RELATIONS }\end{array}$ \\
\hline \multicolumn{6}{|l|}{ Gender } \\
\hline Male & 78.7 & 71.7 & 86.8 & 82.3 & 69.1 \\
\hline Female & 71.2 & 68.1 & 81.5 & 79.6 & 64.8 \\
\hline \multicolumn{6}{|l|}{ Age group } \\
\hline $13-17$ & 61.9 & 59.6 & 75.9 & 72.8 & 63.3 \\
\hline $18-24$ & 74.7 & 67.4 & 82.8 & 79.1 & 69.4 \\
\hline 25-29 & 72.7 & 68.8 & 84.2 & 80.9 & 67.1 \\
\hline 30-35 & 74.9 & 71.4 & 83.1 & 81.2 & 64.0 \\
\hline \multicolumn{6}{|l|}{ Region } \\
\hline Urban Governorates & 73.5 & 72.4 & 86.2 & 80.6 & 66.7 \\
\hline Urban Lower Egypt & 87.7 & 86.6 & 90.0 & 88.6 & 73.5 \\
\hline Rural Lower Egypt & 77.6 & 71.7 & 85.2 & 82.8 & 64.9 \\
\hline Urban Upper Egypt & 76.0 & 69.5 & 77.5 & 77.5 & 73.7 \\
\hline Rural Upper Egypt & 64.0 & 58.6 & 78.5 & 75.5 & 63.6 \\
\hline Frontier Governorates & 80.1 & 78.8 & 85.6 & 83.5 & 71.6 \\
\hline \multicolumn{6}{|l|}{ Urban-rural residence } \\
\hline Urban & 73.3 & 71.8 & 83.7 & 79.0 & 66.8 \\
\hline Rural & 71.5 & 65.9 & 82.2 & 79.5 & 64.3 \\
\hline Informal urban areas & 91.5 & 87.5 & 90.7 & 91.1 & 79.0 \\
\hline \multicolumn{6}{|l|}{ Education level } \\
\hline Illiterate & 63.9 & 61.3 & 74.1 & 73.6 & 56.3 \\
\hline Can read and write & 76.8 & 69.0 & 79.8 & 76.3 & 61.1 \\
\hline Primary & 65.0 & 62.8 & 86.2 & 79.3 & 63.5 \\
\hline Preparatory & 66.7 & 63.5 & 81.5 & 77.3 & 63.5 \\
\hline General secondary & 80.5 & 72.9 & 85.4 & 87.0 & 75.1 \\
\hline Vocational secondary & 76.7 & 71.0 & 84.4 & 82.8 & 68.5 \\
\hline Post-secondary institute & 81.5 & 76.2 & 88.5 & 81.4 & 65.0 \\
\hline University and above & 84.3 & 79.8 & 88.4 & 84.1 & 74.2 \\
\hline \multicolumn{6}{|l|}{ Employment status } \\
\hline Employed & 78.7 & 73.4 & 86.7 & 82.4 & 68.9 \\
\hline Unemployed & 78.5 & 66.5 & 88.5 & 84.3 & 61.6 \\
\hline Out of labor force & 70.3 & 66.8 & 80.7 & 79.0 & 64.9 \\
\hline \multicolumn{6}{|l|}{ Wealth quintile } \\
\hline Lowest & 61.0 & 57.2 & 77.4 & 72.6 & 54.9 \\
\hline Second & 70.0 & 65.8 & 82.5 & 79.7 & 66.5 \\
\hline Middle & 78.5 & 73.3 & 84.0 & 83.3 & 70.2 \\
\hline Fourth & 78.5 & 73.6 & 85.3 & 83.2 & 69.2 \\
\hline Highest & 79.2 & 75.1 & 86.6 & 82.8 & 69.3 \\
\hline Total & 73.9 & 69.4 & 83.4 & 80.6 & 66.3 \\
\hline$(\mathrm{N})$ & $(3,354)$ & $(3,182)$ & $(3,787)$ & $(3,663)$ & $(3,023)$ \\
\hline
\end{tabular}


TABLE A6.9 Mean cost of the shabka and total cost of marriage (in EGP), by background characteristics and marriage cohort, youth aged 13-35, 2014

\begin{tabular}{|c|c|c|}
\hline & SHABKA & TOTAL COST OF MARRIAGE \\
\hline \multicolumn{3}{|l|}{ Gender } \\
\hline Male & 5,998 & 33,910 \\
\hline Female & 5,582 & 32,410 \\
\hline \multicolumn{3}{|l|}{ Age group } \\
\hline $13-17$ & 7,337 & 35,593 \\
\hline $18-24$ & 6,984 & 36,248 \\
\hline $25-29$ & 5,705 & 33,484 \\
\hline $30+$ & 4,850 & 30,394 \\
\hline \multicolumn{3}{|l|}{ Region } \\
\hline Urban Governorates & 4,003 & 43,942 \\
\hline Urban Lower Egypt & 6,192 & 46,089 \\
\hline Rural Lower Egypt & 5,400 & 39,220 \\
\hline Urban Upper Egypt & 5,936 & 20,447 \\
\hline Rural Upper Egypt & 6,859 & 20,007 \\
\hline \multicolumn{3}{|l|}{ Urban-rural residence } \\
\hline Urban & 5,023 & 39,908 \\
\hline Rural & 6,042 & 30,577 \\
\hline \multicolumn{3}{|l|}{ Education level } \\
\hline Illiterate & 4,678 & 21,204 \\
\hline Can read and write & 3,978 & 21,284 \\
\hline Primary & 4,272 & 25,063 \\
\hline Preparatory & 5,511 & 30,782 \\
\hline General secondary & 6,105 & 38,876 \\
\hline Vocational secondary & 5,561 & 32,731 \\
\hline Post-secondary institute & 6,207 & 39,860 \\
\hline University and above & 8,258 & 51,444 \\
\hline \multicolumn{3}{|l|}{ Employment status } \\
\hline Employed & 6,067 & 33,208 \\
\hline Unemployed & 5,614 & 36,316 \\
\hline Out of labor force & 5,504 & 32,549 \\
\hline \multicolumn{3}{|l|}{ Wealth quintile } \\
\hline Lowest & 4,294 & 17,185 \\
\hline Second & 5,442 & 26,060 \\
\hline Middle & 4,962 & 34,189 \\
\hline Fourth & 6,087 & 37,200 \\
\hline Highest & 7,487 & 45,556 \\
\hline \multicolumn{3}{|l|}{ Marriage cohort } \\
\hline 2010-2014 & 6,949 & 38,472 \\
\hline 2005-2009 & 5,075 & 30,515 \\
\hline Before 2004 & 3,964 & 24,853 \\
\hline Total & 5,727 & 33,375 \\
\hline$(\mathrm{N})$ & $(4,717)$ & $(3,685)$ \\
\hline
\end{tabular}


TABLE A6.10 Desired fertility among married and unmarried youth, by background characteristics and marriage cohort, 2009 and 2014, percent

\begin{tabular}{|c|c|c|c|c|c|c|}
\hline & \multicolumn{3}{|c|}{ NEVER-MARRIED YOUTH } & \multicolumn{3}{|c|}{ CURRENTLY MARRIED YOUTH } \\
\hline & $\begin{array}{c}\text { AGE 15-29, } \\
2009\end{array}$ & $\begin{array}{c}\text { AGE 15-29, } \\
2014\end{array}$ & $\begin{array}{c}\text { AGE 13-35, } \\
2014\end{array}$ & $\begin{array}{c}\text { AGE 15-29, } \\
2009\end{array}$ & $\begin{array}{c}\text { AGE 15-29, } \\
2014\end{array}$ & $\begin{array}{c}\text { AGE 13-35, } \\
2014\end{array}$ \\
\hline Male & 2.7 & 3.0 & 3.0 & 2.7 & 3.1 & 3.2 \\
\hline Female & 2.5 & 2.9 & 2.9 & 2.9 & 3.1 & 3.2 \\
\hline \multicolumn{7}{|l|}{ Age group } \\
\hline $15-17$ & 2.6 & 2.9 & - & 2.4 & 3.2 & - \\
\hline $18-24$ & 2.7 & 3.0 & 3.0 & 2.8 & 3.0 & 3.0 \\
\hline 25-29 & 2.6 & 2.9 & 2.9 & 2.9 & 3.2 & 3.2 \\
\hline $30+$ & - & - & 3.0 & - & - & 3.3 \\
\hline \multicolumn{7}{|l|}{ Region } \\
\hline Urban Upper Egypt & 2.8 & 3.2 & 3.2 & 2.9 & 3.5 & 3.6 \\
\hline Rural Upper Egypt & 2.9 & 3.4 & 3.4 & 3.2 & 3.5 & 3.6 \\
\hline Frontier Governorates & 3.0 & 2.9 & 2.9 & 3.2 & 3.2 & 3.2 \\
\hline \multicolumn{7}{|l|}{ Urban-rural residence } \\
\hline Urban & 2.5 & 2.7 & 2.7 & 2.6 & 2.9 & 2.9 \\
\hline Rural & 2.7 & 3.1 & 3.0 & 2.9 & 3.2 & 3.3 \\
\hline Informal urban areas & 2.5 & 2.9 & 2.9 & 2.7 & 3.1 & 3.1 \\
\hline \multicolumn{7}{|l|}{ Education level } \\
\hline Illiterate & 2.9 & 3.2 & 3.2 & 3.2 & 3.4 & 3.6 \\
\hline Can read and write & 2.4 & 2.9 & 2.8 & 3.0 & 3.1 & 3.3 \\
\hline \multicolumn{7}{|l|}{ Employment status } \\
\hline Employed & 2.7 & 3.0 & 3.0 & 2.7 & 3.1 & 3.2 \\
\hline Unemployed & 2.6 & 2.8 & 2.8 & 2.6 & 2.8 & 2.9 \\
\hline Out of labor force & 2.6 & 2.9 & 2.9 & 2.9 & 3.2 & 3.2 \\
\hline \multicolumn{7}{|l|}{ Wealth quintile } \\
\hline Lowest & 2.8 & 3.2 & 3.2 & 3.1 & 3.4 & 3.5 \\
\hline Second & 2.7 & 3.1 & 3.1 & 2.9 & 3.3 & 3.3 \\
\hline Middle & 2.7 & 2.9 & 2.9 & 2.9 & 3.2 & 3.2 \\
\hline Fourth & 2.6 & 2.8 & 2.8 & 2.6 & 3.0 & 3.1 \\
\hline Highest & 2.4 & 2.7 & 2.7 & 2.5 & 2.9 & 2.9 \\
\hline \multicolumn{7}{|l|}{ Marriage cohort } \\
\hline 2010-2014 & - & - & - & - & 3.0 & 3.0 \\
\hline 2005-2009 & - & - & - & - & 3.2 & 3.2 \\
\hline Before 2004 & - & - & - & - & 3.5 & 3.5 \\
\hline Total & 2.6 & 2.9 & 2.9 & 2.8 & 3.1 & 3.2 \\
\hline$(\mathrm{N})$ & $(7,258)$ & $(5,790)$ & $(6,312)$ & $(3,394)$ & $(2,772)$ & $(4,501)$ \\
\hline
\end{tabular}


TABLE A7.1 Youth participation in revolutionary activity since January 252011 , by type of participation and background characteristics, 2014, percent

\begin{tabular}{|c|c|c|c|c|}
\hline & $\begin{array}{c}\text { ANY } \\
\text { PARTICIPATION }\end{array}$ & $\begin{array}{c}\text { POLITICAL } \\
\text { ORGANIZING }\end{array}$ & $\begin{array}{l}\text { NEIGHBOR- } \\
\text { HOOD WATCH }\end{array}$ & PROTEST \\
\hline \multicolumn{5}{|l|}{ Gender } \\
\hline Male & 13.1 & 1.9 & 11.8 & 1.7 \\
\hline Female & 1.5 & 0.5 & 0.5 & 0.9 \\
\hline \multicolumn{5}{|l|}{ Age group } \\
\hline 13-17 & 5.1 & 0.5 & 4.2 & 1.1 \\
\hline $18-24$ & 8.0 & 1.7 & 6.4 & 1.5 \\
\hline $25-29$ & 8.3 & 1.5 & 7.2 & 1.3 \\
\hline $30-35$ & 7.7 & 0.9 & 7.0 & 1.1 \\
\hline \multicolumn{5}{|l|}{ Region } \\
\hline Urban Governorates & 13.9 & 2.0 & 11.3 & 4.0 \\
\hline Urban Lower Egypt & 8.3 & 2.0 & 7.2 & 1.5 \\
\hline Rural Lower Egypt & 9.2 & 1.2 & 8.4 & 0.6 \\
\hline Urban Upper Egypt & 2.1 & 0.7 & 1.4 & 0.4 \\
\hline Rural Upper Egypt & 2.6 & 0.8 & 1.7 & 0.5 \\
\hline Frontier Governorates & 2.6 & 0.4 & 2.3 & 0.0 \\
\hline \multicolumn{5}{|l|}{ Urban-rural residence } \\
\hline Urban & 11.4 & 1.9 & 9.3 & 3.0 \\
\hline Rural & 6.0 & 1.0 & 5.2 & 0.6 \\
\hline Informal urban areas & 4.0 & 0.9 & 3.5 & 0.9 \\
\hline \multicolumn{5}{|l|}{ Education level } \\
\hline Illiterate & 2.6 & 0.3 & 2.2 & 0.3 \\
\hline Can read and write & 5.7 & 0.5 & 5.7 & 0.0 \\
\hline Primary & 6.8 & 0.1 & 6.3 & 0.6 \\
\hline Preparatory & 5.1 & 0.6 & 4.6 & 0.7 \\
\hline General secondary & 7.5 & 0.8 & 6.1 & 2.0 \\
\hline Vocational secondary & 6.9 & 1.0 & 6.0 & 0.9 \\
\hline Post-secondary institute & 10.2 & 2.6 & 7.4 & 1.8 \\
\hline University and above & 12.2 & 3.1 & 9.5 & 2.9 \\
\hline \multicolumn{5}{|l|}{ Marital status } \\
\hline Never married & 8.5 & 1.5 & 7.0 & 1.6 \\
\hline Ever married & 5.4 & 0.7 & 4.9 & 0.7 \\
\hline \multicolumn{5}{|l|}{ Employment status } \\
\hline Employed & 12.8 & 1.8 & 11.5 & 1.7 \\
\hline Unemployed & 13.6 & 2.5 & 11.7 & 2.5 \\
\hline Out of labor force & 4.0 & 0.8 & 2.9 & 1.0 \\
\hline Out of labor force and out of school & 1.9 & 0.5 & 1.1 & 0.5 \\
\hline Out of labor force and in school & 7.0 & 1.3 & 5.4 & 1.8 \\
\hline \multicolumn{5}{|l|}{ Employed } \\
\hline Public wage & 12.4 & 1.8 & 10.7 & 1.2 \\
\hline Private wage & 12.6 & 1.8 & 11.2 & 1.7 \\
\hline Self-employed & 14.9 & 2.6 & 14.4 & 1.7 \\
\hline Nonwage worker & 11.7 & 1.2 & 10.4 & 2.0 \\
\hline \multicolumn{5}{|l|}{ Wealth quintile } \\
\hline Lowest & 3.8 & 0.4 & 3.4 & 0.3 \\
\hline Second & 5.7 & 0.7 & 4.6 & 0.9 \\
\hline Middle & 6.8 & 0.9 & 5.8 & 1.3 \\
\hline Fourth & 9.3 & 1.4 & 8.0 & 1.4 \\
\hline Highest & 10.7 & 2.5 & 8.7 & 2.3 \\
\hline Total & 7.4 & 1.2 & 6.2 & 1.3 \\
\hline$(\mathrm{N})$ & $(10,890)$ & $(10,890)$ & $(10,890)$ & $(10,890)$ \\
\hline (N who responded "yes") & (744) & (123) & (617) & (136) \\
\hline
\end{tabular}




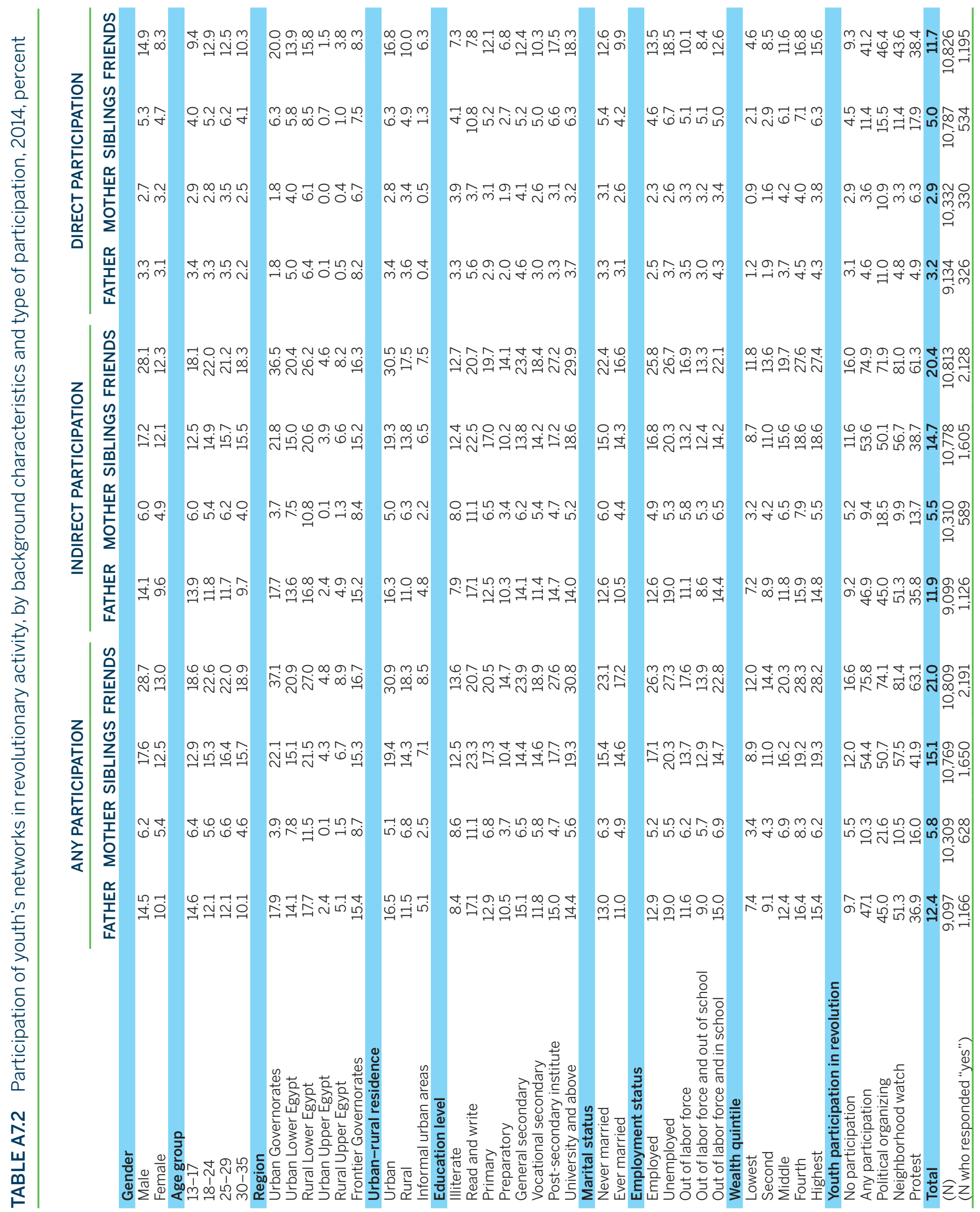


TABLE A7.3 Youth's reasons for nonparticipation in revolutionary activities, by background characteristics (percent, multiple answers allowed), 2014, percent

\begin{tabular}{|c|c|c|c|c|c|}
\hline & $\begin{array}{l}\text { PARENTS' } \\
\text { OPPOSITION }\end{array}$ & $\begin{array}{l}\text { WILL NOT MAKE } \\
\text { A DIFFERENCE }\end{array}$ & $\begin{array}{l}\text { CONFUSED } \\
\text { IF RIGHT OR } \\
\text { WRONG }\end{array}$ & $\begin{array}{l}\text { NOT AGAINST } \\
\text { OLD REGIME }\end{array}$ & OTHER \\
\hline \multicolumn{6}{|l|}{ Gender } \\
\hline Female & 26.3 & 14.1 & 27.7 & 18.4 & 18.1 \\
\hline \multicolumn{6}{|l|}{ Age group } \\
\hline $18-24$ & 30.1 & 15.4 & 29.3 & 18.2 & 12.7 \\
\hline $25-29$ & 22.6 & 16.0 & 29.9 & 20.5 & 15.4 \\
\hline 30-35 & 17.0 & 17.1 & 31.7 & 20.9 & 17.6 \\
\hline \multicolumn{6}{|l|}{ Region } \\
\hline Urban Governorates & 42.4 & 12.5 & 28.3 & 14.3 & 6.4 \\
\hline Rural Upper Egypt & 18.4 & 15.4 & 30.3 & 23.0 & 21.2 \\
\hline Frontier Governorates & 28.5 & 15.3 & 28.5 & 12.8 & 17.0 \\
\hline \multicolumn{6}{|l|}{ Urban-rural residence } \\
\hline Urban & 39.1 & 12.8 & 26.6 & 16.9 & 8.8 \\
\hline Rural & 23.0 & 16.0 & 29.5 & 20.6 & 17.3 \\
\hline Informal urban areas & 21.5 & 18.7 & 33.1 & 13.3 & 12.9 \\
\hline \multicolumn{6}{|l|}{ Education level } \\
\hline Illiterate & 12.9 & 16.4 & 28.5 & 22.3 & 26.3 \\
\hline Read and write & 12.9 & 21.6 & 21.8 & 30.3 & 17.2 \\
\hline \multicolumn{6}{|l|}{ Marital status } \\
\hline Never married & 33.1 & 15.1 & 27.7 & 17.7 & 11.7 \\
\hline Ever married & 17.2 & 15.9 & 31.5 & 20.8 & 19.4 \\
\hline \multicolumn{6}{|l|}{ Employment status } \\
\hline Employed & 24.5 & 16.8 & 30.8 & 19.9 & 13.5 \\
\hline Unemployed & 27.5 & 18.8 & 35.6 & 15.0 & 10.1 \\
\hline Out of labor force & 28.8 & 14.4 & 27.7 & 18.5 & 15.2 \\
\hline Out of labor force and out of school & 22.0 & 15.5 & 28.7 & 20.2 & 18.7 \\
\hline Out of labor force and in school & 39.2 & 12.8 & 26.3 & 16.0 & 10.0 \\
\hline \multicolumn{6}{|l|}{ Wealth quintile } \\
\hline Lowest & 21.2 & 16.8 & 30.0 & 18.2 & 20.1 \\
\hline Second & 21.6 & 13.8 & 28.2 & 22.8 & 19.4 \\
\hline Middle & 26.3 & 15.7 & 30.1 & 18.8 & 12.6 \\
\hline Fourth & 30.9 & 16.8 & 28.7 & 18.3 & 11.0 \\
\hline Highest & 35.8 & 14.1 & 28.5 & 16.2 & 9.8 \\
\hline Total & 27.4 & 15.4 & 29.1 & 18.8 & 14.5 \\
\hline$(\mathrm{N})$ & $(10,146)$ & $(10,146)$ & $(10,146)$ & $(10,146)$ & $(10,146)$ \\
\hline
\end{tabular}


TABLE A7.4 Youth understanding of the events of January 25, 2011 and June 30, 2013, by selected background characteristics and revolutionary activity, 2014, percent

\begin{tabular}{|c|c|c|c|c|c|c|}
\hline & \multicolumn{3}{|c|}{ JANUARY 25, 2011 GOALS } & \multicolumn{3}{|c|}{ JUNE 30, 2013 GOALS } \\
\hline & $\begin{array}{l}\text { VERY } \\
\text { CLEAR }\end{array}$ & $\begin{array}{l}\text { SOMEWHAT } \\
\text { CLEAR }\end{array}$ & $\begin{array}{c}\text { VERY } \\
\text { UNCLEAR }\end{array}$ & $\begin{array}{l}\text { VERY } \\
\text { CLEAR }\end{array}$ & $\begin{array}{l}\text { SOMEWHAT } \\
\text { CLEAR }\end{array}$ & $\begin{array}{c}\text { VERY } \\
\text { UNCLEAR }\end{array}$ \\
\hline \multicolumn{7}{|l|}{ Gender } \\
\hline Male & 39.3 & 45.0 & 15.8 & 45.8 & 41.8 & 12.4 \\
\hline Female & 35.4 & 45.9 & 18.7 & 40.5 & 43.5 & 16.0 \\
\hline \multicolumn{7}{|l|}{ Region } \\
\hline Urban Governorates & 40.3 & 45.7 & 14.0 & 45.8 & 44.4 & 9.8 \\
\hline Urban Lower Egypt & 44.6 & 38.8 & 16.6 & 55.3 & 38.8 & 5.9 \\
\hline Rural Lower Egypt & 32.7 & 49.6 & 17.6 & 44.6 & 43.3 & 12.0 \\
\hline Urban Upper Egypt & 45.0 & 37.3 & 17.7 & 44.7 & 38.7 & 16.5 \\
\hline Rural Upper Egypt & 36.3 & 45.4 & 18.4 & 35.3 & 42.6 & 22.1 \\
\hline Frontier Governorates & 24.4 & 50.1 & 25.5 & 33.4 & 53.4 & 13.2 \\
\hline \multicolumn{7}{|l|}{ Education level } \\
\hline Illiterate & 21.9 & 49.9 & 28.2 & 28.6 & 47.7 & 23.6 \\
\hline Read and write & 27.6 & 49.1 & 23.4 & 43.4 & 38.1 & 18.5 \\
\hline Primary & 30.4 & 44.6 & 25.0 & 37.5 & 45.8 & 16.7 \\
\hline Preparatory & 32.7 & 45.4 & 21.8 & 40.1 & 42.4 & 17.6 \\
\hline General secondary & 40.5 & 44.7 & 14.9 & 42.9 & 44.4 & 12.7 \\
\hline Vocational secondary & 36.6 & 47.0 & 16.3 & 43.5 & 43.0 & 13.5 \\
\hline Post-secondary institute & 42.1 & 49.3 & 8.6 & 50.8 & 41.3 & 7.9 \\
\hline University and above & 50.3 & 40.3 & 9.5 & 52.8 & 38.0 & 9.2 \\
\hline \multicolumn{7}{|l|}{ Wealth quintile } \\
\hline Lowest & 31.0 & 46.1 & 22.9 & 34.7 & 43.8 & 21.5 \\
\hline Second & 36.5 & 43.7 & 19.8 & 42.0 & 39.5 & 18.5 \\
\hline Middle & 39.9 & 43.3 & 16.8 & 45.7 & 42.9 & 11.4 \\
\hline Fourth & 38.3 & 46.8 & 15.0 & 43.6 & 46.6 & 9.8 \\
\hline Highest & 40.4 & 47.0 & 12.6 & 48.6 & 40.7 & 10.7 \\
\hline \multicolumn{7}{|c|}{ Youth participation in revolution } \\
\hline No participation & 37.3 & 45.1 & 17.6 & 42.5 & 43.1 & 14.4 \\
\hline Any participation & 38.3 & 49.6 & 12.1 & 52.0 & 37.3 & 10.8 \\
\hline Political organizing & 58.3 & 29.2 & 12.5 & 56.9 & 27.4 & 15.6 \\
\hline Neighborhood watch & 34.8 & 52.7 & 12.5 & 50.0 & 39.5 & 10.5 \\
\hline Protest & 59.6 & 39.3 & 1.1 & 61.2 & 24.2 & 14.6 \\
\hline Total & 37.4 & 45.4 & 17.2 & 43.2 & 42.6 & 14.2 \\
\hline$(\mathrm{N})$ & & $(10,890)$ & & & $(10,889)$ & \\
\hline
\end{tabular}


TABLE A7.5 Youth self-reported turnout for elections and referendums from 2011-2012, by background characteristics, political participation, and support for January 25 and June 30 (percent)

\begin{tabular}{|c|c|c|c|c|c|c|}
\hline & $\begin{array}{c}2011 \\
\text { CONSTI- } \\
\text { TUTION }\end{array}$ & $\begin{array}{c}2011 \\
\text { PARLIAMENT, } \\
\text { ROUND 1 }\end{array}$ & $\begin{array}{c}2011 \\
\text { PARLIAMENT, } \\
\text { ROUND } 2\end{array}$ & $\begin{array}{c}2012 \\
\text { PRESIDENT, } \\
\text { ROUND } 1\end{array}$ & $\begin{array}{c}2012 \\
\text { PRESIDENT, } \\
\text { ROUND } 2\end{array}$ & $\begin{array}{c}2012 \\
\text { CONSTI- } \\
\text { TUTION }\end{array}$ \\
\hline \multicolumn{7}{|l|}{ Gender } \\
\hline Female & 47.6 & 50.6 & 48.8 & 59.4 & 56.5 & 47.6 \\
\hline \multicolumn{7}{|l|}{ Age group } \\
\hline $20-24$ & 48.7 & 51.4 & 49.5 & 61.7 & 57.9 & 49.0 \\
\hline \multicolumn{7}{|l|}{ Region } \\
\hline Urban Governorates & 60.3 & 60.0 & 57.2 & 68.0 & 62.3 & 60.0 \\
\hline Urban Lower Egypt & 72.7 & 71.4 & 69.9 & 80.8 & 80.1 & 70.1 \\
\hline Rural Lower Egypt & 54.2 & 57.0 & 54.1 & 68.3 & 63.3 & 53.2 \\
\hline Urban Upper Egypt & 47.4 & 53.0 & 52.1 & 61.2 & 60.6 & 45.9 \\
\hline Rural Upper Egypt & 39.9 & 45.8 & 44.5 & 54.4 & 51.4 & 40.3 \\
\hline \multicolumn{7}{|l|}{ Urban-rural residence } \\
\hline Informal urban areas & 73.9 & 74.2 & 74.1 & 76.2 & 77.8 & 69.3 \\
\hline \multicolumn{7}{|l|}{ Education level } \\
\hline Illiterate & 28.0 & 32.3 & 30.5 & 40.8 & 38.8 & 29.2 \\
\hline Can read and write & 41.8 & 46.0 & 40.0 & 60.3 & 56.3 & 41.4 \\
\hline Primary & 40.4 & 44.1 & 43.4 & 56.8 & 53.0 & 42.0 \\
\hline Preparatory & 41.7 & 45.8 & 44.9 & 54.3 & 51.8 & 42.8 \\
\hline General secondary & 49.0 & 52.6 & 48.3 & 61.1 & 60.0 & 46.4 \\
\hline Vocational secondary & 53.6 & 57.0 & 54.5 & 66.3 & 62.4 & 52.5 \\
\hline Post-secondary institute & 70.0 & 70.0 & 66.6 & 75.3 & 73.4 & 65.2 \\
\hline University and above & 70.0 & 70.7 & 69.1 & 80.1 & 75.5 & 68.6 \\
\hline \multicolumn{7}{|l|}{ Marital status } \\
\hline Never married & 52.6 & 55.2 & 52.5 & 64.8 & 60.5 & 51.2 \\
\hline Out of labor force & 45.6 & 48.7 & 46.6 & 57.1 & 54.4 & 45.4 \\
\hline Out of labor force and out of school & 43.3 & 46.7 & 44.6 & 54.6 & 52.0 & 42.7 \\
\hline Out of labor force and in school & 61.3 & 63.0 & 59.8 & 74.0 & 71.0 & 64.1 \\
\hline \multicolumn{7}{|l|}{ Wealth quintile } \\
\hline Lowest & 40.0 & 44.6 & 42.3 & 50.4 & 48.1 & 42.4 \\
\hline Second & 46.7 & 49.9 & 48.6 & 60.4 & 57.7 & 46.2 \\
\hline Middle & 52.4 & 55.3 & 53.6 & 66.7 & 61.4 & 49.6 \\
\hline Fourth & 57.9 & 59.7 & 56.3 & 70.3 & 66.7 & 56.8 \\
\hline Highest & 64.6 & 66.5 & 64.7 & 74.7 & 70.7 & 63.4 \\
\hline \multicolumn{7}{|l|}{ Youth participation in revolution } \\
\hline No participation & 50.5 & 53.6 & 51.6 & 63.2 & 59.7 & 50.0 \\
\hline Any participation & 79.8 & 79.9 & 77.2 & 86.5 & 81.7 & 77.6 \\
\hline Political organizing & 84.3 & 83.7 & 78.5 & 88.6 & 84.7 & 76.5 \\
\hline Neighborhood watch & 79.8 & 80.0 & 77.7 & 86.8 & 81.8 & 77.1 \\
\hline Protest & 85.0 & 79.2 & 81.1 & 91.6 & 85.4 & 86.0 \\
\hline \multicolumn{7}{|l|}{ Youth support for January 25} \\
\hline Did not support & 38.2 & 39.8 & 38.2 & 50.4 & 46.9 & 34.6 \\
\hline Supported & 57.8 & 61.0 & 58.8 & 69.9 & 66.3 & 58.0 \\
\hline \multicolumn{7}{|l|}{ Youth support for June 30} \\
\hline Supported completely & 57.2 & 60.4 & 58.7 & 70.1 & 66.5 & 56.7 \\
\hline Supported partially & 52.0 & 54.1 & 51.3 & 62.4 & 58.4 & 47.8 \\
\hline Did not support & 42.3 & 45.3 & 43.6 & 55.6 & 52.9 & 47.9 \\
\hline Total & 53.0 & 55.8 & 53.7 & 65.1 & 61.5 & 52.3 \\
\hline$(\mathrm{N})$ & $(7,458)$ & $(7,458)$ & $(7,458)$ & $(7,458)$ & $(7,458)$ & $(7,458)$ \\
\hline
\end{tabular}


TABLE A7.6 Percentage of youth who report never and always voting from 2011-2012, and intention to vote in next election, by background characteristics and revolutionary activity

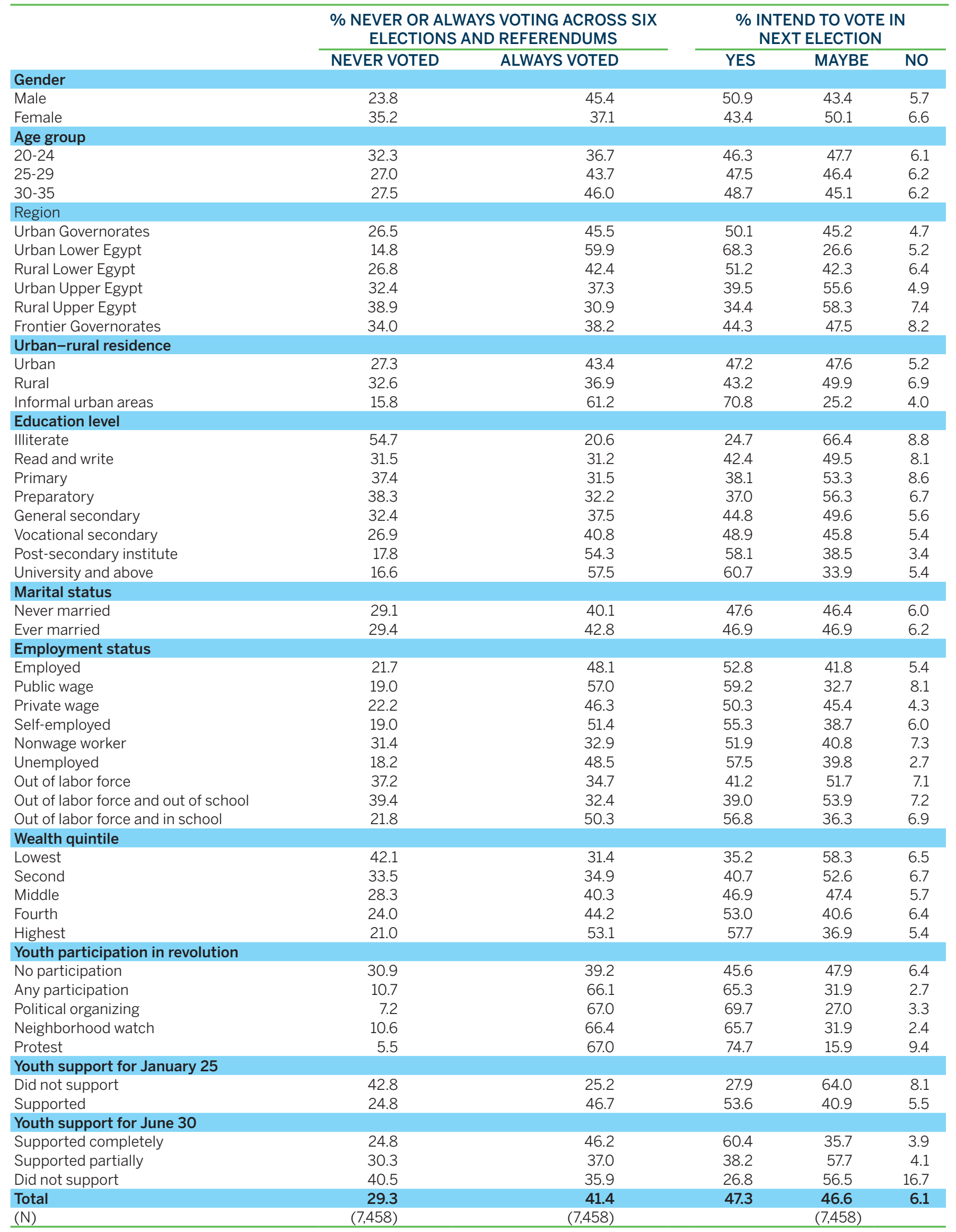


TABLE A7.7 Youths' reasons for not voting in each election or referendum, by selected background characteristics and revolutionary activity (age ineligible excluded), percent

\begin{tabular}{|c|c|c|c|c|c|c|c|c|c|c|c|c|}
\hline & \multicolumn{4}{|c|}{2011 CONSTITUTION } & \multicolumn{4}{|c|}{2011 PARLIAMENT } & \multicolumn{4}{|c|}{2012 PRESIDENCY } \\
\hline & $\begin{array}{l}\text { DON'T } \\
\text { CARE }\end{array}$ & $\begin{array}{c}\text { RE- } \\
\text { FUSED } \\
\text { TO VOTE }\end{array}$ & $\begin{array}{c}\text { NO } \\
\text { VOTING } \\
\text { CARD }\end{array}$ & OTHER & $\begin{array}{l}\text { DON'T } \\
\text { CARE }\end{array}$ & $\begin{array}{c}\text { RE- } \\
\text { FUSED } \\
\text { TO VOTE }\end{array}$ & $\begin{array}{c}\text { NO } \\
\text { VOTING } \\
\text { CARD }\end{array}$ & OTHER & $\begin{array}{l}\text { DON'T } \\
\text { CARE }\end{array}$ & $\begin{array}{c}\text { RE- } \\
\text { FUSED } \\
\text { TO VOTE }\end{array}$ & $\begin{array}{c}\text { NO } \\
\text { VOTING } \\
\text { CARD }\end{array}$ & OTHER \\
\hline \multicolumn{13}{|l|}{ Gender } \\
\hline Male & 66.8 & 25.1 & 1.6 & 6.5 & 64.1 & 25.8 & 2.2 & 7.9 & 57.2 & 31.9 & 2.6 & 8.4 \\
\hline Female & 73.5 & 20.7 & 3.7 & 2.1 & 71.4 & 22.0 & 3.4 & 3.2 & 67.0 & 26.0 & 4.1 & 2.9 \\
\hline \multicolumn{13}{|l|}{ Age group } \\
\hline $18-24$ & 69.0 & 22.8 & 3.4 & 4.8 & 65.8 & 24.2 & 3.9 & 6.2 & 62.5 & 26.7 & 4.5 & 6.3 \\
\hline $25-29$ & 70.7 & 23.7 & 1.9 & 3.6 & 68.4 & 24.9 & 1.8 & 5.0 & 63.4 & 29.4 & 2.1 & 5.1 \\
\hline $30-35$ & 72.4 & 21.4 & 2.5 & 3.7 & 71.8 & 21.5 & 2.3 & 4.5 & 61.1 & 31.7 & 3.2 & 4.1 \\
\hline \multicolumn{13}{|l|}{ Region } \\
\hline Urban Governorates & 60.0 & 36.8 & 1.6 & 1.6 & 57.1 & 38.6 & 2.0 & 2.4 & 47.2 & 47.1 & 1.9 & 3.8 \\
\hline Urban Lower Egypt & 70.4 & 18.1 & 1.1 & 10.4 & 74.2 & 18.6 & 0.7 & 6.6 & 67.7 & 23.9 & 1.0 & 7.3 \\
\hline Rural Lower Egypt & 71.5 & 21.0 & 1.9 & 5.7 & 70.7 & 19.3 & 2.3 & 7.8 & 59.5 & 30.6 & 3.3 & 6.7 \\
\hline Urban Upper Egypt & 81.5 & 16.8 & 0.5 & 1.1 & 76.3 & 20.6 & 2.1 & 1.0 & 84.3 & 12.7 & 2.6 & 0.4 \\
\hline Rural Upper Egypt & 71.0 & 20.4 & 4.9 & 3.8 & 67.4 & 22.4 & 4.6 & 5.7 & 66.7 & 22.2 & 5.0 & 6.2 \\
\hline Frontier Governorates & 76.5 & 19.3 & 1.9 & 2.3 & 74.6 & 19.9 & 1.9 & 3.7 & 69.7 & 24.0 & 2.2 & 4.1 \\
\hline \multicolumn{13}{|l|}{ Education level } \\
\hline Illiterate & 77.5 & 15.8 & 3.9 & 2.8 & 77.2 & 14.4 & 4.9 & 3.5 & 75.1 & 17.2 & 5.5 & 2.2 \\
\hline Can read and write & 83.9 & 11.9 & 4.1 & 0.0 & 83.2 & 12.8 & 4.0 & 0.0 & 71.6 & 19.8 & 5.4 & 3.1 \\
\hline Primary & 72.8 & 20.6 & 2.4 & 4.2 & 75.7 & 17.3 & 1.9 & 5.1 & 67.5 & 26.0 & 2.3 & 4.2 \\
\hline Preparatory & 70.5 & 24.0 & 3.4 & 2.1 & 71.8 & 21.3 & 3.6 & 3.4 & 63.6 & 29.2 & 3.8 & 3.4 \\
\hline General secondary & 67.7 & 28.2 & 1.0 & 3.2 & 56.5 & 35.3 & 3.7 & 4.6 & 51.8 & 40.8 & 3.9 & 3.6 \\
\hline Vocational secondary & 70.4 & 22.2 & 2.7 & 4.8 & 66.8 & 24.6 & 2.2 & 6.5 & 63.0 & 26.7 & 2.7 & 7.7 \\
\hline Post-secondary institute & 55.6 & 37.3 & 0.0 & 7.2 & 55.7 & 33.8 & 0.0 & 10.5 & 44.5 & 43.6 & 0.0 & 11.9 \\
\hline University and above & 61.7 & 31.0 & 1.7 & 5.7 & 56.3 & 35.1 & 2.5 & 6.1 & 46.1 & 45.1 & 3.6 & 5.2 \\
\hline \multicolumn{13}{|l|}{ Wealth quintile } \\
\hline Lowest & 75.2 & 19.6 & 2.8 & 2.5 & 73.6 & 21.3 & 2.2 & 3.0 & 72.8 & 21.3 & 2.8 & 3.1 \\
\hline Second & 72.3 & 20.1 & 3.0 & 4.6 & 72.7 & 20.2 & 3.0 & 4.1 & 68.4 & 22.7 & 3.2 & 5.6 \\
\hline Middle & 71.7 & 23.2 & 1.7 & 3.4 & 66.3 & 25.4 & 2.0 & 6.3 & 64.4 & 28.0 & 2.4 & 5.2 \\
\hline Fourth & 68.8 & 22.3 & 4.1 & 4.7 & 68.5 & 20.6 & 5.5 & 5.4 & 55.0 & 32.2 & 7.5 & 5.4 \\
\hline Highest & 61.7 & 30.4 & 1.8 & 6.1 & 56.2 & 33.2 & 1.6 & 9.0 & 46.1 & 43.7 & 1.5 & 8.6 \\
\hline Total & 70.4 & 22.8 & 2.7 & 4.2 & 68.0 & 23.8 & 2.8 & 5.4 & 62.5 & 28.7 & 3.4 & 5.4 \\
\hline$(\mathrm{N})$ & \multicolumn{4}{|c|}{$(3,351)$} & \multicolumn{4}{|c|}{$(3,401)$} & \multicolumn{4}{|c|}{$(2,800)$} \\
\hline
\end{tabular}




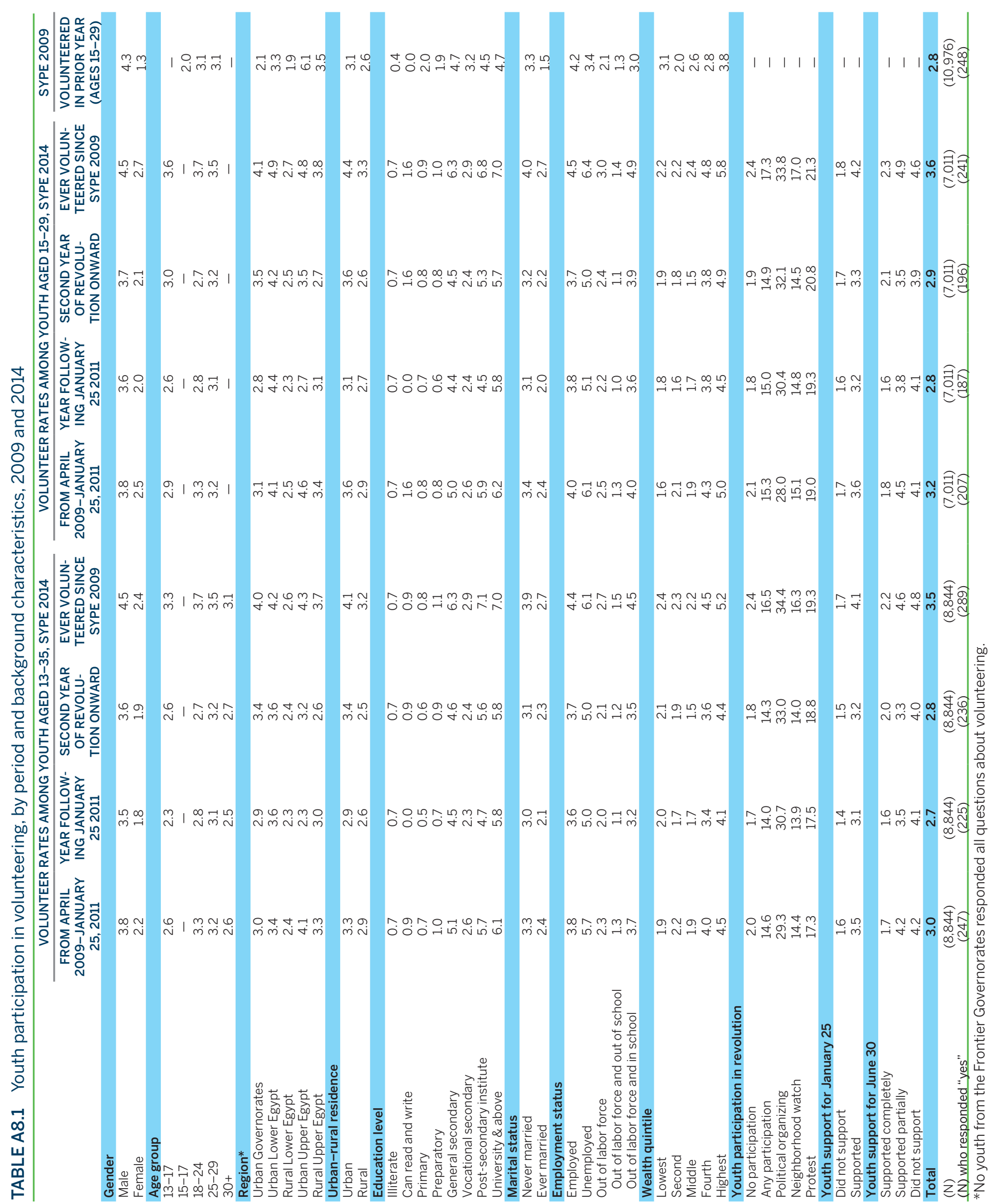


Table A8.2 Youth participation in groups and associations, by period and background characteristics, 2009 and 2014

\begin{tabular}{|c|c|c|c|}
\hline & $\begin{array}{c}\text { YOUTH AGED } \\
13-35 \text { IN } 2014\end{array}$ & $\begin{array}{c}\text { YOUTH AGED } \\
15-29 \text { IN } 2014\end{array}$ & $\begin{array}{l}\text { YOUTH AGED } \\
15-29 \text { IN } 2009\end{array}$ \\
\hline \multicolumn{4}{|l|}{ Gender } \\
\hline Male & 4.1 & 4.2 & 6.6 \\
\hline Female & 1.5 & 1.5 & 3.2 \\
\hline \multicolumn{4}{|l|}{ Age group } \\
\hline $13-17$ & 3.4 & 3.3 & - \\
\hline $15-17$ & - & - & 6.4 \\
\hline $18-24$ & 3.1 & 3.1 & 4.6 \\
\hline $25-29$ & 2.3 & 2.3 & 4.3 \\
\hline $30+$ & 2.3 & - & - \\
\hline \multicolumn{4}{|l|}{ Region } \\
\hline Urban Governorates & 5.8 & 5.8 & 10.6 \\
\hline Urban Lower Egypt & 2.0 & 2.1 & 5.6 \\
\hline Rural Lower Egypt & 2.5 & 2.6 & 3.4 \\
\hline Urban Upper Egypt & 3.0 & 3.4 & 2.8 \\
\hline Rural Upper Egypt & 1.6 & 1.7 & 2.7 \\
\hline Frontier Governorates & 2.8 & 2.9 & 1.9 \\
\hline \multicolumn{4}{|l|}{ Urban-rural residence } \\
\hline Urban & 5.4 & 5.5 & 8.4 \\
\hline Rural & 2.1 & 2.1 & 3.1 \\
\hline Informal urban areas & 0.1 & 0.1 & 4.8 \\
\hline \multicolumn{4}{|l|}{ Education level } \\
\hline Illiterate & 0.0 & 0.0 & 0.5 \\
\hline Can read and write & 0.0 & 0.0 & 10.9 \\
\hline Primary & 1.0 & 1.1 & 3.4 \\
\hline Preparatory & 1.3 & 0.8 & 4.4 \\
\hline General secondary & 6.5 & 6.5 & 11.9 \\
\hline Vocational secondary & 1.4 & 1.5 & 2.0 \\
\hline Post-secondary institute & 4.5 & 4.7 & 3.2 \\
\hline University and above & 7.0 & 6.8 & 13.0 \\
\hline \multicolumn{4}{|l|}{ Marital status } \\
\hline Never married & 3.6 & 3.6 & 6.2 \\
\hline Ever married & 1.4 & 1.2 & 1.8 \\
\hline \multicolumn{4}{|l|}{ Employment status } \\
\hline Employed & 3.2 & 3.2 & 4.9 \\
\hline Unemployed & 5.7 & 5.9 & 4.5 \\
\hline Out of labor force & 2.4 & 2.6 & 5.0 \\
\hline Out of labor force and out of school & 0.7 & 0.7 & 1.4 \\
\hline Out of labor force and in school & 4.9 & 5.0 & 9.5 \\
\hline \multicolumn{4}{|l|}{ Wealth quintile } \\
\hline Lowest & 0.9 & 0.8 & 1.7 \\
\hline Second & 1.4 & 1.4 & 2.0 \\
\hline Middle & 1.2 & 1.3 & 2.7 \\
\hline Fourth & 2.8 & 3.1 & 5.0 \\
\hline Highest & 7.0 & 7.0 & 14.6 \\
\hline \multicolumn{4}{|l|}{ Youth participation in revolution } \\
\hline No participation & 1.4 & 1.4 & - \\
\hline Any participation & 20.8 & 21.1 & - \\
\hline Political organizing & 37.4 & 36.8 & - \\
\hline Neighborhood watch & 19.3 & 19.6 & - \\
\hline Protest & 35.0 & 36.7 & - \\
\hline \multicolumn{4}{|l|}{ Youth support for January 25} \\
\hline Did not support & 1.5 & 1.5 & - \\
\hline Supported & 3.3 & 3.4 & - \\
\hline \multicolumn{4}{|l|}{ Youth support for June 30} \\
\hline Supported completely & 2.5 & 2.7 & - \\
\hline Supported partially & 3.2 & 3.1 & - \\
\hline Did not support & 3.2 & 3.3 & - \\
\hline Total & 2.8 & 2.9 & 4.9 \\
\hline$(\mathrm{N})$ & $(10,861)$ & $(8,579)$ & $(10,976)$ \\
\hline (N) who responded "yes" & (299) & $(246)$ & $(524)$ \\
\hline
\end{tabular}


TABLE A9.1 Youth agreement with the statement, "Educating boys is more important than educating girls," 2009 and 2014, percent

\begin{tabular}{|c|c|c|c|c|c|c|c|c|c|}
\hline & \multicolumn{3}{|c|}{2009 (AGES 15-29) } & \multicolumn{3}{|c|}{2014 (AGES 15-29) } & \multicolumn{3}{|c|}{2014 (AGES 13-35) } \\
\hline & AGREE & DISAGREE & $\begin{array}{l}\text { DON'T } \\
\text { KNOW }\end{array}$ & AGREE & $\begin{array}{l}\text { NEITHER } \\
\text { AGREE } \\
\text { NOR DIS- } \\
\text { AGREE }\end{array}$ & $\begin{array}{c}\text { DIS- } \\
\text { AGREE }\end{array}$ & AGREE & $\begin{array}{l}\text { NEITHER } \\
\text { AGREE } \\
\text { NOR DIS- } \\
\text { AGREE }\end{array}$ & $\begin{array}{c}\text { DIS- } \\
\text { AGREE }\end{array}$ \\
\hline \multicolumn{10}{|l|}{ Gender } \\
\hline Male & 34.9 & 64.4 & 0.7 & 34.2 & 18.7 & 47.1 & 34.9 & 18.2 & 46.9 \\
\hline Female & 13.4 & 86.0 & 0.6 & 20.8 & 12.0 & 67.2 & 21.4 & 12.5 & 66.1 \\
\hline \multicolumn{10}{|l|}{ Education level } \\
\hline Illiterate & 27.4 & 70.2 & 2.4 & 36.6 & 21.7 & 41.8 & 35.0 & 21.8 & 43.2 \\
\hline Can read and write & 9.4 & 73.5 & 17.1 & 35.7 & 33.3 & 31.0 & 40.0 & 22.5 & 37.5 \\
\hline Primary & 30.2 & 69.0 & 0.8 & 38.5 & 19.0 & 42.5 & 38.3 & 18.8 & 42.9 \\
\hline Preparatory & 26.0 & 73.4 & 0.6 & 34.6 & 17.1 & 48.3 & 33.1 & 16.4 & 50.6 \\
\hline General secondary & 18.6 & 81.0 & 0.4 & 18.7 & 12.2 & 69.1 & 18.9 & 11.8 & 69.3 \\
\hline Vocational secondary & 24.3 & 75.4 & 0.3 & 27.8 & 16.1 & 56.1 & 27.7 & 15.9 & 56.4 \\
\hline Post-secondary institute & 27.9 & 71.8 & 0.3 & 24.6 & 11.6 & 63.8 & 26.0 & 13.3 & 60.8 \\
\hline University and above & 16.0 & 83.8 & 0.2 & 21.2 & 11.5 & 67.3 & 22.8 & 11.0 & 66.3 \\
\hline \multicolumn{10}{|l|}{ Region } \\
\hline Urban Governorates & 24.5 & 74.8 & 0.7 & 37.3 & 10.1 & 52.5 & 37.9 & 10.6 & 51.5 \\
\hline Urban Lower Egypt & 12.8 & 86.3 & 1.0 & 21.2 & 15.2 & 63.6 & 23.2 & 14.4 & 62.3 \\
\hline Rural Lower Egypt & 20.8 & 78.4 & 0.8 & 20.7 & 18.8 & 60.5 & 20.7 & 18.5 & 60.9 \\
\hline Urban Upper Egypt & 28.8 & 70.6 & 0.6 & 22.5 & 17.7 & 59.8 & 24.5 & 18.7 & 56.8 \\
\hline Rural Upper Egypt & 32.5 & 67.0 & 0.4 & 32.6 & 14.5 & 52.9 & 32.7 & 14.3 & 53.0 \\
\hline Frontier Governorates & 23.6 & 76.4 & 0.0 & 41.0 & 21.1 & 38.0 & 41.2 & 21.0 & 37.8 \\
\hline \multicolumn{10}{|l|}{ Urban-rural residence } \\
\hline Urban & 21.9 & 77.3 & 0.8 & 30.5 & 13.7 & 55.8 & 31.7 & 13.8 & 54.5 \\
\hline Rural & 26.1 & 73.3 & 0.6 & 26.9 & 16.8 & 56.4 & 26.7 & 16.5 & 56.7 \\
\hline Informal urban areas & 22.5 & 77.1 & 0.4 & 25.5 & 13.1 & 61.5 & 27.8 & 13.3 & 58.9 \\
\hline \multicolumn{10}{|l|}{ Wealth quintile } \\
\hline Lowest & 29.5 & 69.7 & 0.9 & 34.8 & 18.4 & 46.8 & 34.6 & 18.4 & 47.1 \\
\hline Second & 27.2 & 72.1 & 0.7 & 27.6 & 16.1 & 56.3 & 28.8 & 16.3 & 54.8 \\
\hline Middle & 25.7 & 73.8 & 0.6 & 27.4 & 17.2 & 55.4 & 28.0 & 16.9 & 55.1 \\
\hline Fourth & 21.8 & 77.8 & 0.4 & 28.8 & 14.6 & 56.7 & 29.4 & 14.5 & 56.1 \\
\hline Highest & 17.0 & 82.1 & 0.9 & 22.2 & 12.2 & 65.5 & 22.3 & 11.8 & 65.9 \\
\hline \multicolumn{10}{|l|}{ Age group } \\
\hline 15-17 & 24.0 & 75.1 & 0.9 & 26.5 & 13.8 & 59.7 & 26.7 & 14.0 & 59.4 \\
\hline 18-24 & 25.2 & 74.2 & 0.6 & 27.5 & 15.8 & 56.7 & 27.5 & 15.8 & 56.7 \\
\hline $25-29$ & 23.2 & 76.2 & 0.6 & 29.5 & 16.2 & 54.3 & 29.5 & 16.2 & 54.3 \\
\hline 30-35 & - & - & - & - & - & - & 30.7 & 15.0 & 54.3 \\
\hline \multicolumn{10}{|l|}{ Marital status } \\
\hline Never married & 26.4 & 72.9 & 0.8 & 28.0 & 15.7 & 56.3 & 28.3 & 15.6 & 56.1 \\
\hline Ever married & 19.3 & 80.3 & 0.4 & 27.3 & 15.0 & 57.7 & 28.3 & 15.1 & 56.7 \\
\hline \multicolumn{10}{|l|}{ Employment status } \\
\hline Employed & 33.4 & 66.3 & 0.4 & 32.5 & 17.5 & 50.0 & 33.4 & 16.7 & 50.0 \\
\hline Unemployed & 24.0 & 75.4 & 0.6 & 27.8 & 11.3 & 61.0 & 26.3 & 12.2 & 61.5 \\
\hline Out of labor force & 19.8 & 79.4 & 0.8 & 25.5 & 14.8 & 59.7 & 25.6 & 14.9 & 59.4 \\
\hline Total & 24.4 & 75.0 & 0.7 & 27.8 & 15.5 & 56.7 & 28.3 & 15.4 & 56.3 \\
\hline$(\mathrm{N})$ & $(2,491)$ & $(8,433)$ & (68) & $(2,452)$ & $(1,313)$ & $(4,848)$ & $(3,147)$ & $(1,670)$ & $(6,087)$ \\
\hline
\end{tabular}


TABLE A9.2 Youth agreement with the statement, "When job opportunities are scarce, priority must go to men over women," 2009 and 2014, percent

\begin{tabular}{|c|c|c|c|c|c|c|c|c|c|}
\hline & \multicolumn{3}{|c|}{2009 (AGES 15-29) } & \multicolumn{3}{|c|}{2014 (AGES 15-29) } & \multicolumn{3}{|c|}{2014 (AGES 13-35) } \\
\hline & AGREE & NEITHER & $\begin{array}{c}\text { DIS- } \\
\text { AGREE }\end{array}$ & AGREE & $\begin{array}{c}\text { NEITHER } \\
\text { AGREE NOR } \\
\text { DISAGREE }\end{array}$ & $\begin{array}{l}\text { DIS- } \\
\text { AGREE }\end{array}$ & AGREE & $\begin{array}{c}\text { NEITHER } \\
\text { AGREE NOR } \\
\text { DISAGREE }\end{array}$ & $\begin{array}{l}\text { DIS- } \\
\text { AGREE }\end{array}$ \\
\hline \multicolumn{10}{|l|}{ Gender } \\
\hline Male & 92.8 & 6.3 & 0.9 & 68.1 & 19.2 & 12.7 & 68.1 & 19.1 & 12.8 \\
\hline Female & 80.9 & 13.6 & 5.5 & 52.1 & 18.7 & 29.2 & 53.0 & 18.7 & 28.4 \\
\hline \multicolumn{10}{|l|}{ Education level } \\
\hline Illiterate & 88.3 & 9.3 & 2.4 & 64.7 & 22.6 & 12.7 & 63.1 & 24.0 & 12.9 \\
\hline Can read and write & 89.7 & 5.3 & 5.0 & 73.9 & 25.6 & 0.5 & 67.9 & 22.1 & 10.0 \\
\hline Primary & 88.5 & 9.3 & 2.2 & 71.5 & 16.1 & 12.4 & 71.5 & 15.9 & 12.6 \\
\hline Preparatory & 87.2 & 9.6 & 3.3 & 66.3 & 18.3 & 15.4 & 64.1 & 18.0 & 17.9 \\
\hline General secondary & 84.4 & 10.3 & 5.3 & 50.8 & 17.3 & 31.9 & 51.8 & 17.0 & 31.2 \\
\hline Vocational secondary & 88.0 & 9.9 & 2.2 & 61.8 & 19.4 & 18.8 & 62.1 & 19.1 & 18.8 \\
\hline Post-secondary institute & 90.3 & 5.9 & 3.8 & 59.7 & 18.3 & 22.0 & 61.6 & 18.3 & 20.1 \\
\hline University and above & 82.9 & 12.0 & 5.1 & 53.0 & 19.0 & 28.0 & 53.6 & 18.8 & 27.6 \\
\hline \multicolumn{10}{|l|}{ Region } \\
\hline Urban Governorates & 86.7 & 11.0 & 2.3 & 66.8 & 12.4 & 20.9 & 67.4 & 12.2 & 20.4 \\
\hline Urban Lower Egypt & 81.4 & 12.6 & 6.0 & 51.8 & 21.6 & 26.6 & 52.7 & 20.7 & 26.6 \\
\hline Rural Lower Egypt & 83.1 & 12.9 & 4.0 & 59.0 & 24.6 & 16.4 & 58.9 & 24.6 & 16.5 \\
\hline Urban Upper Egypt & 90.5 & 7.0 & 2.5 & 44.1 & 26.0 & 29.9 & 45.8 & 25.8 & 28.4 \\
\hline Rural Upper Egypt & 93.2 & 4.9 & 1.9 & 66.0 & 13.8 & 20.2 & 65.7 & 14.0 & 20.4 \\
\hline Frontier Governorates & 90.4 & 7.9 & 1.8 & 59.7 & 24.9 & 15.4 & 60.6 & 25.1 & 14.3 \\
\hline \multicolumn{10}{|l|}{ Urban-rural residence } \\
\hline Urban & 86.9 & 10.3 & 2.8 & 61.1 & 16.5 & 22.4 & 62.1 & 16.0 & 21.9 \\
\hline Rural & 87.7 & 9.3 & 3.0 & 62.5 & 19.4 & 18.1 & 62.2 & 19.6 & 18.2 \\
\hline Informal urban areas & 83.5 & 11.5 & 5.0 & 45.3 & 24.0 & 30.7 & 47.3 & 23.2 & 29.5 \\
\hline \multicolumn{10}{|l|}{ Wealth quintile } \\
\hline Lowest & 89.9 & 7.8 & 2.4 & 65.3 & 19.2 & 15.5 & 64.9 & 19.4 & 15.7 \\
\hline Second & 87.9 & 9.4 & 2.7 & 59.9 & 19.1 & 21.0 & 60.5 & 18.8 & 20.6 \\
\hline Third & 88.4 & 8.7 & 2.9 & 59.4 & 18.8 & 21.9 & 59.7 & 18.7 & 21.6 \\
\hline Fourth & 85.0 & 11.6 & 3.4 & 61.7 & 18.5 & 19.8 & 62.2 & 18.4 & 19.4 \\
\hline Highest & 83.5 & 12.0 & 4.5 & 57.0 & 19.3 & 23.8 & 57.0 & 19.2 & 23.8 \\
\hline \multicolumn{10}{|l|}{ Age group } \\
\hline $15-17$ & 86.4 & 9.7 & 3.9 & 58.4 & 18.1 & 23.5 & 57.7 & 18.5 & 23.9 \\
\hline $18-24$ & 87.1 & 9.8 & 3.1 & 60.4 & 19.4 & 20.2 & 60.4 & 19.4 & 20.2 \\
\hline $25-29$ & 87.3 & 10.0 & 2.7 & 62.0 & 19.0 & 19.0 & 62.0 & 19.0 & 19.0 \\
\hline $30-35$ & - & - & - & - & - & - & 63.3 & 18.2 & 18.5 \\
\hline \multicolumn{10}{|l|}{ Marital status } \\
\hline Never married & 87.4 & 9.3 & 3.3 & 59.5 & 19.3 & 21.2 & 59.3 & 19.3 & 21.4 \\
\hline Ever married & 86.1 & 11.2 & 2.7 & 62.9 & 18.2 & 18.9 & 63.4 & 18.1 & 18.6 \\
\hline \multicolumn{10}{|l|}{ Employment status } \\
\hline Employed & 91.0 & 7.3 & 1.7 & 66.7 & 17.6 & 15.8 & 66.6 & 17.5 & 15.9 \\
\hline Unemployed & 86.6 & 9.5 & 4.0 & 65.3 & 18.1 & 16.6 & 63.4 & 18.2 & 18.4 \\
\hline Out of labor force & 85.0 & 11.2 & 3.8 & 57.0 & 19.7 & 23.3 & 57.2 & 19.7 & 23.1 \\
\hline Total & 87.0 & 9.8 & 3.2 & 60.4 & 19.0 & 20.6 & 60.7 & 18.9 & 20.4 \\
\hline$(N)$ & $(9,488)$ & $(1,127)$ & (374) & $(5,234)$ & $(1,641)$ & $(1,738)$ & $(6,677)$ & $(2,064)$ & $(2,163)$ \\
\hline
\end{tabular}


TABLE A9.3 Youth responses to the question: "Do you agree that women in your family should vote in elections and referendums?", 2014, percent

\begin{tabular}{|c|c|c|c|c|}
\hline & \multicolumn{2}{|c|}{ AGES 18-29 } & \multicolumn{2}{|c|}{ AGES 18-35 } \\
\hline & YES & NO & YES & NO \\
\hline \multicolumn{5}{|l|}{ Gender } \\
\hline Male & 82.1 & 17.9 & 81.9 & 18.1 \\
\hline Female & 81.0 & 19.0 & 81.1 & 19.0 \\
\hline \multicolumn{5}{|l|}{ Education level } \\
\hline Illiterate & 66.6 & 33.4 & 68.6 & 31.4 \\
\hline Can read and write & 63.4 & 36.6 & 72.0 & 28.0 \\
\hline Primary & 75.8 & 24.2 & 76.2 & 23.8 \\
\hline Preparatory & 73.5 & 26.5 & 74.0 & 26.0 \\
\hline General secondary & 84.2 & 15.8 & 85.3 & 14.8 \\
\hline Vocational secondary & 81.7 & 18.3 & 81.9 & 18.2 \\
\hline Post-secondary institute & 89.2 & 10.8 & 88.8 & 11.2 \\
\hline University and above & 90.3 & 9.7 & 89.9 & 10.1 \\
\hline \multicolumn{5}{|l|}{ Region } \\
\hline Urban Governorates & 85.7 & 14.3 & 85.7 & 14.3 \\
\hline Urban Lower Egypt & 90.0 & 10.0 & 89.6 & 10.4 \\
\hline Rural Lower Egypt & 85.0 & 15.0 & 84.4 & 15.6 \\
\hline Urban Upper Egypt & 78.0 & 22.0 & 78.3 & 21.7 \\
\hline Rural Upper Egypt & 73.8 & 26.2 & 73.8 & 26.2 \\
\hline Frontier Governorates & 71.6 & 28.4 & 70.7 & 29.3 \\
\hline \multicolumn{5}{|l|}{ Urban-rural residence } \\
\hline Urban & 83.4 & 16.6 & 83.4 & 16.6 \\
\hline Rural & 79.3 & 20.7 & 79.1 & 20.9 \\
\hline Informal urban areas & 90.5 & 9.5 & 90.0 & 10.1 \\
\hline \multicolumn{5}{|l|}{ Wealth quintile } \\
\hline Lowest & 68.9 & 31.1 & 69.9 & 30.1 \\
\hline Second & 80.1 & 19.9 & 79.4 & 20.6 \\
\hline Middle & 81.8 & 18.2 & 81.6 & 18.4 \\
\hline Fourth & 84.9 & 15.1 & 85.6 & 14.4 \\
\hline Highest & 89.2 & 10.8 & 88.7 & 11.3 \\
\hline \multicolumn{5}{|l|}{ Age group } \\
\hline $18-24$ & 81.9 & 18.1 & 81.9 & 18.1 \\
\hline $25-29$ & 81.1 & 19.0 & 81.1 & 19.0 \\
\hline 30-35 & - & - & 81.1 & 18.9 \\
\hline \multicolumn{5}{|l|}{ Marital status } \\
\hline Never married & 81.7 & 18.3 & 81.8 & 18.2 \\
\hline Ever married & 81.4 & 18.6 & 81.2 & 18.8 \\
\hline \multicolumn{5}{|l|}{ Employment status } \\
\hline Employed & 81.9 & 18.1 & 82.0 & 18.1 \\
\hline Unemployed & 89.5 & 10.5 & 89.4 & 10.6 \\
\hline Out of labor force & 80.6 & 19.4 & 80.4 & 19.7 \\
\hline Total & 81.6 & 18.4 & 81.5 & 18.5 \\
\hline$(\mathrm{N})$ & $(5,428)$ & $(1,256)$ & $(7,027)$ & $(1,646)$ \\
\hline
\end{tabular}


TABLE A9.4 Youth agreement with the statement, "A girl must obey her brother, even if he is younger," 2009 and 2014, percent

\begin{tabular}{|c|c|c|c|c|c|c|c|c|c|}
\hline & \multicolumn{3}{|c|}{2009 (AGES 15-29) } & \multicolumn{3}{|c|}{2014 (AGES 15-29) } & \multicolumn{3}{|c|}{2014 (AGES 13-35) } \\
\hline & AGREE & DISAGREE & $\begin{array}{l}\text { DON'T } \\
\text { KNOW }\end{array}$ & AGREE & $\begin{array}{l}\text { NEITHER } \\
\text { AGREE } \\
\text { NOR DIS- } \\
\text { AGREE }\end{array}$ & $\begin{array}{c}\text { DIS- } \\
\text { AGREE }\end{array}$ & AGREE & $\begin{array}{l}\text { NEITHER } \\
\text { AGREE } \\
\text { NOR DIS- } \\
\text { AGREE }\end{array}$ & $\begin{array}{c}\text { DIS- } \\
\text { AGREE }\end{array}$ \\
\hline \multicolumn{10}{|l|}{ Gender } \\
\hline Male & 70.6 & 28.8 & 0.5 & 67.5 & 23.9 & 8.6 & 67.5 & 23.9 & 8.6 \\
\hline Female & 48.7 & 50.2 & 1.1 & 53.1 & 29.2 & 17.7 & 53.9 & 28.9 & 17.2 \\
\hline \multicolumn{10}{|l|}{ Education level } \\
\hline Illiterate & 66.9 & 30.8 & 2.4 & 59.1 & 31.2 & 9.7 & 59.0 & 31.2 & 9.8 \\
\hline Can read and write & 53.5 & 29.3 & 17.1 & 64.6 & 27.6 & 7.7 & 65.1 & 27.1 & 7.7 \\
\hline Primary & 64.9 & 34.2 & 0.9 & 70.6 & 20.5 & 9.0 & 70.4 & 21.1 & 8.5 \\
\hline Preparatory & 61.5 & 38.0 & 0.5 & 65.9 & 23.2 & 10.9 & 66.5 & 22.4 & 11.1 \\
\hline General secondary & 52.0 & 46.9 & 1.1 & 57.0 & 28.3 & 14.8 & 57.4 & 28.1 & 14.6 \\
\hline Vocational secondary & 61.6 & 37.7 & 0.7 & 62.2 & 26.4 & 11.4 & 61.8 & 26.6 & 11.7 \\
\hline Post-secondary institute & 57.5 & 42.5 & 0.0 & 61.1 & 22.6 & 16.3 & 60.1 & 23.9 & 16.0 \\
\hline University and above & 47.8 & 51.8 & 0.4 & 53.0 & 28.5 & 18.4 & 53.7 & 28.3 & 18.1 \\
\hline \multicolumn{10}{|l|}{ Region } \\
\hline Urban Governorates & 52.5 & 46.5 & 1.0 & 63.9 & 19.6 & 16.5 & 64.0 & 19.6 & 16.4 \\
\hline Urban Lower Egypt & 51.5 & 47.4 & 1.1 & 53.0 & 31.1 & 15.9 & 54.0 & 30.0 & 16.0 \\
\hline Rural Lower Egypt & 63.8 & 35.4 & 0.8 & 56.4 & 31.4 & 12.1 & 56.9 & 31.7 & 11.4 \\
\hline Urban Upper Egypt & 59.5 & 40.2 & 0.4 & 55.7 & 30.3 & 14.0 & 55.8 & 29.7 & 14.6 \\
\hline Rural Upper Egypt & 65.2 & 34.4 & 0.5 & 67.8 & 21.9 & 10.3 & 67.8 & 22.0 & 10.2 \\
\hline Frontier Governorates & 61.6 & 34.1 & 4.3 & 53.2 & 36.1 & 10.7 & 54.2 & 34.4 & 11.4 \\
\hline \multicolumn{10}{|l|}{ Urban-rural residence } \\
\hline Urban & 53.4 & 45.7 & 0.9 & 59.8 & 26.3 & 13.8 & 60.5 & 25.5 & 14.1 \\
\hline Rural & 64.4 & 34.9 & 0.7 & 62.0 & 26.9 & 11.2 & 62.1 & 27.1 & 10.8 \\
\hline Informal urban areas & 54.5 & 44.3 & 1.2 & 54.5 & 24.2 & 21.3 & 54.6 & 24.3 & 21.1 \\
\hline \multicolumn{10}{|l|}{ Wealth quintile } \\
\hline Lowest & 67.5 & 31.6 & 0.9 & 68.5 & 21.4 & 10.1 & 67.3 & 22.4 & 10.3 \\
\hline Second & 64.1 & 35.4 & 0.5 & 58.5 & 30.6 & 10.9 & 58.9 & 29.3 & 11.8 \\
\hline Middle & 62.4 & 36.7 & 0.9 & 60.8 & 26.8 & 12.4 & 61.7 & 26.8 & 11.5 \\
\hline Fourth & 56.3 & 43.1 & 0.6 & 61.5 & 24.7 & 13.8 & 62.1 & 24.7 & 13.2 \\
\hline Highest & 47.9 & 50.8 & 1.3 & 55.6 & 27.9 & 16.5 & 55.9 & 28.0 & 16.2 \\
\hline \multicolumn{10}{|l|}{ Age group } \\
\hline $15-17$ & 60.1 & 39.1 & 0.8 & 61.2 & 24.5 & 14.3 & 61.4 & 24.5 & 14.1 \\
\hline $18-24$ & 60.2 & 39.0 & 0.9 & 59.8 & 27.0 & 13.2 & 59.8 & 27.0 & 13.2 \\
\hline $25-29$ & 59.3 & 39.9 & 0.8 & 61.5 & 27.0 & 11.5 & 61.5 & 27.0 & 11.5 \\
\hline $30-35$ & - & - & - & - & - & - & 61.9 & 26.2 & 12.0 \\
\hline \multicolumn{10}{|l|}{ Marital status } \\
\hline Never married & 60.9 & 38.3 & 0.9 & 60.1 & 26.5 & 13.4 & 60.0 & 26.4 & 13.6 \\
\hline Ever married & 57.4 & 41.9 & 0.7 & 62.2 & 26.2 & 11.6 & 62.5 & 26.3 & 11.3 \\
\hline \multicolumn{10}{|l|}{ Employment status } \\
\hline Employed & 67.2 & 32.5 & 0.3 & 66.0 & 25.0 & 9.1 & 65.7 & 24.6 & 9.7 \\
\hline Unemployed & 63.5 & 35.7 & 0.9 & 66.7 & 21.0 & 12.3 & 65.7 & 23.5 & 10.9 \\
\hline Out of labor force & 55.8 & 43.1 & 1.1 & 57.5 & 27.6 & 14.9 & 57.8 & 27.6 & 14.6 \\
\hline Total & 59.9 & 39.3 & 0.8 & 60.6 & 26.4 & 12.9 & 60.9 & 26.4 & 12.8 \\
\hline$(\mathrm{N})$ & $(6,455)$ & $(4,421)$ & (116) & $(5,170)$ & $(2,301)$ & $(1,142)$ & $(6,586)$ & $(2,896)$ & $(1,422)$ \\
\hline
\end{tabular}


TABLE A9.5 Youth agreement with the statement, "Boys should help with household chores as much as girls do," 2009 and 2014, percent

\begin{tabular}{|c|c|c|c|c|c|c|c|c|c|}
\hline & \multicolumn{3}{|c|}{2009 (AGES 15-29) } & \multicolumn{3}{|c|}{2014 (AGES 15-29) } & \multicolumn{3}{|c|}{2014 (AGES 13-35) } \\
\hline & AGREE & $\begin{array}{c}\text { DIS- } \\
\text { AGREE }\end{array}$ & $\begin{array}{l}\text { DON'T } \\
\text { KNOW }\end{array}$ & AGREE & $\begin{array}{c}\text { NEITHER } \\
\text { AGREE } \\
\text { NOR DIS- } \\
\text { AGREE }\end{array}$ & $\begin{array}{c}\text { DIS- } \\
\text { AGREE }\end{array}$ & AGREE & $\begin{array}{l}\text { NEITHER } \\
\text { AGREE } \\
\text { NOR DIS- } \\
\text { AGREE }\end{array}$ & $\begin{array}{c}\text { DIS- } \\
\text { AGREE }\end{array}$ \\
\hline \multicolumn{10}{|l|}{ Gender } \\
\hline Males & 27.1 & 72.5 & 0.5 & 20.3 & 28.4 & 51.3 & 20.8 & 28.3 & 51.0 \\
\hline Females & 41.0 & 57.9 & 1.1 & 36.1 & 32.4 & 31.6 & 35.4 & 32.8 & 31.8 \\
\hline \multicolumn{10}{|l|}{ Education level } \\
\hline Illiterate & 34.8 & 62.8 & 2.4 & 21.0 & 35.9 & 43.1 & 22.3 & 35.4 & 42.3 \\
\hline Can read and write & 23.4 & 59.5 & 17.1 & 33.8 & 26.0 & 40.2 & 26.6 & 30.4 & 43.1 \\
\hline Primary & 32.4 & 66.9 & 0.7 & 25.1 & 26.4 & 48.5 & 24.9 & 26.5 & 48.6 \\
\hline Preparatory & 33.9 & 65.5 & 0.6 & 26.4 & 27.6 & 46.0 & 28.8 & 27.5 & 43.7 \\
\hline General secondary & 36.1 & 63.5 & 0.4 & 34.2 & 29.2 & 36.6 & 33.6 & 29.0 & 37.4 \\
\hline Vocational secondary & 32.8 & 66.7 & 0.5 & 25.6 & 31.6 & 42.9 & 25.6 & 31.9 & 42.6 \\
\hline Post-secondary institute & 31.0 & 69.1 & 0.0 & 29.5 & 26.6 & 43.9 & 28.2 & 29.3 & 42.5 \\
\hline University and above & 36.8 & 62.3 & 0.8 & 32.9 & 30.0 & 37.0 & 33.2 & 30.1 & 36.8 \\
\hline \multicolumn{10}{|l|}{ Region } \\
\hline Urban Governorates & 30.5 & 68.6 & 0.9 & 36.7 & 22.6 & 40.6 & 36.6 & 22.9 & 40.5 \\
\hline Urban Lower Egypt & 35.9 & 63.0 & 1.1 & 33.2 & 31.7 & 35.1 & 33.7 & 32.3 & 34.0 \\
\hline Rural Lower Egypt & 35.0 & 64.0 & 1.0 & 25.7 & 34.3 & 40.0 & 25.3 & 35.0 & 39.8 \\
\hline Urban Upper Egypt & 38.5 & 61.0 & 0.5 & 29.6 & 33.6 & 36.7 & 29.5 & 33.3 & 37.3 \\
\hline Rural Upper Egypt & 33.2 & 66.4 & 0.4 & 22.4 & 28.8 & 48.8 & 22.9 & 28.4 & 48.7 \\
\hline Frontier Governorates & 31.5 & 68.6 & 0.0 & 20.4 & 38.3 & 41.3 & 20.2 & 38.8 & 41.0 \\
\hline \multicolumn{10}{|l|}{ Urban-rural residence } \\
\hline Urban & 32.9 & 66.2 & 0.9 & 31.6 & 28.2 & 40.2 & 31.4 & 28.2 & 40.5 \\
\hline Rural & 34.1 & 65.2 & 0.7 & 24.0 & 31.7 & 44.3 & 24.1 & 31.9 & 44.0 \\
\hline Informal urban areas & 35.8 & 63.4 & 0.8 & 40.5 & 27.7 & 31.8 & 41.4 & 28.4 & 30.2 \\
\hline \multicolumn{10}{|l|}{ Wealth quintile } \\
\hline Lowest & 33.3 & 65.9 & 0.8 & 24.5 & 27.1 & 48.4 & 24.7 & 28.0 & 47.3 \\
\hline Second & 32.4 & 67.2 & 0.4 & 24.5 & 34.5 & 41.0 & 24.9 & 33.3 & 41.8 \\
\hline Middle & 32.9 & 66.3 & 0.7 & 28.4 & 31.1 & 40.5 & 28.8 & 31.1 & 40.1 \\
\hline Fourth & 35.2 & 64.1 & 0.7 & 28.5 & 29.2 & 42.3 & 28.9 & 29.7 & 41.4 \\
\hline Highest & 36.0 & 62.8 & 1.2 & 32.1 & 29.4 & 38.5 & 31.6 & 30.1 & 38.3 \\
\hline \multicolumn{10}{|l|}{ Age group } \\
\hline $15-17$ & 35.5 & 63.8 & 0.7 & 29.7 & 27.5 & 42.9 & 30.3 & 27.7 & 42.0 \\
\hline $18-24$ & 32.9 & 66.4 & 0.7 & 27.4 & 30.7 & 41.9 & 27.4 & 30.7 & 41.9 \\
\hline $25-29$ & 34.4 & 64.8 & 0.9 & 27.3 & 31.7 & 41.1 & 27.3 & 31.7 & 41.1 \\
\hline 30-35 & - & - & - & - & - & - & 27.3 & 31.6 & 41.2 \\
\hline \multicolumn{10}{|l|}{ Marital status } \\
\hline Never married & 33.1 & 66.1 & 0.7 & 27.6 & 29.6 & 42.9 & 27.9 & 29.7 & 42.4 \\
\hline Ever married & 35.8 & 63.3 & 0.8 & 28.6 & 32.2 & 39.2 & 28.0 & 31.9 & 40.1 \\
\hline \multicolumn{10}{|l|}{ Employment status } \\
\hline Employed & 29.1 & 70.6 & 0.3 & 22.1 & 28.0 & 49.9 & 23.0 & 28.3 & 48.8 \\
\hline Unemployed & 33.0 & 66.2 & 0.8 & 25.7 & 28.0 & 46.3 & 25.5 & 29.3 & 45.2 \\
\hline Out of labor force & 36.5 & 62.6 & 1.0 & 30.9 & 31.6 & 37.6 & 30.9 & 31.8 & 37.3 \\
\hline Total & 33.9 & 65.4 & 0.8 & 27.8 & 30.3 & 41.9 & 27.9 & 30.5 & 41.6 \\
\hline$(\mathrm{N})$ & $(3,810)$ & $(7,099)$ & (83) & $(2,412)$ & $(2,627)$ & $(3,574)$ & $(3,058)$ & $(3,359)$ & $(4,487)$ \\
\hline
\end{tabular}


TABLE A9.6 Youth agreement with the statement, "Only the husband should decide how household money is spent," 2009 and 2014, percent

\begin{tabular}{|c|c|c|c|c|c|c|c|c|c|}
\hline & \multicolumn{3}{|c|}{2009 (AGES 15-29) } & \multicolumn{3}{|c|}{2014 (AGES 15-29) } & \multicolumn{3}{|c|}{2014 (AGES 13-35) } \\
\hline & AGREE & DISAGREE & $\begin{array}{l}\text { DON'T } \\
\text { KNOW }\end{array}$ & AGREE & $\begin{array}{l}\text { NEITHER } \\
\text { AGREE } \\
\text { NOR DIS- } \\
\text { AGREE }\end{array}$ & $\begin{array}{c}\text { DIS- } \\
\text { AGREE }\end{array}$ & AGREE & $\begin{array}{c}\text { NEITHER } \\
\text { AGREE NOR } \\
\text { DISAGREE }\end{array}$ & $\begin{array}{c}\text { DIS- } \\
\text { AGREE }\end{array}$ \\
\hline \multicolumn{10}{|l|}{ Gender } \\
\hline Male & 60.9 & 38.7 & 0.4 & 55.2 & 27.9 & 16.9 & 55.3 & 27.8 & 16.9 \\
\hline Female & 37.1 & 61.6 & 1.3 & 38.9 & 29.5 & 31.6 & 39.4 & 29.3 & 31.4 \\
\hline \multicolumn{10}{|l|}{ Education level } \\
\hline Illiterate & 58.0 & 40.0 & 2.1 & 54.3 & 28.2 & 17.5 & 53.6 & 29.1 & 17.3 \\
\hline Can read and write & 20.0 & 62.8 & 17.1 & 59.3 & 26.6 & 14.1 & 54.8 & 31.3 & 13.9 \\
\hline Primary & 55.6 & 43.3 & 1.2 & 53.1 & 29.2 & 17.7 & 53.6 & 29.6 & 16.8 \\
\hline Preparatory & 51.0 & 48.2 & 0.8 & 49.1 & 28.1 & 22.8 & 49.2 & 27.3 & 23.5 \\
\hline General secondary & 43.6 & 55.6 & 0.8 & 41.0 & 26.9 & 32.1 & 41.6 & 26.5 & 31.9 \\
\hline Vocational secondary & 48.8 & 50.7 & 0.5 & 50.7 & 28.7 & 20.6 & 49.8 & 28.3 & 21.9 \\
\hline Post-secondary institute & 42.6 & 57.4 & 0.0 & 49.3 & 27.0 & 23.8 & 48.9 & 27.4 & 23.7 \\
\hline University and above & 38.4 & 61.2 & 0.4 & 38.1 & 30.3 & 31.6 & 38.8 & 29.8 & 31.3 \\
\hline \multicolumn{10}{|l|}{ Region } \\
\hline Urban Governorates & 41.1 & 57.5 & 1.4 & 47.0 & 23.9 & 29.2 & 46.9 & 24.2 & 28.9 \\
\hline Urban Lower Egypt & 44.0 & 55.2 & 0.8 & 43.3 & 32.0 & 24.7 & 44.7 & 30.8 & 24.5 \\
\hline Rural Lower Egypt & 52.7 & 46.5 & 0.9 & 41.7 & 33.8 & 24.5 & 41.9 & 34.0 & 24.1 \\
\hline Urban Upper Egypt & 49.1 & 50.5 & 0.5 & 48.2 & 29.1 & 22.8 & 48.0 & 27.1 & 24.9 \\
\hline Rural Upper Egypt & 54.3 & 45.2 & 0.4 & 55.1 & 24.4 & 20.5 & 55.2 & 24.2 & 20.6 \\
\hline Frontier Governorates & 50.8 & 48.1 & 1.1 & 47.2 & 36.3 & 16.5 & 47.0 & 37.1 & 16.0 \\
\hline \multicolumn{10}{|l|}{ Urban-rural residence } \\
\hline Urban & 42.7 & 56.0 & 1.2 & 45.5 & 28.6 & 25.9 & 45.7 & 28.3 & 26.0 \\
\hline Rural & 53.4 & 45.9 & 0.7 & 48.3 & 29.3 & 22.5 & 48.2 & 29.4 & 22.3 \\
\hline Informal urban areas & 46.0 & 53.4 & 0.7 & 48.0 & 25.1 & 26.9 & 48.7 & 23.3 & 28.0 \\
\hline \multicolumn{10}{|l|}{ Wealth quintile } \\
\hline Lowest & 58.1 & 41.2 & 0.8 & 54.5 & 28.0 & 17.5 & 53.8 & 27.5 & 18.7 \\
\hline Second & 54.4 & 45.1 & 0.5 & 48.5 & 30.4 & 21.2 & 49.4 & 29.9 & 20.6 \\
\hline Middle & 51.8 & 47.3 & 1.0 & 48.2 & 28.5 & 23.4 & 47.7 & 28.7 & 23.6 \\
\hline Fourth & 44.7 & 54.5 & 0.9 & 48.0 & 27.6 & 24.5 & 47.8 & 27.2 & 25.0 \\
\hline Highest & 36.0 & 62.8 & 1.2 & 40.2 & 28.9 & 31.0 & 40.6 & 29.0 & 30.4 \\
\hline \multicolumn{10}{|l|}{ Age group } \\
\hline $15-17$ & 49.8 & 49.0 & 1.2 & 46.4 & 26.9 & 26.7 & 46.7 & 27.3 & 26.0 \\
\hline $18-24$ & 49.6 & 49.7 & 0.8 & 46.8 & 29.8 & 23.4 & 46.8 & 29.8 & 23.4 \\
\hline 25-29 & 48.3 & 51.0 & 0.7 & 49.3 & 28.1 & 22.6 & 49.3 & 28.1 & 22.6 \\
\hline $30-35$ & - & - & - & - & - & - & 47.8 & 27.4 & 24.8 \\
\hline \multicolumn{10}{|l|}{ Marital status } \\
\hline Never married & 50.6 & 48.4 & 1.0 & 47.8 & 28.4 & 23.8 & 47.9 & 28.4 & 23.8 \\
\hline Ever married & 45.9 & 53.6 & 0.5 & 46.5 & 29.4 & 24.2 & 46.8 & 28.8 & 24.4 \\
\hline \multicolumn{10}{|l|}{ Employment status } \\
\hline Employed & 58.6 & 41.2 & 0.2 & 54.7 & 26.5 & 18.8 & 53.4 & 26.8 & 19.9 \\
\hline Unemployed & 47.3 & 52.2 & 0.5 & 48.9 & 25.8 & 25.4 & 47.5 & 26.6 & 25.9 \\
\hline Out of labor force & 44.7 & 54.1 & 1.2 & 43.7 & 30.0 & 26.3 & 44.3 & 29.6 & 26.1 \\
\hline Total & 49.3 & 49.9 & 0.9 & 47.4 & 28.7 & 23.9 & 47.5 & 28.5 & 24.0 \\
\hline$(\mathrm{N})$ & $(5,241)$ & $(5,650)$ & $(101)$ & $(4,014)$ & $(2,505)$ & $(2,094)$ & $(5,082)$ & $(3,168)$ & $(2,654)$ \\
\hline
\end{tabular}


TABLE A9.7 Youth agreement with the statement, "A woman must obtain permission from her spouse before doing anything," 2009 and 2014, percent

\begin{tabular}{|c|c|c|c|c|c|c|c|c|c|}
\hline & \multicolumn{3}{|c|}{2009 (AGES 15-29) } & \multicolumn{3}{|c|}{2014 (AGES 15-29) } & \multicolumn{3}{|c|}{2014 (AGES 13-35) } \\
\hline & AGREE & DISAGREE & $\begin{array}{l}\text { DON'T } \\
\text { KNOW }\end{array}$ & AGREE & $\begin{array}{c}\text { NEITHER } \\
\text { AGREE NOR } \\
\text { DISAGREE }\end{array}$ & $\begin{array}{c}\text { DIS- } \\
\text { AGREE }\end{array}$ & AGREE & $\begin{array}{c}\text { NEITHER } \\
\text { AGREE NOR } \\
\text { DISAGREE }\end{array}$ & $\begin{array}{c}\text { DIS- } \\
\text { AGREE }\end{array}$ \\
\hline \multicolumn{10}{|l|}{ Gender } \\
\hline Male & 85.5 & 14.1 & 0.4 & 78.8 & 16.8 & 4.5 & 78.5 & 17.1 & 4.4 \\
\hline Female & 74.3 & 24.8 & 0.9 & 73.6 & 18.7 & 7.6 & 74.0 & 18.6 & 7.4 \\
\hline \multicolumn{10}{|l|}{ Education level } \\
\hline Illiterate & 81.8 & 16.1 & 2.1 & 76.7 & 17.8 & 5.6 & 76.3 & 18.6 & 5.2 \\
\hline Can read and write & 73.2 & 9.7 & 17.1 & 68.9 & 26.9 & 4.2 & 70.5 & 22.7 & 6.8 \\
\hline Primary & 82.0 & 17.1 & 0.9 & 78.6 & 16.8 & 4.6 & 79.4 & 16.6 & 4.0 \\
\hline Preparatory & 80.0 & 19.6 & 0.4 & 79.6 & 15.7 & 4.8 & 79.1 & 16.2 & 4.7 \\
\hline General secondary & 76.0 & 23.5 & 0.6 & 74.1 & 18.5 & 7.5 & 74.0 & 18.3 & 7.7 \\
\hline Vocational secondary & 82.0 & 17.7 & 0.3 & 77.5 & 17.3 & 5.3 & 77.2 & 17.3 & 5.6 \\
\hline Post-secondary institute & 79.6 & 20.1 & 0.3 & 81.3 & 14.1 & 4.6 & 80.7 & 15.5 & 3.8 \\
\hline University and above & 74.7 & 24.9 & 0.5 & 71.7 & 20.0 & 8.4 & 71.9 & 20.1 & 8.0 \\
\hline \multicolumn{10}{|l|}{ Region } \\
\hline Urban Governorates & 71.2 & 27.4 & 1.4 & 79.1 & 14.5 & 6.4 & 79.5 & 14.4 & 6.1 \\
\hline Urban Lower Egypt & 77.4 & 22.1 & 0.5 & 70.6 & 22.0 & 7.5 & 70.2 & 22.5 & 7.3 \\
\hline Rural Lower Egypt & 82.5 & 17.0 & 0.5 & 73.2 & 20.5 & 6.4 & 73.0 & 20.8 & 6.2 \\
\hline Urban Upper Egypt & 83.4 & 16.2 & 0.5 & 69.8 & 21.9 & 8.3 & 70.2 & 21.2 & 8.6 \\
\hline Rural Upper Egypt & 84.5 & 15.2 & 0.4 & 82.2 & 13.7 & 4.1 & 82.2 & 13.7 & 4.2 \\
\hline Frontier Governorates & 79.8 & 19.7 & 0.5 & 71.6 & 22.3 & 6.1 & 72.3 & 22.4 & 5.4 \\
\hline \multicolumn{10}{|l|}{ Urban-rural residence } \\
\hline Urban & 74.8 & 24.2 & 1.1 & 77.1 & 17.2 & 5.8 & 77.2 & 17.2 & 5.7 \\
\hline Rural & 83.4 & 16.2 & 0.4 & 77.5 & 17.2 & 5.3 & 77.3 & 17.5 & 5.2 \\
\hline Informal urban areas & 77.2 & 22.2 & 0.6 & 66.4 & 22.4 & 11.2 & 67.3 & 21.8 & 10.9 \\
\hline \multicolumn{10}{|l|}{ Wealth quintile } \\
\hline Lowest & 85.0 & 14.2 & 0.8 & 80.8 & 15.6 & 3.7 & 80.0 & 15.8 & 4.2 \\
\hline Second & 82.1 & 17.6 & 0.3 & 75.4 & 18.9 & 5.6 & 76.1 & 18.8 & 5.1 \\
\hline Middle & 82.5 & 17.1 & 0.4 & 75.7 & 18.3 & 6.0 & 75.3 & 19.0 & 5.7 \\
\hline Fourth & 79.2 & 20.3 & 0.5 & 74.6 & 19.0 & 6.5 & 75.1 & 18.6 & 6.4 \\
\hline Highest & 70.1 & 28.6 & 1.4 & 75.7 & 16.7 & 7.7 & 75.3 & 17.0 & 7.7 \\
\hline \multicolumn{10}{|l|}{ Age group } \\
\hline $15-17$ & 79.2 & 20.2 & 0.6 & 77.0 & 17.5 & 5.5 & 76.3 & 18.1 & 5.5 \\
\hline $18-24$ & 79.8 & 19.5 & 0.7 & 76.5 & 17.4 & 6.1 & 76.5 & 17.4 & 6.1 \\
\hline $25-29$ & 81.1 & 18.3 & 0.7 & 75.5 & 18.3 & 6.2 & 75.5 & 18.3 & 6.2 \\
\hline $30-35$ & - & - & - & - & - & - & 76.9 & 17.7 & 5.4 \\
\hline \multicolumn{10}{|l|}{ Marital status } \\
\hline Never married & 80.3 & 19.0 & 0.8 & 75.6 & 18.5 & 5.9 & 75.4 & 18.7 & 6.0 \\
\hline Ever married & 79.3 & 20.4 & 0.3 & 78.4 & 15.5 & 6.2 & 78.0 & 16.3 & 5.8 \\
\hline \multicolumn{10}{|l|}{ Employment status } \\
\hline Employed & 83.7 & 16.1 & 0.2 & 79.4 & 16.9 & 3.7 & 78.9 & 17.1 & 4.1 \\
\hline Unemployed & 83.6 & 16.3 & 0.1 & 77.6 & 16.7 & 5.6 & 76.8 & 17.9 & 5.3 \\
\hline Out of labor force & 77.8 & 21.3 & 0.9 & 74.7 & 18.2 & 7.1 & 74.8 & 18.2 & 7.0 \\
\hline Total & 80.0 & 19.4 & 0.6 & 76.3 & 17.7 & 6.0 & 76.3 & 17.8 & 5.9 \\
\hline (N) & $(8,699)$ & $(2,215)$ & (78) & $(6,545)$ & $(1,509)$ & (559) & $(8,292)$ & $(1,926)$ & (686) \\
\hline
\end{tabular}


TABLE A9.8 Youth responses to the question, "Do you think a woman has the right to ask for a separation (divorce or khul)?", 2009 and 2014, percent

\begin{tabular}{|c|c|c|c|c|c|c|}
\hline & \multicolumn{2}{|c|}{2009 (AGES 15-29) } & \multicolumn{2}{|c|}{2014 (AGES 15-29) } & \multicolumn{2}{|c|}{2014 (AGES 13-35) } \\
\hline & YES & NO & YES & NO & YES & NO \\
\hline \multicolumn{7}{|l|}{ Gender } \\
\hline Male & 56.9 & 43.1 & 62.5 & 37.5 & 62.9 & 37.1 \\
\hline Female & 70.8 & 29.2 & 81.0 & 19.0 & 80.6 & 19.5 \\
\hline \multicolumn{7}{|l|}{ Education level } \\
\hline Illiterate & 50.1 & 49.9 & 61.2 & 38.8 & 62.2 & 37.8 \\
\hline Can read and write & 61.4 & 38.6 & 66.1 & 33.9 & 67.8 & 32.3 \\
\hline Primary & 58.7 & 41.3 & 65.2 & 34.8 & 67.0 & 33.0 \\
\hline Preparatory & 62.3 & 37.7 & 69.2 & 30.8 & 70.0 & 30.0 \\
\hline General secondary & 70.0 & 30.0 & 77.1 & 22.9 & 77.6 & 22.4 \\
\hline Vocational secondary & 64.4 & 35.6 & 69.8 & 30.2 & 70.7 & 29.3 \\
\hline Post-secondary institute & 79.0 & 21.0 & 76.6 & 23.5 & 75.7 & 24.3 \\
\hline University and above & 73.2 & 26.8 & 78.1 & 21.9 & 77.1 & 22.9 \\
\hline \multicolumn{7}{|l|}{ Region } \\
\hline Urban Governorates & 69.3 & 30.7 & 73.8 & 26.2 & 74.5 & 25.5 \\
\hline Urban Lower Egypt & 66.2 & 33.8 & 70.2 & 29.8 & 69.3 & 30.7 \\
\hline Rural Lower Egypt & 63.1 & 36.9 & 71.4 & 28.6 & 71.9 & 28.1 \\
\hline Urban Upper Egypt & 63.5 & 36.5 & 65.9 & 34.2 & 64.4 & 35.6 \\
\hline Rural Upper Egypt & 59.5 & 40.5 & 72.7 & 27.3 & 72.9 & 27.1 \\
\hline Frontier Governorates & 50.6 & 49.4 & 56.5 & 43.5 & 56.6 & 43.4 \\
\hline \multicolumn{7}{|l|}{ Urban-rural residence } \\
\hline Urban & 67.4 & 32.6 & 71.1 & 28.9 & 71.3 & 28.7 \\
\hline Rural & 61.3 & 38.7 & 71.7 & 28.3 & 72.1 & 27.9 \\
\hline Informal urban areas & 65.7 & 34.4 & 69.7 & 30.3 & 68.2 & 31.8 \\
\hline \multicolumn{7}{|l|}{ Wealth quintile } \\
\hline Lowest & 54.5 & 45.5 & 65.6 & 34.4 & 66.3 & 33.8 \\
\hline Second & 60.5 & 39.5 & 69.9 & 30.1 & 70.0 & 30.0 \\
\hline Middle & 64.3 & 35.8 & 72.4 & 27.6 & 72.2 & 27.8 \\
\hline Fourth & 69.3 & 30.7 & 69.4 & 30.6 & 69.9 & 30.1 \\
\hline Highest & 70.2 & 29.8 & 77.8 & 22.2 & 77.8 & 22.3 \\
\hline \multicolumn{7}{|l|}{ Age group } \\
\hline $15-17$ & 62.7 & 37.3 & 70.1 & 30.0 & 70.2 & 29.8 \\
\hline $18-24$ & 63.6 & 36.4 & 71.8 & 28.2 & 71.8 & 28.2 \\
\hline $25-29$ & 64.7 & 35.3 & 71.7 & 28.3 & 71.7 & 28.3 \\
\hline $30-35$ & - & - & - & - & 72.3 & 27.7 \\
\hline \multicolumn{7}{|l|}{ Marital status } \\
\hline Never married & 63.5 & 36.5 & 69.6 & 30.4 & 69.6 & 30.4 \\
\hline Ever married & 64.1 & 36.0 & 76.2 & 23.8 & 75.0 & 25.0 \\
\hline \multicolumn{7}{|l|}{ Employment status } \\
\hline Employed & 61.2 & 38.8 & 68.0 & 32.0 & 68.0 & 32.0 \\
\hline Unemployed & 60.3 & 39.7 & 75.5 & 24.5 & 74.6 & 25.4 \\
\hline Out of labor force & 65.3 & 34.7 & 72.7 & 27.3 & 73.2 & 26.8 \\
\hline Total & 63.7 & 36.3 & 71.4 & 28.7 & 71.5 & 28.5 \\
\hline$(\mathrm{N})$ & $(6,993)$ & $(3,997)$ & $(6,163)$ & $(2,450)$ & $(7,820)$ & $(3,084)$ \\
\hline
\end{tabular}


TABLE A9.9 Youth perspectives on when requesting divorce is justified for women, 2009 and 2014

\begin{tabular}{|c|c|c|c|c|c|c|c|}
\hline & \multicolumn{3}{|c|}{2009 (AGES 15-29) } & \multicolumn{2}{|c|}{2014 (AGES 15-29) } & \multicolumn{2}{|c|}{2014 (AGES 13-35) } \\
\hline & YES & NO & DON'T KNOW & YES & NO & YES & NO \\
\hline \multicolumn{8}{|c|}{ If the spouse disrespects her parents } \\
\hline Males & 54.3 & 44.4 & 1.3 & 43.8 & 56.3 & 43.1 & 56.9 \\
\hline Females & 40.0 & 59.2 & 0.9 & 44.9 & 55.2 & 44.1 & 55.9 \\
\hline Total & 46.5 & 52.4 & 1.1 & 44.4 & 55.7 & 43.6 & 56.4 \\
\hline$(\mathrm{N})$ & $(3,140)$ & $(3,777$ & $(76)$ & $(2,774)$ & $(3,389)$ & $(3,461)$ & $(4,359)$ \\
\hline \multicolumn{8}{|c|}{ If the spouse does not listen to her } \\
\hline Males & 39.7 & 59.0 & 1.3 & 27.7 & 72.3 & 28.1 & 71.9 \\
\hline Females & 31.3 & 67.7 & 1.0 & 34.2 & 65.8 & 33.9 & 66.1 \\
\hline Total & 35.1 & 63.7 & 1.1 & 31.2 & 68.8 & 31.3 & 68.7 \\
\hline$(\mathrm{N})$ & $(2,363)$ & $(4,548)$ & $(82)$ & $(2,032)$ & $(4,131)$ & $(2,565)$ & $(5,255)$ \\
\hline \multicolumn{8}{|c|}{ The first time her spouse beats her } \\
\hline Males & 18.3 & 81.0 & 0.7 & 17.9 & 82.1 & 18.5 & 81.5 \\
\hline Females & 24.2 & 75.2 & 0.6 & 25.1 & 74.9 & 24.8 & 75.2 \\
\hline Total & 21.5 & 77.8 & 0.7 & 21.8 & 78.2 & 22.0 & 78.0 \\
\hline$(\mathrm{N})$ & $(1,506)$ & $(5,431)$ & $(56)$ & $(1,353)$ & $(4,810)$ & $(1,713)$ & $(6,107)$ \\
\hline \multicolumn{8}{|c|}{ If the spouse beats her regularly } \\
\hline Males & 79.5 & 19.9 & 0.6 & 69.8 & 30.2 & 69.5 & 30.5 \\
\hline Females & 71.2 & 28.1 & 0.8 & 72.7 & 27.3 & 72.5 & 27.5 \\
\hline Total & 75.0 & 24.4 & 0.7 & 71.4 & 28.6 & 71.2 & 28.8 \\
\hline$(\mathrm{N})$ & $(5,169)$ & $(1,781)$ & $(43)$ & $(4,419)$ & $(1,744)$ & $(5,591)$ & $(2,229)$ \\
\hline \multicolumn{8}{|c|}{ If the spouse does not give her or the children enough money } \\
\hline Males & 54.8 & 44.6 & 0.6 & 35.8 & 64.2 & 36.3 & 63.7 \\
\hline Females & 40.8 & 58.2 & 1.0 & 36.9 & 63.1 & 36.5 & 63.5 \\
\hline Total & 47.2 & 51.9 & 0.8 & 36.4 & 63.6 & 36.4 & 63.6 \\
\hline$(\mathrm{N})$ & $(3,183)$ & $(3,754)$ & $(56)$ & $(2,271)$ & $(3,892)$ & $(2,863)$ & $(4,957)$ \\
\hline \multicolumn{8}{|c|}{ If the spouse wants to take her money } \\
\hline Males & 70.0 & 29.6 & 0.4 & 54.2 & 45.8 & 54.0 & 46.0 \\
\hline Females & 52.2 & 46.6 & 1.2 & 51.7 & 48.3 & 51.7 & 48.3 \\
\hline Total & 60.3 & 38.8 & 0.9 & 52.9 & 47.1 & 52.7 & 47.3 \\
\hline$(\mathrm{N})$ & $(4,096)$ & $(2,829)$ & $(67)$ & $(3,273)$ & $(2,890)$ & $(4,138)$ & $(3,682)$ \\
\hline \multicolumn{8}{|c|}{ If the spouse "knows" another woman } \\
\hline Males & 71.5 & 27.9 & 0.6 & 65.4 & 34.6 & 65.0 & 35.0 \\
\hline Females & 77.9 & 21.1 & 1.0 & 72.8 & 27.2 & 72.1 & 27.9 \\
\hline Total & 75.0 & 24.2 & 0.8 & 69.4 & 30.6 & 68.9 & 31.1 \\
\hline$(\mathrm{N})$ & $(5,237)$ & $(1,701)$ & $(55)$ & $(4,338)$ & $(1,825)$ & $(5,447)$ & $(2,373)$ \\
\hline \multicolumn{8}{|c|}{ If the spouse marries another woman } \\
\hline Males & 56.1 & 43.2 & 0.7 & 66.7 & 33.3 & 67.1 & 33.0 \\
\hline Females & 79.4 & 19.1 & 1.5 & 81.6 & 18.5 & 81.0 & 19.0 \\
\hline Total & 68.8 & 30.1 & 1.2 & 74.8 & 25.2 & 74.7 & 25.3 \\
\hline$(\mathrm{N})$ & $(4,862)$ & $(2,050)$ & $(81)$ & $(4,723)$ & $(1,440)$ & $(5,978)$ & $(1,842)$ \\
\hline \multicolumn{8}{|c|}{ If she hates her spouse } \\
\hline Males & 86.7 & 12.7 & 0.6 & 76.7 & 23.3 & 76.8 & 23.2 \\
\hline Females & 82.0 & 16.7 & 1.3 & 79.2 & 20.8 & 79.2 & 20.8 \\
\hline Total & 84.2 & 14.9 & 1.0 & 78.1 & 21.9 & 78.2 & 21.9 \\
\hline$(\mathrm{N})$ & $(5,798)$ & $(1,126)$ & (69) & $(4,912)$ & $(1,251)$ & $(6,236)$ & $(1,584)$ \\
\hline \multicolumn{8}{|c|}{ If the spouse cannot have children } \\
\hline Males & 42.8 & 54.1 & 3.1 & 49.6 & 50.4 & 49.3 & 50.7 \\
\hline Females & 35.9 & 59.1 & 5.0 & 40.7 & 59.3 & 40.5 & 59.5 \\
\hline Total & 39.1 & 56.8 & 4.1 & 44.8 & 55.2 & 44.5 & 55.5 \\
\hline$(\mathrm{N})$ & $(2,647)$ & $(4,069)$ & $(277)$ & $(2,687)$ & $(3,476)$ & $(3,386)$ & $(4,434)$ \\
\hline \multicolumn{8}{|c|}{ If the spouse suffers from sexual dysfunction } \\
\hline Males & 74.7 & 21.3 & 4.0 & 59.5 & 40.5 & 59.0 & 41.0 \\
\hline Females & 43.2 & 48.8 & 8.0 & 49.6 & 50.4 & 49.5 & 50.5 \\
\hline Total & 57.6 & 36.2 & 6.2 & 54.1 & 45.9 & 53.8 & 46.2 \\
\hline$(\mathrm{N})$ & $(3,826)$ & $(2,742)$ & $(425)$ & $(3,273)$ & $(2,890)$ & $(4,126)$ & $(3,694)$ \\
\hline
\end{tabular}


TABLE A9.10 Youth perspectives on when requesting divorce is justified for men, 2009 and 2014

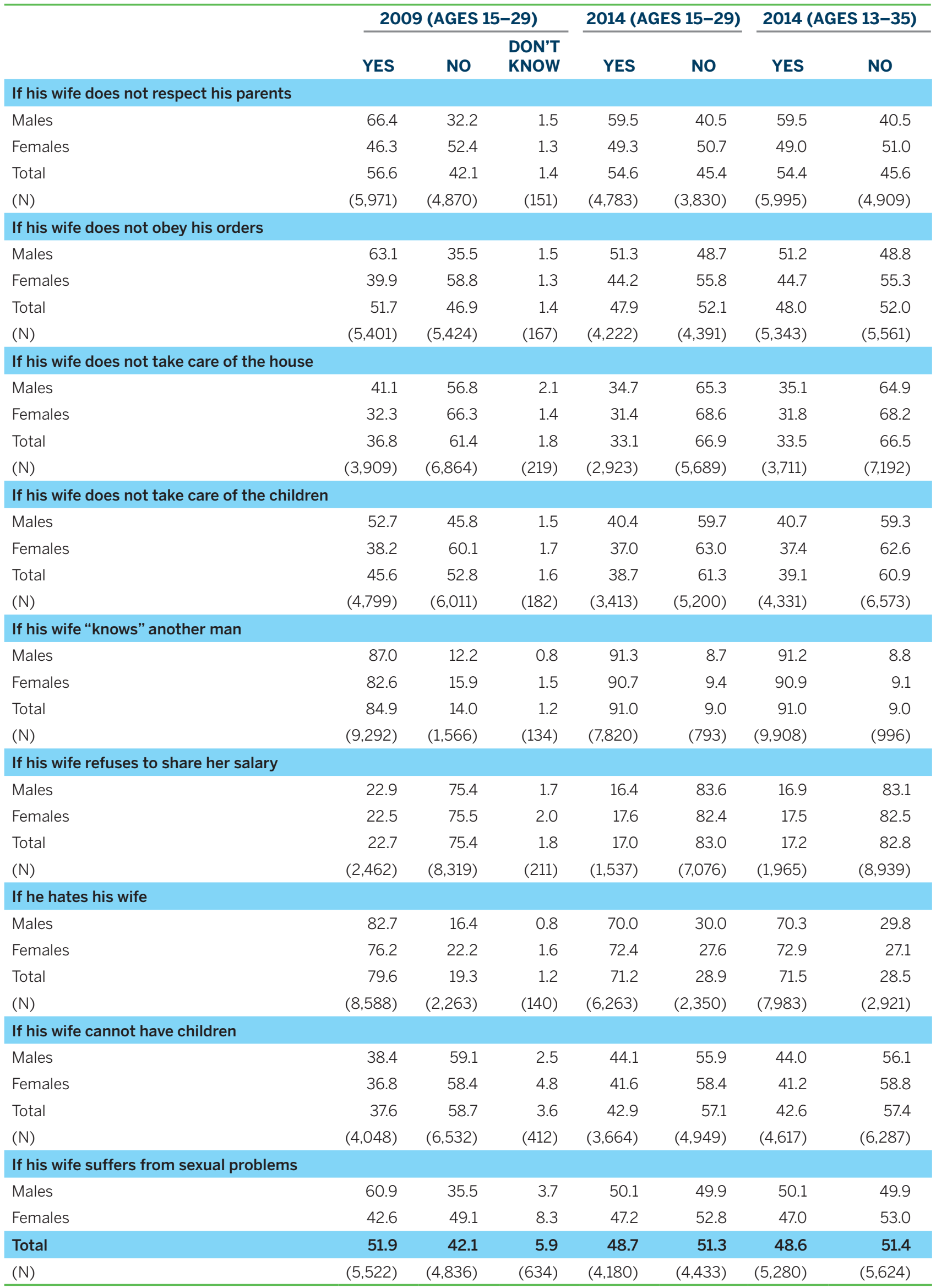


TABLE A9.11 Youth responses to the question, "Do you think that society perceives divorced women respectfully?", 2009 and 2014, percent

\begin{tabular}{|c|c|c|c|c|c|c|}
\hline & \multicolumn{2}{|c|}{2009 (AGES 15-29) } & \multicolumn{2}{|c|}{2014 (AGES 15-29) } & \multicolumn{2}{|c|}{2014 (AGES 13-35) } \\
\hline & YES & NO & YES & NO & YES & NO \\
\hline \multicolumn{7}{|l|}{ Gender } \\
\hline Male & 34.2 & 65.8 & 37.1 & 62.9 & 37.2 & 62.8 \\
\hline Female & 31.4 & 68.6 & 35.4 & 64.6 & 35.3 & 64.8 \\
\hline \multicolumn{7}{|l|}{ Education level } \\
\hline Illiterate & 28.5 & 71.5 & 29.7 & 70.3 & 31.3 & 68.7 \\
\hline Can read and write & 0.0 & 100.0 & 39.3 & 60.7 & 31.6 & 68.4 \\
\hline Primary & 28.6 & 71.4 & 30.5 & 69.5 & 30.6 & 69.4 \\
\hline Preparatory & 33.2 & 66.8 & 32.7 & 67.3 & 33.4 & 66.6 \\
\hline General secondary & 37.0 & 63.0 & 39.8 & 60.2 & 40.2 & 59.8 \\
\hline Vocational secondary & 32.5 & 67.6 & 35.4 & 64.6 & 34.7 & 65.4 \\
\hline Post-secondary institute & 37.5 & 62.5 & 36.0 & 64.0 & 39.1 & 60.9 \\
\hline University and above & 37.8 & 62.2 & 42.8 & 57.2 & 43.9 & 56.1 \\
\hline \multicolumn{7}{|l|}{ Region } \\
\hline Urban Governorates & 36.7 & 63.3 & 42.7 & 57.3 & 43.8 & 56.2 \\
\hline Urban Lower Egypt & 34.1 & 65.9 & 29.2 & 70.9 & 30.2 & 69.8 \\
\hline Rural Lower Egypt & 34.3 & 65.7 & 36.6 & 63.4 & 36.1 & 63.9 \\
\hline Urban Upper Egypt & 30.0 & 70.0 & 29.4 & 70.6 & 28.1 & 71.9 \\
\hline Rural Upper Egypt & 28.2 & 71.8 & 37.6 & 62.4 & 37.1 & 62.9 \\
\hline Frontier Governorates & 32.3 & 67.7 & 22.9 & 77.1 & 23.4 & 76.6 \\
\hline \multicolumn{7}{|l|}{ Urban-rural residence } \\
\hline Urban & 35.9 & 64.1 & 39.1 & 61.0 & 40.1 & 59.9 \\
\hline Rural & 31.6 & 68.5 & 36.9 & 63.1 & 36.4 & 63.7 \\
\hline Informal urban areas & 30.7 & 69.3 & 24.1 & 75.9 & 24.0 & 76.0 \\
\hline \multicolumn{7}{|l|}{ Wealth quintile } \\
\hline Lowest & 28.5 & 71.5 & 34.1 & 65.9 & 33.9 & 66.1 \\
\hline Second & 30.7 & 69.4 & 35.0 & 65.0 & 34.0 & 66.0 \\
\hline Middle & 31.7 & 68.3 & 31.8 & 68.2 & 32.5 & 67.5 \\
\hline Fourth & 35.0 & 65.0 & 38.5 & 61.5 & 38.4 & 61.6 \\
\hline Highest & 39.0 & 61.0 & 40.8 & 59.2 & 41.3 & 58.7 \\
\hline \multicolumn{7}{|l|}{ Age group } \\
\hline $15-17$ & 33.0 & 67.0 & 37.8 & 62.2 & 37.7 & 62.3 \\
\hline $18-24$ & 33.3 & 66.8 & 35.7 & 64.3 & 35.7 & 64.3 \\
\hline $25-29$ & 32.0 & 68.0 & 36.1 & 63.9 & 36.1 & 63.9 \\
\hline $30-35$ & - & - & - & - & 35.9 & 64.1 \\
\hline \multicolumn{7}{|l|}{ Marital status } \\
\hline Never married & 34.1 & 65.9 & 36.9 & 63.1 & 37.2 & 62.9 \\
\hline Ever married & 29.7 & 70.3 & 34.6 & 65.4 & 34.6 & 65.4 \\
\hline \multicolumn{7}{|l|}{ Employment status } \\
\hline Employed & 33.9 & 66.1 & 37.2 & 62.8 & 37.5 & 62.5 \\
\hline Unemployed & 38.2 & 61.8 & 36.4 & 63.7 & 34.7 & 65.3 \\
\hline Out of labor force & 31.8 & 68.2 & 35.8 & 64.2 & 35.7 & 64.3 \\
\hline Total & 32.9 & 67.1 & 36.3 & 63.7 & 36.3 & 63.7 \\
\hline$(\mathrm{N})$ & $(3,632)$ & $(7,357)$ & $(3,013)$ & $(5,600)$ & $(3,797)$ & $(7,107)$ \\
\hline
\end{tabular}




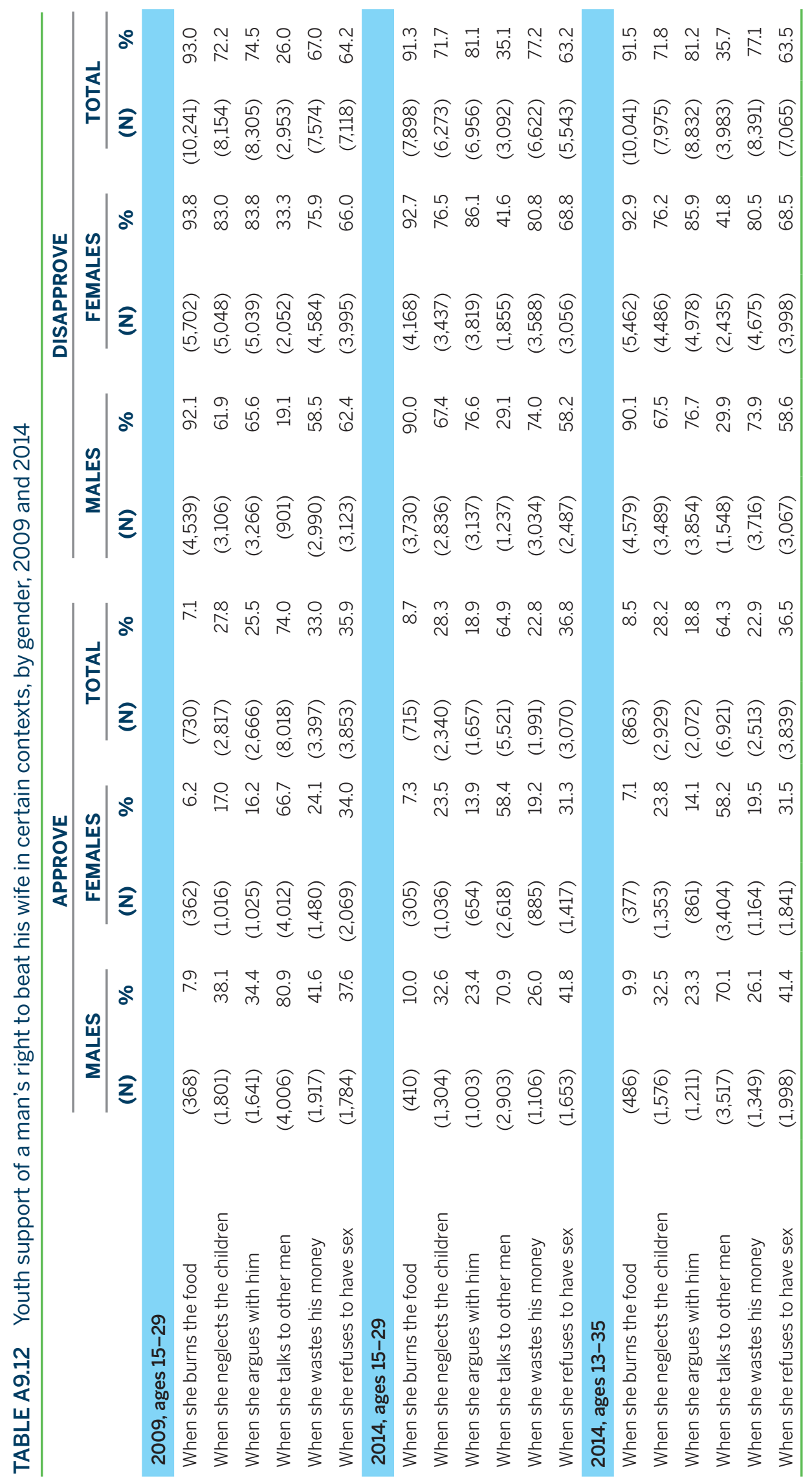


TABLE A9.13 Youth response to the question, "Do you think that women who are harassed in the streets deserve to be if they are dressed provocatively?", 2009 and 2014, percent

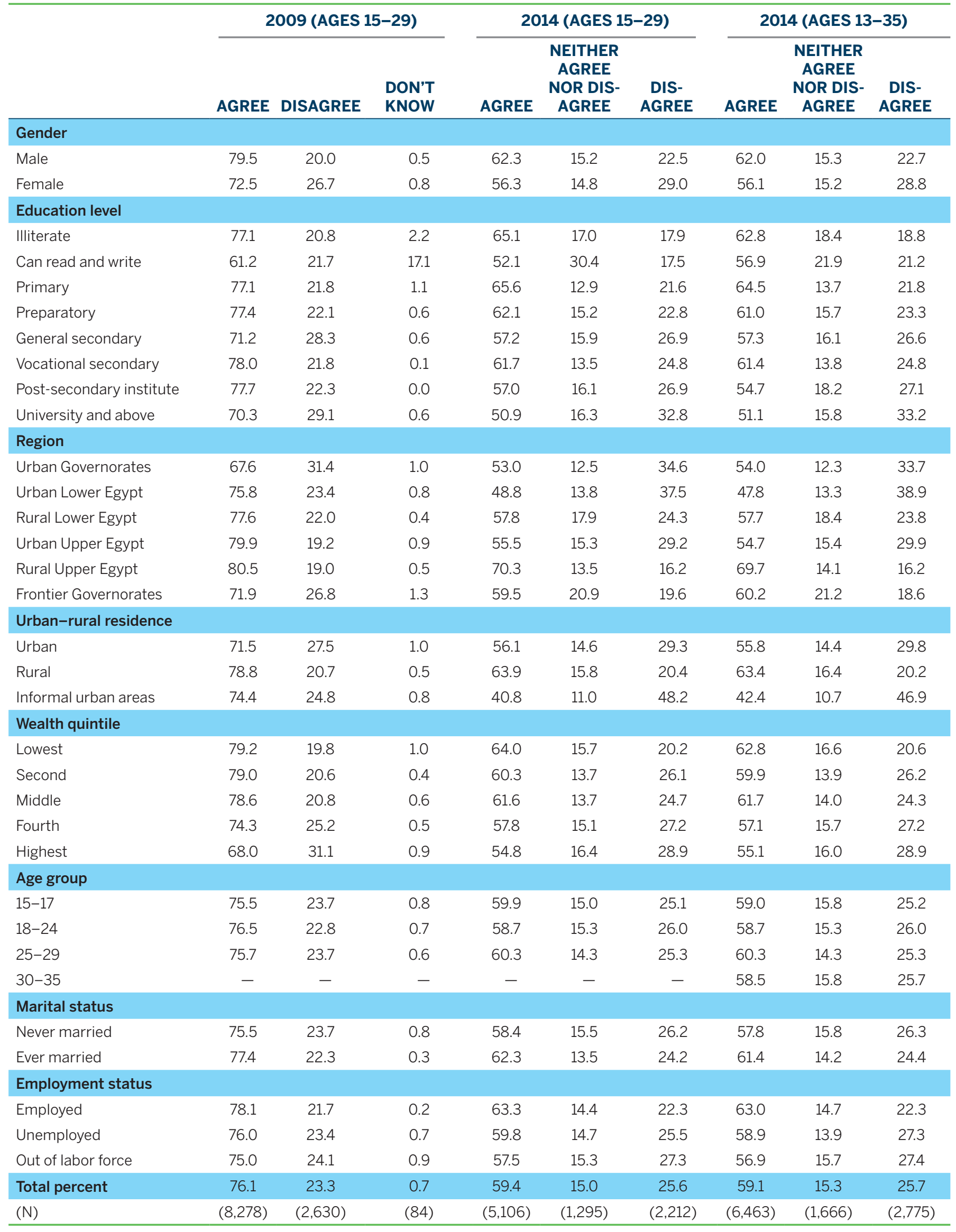




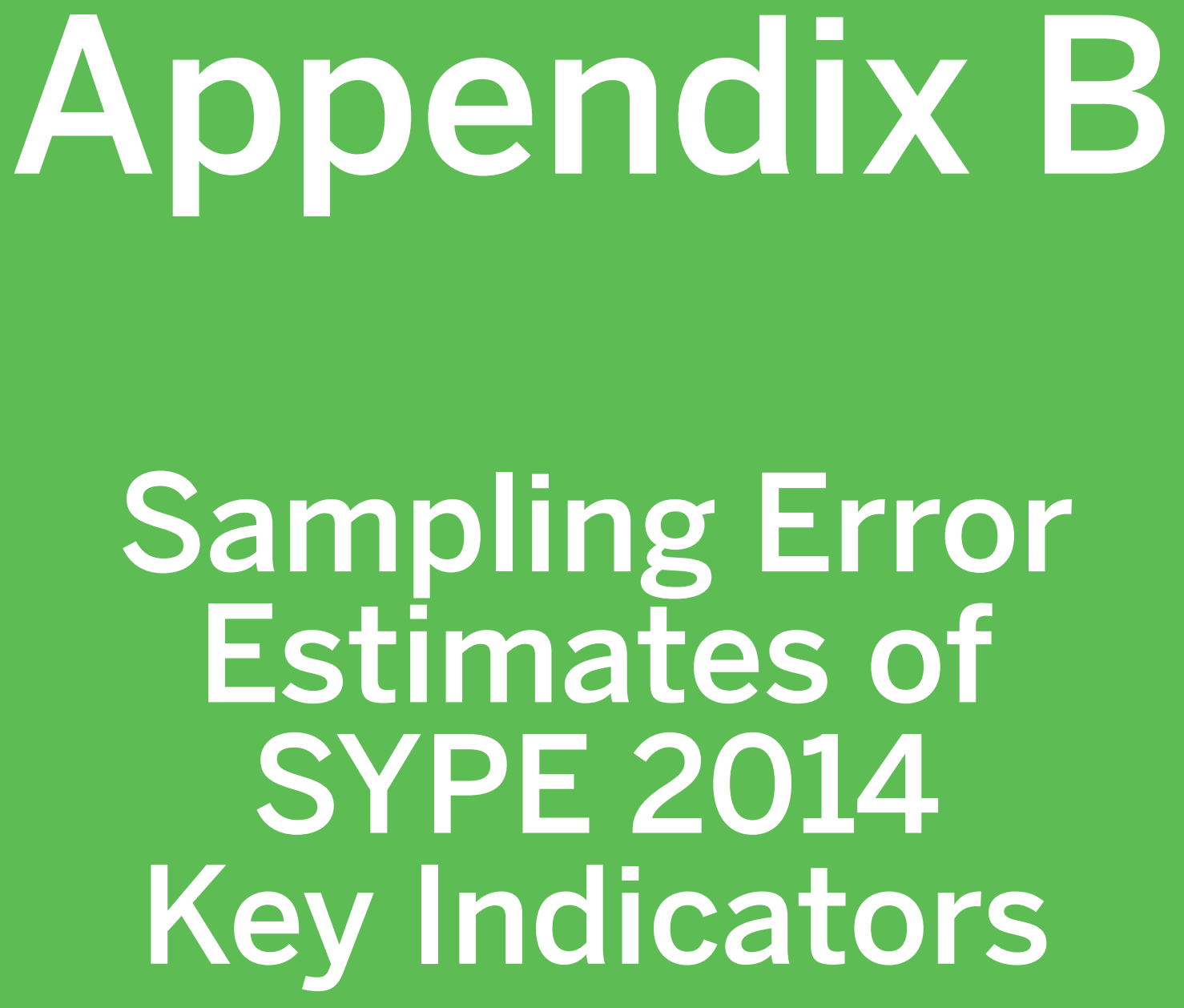

Mohamed Ismail

Ali Rashed 



\section{Introduction}

The accuracy of survey estimates indicates how close the estimate is to its corresponding population value. The difference between the survey estimate and its population value is called the error of the survey estimate. The total error results from the two types of error, namely the sampling error and nonsampling error.

The sampling error arises when the whole population is represented by a part (sample) of it. All other errors in the survey estimate are called nonsampling error which may occur for different reasons during implementation of the sample survey. These reasons may include target population misidentification, questionnaire problems, respondents' bias, processing error, and time period bias among others. Sampling error can be estimated statistically while it is difficult to measure the nonsampling error.

\section{Sampling error estimation}

Standard error (SE) is usually used to measure the sampling error. The standard error is the square root of the variance. Standard error calculation is straightforward in the case of simple random sample. However, since the SYPE data result from a stratified multistage sample design, a more complex formula is used. The STATA SVY module is used to calculate the standard error for key estimates of SYPE 2014.

\section{Precision measures}

Precision measures of survey data estimates may include:

- Standard error (described in previous paragraph)

- Coefficient of variation

- Confidence Interval

- Design effect

\section{Coefficient of variation (CV)}

Coefficient of variation is the relative standard error. It is calculated as the ratio of the estimate sampling error to its value. The reliability of the survey estimates are questionable if $\mathrm{CV}$ exceeds $20 \%$.

\section{Confidence interval (Cl)}

A confidence interval is used to express the uncertainty of survey estimates. The sampling (standard) error is employed to construct a confidence interval of the parameter of interest. A 95\% confidence interval means that when the same sampling method with the same sample size and design is used to select different samples and construct a confidence interval for each sample, the true population parameter is expected to fall within the confidence interval in 95\% of all samples.

However, if the lower bound of the confidence interval for a positive parameter is negative, it must be considered zero. Similarly, whenever the upper bound of a confidence interval exceeds 1 , it must be considered 1 . 


\section{Design effect (DEFF)}

The design effect (deff) measures how much worse the given sample design is than a simple random sample (SRS) of the same size. The DEFF is defined as the ratio of the standard error of the used design to the standard error of SRS of the same sample size. The DEFF shows how much information is gained (or lost) by using the present survey compared to SRS. A DEFF value of 2 indicates that a double size of simple random sample is needed to get the same amount of information obtained by the present sample. A DEFF value of 1 indicates that the present sample conveys the same amount of information obtained by the SRS. Design effect (DEFF) is usually greater than 1 . However, in some cases DEFF is less than 1, which may be due to the presence of outliers and/or small sample size.

\section{Precision estimates for SYPE 2014 key indicators}

Standard error and other precision measures are calculated for several selected SYPE 2014 key estimates. The selected indicators, the type of each estimate (mean, proportion, rate), and the base population are displayed in Table 1.

For each selected indicator, the indicator estimate value (Estimate), its standard error (SE), the 95\% confidence limits (estimates+/- $2 \mathrm{SE}$ ), the coefficient of variation ( $\mathrm{CV}=\mathrm{SE} / \mathrm{estimate}$ ), and the design effect are calculated and reported in Tables S1-S39. See listing on page 222.

Tables S1-S39 can be found online at: popcouncil.org/SYPE2014
It is worth mentioning here that the stratifying variable used for variance estimation is defined as the intersection of variables of urban-rural residence (urban, rural, informal urban area) and geographic region (Urban Governorates, urban Lower Egypt, rural Lower Egypt, urban Upper Egypt, rural Upper Egypt, and Frontier Governorates). This is the same stratification scheme that was followed in designing the SYPE sample where an independent sample was selected from each of the 10 substrata defined by the intersection of the two mentioned variables. The purpose of such stratification is to create the most possible homogeneous strata with regard to the survey variables; hence more precise survey estimates would be attained.

Going through the precision measures tables the standard errors for indicators are smaller for population then for subpopulation. Table 31 for example shows that the standard error for the percentage of married male youth in urban residence (0.012) is smaller than the SE of the same indicator in the urban Upper Egypt (0.029). Consequently, the $95 \% \mathrm{Cl}$ for the percentage of urban married male youth is $(0.188,0.237)$, which is smaller than the corresponding $95 \% \mathrm{Cl}$ for the same indicator in the urban Upper Egypt which is $(0.184,0.297)$. 
TABLE 1 Standard errors for main indicators of SYPE 2014, all Egypt

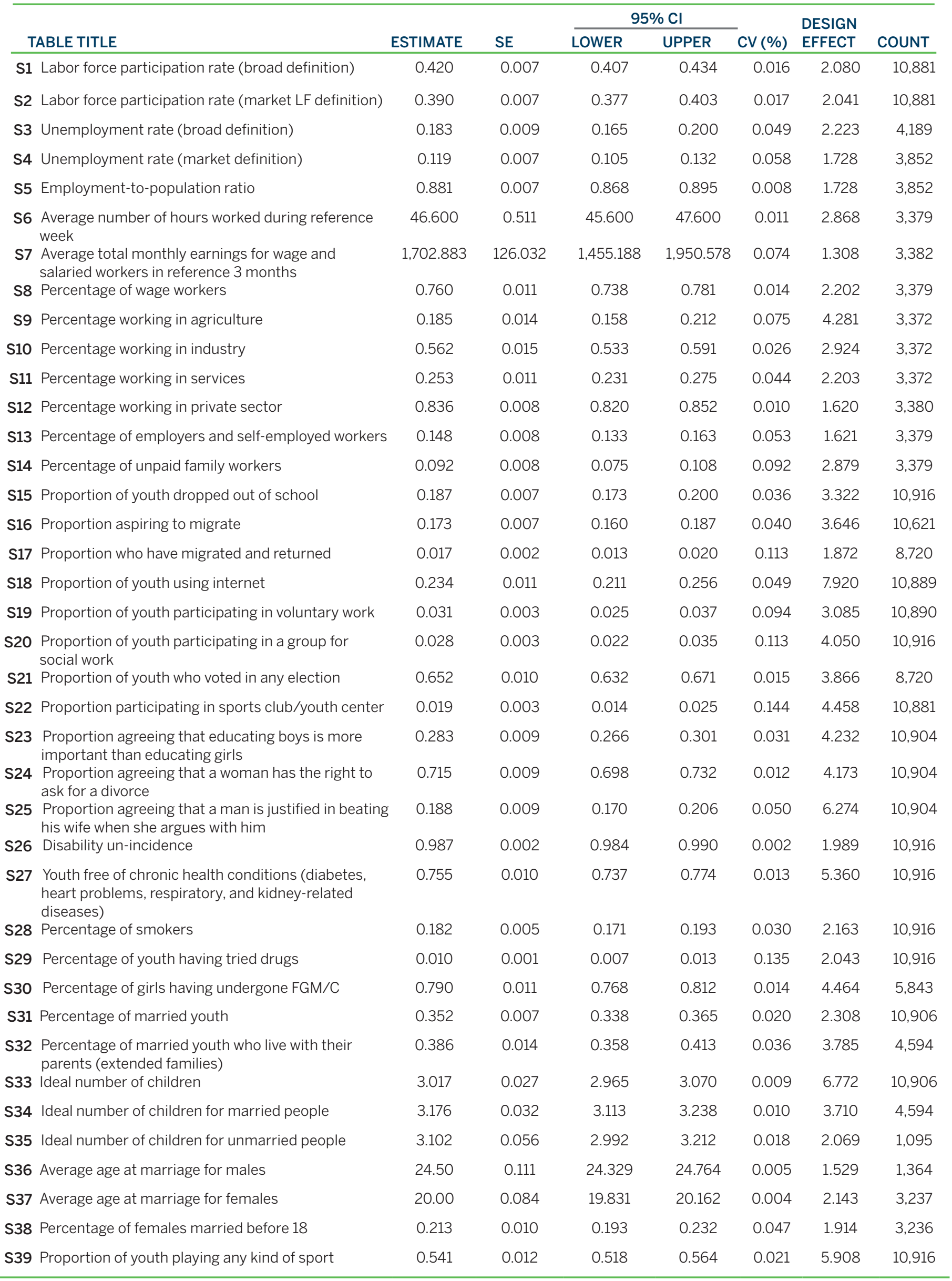


TABLE

NO. TABLE TITLE

S1 Labor force participation rate (broad definition)

S2 Labor force participation rate (market LF definition)

S3 Unemployment rate (broad definition)

S4 Unemployment rate (market definition)

S5 Employment-to-population ratio

S6 Average number of hours worked during reference weak

S7 Average total monthly earnings for wage and salaried workers in reference 3 months

S8 Percentage of wage workers

S9 Percentage working in agriculture

S10 Percentage working in industry

S11 Percentage working in services

S12 Percentage working in private sector

S13 Percentage of employers and self-employed workers

S14 Percentage of unpaid family workers

S15 Proportion of youth dropped out of schoo

S16 Proportion aspiring to migrate

S17 Proportion who have migrated and returned

S18 Proportion of youth using internet

S19 Proportion of youth participating in voluntary work

S20 Proportion of youth participating in a group for social work

S21 Proportion of youth who voted in any election

S22 Proportion participating in sports club/youth center

S23 Proportion agreeing that educating boys is more important than educating girls

S24 Proportion agreeing that a woman has the right to ask for a divorce

S25 Proportion agreeing that a man is justified in beating his wife when she argues with him

S26 Disability un-incidence

S27 Youth free of chronic health conditions (diabetes, heart problems, respiratory, and kidney-related diseases)

S28 Percentage of smokers

S29 Percentage of youth having tried drugs

S30 Percentage of girls having undergone FGM/C

S31 Percentage of married youth

S32 Percentage of married youth live with their parents (extended families)

S33 Ideal number of children

S34 Ideal number of children for married people

S35 Ideal number of children for unmarried people

S36 Average age at marriage for males

S37 Average age at marriage for females

S38 Percentage of females married before 18

S39 Proportion playing any kind of sport

\section{ESTIMATE POPULATION}

Rate All youth 15-35 in labor force relaxing search

Rate $\quad$ All youth 15-35 in labor force with search

Rate Unemployed youth 15-35 in labor force relaxing search

Rate Unemployed youth 15-35 in labor force with search

Ratio All employed youth 15-35 to all youth population

Mean Employed youth 15-35

Mean Employed youth 15-35

Percent Employed workers, youth 15-35

Percent Youth workers in agriculture 15-35

Percent Youth workers in industry 15-35

Percent Youth workers in services 15-35

Percent Youth workers in private sector 15-35

Percent Youth employers and self-employed workers 15-35

Percent Youth unpaid family workers 15-35

Proportion Young people dropped out of school < age 16

Proportion Youth aspiring to migrate 1-35

Proportion Youth who have migrated and returned 1-35

Proportion Youth using internet 1-35

Proportion Youth participating in voluntary work 1-35

Proportion Youth participating in a group for social work 1-35

Proportion Youth who voted in any election 1-35

Proportion Youth participating in sports club/youth center 1-35

Proportion All youth 1-35

Proportion All youth 1-35

Proportion All youth 1-35

Proportion All youth 1-35

Proportion All youth 1-35

Percent All youth 1-35

Percent All youth 1-35

Percent All female youth 1-35

Percent Female 15+, male youth 18+

Percent All currently married youth 1-35

Mean All youth 15-35

Mean Currently married youth, female 15+, male youth $18+$

Mean All unmarried youth 1-35

Mean Male married youth 1-35

Mean Female married youth 15-35

Percent $\quad$ Ever married female 18+

Proportion All youth 1-35 



\section{popluaton \\ COUNCIL \\ Ideas. Evidence. Impact.}

Population Council

One Dag Hammarskjold Plaza

New York, NY 10017

Population Council/Egypt

59 Misr-Helwan Agricultural Road,

Maadi

PO Box 168, Maadi

Cairo, Egypt 11431

popcouncil.org 